Manfred Rosenstock

Die Kontrolle und Harmonisierung nationaler Beihilfen durch die Kommission der Europäischen Gemeinschaften 


\section{Die Kontrolle und Harmonisierung nationaler Beihilfen durch die Kommission der Europäischen Gemeinschaften}

Im Hinblick auf die Sicherung des europäischen Binnenmarktes ist die Vermeidung von Wettbewerbsverzerrungen durch staatliche Beihilfen von großer Bedeutung. Der Verfasser untersucht und beurteilt die Politik der Kommission in diesem Bereich anhand allokationstheoretischer und politökonomischer Subventionsrechtfertigungen sowie der rechtlichen Rahmenbedingungen aufgrund des EG- und EGKS-Vertrages und des EWR-Abkommens. Nach einer Darstellung des Gesamtrahmens wird dabei der Schwerpunkt auf die Bereiche Schiffbau, Stahl- und Automobilindustrie gelegt. Im Anschluß an eine zusammenfassende Bewertung der Erfolge und Probleme der gemeinschaftlichen Subventionskontrolle diskutiert der Autor abschließend verschiedene Ansätze zur Weiterentwicklung der Beihilfenkontrollpolitik.

Manfred Rosenstock wurde 1963 in Offenbach am Main geboren. Von 1982 bis 1987 studierte er Volkswirtschaftslehre an der Universität Frankfurt und der London School of Economics and Political Science. Anschließend war er Wissenschaftlicher Mitarbeiter am Institut für Öffentliche Wirtschaft, Geld und Währung der Universität Frankfurt (1988-1993). Promotion 1994. 
Die Kontrolle und Harmonisierung nationaler Beihilfen durch die Kommission der Europäischen Gemeinschaften 


\section{FINANZWISSENSCHAFTLICHE SCHRIFTEN}

Herausgegeben von den Professoren Albers, Krause-Junk, Littmann, Oberhauser, Pohmer, Schmidt

Band 71

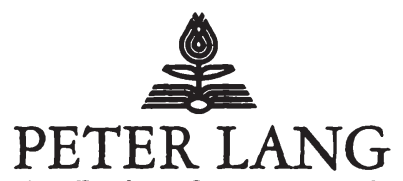

Frankfurt am Main - Berlin · Bern - New York · Paris . Wien

Manfred Rosenstock - 978-3-631-75198-5

Downloaded from PubFactory at 01/11/2019 07:13:36AM

via free access 


\title{
Manfred Rosenstock
}

\author{
Die Kontrolle und \\ Harmonisierung \\ nationaler Beihilfen \\ durch die Kommission \\ der Europäischen \\ Gemeinschaften
}

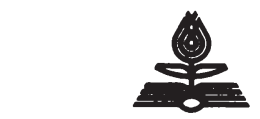

\section{PETER LANG}

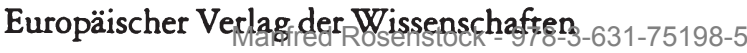


Die Deutsche Bibliothek - CIP-Einheitsaufnahme

Rosenstock, Manfred:

Die Kontrolle und Harmonisierung nationaler Beihilfen durch die Kommission der Europäischen Gemeinschaften / Manfred Rosenstock. - Frankfurt am Main ; Berlin ; Bern ; New York ; Paris ; Wien : Lang, 1995

(Finanzwissenschaftliche Schriften ; Bd. 71)

Zugl.: Frankfurt (Main), Univ., Diss., 1994

ISBN 3-631-49092-5

Open Access: The online version of this publication is published on www.peterlang.com and www.econstor.eu under the international Creative Commons License CC-BY 4.0. Learn more on how you can use and share this work: http://creativecommons. org/licenses/by/4.0.

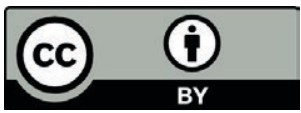

This book is available Open Access thanks to the kind support of ZBW - Leibniz-Informationszentrum Wirtschaft.

NE: GT

\author{
D 30 \\ ISSN 0170-8252 \\ ISBN 3-631-49092-5 \\ ISBN 978-3-631-75198-5 (eBook) \\ (C) Peter Lang GmbH \\ Europäischer Verlag der Wissenschaften \\ Frankfurt am Main 1995 \\ Alle Rechte vorbehalten.
}

Das Werk einschließlich aller seiner Teile ist urheberrechtlich geschützt. Jede Verwertung außerhalb der engen Grenzen des Urheberrechtsgesetzes ist ohne Zustimmung des Verlages unzulässig und strafbar. Das gilt insbesondere für Vervielfältigungen, Übersetzungen, Mikroverfilmungen und die Einspeicherung und Verarbeitung in elektronischen Systemen.

\title{
Printed in Germany 123567
}


Meinem Vater

in dankbarer Erinnerung

Manfred Rosenstock - 978-3-631-75198-5

Downloaded from PubFactory at 01/11/2019 07:13:36AM

via free access 
Manfred Rosenstock - 978-3-631-75198-5

Downloaded from PubFactory at 01/11/2019 07:13:36AM

via free access 


\section{VORWORT}

Die vorliegende Arbeit wurde im Dezember 1994 als Dissertation vom Fachbereich Wirtschaftswissenschaften der Johann Wolfgang Goethe-Universität Frankfurt am Main angenommen. Sie entstand weitgehend während meiner Tätigkeit am dortigen Institut für Öffentliche Wirtschaft, Geld und Währung. Die Arbeit war inhaltlich im Juli 1994 weitgehend abgeschlossen, sie konnte jedoch vor der Drucklegung noch auf den Stand vom Jahresende 1994 gebracht werden.

Mein herzlicher Dank gilt an erster Stelle meinem Doktorvater, Herrn Prof. Dr. Norbert Andel, für den Anstoß zur Beschäftigung mit diesem Thema, für seine stete Diskussionsbereitschaft und für zahlreiche wertvolle Anregungen und kritische Hinweise zu einer ersten Fassung. Herrn Prof. Dr. Dieter Biehl bin ich für die Übernahme des Zweitgutachtens und konstruktive Verbesserungsvorschläge zu Dank verpflichtet. Bei meinen ehemaligen Kolleginnen und Kollegen, Frau Irmgard Benner, Frau Heike Beyer, Herrn Dr. Harald Schlee, Frau Jutta von Dirke und Herrn Martin Kinkel, bedanke ich mich für die angenehme Arbeitsatmosphäre am Lehrstuhl und für die langjährige gute Zusammenarbeit bzw. die gute Zusammenarbeit in der Endphase meiner Tätigkeit.

Den Herausgebern, und insbesondere Herrn Prof. Dr. Gerold Krause-Junk, sei für die Aufnahme dieser Arbeit in die Reihe "Finanzwissenschaftliche Schriften" gedankt.

Der Vereinigung von Freunden und Förderern der Johann Wolfgang GoetheUniversität Frankfurt am Main e.V. gebührt mein Dank für einen Förderungsbeitrag, der mir einen Forschungsaufenthalt bei der Europäischen Kommission in Brüssel ermöglichte.

Ganz besonders danke ich meinen Eltern, meinem viel zu früh verstorbenen Vater und meiner Mutter, für ihren langjährigen und bedingungslosen Rückhalt, ohne den diese Arbeit nicht entstanden wäre.

Manfred Rosenstock 
Manfred Rosenstock - 978-3-631-75198-5

Downloaded from PubFactory at 01/11/2019 07:13:36AM

via free access 


\section{INHALTSVERZEICHNIS}

Abkürzungsverzeichnis $\quad$ XV

1. Einleitung 1

2. Wirtschaftstheoretische Grundlagen 5

2.1. Allokative Begründbarkeit von Subventionen $\quad 6$

2.1.1. Sinkende Durchschnittskosten 6

2.1.2. Externalitäten 8

2.1.2.1. Darstellung des Konzepts 8

2.1.2.2. Mögliche Anwendungsbereiche 13

$\begin{array}{ll}\text { 2.1.2.3. Verwandte Fälle } & 17\end{array}$

2.1.3. Das Infant-Industry-Argument 20

2.1.4. Das Optimalzollargument 23

2.2. Notwendigkeit einer Subventionskontrolle im Gemeinsamen Markt 25

2.2.1. Außenhandelswirkungen von Subventionen im Ein-Gut-Fall 26

2.2.2. Analyse der Außenhandelswirkungen im Zwei-Güter-Fall 28

2.2.2.1. Grundmodell 29

2.2.2.2. Erweiterung um räumliche Faktormobilität 32

$\begin{array}{ll}\text { 2.2.2.3. Faktorpreisrigiditäten } & 34\end{array}$

2.2.2.4. Analyse der Handelswirkungen von Regionalbeihilfen 35

2.2.2.5. Analyse der Handelswirkungen horizontaler Beihilfen 36

2.2.2.6. Handelswirkungen von Beihilfen in einer wachsenden Wirtschaft 37

2.2.2.7. Zusammenfassung $\quad 40$

2.3. Mögliche Gründe allokationsineffizienter Subventionierung 44

2.3.1. Kollektive Präferenz für Industrieproduktion 44

2.3.2. Politökonomische Analyse der Subventionierung 47

3. Regeln und Institutionen des EGV und des EGKSV

3.1 Grundsätzliches Subventionsverbot und Ausnahmen im EGV 55

3.2. Ablauf des Kontrollverfahrens 62

$\begin{array}{ll}\text { 3.3. Die Subventionsregelung des EGKS-Vertrages } & 67\end{array}$ 
3.4. Die Subventionsregeln des GATT und der EFTA im Vergleich zur EG 70

4. Bisherige Erfahrungen mit der Subventionskontrolle 79

4.1. Überblick über die Ausgestaltung der Politik $\quad 79$

4.1.1. Ad-hoc-Entscheidungen in der Anfangsphase $\quad 80$

4.1.2. Die Entwicklung von Regeln für sektorale Beihilfen 86

4.1.2.1. Die Erarbeitung allgemeiner Leitlinien 86

4.1.2.2. Beihilfenkontrolle in einigen Krisensektoren $\quad 88$

4.1.2.3. Beihilfenpolitik in Wachstumsindustrien 94

4.1.3. Die Entwicklung von Regeln für regionale Beihilfen 95

4.1.3.1. Problemstellung und erste Kontrollansätze 95

4.1.3.2. Die Entwicklung und Anwendung detaillierter Beurteilungsregeln 96

4.1.3.3. Ein differenzierterer und systematischerer Ansatz 104

4.1.4. Die Entwicklung von Regeln für horizontale Beihilfen 111

4.1.4.1. Allgemeine Investitions- und Beschäftigungsbeihilfen 111

4.1.4.2. Beihilfen für FuE- und Umweltschutzmaßnahmen 114

4.1.4.3. Beihilfen an öffentliche Unternehmen 120

4.2. Subventionen für die Schiffbauindustrie 129

4.2.1. Situation und Entwicklung der Schiffbauindustrie nach $1945 \quad 129$

4.2.2. Reaktion der Mitgliedstaaten 130

4.2.3. Harmonisierungsarbeiten der Kommission $\quad 132$

4.2.3.1. Erste Ansätze zur Subventionskontrolle während des Schiffbaubooms 132

4.2.3.2. Harmonisierungsrückschritte in der Krise 138

4.2.3.3. Ein neuer Anlauf zur umfassenden Kontrolle $\quad 150$

4.2.4. Außenwirkungen der Subventionen und außenwirtschaftliche Absicherung der Subventionspolitik 162

4.2.4.1. Die OECD-Exportkreditabkommen 163

4.2.4.2. Verhandlungen zur Überwindung der Schiffbaukrise 165

4.2.5. Beurteilung der Subventionskontrollpolitik 169

4.2.5.1. Der Weltschiffbau in der Krisenphase 169

4.2.5.2. Die Entwicklung des Subventionsniveaus 172

4.2.5.3. Erfolge bei der Harmonisierung und Kontrolle? 177

4.2.5.4. Wettbewerbs- und Handelswirkungen der Subventionskontrollpolitik 
4.2.5.5. Subventionskontrolle als Mittel der Industriepolitik

4.3. Subventionen für die Stahlindustrie

4.3.1. Situation und Entwicklung bis zum Krisenausbruch

4.3.2. Kommissionshandeln in der 1. Krisenphase 1975-80

4.3.2.1. Die Krisenpläne

4.3.2.2. Erste Ansätze zu verstärkter Subventionskontrolle

4.3.2.3. Der Weg zum 1. Beihilfekodex

4.3.3. Beihilfenkontrolle unter den beiden ersten Kodizes 203

4.3.3.1. Der 1. Beihilfenkodex von 1980

$\begin{array}{ll}\text { 4.3.3.2. Der 2. Beihilfenkodex von } 1981 & 207\end{array}$

4.3.3.3. Die Umsetzung des zweiten Kodex 208

4.3.3.4. Verlängerung des Kodex und Fazit 217

4.3.4. Subventionskontrolle nach der Krise 219

4.3.4.1. Der 3. Kodex - Einengung der Subventionierungsmöglichkeiten?

4.3.4.2. Konvergenz mit den EWG-Vorschriften: Die 4. und 5. Kodizes und der Gemeinschaftsrahmen

4.3.5. Außenwirtschaftliche Absicherung der Subventionspolitik 230

4.3.5.1. Importrestriktionen der Gemeinschaft 230

4.3.5.2. Beschränkungen der EG-Stahlexporte 231

4.3.5.3. Internationale Ansätze zur Subventionskontrolle 233

4.3.6. Beurteilung der Subventionskontrollpolitik 234

4.3.6.1. Die Entwicklung der EG-Stahlindustrie seit dem Krisenausbruch 234

4.3.6.2. Die Entwicklung des Subventionsniveaus 238

4.3.6.3. Erfolge bei der Harmonisierung und Kontrolle? 241

4.3.6.4. Wettbewerbs- und Handelswirkungen der Subventionskontrollpolitik 245

4.3.6.5. Subventionskontrolle als Mittel der Industriepolitik 250

4.4. Subventionen für die Automobilindustrie 258

4.4.1. Entwicklung des Industriezweiges 258

4.4.2. Erste Ansätze zur Subventionskontrolle 260

4.4.3. Versuche der Entwicklung eines umfassenderen Kontrollkonzepts 263

4.4.4. Die Umsetzung des Konzepts in der Genehmigungspraxis 265

4.4.4.1. Einige Anwendungsfälle 265

4.4.4.2. Fazit - Der Stand 1987 
4.4.5. Die Entwicklung des Gemeinschaftsrahmens 272

4.4.6. Durchsetzungsprobleme $\quad 277$

4.4.7. Die Entscheidungspraxis während der Übergangsphase 281

4.4.7.1. Der Inhalt der ursprünglichen Entscheidungen 281

4.4.7.2. Die Umsetzung der Entscheidungen 286

4.4.7.3. Der Fall Volvo Car BV 290

4.4.8. Die Anwendung des Gemeinschaftsrahmens 293

4.4.9. Die Verlängerung des Gemeinschaftsrahmens 304

4.4.10. Außenwirtschaftliche Absicherung der Subventionspolitik 305

4.4.10.1. Die Handelspolitik der EG im Kfz-Bereich gegenüber Japan 306

4.4.10.2. Die Ausdehnung der Subventionskontrolle auf Partnerländer mit Freihandelsabkommen 308

4.4.11. Beurteilung der Subventionskontrollpolitik 310

4.4.11.1. Die jüngere Entwicklung der Automobilindustrie $\quad 310$

4.4.11.2. Die Entwicklung des Subventionsniveaus 313

4.4.11.3. Erfolge bei der Harmonisierung und Kontrolle? 313

4.4.11.4. Wettbewerbs- und Handelswirkungen der Subventionskontrollpolitik 316

4.4.11.5. Subventionskontrolle als Mittel der Industriepolitik 317

5. Fazit: Erfolge und Probleme bei der supranationalen Kontrolle nationaler Subventionen

5.1. Der heutige Stand der Subventionsvergabe durch die Mitgliedstaaten 321

5.2. Probleme der Umsetzung theoretischer Anforderungen in konkrete Konzepte und Leitlinien

5.2.1. Theoretische Subventionsrechtfertigungen und praktische Genehmigungskriterien 328

5.2.2. Relative Verzerrungsintensität und Intensität der Kontrolle 333

5.3. Probleme bei der Durchsetzung des Prüfungsverfahrens 335

5.3.1. Durchsetzung der Notifizierungspflicht der Mitgliedstaaten 335

5.3.2. Entwicklung der Regelung des Prüfungsverfahrens und deren Umsetzung

5.3.3. Transparenz des Kommissionshandelns $\quad 345$

5.3.4. Durchsetzung der Kommissionsentscheidungen 347

5.3.5. Erreichung der Rückzahlung illegaler Subventionen 351 
5.4. Inhaltliche Beurteilung der Subventionskontrollpolitik

5.4.1. Subventionskontrolle unter wechselnden Rahmenbedingungen

5.4.1.1. Kontrollprobleme in den Krisenphasen

5.4.1.2. Binnenmarktprogramm und Verschärfung der Beihilfenkontrolle

5.4.2. Gemeinschaftsrahmen als Instrument der Beihilfenkontrolle Bedeutung und Kritik

5.4.3. Das Problem der Beeinflussung der Kapazitätsentwicklung

5.4.4. Politökonomische Aspekte der Beihilfenkontrolle

5.4.4.1. Das Verhalten der beteiligten Gruppen

5.4.4.2. Das Problem der Kontrolle von Beihilfen an öffentliche Unternehmen

5.4.5. Zum Verhältnis von Wettbewerbs- und Regionalpolitik

5.4.6. Subventionskontrolle und Außenhandelspolitik - Kommissionsvs. Ratskompetenz

5.4.7. Subventionskontrolle als supranationale Lösung des Konflikts zwischen "freier Marktwirtschaft" und "Wohlfahrtsstaat"

6. Mögliche Reformansätze und Alternativen zur jetzigen Regelung

6.1. Generelles Subventionsverbot

6.2. Zentralisierung der Subventionen

6.3. Aufteilung der Subventionskompetenz auf verschiedene Ebenen mit Höchstgrenzen

6.4. Internationale Regeln in Orientierung am GATT

6.5. Festigung des bestehenden regelgebundenen Systems

6.5.1. Erhöhung der Effektivität des Prüfungsverfahrens

6.5.2. Verbesserung der inhaltlichen Aspekte der Beihilfenkontrolle

Anhang: Vertragsartikel

Literaturverzeichnis 
Manfred Rosenstock - 978-3-631-75198-5

Downloaded from PubFactory at 01/11/2019 07:13:36AM

via free access 


\section{ABKÜRZUNGSVERZEICHNIS}

AMC

AWES

B

BAe

BFR

BL

BMF

BMWi

BRT

BSÄ

BSC

COREPER

D

DAC

DTK

GD

DG III

DG IV

DG XII

DK

E

EBRD

ECU

EEA

EFTA

EFRE

EG

EGKS

EGKSV
American Motor Corporation

Association of West European Shipbuilders

Belgien

British Aerospace

Belgischer Franken

British Leyland Motor Corp.

Bundesministerium der Finanzen

Bundesministerium für Wirtschaft

Bruttoregistertonne

Bruttosubventionsäquivalent

British Steel Corporation

Comité des Représentants Permanents (Ausschuß der ständigen Vertreter)

Deutschland

Development Assistance Committee

Durchschnittskosten

Generaldirektion der EG-Kommission

Generaldirektion für Binnenmarkt und gewerbliche Wirtschaft

Generaldirektion für Wettbewerb

Generaldirektion für Wissenschaft, Forschung und Entwicklung

Dänemark

Spanien

European Bank for Reconstruction and Development

Europäische Währungseinheit

Einheitliche Europäische Akte

European Free Trade Association

Europäischer Fonds für Regionalentwicklung

Europäische Gemeinschaften

Europäische Gemeinschaft für Kohle und Stahl

Vertrag zur Gründung der EGKS 
EGV

EIB

EP

ERE

ESA

ESF

EU

EuGH

EWG

EWGV

EWR

$\mathrm{F}$

FAZ

FG

FIM

FN

FNP

FuE

GA

GATT

GBRT

GK

GM

GR

GuV

I

IMF

IRL

KfW

KMU

L

MECU
Verträge zur Gründung der Europäischen Gemeinschaft

Europäische Investitionsbank

Europäisches Parlament

Europäische Rechnungseinheit

EFTA Surveillance Authority

Europäischer Sozialfonds

Europäische Union

Europäischer Gerichtshof

Europäische Wirtschaftsgemeinschaft

Vertrag zur Gründung der EWG

Europäischer Wirtschaftsraum

Frankreich

Frankfurter Allgemeine Zeitung

Förderungsgesetz

Fonds industriel de modernisation

Fußnote

Frankfurter Neue Presse

Forschung und Entwicklung

Gemeinschaftsaufgabe

General Agreement on Tariffs and Trade

Gewichtete Bruttoregistertonne

Grenzkosten

Gemeinsamer Markt

Griechenland

Gewinn- und Verlustrechnung

Italien

International Monetary Fund

Irland

Kreditanstalt für Wiederaufbau

Kleine und mittlere Unternehmen

Luxemburg

Millionen ECU 
MFA

MIRU

MITI

MRS

MRT

MS

NIC

NKA

NL

NSÄ

NTB

NUTS

OC

OECD

$\mathrm{P}$

PPF

PSA

RE

RL

RWI

SAJ

SKR

SVR

TES

UK

VCBV

VER

w

WP6
Multi-Fibre Agreement

Motor Industry Research Unit

Ministry for International Trade and Industry, Japan

Marginale Rate der Substitution

Marginale Rate der Transformation

Mitgliedstaaten der EG

Newly Industrialized Countries

Nutzen-Kosten-Analysen

Niederlande

Nettosubventionsäquivalent

Non-tariff Barriers

Nomenclature des unités territoriales statistiques (Systematik der statistischen Gebietseinheiten)

Offer Curve

Organization for Economic Co-operation and Development Portugal

Production Possibility Frontier (Produktionsmöglichkeitenkurve)

Peugeot Societé Anonyme (Peugeot-Konzern)

Rechnungseinheit der EG

Richtlinie

Rheinisch-Westfälisches Institut für Wirtschaftsforschung

Shipbuilders Association of Japan

Schwedische Kronen

Sachverständigenrat zur Begutachtung der gesamt-

wirtschaftlichen Entwicklung

Temporary Employment Subsidy

Vereinigtes Königreich (Großbritannien)

Volvo Car BV

Voluntary Export Restraint Agreement

Lohnsatz

Working Party 6 (Schiffbauausschuß der OECD) 
Manfred Rosenstock - 978-3-631-75198-5

Downloaded from PubFactory at 01/11/2019 07:13:36AM

via free access 
A free trade regime that does not rein in or seek to regulate artificial subventions will likely help trigger its own demise.

Jagdish Bhagwati ${ }^{1}$

\section{EinLeitung}

Das Projekt der Vollendung des europäischen Binnenmarktes bis Ende 1992 stellte nach den gescheiterten Plänen zur Vollendung der Wirtschafts- und Währungsunion aus den Jahren 1969-71 und der Etablierung des Europäischen Währungssystems 1979 den jüngsten Anlauf der Mitgliedstaaten der Europäischen Gemeinschaften zur Intensivierung ihrer wirtschaftlichen Integration dar ${ }^{2}$. In einem 1985 veröffentlichten Weißbuch ${ }^{3}$ hatte die Kommission die bestehenden Integrationsmängel dargelegt und knapp 300 Vorschläge in drei Gruppen (Beseitigung der technischen, der materiellen und der steuerlichen Schranken) aufgelistet, deren Verabschiedung und Umsetzung durch die Mitgliedstaaten bis zum 31.12.1992 die Verwirklichung der fünf Grundfreiheiten des Gemeinsamen Marktes (Freiheit des Waren-, Dienstleistungs- und Kapitalverkehrs, der Arbeitnehmer und der Niederlassung) sichern sollte. Während die Verabschiedung der Richtlinien fristgerecht erfolgte, gibt es bei der Umsetzung, vor allem in einigen Dienstleistungsbereichen, noch Verzögerungen.

Für die Realisierung der ersten und grundlegenden Freiheit, nämlich derjenigen des Warenverkehrs, wurde bereits bei Gründung der EWG ein fester Zeitplan vereinbart, innerhalb dessen sie durch den Aufbau einer Zollunion und die Abschaffung quantitativer Restriktionen (Quoten) im Handel zwischen den EG-Staaten erreicht werden sollte. Die vorzeitige Erfüllung dieses Zeitplans mit der Verwirklichung der Zollunion 1968 und der vorherigen Eliminierung der Quoten $1962^{4}$ sicherte jedoch nicht die volle Freiheit des Warenverkehrs. Denn abgesehen von technischen oder steuerlichen Hemmnissen, deren Abbau auf der Basis der Vorschläge im Weißbuch angegangen wurde, besteht stets die Gefahr, daß die Mitgliedstaaten die abgeschafften Zölle und Quoten durch Subventionen an nationale Industriezweige oder Einzelunternehmen substituieren, um sich auf diese Weise Vorteile im Wettbewerb

\footnotetext{
1 1988, S. 35.

2 Als nächstes Ziel ist nach dem Vertrag von Maastricht über die EU nunmehr die Wirtschafts- und Währungsunion vorgegeben.

3 Europäische Gemeinschaften, Kommission 1985e.

4 Vgl. Harbrecht 1984, S. 145, 149.
} 
mit Konkurrenten aus den Partnerstaaten zu verschaffen. Der Anreiz für solches Verhalten steigt in Situationen wirtschaftlicher Krisen, seien es nun konjunkturelle Abschwünge oder Probleme des regionalen oder sektoralen Strukturwandels, noch erheblich an, da dann die marktwirtschaftlichen Mechanismen zur Lösung allein nicht auszureichen scheinen und der Druck betroffener Interessengruppen auf die politisch Verantwortlichen zunimmt. Entsprechende Reaktionen der anderen Mitgliedstaaten können dann eine umfassende Wiedererrichtung von Handelsbarrieren bewirken und so die erhofften Vorteile der wirtschaftlichen Integration zunichte machen.

Die Notwendigkeit, hier eine gemeinschaftliche Kontrolle und Begrenzung zu erreichen, wurde bereits von den Vätern des EWG-Vertrages erkannt, die der EGKommission in Art. 92-94, wie später zu zeigen sein wird, weitgehende Kompetenzen zuerkannten. Der Untersuchung der Nutzung dieser Kompetenzen durch die Kommission und der ökonomischen Konsequenzen ihres Handelns auf diesem Gebiet dient die vorliegende Arbeit.

Nach einigen einleitenden Bemerkungen zur Abgrenzung des Subventionsbegriffs sollen im 2. Kapitel zunächst allokationstheoretische Rechtfertigungen für staatliche Eingriffe mittels Subventionen dargelegt werden, die um eine Analyse der Aussagen der Theorie wirtschaftlicher Integration zu den Notwendigkeiten einer Subventionskontrolle innerhalb einer Zollunion bzw. eines Gemeinsamen Marktes ergänzt werden. Eine Betrachtung anderer möglicher Ansätze zur Begründung von Subventionen schließt die theoretischen Überlegungen ab.

In Kapitel 3 werden die rechtlichen Regelungen des EG-Vertrages untersucht ${ }^{5}$, in denen sowohl Kriterien für die Zulässigkeit nationaler Subventionen als auch Regeln für den Ablauf des Kontrollverfahrens festgelegt sind. Ihre relative Tragweite wird durch einen Vergleich mit den Regeln zweier anderer mit Fragen des internationalen Handels befaßter Institutionen, und zwar der EFTA und des GATT, deutlich.

Den eigentlichen Schwerpunkt der Arbeit bildet die Untersuchung der Politik der Kommission im Kapitel 4, die sich nach einer Darstellung des Gesamtrahmens auf drei bedeutende Bereiche subventionspolitischer Staatseingriffe konzentriert. Hierbei sind zum einen die Konzepte der Kommission an den theoretischen Erfordernissen aus Kap. 2 und den rechtlichen Möglichkeiten aus Kap. 3 zu messen, zum anderen ist die tatsächliche Politik mit den ursprünglichen Konzepten zu vergleichen und im Hinblick auf ihre Auswirkungen nach innen auf die Wettbewerbssituation innerhalb

5 Auf die abweichende Regelung des EGKSV wird ebenfalls eingegangen. 
des Gemeinsamen Marktes und nach außen auf die Handelspolitik der EG zu beurteilen.

Diese Detailanalyse erlaubt in Verknüpfung mit den vorher entwickelten theoretischen Kriterien und rechtlichen Rahmenbedingungen eine Bewertung der Erfolge und Probleme einer supranationalen Kontrolle nationaler subventionspolitischer Eingriffe, die in Kap. 5 erfolgt. Diese Bewertung geschieht sowohl im Hinblick auf die Durchsetzung des Prüfungsverfahrens als auch auf die inhaltliche Ausgestaltung der Kontrollkriterien. Beim letzten Aspekt werden zudem Verbindungen zu anderen gemeinschaftlichen Politikbereichen, wie der Industrie-, Regional- und Außenhandelspolitik, deutlich.

Dieses Ergebnis der Untersuchung bildet dann den Ausgangspunkt für eine vergleichende Betrachtung möglicher Reformansätze und Alternativen zur Weiterentwicklung der gemeinschaftlichen Subventionskontrollpolitik (Kap. 6). Hierbei werden extreme Zentralisierungsansätze, wie ein generelles Subventionsverbot oder eine ausschließliche Vergabekompetenz der supranationalen Ebene, ebenso diskutiert wie partielle Verlagerungen der Kontrolle auf nationale und internationale Ebenen. Schließlich werden Vorschläge zur Erhöhung der Effektivität des bestehenden Systems gemacht, die sowohl beim Verfahren als auch bei der inhaltlichen Ausgestaltung ansetzen und die auch mit Blick auf ihre Verträglichkeit mit den Zielen des Binnenmarktprojekts analysiert werden. 
Manfred Rosenstock - 978-3-631-75198-5

Downloaded from PubFactory at 01/11/2019 07:13:36AM

via free access 
If an economist sticks rigidly to the proposition that there is something absolute about policy recommendations based on welfare economics, with its emphasis on consumer sovereignty, then he is likely to be in a minority of one!

Alan T. Peacock ${ }^{1}$

\section{WIRTSCHAFTSTHEORETISCHE GRUNDLAGEN}

Es entspricht schon fast einer Tradition, jede Arbeit zu einem Subventionsthema mit Überlegungen zum Subventionsbegriff zu beginnen. Da keine allgemein anerkannte, quasi "naturwissenschaftliche" Definition von Subventionen existiert, sind hier den Variationsmöglichkeiten der Definitoren kaum Grenzen gesetzt. An dieser Stelle soll zunächst nur eine grobe Bestimmung erfolgen, die es vor allem erlaubt, einige Aspekte auszuschließen, da später im Zusammenhang der Diskussion der EGVerträge (Kapitel 3) eine erneute Begriffsklärung notwendig werden wird.

Subventionen ${ }^{2}$ sind selektive begünstigende finanzielle Eingriffe der öffentlichen Hand in den Unternehmenssektor. Hierbei sind Unterstützungen für im Besitz des Staates befindliche Unternehmen eingeschlossen, Finanzausgleichsmaßnahmen zwischen Gebietskörperschaften jedoch ebenso ausgeschlossen wie Transfers sozialer Art an private Haushalte, deren Primärziel die Erhöhung des Einkommens der Begünstigten ist. Von den Empfängern wird keine direkte Gegenleistung erwartet, jedoch erfolgt die Gewährung unter Auflagen bzgl. des Empfangs oder der Verwendung der Hilfen, wodurch sich aus Sicht der Unternehmen relevante relative Preise verändern ${ }^{3}$. Ziel des öffentlichen Subventionsgebers ist es, hierdurch Verhaltensänderungen der Privaten zu veranlassen, um so die marktwirtschaftlichen Allokations- bzw. Distributionsergebnisse oder die auftretenden zyklischen Schwankungen der Wirtschaftstätigkeit entsprechend politischen Zielen zu korrigieren.

1 1990, S. 25.

2 Vgl. auch die Definitionen bei Andel 1970, S. 4-6, Hansmeyer 1977, S. 961-963, Prest 1976, S. 65, Seidel 1985, S. 67/68 und Zachau-Mengers 1930, S. 4.

3 Hinsichtlich der Form der Subventionsvergabe ist zu sagen, daß Subventionen nicht nur in Form direkter Finanzhilfen gewährt werden können, sondern bspw. auch als Steuervergünstigungen, zinsverbilligte Kredite oder Bürgschaften ohne adäquate Risikoprämien usw. Insbesondere bei den letztgenannten Formen entspricht der Nominalbetrag der staatlichen Zahlung nicht dem Beihilfeelement, sondern letzteres liegt niedriger. 


\subsection{Allokative Begründbarkeit von Subventionen}

Das politische Ziel mag zunächst nur darin bestehen, eine Abweichung vom Allokationsoptimum aufgrund eines Marktversagens zu beheben. Hierfür sind verschiedene Ursachen denkbar.

\subsubsection{Sinkende Durchschnittskosten 4}

Einer dieser möglichen Gründe einer Verfehlung der Allokationseffizienz ist in sinkenden langfristigen Durchschnittskosten einzelner Produzenten im gesamten Bereich der Marktnachfrage zu sehen. Für dieses Phänomen können zwei Ursachen verantwortlich $\operatorname{sein}^{5}$ : Zum einen können steigende Skalenerträge auftreten, d.h. daß aus technischen oder organisatorischen Gründen mit steigendem Output die Produktionskosten unter der Annahme konstanter Faktorpreise unterproportional wachsen. In diesem Fall sinken sowohl die Durchschnitts- (DTK) als auch die Grenzkosten (GK), wobei letztere niedriger sind als erstere. Zum anderen mag die Produktion mit hohen Fixkosten verbunden sein, die durch Unteilbarkeit des Kapitaleinsatzes verursacht sind. Bei überragender Bedeutung dieser Fixkostenblöcke kann ihre Degression mit steigendem Output selbst bei wachsenden Grenzkosten noch $\mathrm{zu}$ fallenden DTK führen.

Abb. 2-1 Sinkende Durchschnittskosten 6

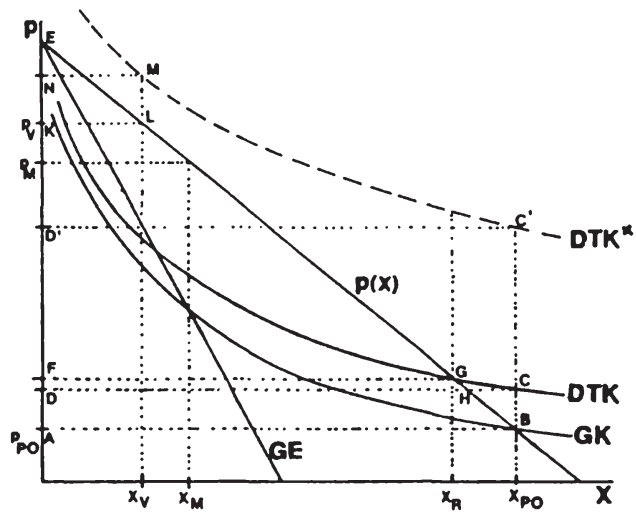

4 Vgl. zu einer guten überblicksartigen Darstellung Pfähler 1984, S. 470-475.

5 Vgl. Knight 1924, S. $595 f$.

6 Quelle: Pfähler 1984. 
Im "reinen" Fall steigender Skalenerträge führt eine Preisbildung nach der Grenzkostenpreisregel für alle Unternehmen zu Verlusten in Höhe von (DTK - GK)* $\mathrm{x}_{\mathrm{po}}=$ $\mathrm{ABCD}$ (Abb. 2-1). Daher werden sie ihre Ausbringung nur bis zu jener Menge $\mathrm{x}_{R}$ erhöhen, bei der der Preis den DTK entspricht. Liegt diese Menge im Vergleich zur gesamten Produktion der Branche relativ hoch, so können einer oder wenige Anbieter, die in der Lage sind, ihre Produktionsmenge laufend zu erhöhen und einen Teil der Kostensenkung zu Preissenkungen nutzen, alle anderen Produzenten aus dem Markt drängen; es entsteht ein enges Oligopol oder im Extremfall sogar eine Monopolsituation7. Ist der (Wieder-)Eintritt in den Markt für potentielle Konkurrenten mit hohen Kosten verbunden, so kann der Anbieter dieses sog. natürliche Monopol aufrechterhalten und bei der Menge $x_{M}$ seinen Gewinn bei $p_{M}$ maximieren.

Beide Mengen $x_{R}$ und $x_{M}$ stellen ineffiziente Lösungen dar, da sie unterhalb der optimalen Ausbringungsmenge $\mathrm{x}_{\mathrm{po}}$ bleiben. In diesen Fällen kann ein staatlicher Eingriff zu einer Wohlfahrtssteigerung führen, wenn der Staat den Anbieter zur Grenzkostenpreissetzung verpflichtet und seinen Stückverlust bei $\mathrm{x}_{\mathrm{po}}$ in Höhe von DTKGK durch eine Subvention abdeckt. Ein Vergleich der gesellschaftlichen Gesamtwohlfahrt zwischen den Produktionsmengen $x_{R}$ und $x_{p o}$ zeigt folgendes: In der Situation $x_{R}$ beträgt der Netto-Wohlfahrtsgewinn (Gesamtnutzen der Konsumenten minus Gesamtkosten der Produktion) FGE. Bei der Produktion von $\mathrm{x}_{\mathrm{po}}$ hingegen steigt die Konsumentenrente ${ }^{8}$ auf $\mathrm{ABE}$, die Steuerzahler müssen jedoch die Ressourcen zur Abdeckung der Verluste der Produzenten von $A B C D$ aufbringen. Dieser Netto-Wohlfahrtsgewinn $\mathrm{ABE}-\mathrm{ABCD}=\mathrm{DHE}-\mathrm{HBC}$ übersteigt denjenigen bei kostendeckender Preissetzung FGE um FDHG - HBC. Selbst im Fall einer höher liegenden Durchschnittskostenkurve DTK* kann ein sozialer Vorteil durch Verlustsubventionierung entstehen, wenn im Vergleich zur privaten Alternative Nichtaufnahme der Produktion der Gewinn an Konsumentenrente ABE die Wohlfahrtskosten der Verlustfinanzierung von $\mathrm{ABC}$ ' $\mathrm{D}^{\prime}$ übersteigt.

Bei der Verwirklichung dieser allokativ optimalen Lösung entstehen Probleme durch die hohen Informationsanforderungen bzgl. der Lage der Kosten- und Nachfragekurven bzw. der individuellen Wohlfahrtsgewinne und -verluste, so daß wohl nur eine Näherung an die optimale Subventionshöhe und Ausbringungsmenge erreicht werden kann. Weiterhin sind Effizienzkosten durch die Subventionsaufbringung zu erwarten, von denen jedoch hier und in den Folgeabschnitten

\footnotetext{
7 Vgl. Lehner/Meiklejohn/Reichenbach 1991, S. 20.

8 Diese sei hier als Wohlfahrtsmaß akzeptiert. Zur Problematik dieser Vorgehensweise vgl. Sohmen 1976, S. 404-407.
} 
abstrahiert wird. Bei dynamischer Betrachtung besteht zudem die Gefahr, daß aufgrund der staatlichen Verlustdeckungsgarantie der private Anbieter nicht kostenminimal produziert und auch keinen Anreiz hat, Innovationen vorzunehmen (AverchJohnson-Effekt) ${ }^{9}$.

\subsubsection{Externalitäten}

\subsubsection{Darstellung des Konzepts 10}

Von allen Argumenten für allokationspolitisch motivierte staatliche Eingriffe mittels Subventionen ist das des Auftretens externer Effekte wohl das am häufigsten vorgebrachte. Unter externen Effekten versteht man die aus der Produktions- oder Konsumaktivität eines Wirtschaftssubjekts auftretenden Wirkungen auf die Produktionsmöglichkeiten oder den Nutzen (somit die Wohlfahrt) anderer Wirtschaftssubjekte, die nicht über den Markt- und Preismechanismus gesteuert werden (Bsp. Wasserverschmutzung durch Industrieunternehmen mit Schädigung von Fischern) ${ }^{11}$.

Externe Effekte können nur aufgrund der Unvollständigkeit des Systems von Märkten auftreten. Dieser Mangel entsteht durch das Fehlen durchsetzbarer Eigentumsrechte an von mehreren Individuen genutzten Gütern (Bsp. Luft), entweder weil Nichtausschließbarkeit der Nutzung vorliegt oder weil der Ausschluß mit zu hohen Transaktions- und Kontrollkosten verbunden ist 12 .

Verursacher und Betroffene von Externalitäten können jeweils einzelne oder Gruppen von Produzenten oder Konsumenten sein, wobei die Stärke der externen Effekte als Folge der Tatsache der Produktion oder des Konsums fix sein kann oder mit deren Menge variieren kann ${ }^{13}$. Im folgenden soll lediglich der Fall der produktions- oder konsumvariablen Externalitäten betrachtet werden.

9 Vgl. Averch/Johnson 1962, S. 1052-1069, und Pfähler 1984, S. 475, 472.

10 Eine gute lehrbuchartige Gesamtdarstellung für den Fall der geschlossenen Wirtschaft bieten Boadway/Wildasin 1984, S. 105-126.

11 Häufig werden diese eigentlichen "realen" Externalitäten (auch technologische externe Effekte genannt) den sog. pekuniären Externalitäten, bei denen Nachfrage- oder Angebotsveränderungen auf einem Markt zu Preisveränderungen auf anderen Märkten führen (Bsp. Bau einer Brücke und Beeinflussung von Nachfrage und Preis nach Fährschiffleistungen) gegenübergestellt. Vgl. Scitovsky 1954, S. 143-147. Im letzten Fall findet aber nur eine Umverteilung von Renten über Märkte statt, es handelt sich nicht eigentlich um externe Effekte außerhalb der Marktbeziehungen. Vgl. Schumann 1987, S. 405/406.

12 Vgl. Meade 1973, S. 18, 34.

$13 \mathrm{Vgl}$. Buchanan/Stubblebine 1962, S. 372f. 
Das Auftreten externer Effekte bei der Produktion führt zu einer ineffizienten Ausbringungsmenge der mit ihnen verbundenen Güter durch den Markt, da die Hersteller jeweils die Produktion bis zur Gleichheit von Preis und privaten Grenzkosten ausdehnen werden. Das Pareto-Optimum wird jedoch erreicht, wenn der Preis den sozialen GK entspricht, was bei Vorliegen externer Kosten (Erträge) bei einer gegenüber dem Marktgleichgewicht niedrigeren (höheren) Produktionsmenge gelingt.

Sind die externen Kosten oder Erträge abhängig von der Einsatzmenge eines Faktors durch den verursachenden Produzenten, so sollten diese externen Grenzprodukte bei der Bestimmung der Faktorentlohnung eingehen, so daß bei vorgegebener Marktrendite bzw. -entlohnung die optimale Faktoreinsatzmenge in dieser Branche steigt oder fällt. Treten hingegen Nutzeninterdependenzen zwischen Konsumenten auf, so müßte der Verursacher zur Erreichung des Optimums diese externen Vor- oder Nachteile anderer Wirtschaftssubjekte aus seinem Konsum bei der Ermittlung des Haushaltsoptimums erfassen.

Da externe Effekte definitionsgemäß nicht auf Märkten gehandelt werden, werden die eben beschriebenen sozialen Optima trotz individuell rationalen Verhaltens verfehlt, da die Marktpreise die sozialen Kosten und Erträge verzerrt wiedergeben.

Zur Lösung dieses Problems sind diverse Ansätze entwickelt worden, die man in drei Gruppen trennen kann: Auf der einen Seite kann der Staat durch Festlegung von Eigentumsrechten versuchen, die Privaten zu Verhandlungen zu veranlassen mit dem Ziel, das allokative Optimum zu erreichen (Coase-Lösungen 14); auf der anderen Seite kann er durch finanzielle Anreiz- und Sanktionsmechanismen (Steuern bzw. Subventionen) die relativen Preise direkt verändern, um so die marktlichen Verzerrungen zu korrigieren (Pigou-Lösungen ${ }^{15}$ ). Schließlich kann der Staat bei negativen Externalitäten einen Markt für diese negativen externen Effekte (z.B. Verschmutzungsrechte) schaffen, indem er sich das Eigentum an derartigen Verschmutzungsrechten zunächst selbst zuteilt, um es dann bis zu einer gesellschaftlich definierten Höchstgrenze zu verkaufen. Diese sog. Zertifikatslösung führt zu einer effizienten Kontrolle der Erzeugung negativer Externalitäten, da diejenigen Erzeuger solche Zertifikate erwerben werden, deren Kosten der Emissionsreduktion am höchsten liegen. Zur Erzielung des Optimums müssen die Erzeuger solche Rechte auch untereinander handeln können. Hier soll nun lediglich auf den zweiten Ansatz, und zwar nur auf die Möglichkeit des Einsatzes von Subventionen zur Internalisierung externer Effekte, eingegangen werden.

14 Vgl. Coase 1960, S. 1-44.

15 Vgl. Pigou 1962, S. $192 \mathrm{ff}$. 
Zunächst sei der Fall externer Erträge (positiver Externalitäten) betrachtet. In der Abb. 2-2 ist die Situation eines Produzenten mit konstanten Grenzkosten dargestellt, der sich einer fallenden Marktnachfragekurve (marginalen Kurve des privaten Vorteils) $\mathrm{N}_{\mathrm{pr}}$ gegenübersieht. Unter Wettbewerbsbedingungen wird im Punkt E die Menge $\mathrm{x}_{\mathrm{p}}$ produziert. Nun sei die Produktion von $\mathrm{X}$ mit externen Vorteilen für andere Wirtschaftssubjekte $\mathrm{MV}_{\mathrm{B}}$ verbunden, deren Höhe mit der Menge von $\mathrm{x}$ wächst. Addiert man diese externen Vorteile zu den internen aus der Produktion des Gutes, erhält man die Kurve des sozialen Vorteils $\mathrm{N}_{\text {soz }}$. Das gesellschaftliche Optimum liegt also in $\mathrm{C}$ bei $\mathrm{x}^{*}$. Es wird erreicht, indem der Staat den Produzenten eine Stücksubvention von BC, der Differenz zwischen privatem Vorteil und privaten Kosten im sozialen Optimum, gewährt 16 . Für den Produzenten ist für $\mathrm{x}<\mathrm{x}^{*}$ die Summe aus Subvention und erzielbarem Preis für Gut $\mathrm{X}$ immer höher als die Grenzkosten, so $\mathrm{da} ß$ er nun einen Anreiz besitzt, die Produktion bis $\mathrm{x}^{*}$ auszudehnen. Die Wohlfahrtsanalyse zeigt, daß neben dem Subventionstransfer in Höhe von ABCD vom Staat an die Produzenten die von der Externalität Betroffenen BCFE gewinnen, während die Produzenten für den Verlust von EBC durch die Subvention mehr als entschädigt werden. Der soziale Gewinn beträgt somit ECF 17 .

Abb. 2-2 Subventionen bei positiven Externalitäten

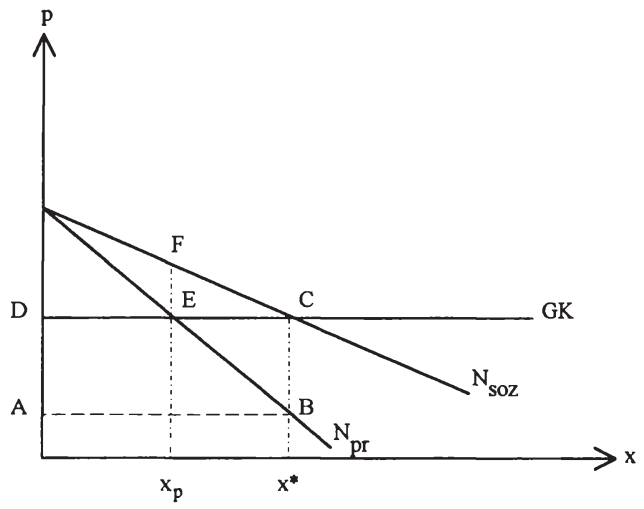

Intuitiv weniger einleuchtend ist die Internalisierung mittels Subventionen im Falle negativer externer Effekte. Doch auch hier kann auf diese Weise das allokativ gewünschte Ergebnis erreicht werden. Abb. 2-3 gleicht Abb. 2-2 mit dem Unter-

16 Vgl. Sohmen 1976, S. 232.

17 Vgl. Ebenso wie im Fall der sinkenden Durchschnittskosten wird unterstellt, daß mit der Aufbringung der Subventionsmittel keine Mehrbelastungen verbunden sind. 
schied, daß nun die Empfänger der Externalität negativ von ihr betroffen sind, und somit die $\mathrm{MV}_{\mathrm{B}}$ als Kosten zu GK addiert werden müssen, um die gesellschaftliche Grenzkostenkurve $\left(\mathrm{GK}+\mathrm{MV}_{\mathrm{B}}\right)$ zu erhalten. Das soziale Optimum bei $\mathrm{x}^{*}$ liegt nun bei einer geringeren Ausbringungsmenge als das privatwirtschaftliche $x_{p}$. Es wird erreicht durch eine staatliche Subvention von AD, der Externalität im Optimum, pro reduzierte Outputeinheit ausgehend vom privaten Optimum $x_{p}$. Der Anreiz zur Produktionsreduktion entsteht für A dadurch, daß für $\mathrm{x}>\mathrm{x}^{*}$ die Summe aus Subvention $(A D=G C)$ und Einsparung an Ressourcenkosten $C X_{p}$ höher ist als der entgangene Gewinn aus dem Verzicht auf die Produktion. Wiederum offenbart die Wohlfahrtsanalyse einen sozialen Gewinn aus der Internalisierung, denn neben dem Subventionstransfer AGCD vom Staat an die Produzenten steht den Verlusten an Konsumentenrente von ACD der Nachteilsrückgang der von der Externalität Betroffenen von $\mathrm{ABCD}$ gegenüber, so daß der Gesellschaft ein Gewinn von $\mathrm{ABC}$ verbleibt.

Wird die positive oder negative Externalität durch den Einsatz eines Produktionsfaktors ausgelöst, so ist die eben dargestellte Analyse entsprechend auf den Faktormarkt zu übertragen.

Abb. 2-3 Subventionen bei negativen Externalitäten

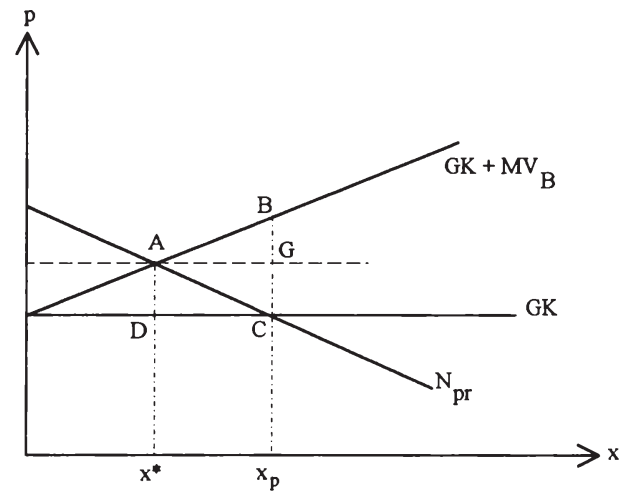

Die vorangegangene Partialanalyse läßt sich auf eine 2-Sektoren-Wirtschaft übertragen, anhand derer auch die Außenhandelswirkungen demonstriert werden können. Die Transformationskurve PP' in Abb. 2-4 zeigt die "wahren" Produktionsmöglichkeiten der Gesellschaft, d.h. die soziale Transformationsrate ${ }^{18}$. Es sei angenommen, daß die Produktion von x positive externe Effekte verursacht. Im Falle der geschlos-

18 Vgl. Rose 1986, S. 426-429. 
senen Wirtschaft stellt sich dann etwa die Preisgerade $p_{h}$ ein, bei der das Preisverhältnis dem der privaten Grenzkosten entspricht. In Punkt A tangiert die Preisgerade eine Indifferenzkurve, d.h. hier entspricht die Grenzrate der Substitution (MRS) der privaten Grenzrate der Transformation (MRT). Dieser Punkt ist jedoch ineffizient, da das Preisverhältnis nicht der sozialen MRT entspricht. Bei Aufnahme des Außenhandels muß sich das Inland (kleines Land) auf das Weltmarktpreisverhältnis $\mathrm{p}_{\mathrm{i}}$ einstellen, bei dem der Preis von $\mathrm{x}$ niedriger liegt als vorher. Aufgrund des verzerrten Inlandspreisverhältnisses spezialisiert sich das Inland auf Gut y, produziert in B und erreicht durch Tausch (Export von y) den Punkt C, in dem die MRS dem Weltmarktpreisverhältnis $\mathrm{p}_{\mathrm{i}}\left(\mathrm{MRT}_{\mathrm{a}}\right)$, nicht aber der MRT $\mathrm{T}_{\mathrm{i}}$ entspricht und dessen Nutzenniveau unterhalb desjenigen bei Autarkie liegt ${ }^{19}$.

Das soziale Optimum wird durch eine Subventionierung der Produktion von $\mathrm{x}$ verwirklicht ${ }^{20}$, durch die die private $\mathrm{MRT}_{\mathrm{i}}$ an die soziale $\mathrm{MRT}_{\mathrm{i}}$ und das Weltmarktpreisverhältnis (Terms of trade, $\mathrm{MRT}_{\mathrm{a}}$ ) angeglichen und so der Produktionspunkt D erreicht wird, von dem aus das Inland durch Export von $\mathrm{x}$ und Import von y das höchstmögliche Nutzenniveau in E erreicht.

Abb. 2-4 Externalitäten und Außenhandel (Indifferenzkurven wurden nicht eingezeichnet)

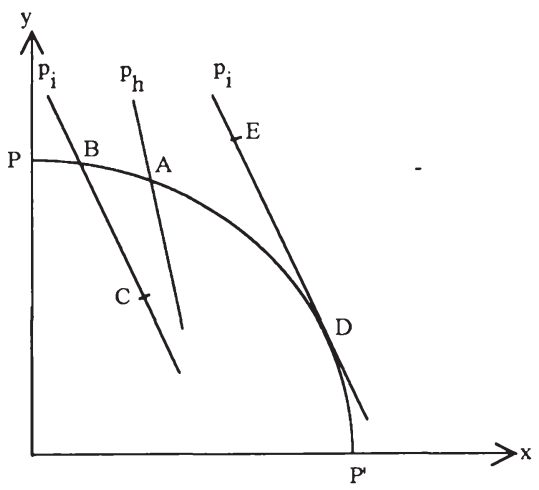

Auch wenn in beiden Situationen im Modell das Allokationsoptimum erreicht wird, so sind doch Probleme bei der praktischen Umsetzung zu erwarten. Zunächst entsteht die Schwierigkeit der Festlegung der Bemessungsgrundlage. Sie muß der

19 Vgl. Bhagwati/Ramaswami 1963, S. 45/46.

20 Vgl. Rose 1986, S. 435. 
Produktion (bzw. den durch sie verursachten Externalitäten) vor einem staatlichen Eingriff entsprechen. Genauer gesagt muß es das Produktionsvolumen sein, bevor die Produzenten von der Einführung der Subvention Kenntnis erhalten, da für sie ansonsten im 2. Fall der Anreiz besteht, die Produktion und damit die Externalität (z.B. Verschmutzung) noch zu erhöhen bzw. im 1. Fall beide umgekehrt zu senken, um so das zu erhaltende Subventionsvolumen zu erhöhen.

Des weiteren bieten die Extraprofite aufgrund der Subventionierung einen Anreiz zum Markteintritt. Bei steigenden GK aller Anbieter führt ihr Hinzukommen zu einer Senkung des Outputs aller Marktteilnehmer bei gleichzeitiger Erhöhung des Branchenoutputs. Während dieser Effekt bei positiven Externalitäten erwünscht ist, konterkariert er bei negativen externen Effekten die Zielsetzung der Subvention, so daß hier eine Schließung des Marktes notwendig wird 21 .

Schließlich verlangt eine Subventionierung in Höhe des externen Schadens oder Nutzens der Betroffenen einen verschieden hohen Subventionssatz je nach Stärke der Betroffenheit. Wird ein derartig differenziertes System aus praktischen oder rechtlichen Gründen abgelehnt, so kann das allokative Optimum nicht genau erreicht werden $^{22}$.

\subsubsection{Mögliche Anwendungsbereiche}

Ein möglicher Anwendungsfall für Subventionen beim Auftreten externer Erträge findet sich im Bereich von Forschung und Entwicklung. Erfolgreiche FuE in der Industrie führt häufig zu Kostensenkungen in der Produktion (Verfahrensinnovation), wodurch dem Unternehmen zusätzliche Erträge entstehen. Gleichzeitig wäre es aber möglich, daß andere Wettbewerber in diesem Markt ohne zusätzliche Entwicklungskosten dieses Verfahren nutzen. Hat der Innovator keine Mittel, dies zu verhindern, so werden seine FuE-Aufwendungen ineffizient niedrig sein, da es ihm nicht gelingt, die externen Erträge bei seinen Konkurrenten zu internalisieren ${ }^{23}$.

Das heute i.d.R. angewandte Verfahren zur Lösung dieses Problems ist das Patentsystem, das jedoch ebenfalls ineffizient ist ${ }^{24}$. Führt eine Verfahrensinnovation bspw. zu einer Kostensenkung von $\mathrm{GK}_{0}$ auf $\mathrm{GK}_{1}$ (vgl. Abb. 2-5) und kann der Innovator aufgrund des Patentschutzes andere von dessen Nutzen ausschließen, so wird er einen Preis knapp unter $\mathrm{GK}_{0}$ setzen, um so alle Konkurrenten aus dem Markt zu

\footnotetext{
21 Vgl. Meade 1973, S. 64.

22 Vgl. Cornes/Sandler 1986, S. 54/55, 59.

23 Vgl. Vickers 1985, S. 208.

24 Vgl. Boadway/Wildasin 1984, S. 127.
} 
drängen. Die dabei gewonnene Innovationsrente von fast ADEB stellt den Anreiz zur Forschung dar und wird zumindest z.T. zur Aufbringung der FuE-Kosten benötigt. Bei einer Preissenkung auf $\mathrm{GK}_{1}$ jedoch wäre ein sozialer Gewinn von AGEB zu verbuchen, der die Innovationsrente um das Marshallsche Dreieck DGE übersteigt. DGE wäre somit auch der gesellschaftliche Nettogewinn, wenn es gelänge, durch Forschungssubventionen selbst bei gleichem FuE-Output den Innovator zur Preissetzung bei $\mathrm{GK}_{1}$ zu veranlassen. Deren Höhe läßt sich an Abb. 2-6 illustrieren: Hier werden steigende Grenzkosten und sinkende Grenzerträge mit steigenden Innovationen angenommen. Aus Sicht des Unternehmens liegt das Optimum bei OD Innovationsausgaben. Das gesellschaftliche Optimum einschließlich der externen Erträge liegt jedoch bei OE. Dieses kann nun durch eine Subvention in Höhe von AC pro Innovationsausgabeneinheit erreicht werden, um so die Grenzkosten des Unternehmens zu senken. Die dargestellte Argumentation ist übertragbar auf die Entwicklung von Schlüsseltechnologien, von denen spillouts auf andere Industrien erwartet werden 25 . Generell kann man erwarten, daß die Differenz zwischen sozialen und privaten Grenzerträgen vor allem im Bereich der Grundlagenforschung groß ist, da hier die unmittelbaren Erträge des forschenden Unternehmens gering sind, während die Anzahl der potentiellen Empfänger externer Erträge durch die i.d.R. breite Nutzbarkeit der Erträge der Grundlagenforschung außerordentlich groß ist.

Abb. 2-5 Patentsystem vs. FuE-Subventionen 26

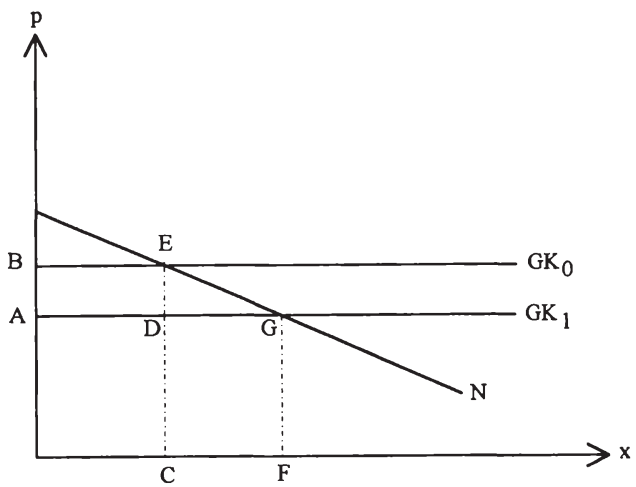

25 Vgl. Klodt 1987, S. 5-6. Ein weiteres Argument besteht darin, daß selbst bei Vergabe von Lizenzen an Konkurrenten die Gebühr weit über den i.d.R. sehr geringen Kosten des Wissenstransfers liegt, so daß über die Umlegung der Gebühren auf den Produktpreis dieser zu hoch und die Diffusion dementsprechend ineffizient niedrig liegt. Vgl. Chard/Macmillen 1979, S. $134 f$.

26 Quelle: Klodt 1987. 
Die Problematik dieses an sich effizienten Ansatzes liegt in der Verteilung des Risikos und in den Informationsanforderungen. Während beim Patentsystem das Risiko des Erfolges der Forschung allein beim Unternehmen liegt, geht dieses bei Subventionen auf den Staat über, der somit über sehr große Informationen bzgl. der zukünftigen externen Erträge bestimmter Forschungsrichtungen verfügen muß 27 .

Abb. 2-6 Wirkungen von FuE-Subventionen28

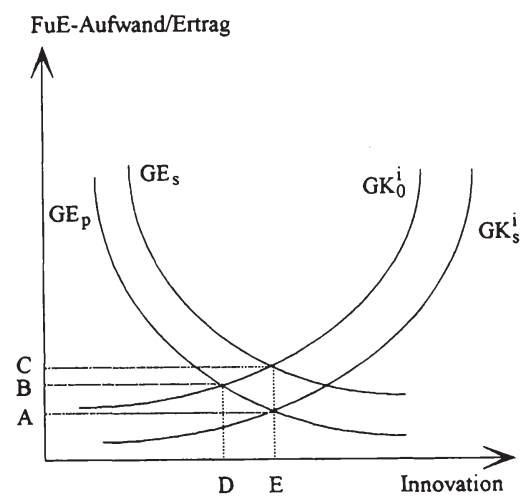

Subventionen zur Internalisierung negativer externer Effekte spielen vor allem im Umweltschutzbereich eine Rolle, wenn Verschmutzer eine Förderung für solche Investitionen erhalten, die zu einer Emissionsverminderung führen. Solche Hilfen sind Ausdruck der Anwendung des Gemeinlastprinzips.

Die Externalitätenbetrachtung kann auch zur Rechtfertigung einer Regionalpolitik benutzt werden. Kürzere Transportwege durch größere Nähe zu Kunden und Lieferanten, gut ausgebaute Verkehrsinfrastruktur und evtl. Vorteile der Großserienproduktion führen zu höheren Faktorentgelten in Ballungszentren, die Anreiz zur weiteren Ballung bieten. Diese Entgelte berücksichtigen jedoch nicht die externen Kosten der Ballung, wie z.B. Verschmutzung mit ihren weiteren Folgen (Krankheit), Lärm, Verkehrsprobleme, u.ä.m. Nimmt man an, daß viele dieser Probleme erst oberhalb eines gewissen Schwellenwertes an Ballung entstehen, so wäre eine partielle Verlagerung der Produktion in dünn besiedelte und/oder wenig industrialisierte Gebiete mit sozialen Vorteilen, d.h. einer Allokationsverbesserung, verbunden ${ }^{29}$.

27 Vgl. Brümmerhoff 1987, S. 70.

28 Quelle: Klodt 1987.

29 Vgl. Biehl/Münzer 1980, S. 136/137, und Biehl 1981, S. $132 \mathrm{f}$. 
Im Sinne des Externalitätenansatzes wären hier somit Subventionen für die Verlagerung von Produktionseinheiten aus Ballungszentren in andere Gebiete gerechtfertigt, wobei neben Subventionen für die Produktion auch solche für die Faktoren Arbeit bzw. Kapital denkbar sind, da beide Faktoren für einen Teil der oben angeführten Ballungskosten verantwortlich sind 30 .

Eine weitere Rechtfertigung für Faktorsubventionen ist in den sog. "Einkommensverlustexternalitäten" 31 zu finden. Hiermit ist gemeint, daß der Nutzen von Individuen von plötzlichen und wahrnehmbaren Realeinkommensverlusten anderer Individuen negativ beeinflußt wird, so daß versucht wird, solche Verluste zu verhindern (Mitleidsaspekt). Eine weitere Motivation zum Ausgleich solcher Verluste besteht in der Unsicherheit darüber, ob man in Zukunft nicht selbst in der Situation des potentiellen Verlierers sein könnte (Versicherungsaspekt) ${ }^{32}$. Corden 33 spricht in diesem Zusammenhang von einer konservativen sozialen Wohlfahrtsfunktion, die risikoscheuem Verhalten gerecht wird. Da der Nutzen aus der Kompensation der Verlierer Aspekte eines öffentlichen Gutes besitzt, ist kollektives Handeln angebracht. Tritt ein plötzlicher Einkommensverlust einer Gruppe auf, bspw. der Produktionsfaktoren in einer bestimmten Industrie aufgrund von Verlusten an Wettbewerbsfähigkeit gegenüber ausländischen Konkurrenten, so läge die beste Lösung darin, den Verdrängungsmechanismus arbeiten zu lassen und die Verluste der im Inland Betroffenen durch von den Gewinnern mittels Steuern finanzierte Sozialtransfers auszugleichen. Neben den Effizienzkosten der Mittelaufbringung und Feststellung der Anspruchsberechtigung wird dies jedoch durch das Problem erschwert, die Gewinner und Verlierer sowie die Höhe der jeweiligen Gewinne und

30 Der von Biehl/Münzer (1980) vertretene Ansatz geht insofern weiter als die hier vorgenommene Analyse, da die Autoren im Sinne eines "Tax-cum-subsidy-approach" neben den Subventionen für Investitionen in unterentwickelten Räumen eine simultane Besteuerung überagglomerierter Räume vorschlagen. In einer langfristigen Perspektive wäre es allerdings wichtiger, das regionale Entwicklungspotential benachteiligter Regionen zu erhöhen, v.a. durch Verbesserung der dortigen Infrastruktureinrichtungen. Auf diese Weise können die erzielbaren Faktorentgelte in diesen Regionen erhöht und Investitionen leichter attrahiert werden, während die Notwendigkeit für direkte Beihilfen an die Produktionsfaktoren sinkt. Vgl. Biehl 1988, S. 94f. Da eine solche Infrastrukturförderung aus der hier benutzten Subventionsdefinition ebenso wie der (in Kap. 3 dargelegten) Beihilfendefinition des EGV herauställt und damit über die Problemstellung dieser Arbeit hinausführt, soll sie im weiteren nicht mehr betrachtet werden.

31 Dieser Begriff wurde von Chard/Macmillen (1979, S. 137) geprägt.

32 Vgl. Corden 1974, S. 107f., und Harzem 1988, S. 158, 160/161.

33 1974, S. 107. 
Verluste zu bestimmen. Aufgrund dieser Informationsprobleme bietet sich als zweitbeste Lösung die Subventionierung der Produktionsfaktoren in dieser Industrie an ${ }^{34}$.

Dieser Schutz hätte dann vorübergehend und degressiv zu sein, da einerseits die konservative soziale Wohlfahrtsfunktion nur Schutz vor abrupten Einkommensverlusten verlangt, andererseits im Laufe der Zeit Informationen über Gewinner und Verlierer gesammelt werden können, die danach direkte Umverteilungsmaßnahmen erlauben $^{35}$. Bei dynamischer Betrachtung ist das Ziel noch besser durch Anpassungsbeihilfen an die potentiell Freigesetzten zu erreichen, vor allem wenn die Anpassung ohne staatlichen Eingriff zu langsam abläuft, da Informationsdefizite bestehen oder die private Risikoaversion bzw. die privaten Mobilitätskosten aufgrund der Notwendigkeit einer Umschulung höher als die entsprechenden sozialen Größen sind. In bezug auf die Mobilitätskosten paßt dieses Argument auch zum vorgenannten Aspekt der Regionalbeihilfen. Im Vergleich zu einem Einkommensschutz mittels Zollschranken führen sowohl Anpassungshilfen als auch Einkommensbeihilfen zu einer pareto-besseren Ressourcenverwendung ${ }^{36}$. Dennoch verläßt diese Betrachtung den engen Rahmen des allokativen Marktversagens insoweit, als sie Aspekte der Einkommensverteilung (im Sinne einer paretooptimalen Umverteilung) in die Nutzenfunktionen der Individuen eingehen läßt.

\subsubsection{Verwandte Fälle}

Ein ähnlicher Ansatz versucht, Umstrukturierungshilfen mit dem Argument unvollkommener Informationen zu rechtfertigen. Verlangen Veränderungen der Technologie oder der Marktbedingungen die Umstrukturierung einer Industrie hin zu größeren Einheiten, so ist ein allokatives Argument für Fusionen gegeben. Hierbei bestehen aber i.d.R. Informationsdefizite über die Struktur und Situation der jeweiligen potentiellen Partnerfirmen. Die Kosten der Informationsbeschaffung sind für ein einzelnes Unternehmen eventuell prohibitiv hoch; zudem haben sie partiell den Charakter eines öffentlichen Gutes ${ }^{37}$. Hier können Umstrukturierungshilfen des Staates zur Beschaffung von Information und Beratung, zur Partnersuche und

34 Vgl. Chard/Macmillen 1979, S. 138.

35 Vgl. ebenda und Corden 1974, S. 108-110.

36 Vgl. Corden 1974, S. 110-112. Allerdings sind wiederum die Effizienzkosten der Subventionsautbringung gegenzurechnen.

37 Hierbei ist allerdings zu berücksichtigen, daß das Kriterium der Nichtrivalität nicht vollständig erfüllt ist, da der Wert der Informationen über potentielle Fusionspartner für ein Unternehmen sinkt, wenn diese Information auch Konkurrenzunternehmen bekannt ist. 
Reorganisation den Anpassungsprozeß beschleunigen und so Effizienzverluste aufgrund von Informationsmängeln verhindern ${ }^{38}$.

Diese Argumentation erscheint allerdings eher fragwürdig. Zum einen bleibt unklar, welche Informationen der Staat wie beschafft und wem er sie zur Verfügung stellt; zum anderen ist hier die Gefahr einer gezielten Industriestrukturpolitik, die weit über die Korrektur eines möglichen Marktversagens hinausgeht, außerordentlich groß.

Zuletzt sei noch der Fall inflexibler Reallöhne betrachtet ${ }^{39}$. Im neoklassischen Arbeitsmarktgleichgewicht müssen zur Erreichung von Vollbeschäftigung die Geldlöhne dem Wertgrenzprodukt der Arbeit entsprechen. Dies wird z.B. durch Mindestlohnregelungen für die am wenigsten qualifizierten Arbeitnehmer verhindert, so daß ihre Löhne über dem Grenzprodukt ihrer Arbeit liegen. Dieses Problem kann vor allem in wenig entwickelten Regionen eines Landes auftreten, wenn die Mindestlohnregelungen an den Grenzprodukten in den produktivsten Regionen, in denen mit größerem Kapitaleinsatz und bspw. einer besseren Infrastrukturausstattung produziert wird, ausgerichtet sind (z.B. landeseinheitliche Tarifverträge) ${ }^{40}$.

Existieren derartige Mindestlohnregelungen in einem Industriezweig oder einer Region, nicht jedoch in den anderen, so findet eine ineffiziente Faktorallokation statt, d.h. das Verhältnis der Grenzprodukte von Kapital und Arbeit ist nicht mehr in allen Industriezweigen bzw. Regionen gleich; statt dessen muß das Grenzprodukt der Arbeit im regulierten Sektor höher liegen, und es wird dort eine suboptimale Arbeitsmenge eingesetzt. Somit produziert das Land nicht auf der Kontraktkurve, und die Produktionsmöglichkeitenkurve (PPF) in Abb. 2-7 wird zum Ursprung gezogen (Kurve PAP statt PBP ohne Faktorpreisverzerrung) ${ }^{41}$. Im Freihandelsfall gelte die Preisgerade $\mathrm{p}_{\mathrm{i}}$. Das Inland produziert dann auf der suboptimalen PPF in C und erreicht durch Handel den Punkt D. In diesem Punkt entspricht die gesellschaftliche MRT nicht den Terms of trade. Protektion mittels eines Importzolls kann abhängig von der Höhe der Produzentengewinne und Konsumentenverluste das Land auf ein höheres oder niedrigeres Wohlfahrtsniveau bringen. Zahlt das Inland hingegen den Produzenten im regulierten Sektor eine Stücksubvention, so wird die inländische MRT auf der restringierten PPF den Terms of trade angeglichen, so daß das Inland in A produziert und durch Außenhandel in F konsumieren kann, somit ein

\footnotetext{
38 Vgl. Hübner/Feiler 1982, S. 9-11.

39 Vgl. Kenen 1989, S. 192-194.

40 Vgl. Biehl 1992, S. 73-75, und The Economist 1989, S. 59.

$41 \mathrm{Vgl}$. Johnson 1965, S. 17/18, 24.
} 
höheres Wohlfahrtsniveau als bei Freihandel erreichen kann. Dennoch ist diese Lösung nicht optimal, da die eigentliche Verzerrung der Faktorgrenzproduktivitäten zwischen den beiden Sektoren oder Regionen nicht beseitigt wird. Dies wiederum gelingt durch eine Subventionierung des Faktors Arbeit im Sektor mit der Mindestlohnregelung. Hierdurch erreicht das Inland die unverzerrte PPF PBP, produziert in $\mathrm{B}$, konsumiert in $\mathrm{E}$ und erreicht das optimale Wohlfahrtsniveau 42 .

Abb. 2-7 Subventionen bei Mindestlohnregelungen

(Indifferenzkurven wurden nicht eingezeichnet)

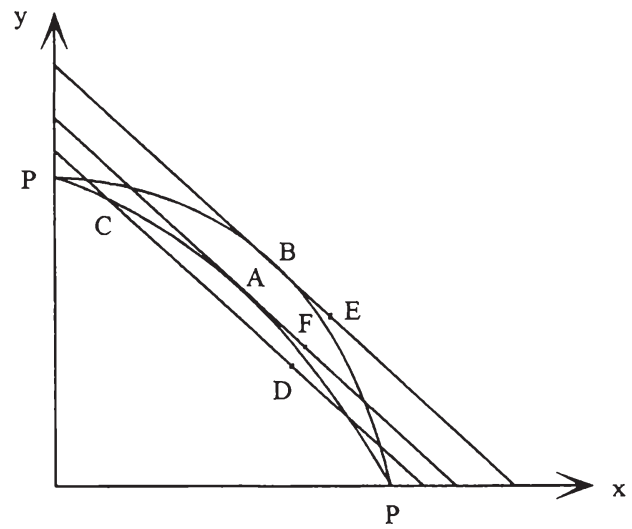

Buchanan und Moes ${ }^{43}$ schlagen eine Subvention an alle Arbeitgeber in Abhängigkeit von der Lohnsumme vor, die aus einer proportionalen Lohnsteuer auf alle Lohneinkommen finanziert wird. Auf diese Weise fällt aus Sicht der Arbeitgeber (aufgrund der Subvention) der Lohn der wenig qualifizierten Arbeitnehmer in den mindestlohngeschützten Sektoren, so daß die Nachfrage nach diesen nun steigt und Vollbeschäftigung erreicht wird. Zwar fällt auch der Nettolohn dieser Arbeitnehmer (aufgrund der Steuer); da dieser jedoch noch über dem Marktlohn in den nichtgeschützten Sektoren liegt, findet keine Abwanderung statt ${ }^{44}$. Mit der Beseitigung

42 Vgl. Bhagwati/Ramaswami 1963, S. 48-50. Diese Betrachtung abstrahiert wiederum von den Eftizienzkosten der Subventionsaufbringung und unterstellt ferner, daß die Lohnsubventionen nicht etwa einen Anreiz zu weiteren Lohnerhöhungen schaffen.

43 1960, S. 436.

44 Buchanan/Moes (1960, S. 436f.) nehmen jedoch eine Angleichung der Löhne wenig qualifizierter Arbeitnehmer in beiden Sektoren an, da aufgrund der steigenden Arbeitsnachfrage im geschützten Sektor solche Arbeitnehmer aus dem nichtgeschützten Sektor dorthin abwandern, wodurch die Marktlöhne im nichtgeschützten Sektor steigen. 
von Arbeitslosigkeit oder unterqualifizierter Beschäftigung wird die ökonomische Effizienz erhöht, und ineffiziente mindestlohninduzierte Faktorwanderungen werden vermieden, indem die Marktunvollkommenheit beseitigt wird. Ähnlich wie in Abschnitt 2.1.2.2 handelt es sich hier um eine zweitbeste Lösung, die nur ergriffen werden sollte, wenn eine Aufhebung der Mindestlohnregeln nicht gelingt 45 .

\subsubsection{Das Infant-industry-Argument}

Während die bisher dargestellten allokativen Subventionsrechtfertigungen auf statischen Aspekten des Marktversagens aufbauten, ist das Infant-industry-Argument explizit dynamisch ${ }^{46}$. Ausgangspunkt der Überlegungen ist die Existenz "junger", nicht ausgereifter Industriezweige im Inland, die zunächst gegenüber den weiterentwickelten ausländischen Konkurrenten nicht wettbewerbsfähig sind, bei denen aber davon ausgegangen wird, daß vorübergehende Protektionsmaßnahmen ihre Entwicklung derart fördern, daß sie nach dieser Wachstumsphase auch ohne Schutzmaßnahmen auf den Weltmärkten wettbewerbsfähig sein können ${ }^{47}$. Ohne temporären Schutz gelänge dieses Wachstum nicht, so daß dann eine sozial ineffiziente Allokation aufträte. Notwendig zur Rechtfertigung von Infant-industry-Schutz ist allerdings nicht nur, daß die betreffende Industrie später bei Freihandel wettbewerbsfähig ist, sondern auch, daß eventuelle gesellschaftliche Wohlfahrtsverluste in der Übergangsphase durch höhere Wohlfahrtsgewinne nach der Rückkehr zum Freihandel überkompensiert werden ${ }^{48}$.

Welche Argumente für vorübergehenden Infant-industry-Schutz sind nun denkbar? Man kann hier zwischen internen und externen Ersparnissen unterscheiden:

Interne Ersparnisse können sich aus dem Verlauf der Produktionsfunktion ergeben. Steigen die DTK mit steigender Ausbringungsmenge zunächst an und fallen dann aufgrund der Vorteile der Massenproduktion, so sind zuerst große Investitionen notwendig, um später aufgrund der geringeren Stückkosten auf den Weltmärkten wettbewerbsfähig zu sein. Dieses Argument greift dann am besten, wenn die Economies of scale nicht von einer einzelnen Firma, sondern nur von der Branche als Ganzes erzielt werden können, bspw. durch Massenproduktionsvorteile eines $\mathrm{Zu}$ -

45 Wie bereits oben (Abschn. 2.1.2.2) im Zusammenhang mit regionalpolitischen Maßnahmen diskutiert, besteht eine auf längere Sicht alternative Politik darin, bspw. durch öffentliche Infrastrukturinvestitionen das Entwicklungspotential einer Region zu erhöhen.

46 Vgl. Johnson 1965, S. 27.

47 Vgl. Rose 1986, S. 485.

48 Vgl. Södersten 1980, S. 197/198. 
lieferers, da sonst eine einzelne Firma durch Expansion im Inland unter Verdrängung der inländischen Konkurrenten die kritische Größe erreichen könnte ${ }^{49}$ (s. auch oben Abschn. 2.1.1). Eine Rechtfertigung für staatliche Hilfen in dieser Übergangsphase ergibt sich hieraus allerdings noch nicht, da bei vollkommenen Kapitalmärkten und vollständiger Information über die Profitabilität der Expansion die notwendigen Kredite zum Marktzins bereitgestellt werden. Funktionieren jedoch die Kapitalmärkte unzureichend oder verhindern Pessimismus und Risikoscheu die Aufbringung von Kreditmitteln für das Expansionsprojekt, so ist eine Begründung für staatliches Eingreifen gegeben, das entweder in der Veröffentlichung fehlender Informationen oder in Subventionen für Kreditvermittlung bzw. öffentlicher Kreditvergabe zu marktüblichen Konditionen bestehen kann ${ }^{50}$.

Das zentrale Argument für Infant-industry-Schutz besteht jedoch im Vorhandensein externer Ersparnisse, insbesondere durch Lernen/Ausbildung, aufgrund derer die sozialen Erträge aus einer Investition in eine Infant industry die privaten übersteigen können. Hierbei ist gemeint, daß das Umgehen mit einer neuen Technik zu Wissenserwerb insbesondere bei den Arbeitnehmern führt, die hieran ausgebildet werden und dieses erworbene Wissen dann in anderen Firmen anwenden können, ohne daß ihnen Kosten der Weitergabe entstehen oder das ausbildende Unternehmen hierfür entschädigt wird ${ }^{51}$.

Dieser klassische Fall externer Erträge vermindert die Attraktivität sozial optimaler Ausbildungsinvestitionen für das Pionierunternehmen. In dieser Situation entspricht die Grenzrate der Transformation im Inland weder der MRS noch der MRT $\left(\mathrm{MRT}_{\mathrm{i}} \neq \mathrm{MRT}_{\mathrm{a}}=\mathrm{MRS}\right)$. Diese binnenbedingte Verzerrung kann nur durch inländische Maßnahmen ausgeglichen werden, und zwar hier durch Subventionen in Höhe der externen Erträge der Ausbildung an das Pionierunternehmen, die die MRT der inländischen Produzenten an die MRS der inländischen Konsumenten und die Terms of trade angleicht. Die Erhebung eines Importzolles hingegen könnte nur die Gleichheit der inländischen MRT mit den Terms of trade erreichen, würde jedoch gleichzeitig über Preiserhöhungen für das Importsubstitut die MRS der Konsumenten verzerren $^{52}$.

49 Vgl. Kenen 1989, S. 197.

50 Vgl. Johnson 1965, S. 27, 29.

$51 \mathrm{Vgl}$. Stegemann 1989, S. 85/86.

52 Vgl. Södersten 1980, S. 199. 
Abb. 2-8 Das Infant-industry-Argument

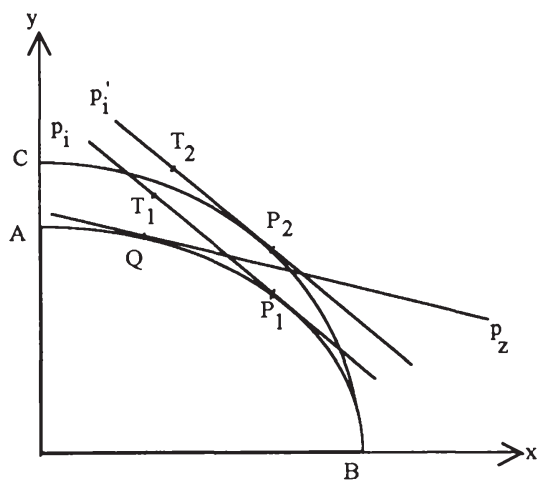

Die graphische Darstellung in Abb. 2-8 verdeutlicht den Sachverhalt ${ }^{53}$ : Zunächst sieht sich das Inland der PPF AB gegenüber. Unter Freihandel gilt das Weltmarktpreisverhältnis $\mathrm{p}_{\mathrm{i}}$, bei dem im Inland in $\mathrm{P}_{1}$ produziert und nach Außenhandel in $T_{1}$ konsumiert wird. Eine vorübergehende Unterstützung der Produzenten in der Infant industry y führt zu einer Expansion der Produktionsmöglichkeiten auf CB. Nach dem "Erwachsenwerden" der Infant industry kann das Inland bei Gültigkeit der alten Terms of trade (Kleines-Land-Fall) in $\mathrm{P}_{2}$ produzieren und durch Außenhandel $\mathrm{T}_{2}$ erreichen, das rechts oberhalb $\mathrm{T}_{1}$ liegt und somit bei beliebigen Präferenzen der Inländer einem höheren Nutzenniveau entspricht. Erfolgt die vorübergehende Unterstützung der inländischen Produzenten in Form eines (angenommen prohibitiven) Importzolls, der die Preisgerade auf $\mathrm{p}_{\mathrm{z}}$ dreht, so wird das Inland in $\mathrm{Q}$ produzieren und konsumieren und somit im Vergleich zum Freihandelspunkt $T_{1}$ zunächst einen Wohlfahrtsverlust erleiden, der durch den späteren Gewinn in $T_{2}$ mehr als kompensiert werden muß. Eine Subventionierung der Ausbildungsinvestition in Höhe ihrer externen Erträge hingegen vermeidet die wohlfahrtsvermindernden Konsumeffekte aufgrund der verzerrten inländischen Preisverhältnisse, indem sie $p_{i}$ weiterhin bestehen läßt, und erlaubt dem Inland eine Produktionsausweitung entlang einem Anpassungspfad von $P$. nach $P_{2}$ bei gleichzeitiger Verlagerung des Konsumpunktes entlang $\mathrm{T}_{1} \mathrm{~T}_{2}$. Diese Aussage gilt allerdings nur unter der Annahme, daß die Aufbringung der Mittel für die Subvention und ihre Verteilung an die Produzenten keine höheren

$53 \mathrm{Vgl}$. zum folgenden Kenen 1989, S. 198-200. 
Wohlfahrtskosten verursachen als die Errichtung von Zollschranken und die Zollerhebung 54 .

Die eigentliche Problematik des Infant-industry-Arguments liegt in der Auswahl der zu schützenden Industrien. Es stellt sich die Frage, woher die Regierung die Information erhält, in welchen Industrien mit Economies of scale bzw. Economies of experience zu rechnen ist. Bei einer falschen Auswahl, wenn also der Industriezweig niemals "erwachsen" wird, besteht die Notwendigkeit der Subventionierung fort, und der Wohlfahrtsgewinn aus der Expansion der Produktionsmöglichkeiten wird nicht erzielt; es ist im Gegenteil mit sozialen Verlusten zu rechnen 55 .

\subsubsection{Das Optimalzollargument}

Die in den vorangegangenen Abschnitten diskutierten Subventionsrechtfertigungen basierten alle auf internen Verzerrungen, d.h. auf im Inland begründeten Abweichungen vom Ideal der vollkommenen Konkurrenz mit voller Anrechnung aller Kosten beim Verursacher. Ihre Korrektur durch in geeigneter Weise festgesetzte Subventionen führte zu einer Verbesserung der inländischen Wohlfahrt, ohne die Wohlfahrt der anderen Volkswirtschaften zu schädigen, da sie weiter auf der gleichen Preisgeraden im Pareto-Optimum handeln. Das nun vorzustellende Optimalzollargument paßt nicht in diese Kategorie. Es betrachtet die Situation eines "großen" Landes, das aufgrund seiner Nachfrage bzw. seines Angebotes auf den internationalen Märkten die dort herrschenden Preise beeinflussen kann und das mittels außenhandelspolitischer Maßnahmen die Terms of trade so verändern kann, daß sich die inländische Wohlfahrt auf Kosten der Wohlfahrt des Rests der Welt erhöht ${ }^{56}$.

Wie bereits oben erwähnt, erreicht ein Land bei Außenhandel sein Wohlfahrtsoptimum, wenn gilt $\mathrm{MRS}_{\mathrm{i}}=\mathrm{MRT}_{\mathrm{i}}=\mathrm{MRT}_{\mathrm{a}}$. Herrscht im Inland vollkommener Wettbewerb (die Existenz von Marktunvollkommenheiten im Sinne der Abschnitte 2.1.1 - 2.1.3 sei nun ausgeschlossen), so werden die inländischen MRS und MRT zwischen zwei beliebigen Gütern ihrem Preisverhältnis im Inland entsprechen. Im "Kleines-Land-Fall" bei für das Inland gegebenen Weltmarktpreisen sind sie zudem gleich dem Weltmarktpreisverhältnis dieser Güter, so daß obige Gleichgewichtsbedingung erfüllt ist $\mathrm{t}^{57}$.

54 Vgl. Johnson 1965, S. 7-8.

55 Vgl. Rose 1986, S. 489.

56 Vgl. Kenen 1989, S. 183.

57 Vgl. Graaff 1957, S. 124-127. 
Ist das Inland nun ein großes Land, so werden zusätzliche Nachfrage bzw. Angebot ihrerseits die Weltmarktpreise verändern. Zusätzliche Exporte erbringen einen Grenzerlös, der im Normalfall geringer als der bisherige Preis ist, während die Grenzkosten zusätzlicher Importe oberhalb ihres Preises liegen. Hier liegt also eine Analogie zur Preisbildung in Monopolsituationen vor. Die Transformationsrate zwischen zwei Gütern durch Außenhandel entspricht also jetzt dem Verhältnis ihrer Grenzerlöse bzw. Grenzkosten, so daß eine Erfüllung der obigen Gleichgewichtsbedingung nunmehr folgendes verlangt $t^{58}:\left(p_{a}{ }^{x}+a^{x}\right) /\left(p_{a}{ }^{y}+a^{y}\right)=p_{i} x / p_{i} y$, wobei $a^{k}$ der Differenz zwischen sozialen Grenzkosten bzw. -erlös eines Gutes und dessen Preis entspricht. Die $\mathrm{a}^{\mathrm{k}}$ schließen bei Existenz von Kreuzpreiselastizitäten ungleich 0 auch die Wirkungen zusätzlicher Importnachfrage bzw. Exportangebots durch das Inland auf die relativen Preise anderer Güter über Substitutions- und Komplementaritätsprozesse in Konsum und Produktion ein ${ }^{59}$.

Das Auftreten der aj führt nun dazu, daß aus Sicht des Inlands bei Freihandel die obige Gleichgewichtsbedingung verletzt ist. Es ergibt sich nämlich $p_{a} x / p_{a} y=p_{i} x / p_{i} y$

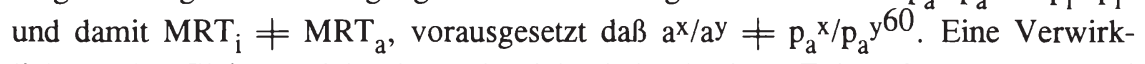
lichung des Gleichgewichts kann das Inland durch einen Zoll auf Importe, da bei diesen i.d.R. GK $>$ p und somit a $>0$ gilt, bzw. Subventionen für Exporte, da hier i.d.R. $p>$ GE und somit a $<0$ gilt, erreichen, im 2-Güter-Fall durch einen einfachen Wertzoll auf das Importgut, dessen Höhe unter Vernachlässigung von Kreuzpreiseffekten dem Kehrwert der ausländischen Angebotselastizität entspricht ${ }^{61}$.

Der Wohlfahrtsgewinn für das Inland entspringt hierbei einer Verbesserung seiner Terms of trade. Die Erhebung eines Importzolls führt über steigende Konsumentenpreise im Inland zu abnehmender Importnachfrage, wodurch die Produzentenpreise im Ausland unter den bisherigen Wert fallen. Bei definitionsgemäß ausgeglichenem Außenhandel sinkt das Exportvolumen ebenfalls, wodurch die Exportpreise steigen. Dieser Verbesserung der Terms of trade stehen die Wohlfahrtsverluste aus einer suboptimalen Spezialisierung in der Weltwirtschaft und aus der Verzerrung der inländischen Konsumwahlentscheidungen entgegen. Das Optimum wird bei Erfüllung der obigen Gleichgewichtsbedingung verwirklicht, da dort die Grenzgewinne aus der Terms-of-trade-Verbesserung den genannten Grenzverlusten gleich sind 62 .

\footnotetext{
58 Vgl. Corden 1957 S. 238-239.

59 Vgl. Graaff 1950, S. 54.

60 Vgl. ebenda, S. 53.

61 Vgl. Graaff 1957, S. 130-131.

62 Vgl. Corden 1974, S. 158, 161-164, 167.
} 
Es sind nun eine Reihe von Ursachen denkbar, aufgrund derer eine Verringerung des Außenhandels durch Importzölle die Terms of trade verschlechtert, so daß der Optimalzoll dann einer Subvention entspricht. Im 2-Güter-Fall kann dies nur gelten, wenn das Importgut ein Giffen-Gut ist, die Nachfrage also mit dem Preis steigt ${ }^{63}$. Sind im Mehrgüterfall Ex- und Importe eines Landes enge Substitute auf dem Weltmarkt, so können die sozialen GK der Importe unter ihrem Preis liegen, weil die zusätzliche Importnachfrage des Inlandes die Preise der Exportgüter erhöhen und so die Terms of trade verbessern kann. In diesem Fall wären Importsubventionen optimal. Führen Exporte von Investitionsgütern zu niedrigeren Importpreisen in der Zukunft (durch Anwendung besserer Technologie), so sind Exportsubventionen zur Terms-of-trade-Verbesserung nötig ${ }^{64}$. Dasselbe gilt für Importsubventionen, wenn aufgrund stark steigender Skalenerträge im Ausland steigende Importe zu Preissenkungen für Importe führen. Corden 65 nennt noch weitere Fälle, bei denen die Zollerhebung aufgrund von Einkommensumverteilungs- oder Nachfrageverschiebungseffekten zu Verschlechterungen der Terms of trade führen kann. Komplementaritäts- und Substitutionseffekte entscheiden hierbei, ob Außenhandelszölle (-steuern) oder -subventionen zu einer Wohlfahrtsverbesserung des Inlandes führen 66 .

Der inländischen Netto-Wohlfahrtserhöhung aufgrund der Terms-of-trade-Verbesserung steht jedoch eine Verminderung der Wohlfahrt des Auslands gegenüber, wie sich im 2-Güter-Fall graphisch leicht demonstrieren läßt ${ }^{67}$. Dies kann das Ausland zu Gegenmaßnahmen zur Verbesserung seiner Terms of trade zu Lasten des Inlandes veranlassen, die wieder Retorsionsmaßnahmen im Inland hervorrufen usw. Dieser Versuch der jeweiligen Verbesserung der Terms of trade führt zu immer weiterer Entfernung vom effizienten Außenhandelsvolumen bei gleichzeitig sinkender Wohlfahrt der Welt als Ganzes ${ }^{68}$.

\subsection{Notwendigkeit einer Subventionskontrolle im Gemeinsamen Markt}

Mit der Darstellung des Optimalzollarguments im vorhergehenden Abschnitt wurde die Notwendigkeit einer Subventionskontrolle in einheitlichen Wirtschaftsräumen bereits in Ansätzen deutlich. Bei Abwesenheit anderer Handelshemmnisse zwischen Staaten, wie dies in einem Gemeinsamen Markt gegeben

\footnotetext{
63 Vgl. Graaff 1950, S. 54.

$64 \mathrm{Vgl}$. Graaff 1957, S. 137.

65 1974, S. 192-194.

66 Vgl. Graaff 1957, S. 138.

67 Vgl. dazu Södersten 1980, S. 180.

68 Vgl. Corden 1974, S. 173-174.
} 
ist, kann ein großes Land durch Festlegung optimaler Subventionssätze über eine Verbesserung seiner Terms of trade die eigene Wohlfahrt auf Kosten der Partnerländer verbessern ${ }^{69}$. Im folgenden sollen diese Effekte graphisch erläutert und nach Subventionstypen differenziert werden. Dabei wird angenommen, daß vollkommene Konkurrenz und (zunächst) fixes Faktorangebot vorliegen und eine verzerrungsfreie Erhebung der Steuern zur Zahlung der Subventionen möglich ist.

\subsubsection{Außenhandelswirkungen von Subventionen im Ein-Gut-Fall}

Beginnt man mit einer einfachen partialanalytischen Betrachtung des Marktes für ein Gut $\mathrm{x}$, das sowohl im Inland I als auch in den Partnerländern $\mathrm{P}$ produziert werde, und bei dessen Herstellung P komparative Vorteile habe, I also Importland ist, so lassen sich folgende Effekte einer Ad-valorem-Subvention zeigen ${ }^{70}$ :

Die inländische Subvention 71 führt zu einer Verlagerung der inländischen (und auch der Unions-) Angebotskurve nach unten auf $\mathrm{S}_{\mathrm{i}} \mathrm{s}$ bzw. $\mathrm{S}_{\mathrm{u}} \mathrm{s}$ und zu einer Ausweitung der Gesamtnachfrage von $\mathrm{x}^{*}$ auf $\mathrm{x}^{\mathrm{s}}$ aufgrund des gefallenen Preises. Diese Nachfrage wird nun zu einem größeren Teil von den inländischen Produzenten befriedigt $\left(\mathrm{x}_{\mathrm{i}}^{\mathrm{s}}\right.$ statt $\left.\mathrm{x}_{\mathrm{i}}{ }^{*}\right)$, deren komparativer Nachteil durch die Subvention abgenommen hat, so daß die inländische Importmenge hier von GI auf HK fällt ${ }^{72}$. Aufgrund der fallenden Importpreise verbucht das Inland einen Terms-of-trade-Gewinn, jedoch durch die Produktionsverlagerung von den effizienten Partnerländern ins Inland (trade destruction) einen Effizienzverlust, so daß die Gesamtwohlfahrtsveränderung unsicher bleibt. Die Partnerländer hingegen verlieren sowohl aufgrund ihrer fallenden Terms of trade als auch aufgrund der Trade destruction ${ }^{73}$; ihr Verlust an

69 Vgl. Chard/Macmillen 1979, S. 137. Wie schon in Abschnitt 2.1.4 wird auch hier von der Existenz interner Verzerrungen abstrahiert.

70 Vgl. Soltwedel et al. 1988, S. 61/62. Mögliche Effekte auf Drittländer, die nicht dem Gemeinsamen Markt angehören, werden hier nicht betrachtet.

71 Wie am Beginn dieses Kapitels erwähnt, können Subventionen in vielen verschiedenen Formen gewährt werden, bei denen der Nominalbetrag der staatlichen Zahlung nicht immer dem Beihilfeelement entspricht. Zur Vergleichbarmachung und Aggregation der verschiedenen Typen müssen diese Beihilfeelemente berechnet, ihr Gegenwartswert zur Eliminierung unterschiedlicher Auszahlungsstrukturen ermittelt und auch steuerliche Effekte erfaßt werden. Bei der folgenden Analyse wird angenommen, daß eine solche Berechnung vorgenommen und das (weiter unten in Kap. 4 so bezeichnete) Nettosubventionsäquivalent ermittelt wurde.

72 Vgl. Meade 1955, S. 168.

73 Vgl. analog Kenen 1989, S. 175/176. 
Abb. 2-9 Außenhandelswirkungen einer Subvention im 2-Länder-Fall (Partialanalyse)
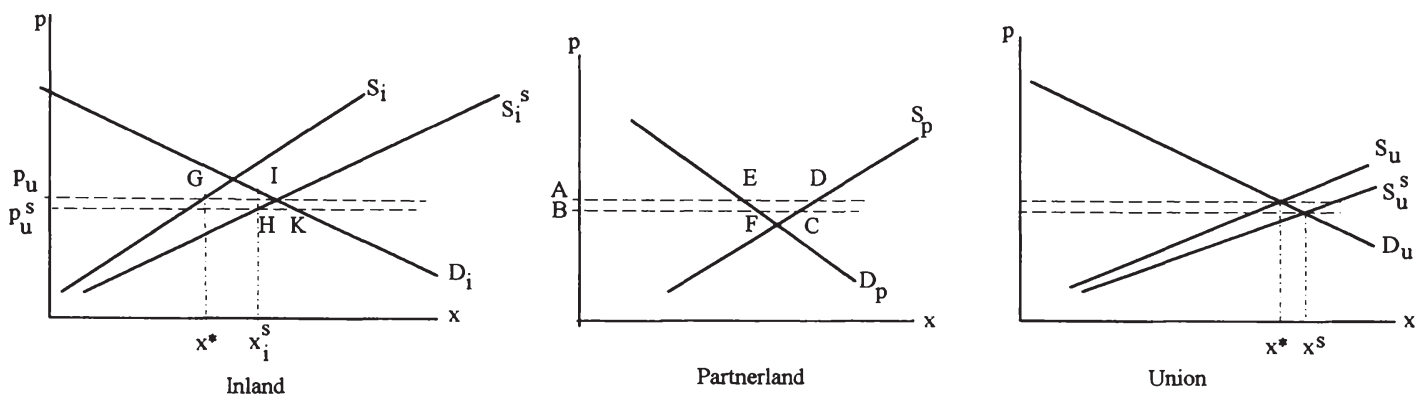
Produzentenrente $\mathrm{ABCD}$ übersteigt den Gewinn an Konsumentenrente $\mathrm{ABFE}$ deutlich.

Betrachtet man den umgekehrten Fall, also eine inländische Subventionierung eines Gutes y, bei dessen Produktion es ohnehin komparative Vorteile hat ${ }^{74}$, so verliert das Inland aufgrund fallender Terms of trade. Zwar gewinnen die Inlandsproduzenten von y durch Subvention und erhöhte Ausbringungsmenge, und auch die Konsumentenrente der Nachfrager nach diesem Gut steigt, jedoch müssen die Steuerzahler die Ressourcen für die Subvention aufbringen, und die Konsumenten von (hier nicht betrachteten) Importgütern verlieren an Konsumentenrente. Im Unterschied zum ersten Fall gewinnen die Partnerländer, da in ihnen der Gewinn an Konsumentenrente den Rentenverlust der verbliebenen Produzenten deutlich übersteigt.

\subsubsection{Analyse der Außenhandelswirkungen im Zwei-Güter-Fall}

Um nun die Frage nach den Wirkungen von Subventionen auf die Ökonomien der Partnerländer genauer beantworten und Unterschiede zwischen verschiedenen Subventionstypen herausarbeiten zu können, soll die Analyse auf den 2-Güter-2-Faktor2-Länder-Fall erweitert werden, der für die Betrachtung von Regionalsubventionen noch um je 2 Regionen pro Land ergänzt wird ${ }^{75}$. Es sollen die Güter $x$ und y produziert werden, wobei y kapitalintensiv in seiner Herstellung sei. Das Inland I habe nun komparative Vorteile bei der Produktion von y, was im Kontext des HeckscherOhlin-Modells bedeutet, daß I reichlich mit Kapital ausgestattet ist, während dieser Faktor im Ausland A relativ knapp ist. Weiterhin bestehe das Inland aus den Regionen a und b, das Ausland aus c und d, von denen die Regionen a und c innerhalb ihres jeweiligen Landes komparative Vorteile bei der Produktion von y haben sollen.

Wie die Diskussion des Optimalzollarguments in Abschnitt 2.1.4 zeigte, verfehlt ein Land mit monopolartiger Macht im Außenhandel im Freihandelszustand sein nationales Wohlfahrtsoptimum, da sich $\mathrm{MRS}=\mathrm{MRT}_{\mathrm{i}} \neq \mathrm{MRT}_{\mathrm{a}}$ einstellt. Zur Korrektur dieser Außenhandelsverzerrung, d.h. der externen Transformationsrate, müssen deshalb Zölle bzw. Ex- oder Importsubventionen eingesetzt werden, mit denen das Inland sein Pareto-Optimum erreichen kann. Ist die Möglichkeit zur Anwendung dieser Instrumente bspw. in einem Gemeinsamen Markt nicht gegeben und werden stattdessen zweitbeste Subventionstypen, die nicht an der eigentlichen Ursache der Verzerrung ansetzen, gewählt, wie z.B. Subventionen auf die Ausbringungsmenge, den Faktoreinsatz oder die Produktion in einer bestimmten Region, dann werden im

74 Vgl. dazu Soltwedel et al. 1988, S. 62/63.

75 Vgl. Soltwedel et al. 1988, S. 56. 
Inland zusätzliche Verzerrungen induziert, d.h. die Transformations- und Substitutionsraten verändern sich ungleichmäßig, so daß im Endergebnis möglicherweise $\mathrm{MRS} \neq \mathrm{MRT}_{\mathrm{i}}=\mathrm{MRT}_{\mathrm{a}}$ erreicht wird - somit das Optimum verfehlt wird ${ }^{76}$. Diese zusätzliche politikinduzierte Konsum- und Produktionsverzerrung im Inland bewirkt einen Wohlfahrtsverlust, der gegen einen möglichen Terms-of-trade-Gewinn aufzurechnen ist. Letzterer ist somit bei den im folgenden diskutierten Einzelfällen notwendig, aber nicht hinreichend für eine inländische Wohlfahrtsverbesserung; gleichzeitig auftretende Veränderungen im Außenhandelsvolumen bestimmen, in Form welcher Güter der potentielle inländische Gewinn verzehrt wird.

\subsubsection{Grundmodell}

Ausgangspunkt der Betrachtung sei das Freihandelsgleichgewicht vor Einführung von Subventionen (Abb. 2-10). In das Produktionskoordinatensystem sind im II. und IV. Quadranten die PPF des In- und Auslands dargestellt, wobei die Punkte $\mathrm{H}_{\mathrm{I}}$ und $\mathrm{H}_{\mathrm{A}}$ die Produktionsgleichgewichte bei vorgegebenem Weltmarktpreisverhältnis zeigen. Die Konsumpräferenzen der Haushalte drücken sich in den Tauschkurven (OC) des In- und Auslands zwischen $0_{\mathrm{K}}$ und $0_{\mathrm{P}}$ aus. Die Konsumpunkte der beiden Länder als Ergebnis des Außenhandels sind nun nicht als Bewegungen auf der Weltmarktpreisgerade (Terms of trade) dargestellt, sondern als Verschiebung des Koordinatenursprungs nach "links unten" bei Beibehaltung des Gleichgewichtspunktes dadurch, daß das Inland Gut $x$ importiert und y exportiert ${ }^{77}$.

Nun führe das Inland eine sektorale Subvention für die Produktion des wenig wettbewerbsfähigen Gutes $\mathrm{x}$ ein. Hierdurch steigt zunächst der inländische Produzentenpreis für $\mathrm{x}$ an. Dies führt zu einer Ausweitung der Inlandsproduktion von $\mathrm{x}$ zu Lasten von y, somit fallenden Ex- und Importen (d.h. einer nach innen verlagerten OC) bei allerdings verbesserten Terms of trade $\left(0_{k} 0_{s}\right)$, da mit der erhöhten Produktion des Importgutes $x$ dessen relativer Konsumentenpreis fällt ${ }^{78}$. Abbildung 211 , in der die Koordinatenachsen wiederum so adjustiert sind, daß Produktions- und

76 Vgl. Bhagwati/Ramaswami/Srinivasan 1969, S. 1005/1006, 1008 und Bhagwati 1971, S. 77 und 79.

77 Vgl. Meade 1952, S. 19-23. Die Punkte $A^{I_{K}}$ und $A^{A}{ }_{K}$ zeigen den Nutzen der beiden Staaten in der hypothetischen Autarkiesituation im Konsumkoordinatensystem.

Eine Analyse der Lage in den beiden Regionen zeigt eine weitgehende Spezialisierung beider Regionen der beiden Länder auf das jeweilige Exportgut, was für die Regionen $b$ und $c$ gegenüber einer hypothetischen Autarkiesituation starke Umstrukturierungen mit sich bringt. Vgl. Soltwedel et al. 1988, S. 65, 68.

78 Vgl. Krauss 1979, S. 79. 
Abb. 2-10 Freihandelsgleichgewicht im 2-Länder-Fall
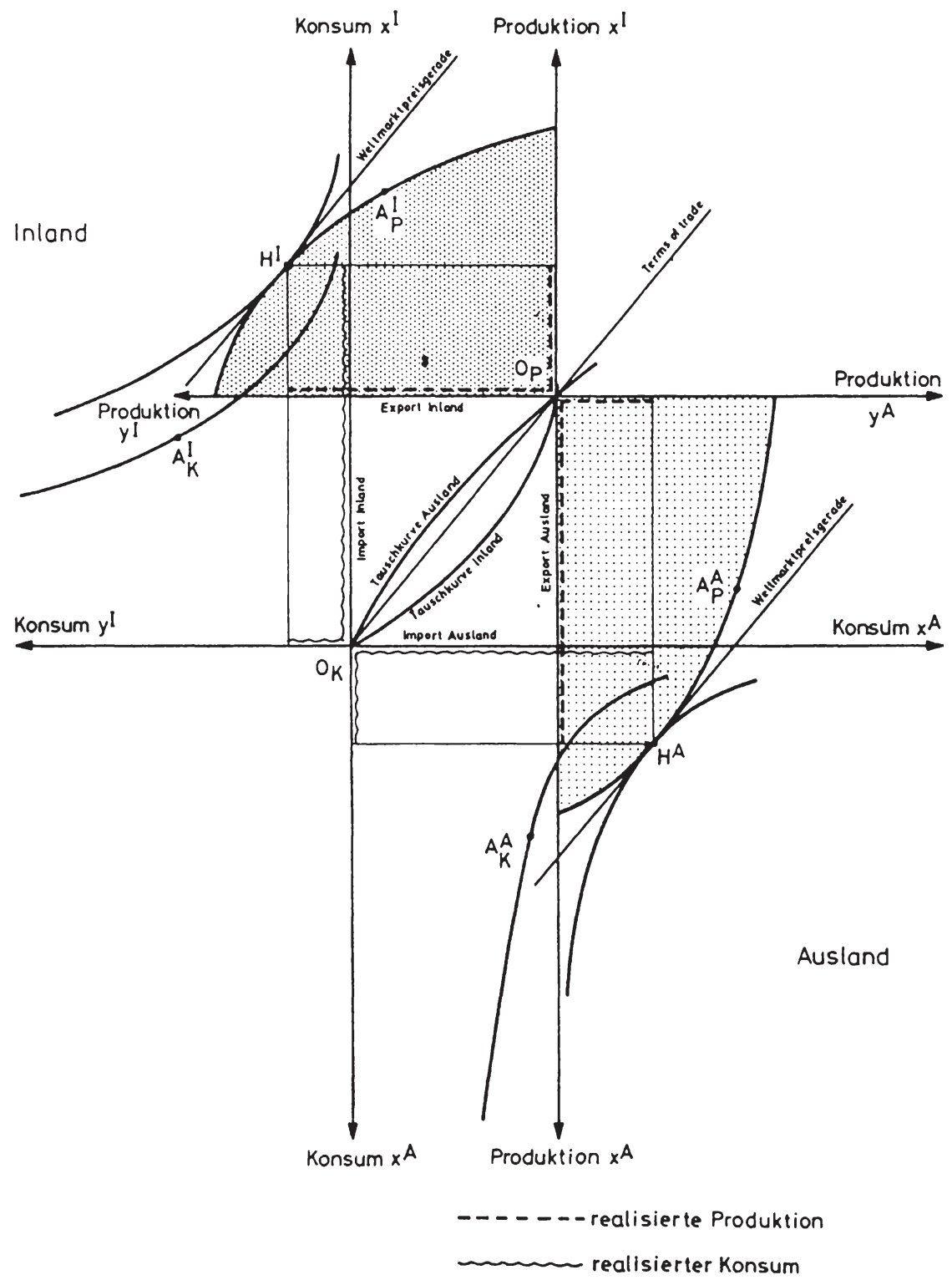
Konsumpunkt nach Subvention zusammenfallen, zeigt, daß im neuen Gleichgewicht $\mathrm{S}_{\mathrm{I}}$ die Weltmarktpreisgerade eine Indifferenzkurve tangiert $\left(\mathrm{MRS}=\mathrm{MRT}_{\mathrm{a}}\right.$ ), während die Produzentenpreisgerade die PPF tangiert. Das Auseinanderfallen der beiden Transformationsraten zeigt die Abweichung vom globalen Optimum ${ }^{79}$. Dennoch erreicht das Inland eine Wohlfahrtsverbesserung, da der positive Terms-of-trade-Effekt die Verluste aus der verzerrten Produktions- und Konsumstruktur überwiegt; das Ausland hingegen erleidet einen Wohlfahrtsverlust aus beiden Effekten ${ }^{80}$.

Abb. 2-11 Sektorale Subventionen für die importkonkurrierende Industrie im 2-Länder-Fall

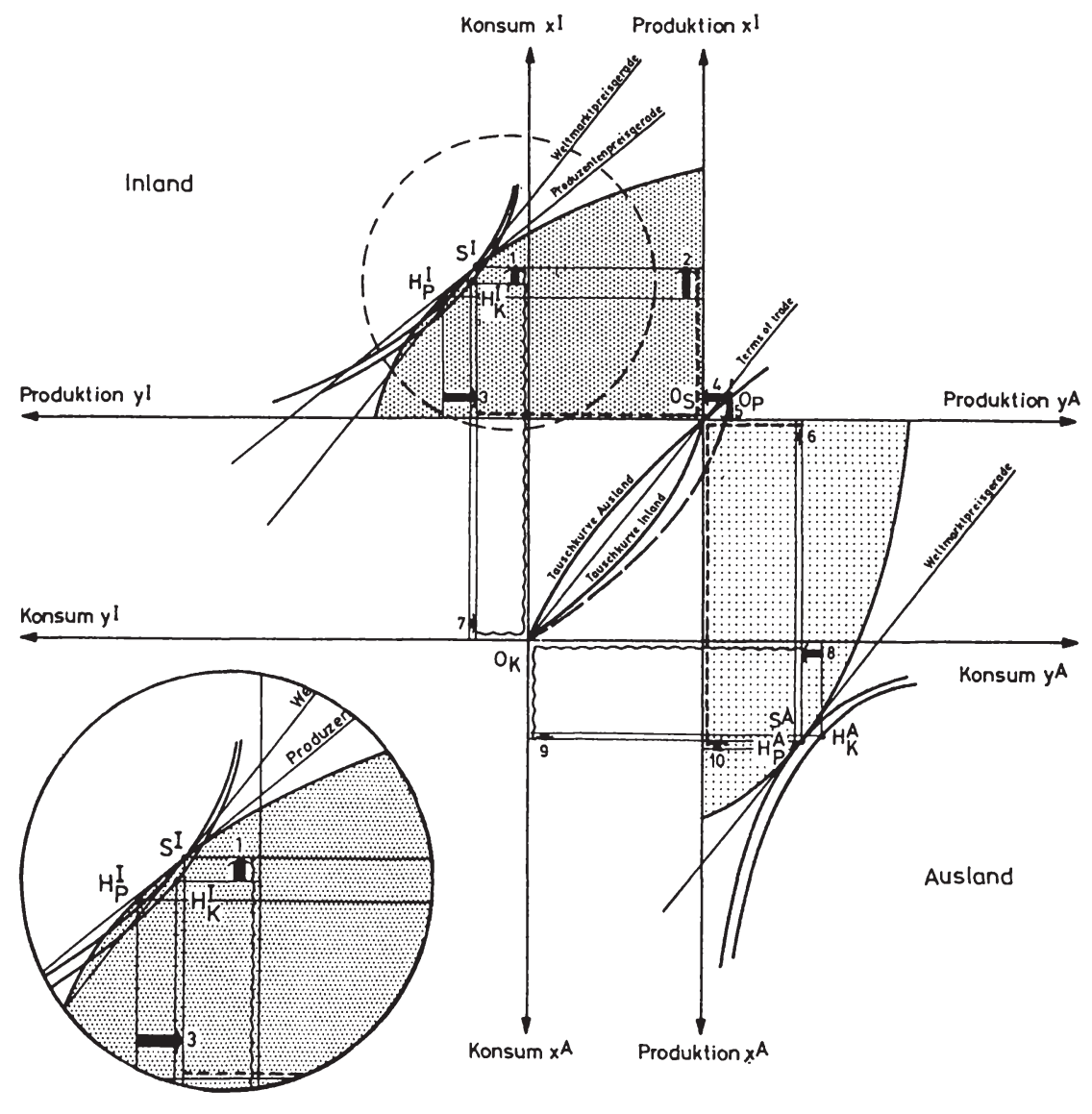

$79 \mathrm{Vgl}$. Soltwedel et al. 1988, S. 68-71.

80 Vgl. Hiemenz/Weiss 1984, S. 5. 
Subventioniert das Inland hingegen die Produktion des wettbewerbsfähigen Gutes y, so wird dessen Angebot erhöht, der Spezialisierungsgrad des Inlandes steigt bei allerdings verschlechterten Terms of trade. Das Ausland erhöht ebenfalls die Produktion des Gutes, in dem es komparative Vorteile hat, um die Einschränkung in I zu kompensieren. Es gewinnt durch verbesserte Terms of trade bei vermehrtem Außenhandel, während das Inland verliert ${ }^{81}$.

Bezüglich der Entwicklung der Faktoreinkommen bei sektoralen Subventionen läßt sich folgendes sagen: Da intersektorale Faktormobilität vorausgesetzt ist, führt die subventionsinduzierte Produktions- und Konsumverlagerung auch zu entsprechenden Faktorumschichtungen auf der jeweiligen Kontraktkurve der beiden Länder bzw. ihrer Regionen. Eine Subventionierung des arbeitsintensiven Gutes $\mathrm{x}$ im Inland führt zur Umsetzung beider Faktoren in diese Industrie. Der ohnehin knappe Faktor L wird dadurch noch knapper, sein Entgelt steigt, was zur Substitution durch Kapital führt, dessen Intensität bei gleichzeitiger Erhöhung der Arbeitsproduktivität steigt. Der Protektionismus im Inland nützt also entsprechend dem Stolper-SamuelsonTheorem dem knapperen Faktor $L^{82}$. Im Ausland erhöhen sich hingegen Kapitalproduktivität und -rendite. Eine inländische Subventionierung des wettbewerbsfähigen kapitalintensiven Gutes y hätte hingegen auf den in- und ausländischen Faktormärkten genau die umgekehrten Effekte ${ }^{83}$.

\subsubsection{Erweiterung um räumliche Faktormobilität}

Die vorstehende Analyse soll nun erweitert und modifiziert werden, indem zusätzlich zur bisher betrachteten intersektoralen auch interregionale und später internationale Faktormobilität eingeführt wird. Dieser Mobilitätsgrad wird zwischen Faktoren sehr stark variieren, völlig immobil sind die sog. Potentialfaktoren ${ }^{84}$, während Geldkapital fast uneingeschränkt mobil ist. Im Modell werden drei Mobilitätsgrade unterschieden. Neben dem vollständig mobilen Faktor Kapital $\mathrm{K}$ und dem immobilen Faktor Arbeit L wird der Faktor Humankapital F mit eingeschränkter

81 Vgl. Krauss 1979, S. 76-78 sowie 94-96.

82 Vgl. Johnson 1971, S. 36/37.

$83 \mathrm{Vgl}$. Soltwedel et al. 1988, S. 77/78.

84 zu diesen zählt Biehl (1976, S. 60-65) u.a. die wirtschaftsgeographische Lage, die Ausstattung mit Infrastruktur oder natürlichen Ressourcen. Vgl. zu deren Bedeutung auch oben Abschnitt 2.1.2.2. Obwohl solche Faktoren auch komparative Kostenvorteile von Regionen begründen können, wird von ihnen in der folgenden Analyse abstrahiert. 
Mobilität und einer Präferenz für eine Region (im Inland a) eingeführt ${ }^{85}$. Diese Präferenz des Faktors wird zum einen zu seiner ungleichen Verteilung über die Regionen eines Landes führen, zum anderen bewirkt sie, daß Wanderungen in die nichtpräferierte Region erst oberhalb eines gewissen Schwellenwerts für die Differenz der Faktorentlohnung einsetzen. Die Einbeziehung unterschiedlicher Grade von Faktormobilität macht Situationen denkbar, in denen eine Region aufgrund ihrer geringen Ausstattung mit einem Faktor sich völlig auf die Erstellung des Gutes spezialisiert, mit dessen Haupteinsatzfaktor sie reichlicher versehen ist, wodurch dann die Faktorproduktivitäten und -entgelte interregional differieren können. Geht man von einer höheren Ausstattung der Region a mit Faktor F aus, so variieren die Produktionsfunktionen zwischen den Regionen, $\mathrm{L}$ und $\mathrm{K}$ sind in a zunächst produktiver und $\mathrm{K}$ wandert dementsprechend aus $\mathrm{b}$ nach $\mathrm{a}$ ab, bis sich seine Entlohnung angeglichen hat. In diesem Fall wird $\mathrm{K}$ in b so knapp, daß sich diese Region auf das arbeitsintensive Gut $\mathrm{x}$ spezialisiert, also eine Randlösung auftritt, in der das Arbeitsentgelt in $\mathrm{b}$ geringer ist als in $\mathrm{a}^{86}$.

Unter diesen Bedingungen führt eine sektorale Subvention neben den bereits beschriebenen Effekten auf in- und ausländische Preise und Produktionsmengen sowie die Terms of trade zu weiteren Veränderungen:

$\mathrm{Da} \mathrm{b}$ vollkommen auf $\mathrm{x}$ spezialisiert ist, bewirkt eine Subvention hierfür lediglich eine Produktionsausweitung in a mit relativem Reallohnanstieg dort, während in b die Subvention zunächst als Transfer die Einkommen beider Faktoren erhöht. Dies führt zur Zuwanderung von $\mathrm{F}$ und $\mathrm{K}$, bis ein neues Gleichgewicht erreicht ist, in dem der Lohnsatz $\mathrm{w}$ in b ansteigt. Die inländische Produktion verlagert sich also zu $\mathrm{x}$ bei geringerer Effizienz des Kapitaleinsatzes, die Terms of trade steigen bei reduziertem Außenhandelsvolumen und verstärkter Produktion von y im Ausland. Wird umgekehrt y subventioniert, so steigen Produktion und Faktorentgelte in a, wo y produziert wird, $\mathrm{F}$ und $\mathrm{K}$ wandern aus $\mathrm{b}$ zu, wo w fällt. Bei verstärktem Außenhandel und verschlechterten Terms of trade für das Inland spezialisiert sich das Ausland auf $\mathrm{x}^{87}$. Interregionale Faktormobilität verstärkt also die Wirkung einer sektoralen Beihilfe. Bei internationaler Kapitalmobilität führt die Subvention zu Kapitalimporten nach Region b (Subvention für $\mathrm{x}$ ) oder a (Subvention für $\mathrm{y}$ ). Im Ausland verstärken sich dadurch die komparativen Vorteile für und die Produktion von Gut $\mathrm{x}$, die

85 a könnte eine städtische Region sein, für die F bspw. aufgrund besseren kulturellen Angebots Präferenzen hegt. Vgl. Soltwedel et al. 1988, S. 81/82.

$86 \mathrm{Vgl}$. Soltwedel et al. 1988, S. 82-85.

$87 \mathrm{Vgl}$. Soltwedel et al. 1988, S. 88/89. 
zunehmende Spezialisierung erhöht die Außenhandelsneigung. Im Inland sinkt hingegen diese Neigung bei einer Subventionierung des Importgutes $\mathrm{x}$ bei steigenden Terms of trade, so daß die Wirkung auf das Handelsvolumen unsicher ist. Wird das inländische Exportgut gefördert, so steigt der Außenhandel bei jedoch unsicherem Terms-of-trade-Effekt, da er in beiden Staaten isoliert betrachtet zu einer Verschlechterung tendiert.

\subsubsection{Faktorpreisrigiditäten}

Bisher wurde im Modell von Faktorpreisflexibilität und damit von Vollbeschäftigung ausgegangen. Nun wird eine Preisuntergrenze für den Faktor Arbeit im Inland betrachtet (im Unterschied zu Abschnitt 2.1.2.3 wird hier ein großes Land untersucht). Verlangt die Nachfragestruktur eine Umschichtung der Produktion von $\mathrm{x}$ nach $\mathrm{y}$, so steigt die Arbeitsintensität in beiden Branchen, so daß der Lohnsatz fallen müßte. Verhindern die Faktorpreisrigiditäten dies, so wird die inländische Kontraktkurve (und die PPF) verlassen, ein Teil des Faktors Arbeit bleibt unterbeschäftigt, und die Produktionsmöglichkeiten der Volkswirtschaft sinken 88 . Zusätzlich fallen hier die Terms of trade. Diese Situation kann auch bei unterschiedlicher Verteilung des Humankapitals (siehe oben) und immobiler Arbeit sowie landeseinheitlichen Tarifverträgen vor allem in Region b verstärkt auftreten. Wandert in dieser Situation das Kapital, dessen Rendite durch die geringere Arbeitsintensität ebenfalls sinkt, aus b ab, so müßte der Lohn in b weiter sinken, so daß die Arbeitslosigkeit in einem kumulativen Prozeß weiter anstiege. Solche Entwicklungen bilden in der Realität häufig den Auslöser für Subventionsprogramme ${ }^{89}$.

Eine Subventionierung des Importgutes x (arbeitsintensiv) senkt implizit den Faktorpreis über eine Erhöhung des Produzentenpreises und führt zu einer Abnahme der Arbeitslosigkeit bei steigender Kapital- und Humankapitalproduktivität, deren Abwanderung aus b somit gestoppt werden kann. Der Lohnsatz steigt solange nicht, wie der Vollbeschäftigungsproduktionspunkt noch nicht erreicht wird, es entsteht also ein Mengeneffekt. Die zunehmende Inlandsproduktion von x führt im Ausland zur Umstrukturierung hin zu y bei sinkendem Außenhandel und fallenden Terms of trade. Hierdurch und durch evtl. Kapitalwanderungen ins Inland müßte der Lohnsatz im Ausland fallen. Existiert hier ebenfalls eine Preisuntergrenze, so gelingt dem Inland durch die Subvention ein Export von Arbeitslosigkeit ${ }^{90}$.

\footnotetext{
$88 \mathrm{Vgl}$. Hiemenz/Weiss 1984, S. 9.

$89 \mathrm{Vgl}$. Soltwedel et al. 1988, S. 96/98.

$90 \mathrm{Vgl}$. Soltwedel et al. 1988, S. 98/99, analog für Zölle Södersten 1980, S. 183.
} 
Umgekehrt bewirkt eine Subvention für das kapitalintensive Exportgut y einen weiteren Druck auf den Lohnsatz insbesondere in Region b, der bei Rigiditäten die Arbeitslosigkeit weiter erhöht. Die Produktionsmöglichkeiten im Inland sinken, der Außenhandel steigt bei fallenden Terms of trade ${ }^{91}$. Das Ausland kann hierdurch und mittels Kapitalimporten eine Wohlfahrtserhöhung erfahren.

\subsubsection{Analyse der Handelswirkungen von Regionalbeihilfen}

Bisher beschränkte sich die Betrachtung auf spezifisch sektororientierte Subventionen. Einen weiteren wichtigen Aspekt staatlicher Strukturpolitik stellen jedoch Regionalförderungsmaßnahmen dar, die zur Internalisierung externer Ballungskosten beitragen und gleichzeitig mittels Subventionen Produktionspotential und -struktur sowie das Einkommens- und Beschäftigungsniveau benachteiligter Regionen verbessern sollen.

Auch derartige Maßnahmen lassen sich im bisher betrachteten Modell darstellen. Die Subvention wird sektorneutral zunächst an alle Produzenten einer Region, hier der inländischen Region b, gewährt. Im einfachsten Fall unter Annahme interregionaler Faktorimmobilität und Vollbeschäftigung werden die Faktoreinkommen in b zu Lasten von a steigen, was bei gleichen Konsumentenpräferenzen nur das relative Konsumniveau in b erhöht, die Konsum- und Produktionsstruktur sowie die Preisverhältnisse aber nicht verändert. Aufgrund der Immobilitäts- und Vollbeschäftigungsannahmen wird auch die Produktionshöhe in b sich nicht verändern. Aus all dem folgt, daß das Ausland von dieser Subvention nicht betroffen wird 92 .

Wegen der restriktiven Annahmen liefert dieses Ergebnis allerdings keinen "Freispruch" für regionale Subventionen in einem Gemeinsamen Markt, denn bei Einführung von interregionaler Faktormobilität ändert sich das Bild: Wie oben dargelegt, sei die Kapital- und Humankapitalintensität vor Subventionen in a höher, somit auch der dortige Arbeitslohn, während sich b auf das arbeitsintensive Gut $x$ spezialisiere. Eine Subvention für b erhöht wiederum zunächst alle Faktorentgelte in $\mathrm{b}$, was zur Zuwanderung von $\mathrm{F}$ und $\mathrm{K}$ aus a und auch aus dem Ausland führt. Arbeitsproduktivität und Lohnsatz in $b$ steigen, bei entsprechend hohen Subventionen und Zuwanderung von $\mathrm{F}$ und $\mathrm{K}$ kann sogar evtl. die Produktion von y in $\mathrm{b}$ aufgenommen werden. Zunächst jedoch steigt die inländische x-Produktion bei sinkender Effizienz, da die Grenzproduktivität des Kapitals in b geringer als in a ist, und damit steigen die Terms of trade bei abnehmendem Außenhandelsvolumen, was auch

91 Vgl. Soltwedel et al. 1988, S. 99.

$92 \mathrm{Vgl}$. Soltwedel et al. 1988, S. 72/73. 
das Ausland zur Umstrukturierung zugunsten von y zwingt. Wandert zudem Kapital aus dem Ausland ab, so fallen dort die Produktionsmöglichkeiten insbesondere des kapitalintensiven Gutes y, was nun zu weiterer Spezialisierung des Auslands in Richtung auf $x$ führt. Der gesunkenen Handelsneigung des Inlands steht eine gestiegene des Auslands gegenüber, weshalb der Nettoeffekt unsicher bleibt ${ }^{93}$.

Werden nun noch Lohnstarrheit und damit Unterbeschäftigung im Inland eingeführt, muß das Ergebnis weiter modifiziert werden. Vor der Subventionsvergabe herrschte in Region b Arbeitslosigkeit. Eine Regionalsubvention wirkt in b, da dort nur x produziert wird, wie eine sektorale Subvention für x. Sie führt somit zur Produktionsausweitung und Zuwanderung von $\mathrm{F}$ und $\mathrm{K}$. Durch beide Faktoren sinkt die Arbeitslosigkeit in $\mathrm{b}$ und die Produktionsmöglichkeiten des Inlandes steigen (Erweiterung der PPF). Da die Ausweitung das Importgut $\mathrm{x}$ betrifft, steigen die inländischen Terms of trade bei fallendem Außenhandel. Wiederum muß das Ausland aufgrund der Preissignale zur Produktion von y umstrukturieren, während die Abwanderung des Kapitals eine Spezialisierung auf Gut x fördert ${ }^{94}$.

\subsubsection{Analyse der Handelswirkungen horizontaler Beihilfen}

Neben den beiden bisher betrachteten Subventionsformen sind viele andere Typen nicht sektor- oder regionalspezifischer Unterstützungsmaßnahmen denkbar. Aus dieser vielschichtigen Gruppe sog. horizontaler Beihilfen sollen nun noch die allgemeinen Faktorbeihilfen herausgegriffen werden, die in allen Regionen und Sektoren in Abhängigkeit von der Einsatzmenge eines Faktors, also bspw. als Lohnsubventionen, Investitionsbeihilfen oder auch Fördermaßnahmen zur Humankapitalbildung, gezahlt werden.

Im einfachsten Modell mit immobilen Faktoren und Vollbeschäftigung sind die Wirkungen einer Faktor- ähnlich der einer Regionalsubvention. Es findet eine Einkommensumverteilung zugunsten des unterstützten Faktors statt, die keinerlei Allokationseffekte am Faktor- oder Gütermarkt hat und auch das Ausland nicht tangiert ${ }^{95}$.

Die Einführung interregionaler Faktormobilität verändert das Ergebnis im Gegensatz zum Fall regionaler Subventionen zunächst nicht, da die Subvention dem geförderten Faktor in allen Regionen zuteil wird und sein relatives Einkommen überall im

93 Vgl. Soltwedel et al. 1988, S. 90/91.

94 Vgl. Soltwedel et al. 1988, S. 99/100.

$95 \mathrm{Vgl}$. Soltwedel et al. 1988, S. 73/74. 
gleichen Maße erhöht, so daß Wanderungen nicht stattfinden. Jedoch sind Kapitalimporte aus dem Ausland zu erwarten, wenn Kapital über Grenzen mobil ist und im Inland gefördert wird. In beiden Regionen des Inlands steigen die Produktionsmöglichkeiten für beide Güter und aufgrund der höheren Kapitalintensität erhöht sich zudem die Arbeitsproduktivität. Die Exportbereitschaft des Inlands steigt, während die Entwicklung der Terms of trade aufgrund der Ausweitung beider Produktionszweige unsicher ist. Die Produktionsmöglichkeiten des Auslands fallen aufgrund der Kapitalabwanderung und die Spezialisierung auf das arbeitsintensive Gut x nimmt $\mathrm{zu}^{96}$.

Wird nun die Möglichkeit von Arbeitslosigkeit im Inland in die Analyse einbezogen, so erscheint zunächst eine Lohnsubvention das gegebene Mittel. Jedoch bewirken auch Kapitalsubventionen über Kapitalimporte und steigende Kapitalintensität höhere Arbeitsproduktivität und damit im Fixlohnfall in der Region b, in der Kapitalmangel herrscht, eine Abnahme der Unterbeschäftigung. Wie jedoch bereits in Abschnitt 2.1.2.3 deutlich wurde, ist hier eine direkte Lohnsubvention effizienter. Diese vermindert allerdings die Arbeitslosigkeit nicht, wenn der Lohnsatz in b fest an denjenigen in a gekoppelt ist, da dann eine allgemeine Lohnsubvention aufgrund der Knappheit von $\mathrm{L}$ in a dort das Entgelt erhöht und die Region b nachzieht, so daß aus Produzentensicht der alte Lohnsatz erhalten bleibt. Ist der Lohnsatz allerdings an den Kapitalzins gebunden (feste Lohnquote), dann verbilligt eine Lohnsubvention das Arbeitsentgelt aus Produzentensicht und erhöht das Beschäftigungsniveau in $\mathrm{b}^{97}$.

\subsubsection{Handelswirkungen von Beihilfen in einer wachsenden Wirtschaft}

Bisher blieb die Analyse der Subventionswirkungen im In- und Ausland auf den Fall der stationären Wirtschaft beschränkt. Häufig werden jedoch Beihilfen gerade mit dem Ziel vergeben, das Wachstum eines bestimmten Sektors zu beschleunigen oder den Niedergang einer Region oder eines Sektors aufgrund technologischer oder Nachfrageveränderungen abzufedern ${ }^{98}$. Solche Aspekte können in das bisher betrachtete Modell einbezogen werden, indem das Faktorangebot und damit die Produktionsmöglichkeiten als variabel und preiselastisch angesehen werden.

Es sei angenommen, daß sich im Zeitablauf die Präferenzen der Konsumenten zugunsten des kapitalintensiven Gutes y verändern, und zwar im In- und Ausland. Im Wachstumsprozeß führt diese Präferenzveränderung somit zu verstärkter Kapital-

$96 \mathrm{Vgl}$. Soltwedel et al. 1988, S. 91.

$97 \mathrm{Vgl}$. Soltwedel et al. 1988, S. 100.

98 Vgl. Hufbauer/Shelton Erb 1984, S. 21. 
nachfrage, so daß dessen relatives Entgelt zu Lasten des Lohnes des weniger nachgefragten Faktors Arbeit ansteigt, was wiederum nachfragebedingt zu einer Erhöhung der Ausstattung mit diesem Faktor führt ${ }^{99}$. Erhöht sich zudem die Ausstattung des Inlands mit Humankapital, das Präferenzen für Region a hat, so steigen die Erträge der anderen Faktoren und insbesondere des Faktors L in dieser Region stärker als in b, wodurch eine Kapitalzuwanderung von b nach a einsetzt. Der Arbeitslohn in Region b, die zudem auf das weniger nachgefragte Gut spezialisiert ist, wird hierdurch relativ zur Region a fallen, es entstehen also regionale Polarisierungsprobleme. Als Gegenargument gegen eine solche Entwicklung führen Soltwedel et al. ${ }^{100}$ allerdings an, daß im Lebenszyklus eines Produkts dies in späteren Phasen standardisiert mit wenig Humankapital produziert werden kann, so daß die Produktion dann in Regionen wie b mit geringeren Lohnsätzen verlagert werden kann, und auf diese Weise die Regionalprobleme abnehmen. Auf die Frage der relativen Stärke beider Effekte soll hier nicht eingegangen werden. Vielmehr interessiert die Frage der in- und ausländischen Wirkungen staatlicher subventionistischer Eingriffe in den Wandlungsproze $\beta$ :

Werden sektorale Subventionen zugunsten des schrumpfenden Sektors im Inland eingesetzt, so steigen aufgrund der Verbilligung dieses Gutes die Nachfrage und der Arbeitslohn. Der Umstrukturierungsprozeß zugunsten von Gut y wird verlangsamt, wodurch die nachfragebedingte Zunahme des Angebots von Kapital und Humankapital auch gebremst wird. Dies verhindert langfristig einen Lohnanstieg aufgrund zunehmender Kapitalintensität und verstärkt bei angenommen säkularer Präferenzverschiebung den Anpassungsbedarf. Im Ausland hingegen muß zunächst der immobile Faktor Arbeit einen Entlohnungsrückgang hinnehmen, auf längere Sicht wird jedoch der Umstrukturierungsprozeß im Ausland in Richtung auf y beschleunigt und damit bei wachsendem Kapitalangebot die Wohlfahrt des Auslands erhöht ${ }^{101}$. Die weltwirtschaftliche Effizienz ist in dieser Situation allerdings geringer als ohne Subventionen, da die Produktionsstruktur nicht den komparativen Vorteilen entspricht.

Regionale Subventionen zugunsten der Region b, die Gut x produziert, haben ähnliche Wirkungen. Wiederum steigt der Lohnsatz, wenn auch nur in Region $b$, und der Strukturwandel wird, wenn auch in geringerem Maße, gebremst. Langfristig werden wiederum die Anreize zur Kapital- und Humankapitalbildung in Region b

\footnotetext{
$99 \mathrm{Vgl}$. Soltwedel et al. 1988, S. 106/107.

100 1988, S. 108/109.

101 Vgl. Hiemenz/Weiss 1984, S. 5/6, 9-11.
} 
gemindert, also auch die Chancen einer Produktivitätserhöhung des Faktors Arbeit. Evtl. sinken auch die Innovationsanreize für Region a, da dort erarbeitete Produktivitätsvorsprünge durch Regionalsubventionen wieder eingeebnet werden. Im Ausland sinkt wie im 1. Fall zunächst die Entlohnung des Faktors Arbeit, langfristig gewinnt das Ausland jedoch durch beschleunigte Umstrukturierung 102 .

Einen anderen wichtigen Aspekt staatlicher Industriepolitik stellt der Versuch dar, Zukunftsindustrien zu erkennen und diese zu fördern, um damit Wachstum und Strukturwandel zu beschleunigen ${ }^{103}$. Werden also Subventionen an den Sektor y gegeben, so steigt die Produktion dieses Gutes und damit auch der Anreiz, das Kapital- und Humankapitalangebot auszuweiten. Die verbesserte Faktorausstattung beschleunigt das Wachstum und die Arbeitsproduktivität ${ }^{104}$ und kann langfristig auch die Situation der benachteiligten Region b verbessern. Die inländische Produktionsumschichtung verstärkt den Außenhandel, bei stark steigender Weltnachfrage nach Gut y werden sich die Terms of trade zudem nicht verschlechtern, das Inland kann also seine Wohlfahrt relativ zum Ausland verbessern. Voraussetzungen für das Gelingen dieser Strategie sind allerdings, daß der Staat zum einen die Wachstumsbranchen schneller und präziser entdeckt als der Markt ${ }^{105}$ und daß zum anderen die Faktorangebotserhöhung und Faktorumsetzung durch die Subventionen beschleunigt werden kann. Ist der Strukturwandel entscheidend von einer Zunahme des Faktorangebots abhängig, so sind wiederum allgemeine Faktorsubventionen das effizientere Mittel $^{106}$. Selbst eine Förderung eines nur interregional mobilen Faktors (z.B. Humankapital bei FuE-Subventionierung) kann jetzt auf eine Erhöhung des Angebots dieses Faktors und damit eine Beschleunigung des Wachstumsprozesses hinwirken $^{107}$, sofern es möglich ist, die Faktorbildungsprozesse tatsächlich zu beschleunigen. Betrachtet man hierzu den Fall je eines Unternehmens in einer bestimmten Branche im In- und Ausland, deren mögliche Erträge aus einem gegebenen FuEVolumen von den FuE-Ausgaben im anderen Land invers abhängen, so führt eine subventionsinduzierte Ertragserhöhung im Inland zu einer Verlagerung der Reaktionsfunktionen und des Gleichgewichts zugunsten des Inlands, dessen technologi-

$102 \mathrm{Vgl}$. Soltwedel et al. 1988, S. 110/111, 121.

103 Vgl. Klodt 1987, S. 3.

104 Vgl. Schuster 1984, S. 73, 79.

105 Kritisch hierzu: Hiemenz/Weiss 1984, S. 12, Stegemann 1989, S. 93 und Wiseman 1981, S. 62.

106 Vgl. Krugman 1983, S. 346.

107 Vgl. Vickers 1985, S. 211. 
sche Position sich dadurch verbessert ${ }^{108}$. Bezieht man Drittmärkte in die Betrachtung ein, so wird der Marktanteil des Inlands dort folglich auch steigen, die inländische Faktorsubvention wirkt also wie eine Exportförderung zu Lasten der Industrie im Ausland, es handelt sich hier somit um das typische Beispiel einer Beggar-thyneighbour-policy 109 .

\subsubsection{Zusammenfassung}

Die bisherige Analyse war durch die Vielfalt der betrachteten Subventionstypen, Annahmen und Effekte recht komplex. Versucht man, die Ergebnisse zu strukturieren, so zeigen sich im Prinzip drei Wirkungskanäle, die jeweils die Situation sowohl im In- als auch im Ausland beeinflussen:

Zunächst verändern Subventionen über ihre Preis- und Nachfragewirkungen die inländische sektorale Produktionsstruktur und damit auch die Terms of trade. Weiterhin finden im Inland Wanderungen der mobilen Faktoren zwischen den Regionen statt, die die jeweiligen regionalen Produktionsmöglichkeiten und -funktionen beeinflussen. Auch hierdurch verändern sich die Terms of trade und die sektorale Produktionsstruktur. Schließlich führen Subventionen zu Wanderungen des mobilen Faktors vom Aus- ins Inland und erhöhen so die Produktionsmöglichkeiten des Inlands 110 .

Vergleicht man die drei vorgestellten Subventionsarten, so zeigt sich, daß bei sektoralen Subventionen alle drei Effekte wirksam sind. Eine regionale Beihilfe hingegen verändert Güterpreise und Produktionsstruktur im Inland nicht direkt, es treten lediglich Faktorwanderungen aus dem In- und Ausland in die geförderte Region mit ihren sektoralen Nebenwirkungen auf. Eine allgemeine Faktorsubvention für einen mobilen Faktor schließlich wird auch die interregionale Faktorverteilung im Inland nicht beeinflussen, sondern führt lediglich zu einem Import des geförderten Faktors aus dem Ausland ${ }^{11}$.

Das Ausland wird von den ersten beiden Wirkungsverläufen via Veränderungen der Terms of trade und des Außenhandels, vom dritten Verlauf über Abwanderungen des Faktors Kapital betroffen. Eine inländische Subvention des Importgutsektors ver-

108 Vgl. Jacquemin 1989, S. 498. Gelingt es, dabei das Konkurrenzunternehmen vom Markt zu verdrängen, so kann das subventionierte Unternehmen bei fallenden DK eine Innovationsrente erzielen. Vgl. Klodt 1987, S. 13/14.

109 Vgl. Krugman 1983, S. 346.

$110 \mathrm{Vgl}$. Soltwedel et al. 1988, S. 93.

$111 \mathrm{Vgl}$. Soltwedel et al. 1988, S. 93, 102. 
schlechtert die ausländischen Terms of trade ${ }^{112}$ bei abnehmendem Außenhandel, das umgekehrte gilt bei Subventionen für das inländische Exportgut. Das Ausland muß die Produktion zu Lasten des im Inland geförderten Gutes umstrukturieren, und die Entlohnung des für diese Produktion wichtigeren Faktors fällt ${ }^{113}$. Zwar erreicht das Ausland bei inländischen Produktionssubventionen für das Exportgut y oder bei reinen Exportsubventionen für y eine Wohlfahrtssteigerung; nutzen die inländischen Produzenten diese Subventionen jedoch, um ausländische Konkurrenten aus dem Markt zu drängen und anschließend höhere Monopolpreise zu erheben, so wird das Ausland dann einen Wohlfahrtsverlust erleiden ${ }^{14}$. Dies gilt jedoch nur, wenn es dem Inland gelingt, den Marktwiedereintritt ausländischer Produzenten zu verhindern, was je nach Industriezweig unterschiedlich wahrscheinlich ist 115 . Bei Einbeziehung internationaler Kapitalmobilität in die Betrachtung führen alle Subventionstypen zu einer Abwanderung von Kapital aus dem Ausland, wodurch dessen Produktionsmöglichkeiten und Wohlfahrtspotential insbesondere bezogen auf die Erstellung des kapitalintensiven Gutes sich verschlechtern, auch wenn sich bei inländischer Förderung des kapitalintensiven Exportgutes y die ausländischen Terms of trade durch die wanderungsbedingte Erhöhung der Ausbringung von y im Inland verbessern $^{116}$. Läßt man schließlich auch Arbeitslosigkeit durch Fixlohnannahmen im Ausland zu, so führt eine Subventionierung von Gut x im Inland im Ausland zu potentiell sinkenden Löhnen und bei Verhinderung dieser Senkung zu importierter Arbeitslosigkeit. Diese kurze Zusammenfassung zeigt, daß das Ausland durch inländische Subventionen möglicherweise Wohlfahrtsverluste erleidet, die durch Termsof-trade-Verschlechterungen, Verringerung des Kapitalangebotes und damit der Produktionsmöglichkeiten sowie durch Arbeitslosigkeit verursacht sein können. Die stärksten Effekte treten bei sektoralen, die geringsten bei allgemeinen Faktorsubventionen auf.

Ist das Ausland nicht bereit, die Wohlfahrtsverluste oder die extern determinierten Umstrukturierungen hinzunehmen, so kann es Retorsionsmaßnahmen in Form eige-

112 Die Stärke dieser Veränderung ist abhängig von den ausländischen Preiselastizitäten der Nachfrage und des Angebotes; je höher sie sind, desto weniger fallen die Terms of trade. Vgl. Södersten 1980, S. 177.

$113 \mathrm{Vgl}$. Soltwedel et al. 1988, S. 93, 116.

$114 \mathrm{Vgl}$. Hufbauer/Shelton Erb 1984, S. 5.

115 Vgl. Chard/Macmillen 1979, S. 134, und Lehner/Meiklejohn/Reichenbach 1991, S. 24f. In diesem Fall kommt es zudem im Inland auch zu wohlfahrtsmindernden intersektoralen Verzerrungen.

$116 \mathrm{Vgl}$. Soltwedel et al. 1988, S. 117/118. 
ner Subventionen ergreifen: Betrachtet man eine inländische Subvention des Importgutes und will das Ausland die Veränderung seiner Produktionsstruktur kompensieren, so wird es ebenfalls Gut x subventionieren. Hierdurch fallen jedoch die ausländischen Terms of trade und sein Wohlfahrtsniveau weiter ${ }^{17}$. Das Ausland erreicht wieder seine alte Produktionsstruktur, während aufgrund der gestiegenen Nachfrage das Inland weiterhin mehr x produziert als vor der Subvention. Ist das Inland bestrebt, die Produktionsstruktur, die es vor der Retorsion hatte, zu erhalten, wird es mit Gegen-Gegenmaßnahmen reagieren, auf die das Ausland antwortet, usw. Der Prozeß erreicht evtl. ${ }^{118}$ ein neues Gleichgewicht, wenn aufgrund der fallenden Preise für $\mathrm{x}$ die Nachfrage nach diesem Gut so gestiegen ist, daß das Ausland die ursprüngliche Produktionsstruktur bewahren kann, das Inland jedoch die durch die Ausgangssubvention angestrebte Struktur ebenfalls erreicht ${ }^{19}$. Das Weltwohlfahrtsniveau wird aufgrund der massiven Preisverzerrungen dann allerdings unter demjenigen vor Subventionen liegen, wobei vor allem das Ausland die Verluste trägt. Für das Ausland wäre daher eine Subventionierung des eigenen Importgutes sinnvoller, da es hierdurch die Verschlechterung der Terms of trade rückgängig machen und einen Teil des Wohlfahrtsverlustes auf das Inland rückwälzen könnte ${ }^{120}$.

Will das Ausland die Produktionsmöglichkeitseinschränkungen durch Kapitalexporte verhindern, muß es eine Faktorsubvention zugunsten von $\mathrm{K}$ gewähren. Hierdurch wird $\mathrm{K}$ immobil, die inländischen Wohlfahrtserhöhungen durch Kapitalangebotserhöhung werden zunichte gemacht, während es dem Faktor Kapital jetzt gelingt, in beiden Ländern eine Rente zu erzielen ${ }^{121}$.

Wie die bisherige Analyse gezeigt hat, kann in Abwesenheit weiterer Handelsbeschränkungen das Inland als großes Land durch gezielte Subventionen Wohlfahrtsgewinne mittels Terms-of-trade-Verbesserungen oder Kapitalimporten auf Kosten anderer Länder erzielen, wobei die Möglichkeiten hierzu bei sektoralen gröBer als bei regionalen Subventionen und hier wiederum größer als bei allgemeinen Faktorbeihilfen sind. Das Ausland kann sich hiergegen durch Retorsionsmaßnahmen wehren, die zwar den inländischen Wohlfahrtsgewinn zunichte machen können, die Gesamtwohlfahrt aller beteiligen Länder mit steigendem Subventionsniveau jedoch immer weiter vermindern. Sollen diese Formen einer Beggar-thy-neighbour-

\footnotetext{
$117 \mathrm{Vgl}$. Soltwedel et al. 1988, S. 103.

118 Die Möglichkeit zyklischer Entwicklungen ohne Gleichgewicht zeigt Johnson 1958, S. 42-44.

$119 \mathrm{Vgl}$. Soltwedel et al. 1988, S. 104.

$120 \mathrm{Vgl}$. Hiemenz/Weiss 1984, S. 6/7.

$121 \mathrm{Vgl}$. Soltwedel et al. 1988, S. 104.
} 
policy 122 und die ineffizienten Produktionsstrukturveränderungen, die im Gegensatz zum Zollfall u.U. mit übermäßigen Ausweitungen des Außenhandelsvolumens verbunden sind (ineffiziente Trade creation statt Trade destruction), verhindert werden, so sind Kontrollen der Subventionsvergabe nötig, die je nach Subventionstyp verschieden strikt sein müssen. Annähernd gleichhohe Subventionen in allen Ländern sind hierbei bei Beschränkung der Analyse auf einen Sektor oder auch aus innergemeinschaftlichen verteilungspolitischen Gründen zwar besser als Subventionen in lediglich einem Land, jedoch schlechter als völlige Subventionsvermeidung, da intersektorale Verzerrungen und ineffiziente Faktorwanderungen für die Union als Ganzes auftreten ${ }^{123}$. Dies gilt nicht, wenn es der Gemeinschaft gelingt, durch Veränderung des Weltmarktpreisverhältnisses zu ihren Gunsten und möglicherweise durch Kapitalimporte die innergemeinschaftlichen Verluste aus diesen Verzerrungen unter Ausbeutung des Rests des Welt zu überkompensieren ${ }^{124}$.

Die Möglichkeit, mittels Beihilfen zu Lasten anderer Länder Wohlfahrtsgewinne zu erzielen bzw. durch Retorsionsmaßnahmen dies zu verhindern, erklärte die Vergabe von Subventionen aus wohlfahrtstheoretischer Sicht 125 . Die praktische Relevanz dieser Möglichkeit, über die Vergabe von Subventionen an einzelne Branchen signifikante Terms-of-trade-Gewinne zu erzielen, wird jedoch stark angezweifelt ${ }^{126}$. Zudem zeigte sich bei der Analyse von Subventionswirkungen im Wachstumsprozeß, daß Beihilfen für schrumpfende Industrien den Strukturwandel behindern und durch mangelnde Bildung zusätzlichen Kapitals und Humankapitals die inländische Wohlfahrt auf längere Sicht vermindern, während das Ausland umgekehrt Wohlfahrtserhöhungen erreicht. Da man der inländischen Wirtschaftspolitik kaum Altruismus unterstellen kann, sind derartige Maßnahmen aus wohlfahrtstheoretischer Sicht unverständlich. Zur Erklärung dieser Phänomene müssen andere Erklärungsansätze herangezogen werden, deren Diskussion der folgende Abschnitt dienen soll.

122 ähnlich Södersten 1980, S. 183/184.

$123 \mathrm{Vgl}$. Andel 1965, S. 7, 17.

124 Die Auswirkungen von Subventionen auf den Rest der Welt wurden hier bewußt aus der Analyse ausgeklammert, da der Schwerpunkt dieser Arbeit auf der Subventionskontrolle innerhalb des Gemeinsamen Marktes liegt. Derartige Auswirkungen im Rahmen eines partialanalytischen Modells untersucht Andel (1965, S. 9-11).

125 Wie bereits oben erläutert, wurde in der Analyse dieses Abschnitts von internen Verzerrungen im Sinne der Abschnitte 2.1.1 - 2.1.3 abstrahiert.

126 Vgl. Chard/Macmillen 1979, S. 133. 


\subsection{Mögliche Gründe allokationsineffizienter Subventionierung}

Die hier zunächst vorgebrachten Ansätze firmieren im allgemeinen unter der Überschrift der "non-economic arguments for protection". Sie betonen zusätzliche, d.h. über die traditionellen allokationstheoretischen Modelle hinausgehende, Nutzen für eine Gemeinschaft aus erhöhter inländischer Produktion eines Gutes oder aus erhöhtem Selbstversorgungsgrad, d.h. geringerer relativer Importabhängigkeit. Im letzteren Fall ist eine Zollerhebung das optimale Mittel zur Zielerreichung, da sie sowohl den Konsum senkt als auch die Inlandsproduktion erhöht. Im ersten Fall hingegen erweisen sich Produktionssubventionen als geeigneter, da sie eine Erhöhung der Inlandsproduktion erreichen, ohne die Konsumstruktur direkt zu verändern (bei Annahme fixer Weltmarktpreise) ${ }^{127}$. Argumente für eine solche Erhöhung bestehen z.B. in strategischen Überlegungen, nach denen im Fall militärischer Auseinandersetzungen bestimmte lebenswichtige Güter im Inland produzierbar und verfügbar sein sollen, oder in Prestigegewinnen, die mit der Existenz oder dem Wachstum bestimmter Branchen in einem Land verbunden sind 128 .

\subsubsection{Kollektive Präferenz für Industrieproduktion}

Die Wirkungen einer solchen Politik lassen sich folgendermaßen formal darstellen: Johnson ${ }^{129}$ nimmt an, daß die Bevölkerung eine kollektive Präferenz für die Produktion industrieller Güter hat und somit bereit ist, Ressourcen und Wohlfahrt im üblichen allokationstheoretischen Sinn aufzugeben, um die Industrieproduktion zu steigern. Industrielle Produktion (allgemein oder auf bestimmte Branchen beschränkt) hat somit einen Öffentlich-Guts-Charakter, bietet der Gesellschaft also zusätzliche externe Nutzen. Aufgrund dieser Eigenschaft muß der Staat durch Fördermaßnahmen diese Produktion erhöhen, bis der kollektive Grenznutzen aus ihr den zusätzlichen privaten Grenzkosten der verzerrten Produktionsstruktur entspricht. Je nach Stärke der kollektiven Präferenz für die Produktion eines bestimmten Gutes und je nach den Verzerrungskosten werden die Subventionssätze zwischen verschiedenen Industrien variieren.

Beschränkt man sich auf die Betrachtung eines Industriezweiges, so läßt sich die Problematik wie folgt graphisch darstellen ${ }^{130}: S_{w}$ sei die Angebotskurve des Rests der Welt (Kleines-Land-Fall), die zum Weltmarktpreis unendlich elastisch ist, $S_{\mathrm{i}}$ und

\footnotetext{
127 Vgl. Krauss 1972, S. 428.

$128 \mathrm{Vgl}$. Hindley 1974 , S. 29.

129 1965a, S. 258-260.

$130 \mathrm{Vgl}$. Johnson 1965a, S. 261.
} 
$D_{i}$ seien die inländischen Angebots- und Nachfragekurven. Im Freihandelszustand produziert das Inland $\mathrm{p}_{\mathrm{w}} \mathrm{A}$, die Importe betragen $\mathrm{AB}$. Der kollektive Grenznutzen inländischer Produktion komme in der Differenz zwischen den Kurven V und $S_{w}$ zum Ausdruck, während der Abstand zwischen $S_{i}{ }^{*}$ und $S_{w}$ die zusätzlichen allokativen Kosten subventionsinduzierter Inlandsproduktion darstelle. Das inländische Optimum wird somit in D erreicht, das Inland produziert $\mathrm{p}_{\mathrm{w}} \mathrm{E}$, wobei der kollektive Grenznutzen $\mathrm{p}_{\mathrm{w}} \mathrm{v}$ den Grenzkosten entspricht. Dieser Punkt wird erreicht durch eine inländische Subvention in Höhe von CE im Optimum, die die inländische Angebotskurve nach unten auf $S_{i}{ }^{2}$ verschiebt. Aus dieser Analyse folgt, daß bei gleichen Präferenzen für industrielle Produktion das Subventionsniveau mit fallender Konkurrenzfähigkeit steigt. Umgekehrt wird ein Land mit einem großen exportorientierten industriellen Sektor ein eher geringes Protektionsniveau halten, da im allgemeinen Gleichgewicht verringerte Importe und eine Ressourcenverlagerung in den Importsubstitutionssektor zu verringerter Industrieproduktion im Exportsektor führen und damit zusätzliche Kosten in Form verringerten kollektiven Konsums mit sich bringen ${ }^{131}$. Ist die inländische Präferenz für industrielle Produktion so groß, daß der Gleichgewichtspunkt jenseits des Selbstversorgungspunkts liegt, so kann er durch gezielte Exportsubventionen erreicht werden, die zur Vermeidung von Reimporten allerdings mit Importzöllen verbunden sein müssen. Im Falle variabler Terms of trade führt die eben dargelegte Argumentation zu höheren optimalen Subventionssätzen als im orthodoxen Fall ${ }^{132}$ (siehe Abschnitt 2.1.4).

Betrachtet man im Kontext des Johnsonschen Modells die Situation eines Gemeinsamen Marktes ${ }^{133}$, so wird ein Partnerland stets dann bereit sein, Subventionen in einem anderen Mitgliedsland zu akzeptieren, wenn dadurch lediglich Drittlandsimporte durch Partnerimporte verdrängt werden (trade diversion), nicht jedoch, wenn Inlandsproduktion substituiert wird (trade creation), vorausgesetzt, daß eigene Subventionen mit denselben Wirkungen in anderen Mitgliedsländern ebenfalls akzeptiert werden. Auf diese Weise kann es allen Mitgliedsländern gelingen, ihre Industrieproduktion auszuweiten und somit ihren Gesamtnutzen zu erhöhen, soweit der Gewinn hieraus die Trade-diversion-Effizienzverluste übersteigt. Ein Wille zur Subventionsbegrenzung besteht also nur insoweit, als durch Partnersubventionen eigene (evtl. ebenfalls subventionierte) Produktion gemindert wird. Dieser Wille ist in den Ländern am stärksten, deren Industrie die höchste Wettbewerbsfähigkeit

\footnotetext{
131 Vgl. Johnson 1965a, S. 268/269.

132 Vgl. Johnson 1965a, S. 262/264.

133 ähnlich Johnson 1965a, S. 274, 277, 280.
} 
besitzt und die somit innerhalb des Gemeinsamen Marktes bei Akzeptanz eigener Subventionen durch die Partner kaum Produktionsausweitungen erzielen können. Umgekehrt wird eine allgemeine und umfassende Subventionskontrolle nur dann akzeptiert, wenn die Produktionsverluste sich ungefähr gleich auf die Mitgliedstaaten verteilen, d.h. also wenn die Effizienzunterschiede zwischen den Partnern nicht sehr groß sind oder sich über die Industriezweige ausgleichen ${ }^{134}$.

Abb. 2-12 Subventionen bei Präferenz für industrielle Produktion

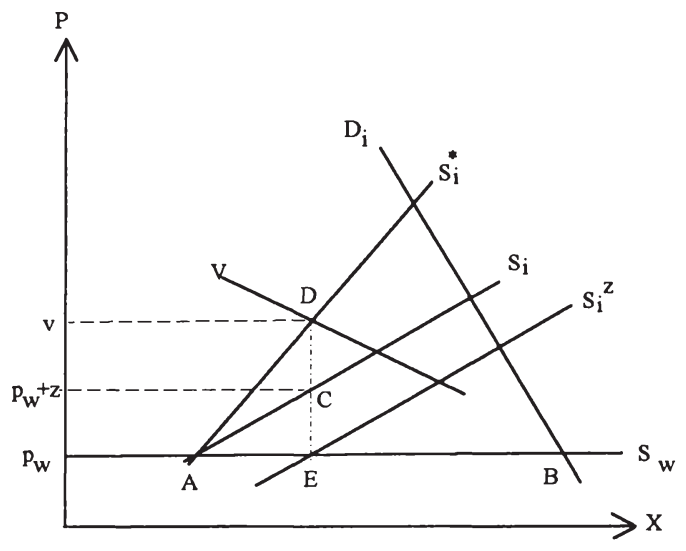

Die eben diskutierten nicht-monetären Erträge einer subventionsinduziert erhöhten Produktion in bestimmten Industriebereichen, wie Prestige, Stolz, Identifikationsmöglichkeiten, macht Breton ${ }^{135}$ zum Bestandteil einer ökonomischen Theorie des Nationalismus. Er sieht sie jedoch eher als vorgeschobene Propagandaargumente an, während der eigentliche Ertrag vermehrter Inlandsproduktion in zusätzlichen gut dotierten Arbeitsplätzen für die Mittelschicht liege. Da ihr Wertgrenzprodukt in diesen Tätigkeiten jedoch unter demjenigen im Ausland liegt (nur deshalb sind überhaupt Subventionen nötig), erleidet die Gesellschaft aus dieser "Investition in Nationalismus" einen Verlust, den die Arbeitnehmerschicht netto finanziert, da alle Bürger an der Aufbringung der Subventionen beteiligt sind, jedoch nur die Mittelschicht über die neuen Arbeitsplätze profitiert. Ziel der Subventionen

\footnotetext{
134 ähnlich Johnson 1965a, S. 273, 278, 280/281. Jenseits dieses Modells können allerdings wettbewerbsfähigere Staaten die Teilnahme solcher Staaten, die stärkere Produktionseinbrüche zu befürchten haben, durch Transferzahlungen oder Konzessionen in nichtindustriellen Bereichen (z.B. Landwirtschaft) erkaufen.
}

135 1964, S. 376-381. 
ist also nicht, wie beim Optimalzollargument, die ausländischen Anbieter zu Preissenkungen zu zwingen und damit die inländischen Terms of trade zu erhöhen, sondern inländische Produktion zu Lasten von Importen auszubauen, um damit die inländische Umverteilung durchzuführen. Die Erzeugung der oben erwähnten nationalen Gefühle soll hierbei einen Widerstand der inländischen Verlierer vermeiden helfen.

\subsubsection{Politökonomische Analyse der Subventionierung}

Das Johnson-Modell geht sehr allgemein von einer Präferenz für industrielle Produktion aus, deren Verwirklichung $\mathrm{zu}$ internationaler Umverteilung führen kann. Bretons Ansatz zeigt, daß hiermit auch starke Redistributionseffekte im Inland verbunden sind. Es stellt sich nun die Frage, auf welche Weise es Vertretern bestimmter Industriezweige im Zusammenspiel mit Politik und Bürokratie gelingt, eine Präferenz für ihre Produktion zu erzeugen und damit Unterstützung zu erhalten, und welche Charakteristika ein Industriebereich besitzen muß, um hierbei besonders erfolgreich zu sein. Diesen Fragestellungen gehen die politökonomischen Ansätze des Protektionismus nach.

Im Einklang mit den üblichen Annahmen der Public-choice-Betrachtung wird den Politikern Stimmenmaximierung und den Bürokraten Budget- bzw. Bedeutungsmaximierung unterstellt. Für das Wählerverhalten von Gruppen von Bürgern seien strukturelle Veränderungen in ihren Arbeits- und Lebensbedingungen, also z.B. Einkommensminderung oder Arbeitsplatzverlust, besonders bedeutsam ${ }^{136}$. Die Regierung verfügt über Mittel, bspw. in Form von Subventionen, um derartige Veränderungen, die u.a. durch Nachfrageverlagerungen oder verstärkte ausländische Konkurrenz in einzelnen Sektoren oder Regionen auftreten können, abzuschwächen. Sie handelt dabei unter unvollkommener Information über die genauen Probleme einzelner Sektoren oder Regionen und über die exakte Wirkung einzelner Maßnahmen ${ }^{137}$. Über solche Informationen verfügen Verbände, die die Lage ihrer Mitglieder gut kennen und somit auch Datenmaterial zur Politikberatung liefern können. Außerdem können sie quasi kostenlos Informationen über Maßnahmen der Regierung und deren Auswirkungen an ihre Mitglieder weiterleiten und so deren Wahlverhalten beeinflussen ${ }^{138}$. Sie treten umgekehrt als Nachfrager nach staatlichen Schutzmaßnahmen wie Subventionen auf, mit denen Verschlechterungen der

136 Vgl. Peters 1981, S. 230.

137 Vgl. Curzon Price 1986, S. 211.

138 Vgl. Harzem 1988, S. 119-120. 
Einkommenssituation ihrer Mitglieder aus den oben genannten Gründen verhindert oder Verbesserungen erreicht werden können. Peters ${ }^{139}$ beschreibt dieses Ziel als Maximierung der Verzinsung des Verbandskapitals, d.h. der Verbandsorganisationskosten, durch die Erzielung staatlicher Strukturhilfen. Besteht die Möglichkeit, durch Aktivitäten des Verbandes, d.h. Information der Politiker und Bürokraten über Probleme ihrer Mitglieder oder Androhung von Maßnahmen, die auch Dritte negativ beeinflussen (z.B. Streiks), welche wiederum einen Teil der Schuld für ihre Nachteile in fehlenden oder falschen Aktionen der Regierung sehen, die Höhe staatlicher Hilfen zu beeinflussen, so werden solche Verbände einen Teil ihrer Ressourcen in derartige Lobbyaktivitäten investieren, um möglichst hohe Hilfen zu erhalten ${ }^{140}$. Es überrascht nicht, daß solche Verbände Gruppen von Wählern i.d.R. in ihrer Eigenschaft als Produzenten vertreten, da die Wähler ihr Einkommen vorwiegend aus einer Quelle beziehen, somit von negativen Veränderungen dort stärker betroffen sind als von Preiserhöhungen bei einzelnen Gütern auf der Konsumseite, wodurch es für sie rational wird, sich über Ursachen von Veränderungen und mögliche staatlich unterstützte Gegenmaßnahmen besser zu informieren. Daher ist es auch für die Regierung rational, Produzenteninteressen zu fördern, da sich die Kosten dieser Unterstützungen, z.B. in Gestalt höherer Steuern oder verschuldungsbedingt höherer Zinsen, auf breite Bevölkerungsschichten verteilen, die in ihrer Eigenschaft als Konsumenten ihr Wahlverhalten kaum ändern, solange bspw. Steuererhöhungen nicht zu stark ausfallen ${ }^{141}$. Für den politischen Unternehmer hat die starke Wirkung einer begrenzten Förderung einer Gruppe auf deren Stimmabgabeverhalten über die Mitwirkung des Verbandes den Vorteil, daß ihm weiterhin Ressourcen für die Gewinnung anderer Wähler zur Verfügung bleiben.

Das Verhalten der Bürokraten bestimmt sich aus ihrer i.d.R. auf einen bestimmten Industriezweig begrenzten Zuständigkeit. Hierdurch sind Prestige und Bedeutung einer Behörde sowie ihr verfügbares Budget abhängig von der Existenz einer bestimmten Branche und dem Nutzen der dort beschäftigten Produktionsfaktoren ${ }^{142}$. Diese Konstellation fördert eine partialanalytische Betrachtung seitens der Bürokra-

1391981, S. 231.

$140 \mathrm{Vgl}$. Bernholz/Breyer 1984, S. 355. Krueger (1974) führt für dieses Verhalten den Begriff "Rent seeking" ein, bezieht ihn jedoch stärker auf durch staatliche Restriktionen verliehene Monopolmacht. Für das Streben nach Subventionen sind die später geprägten Begriffe Revenue seeking und Directly unproductive profit-seeking activities passender. Zur Entwicklung der Konzepte vgl. Ashoff 1988, S. 107/108.

$141 \mathrm{Vgl}$. Bernholz/Breyer 1984, S. 376-378.

142 Vgl. Messerlin 1981, S. 474. 
ten und den Ansatz einer konservativen sozialen Wohlfahrtsfunktion (siehe oben, Abschn. 2.1.2.2) bezüglich des von ihnen betrauten Sektors. Hierin ist eine natürliche Tendenz zur Kollusion zwischen Bürokraten und Verbänden angelegt, die noch dadurch verstärkt wird, daß Vertreter der Interessenverbände bei Gesprächen mit den vorgesetzten Politikern (Ministern) die Tätigkeiten der Staatsbediensteten positiv darstellen und damit deren berufliches Fortkommen fördern können ${ }^{143}$. Messerlin ${ }^{144}$ argumentiert sogar, daß Bürokraten spezifisch protektionistische Maßnahmen in stärkerem Maße als Politiker einsetzen werden, da sie für ihren begrenzten Zuständigkeitsbereich auch lediglich ein begrenztes Inventar an Mitteln zur Verfügung haben, während die Politiker die Möglichkeit besitzen, die Faktoren, die in einer Freihandelssituation verlieren, durch allgemeine Transferzahlungen zu entschädigen 145 .

Vergleicht man nun Subventionen mit anderen staatlichen Schutzmaßnahmen für bestimmte Branchen, so lassen sich aus dem Blickwinkel der drei betrachteten Gruppen durchaus Vorteile des Einsatzes von Subventionen ausmachen:

Aus Sicht der Interessenverbände, die ihr Verbandskapital maximieren wollen, sind vor allem solche Hilfsmaßnahmen vorzuziehen, die das Free-rider-Problem minimieren, die also verhindern, daß Nichtverbandsmitglieder, die sich nicht an der Aufbringung des Verbandskapitals beteiligen, von den staatlichen Maßnahmen profitieren. Dies spricht gegen Zölle und Quoten, die über erhöhte Preise und Gewinnmargen Anreize zum Markteintritt bieten, und für Subventionen, bei deren Ausgestaltung durch Begrenzung der Hilfen auf existierende Anbieter implizite Markteintrittsbarrieren errichtet werden können ${ }^{146}$. Aus wohlfahrtstheoretischer Sicht läßt sich für diese Vorgehensweise auch anführen, daß die Kosten durch Rent seeking, d.h. durch allokationssuboptimale Investition in rentenbringende Aktivitäten, auf diese Weise vermindert werden. Ein alternativer Weg zur Zielerreichung aus Sicht der Lobbies sind sie begünstigende Regulierungen (Ge- und Verbote), die den Vorteil besitzen, das staatliche Budget nicht direkt zu belasten, wodurch zum einen die Kosten für Dritte weniger transparent sind, zum anderen eine Konkurrenz mit anderen Verbänden um knappe staatliche Mittel vermieden wird ${ }^{147}$. Andererseits ist vermutlich bei Regulierungen mit längeren Wirkungsverzögerungen zu rech-

\footnotetext{
143 Vgl. Frey 1985, S. 29, und Peacock 1990, S. 25.

144 1981, S. 475, 471/472.

$145 \mathrm{Zu}$ den hierbei auftretenden Problemen vgl. Abschnitt 2.1.2.2.

146 Vgl. Curzon Price 1986, S. 205.

147 Vgl. Peters 1981, S. 231.
} 
nen. Dieses Argument spricht auch aus Sicht der Politiker eher für Subventionen, die schnelle Handlungsfähigkeit demonstrieren und flexibel gestaltbar sind ${ }^{148}$. Die Kosten der Mittelaufbringung für Subventionen sind hingegen eher unmerklich, da für die Wähler die alternativ erstellten öffentlichen Güter bzw. die möglich gewesenen Steuersenkungen oder niedrigeren Zinsen unbekannt bleiben ${ }^{149}$. Im Vergleich zu Mindestpreisen oder Zöllen haben Subventionen zudem den Vorteil, daß aufgrund der Preissteigerungen durch die anderen Maßnahmen ein Teil des Belastungsspielraums der Wähler bereits verbraucht wird, während Subventionen bei entsprechender Nachfrageelastizität zu Preissenkungen führen können, so daß ein evtl. zusätzlicher Belastungsspielraum für Steuererhöhungen gegeben ist ${ }^{150}$. Allerdings ist diesem Argument entgegenzusetzen, daß durch die Subventionsvergabe auch der staatliche Budgetspielraum geschrumpft ist, während er bspw. bei Zöllen steigt.

Bezieht man schließlich noch die Interessenlage der Bürokraten ein, so sind Subventionen, aber auch andere NTBs, aus ihrer Sicht vorteilhaft, da sie gezielt auf die von der jeweiligen Behörde betreute Branche zugeschnitten werden können. Des weiteren erfordert die Administration relativ komplizierter Subventionsprogramme das Fachwissen der Bürokraten, deren Einflußmöglichkeit und Gestaltungsspielraum damit auch gegenüber den Politikern steigt ${ }^{151}$.

Gerade in Anbetracht der Interessenlagen von Politikern und Verbänden ist nicht damit zu rechnen, daß für alle Industriezweige (bzw. Regionen) die Wahrscheinlichkeit, Subventionen zu erhalten, gleich hoch ist. Bei Ansetzung einer Stimmenmaximierungszielsetzung werden Politiker geneigt sein, Subventionen vor allem an von Schrumpfung bedrohte Industrien mit einer hohen Beschäftigtenzahl zu vergeben, da ihr Niedergang stark negative Auswirkungen auf die Lebensbedingungen einer großen Zahl von Wählern (Arbeitnehmer und ihre Familien sowie indirekt betroffene Dienstleistungen, wie z.B. den Einzelhandel) hätte ${ }^{152}$. Sind diese Industrien stark regional konzentriert oder sind umgekehrt mehrere Branchen einer Region betroffen, so ist die Gefahr von Wahlverlusten und damit die Neigung zur Subventionsvergabe noch höher. Dies gilt insbesondere für Großbetriebe. Die Unterstützung kann auf so viele Branchen oder Regionen ausgedehnt werden, wie dies ohne merkliche wählerbeeinflussende Steuererhöhungen möglich ist, was in Zeiten

\footnotetext{
148 Vgl. Andel 1992, S. 252/253.

149 Vgl. Curzon Price 1986, S. 206.

150 Vgl. Bernholz/Breyer 1984, S. 381.

151 Vgl. Harzem 1988, S. 138-141.

152 Vgl. Peters 1981, S. 232.
} 
guten allgemeinen Wachstums um so leichter fällt. Hierbei ist noch zu berücksichtigen, daß Beihilfen für bestimmte Regionen evtl. durch Verbreitung über die Medien sogar das Bild der Regierung im Gesamtstaat verbessern können (Demonstration von Entscheidungsfähigkeit und sozialem Verantwortungsbewußtsein), auch wenn Kosten für den Rest der Bevölkerung anfallen ${ }^{153}$. Aus Sicht der Branchen/Verbände sind im Falle der Schrumpfung die Kosten kollektiven Handelns im Vergleich zu den potentiellen Einkommensgewinnen bzw. vermiedenen Verlusten für die in dieser Industrie gebundenen Faktoren auch gering, so daß der Anreiz zum Rent seeking groß wird. Zudem wirkt die Gefahr zukünftiger Einkommenssenkungen auch als faktische Eintrittsbarriere im Inland, so daß die Gefahr von Free-rider-Verhalten gering erscheint ${ }^{154}$.

Vergleicht man die Subventionserzielungsmöglichkeiten in föderalen und zentralistischen Systemen, so haben in zentralistischen Staaten wohl nur große Lobbies die Chance, bei der Regierung Gehör zu finden, während in föderalistischen Systemen untergeordnete Exekutiven Informationen über Problemsituationen benötigen, die sie von lokalen Interessengruppen erhalten können, deren Macht hierdurch steigt. Andererseits wird in einem Einheitsstaat die zentrale Exekutive aufgrund ihres geringeren Überblicks über Regionalprobleme Kompetenzen an lokale Bürokratien abtreten, die dann wiederum dem Einfluß lokaler Lobbies ausgesetzt sind ${ }^{155}$. Eine eindeutige Antwort auf die Frage nach der Rent-seeking-Anfälligkeit verschiedener Staatsorganisationen kann somit nicht gegeben werden.

Schließlich stellt sich noch die Frage, inwieweit die Subventionserzielungsmöglichkeiten und -vergabewahrscheinlichkeiten durch das Hinzukommen einer neuen staatlichen Ebene, hier also der EG, verändert werden ${ }^{156}$. Die Behörde/Regierung der Gemeinschaft, d.h. die Kommission, befindet sich in einem Dilemma, da sie einerseits versuchen wird, ihren Einfluß auf Kosten der nationalen Regierungen auszudehnen, andererseits von diesen Regierungen jedoch für ihre Wiederwahl abhängig ist, so daß jedes Kommissionsmitglied einen Anreiz hat, die nationalen Interessen zu verfolgen. Eine Erhöhung ihres eigenen zu Lasten des nationalen Einflusses erreicht die Kommission, indem sie entsprechend den Vertragsvorschriften den innergemeinschaftlichen Freihandel sichert und verhindert, daß der Zollabbau durch Erhöhung anderer protektionistischer Elemente, wie z.B. von

153 Vgl. Gröbner 1983, S. 100.

154 Vgl. Chard/Macmillen 1979, S. 140.

155 Vgl. Bernholz/Breyer 1984, S. 365-367.

156 Vgl. zum folgenden: Frey/Buhofer 1986, S. 336-340. 
Subventionen, in seiner Wirkung zunichte gemacht wird. Gelingt dies, so wird die Kommission gleichzeitig zum Adressaten protektionistischer Forderungen "leidender" Industrien, denen sie durch Regulierungen auf Gemeinschaftsebene, die nationale Hilfsmaßnahmen unter Kommissionskontrolle stellen, entgegenkommt. Die relativen Organisationskosten potentiell protektionistischer Produzenteninteressen im Vergleich zu gegenläufig wirkenden Konsumentenverbänden sinken auf der höheren Ebene weiter, da ihr Informationsvorteil steigt. Hierdurch verbessern sich für die Kommissionsdienststellen die Möglichkeiten, direkte Beziehungen zu den relevanten Interessenverbänden aufzubauen und somit, wie oben für nationale Bürokratien dargelegt, zum Anwalt protektionistischer Interessen zu werden. Die nationalen Regierungen werden sich tendenziell für die Interessen ihrer Produzenten einsetzen, da ihnen die Wahlvorteile allein zugutekommen, während die Effizienzkosten verzerrter Produktion auf die gesamte Gemeinschaft abgewälzt werden können. Gelingt es ihnen, Genehmigungen für die Subventionierung ihrer Industrien zu erhalten, werden sie Subventionen der Partnerstaaten in anderen Branchen akzeptieren. Diese Entwicklung wird zu gemeinschaftlichen Wohlfahrtsverlusten und einem pareto-inferioren Zustand führen. Die Kommission hingegen gewinnt als Mediator, Verwalter und Kontrolleur an Einfluß, indem sie "serves the national governments' interests by doing the 'dirty' protectionist work." 157 Da die nationalen Regierungen den Erfolg von Subventionsmaßnahmen weiterhin für sich verbuchen können, Arbeitsplatzverluste aufgrund von gemeinschaftlichen Beschränkungen jedoch der Kommission anlasten können, vermuten Frey und Buhofer ${ }^{158}$ ein höheres Protektionsniveau als in Nationalstaaten oder Freihandelszonen bei stärkerer Betonung von Subventionen zu Lasten von Zollschutz. Dem kann jedoch entgegengehalten werden, daß, ähnlich dem "Ankerargument" für feste Wechselkurse ${ }^{159}$, Regierungen, die das inländische Subventionsniveau aufgrund etwa einer liberalen Grundeinstellung abbauen wollen, um Ineffizienzen durch Strukturverkrustungen zu vermindern, diese Politik betreiben und gleichzeitig die Verantwortung für Verbote oder Beschränkungen von Subventionsprogrammen auf die Kommission abwälzen können, um sich so vor den Folgen der Lobbyproteste für ihre Wiederwahlchancen zu schützen. Entspringt die liberale Grundeinstellung der Regierung dem gesellschaftlichen Grundkonsens, dem sich auch die Lobbies unterwerfen müssen, so werden sie sogar die Bemühung der Regierung um effektive Subventionskontrolle unterstützen ${ }^{160}$. Dies setzt allerdings vor-

157 Frey/Buhofer 1986, S. 340.

158 ebenda, S. 341.

$159 \mathrm{Vgl}$. Einzig 1970, S. 20/21.

160 Vgl. Chard/Macmillen 1979, S. 140. 
aus, daß die Kommission "mitspielt", was nur gelingt, wenn die Wiederernennungschancen der Kommissare für sie ersichtlich von diesem Verhalten abhängen, so daß die o.g. bürokratietypischen Verhaltensweisen davon dominiert werden.

Die eben dargelegte politökonomische Analyse führt zu einer Erweiterung und Modifikation der Modelle von Breton und Johnson. Die von Johnson postulierte Präferenz für industrielle Produktion äußert sich nämlich häufig präziser ausgedrückt als Präferenz für die Erhaltung bestehender Industrien und Strukturen. Ihr liegt eine stark verteilungspolitisch geprägte Motivation zugrunde, die auf die Vermeidung starker Einkommensverluste für einzelne hinzielt, um so aus Sicht der Regierung unerwünschte politische Verschiebungen zu verhindern ${ }^{161}$. Wir beobachten hier also eine im Sinne von Corden ${ }^{162}$ konservative soziale Wohlfahrtsfunktion. Auch die Bretonsche Analyse erweist sich als zu pauschal. Die Umverteilung erfolgt nicht generell von den Arbeitnehmern zur Mittelschicht, sondern vor allem zugunsten der organisierten Lobbies, vorwiegend von den Konsumenten zu den Produzenten, und hier zugunsten aller beschäftigten Faktoren. Des weiteren kann man eine Umverteilung von Kleinbetrieben zu Großunternehmen unterstellen, da letztere mehr Ressourcen auch in Einzellobbyaktivitäten investieren können. Da in den Großbetrieben tendenziell besser ausgebildete und auch besser bezahlte Arbeitnehmer beschäftigt sind, die Facharbeiter also quasi zur Mittelschicht gerechnet werden können, kann man für diesen letzten Aspekt Bretons These sogar akzeptieren. Am ehesten paßt sie jedoch auf die Subventionierung von Forschung und Entwicklung, da hier zunächst Arbeitsplätze für hochqualifizierte Spezialisten geschaffen werden und bei späterer industrieller Umsetzung der Ergebnisse zunehmend "Mittelschichtarbeitsplätze" entstehen.

Schließlich zeigt die politökonomische Analyse auch, daß sich die Wohlfahrtsverluste aus nicht allokativ begründbaren Subventionen nicht auf diejenigen aus ineffizienten Produktionsstrukturen beschränken, wobei diese schon dynamische Aspekte wie das Entstehen einer Subventionsmentalität einschließen, d.h. das Fehlen eines Anreizes zur Verbesserung der betrieblichen Effizienz aufgrund des Wissens um die Verfügbarkeit von Subventionen (moral hazard) ${ }^{163}$; hinzu kommen die Wohlfahrtsverluste aus Rent-seeking-Aktivitäten von Verbänden und Einzelunternehmen, da hier Produktionsfaktoren aus wertschöpfenden Bereichen abgezogen und zur Erzie-

161 Vgl. Gröbner 1983, S. 101

162 1974, S. 107.

$163 \mathrm{Vgl}$. Hiemenz/Weiss 1984, S. 13/14. 
lung von Umverteilungsgewinnen eingesetzt werden 164 . Da sich die Lobbyaktivitäten konkurrierender Verbände zum Teil neutralisieren, ist diese Verhaltensweise für einige Interessengruppen möglicherweise nicht einmal einzelwirtschaftlich vorteilhaft, wenn der Erwartungswert ihrer Nettogewinne aus Rent-seeking-Aktivitäten negativ ist, was insbesondere bei unvollkommener Information über Konkurrenzaktivitäten und staatliches Verhalten auftreten kann 165 .

164 Vgl. Frey 1985, S. 20. Der Wohlfahrtsverlust bestimmt sich als Produkt aus der Menge der abgezogenen Produktionsfaktoren und ihrem Wertgrenzprodukt, beim Faktor Arbeit also dem Lohnsatz. Vgl. Krueger 1974, S. 300/301.

165 Vgl. Tullock 1971, S. 639-641. 
Wenn ich ... gefragt werde, welches neben dem Gemeinsamen Markt als solchem und seiner institutionellen Ausformung die wichtigste Institution der Rechtsordnung der Europäischen Gemeinschaft ist, ist die Antwort eigentlich klar: Es ist die Beihilfenaufsicht.

Martin Seidel ${ }^{1}$

\section{REGELN UND INSTITUTIONEN DES EGV UND DES EGKSV}

Nachdem im vorhergehenden Kapitel normative Kriterien für die Vergabe von Subventionen und für deren supranationale Kontrolle untersucht wurden, stellt sich nun die Frage, ob und wie solche Kriterien und entsprechende Verfahren im EGVertrag kodifiziert sind. Der grundsätzliche Rahmen wird hierbei bereits aus der Präambel deutlich, die die Gewährleistung eines "redlichen Wettbewerbs" fordert, zeigt sich aber noch deutlicher in der Verpflichtung der EG nach Art. $3 \mathrm{f}$ zur "Errichtung eines Systems, das den Wettbewerb innerhalb des Gemeinsamen Marktes vor Verfälschung schützt"2 . Diese an einer liberalen wettbewerblichen Ordnung orientierten Basisnormen bilden quasi einen "Überbau", in den sich die gemeinschaftlichen Subventionskontrollregeln einzufügen haben.

\subsection{Grundsätzliches Subventionsverbot und Ausnahmen im EGV}

In Art. 92 Abs. 1 legt der EG-Vertrag ein grundsätzliches Subventionsverbot fest, das aber sowohl durch die einschränkenden Bedingungen dieses Absatzes als auch die Ausnahmetatbestände der Abschnitte 2 und 3 begrenzt ist, somit weder unbedingt noch absolut gilt ${ }^{3}$. Der Subventions- bzw. Beihilfenbegriff ist hier in einem sehr umfassenden Sinne zu verstehen, er schließt alle Maßnahmen staatlicher oder vom Staat eingerichteter Organe ein, die Unternehmen direkt begünstigen oder deren Belastung relativ zu anderen vermindern. Dies schließt auch staatliche Kapitalbeteiligungen an privaten Unternehmen ein, wenn sich Private $\mathrm{zu}$ den gegebenen Bedingungen nicht engagiert hätten ${ }^{4}$. Um es der Kommission zu ermöglichen, auch neuartige Subventionsformen einzelner MS zu überwachen, führt der EG-Vertrag keine

11984 , S. 87.

2 Die Texte der EG-Verträge werden hier und im folgenden zitiert nach: Europäische Gemeinschaften 1987.

3 Vgl. v. Wallenberg 1992, S. 2.

4 Vgl. Caspari 1987, S. 78/79, und Ross 1986, S. 878-879. 
Beispiele für Subventionstypen an. Die Kommission hat allerdings in einer Antwort auf eine parlamentarische Anfrage einmal illustrativ eine Anzahl möglicher Formen genannt ${ }^{5}$.

Die erste Einschränkung des Beihilfenverbots besteht darin, daß es nur für die Begünstigung bestimmter Unternehmen oder Produktionszweige gilt. Allgemeine Konjunkturprogramme, z.B. in Gestalt von quasi-automatischen Investitionszulagen, fallen somit nicht unter das Subventionsverbot; ihre Koordinierung erfolgt anhand anderer Vertragsvorschriften ${ }^{6}$. Eine Rechtfertigung der Ausgliederung dieser Aspekte aus der Beihilfenkontrolle kann darin gesehen werden, daß hierdurch bewirkte Veränderungen der gesamtwirtschaftlichen Nachfrage und ihrer außenwirtschaftlichen Komponenten über den Wechselkurs ausgeglichen werden können.

Die Begrenzung des Verbots auf wettbewerbsverfälschende Beihilfen bewirkt insofern eine Einschränkung, als hiermit Maßnahmen zur Korrektur von Fällen allokativen Marktversagens, die in Kapitel 2.1.1-2.1.3 betrachtet wurden, aus dem Verbot herausfallen. Darüber hinausgehende Subventionen, deren Ziel es ist, die Wettbewerbsbedingungen zu verändern, bspw. auch dadurch, daß Marktzutrittsschranken geschaffen oder erhöht werden, werden damit jedoch weiterhin erfaßt. Da die Trennung zwischen beiden Aspekten eine genaue Analyse erfordert, sind jedoch auch Beihilfen zur Marktversagenskorrektur meldepflichtig, wobei es der Kommission obliegt, Obergrenzen zu ermitteln. Letztlich wird die Kommission in ihrer Entscheidungspraxis implizit eine höchstzulässige Wettbewerbsverzerrung festlegen 7 .

Auch Subventionen mit rein lokalen Effekten sind aus der Kontrolle ausgeschlossen, da sie nicht unter das Kriterium der Beeinträchtigung des Handels zwischen den Mitgliedstaaten fallen. Diese einschränkende Bedingung macht die begrenzte Aufgabe der gemeinschaftlichen Subventionskontrolle deutlich, die lediglich den Intra-EG Handel vor Verzerrungen und Beschränkungen schützen soll, während für die nationalen Wettbewerbsverhältnisse die MS selbst zuständig sind und für das Verhältnis zu Drittstaaten die Regeln des GATT (s. unten Abschn. 3.4) gelten. Hierfür sehen die Art. 112/113 eine Koordinierung der Subventionen der EGMitgliedstaaten vor. Eine Entscheidung über die Existenz einer Handelsverzerrung

5 Vgl. Schina 1987, S. 13 und EWG, Kommission 1963a, S. 2235.

$6 \mathrm{Vgl}$. Thiesing 1983, S. 1588, 1595. Sie wären auch aufgrund der theoretischen Definition aus Kap. 2 nicht als Subvention zu betrachten, da ihnen das Merkmal der selektiven Begünstigung fehlt.

7 Vgl. Chard/Macmillen 1979, S. 142. 
(die natürlich auch in einer ineffizienten Ausweitung des Intra-EG Handels bestehen $\mathrm{kann}^{8}$ ) ist anhand einer Analyse des relevanten Marktes und der dort vorhandenen Wettbewerbsverhältnisse zwischen Unternehmen aus verschiedenen MS zu treffen. Je höher der Wettbewerbsdruck bspw. durch Kapazitätsüberhänge und/oder sinkende Nachfrage ist, um so stärker wird die Position eines Unternehmens durch eine Subvention von gegebener Höhe verbessert und der Intra-EG Handel verzerrt ${ }^{9}$. Auch indirekte Effekte auf den EG-Binnenhandel sind denkbar, so z.B. wenn Subventionen für Drittlandsexporte eines Unternehmens zur Verdrängung anderer Firmen auf Drittmärkten und so möglicherweise zu deren Ausscheiden aus dem Markt auch innerhalb der EG führen 10 .

Schließlich ist das Subventionsverbot auch dahingehend eingeschränkt, daß anderslautende Vertragsvorschriften Vorrang haben ${ }^{11}$. Hier sind zunächst die sektoralen Vorschriften für die Landwirtschaft und den Verkehr zu erwähnen. Im Agrarbereich bestimmt nach Art. 42 der Rat die Anwendbarkeit der Beihilfeartikel; so kann er z.B. Subventionen zur Entwicklung oder Aufhebung der Benachteiligung von Regionen genehmigen. Tatsächlich sehen die meisten Marktordnungen die volle Anwendung der Art. 92-94 vor. Für den Verkehrssektor bestimmt Art. 77, daß die Subventionen der Überprüfung durch die Kommission unterliegen, er erweitert jedoch den Ausnahmekatalog (siehe unten) um Beihilfen zur Koordination des Verkehrs und zum Ausgleich von Lasten, die die Verkehrsbetriebe als öffentliche Dienstleistungsunternehmen zu erbringen haben. Auch für staatliche Finanzmonopole gilt insofern eine Sonderregel, als die Erfüllung ihrer Aufgaben nach Art. 90 Vorrang vor den Beihilferegeln hat. Eine weitere Ausnahme existiert nach Art. 223 für den Rüstungsbereich. Hier dürfen die MS Produktionssubventionen zur Wahrung ihrer Sicherheitsinteressen gewähren, doch sollen diese nicht zu Wettbewerbsverzerrungen bei nichtmilitärischen Gütern führen - eine sicherlich schwer zu erfüllende Bedingung, wenn man bedenkt, wie viele Produktionsanlagen, Produktionstechniken und Produkte sowohl militärisch als auch für Zivilproduktion nutzbar sind.

Neben diesen sektoral orientierten Ausnahmen erlauben die Artikel 108 und 109 den MS auch, zur Bekämpfung ernster Zahlungsbilanzprobleme Subventionen einzusetzen. Diese Vorschrift, die sehr stark die Probleme aus der Ära ihres Ent-

8 Vgl. Bleckmann 1984, S. 445.

9 Vgl. Schina 1987, S. 34.

$10 \mathrm{Vgl}$. Beutler et al. 1987, S. 359.

$11 \mathrm{Vgl}$. zum folgenden v. Wallenberg 1992, S. 9f., $22 \mathrm{f}$. 
stehens während der Gültigkeit des Bretton-Woods-Systems widerspiegelt, dürfte heute bei höherer Kapitalmobilität und flexibleren Wechselkursen nur noch eine geringe Rolle spielen.

Schließlich ermöglicht Art. 226, daß Subventionen als vorübergehende Schutzmaßnahmen für die Wirtschaft neuer MS genehmigt werden können, wie dies bspw. im Protokoll Nr. 30 betreffend Irland zu dessen Beitrittsakte geschah ${ }^{12}$.

Nachdem nun der sachliche Anwendungsbereich der Subventionskontrollregeln des EGV abgegrenzt worden ist, gilt es, die Befreiungen, die diese Regeln selbst ermöglichen, zu analysieren. Hierbei sind die De-jure-Ausnahmen des Art. 92,II von den diskretionären Ausnahmen nach Art. 92,III zu unterscheiden.

Die in Art. 92, II genannten Ausnahmen sind Subventionen im Sinne von Art. 92,I. Somit gelten für sie die in Abschnitt $3.2 \mathrm{zu}$ behandelnden Verfahrensregeln, insbesondere die Meldepflicht. Jedoch kann die Kommission Beihilfen dieser Kategorien nicht untersagen 13 .

Die unter Art. 92,II, a genannten Verbraucherbeihilfen 14 fallen eigentlich in den Bereich der Sozialpolitik. Hierbei ist nicht an eine generelle Preissubventionierung bestimmter Güter gedacht, sondern die niedrigeren Preise dürfen i.d.R. nur Teilen der Bevölkerung zugute kommen, und die Beihilfe darf auch nicht direkt an die Produzenten gezahlt werden. Als Beispiel für diese Kategorie wird immer wieder freie oder verbilligte Schulmilch für Kinder genannt ${ }^{15}$. Den MS wird hiermit also die Möglichkeit zu meritorischen Eingriffen gegeben, die natürlich Nachfrageverlagerungen zu Lasten nichtsubventionierter Substitutionsgüter auslösen. Hingegen ist eine Diskriminierung bei der Subventionsvergabe gegenüber ausländischen Erzeugnissen verboten, so daß insoweit eine direkte Handelsverzerrung vermieden wird 16 .

12 Vgl. Europäische Gemeinschaften 1987, Bd. II, S. 85.

13 Vgl. EG, Kommission 1983e, S. 396.

14 "Beihilfen sozialer Art an einzelne Verbraucher, wenn sie ohne Diskriminierung nach der Herkunft der Waren gewährt werden"

15 Vgl. v. Wallenberg 1992, S. 9.

16 Vgl. Swann 1988, S. 138. 
Dies ist bei den in den Abschnitten 92,II b und c genannten Subventionen zur Behebung von Naturkatastrophen und für das Zonenrandgebiet und West-Berlin 17 nicht so offensichtlich. Die ökonomische Begründung für diese Ausnahmen besteht darin, daß den betroffenen Regionen ein Ausgleich für "ungewöhnliche, nicht wirtschaftlich bedingte Nachteile" 18 gewährt werden soll, so daß mit Hilfe der Subventionen für sie quasi normale Wettbewerbsbedingungen wiederhergestellt werden. Die zur Erreichung dieses Ziels notwendigen staatlichen Aufwendungen begrenzen dementsprechend die erlaubte Subventionshöhe, wie dies für die Zonenrand- und Berlinförderung auch in den im Rahmen der Grundsätze für Regionalhilfen festgelegten Subventionshöchstsätzen zum Ausdruck kommt (siehe Abschnitt 4.1.3). Während das Subventionsargument für Naturkatastrophen unmittelbar einleuchtet, wurde dieselbe Begründung für die Zonenrandförderung im Laufe der Zeit aufgrund der stattfindenden Umorientierung der dortigen Betriebe immer fragwürdiger ${ }^{19}$, und heute haben diese Gebiete aufgrund des Verschwindens der innerdeutschen Grenze keine speziellen Nachteile mehr.

Im Gegensatz zu den De-jure-Ausnahmen vom Subventionsverbot in Art. 92,II handelt es sich bei Art. 92,III um Kann-Ausnahmen, die der Kommission (Punkte ad) bzw. dem Rat (Punkt e) einen erheblichen Beurteilungsspielraum lassen 20. Die hier betrachteten Subventionen führen alle zu Veränderungen der Handelsströme, sind somit eigentlich mit dem EGV unvereinbar. Sie haben jedoch gleichzeitig positive Effekte bzgl. gemeinschaftlicher Ziele, so daß zur Entscheidungsfindung eine Kosten-Nutzen-Analyse für den Einzelfall notwendig wird 21 , um sowohl die Frage nach der grundsätzlichen Erlaubtheit als auch die der maximal tolerierbaren Höhe der Subvention zu klären. Hier klingt deutlich das Konzept der Internalisierung positiver Externalitäten, d.h. der Korrektur der in der Ausgangssituation bestehenden Verzerrungen (Marktunvollkommenheiten), an. Dementsprechend muß die Kommission in ihren Entscheidungen im Einzelfall das Vorliegen eines Beitrages zur gemeinschaftlichen Zielverwirklichung durch das Unternehmen prüfen, der ohne die

17 "b) Beihilfen zur Beseitigung von Schäden, die durch Naturkatastrophen oder sonstige außergewöhnliche Ereignisse entstanden sind;

c) Beihilfen für die Wirtschaft bestimmter, durch die Teilung Deutschlands betroffener Gebiete der Bundesrepublik Deutschland, soweit sie zum Ausgleich der durch die Teilung verursachten wirtschaftlichen Nachteile erforderlich sind."

18 Schlieder/Schröter 1981, S. 504.

$19 \mathrm{Vgl}$. Schina 1987, S. 42.

20 Zum Vertragstext vgl. Anhang.

$21 \mathrm{Vgl}$. Andel 1990, S. 176. 
Subvention allein aufgrund der Marktkräfte nicht zustande käme22 ${ }^{2}$ Diese Entscheidungsmaßstäbe der Kommission, deren zugrundeliegende Beurteilungskriterien sie für häufig auftretende Klassen von Subventionen in Grundsätzen, Richt- oder Leitlinien konkretisiert, unterliegen, wie später gezeigt wird, einer zusätzlichen Kontrolle durch den Europäischen Gerichtshof (EuGH).

Art. 92,III stellt sicherlich die wichtigste Regel der gemeinschaftlichen Subventionskontrollpolitik dar. Er ermöglicht Regionalsubventionen entsprechend der Unterabschnitte a) und c), wobei a) nur auf sozioökonomisch benachteiligte Gebiete mit sehr niedrigem Lebensstandard oder hoher Arbeitslosigkeit gemessen am EGNiveau zielt. Abgesehen von Luxemburg und Irland können Subventionem aufgrund dieser Ausnahmeregelung auch nur für Teile eines MS gewährt werden23. Die Ausnahme nach c) ("Beihilfen zur Förderung der Entwicklung gewisser ... Wirtschaftsgebiete") erlaubt die Genehmigung von Regionalhilfen auch für weniger benachteiligte Gebiete, z.B. relativ zurückgebliebene Regionen reicher MS, bindet diese jedoch daran, daß nur sehr geringe Handels- oder Standortverzerrungen durch sie ausgelöst werden, da solche Verzerrungen den Gewinn an gemeinschaftlicher Zielverwirklichung (Verringerung des regionalen Gefälles) überkompensieren könnten. Dieselbe Einschränkung sieht Art. 92,III,c auch für sektorale Subventionen zur Förderung der Entwicklung gewisser Wirtschaftszweige vor. Für beide Beihilfekategorien gilt, daß genehmigungsfähige Beihilfen einen Beitrag zur Umstrukturierung der Region oder des Sektors leisten müssen, der diese über das marktbestimmte Maß hinaus beschleunigt. Dies bedeutet für einen Krisensektor i.d.R. Maßnahmen zur Förderung der Rationalisierung bzw. Umstellung der Produktion des Unternehmens bei gleichzeitiger Abfederung der sozialen Folgen mit dem Ziel, daß die betroffenen Branchen nach der Umstrukturierung ohne weitere staatliche Hilfen wettbewerbsfähig sind 24 . Die Einschränkung der Subventionsvergabemöglichkeit bzgl. Handelsverzerrungen soll insbesondere verhindern, daß durch nationale Fördermaßnahmen die Anpassungskosten im Sinne einer Beggar-thyneighbour-policy auf andere MS abgewälzt werden 25 .

Auch in Unterabschnitt b) werden zwei Ausnahmekategorien genannt, die zur Genehmigung von Subventionen führen können. Bei den "wichtigen Vorhaben von gemeinsamem europäischen Interesse" wird dieses Interesse aus den Zielen des EGV

22 Vgl. Caspari 1987, S. 81.

$23 \mathrm{Vgl}$. Thiesing 1983, S. 1606-1607.

24 Vgl. Schlieder/Schröter 1981, S. 505.

25 Vgl. Curzon-Price 1986, S. 218. 
bzw. spezieller gemeinschaftlicher Programme definiert. Auch wenn nur Unternehmen in einem oder wenigen MS direkt von den Beihilfen profitieren, so müssen doch alle ein Interesse daran haben. Als Beispiel mögen Subventionen für Energiesparinvestitionen aufgrund einer gemeinsamen Energiepolitik dienen ${ }^{26}$. Treten hier allerdings Nutzenspillovers in andere Gemeinschaftsländer auf, so wäre eine Beteiligung dieser MS oder der Gemeinschaft an den Beihilfen korrekt.

Bei der "beträchtlichen Störung im Wirtschaftsleben eines MS" ist wohl an eine allgemeine tiefe Rezession in einem MS zu denken, die dieser durch stimulierende Maßnahmen, z.B. Investitionsbeihilfen, im Sinne einer keynesianisch orientierten antizyklischen Wirtschaftspolitik bekämpfen dürfen soll, um einen weiteren Anstieg der Arbeitslosigkeit zu verhindern27. Beispiele für die Anwendung dieses Passus waren Maßnahmen der italienischen Regierung während der Krise 1971 oder aller MS während der 1. Ölkrise 1974/75. Subventionen zur Lösung von Zahlungsbilanzproblemen fallen hingegen unter die Koordinierungsregeln der Art. 108/10928.

Durch den Vertrag über die Europäische Union wurde ein neuer Unterabschnitt d) eingefügt, der die Genehmigung von "Beihilfen zur Förderung der Kultur und der Erhaltung des kulturellen Erbes" ermöglicht, wobei wiederum die Einschränkung bezüglich einer dem gemeinsamen Interesse zuwiderlaufenden Beeinträchtigung der Handels- und Wettbewerbsbedingungen gemacht wird. Er ergänzt Art. 128 des Vertrages, der die Gemeinschaft verpflichtet, zur Förderung der Kulturen in den MS beizutragen. Dieser neue Ausnahmetatbestand hat wohl stärker symbolischen Charakter als eine große Wirkung auf die Wettbewerbspolitik; sein bedeutendster Anwendungsbereich dürfte in der Förderung der europäischen Filmproduktion zu liegen kommen 29.

Die grundsätzliche Kompetenz der Kommission im Subventionskontrollbereich wird aufgrund des Unterabschnitts e) durch die Möglichkeit des Rates ergänzt, durch eine Entscheidung mit qualifizierter Mehrheit zusätzliche Arten von Beihilfen als gemeinschaftskonform zu erklären. Die hierbei zu erlassenden Richtlinien und Verordnungen erweitern den Ausnahmekatalog des Abschnitts II und legen gleichzeitig Genehmigungskriterien fest. Die Möglichkeit, hier im Sinne der oben diskutierten politökonomischen Ansätze zusätzliche allokativ ungerechtfertigte Befreiungstatbestände zu schaffen, wird wohl auch durch die Voraussetzung eines Kommissions-

$26 \mathrm{Vgl}$. v. Wallenberg 1992 , S. $12 \mathrm{f}$.

27 Vgl. Swann 1983, S. 46.

28 Vgl. Schina 1987, S. 59.

29 Vgl. Petersen 1993, S. 21. 
vorschlages zumindest dann kaum begrenzt, wenn mehrere MS betroffen sind. Bisher wurden allerdings im Rahmen dieses Abschnitts lediglich sieben Richtlinien zur Regelung von Schiffbausubventionen erlassen 30 . Wie diese Regelungen und ihre Auswirkungen zu beurteilen sind, soll in Abschnitt 4.2 untersucht werden.

\subsection{Ablauf des Kontrollverfahrens}

Mit dem Verbot und den Ausnahmeregelungen des Art. 92 ist der Rahmen für die Subventionskontroll- und -harmonisierungstätigkeit der Kommission gesteckt. Um den Erfolg dieser Kontrollaktivitäten zu sichern, waren nun noch Regeln für den Ablauf des Verfahrens sowie die Rechte und Pflichten der Beteiligten zu setzen. Dies geschah in den Art. 93 und 94 EGV, die zunächst auf alle Subventionen Anwendung finden, da die Klärung der Vereinbarkeit mit dem Vertrag erst am Ende des Prüfungsprozesses steht. Wiederum erhält die Kommission hier umfassende Kompetenzen, die nur im Ausnahmefall des Art. 93,II,3 auf den Rat übergehen. Bezüglich des Ablaufs der Prüfung unterscheidet man zwischen dem präventiven Verfahren nach Art. 93,III für neue Subventionen und dem repressiven Verfahren nach Art. 93, I für bestehende Beihilfen 31 .

Plant ein MS die Einführung einer neuen oder Umgestaltung 32 einer bestehenden Beihilfe, so ist er verpflichtet, dies der Kommission zu melden. Diese Meldung (Notifizierung), die möglichst schon während des Gesetzgebungsverfahrens zu erfolgen hat, sollte eindeutig sein, einen expliziten Bezug auf Art. 93 enthalten und auch die Zielsetzung der Beihilfe neben ihrer Ausgestaltung darlegen. Sie ist an das Generalsekretariat der Kommission zu senden, lediglich Anwendungsfälle allgemeiner Beihilfensysteme gehen direkt an die GD Wettbewerb. Nichtnotifizierung durch einen MS ist als Vertragsverletzung anzusehen, gegen die der Kommission nach neuerer Rechtsprechung des EuGH mehrere Möglichkeiten zur Erzwingung der Unterbrechung der Gewährung zur Verfügung stehen (s. u. Abschn. 5.2). Eine solche Subvention fällt natürlich nicht unter die Regeln für bestehende Beihilfen. Nach Erhalt muß die Kommission innerhalb von 15 Werktagen die Vollständigkeit der

30 Vgl. v. Wallenberg 1992, S. 21.

$31 \mathrm{Vgl}$. Soltwedel et al. 1988, S. 48.

32 Eine Umgestaltung liegt vor, wenn durch Änderung wesentlicher Bestandteile Auswirkungen auf den Wettbewerb auftreten können, z.B. Erhöhung, Verlängerung, Erweiterung des Kreises der Beteiligten; inflationsbedingte Anpassungen der Subventionshöhe sind keine Umgestaltungen. 
Unterlagen prüfen und evtl. zusätzliche Informationen anfordern. Sind die Unterlagen vollständig, so beginnt die Periode der sog. Vorprüfung33.

Während dieser Vorprüfungsphase, die nach einem Urteil des EuGH aus dem Jahre 1973 maximal 2 Monate dauern darf, für die sich die Kommission intern aber eine Frist von 30 Werktagen gesetzt hat ${ }^{34}$, erfolgt eine erste Meinungsbildung anhand der Unterlagen, ohne daß eine Anhörung anderer MS oder von Konkurrenten erfolgt. Da die gewährenden MS gerade bei Existenz wirtschaftlicher Probleme, die schnelles Handeln erfordern, ein Interesse an der schleunigen Abwicklung der Vorprüfung haben, ist zu erwarten, daß sie sich kooperativ verhalten. Dies gilt umso mehr, als während der Vorprüfung die Anwendung der Subvention verboten ist ${ }^{35}$. Hat die Kommission am Ende dieser Prüfung keine Einwände gegen das Vorhaben, so informiert sie den MS darüber, so daß dieser das Subventionsprogramm dann in Kraft setzen kann. Dies gilt auch, wenn die Kommission nach Ablauf der o.g. Prüfungsfrist eine Mitteilung unterläßt. Eine Information betroffener Dritter muß nicht stattfinden ${ }^{36}$. Mit der Akzeptanz fällt das Subventionsprogramm unter die laufende Kontrolle für bestehende Beihilfen.

Hat die Kommission hingegen Zweifel an der Vereinbarkeit einer Subvention mit den Regeln des Art. 92, so leitet sie das förmliche Verfahren ein. Dies geschieht durch Publikation einer Mitteilung im Amtsblatt C, in der der Sachverhalt kurz dargelegt wird und alle interessierten Parteien, d.h. andere MS, das empfangende Unternehmen, potentiell nachteilig betroffene Konkurrenten und ihre Verbände, aufgefordert werden, sich zum fraglichen Subventionsprogramm und seinen Auswir-

33 Bei Subventionsregelungen für Kleinunternehmen von geringer Höhe bezogen auf das Investitionsvolumen bzw. pro Beschäftigten wird ein vereinfachtes Prüfungsverfahren angewandt. Solche Regelungen werden von der Kommission grundsätzlich innerhalb einer verkürzten Frist von 20 Arbeitstagen befürwortet ebenso wie Verlängerungen genehmigter Beihilferegelungen bzw. die Erhöhung ihrer Mittel um nicht mehr als 20\%. Bei Anwendungsfällen bereits akzeptierter allgemeiner Rahmenprogramme entfällt unterhalb bestimmter Schwellenwerte sogar die Meldepflicht.

Hier haben also die Aspekte der administrativen Vereinfachung und der Konzentration auf bedeutende Fälle Vorrang vor einer umfassenden Kontrolle, die letztlich an den begrenzten Ressourcen der Kommission scheitert. Vgl. v. Wallenberg 1992, S. 9, Schina 1987, S. 139f., 153, und EG, Kommission 1990e, S. 2, sowie 1985a, S. 147-49, und 1979e.

34 Vgl. Caspari 1987, S. 77, und Schina 1987, S. 144f. Dies gilt für einzelne Anwendungsfälle. Für Beihilferegelungen (sog. Regimes) wendet die Kommission die Zweimonatsfrist an.

35 Vgl. v. Wallenberg 1992, S. 9-10.

36 Vgl. Beutler et al. 1987, S. 364, und Ross 1986, S. 874/875. 
kungen zu äußern 37 . Bei der Ausgestaltung dieser Aufforderung muß die Kommission zwischen dem Vertrauensschutz des begünstigten Unternehmens und der Klarheit des Sachverhalts für die betroffenen Dritten abwägen. Sie setzt eine Frist von i.d.R. einem Monat für schriftliche Äußerungen; eine mündliche Verhandlung findet nicht statt. Der Erhalt zusätzlicher Informationen und Stellungsnahmen erlaubt ihr eine gründliche Prüfung, deren Dauer jedoch aus den o.g. Gründen auf i.d.R. 3 Monate begrenzt werden soll. Führt die Hauptprüfung zur Ablehnung des Subventionsvorhabens, so veröffentlicht die Kommission eine begründete Entscheidung im ABl. L. Wird das Programm hingegen akzeptiert, so erfolgten lange Zeit nur Kurzinformationen im monatlichen Bulletin und im jährlichen Wettbewerbsbericht 38 . Häufig führt die Prüfung zu Konsultationen mit dem gewährenden MS, in denen die Kommission substantielle Änderungen der Subventionsgestaltung vorschlägt. Wird eine Subvention nach derartigen Änderungen akzeptiert, so veröffentlicht die Kommission detailliertere Informationen. Außerdem werden die anderen Verfahrensbeteiligten schriftlich informiert ${ }^{39}$. Dennoch ist die Entscheidungspraxis der Kommission aus Sicht der Öffentlichkeit bis in die 80er Jahre als wenig transparent kritisiert worden, da anhand der Veröffentlichungen ihre Abwägungen häufig nicht nachvollziehbar waren 40 (Zu neueren Entwicklungen vgl. Abschnitt 5.3).

Erst mit der Genehmigung der Kommission darf der MS die Subvention gewähren. Sie unterliegt dann der laufenden Kontrolle für bestehende Beihilfen nach Art. 93,I. Diese erstreckt sich auch auf sog. "Altbeihilfen", die in den MS vor 1958 bzw. vor ihrem späteren EG-Beitritt bestanden, sowie auf solche Subventionen, v.a. Subventionsprogramme, die nach der Vorprüfung akzeptiert wurden bzw. bei denen sich die Kommission nicht äußerte 41 . Ziel dieser laufenden Kontrolle ist die jederzeitige Vereinbarkeit aller Subventionen mit dem EGV. Die laufende Prüfung ist notwendig, da eine geänderte Wirtschaftslage eine vorher genehmigte Beihilfe als ungerechtfertigt erscheinen lassen kann. Zudem sind die betreffenden nationalen Gesetze häufig so allgemein formuliert und die Vergabegrundsätze so intransparent, daß nur eine ständige Prüfung der Vergabepraxis die Einhaltung der Vertragsregeln sichert ${ }^{42}$. Das repressive Verfahren läuft in einem eher kooperativen Rahmen ab. Die MS sind bei den meisten Programmen verpflichtet, die Kommission durch

37 Vgl. Andel 1990, S. 177.

$38 \mathrm{Vgl}$. Schina 1987 , S. 148/149, 152/153.

39 Vgl. v. Wallenberg 1992, S. 5.

$40 \mathrm{Vgl}$. Neundörfer 1984, S. 100.

$41 \mathrm{Vgl}$. Soltwedel et al. 1988, S. 48.

$42 \mathrm{Vgl}$. Beutler et al. 1987, S. 362. 
regelmäßige Berichte über die von ihnen gewährten Subventionen zu unterstützen. Sieht die Kommission Änderungen an bestehenden Programmen, wie z.B. Verkürzung der Dauer oder Einschränkung des Empfängerkreises, als notwendig an, so gibt sie eine entsprechende Empfehlung (sog. zweckdienliche Maßnahme) an den MS ab, die jedoch informell ist und für den MS erst durch dessen Akzeptanz bindend wird. Gelingt jedoch auf diesem gütlichen Weg keine Einigung, so kann die Kommission das förmliche Verfahren nach Art. 93,II in der oben dargelegten Weise einleiten und eine verbindliche Entscheidung treffen. Diese gilt jedoch nicht rückwirkend und schließt eine Rückforderung gewährter Subventionen (s. unten) aus 43 .

In jüngerer Zeit wurde die Vorschrift des Art. 93,I EGV auch dazu genutzt, eine intensivere Kontrolle aller Beihilfen (v.a. derer aus genehmigten allgemeinen Programmen) für bestimmte Sektoren mittels detaillierter Regelwerke, der sog. Gemeinschaftsrahmen, zu etablieren 44 . Der Gemeinschaftsrahmen wird dabei als zweckdienliche Maßnahme angesehen und stellt eine Empfehlung an alle MS dar, die für jeden MS wiederum erst mit der formellen Akzeptanz des Rahmens wirksam wird. Bei einer Weigerung eines oder mehrerer MS kann die Kommission wie oben das förmliche Verfahren gegen den oder die MS einleiten, das sich dann gegen alle dem betreffenden Sektor potentiell zugutekommenden Beihilfeprogramme richten würde.

Sieht die Kommission nach Ende des förmlichen Verfahrens eine Subvention als unvereinbar mit dem EGV an, so muß sie die Nichtanwendbarkeit der Ausnahmen aus Art. 92 anhand von Informationen über den relevanten Markt erläutern. Der Wortlaut der Entscheidung geht dem gewährenden MS und den im Verfahren beteiligten Dritten $\mathrm{zu}^{45}$. Bei völliger Unvereinbarkeit wird die Kommission eine Aufhebung, bei Unvereinbarkeit lediglich einzelner Vorschriften eine Umgestaltung verlangen, wobei sie im letzten Fall Kriterien für die erforderlichen Änderungen darlegen muß. In Orientierung am administrativen oder legislativen Aufwand der Aufhebung bzw. Umgestaltung muß sie eine Frist setzen. Handelt der MS nicht innerhalb dieser Frist, so können Kommission und betroffene MS vor dem EuGH Klage erheben 46 . Umgekehrt können die MS gegen eine Entscheidung der Kommission innerhalb von zwei Monaten vor dem EuGH Klage erheben 47.

43 Vgl. Schina 1987, S. 167.

$44 \mathrm{Vgl}$. dazu unten Abschn. 4.1.2, 4.4 und 5.4.2.

$45 \mathrm{Vgl}$. ebenda, S. 153.

46 Vgl. EG, Komission 1983e, S. 398/399.

47 Vgl. Seidel 1985, S. 65. 
Hatte der MS die Notifizierung der Kommission über ein Subventionsvorhaben verspätet vorgenommen bzw. ganz unterlassen (und die Kommission auf anderem Wege davon erfahren) oder die Auszahlungssperre während des laufenden Verfahrens mißachtet, so kann die Kommission im Fall der Ablehnung eines Programms die Rückforderung der gezahlten Beihilfen verlangen. Voraussetzung hierfür ist, daß die Kommission die Begünstigten durch eine Mitteilung im Amtsblatt auf die Möglichkeit einer Rückforderung hinwies, damit diese sich nicht auf einen Vertrauensschutz berufen können. Das Verfahren der Rückforderung richtet sich nach dem jeweiligen nationalen Recht der MS, wobei hierdurch Probleme der Gleichbehandlung der Unternehmen in verschiedenen MS entstehen können (s.u. Abschnitt 5.3.5).

Abweichend von der generellen Prüfungskompetenz der Kommission kann der Rat in Ausnahmefällen bestimmte Beihilfen als mit dem EGV vereinbar erklären (Art. 93,II). Dies kann nur einstimmig auf Antrag des gewährenden MS geschehen. Diese Regelung ermöglicht dem Rat, in Grenzen eine eigene Subventionskontrollpolitik zu betreiben, auch wenn die Ausnahmen des Art. 92,II und III nicht vorliegen, also Wettbewerbsverfälschungen oder Handelsverzerrungen vorliegen. "Außergewöhnliche Umstände" im Sinne dieser Regelung können wohl nur bei erheblichen sektoralen oder regionalen Problemen in einem Land vorliegen, bei denen die Kommission die Ausnahmen der Art. 92,III,a und b nicht akzeptiert. Der Rat besitzt allerdings nicht die Kompetenz, dem MS die Umgestaltung der Beihilfe vorzuschlagen, jedoch kann letzterer das Vorhaben selbst modifizieren ${ }^{48}$. Mit dem Antrag eines MS wird ein bereits eingeleitetes Prüfungsverfahren durch die Kommission für 3 Monate suspendiert; entscheidet der Rat nicht binnen dieser Frist, so lebt das Mandat der Kommission danach wieder auf. Ein Antrag des MS nach einer Ablehnung durch die Kommission ist ausgeschlossen, da der Rat sonst zur Beschwerdeinstanz würde ${ }^{49}$. Akzeptiert der Rat den Antrag des MS, so unterliegt die Subvention dann als bestehende Beihilfe der Überwachung durch die Kommission; diese kann allerdings keine Entscheidung zur Aufhebung der Subvention erlassen, sondern nur beim Rat in diese Richtung wirken. Die Existenz dieser Regelung im EGV erlaubt die Anerkennung überragender politischer Erwägungen in außergewöhnlichen Situationen, jedoch wird die Möglichkeit häufiger Tauschhändel durch die Einstimmigkeitsregel begrenzt ${ }^{50}$.

Schließlich gibt Art. 94 dem Rat noch die Möglichkeit, auf Vorschlag der Kommission und nach Anhörung des EP Durchführungsverordnungen zu Art. 92 und 93

48 Vgl. v. Wallenberg 1992, S. 6-7.

$49 \mathrm{Vgl}$. Schina 1987, S. 151.

50 ebenda, S. 152. Ihre Anwendung beschränkte sich bisher weitgehend auf den Agrarbereich. 
zu erlassen. Diese können nur zur Konkretisierung der Ausnahmen vom Beihilfeverbot dienen, dürfen jedoch keine zusätzlichen Beihilfegruppen vom Verbot freistellen 51 . Hingegen können solche Verordnungen die Ratsentscheidungen nach Art. 92,III,e konkretisieren und Beihilfegruppen vom Vorprüfungsverfahren des Art. 93,III ausnehmen. Die potentielle Aufweichungsmöglichkeit der präventiven Beihilfenkontrolle, die dieser Artikel bietet ${ }^{52}$, wurde allerdings bisher noch nie selbständig, sondern nur im Verkehrsbereich in Verbindung mit Art. 77 genutzt.

\subsection{Die Subventionsregelung des EGKS-Vertrages}

Im Vergleich zu den komplexen Verbots-, Ausnahme- und Verfahrensregeln im EGV erscheint die Subventionsregelung des älteren EGKSV zunächst klar und eindeutig. Art $4 \mathrm{c}$ bestimmt, daß als "unvereinbar mit dem Gemeinsamen Markt für Kohle und Stahl ... innerhalb der Gemeinschaft gemäß den Bestimmungen dieses Vertrages aufgehoben und untersagt" werden: "von den Staaten bewilligte Subventionen oder Beihilfen ..., in welcher Form dies auch immer geschieht." Dieses anscheinend absolute Subventionsverbot wird jedoch in mehrerer Hinsicht partiell durchbrochen.

Zum einen weist die Formulierung "gemäß den Bestimmungen dieses Vertrages" darauf hin, daß anderslautende spezielle Vorschriften dem Verbot vorgehen. So wird die Regelung des Art. 71, die den MS die Kompetenz für die Handelspolitik beläßt, dahingehend interpretiert, daß für Montanprodukte Exportsubventionen bei Ausfuhren in Drittstaaten erlaubt sind, obwohl diese indirekt auch die Wettbewerbspositionen der Unternehmen innerhalb des GM beeinflussen 53 . Weiterhin gestattet Art. 56, daß bei Entlassungen die MS Abfindungszahlungen an die Mitarbeiter übernehmen und deren Umschulung finanzieren, wenn die Kommission einen ebenso hohen Subventionsbetrag aus EGKS-Mitteln genehmigt ${ }^{54}$. Diese Bevorteilung gegenüber Nicht-Montanunternehmen, die zu intersektoralen Wettbewerbsverzerrungen führen kann, wird aufgrund der partialanalytischen Betrachtungsweise der lediglich eine sektorale Integration anstrebenden Montanunion vernachlässigt. In Analogie zu Art. 92,II c EGV werden weiterhin Subventionstarife im Frachtverkehr für Montanunternehmen bspw. für Betriebe im Zonenrandgebiet nach Art. 70,IV akzeptiert 55 . Eine

51 Vgl. EG, Kommission 1983e, S. 400.

52 Sie würde jedoch vermutlich durch die Kontrolle des EuGH eingeschränkt.

$53 \mathrm{Vgl}$. Koppensteiner 1965, S. 180-184.

54 Vgl. ebenda, S. $116 / 117$.

$55 \mathrm{Vgl}$. ebenda, S. 120/121. 
bedeutsame Möglichkeit der Subventionierung von Montanunternehmen besteht in der Übernahme der Finanzierung der Sozialversicherung, im deutschen System also vor allem der Arbeitgeberbeiträge, durch den Staat. Für diesen Fall verweist Art. 68 die Hohe Behörde auf die Maßnahmen nach Art. 6756. Dieser letztgenannte Artikel spielt in der Diskussion des Subventionsverbots in der Montanunion eine bedeutende Rolle. Er gibt der Hohen Behörde bei wirtschaftspolitischen Maßnahmen eines MS, die eine fühlbare Auswirkung auf die Wettbewerbsbedingungen im Montanbereich haben, zusätzliche Eingriffsmöglichkeiten. Vergrößern die Maßnahmen die Unterschiede in den Produktionskosten zu Lasten der inländischen Montanindustrie, kann die Hohe Behörde das Inland zu Subventionen ermächtigen. Geschieht dies zu Lasten der Montanbetriebe in den Partnerstaaten, richtet die Hohe Behörde Empfehlungen an das Inland, diese Wirkungen durch geeignete Maßnahmen zu beseitigen. Derartige Empfehlungen kann die Hohe Behörde auch an einen MS richten, dessen Maßnahmen die innergemeinschaftlichen Unterschiede der Produktionskosten zugunsten oder zu Lasten der Inlandsproduzenten vermindern 57 . Im o.g. Fall der staatlichen Übernahme der Sozialversicherungsbeiträge greifen die letzten beiden Regeln - die Kommission erläßt also nicht-bindende Empfehlungen, von einem Verbot ist keine Rede.

Diese Regelung wird wiederum nur aus dem Partialintegrationscharakter der EGKS verständlich. Der A-priori-Widerspruch zwischen Art. 4 c, der Subventionen verbietet, und Art. 67, der ihre Existenz implizit voraussetzt, wird dadurch aufgelöst, daß sich Art. 67 auf allgemeine wirtschaftspolitische Maßnahmen mit Auswirkungen auf den Montanbereich bezieht ${ }^{58}$. Die Kompetenz für solche allgemeinen Maßnahmen, wie z.B. Wechselkurs- oder Steueränderungen oder Korrekturen bei wirtschaftsrelevanten Rechtsnormen, verbleibt bei den MS; sollten sie jedoch besonders starke Auswirkungen auf den Montanbereich im Vergleich zu anderen Branchen haben, so greifen die Regeln des Art. 67, der somit vorrangig dem Schutz der Wettbewerber und nicht des Wettbewerbs dient 59 . Auch Anwendungsfälle solcher horizontalen und regionalen Beihilfenprogramme der MS, die ebenfalls Unternehmen im Montanbereich zugutekommen können, wären aufgrund dieser Interpretation nach Art. 67 EGKSV und Art. 92 EGV sowie den Verfahrensregeln des Art. 93 EGV zu beurteilen 60 .

56 Vgl. ebenda, S. 178/179.

$57 \mathrm{Vgl}$. Stotz 1983, S. 98/99.

$58 \mathrm{Vgl}$. Hochbaum 1962, S. 126, und Stotz 1983, S. 104.

$59 \mathrm{Vgl}$. Koppensteiner 1965, S. 152/153.

$60 \mathrm{Vgl}$. Dominick 1984, S. 392, und Thiesing 1983, S. 1620. 
Als Resultat dieser Überlegungen und Interpretationen wird deutlich, daß lediglich rein sektorale Beihilfen für die Montanindustrie unter das absolute Verbot des Art. 4 c fallen würden. Hierin steckt natürlich die Gefahr, daß bei eigentlich sektoralen Subventionen der Begünstigtenkreis erweitert wird, damit diese dann als horizontale Beihilfen gelten können und somit die Regeln des Art. 67 Anwendung finden61. Auch im Bereich der sektoralen Beihilfen werden jedoch Einschränkungen gemacht. Koppensteiner 62 argumentiert, daß der Gemeinsame Markt im Montanbereich als Wettbewerbsmarkt konzipiert ist und daß somit Subventionen nur insoweit verboten sind, wie sie den Wettbewerb verfälschen. Subventionen "sozialer" Art in Analogie zu den Ausnahmen des Art. 92,II EGV, die lediglich die normalen Wettbewerbsbedingungen wiederherstellen, unterliegen nicht diesem Verbot.

Selbst dieses stark eingeschränkte Subventionsverbot "überlebte" jedoch die Kohlekrise Anfang der 60er- und die Stahlkrise seit Mitte der 70er-Jahre nicht63. Kommission und Rat definierten diese Krisen als nach dem Vertrag nicht vorgesehene Fälle64, die nach Art. 95 EGKSV Kommissionsentscheidungen zur Sicherung der Vertragsziele erlaubten. In diesen Entscheidungen 65 wurde das Subventionsverbot des Art. $4 \mathrm{c}$ nur auf unkoordinierte nationale Beihilfen bezogen, während für Subventionen von gemeinschaftlichem Charakter, die den Zielvorstellungen der Gemeinschaft entsprechen, Genehmigungskriterien festgelegt wurden. Diese Kriterien wurden detailliert für verschiedene Subventionstypen von Forschungs- bis zu SchlieBungsbeihilfen aufgelistet.

Dazu traten Verfahrensregeln, die analog dem EGV gestaltet wurden. So sind die MS zur vorherigen Meldung aller Beihilfevorhaben verpflichtet, eine Inkraftsetzung ist erst nach Genehmigung durch die Kommission und Erfüllung aller ihrer Bedingungen durch den MS gestattet. Hat die Kommission Zweifel an der Konformität eines Vorhabens mit ihren Entscheidungen, so leitet sie ein Prüfungsverfahren ein, dessen Dauer im Stahlbereich seit 1981 auf 3 Monate festgelegt ist 66 . Bei den wichtigsten Subventionsvorhaben ist sie verpflichtet, die Stellungnahmen aller MS einzuholen. Nach Ende der Prüfung werden alle MS von der Kommissionsentschei-

61 Vgl. hierzu: Dominick 1986, S. 594. Hausner (1987, S. 112-118) lehnt daher ebenso wie Stotz (1983, S. 245-247) diese Argumentation ab.

62 1965, S. 42. Diese Auffassung wird jedoch von Hausner (1987, S. 93-98) kritisiert.

63 Vgl. Swann 1983, S. 56.

64 Vgl. z.B. EG, Kommission 1980, S. 5.

65 Vgl. EGKS, Hohe Behörde 1965, 1967; EG, Kommission 1980d, 1981c, 1985d, 1989d und $1991 \mathrm{e}$.

66 Vgl. z.B. EG, Kommission 1981c, S. 17, Art. 8. 
dung unterrichtet. Leitet die Kommission nicht innerhalb von 2 Monaten nach Meldung eines Vorhabens das Verfahren ein, so darf der MS nach einer Mitteilung an sie mit der Gewährung der Subvention beginnen. In diesem Fall oder bei expliziter Genehmigung unterliegt die Subvention danach der laufenden Kontrolle durch die Kommission.

Abschließend kann man feststellen, daß das kategorische Subventionsverbot des EGKSV nicht nur durch einige Spezialvorschriften eingeschränkt, sondern durch die Entscheidungen der Kommission und des Rates im Kohle- und Stahlbereich weitgehend außer Kraft gesetzt wurde. Ob der sich aufdrängende Eindruck, daß die Ausnahmen und Genehmigungsmöglichkeiten aufgrund dieser Entscheidungen, abgesehen von den letzten Stahlentscheidungen von 1989 und 1991, noch deutlich großzügiger als in den dem EGV unterliegenden Bereichen ausgefallen sind, gerechtfertigt ist, soll im Abschnitt 4.3 genauer untersucht werden.

Im Unterschied zu den Regeln des EGV kann bei Verstößen gegen das Verbot des Art. 4c die Kommission nicht vor dem EuGH klagen. Hier bleibt nach Art. 88 lediglich die Möglichkeit, den Rat zu befassen, der mit Zweidrittelmehrheit Gegenmaßnahmen betroffener MS gestatten kann. Diese Regel wirkt in bezug auf den Gemeinsamen Markt eher destruktiv67. Sie ist im Ansatz eher den Vorgehensweisen in EFTA und GATT ähnlich, deren Regeln nun dargelegt werden sollen.

\subsection{Die Subventionsregeln der EFTA und des GATT im Vergleich zur EG}

Der Problematik, eine Entscheidung über die Behandlung staatlicher Beihilfen zu treffen, sieht sich jede internationale Organisation, die den Handelsaustausch zwischen den Mitgliedstaaten regeln und fördern will, ausgesetzt, da Subventionen einen bedeutenden Einfluß auf diesen Handel haben können. Nachdem nun die diesbezüglichen Regeln und Institutionen der EG ausführlich dargestellt worden sind, soll die Betrachtung um die Konzepte der EFTA und des GATT erweitert werden. Während die EG den Freihandel zwischen den MS mit einer supranationalen Exekutive mit Kontroll- und Regelungskompetenzen verbindet, sind GATT und EFTA lediglich intergouvernementale Organisationen mit dem Ziel eines Freihandels (EFTA) bzw. einer Reduktion von Zöllen und anderern Handelsbarrieren im Kontext einer multilateralen Handelsliberalisierung (GATT) zwischen den MS. Auch wenn diese Unterschiede der Strukturen zu anderen Lösungsansätzen bzgl. des Subventionsproblems führen müssen, sollen die Regeln dennoch dargestellt werden, da sie bei der Diskus-

67 Vgl. Caspari 1990, S. $18 f$. 
sion einer Weiterentwicklung der gemeinschaftlichen Subventionskontrollpolitik interessante Denkanstöße liefern können.

Art. 2 der Stockholmer Konvention zur Errichtung der EFTA68 bestimmt als eines der Ziele der Assoziation die Gewährleistung "gerechter Wettbewerbsbedingungen" im Handel zwischen den MS. Dementsprechend enthält Art. 13,I ein Verbot von Subventionen für Exporte in andere MS. Die Liste der verbotenen Exportfördermaßnahmen (Anhang C), die aus einer entsprechenden Liste der OECD übernommen wurde69, enthält neben direkten Zahlungen auch bspw. überhöhte Steuerrückvergütungen oder Exportkredite zu Zinsen unterhalb des Marktniveaus. Ergänzend werden auch solche Subventionen untersagt, deren Hauptziel bzw. -wirkung darin besteht, die Vorteile aus dem Abbau der Zölle und Quoten, d.h. die Intensivierung des Handels und Wettbewerbs, zu vereiteln. Hierbei sind die Formulierungen Hauptziel und -wirkung zu beachten, die z.B. Subventionen zur Bekämpfung der Arbeitslosigkeit durch Förderung von Betriebsansiedlungen gestatten, auch wenn diese die Nebenwirkung einer Handelsverzerrung haben 70 .

Ein Beschluß des EFTA-Rates von 196871 führte zu einer detaillierteren Interpretation dieser knappen Regelung. So muß die Schädigung bzw. Vereitelung der Vorteile aus einer Subvention in einem Partnerstaat tatsächlich in Form einer direkten oder indirekten Handelsbeeinflussung meßbar sein, eine lediglich potentielle Verzerrung genügt nicht. Generell werden vertragskonforme Subventionen als legitimes Mittel der Wirtschaftspolitik der MS anerkannt, die lediglich die EFTA-Ziele fördern sollen. Im Gegensatz zur EG besteht in der EFTA keine Verpflichtung zur Subventionsharmonisierung. Im einzelnen legte der Ratsbeschluß fest, daß staatliche Kredite zu Marktkonditionen und staatliche Bürgschaften zu kostendeckenden Prämien sowie Steuerermäßigungen auf Anlagen, die eine Abschreibung von nicht mehr als $100 \%$ der Anschaffungskosten erlauben, nicht unter das Verbot des Art. 13 fallen72. Als akzeptabel im Sinne des Abkommens gelten FuE-Subventionen, Exportförderungen durch Messen oder sog. "nationale Wochen" sowie Unterstützung durch allgemeine staatliche Leistungen. Ebenfalls vertragskonform sind Rationalisierungshilfen, solange sie nicht speziell exportfördernd oder importsubstituierend wir-

68 jeweils zitiert nach: EFTA 1975.

69 Vgl. Curzon-Price 1974, S. 96.

$70 \mathrm{Vgl}$. van Meerhaeghe 1971, S. 350.

71 Vgl. EFTA 1980, S. 53-55.

72 Bei den Bürgschaften wäre allerdings eine Differenzierung der Prämien entsprechend dem Risikograd geboten, da bei einheitlichen Prämien eine Quersubventionierung von Branchen höheren Risikos stattfindet. 
ken bzw. den "fairen Wettbewerb" stören; die letztgenannte Bedingung beschränkt auch die möglichen Regionalsubventionen, wobei jedoch das Ziel, den Problemregionen gleiche Wettbewerbschancen wie den Zentralregionen zu ermöglichen, betont wird. Schließlich sind auch Produktionssubventionen für Bereiche gestattet, in denen kein Intra-EFTA-Handel existiert.

Während die zuerst genannten Formen staatlicher Unterstützung wohl auch nach den Regeln des EGV problemlos akzeptiert würden, sind die Restriktionen bzgl. der anderen Subventionstypen sehr allgemein und großzügig gefaßt und recht deutlich auf die Verhinderung von Exportsubventionen konzentriert, die im EG-Bereich nur quasi die "Untergrenze" der Subventionskontrolle bilden. Die Aussage in der Ratserklärung, daß erlaubte Subventionen nicht so angewandt werden sollen, daß sie Partnerprodukte gegenüber Inlandsprodukten diskriminieren, verwundert eher, da eine Verbesserung der Wettbewerbsposition inländischer gegenüber ausländischen Produkten doch häufig gerade das Ziel einer Subventionierung darstellt.

Den Ablauf des Kontrollverfahrens für nationale Subventionen regelt Art. 13,II. Das Verfahren wird ausdrücklich auch auf solche Subventionen angewandt, die nicht aufgrund Abschnitt I verboten sind, aber die Vorteile aus dem Zoll- und Quotenabbau vermindern. Diese Regelung, die bspw. auf an sich vertragskonforme Subventionen, deren Anwendung den Handel verzerrt, angewandt werden kann, überrascht insofern, als sie Gegenmaßnahmen gestattet, obwohl kein Bruch der EFTAKonvention vorliegt; hier ist ein Mangel der Konvention zu sehen, der wohl die fehlende Bereitschaft der MS zu einem Souveränitätsverzicht aufzeigt ${ }^{73}$. Aufgrund dieser Norm sind Subventionen für Exporte nach Drittstaaten ebenso erlaubt wie Subventionen für Güter, auf die das Inland keinen Importzoll erhebt, da hierdurch die Vorteile der EFTA-MS aus dem gegenseitigen Zoll- und Quotenabbau nicht direkt beeinträchtigt werden 74 .

Fühlt sich nun ein MS durch die Subvention eines anderen MS um seine Vorteile aus der EFTA gebracht, so muß er zunächst versuchen, eine bilaterale Lösung zu finden 75 . Scheitert dies, so wird er sich vor dem EFTA-Rat beschweren, der ein Prüfungsverfahren unter möglichem Einschluß eines Expertenkomitees einleitet und am Ende eine Empfehlung an den gewährenden MS richten kann. Weigert sich dieser, der Empfehlung nachzukommen, so kann der Rat mit Mehrheit den geschädigten MS ermächtigen, bestimmte Verpflichtungen aus dem EFTA-Abkommen gegen-

73 Vgl. Curzon-Price 1974, S. 98.

74 Vgl. ebenda, S. 99-100.

75 Vgl. Art. 13,II und 31. 
über dem subventionierenden MS, also bspw. die Zollaussetzung, aufzuheben. Diese Gestattung von im Sinne des Vertrages eigentlich destruktiven Gegenmaßnahmen, die nach dem EGV undenkbar ist, rührt aus der mangelnden Autorität des EFTARates zur Durchsetzung seiner Entscheidungen. Im oben erwähnten Ratsbeschluß von 1968 wurden zudem die MS gebeten, über alle neuen Subventionen möglichst vor Einführung den anderen MS zu berichten, um eine Diskussion über mögliche Schädigungen zu erlauben. Das EFTA-Sekretariat wurde beauftragt, Listen über die in den MS existierenden Subventionen zu führen ${ }^{76}$. Da diese Anregung offensichtlich wirkungslos blieb, wurde sie im November 1987 in eine bindende Verpflichtung umgewandelt. Seit 1988 werden Listen der bestehenden Subventionen zwischen der EFTA und der EG ausgetauscht und die Meinungen der jeweils anderen Seite eingeholt 77 .

Zwischen allen EFTA-Staaten und der EG bestehen zudem Freihandelsabkommen, deren Artikel 2378 ein Verbot wettbewerbsverzerrender Subventionen für einzelne Unternehmen oder Produkte (d.h. sektoraler Subventionen) enthält, soweit diese den Handel beeinträchtigen. Fühlt sich eine Partei durch Subventionen dennoch geschädigt, so wird ein Untersuchungskomitee eingerichtet. Führt dessen Empfehlung nicht zu einer Abschaffung der Subvention oder wird binnen drei Monaten keine Einigung erzielt, so kann der geschädigte Partner Gegenmaßnahmen, insbesondere durch Aufhebung der Zollfreiheit, ergreifen.

Für diejenigen EFTA-MS, die dem Abkommen über den Europäischen Wirtschaftsraum (EWR) beigetreten sind, gelten seit dem 1.1.1994 de facto dieselben Beihilferegeln wie für die EG. Zur Durchsetzung dieser in Art. 61 und 62 EWRAbkommen festgelegten Inhalts- und Verfahrensregeln für die betroffenen EFTA-MS wurde mit der EFTA Surveillance Authority (ESA) eine der GD Wettbewerb nachempfundene Überwachungsbehörde geschaffen. Bei ihren jeweiligen Entscheidungen zu Beihilfen müssen zudem sowohl DG IV als auch die ESA die Auswirkungen auf den jeweiligen Partner berücksichtigen, so daß damit auch für die Beihilfenkontrolle ein einheitlicher Wirtschaftsraum geschaffen wurde.

Schließlich erlaubt Art. 17 der EFTA-Konvention allen MS, gegenüber subventionierten Importen Maßnahmen zu ergreifen, die ihnen aufgrund anderer Verträge zustehen, wobei auch ein MS Maßnahmen anwenden kann, wenn ein anderer MS geschädigt wird. Diese Klausel spielt vor allem auf die Regeln des GATT an.

$76 \mathrm{Vgl}$. EFTA 1980, S. 55.

$77 \mathrm{Vgl}$. EFTA 1988, S. 16/17, und 1989, S. 15.

78 Vgl. EFTA 1980, S. 137/138. 
Art. III,8b des GATT 79 erlaubt grundsätzlich Subventionen an inländische Produzenten. Jedoch verpflichtet Art. XVI, Abschnitt A jeden MS, bei Subventionen, die direkt oder indirekt die Exporte eines Produkts erhöhen bzw. die Importe vermindern, den anderen Vertragsparteien eine Mitteilung über Art und Ausmaß dieser Beihilfe, ihre möglichen Handelswirkungen und die Gründe für die Vergabe zu machen. Bei einer Schädigung der Produzenten einer anderen Vertragspartei besteht eine Verpflichtung zu Konsultationen über Begrenzungsmöglichkeiten der Subvention. Auf diesen Abschnitt A beschränkte sich der ursprüngliche Text des GATT80; weitergehende Regeln aus der Havanna-Charta fanden erst 1962 (Jahr des Inkrafttretens) in allerdings abgeschwächter Form Eingang in das GATT als Abschnitt B81. In ihm werden die negativen Wirkungen von Exportsubventionen auf die Interessen ausländischer Ex- oder Importeure betont und deshalb Exportsubventionen für NichtGrundstoffe untersagt, wenn diese einen Verkauf im Ausland zu niedrigeren Preisen als im Inland ermöglichen. Diese Regelung sollte ursprünglich bereits 1958 in Kraft treten; da dies jedoch scheiterte, wurde die Standstill-Verpflichtung gegen die Einführung neuer Exportsubventionen 1960 verlängert und gleichzeitig festgelegt, daß das Exportsubventionsverbot mit seiner Akzeptanz durch die westlichen Industrieländer für die Unterzeichnerstaaten wirksam werden sollte82, was, wie oben erwähnt, 1962 der Fall war. Für Grundstoffe einschließlich Mineralien blieben jedoch Exportsubventionen erlaubt, solange sie dem subventionierenden Staat nicht mehr als einen "angemessenen Anteil" am Welthandel garantierten, wobei die Festlegung dieses Anteils sich an den tatsächlichen Anteilen der vorangegangenen Jahre orientierte.

Die heute gültigen Subventionsregeln des GATT fußen zusätzlich auf dem sog. Subventionskodex, der im Verlauf der Verhandlungen der Tokio-Runde erarbeitet wurde 83 und vor allem die Regeln des Art. XVI präzisiert, jedoch nur wenig erweitert. Im Kodex werden Exportsubventionen für Nicht-Grundstoffe kategorisch verboten, wobei ein Anhang eine Liste möglicher Formen von Exportsubventionen enthält. Für Grundstoffe (allerdings jetzt ausschließlich Mineralien) wurde die alte Regelung übernommen, wobei allerdings wegen Abgrenzungsschwierigkeiten auf

79 jeweils zitiert nach Senti 1986, Anhang 4, S. 371-432.

$80 \mathrm{Vgl}$. z.B. Imhoff 1952, S. 145/146.

81 Vgl. Senti 1986, S. 171-172.

82 Vgl. Dam 1970, S. 145/146.

$83 \mathrm{Vgl}$. Hufbauer/Shelton Erb 1984, S. 12. Nach dieser Quelle (S. 135-154) wird auch der Text des Subventionskodex (Übereinkommen zur Auslegung und Anwendung der Artikel VI, XVI und XXIII des Allgemeinen Zoll- und Handelsabkommens) zitiert. 
den Vergleich der Inlands- mit den Auslandspreisen verzichtet und gleichzeitig die Referenzperiode auf die vorangegangenen drei Kalenderjahre begrenzt wird. Ziel der Regelung ist, eine subventionsinduzierte Verdrängung ausländischer Produzenten zu vermeiden. Hingegen werden andere Arten von Subventionen als wichtige Instrumente staatlicher Wirtschaftspolitik, z.B. zur Regional- oder Forschungsförderung, als konjunktur- oder strukturpolitische Instrumente als legitim anerkannt. Jedoch verpflichten sich die Signatarstaaten, sich um eine Vermeidung von Handels- oder Wettbewerbsverzerrungen, insbesondere der Schädigung der Industrieproduktion oder der Exportchancen anderer Staaten, durch die Subventionen zu bemühen - eine sicherlich eher schwache Selbstbindung.

Die strengere Behandlung von Exportsubventionen erklärt sich wohl vor allem mit der unmittelbaren Verletzung des Vertragsziels "freier Welthandel", der keine positiven Aspekte (wie etwa auch im EGV gefordert) gegenüberstehen, daneben mit der stärkeren erreichbaren Handelsverzerrung pro gewährter Subventionseinheit durch sie $^{84}$ sowie mit dem partiellen Abwertungseffekt für den Warenhandelsbereich, den allgemeine Exportsubventionen mit sich bringen und der im ursprünglichen Rahmen fester Wechselkurse, der der Welthandelsordnung des GATT zugrundelag, als illegitim angesehen wurde 85 . Weiterhin wird deutlich, daß das Verbot von Exportsubventionen primär dem Schutz ausländischer Produzenten dient ${ }^{86}$, was sich auch in den Verfahrensregeln bei Verstößen gegen das Subventionsverbot zeigt.

Die detaillierte und relativ transparente Festlegung der Regeln bzgl. Gegenmaßnahmen ist der eigentliche Fortschritt des Subventionskodex. Er eröffnet zwei Verfahrenswege für von ausländischen Subventionen negativ betroffene Unternehmen, das sog. Behördeverfahren und das Klageverfahren, die von einem betroffenen MS zwar beide parallel betrieben werden können, wobei jedoch nur die Ergebnisse eines Verfahrens in Maßnahmen umgesetzt werden können.

Das Behördeverfahren 87 wird durch Antrag des betroffenen Unternehmens an die jeweilige nationale Stelle zur Untersuchung eines Subventionsfalles eröffnet. In ihm hat das Unternehmen bzw. der Verband Existenz und vermutliche Höhe der Subvention, eine materielle Schädigung und einen Kausalzusammenhang zwischen Schaden und Subvention nachzuweisen. Eröffnet die Behörde das Verfahren, muß sie den subventionierenden Staat und das empfangende Unternehmen informieren, um diesen

$84 \mathrm{Vgl}$. Krauss 1979, S. 73-76.

85 Vgl. Dam 1970, S. 133-134.

86 Vgl. Krauss 1979, S. 87 und die in Abschnitt 2.3 dargestellten Argumente.

87 Art. 1-6 Subsidies Code. 
Möglichkeit zu einer Stellungnahme zu geben. Bei der Feststellung des Schadens sind die Höhe der subventionierten Importe und die Veränderungen von Inlandspreisen und Produktionsmengen der inländischen Konkurrenz nachzuweisen, ebenso wie der Kausalzusammenhang zwischen beiden durch Ausschluß anderer Einflußfaktoren. Sieht die nationale Behörde klare Anzeichen der Erfüllung der o.g. Tatbestände, kann sie zur Vermeidung weiterer Schäden für die Inlandsproduzenten vorläufige Ausgleichszölle erlassen, die jedoch nach maximal 4 Monaten entweder aufgehoben oder in endgültige Ausgleichszölle (countervailing duties) überführt werden müssen. Das gesamte Verfahren darf maximal ein Jahr dauern; vom Ergebnis ist das GATT-Komitee für Subventionen zu unterrichten. Die Höhe der Ausgleichszölle darf die Höhe der Subvention nicht übersteigen, kann diese aber unterschreiten, wenn dies zur Aufhebung ihrer Wirkungen genügt. Die Zölle werden nicht erhoben, wenn die Subvention aufgehoben wird oder der ausländische Produzent freiwillig seine Preise erhöht - hieran zeigt sich wiederum die Orientierung am Produzenteninteresse. Die Gefahr dieses unilateralen Behördenverfahrens wird von Krauss 88 sehr klar wie folgt beschrieben: "The so-called aggrieved party is judge, jury and executioner - a situation that invites protectionist abuse."

Als alternative Vorgehensweise steht den MS des GATT das sog. Klageverfahren 89 offen. Sie können es ergreifen, wenn sie bspw. aufgrund von Informationen inländischer Unternehmen den Verdacht haben, daß ein anderer Partnerstaat verbotene Exportsubventionen gewährt oder daß er andere Subventionen vergibt, die die inländische Industrie schädigen bzw. den Nutzen des Inlands aus der liberalen Handelsordnung des GATT schmälern 90 (Anklang an EFTA-Regeln). Legt der beschwerdeführende Staat Beweise vor, so ist der andere MS verpflichtet, in Konsultationen einzutreten. Führen diese nach 30-60 Tagen nicht zu einer Einigung, wird das Subventionskomitee des GATT mit der Angelegenheit befaßt. Wird auch hier innerhalb eines Monats keine Lösung gefunden, so wird ein Sonderausschuß (Panel) eingerichtet, der nach maximal 60 Tagen den Streitparteien Lösungsvorschläge unterbreitet. Scheitert dieser Versuch, wird das Komitee unterrichtet, das eine Empfehlung abgibt, wenn es einen Verstoß gegen die Subventionsregeln sieht. Wird diese Empfehlung mißachtet, kann das Komitee dem geschädigten MS die Erlaubnis zu Gegenmaßnahmen, die z.B. in der Rücknahme von Zollkonzessionen oder anderen Verpflichtungen oder auch in Ausgleichssubventionen bestehen

881979 , S. 91.

89 Art. 12, 13, 17, 18 Subsidies Code.

90 Die Voraussetzungen zur Einleitung dieses Verfahrens sind also im Verhältnis zum Behördeverfahren weniger streng gefaßt. Vgl. Latz 1989, S. 12. 
können, wobei letztere inländischen Exportunternehmen auf Drittmärkten gegen subventionierte Konkurrenten helfen können ${ }^{91}$, erteilen. Angesichts der Komplexität dieses mehrstufigen Verfahrens und seiner Dauer von maximal 6-7 Monaten überrascht es nicht, daß das Behördeverfahren zur Lösung von Subventionsfällen eine weit höhere Bedeutung hat ${ }^{92}$.

Ähnlich der EFTA fehlen dem GATT exekutive Vollmachten zur Durchsetzung von Entscheidungen, so daß es auf Konsultationen und Kooperation angewiesen ist und beim Scheitern dieses Weges Wettbewerbsverfälschungen nur mittels Durchbrechung seiner eigenen Regeln - durch Ausgleichszölle oder andere Maßnahmen korrigieren kann ${ }^{93}$, wodurch der im Konzept der Multilateralität und in der Offenheit der Märkte liegende eigentliche Wert des Abkommens weiter durchlöchert wird 94 . Dieses Kernproblem wurde auch durch die neuen Regelungen zu Subventionen, die eines der Resultate der kürzlich beendeten Uruguay-Runde bilden, nicht gelöst. Auf diese Änderungen wird weiter unten in Abschnitt 6.4 eingegangen.

$91 \mathrm{Vgl}$. Hufbauer/Shelton Erb 1984, S. 14.

92 Vgl. Senti 1986, S. 208.

93 Vgl. Bleckmann 1984, S. 426.

$94 \mathrm{Vgl}$. Frey/Buhofer, 1986, S. 333. 
Manfred Rosenstock - 978-3-631-75198-5

Downloaded from PubFactory at 01/11/2019 07:13:36AM

via free access 


\section{BiSherige ERfAHRUNGEN MIt DER SUbVENTIONSKonTrolle}

Angesichts der häufig beklagten Tatsache, daß Subventionen bereits auf der nationalen Ebene trotz der weitverbreiteten Tendenz, sie scharf zu verurteilen und ihren Abbau zu fordern, immer wieder allen Versuchen einer verschärften rechtlichen und politischen Kontrolle widerstanden, sind die eben dargelegten Regeln des EGV sicherlich überraschend und bemerkenswert. Sie erlauben auf der supranationalen Ebene der EG-Kommission einen wesentlich höheren Grad von Kontrolle und Beeinflussung, als er auf den nationalen Ebenen vorhanden ist, und geben ihr dabei zudem noch einen hohen diskretionären Spielraum ${ }^{1}$. Die folgenden Ausführungen dienen der Untersuchung, inwieweit es der Kommission gelungen ist, diesen Spielraum zu nutzen, und welche Ziele sie dabei verfolgt hat. Nach einem allgemeinen Überblick über das Kommissionshandeln bei sektoralen, regionalen und horizontalen Beihilfen ${ }^{2}$ werden dabei in den Abschnitten 4.2-4.4 drei Sektoren einer detaillierten Untersuchung unterzogen ${ }^{3}$. Die Auswahl der betrachteten Sektoren beruht darauf, daß im Schiffbau-, Stahl- und Kfz-Bereich die hohe Bedeutung staatlicher Subventionierung zur Beurteilung vieler Fälle und der Erarbeitung detaillierter Regelwerke durch die Kommission führte. In diesen Bereichen ergibt sich daher die Möglichkeit, über die Analyse von Einzelfällen eine detailliertere Einsicht in das Vorgehen der Kommission zu gewinnen. Gleichzeitig spielen in diesen Sektoren die Regeln für regionale und horizontale Beihilfen bei der Beurteilung von Einzelfällen eine gewichtige Rolle, so daß auch sie somit in die Betrachtung einbezogen werden konnten.

\section{1. Überblick über die Ausgestaltung der Politik}

Die Bedeutung einer umfassenden gemeinschaftlichen Subventionskontrolle bei der Schaffung eines Gemeinsamen Marktes wurde bei den Vorarbeiten zu den Römischen Verträgen bereits frühzeitig erkannt. So enthielt schon der Spaak-Bericht, der die Grundlage der Verhandlungen über die EWG bildete, Regelungen zur Subventionskontrolle, die den späteren Vertragsartikeln sehr nahe kamen ${ }^{4}$. Dies betraf die generelle Unvereinbarkeit und mögliche Ausnahmebereiche, wie z.B. soziale Subventionen (später Art. 92,IIa) und Regionalhilfen (später Art. 92,IIIa und c) sowie

\footnotetext{
1 Vgl. Andel 1990, S. 175, 177.

2 Als horizontale Beihilfen werden hierbei, wie in Kap. 2.2 erläutert, alle nicht spezifisch sektoral oder regional orientierten Subventionen verstanden.

3 Ein statistischer Überblick zu Gesamtumfang und -struktur der von den MS vergebenen Beihilfen wird am Anfang des folgenden Kapitels gegeben.

4 Vgl. Regierungsausschuß 1956, S. 61-63.
} 
vorübergehende Ausnahmen für marginale Betriebe, um ihren Erhalt beim Abbau der Zollschranken zu sichern (diese Regelung fand später keine Aufnahme im Vertrag). Ferner enthält der Spaak-Bericht Passagen zur Notifizierungspflicht der MS und zum Prüfungsrecht der Kommission sowie die Vorstellung, daß die Kommission die verschiedenen Subventionen nach ihrer Wirkung und Zweckmäßigkeit ordnen solle. Nach dieser ursprünglichen Konzeption sollten Kommissionsentscheidungen zur Abschaffung von Beihilfen, zu Ausnahmebedingungen und Fristen nur nach Anhörung des Rates erfolgen können, wobei ein Unvereinbarkeitsbeschluß für allgemeine Maßnahmen im Rat der Einstimmigkeit bedurft hätte. Diese Verfahrensregeln bildeten dann auch bei der Regierungskonferenz den Hauptstreitpunkt zwischen den MS. Gegen den französischen Widerstand setzten Deutschland und die Niederlande größere Vollmachten für die Kommission in Gestalt einer alleinigen Entscheidungsbefugnis in Beihilfesachen durch, da Kompetenzen für den Rat die Gefahr von Kuhhändeln mit sich gebracht hätten 5 .

Grob gesprochen läßt sich die Vorgehensweise der Kommission in Beihilfefragen seit Gründung der EWG in zwei Phasen einteilen: In der Zeit von 1959 bis etwa 1967/69 ging es zunächst um die Interpretation der Tragweite der Vertragsregeln und um die Abgrenzung der Macht und der Rahmenbedingungen für das Kommissionshandeln. In der Folgezeit entwickelte die Kommission dann systematische Ansätze zur Kontrolle verschiedener Kategorien von Beihilfen, wobei dies detaillierte materielle Beurteilungskriterien ebenso einschloß wie Kodifikationen der Verfahrensregeln 6 .

\subsubsection{Ad-hoc-Entscheidungen in der Anfangsphase}

In den ersten Jahren nach Gründung der EWG stand die Beihilfenkontrolle zunächst nicht im Vordergrund des Kommissionsinteresses, vielmehr besaß der Abbau von Zöllen und Quoten Priorität. Eine Aufgabe von DG IV in dieser Phase bestand jedoch darin zu verhindern, daß dieser Abbau von den MS durch Einführung anderer diskriminierender Maßnahmen wie z.B. Beihilfen konterkariert wurde und die Unternehmen sich auf diese Weise dem verstärkten Wettbewerb entzogen hätten 7 . Hierzu galt es zunächst, den Umfang der Kontrollaufgabe zu definieren. Zu diesem Zweck wurden unmittelbar nach Errichtung der EWG Arbeitsgruppen aus Vertretern der DG IV und nationalen Beamten eingesetzt, die Grundfragen, wie z.B.

\footnotetext{
5 Vgl. Küsters 1982, S. 368f.

6 Vgl. Warnecke 1978, S. 146, 149.

7 Vgl. von der Groeben 1982, S. 87.
} 
den Beihilfenbegriff, Beurteilungskriterien, Notifizierungsverfahren und Kontrollverfahren für bestehende Beihilfen, diskutierten und erste Lösungen entwickelten ${ }^{8}$. In dieser Phase setzte die Kommission ihr Recht durch, sowohl bestehende als auch neue Beihilfenprogramme der Zentralstaaten und ebenso der Länder und Provinzen zu untersuchen ${ }^{9}$, und etablierte ihre Position gegenüber anderen DGs, etwa für Regional- und Industriepolitik 10 .

Diese enge Kooperation zwischen Kommission und MS wurde auch in Fragen der materiellen Beurteilung von Beihilfen beibehalten. Dies war sicherlich bei der Erstellung eines Inventars der bestehenden Beihilfen unverzichtbar, das DG IV dann Ende 1963 komplettieren konnte und das ohne die Landwirtschaft bereits 450 Regelungen umfaßte ${ }^{11}$. Überraschender war die Ansetzung multilateraler Diskussionen jedoch bei der Kontrolle einzelner Beihilfevorhaben, die der Kommission von den jeweiligen MS gemeldet worden waren. Sie boten den betroffenen anderen MS jedoch die Möglichkeit, Bedenken zu äußern, und erhöhten die Transparenz der Beihilfenaufsicht ${ }^{12}$.

Einzelne Beihilfefälle, die der Kommission von den MS gemeldet wurden, untersuchte sie auf einer Ad-hoc-Basis, wobei nur sehr wenige negative Entscheidungen getroffen wurden. In der Regel kam es zur Akzeptanz der Projekte, zum Teil nach von der Kommission empfohlenen Modifikationen ${ }^{13}$. So wurden von 292 Regelungen, zu denen die Kommission bis 1964 Stellung genommen hatte, nur 13 abgelehnt und rund 60 weitere modifiziert ${ }^{14}$. Unter den Subventionen während dieser Periode spielten solche für die Landwirtschaft und das Verkehrswesen eine bedeutende Rolle 15 .

In dieser Wiederaufbauphase der europäischen Wirtschaft mit weitgehend guter Konjunkturlage, in der keynesianisches Denken die Wirtschaftspolitik der MS domi-

8 Vgl. von der Groeben 1982, S. 88, und EWG, Kommission 1960, S. 124-126.

9 Dabei wurde von ihr ein umfassender Beihilfenbegriff zugrundegelegt. Vgl. oben Abschn. 3.1. Allerdings hatte sie Probleme, von allen Programmen Kenntnis zu erhalten. Vgl. unten Abschn. 5.3.1.

10 Vgl. Warnecke 1978, S. 147.

11 Vgl. EWG, Kommission 1964, S. 77, und von der Groeben 1967a, S. 197.

12 Vgl. Warnecke 1978, S. 149, und EWG, Kommission 1959, S. 91.

13 Einige Beispiele finden sich in McLachlan/Swann 1967, S. 51f., wobei es der Kommission z.T. auch gelang, die MS dazu zu bewegen, Beihilferegime auslaufen zu lassen.

14 Vgl. von der Groeben 1967a, S. 197.

15 Vgl. Poelmans 1970, S. 311-315. Diese Bereiche sollen jedoch in dieser Arbeit ausgeklammert werden. 
nierte, hatte sich die Kommission häufig mit Rahmengesetzen zur allgemeinen Investitions- und Wachstumsförderung, wie z.B. für Frankreich, Italien und Belgien, oder zur Förderung benachteiligter Regionen, wie z.B. für den Mezzogiorno und für die Provinz Limburg (Niederlande), zu befassen. Hierbei legte die Kommission großen Wert auf die Möglichkeit, einzelne Anwendungsfälle dieser Rahmengesetze prüfen zu können, da aufgrund der Unbestimmtheit der Gesetze nur so eine adäquate Beurteilung gelingen konnte ${ }^{16}$. Damit stieß sie jedoch auf den Widerstand einzelner MS, der nur sehr langsam überwunden werden konnte ${ }^{17}$, so daß die Kommission nur einige solcher Anwendungsfälle prüfen konnte. In einem dieser Fälle erließ sie 1964 eine negative Entscheidung, und zwar betraf dies den belgischen Plan zur Gewährung von Zinszuschüssen an die Ford Traktorenwerke in Antwerpen. Als Begründung der Ablehnung dienten die stagnierende Nachfrage und die gemeinschaftsweite Überkapazität im Traktorenbereich, wodurch die Errichtung subventionierter neuer Kapazitäten den Wettbewerb gegenüber den nicht subventionierten Konkurrenten in Deutschland und Frankreich verzerren würde 18. Eine weitere negative Entscheidung betraf einen Plan Italiens für Textilbeihilfen, der in Teilen von der Kommission abgelehnt wurde (Einkommensteuerbefreiung). Des weiteren verpflichtete die Kommission die italienische Regierung dazu, einen Passus in das Gesetz aufzunehmen, der eine Kapazitätserhöhung mittels Beihilfen verhinderte ${ }^{19}$. Bereits hier wurde also versucht, ökonomische Kriterien zur Beurteilung sektoraler Hilfen zu entwickeln, wobei die besondere Lage des Sektors und die Frage von Überkapazitäten im Vordergrund standen, da in solchen Fällen subventionierte Expansionen einzelner Unternehmen besonders scharfe Auswirkungen auf die Preise und damit die Rentabilität der Konkurrenten gehabt hätten. Generell stand die Kommission Beihilfen zur Regionalförderung sehr wohlwollend gegenüber und akzeptierte auch sektorale Beihilfen, wenn sie zeitlich degressiv waren, zur Sanierung der Branche beitrugen und nicht den Charakter von Betriebsbeihilfen besaßen 20 .

Im Bereich der sektoralen Beihilfen lag dabei der Schwerpunkt neben der Filmförderung, bei der die Kommission eine Einbeziehung von Filmen aus anderen MS als Vorstufe zu einem von ihr geplanten gemeinsamen System erreichte ${ }^{21}$, im Werf-

16 Vgl. EWG, Kommission 1960, S. 127.

17 Vgl. von der Groeben 1982, S. 88, und EWG, Kommission 1962, S. 86.

18 Vgl. EWG, Kommission 1965, S. 81, und 1964a, S. 3257-3259.

19 Vgl. Warnecke 1978, S. 149, und EWG, Kommission 1966, S. 85f.

20 Vgl. von der Groeben 1967a, S. 197, und EWG, Kommission 1965, S. 80.

21 Vgl. EWG, Kommission 1963, S. 79, und 1966, S. 84f. Diesen Vorschlag unterbreitete die Kommission dann 1970. Schon hier sind erste Ansätze zu industriepolitischer Lenkung zu erken- 
tensektor. Für die Übergangszeit enthielt Art. 92, IIIc EWGV spezielle Regeln für Schiffbaubeihilfen, indem er sie soweit gestattete, wie sie lediglich einem fehlenden Zollschutz für Schiffe entsprachen. Der Abbau sollte dann parallel zum Zollabbau erfolgen. Die Krisenlage des Sektors in der Gemeinschaft machte bereits in den frühen 60er Jahren eine detaillierte Beschäftigung mit Beihilfeprojekten notwendig. Der Entwurf einer RL für Schiffbausubventionen durch die Kommission im Jahre 1965 stellte dann den Einstieg zum Übergang in die zweite Phase der systematischen Erstellung von Kriterien für bestimmte Beihilfekategorien dar, wobei die RL allerdings erst vier Jahre später vom Rat akzeptiert wurde 22 . Die Entwicklung der Schiffbaurichtlinie ebenso wie die gleichzeitig erarbeiteten Regeln für Kohlesubventionen (s. unten 4.1.2) zeigen eine generelle Verschiebung in den Schwerpunkten der Strukturpolitik der MS. Im Unterschied zu den vorher dominierenden Konjunkturprogrammen und Hilfen für rückständige Regionen traten nun die Probleme von Industrien im Niedergang und den durch diesen Prozeß betroffenen alten Industrieregionen in den Vordergrund des Interesses 23 . Die Konzentration der Beihilfenpolitik der MS und ihrer Kontrolle durch die Kommission auf Probleme des Strukturwandels wurde durch dessen Beschleunigung im Zuge der Ölkrisen noch verschärft.

Generell griffen die MS mit der Erreichung der Zollunion 1968 jedoch vermehrt zum "Ersatzprotektionsmittel" Beihilfe 24 , was zum einen in einer steigenden Zahl von Kommissionsentscheidungen deutlich wird (vgl. Tabelle 4.1-1). Zum anderen entwickelte die Kommission, nachdem sie in den sechziger Jahre auf einzelne Fälle mit Ad-hoc-Entscheidungen reagiert hatte, nun in steigender Zahl Richtlinien, Entscheidungen und Gemeinschaftsrahmen für einzelne Sektoren oder Beihilfekategorien. Diese legten in größerem Detail und zugeschnitten auf das jeweilige Problemfeld Genehmigungskriterien im Sinne einer maximal tolerierbaren Beeinflussung des Wettbewerbs sowie Verfahrensregeln fest.

Auch wenn viele der eingeschlagenen Politiken und der verwendeten Beurteilungskriterien bereits Ansätze enthielten, die später weiterentwickelt oder verfeinert wurden, so ist die Beihilfenkontrolle in jener Zeit dennoch wohl nicht sehr wirkungsvoll gewesen. Bezeichnend hierfür ist das Urteil des früheren Generaldirektors

nen, wenn die Kommission zur Überlebenssicherung der Branche Subventionen für notwendig erklärt.

22 Die Subventionskontrollpolitik der Kommission im Schiftbausektor ist Gegenstand einer detaillierten Untersuchung im Abschnitt 4.2.

23 Vgl. Bayliss 1985, S. 224f.

24 Vgl. Warnecke 1978, S. 151. 
Tab. 4.1-1

Maßnahmen im Rahmen der Kontrolle staatlicher Beihilfen

(mit Ausnahme von Landwirtschaft, Fischerei und Verkehr)

\begin{tabular}{|c|c|c|c|c|c|c|c|}
\hline \multirow[t]{2}{*}{ Jahr } & \multirow{2}{*}{$\begin{array}{l}\text { Gemeldete } \\
\text { Vorhaben }\end{array}$} & \multirow[b]{2}{*}{ Insgesamt } & \multicolumn{4}{|c|}{ Maßnahmen der Kommission } & \multirow{2}{*}{$\begin{array}{c}\text { Zurückgezogene } \\
\text { Vorhaben }\end{array}$} \\
\hline & & & $\begin{array}{l}\text { Keine } \\
\text { Einwände }\end{array}$ & $\begin{array}{l}\text { Eröffnung des } \\
\text { Verfahrens* }\end{array}$ & $\begin{array}{l}\text { Einstellung des } \\
\text { Verfahrens* }\end{array}$ & $\begin{array}{l}\text { Abschließende } \\
\text { Entscheidung* }\end{array}$ & \\
\hline 1970 & n.v. & 21 & 15 & & 6 & 1 & n.v. \\
\hline 1971 & n.v. & 18 & 11 & & 7 & 3 & n.v. \\
\hline 1972 & n.v. & 35 & 24 & & 1 & 3 & n.v. \\
\hline 1973 & n.v. & 22 & 15 & & 7 & 4 & n.v. \\
\hline 1976 & n.v. & 47 & 33 & & 4 & 2 & n.v. \\
\hline 1977 & n.v. & 112 & 99 & & 3 & 1 & n.v. \\
\hline 1978 & n.v. & 137 & 118 & & 9 & - & n.v. \\
\hline 1979 & n.v. & 133 & 79 & & 4 & 3 & n.v. \\
\hline 1980 & n.v. & 105 & 72 & & 3 & 2 & n.v. \\
\hline 1984 & 162 & 314 & 201 & 58 & 34 & 21 & 6 \\
\hline 1985 & 133 & 178 & 102 & 38 & 31 & 7 & 11 \\
\hline 1986 & 124 & 181 & 98 & 47 & 26 & 10 & 5 \\
\hline 1987 & 326 & 274 & 205 & 27 & 32 & 10 & 1 \\
\hline 1988 & 375 & 387 & 311 & 31 & 32 & 13 & - \\
\hline 1989 & 296 & 334 & 254 & 37 & 27 & 16 & 7 \\
\hline 1990 & 429 & 421 & 352 & 33 & 24 & 12 & 2 \\
\hline 1991 & 417 & 475 & 415 & 36 & 18 & 6 & n.v. \\
\hline 1992 & 452 & 502 & 455 & 30 & 31 & 6 & n.v. \\
\hline 1993 & 475 & 435 & 399 & 30 & 19 & 7 & n.v. \\
\hline
\end{tabular}

* nach Art. 93 Abs. 2 EGV oder Art. 8 Abs. 3 der Entscheidung 2320/81/EGKS bzw. der folgenden Stahlkodizes Quelle: EG, Kommission 1981a, S. 122; 1991a, S. 155; 1994d, S. 42. 
für Wettbewerbspolitik, Manfred Caspari, über diese Phase25: "Man lebte in einer Welt der Harmonie, und man wollte einander nicht weh tun."

Diese Aussage gilt, wenn auch mit Einschränkungen, sicherlich ebenfalls für einen weiteren Schwerpunkt der Kommissionsarbeit in den ersten Jahren, die Abschaffung von Exportsubventionen für die Intra-EG-Ausfuhr. Da diese Beihilfen, wie oben in Teil 3 dargelegt, pro Geldeinheit die stärksten Verzerrungen des Handels verursachen, wurden sie von der Kommission schon sehr früh attackiert, wobei auch einige Erfolge zu verzeichnen waren. So untersuchte sie ab 1961 v.a. Ausfuhrkredite und -bürgschaften und machte Vorschläge zur stufenweisen Abschaffung, so z.B. bei italienischen Vorschriften zur Rückerstattung von Zöllen und Steuern bei der Ausfuhr ${ }^{26}$. Aber erst im Laufe der 70er Jahre wurde dann die Aufhebung der französischen und italienischen Exportpreisgarantiesysteme und der Vorzugsdiskontsätze für Wechsel aus Exportgeschäften in Belgien, Frankreich und Italien durchgesetzt $^{27}$. Die Kommissionsauffassung, daß diese Systeme im Intra-EG-Handel abzuschaffen seien und die Durchsetzung dieser Forderung wurde nach anfänglichen Problemen durch ein Urteil des EuGH unterstützt ${ }^{28}$. Auch steuerliche Vorteile für ausländische Niederlassungen französischer Unternehmen, in mehreren MS gewährte Zuschüsse an Unternehmen zur Markterschließung in anderen MS, und spezifisch sektorale Absatzfördermaßnahmen Italiens wurden auf Druck der Kommission aufgehoben ${ }^{29}$. Gegen Zinssubventionen für Intra-EG-Exportkredite schritt die EG ab Mitte der 70er Jahre ein. Ihre Untersuchungen ergaben, daß solche Beihilfen noch in Frankreich und Großbritannien sowie in den Niederlanden existierten. Deren Abschaffung wurde dann allerdings bis 1980, im Falle der Niederlande nach einer Verfahrenseröffnung und unter der Drohung einer Aktion vor dem EuGH, durch-

25 1987, S. 86.

26 Vgl. EWG, Kommission 1962, S. 86f., und 1963, S. 80. Allgemein zur Kommissionspolitik: EWG, Kommission 1966, S. 82f.

27 Vgl. EG, Kommission 1977a, S. 142f.

28 Vgl. EWG, Kommission 1967, S. 112f., EG, Kommission 1971, S. 38, und 1972a, S. 161f., sowie Mutti 1982, S. 29.

29 Vgl. EG, Kommission 1974a, S. 97, und 1977a, S. 143-146, sowie 1980a, S. 137. Eine Ausnahme machte die Kommission lediglich für Beihilfen für nordirische KMU zur MarkterschlieBung in Großbritannien und den anderen MS, wobei sie die besonderen ökonomischen Probleme Nordirlands ebenso als Begründung anerkannte wie die zeitliche Begrenzung auf Starthilfen, die diese Beihilfe nach Ansicht der Kommission einer Investitionsbeihilfe annäherte. Vgl. ebenda, S. 137-139. 
gesetzt $^{30}$. Mit den verschiedenen Erweiterungen der Gemeinschaft achtete die Kommission dann auch darauf, daß die jeweiligen Extra-EG-Exportfördersysteme der alten MS nach dem Beitritt nicht mehr auf die neuen MS angewandt wurden 31 und daß die Beitrittsländer ihre Systeme nicht im Intra-EG-Handel beibehielten. Für Griechenland wurden dabei solche Beihilfen aufgrund der schweren Krise in diesem Land ausnahmsweise temporär und degressiv genehmigt ${ }^{32}$. Weitere Beihilfen wurden jedoch später abgelehnt. Da Griechenland die negative Entscheidung nicht umsetzte, war die Kommission gezwungen, vor dem EuGH zu klagen 33 . Anfang der 90er Jahre war dann die Abschaffung aller Intra-EG-Exportbeihilfen erreicht ${ }^{34}$.

Bezüglich der Beihilfen für Extra-EG-Exporte, insbesondere von Exportkreditversicherungen, Zinsverbilligungen und gebundenen Entwicklungsbeihilfen, die einen indirekten Effekt auf den Wettbewerb innerhalb der Gemeinschaft haben können, verabschiedete der Rat 1977 zunächst Orientierungen 35. Hier hat die Kommission 1990 begonnen, detaillierte Mitteilungen von den MS zu ihren jeweiligen Regelungen zu verlangen. Diese Beihilfen sind nach Art. 112 EGV zu harmonisieren, was aber bis dahin nicht geschehen war ${ }^{36}$. Hierzu erarbeitete die Kommission Leitlinien, wobei die MS bezüglich einer Regelung der Zinsverbilligungen Widerstand leisteten. Da auf OECD-Ebene strengere Regelungen erarbeitet wurden, hat die Kommission diesen Entwurf zurückgestellt ${ }^{37}$.

\subsubsection{Die Entwicklung von Regeln für sektorale Beihilfen}

\subsubsection{Die Erarbeitung allgemeiner Leitlinien}

Neben den eben erwähnten speziellen Regeln für die Werftindustrie versuchte die Kommission, allgemeine Beurteilungskriterien für sektorale Beihilfen zu entwickeln.

30 Vgl. EG, Kommission 1978a, S. 201f., 1979a, S. 171f., 1980a, S. 103 und 140f., und Swann 1983, S. 47. Außerhalb der EG wurde der Exportkreditbeihilfenwettlauf durch ein OECDAbkommen im Jahre 1978 begrenzt. Vgl. Malkin 1990, S. 51.

31 Im Falle französischer Beihilfen für Exporte nach Griechenland nach dessen EG-Beitritt erließ die Kommission hier eine Verbotsentscheidung. Vgl. EG, Kommission 1982a, S. 171, und 1983a, S. 149f.

32 Vgl. EG, Kommission 1987a, S. 170.

33 Vgl. EG, Kommission 1992a, S. 190.

34 Vgl. Lehner/Meiklejohn/Reichenbach 1991, S. 72.

35 Vgl. EG, Kommission 1978a, S. 200.

36 Vgl. Lehner/Meiklejohn/Reichenbach 1991, S. 72f., und Gilchrist/Deacon 1990, S. 40f.

37 Vgl. EG, Kommission 1993a, S. 209f. 
Bereits das Industriememorandum von 1970 enthielt hierzu erste Überlegungen 38 . So wurden Subventionen als Starthilfen in Industrien mit fortgeschrittener Technologie als akzeptabel angesehen (Infant-industry-Argument, vgl. Abschn. 2.1.3), ebenso zum Ausgleich von Wettbewerbsverzerrungen durch Drittländer und zur Unterstützung von Rationalisierungs- und Umstrukturierungsmaßnahmen. Solche Beihilfen sollten jedoch mit regionalen Subventionen und Forschungsfördermaßnahmen verknüpft werden, die Diversifizierung von Unternehmen in Krisenbranchen vorrangig unterstützen und nicht erst beim Eintritt schwerer Krisen, sondern bereits vorausschauend gewährt werden.

Diese Leitsätze erscheinen eher als Ausdruck eines interventionistischen Politikkonzepts, allerdings mehr in Form einer aktiv gestaltenden denn einer reaktiven Variante. Die tatsächliche Politik der Kommission im Bereich der sektoralen Beihilfen bestand jedoch vorwiegend in der Reaktion auf krisenhafte Entwicklungen in einzelnen Sektoren mittels detaillierter Regelwerke. Dies gilt neben den eben erwähnten Werften vor allem für die Textil- und Stahlindustrie (ab 1971 bzw. 1977/80), mit Einschränkungen auch für den Automobilbereich (ab 1987/89). Die beiden letztgenannten Branchen werden in den Abschnitten 4.3 und 4.4 im einzelnen diskutiert.

Mehr formale Kriterien zur Beurteilung sektoraler Beihilfen lieferte die Kommission im 1. Wettbewerbsbericht ${ }^{39}$. Die Akzeptanzkriterien für Beihilfen blieben sehr allgemein. Sie sollen auf das in Relation zum Problem notwendige Maß beschränkt bleiben, degressiv, transparent und an Umstrukturierung gebunden sein, die langfristige Überlebensfähigkeit des Unternehmens ohne Beihilfen sichern und eine Verlagerung der Probleme auf andere MS vermeiden. Sie implizieren zumindest in Krisensektoren die Notwendigkeit von Kapazitätskürzungen 40 .

Auch in der Rezessionsphase nach 1974 wurde versucht, diese generellen Kriterien zur Beurteilung sektoraler Beihilfen weiter zu entwickeln. Das Resultat wurde 1978 in einer Mitteilung an den Rat publiziert ${ }^{41}$, wobei zum einen die Kriterien von 1971 übernommen, zum anderen ergänzt werden. Beihilfen seien in den Situationen angebracht, wenn die Marktbedingungen "Fortschritte bei bestimmten wirtschaftlichen und sozialen Zielsetzungen" entweder verhindern oder nur innerhalb unan-

\footnotetext{
38 Vgl. EG, Kommission 1970b, S. 266f.

39 Vgl. EG, Kommission 1972a, S. 146f.

40 Vgl. Pelkmans 1984, S. 263. Diese Haltung bestätigte die Kommission später explizit. Vgl. EG, Kommission 1979a, S. 140.

41 Vgl. EG, Kommission 1978c.
} 
nehmbar langer Fristen bzw. mit hohen sozialen Kosten ermöglichen oder zu einem selbstzerstörerischen Wettbewerb führen. Eine Präzisierung insbesondere des letzten Aspekts fehlt. Konflikte zwischen sektoralen und regionalen Aspekten seien bei der Beurteilung einzelner Beihilfefälle individuell zu lösen. Bei allen Beihilfen achtet die Kommission zudem auf den Beitrag der geförderten Maßnahme zur Verwirklichung von Gemeinschaftszielen, wie z.B. die Entwicklung benachteiligter Regionen 42 .

Jedoch wurden angesichts der verschlechterten Gesamtlage zusätzliche "weiche" Kriterien für Krisenbranchen angefügt 43 : Beihilfen zur Erhaltung des Status quo sollen zwar nicht annehmbar sein, längerdauernde Hilfen zur Verminderung der sozialen Kosten der Anpassung können jedoch akzeptiert werden, d.h. daß auch zeitlich begrenzte Betriebsbeihilfen (sog. Begleitbeihilfen) während der Durchführung von Umstrukturierungsprogrammen genehmigungsfähig sein können. Ebenso waren Rettungsbeihilfen bis zur Ausarbeitung von Umstrukturierungskonzepten akzeptabel, allerdings nur als Liquiditätshilfen (kurzfristige Kredite zu Marktzinsen oder Kreditgarantien) für eine Zeit von bis zu 6 Monaten ${ }^{44}$. Hinzu kam hier noch das Verbot der Förderung von Kapazitätsausweitungen durch jedwede Art von Subventionen, um so einen direkten Export von Arbeitslosigkeit auf stagnierenden Märkten zu vermeiden 45 . Nur für diese Branchen werden Gemeinschaftsrahmen als nützlich angesehen ${ }^{46}$, ansonsten wird in ihnen die Gefahr gesehen, daß sie mit ihren detaillierten Genehmigungskriterien eher zu weiteren Subventionen Anreiz bieten könnten. Als Reaktion auf spezifisch sektorale Krisen wurden mehrere solcher Regelwerke entwickelt, deren wichtigste in den Abschnitten 4.2-4.4 im Detail analysiert werden. Nachfolgend soll zur Vervollständigung des Bildes kurz auf weitere sektorale Regelwerke eingegangen werden.

\subsubsection{Beihilfenkontrolle in einigen Krisensektoren}

In der Textilindustrie hatte das Vordringen der Entwicklungsländer, insbesondere aus dem südostasiatischen Raum, ab den 60er Jahren zu erheblichen Problemen und Arbeitsplatzverlusten in dieser Branche in einigen MS geführt, denen diese mit Sub-

42 Vgl. Cownie 1986, S. 250-253.

43 Vgl. Swann 1988, S. 140f., und EG, Kommission 1979a, S. 140f.

44 Vgl. EG, Kommission 1979a, S. 176f.

45 Selbst der Erhalt eines Unternehmens in Schwierigkeiten mittels Beihilfen führt bei einer umfassenderen Analyse jedoch schon zum Export von Arbeitslosigkeit, da beim Eintritt des Alternativszenarios eines Marktaustritts des betreffenden Unternehmens die Konkurrenten in anderen MS an Marktanteilen gewännen.

46 Vgl. auch EG, Kommission 1972a, S. 147f. 
ventionen zur Anpassungsförderung zu begegnen suchten 47 . Um hier einen Beihilfenwettlauf zu unterbinden, erließ die Kommission 1971 einen Gemeinschaftsrahmen 48 , der den MS empfahl, alle Fördermaßnahmen für diese Branche in sektorspezifische Programme zu kleiden, und die MS zudem in Bekräftigung der Verpflichtung aus Art. 93,II zur Anmeldung aller spezifischen Förderungsvorhaben für diesen Bereich (sektorspezifische Hilfsprogramme und Ad-hoc-Hilfen) verpflichtete sowie Beurteilungskriterien für einzelne Beihilfekategorien festlegte. So strebte die Kommission insbesondere danach, daß die MS ihre Unterstützung auf FuE-Maßnahmen (Faserentwicklung), Marktbeobachtung und -prognose sowie Kapazitätsabbau und Umstellung einzelner Betriebe auf andere Tätigkeiten lenkten 49 . Eine Konzentration der Unternehmen in diesem Sektor wurde wohlwollend betrachtet ${ }^{50}$. Subventionen für Modernisierungsinvestitionen, die starke Auswirkungen auf den innergemeinschaftlichen Wettbewerb haben, wurden hingegen kritischer gesehen und sollten nur bei besonders schwerwiegenden sozialen Problemen genehmigt werden, sofern sie nicht mit einer Kapazitätsausweitung verbunden waren. Für die Behandlung von Beschwerden wurde ab 1973 ein multilaterales Konsultationsverfahren eingeführt ${ }^{51}$. Das Verbot von subventionierten Kapazitätsausweitungen in Krisenbereichen der Textilindustrie wurde in einem modifizierten Rahmen 197752 nochmals bekräftigt, wobei die Kommission unter dem Eindruck der allgemeinen Rezession präzisierte, daß in solchen Bereichen, in denen ein Preiseinbruch zu beobachten war, nur Subventionen, die mit einer Produktionsumstellung in andere Bereiche verbunden waren, gestattet werden konnten 53 . Anfang der 80 er Jahre versuchte die Kommission zudem, die Kontrolle der Anwendung allgemeiner Beihilferegelungen auf die Textilindustrie zu verbessern, indem sie eine Ex-post-Kontrolle aller Beihilfen an diesen Sektor vorschlug54, deren Umsetzung jedoch nicht gelang (vgl. auch die Entwicklung im Kfz-Sektor in Abschn. 4.4). Inzwischen sieht die Kommission die

47 Vgl. EG, Kommission 1970b, S. 250, Hoischen 1989, S. 108, und Thies 1989, Annex 3, S. 1.

48 Vgl. EG, Kommission 1971c.

49 Vgl. Neundörfer 1984, S. 88f., und Cownie 1986, S. 259, sowie Thies 1989, Annex 3, S. 2. Dieses Umstellungsziel war auch Kern der Empfehlungen einer von der Kommission in Auftrag gegebenen Studie aus dem Jahre 1969. Vgl. Chard/Macmillen 1979, S. 142f.

50 Vgl. EG, Kommission 1972a, S. 153.

51 Vgl. EG, Kommission 1974a, S. 89.

52 Vgl. EG, Kommission 1977d.

53 Vgl. Chard/Macmillen 1979, S. 144.

54 Vgl. EG, Kommission 1982a, S. 147f. 
Rahmenregelungen für die Textilindustrie nicht mehr als verpflichtenden Gemeinschaftsrahmen, sondern lediglich als Orientierungen an 55 .

Insbesondere in den 70er Jahren war die Unterstützung der Textilindustrie in fast allen MS weit verbreitet, wobei einige der Programme im Widerspruch zu den Kriterien des Gemeinschaftsrahmens standen, indem sie den Charakter von Betriebsbeihilfen ohne Umstrukturierungsanzreize besaßen, so daß die Kommission hier eine Änderung der Entwürfe durchsetzen mußte 56 . Hierbei kam es in häufig zu Verfahrenseröffnungen und in mehreren Fällen zu langwierigen Verhandlungen über Modifikationen der Beihilfeprojekte sowie zu Klagen vor dem EuGH, was zu erheblichen Zeitverzögerungen zwischen der Einführung einer vertragswidrigen Maßnahme und ihrer schließlichen Abschaffung oder Modifizierung führte ${ }^{57}$. Generell gelang es der Kommission jedoch, wenn auch mit Zeitverzögerungen, die Regeln des Gemeinschaftsrahmens konsistent durchzusetzen 58 .

Der eingeleitete Umstrukturierungsprozeß erwies sich zunächst als außerordentlich erfolgreich. Die Textilunternehmen modernisierten ihre Anlagen und spezialisierten sich auf Produkte hoher Qualiät. Als Konsequenz hieraus erklärte die Kommission 1984, daß nunmehr keine weiteren Umstrukturierungsbeihilfen nötig und genehmigungsfähig seien 59 . Diese Erklärung wurde auch umgesetzt, und die geplanten Beihilfenprojekte einiger MS wurden durch negative Entscheidungen verboten 60 . Abgesehen von einem Fall griechischer Beihilfen wurden seit 1984 keine Umstrukturierungs- oder Investitionsbeihilfen genehmigt 61 .

Die Beihilfenkontrollpolitik nach innen wurde ergänzt durch eine protektionistische Außenhandelspolitik, die über mehrere internationale Abkommen, v.a. die Multifaserabkommen (MFA) seit 1974, den Import von Textilien aus Ländern der

55 Vgl. Jallon 1993, S. 326.

56 Vgl. EG, Kommission 1977d; vgl. auch zu Einzelfällen bspw. EG, Kommission 1978a, S. 173176, sowie 1979a, S. 156f., 1980a, S. 125-127, und 1983a, S. 137f.

57 Vgl. Chard/Macmillen 1979, S. 147-54, und Schina 1987, S. 85, sowie Ross 1986, S. 885f. Belgische Beihilfen zur Umstrukturierung der Textilindustrie (Claes-Plan), die von der Kommission genehmigt worden waren, verwarf der EuGH aufgrund einer Klage Deutschlands. Dies geschah allerdings nicht wegen einer Überschreitung des Ermessensspielraums durch die Kom-

mission sondern wegen Verfahrensfehle
58 Vgl. Chard/Macmillen 1979, S. 154.

59 Vgl. EG, Kommission 1985, S. 166, und Beutler et al. 1987, S. 361.

60 Vgl. EG, Kommission 1985a, S. 165-169, und 1986a, S. 168f.

61 Vgl. Thies 1989, Annex 3, S. 2-4, und Caspari 1985, S. 62. 
Dritten Welt in die EG begrenzten62. Bei der Detailbetrachtung einzelner Branchen in den Abschnitten 4.2-4.4 wird deutlich werden, daß diese Verknüpfung nicht außergewöhnlich ist, wobei allerdings die relativen Gewichte der beiden Politiken variieren. Im Textilsektor überstieg die Bedeutung des Außenhandelsprotektionismus diejenige der Subventionierung erheblich63.

Da die Kunstfaserindustrie seit 1975 unter den gleichen Überkapazitätsproblemen litt, z.T. auch aufgrund der Expansion subventionierter Staatsunternehmen ${ }^{64}$, wurde die spezielle Kontrolle mittels eines eigenen Gemeinschaftsrahmens ab 1977 auch auf diesen Bereich ausgedehnt. Der Rahmen führte eine separate Meldepflicht für alle Beihilfen zugunsten von Unternehmen dieses Sektors (auch im Rahmen genehmigter regionaler oder allgemeiner Programme) ein, wobei hier Beihilfen zum Kapazitätsausbau grundsätzlich abgelehnt und nur solche Hilfen positiv beurteilt wurden, die zu einer Umstellung, Umstrukturierung bzw. einem Kapazitätsabbau führen. Die Kapazitätsentwicklung in den einzelnen Teilbereichen der Kunstfaserherstellung findet bei der Bemessung der geforderten Kapazitätsreduktion ebenso Berücksichtigung wie die regionale Förderwürdigkeit des betreffenden Standortes (der Beitrag zur Kohäsion) und die geplante Beihilfeintensität65. Dieses Verbot subventionierter Kapazitätsausweitungen bietet für die bestehenden Produzenten eine partielle Abschottung gegen Marktzutritte, da sie für Umstrukturierungsinvestitionen bspw. in Regionalfördergebieten, die zur Erhöhung von Produktivität und Produktqualität ohne gleichzeitige Kapazitätsausweitung führen, Fördermittel erhalten können66, während Neueinsteiger in den Markt selbst in Regionalfördergebieten keine Beihilfen erhalten können. Hier sind wettbewerbspolitische Probleme gegeben, insbesondere auch wegen der vorhandenen Kartellierungstendenzen in der Branche67. Allerdings bleiben nicht subventionierte

62 Vgl. Warnecke 1978, S. 162, Hitiris 1991, S. 306f., und Geister 1982, S. 216.

63 Vgl. Mutti 1982, S. 50.

64 Vgl. Caspari 1990, S. 19, und Swann 1983, S. 157. Subventionen in Gestalt zinsgünstiger Kredite vergab dabei auch die EIB. Vgl. Geister 1981, S. 148.

65 Vgl. EG, Kommission 1978a, S. 172f. Diese Regelung, die ursprünglich nur für zwei Jahre galt, wurde seitdem regelmäßig verlängert, 1985 auf weitere Kunstfasern und 1992 auf die Polymerisation erweitert, und gilt heute noch. Vgl. EG, Kommission 1992b, S. 2f., 1986a, S. 171, und Schina 1987, S. 85, sowie Thies 1989, Annex 3, S. 6.

66 Vgl. bspw. EG, Kommission 1992a, S. 167, mit einer Entscheidung zu Beihilfen in Portugal.

67 Angesichts der Überkapazitäten planten die Produzenten ein solches Krisenkartell mit Produktionsquoten, wobei sie von DG III unterstützt wurden. Aufgrund des Widerstandes von DG IV wurde ein Kapazitätsstillegungskartell der Produzenten erst von der Kommission genehmigt, nachdem die ursprünglich geplanten Produktionsquotenabsprachen aufgehoben worden waren. 
Expansionen weiterhin möglich. Für FuE- und Umweltschutzbeihilfen gelten die Regeln der jeweiligen horizontalen Rahmen. Die Anwendung des Rahmens führte zu einer Reihe negativer Entscheidungen mit Rückzahlungsforderungen der Kommission oder Rücknahmen von Beihilfeprojekten durch die betreffenden MS68. Bis 1988 gelang zudem eine Reduktion der Kapazität um ca. 25\%. Während damit zunächst die Umstrukturierung erfolgreich abgeschlossen zu sein schien, führte die zunehmende Konkurrenz aus Fernost und den USA wieder zu einem Fall der Kapazitätsausnutzung und stagnierenden Preisen, so daß weitere Schließungen nötig sein werden 69 .

Im EGKS-Bereich 70 hatte sich die Kommission mit Beihilfen an den Kohlenbergbau vor allem in Belgien und Frankreich zu befassen. Obwohl diese Beihilfen nach dem Ende der Übergangsphase dieses Vertrages 1958 eigentlich strikt verboten waren, gelang ihre Abschaffung zunächst nur in Frankreich, während für den außerordentlich ineffizienten belgischen Bergbau weiterhin verschiedene Subventionen, die z.T. durch EGKS-Mittel aufgestockt wurden, gegeben werden konnten und zudem noch eine temporäre Marktabschottung toleriert wurde. Allerdings erreichte die Kommission eine Beschränkung der Beihilfen auf diejenigen Zechen, die als überlebensfähig eingestuft wurden, und unterstützte die Umschulung der entlassenen Arbeiter in den anderen Zechen. Bis 1964 sank die Zahl der belgischen Zechen auf die Hälfte, die überlebenden hatten sich jedoch trotz großzügiger Hilfen nicht an das Produktivitätsniveau der anderen Gemeinschaftsländer angenähert. In der ausbrechenden Kohlekrise der 60er Jahre mußte die Kommission dann die Gewährung von Beihilfen in allen MS tolerieren. Sie erließ einen Subventionskodex, nach dem zunächst Beihilfen für die Sozialversicherung der Bergleute und Rationalisierungshilfen, später auch Beihilfen zur Preisreduktion von Kokskohle für die Stahlindustrie erlaubt waren 71 . Das absolute Beihilfenverbot des Art. 4 c EGKSV wurde also bereits frühzeitig angesichts von Struktur- und Konjunkturproblemen "zum Pappschwert degradiert"72, und die Kohlesubventionierung spielte dann nach Schließung

Dieses Kartell hatte bis 1985 Bestand. Vgl. Curzon Price 1990, S. 173f., Caspari 1990, S. 19, und Thies 1989, Annex 3, S. 4.

68 Vgl. Thies 1989, Annex 3, S. 7f., und bspw. EG, Kommission 1987a, S. 143.

69 Vgl. Thies 1989, Annex 3, S. 5f.

70 Obwohl dieser Paragraph zum Teil auch die Politik in der Anfangsphase erfaßt, wird er wegen des späteren Erlasses eines sektoralen Beihilfenkodex hier eingeordnet.

71 Vgl. EGKS, Hohe Behörde 1965a, S. 480. Diese Entscheidung wurde dann regelmäßig (zuletzt 1986) verlängert. Vgl. Caspari 1987, S. 83f., und detaillierter zu den Kohlebeihilfen:

72 McLachlan/Swann 1967, S. 42-50, sowie van Meerhaeghe 1971, S. 247f.

2 Caspari 1982, S. 5. 
der letzten belgischen Zechen und der weitgehenden Einstellung der Kohlesubventionierung in Großbritannien im Laufe der 80er Jahre v.a. in Deutschland eine große Rolle, wo sie im Durchschnitt der Jahre 1986-88 mit 7,3 Mrd. ECU 56\% der gesamten Kohlesubventionierung der MS ausmachte ${ }^{73}$. Die Darlegungen zu den Stahlbeihilfen in Abschnitt 4.3 werden zeigen, daß im Stahlbereich die Entwicklung der Beihilfenkontrolle ähnlich verlief.

Ein besonderes Problem stellte in einigen Sektoren 74 die Finanzierung von Beihilfen über parafiskalische Abgaben dar, die bspw. in Frankreich zugunsten der Textilindustrie bestand. Hierbei wurde eine steuerähnliche Abgabe auf den gesamten Verbrauch der Erzeugnisse dieses Sektors erhoben, deren Ertrag dann zur Förderung der Forschung und Modernisierung der einheimischen Industrie, z.T. unter Einschaltung sektorspezifischer Institute, eingesetzt wurde ${ }^{75}$. Da diese Abgabe auch auf Importe erhoben wurde, während die ausländischen Unternehmen von den Arbeiten der Institute nicht profitieren, da diese auf die Bedürfnisse der einheimischen Industrie ausgerichtet waren, bzw. den Exporteuren ähnliche Institute in ihren eigenen Ländern zur Verfügung standen, sah die Kommission hierin eine direkte Diskriminierung der Importe (Abgabe gleicher Wirkung wie ein Zoll), die über die eigentlichen Wirkungen der - möglicherweise genehmigungsfähigen - Beihilfe hinausging, leitete zunächst das formelle Prüfungsverfahren ein und erließ dann eine negative Entscheidung, sofern die Finanzierungsart nicht geändert wurde 76 . Die hiergegen gerichtete Klage Frankreichs wies der EuGH ab, wobei er die Argumentation einer über die eigentliche Beihilfe hinausgehenden Diskriminierung und Verzerrung des Wettbewerbs akzeptierte ${ }^{77}$. Danach hob die französische Regierung die Erhebung der Abgabe auf Intra-EG-Importe auf 78 . Die inkompatible Subvention war allerdings viereinhalb Jahre wirksam gewesen ${ }^{79}$. Auch in den Fällen, die andere Sektoren betrafen, eröffnete die Kommission jeweils das Verfahren und verpflichtete die MS, Importe von der Erhebung der Abgabe freizustellen, während sie die jeweilige sekto-

73 Vgl. Lehner/Meiklejohn/Reichenbach 1991, S. 41f., daneben: Caspari 1985, S. 57, Michaelis 1987, S. 99f., und Seidel 1984, S. 80.

74 So bspw. in den Uhren- und Lederindustrien in Frankreich oder der Papierindustrie in Italien. Vgl. u.a. EG, Kommission 1973a, S. 109-113, und bereits 1970, S. 75.

75 Vgl. Hoischen 1989, S. 103.

76 Vgl. EG, Kommission 1968, S. 76, und 1970, S. 75.

77 Vgl. EG, Kommission 1971, S. 33, und EuGH 1970, Urteil in der RS 47/69.

78 Vgl. EG, Kommission 1972a, S. 159.

79 Vgl. Chard/Macmillen 1979, S. 148. 
rale Förderung, die häufig vor allem den KMU zugutekam, i.d.R. akzeptierte80. Spätere französische Textilbeihilfen, die erneut aus einer parafiskalischen Abgabe finanziert wurden, verbot die Kommission trotz der Freistellung der Importe, da diese Beihilfe aufgrund ihrer langen Dauer Betriebsbeihilfencharakter hatte81. Da Frankreich (und in geringerem Umfang Italien) immer wieder Beihilfen diesen Typus für verschiedene Industrien notifizierte, mußte die Kommission durch die Eröffnung des Verfahrens nach Art. 93,II stets erneut sicherstellen, daß einerseits Intra-EG-Importe von der Abgabenpflicht ausgenommen, andererseits die Abgaben auf Exporte erhoben und lediglich für Forschungsinstitute zugunsten der KMU u.ä. jedoch nicht für direkte Betriebsbeihilfen an einzelne Unternehmen verwandt wurden 82 .

\subsubsection{Beihilfenpolitik in Wachstumsindustrien}

In High-tech-Sektoren, wie bspw. dem Flugzeugbau, der Chip- oder der Computerindustrie, basierte die Beihilfenkontrollpolitik der Kommission sehr stark auf dem industriepolitischen Ansatz des "picking the winners"83. Angesichts der technischen Rückständigkeit der europäischen Produzenten und der Aufsplitterung in viele im Weltmaßstab kleine Unternehmen war sie bereit, Beihilfen für FuE und Investitionen sowie subventionierte oder verbürgte Kredite für Käufer der Produkte nach Art. 92,IIIc oder nach 92,IIIb als Förderung von Maßnahmen von gemeinsamem europäischem Interesse zu genehmigen, wobei sie sehr stark auf eine Kooperation der europäischen Firmen zur Verbesserung ihrer Wettbewerbsfähigkeit drängte bzw. vorhandene Kooperationen explizit guthie $\beta^{84}$. In der Computerindustrie erfolgte dabei bspw. die Bildung des UNIDATA-Konsortiums, das dann jedoch auseinanderfiel und in Frankreich durch die Bildung eines staatlich geförderten nationalen Kon-

80 Vgl. z.B. EG, Kommission 1974a, S. 91f. Frankreich versuchte der Kontrolle der Kommission in der Uhrenindustrie durch Verlagerung der Abgabenerhebung ins Inland auszuweichen. Dies wurde jedoch von der Kommission entdeckt und die Importeure erhielten die Abgabe zurückerstattet. Vgl. EG, Kommission 1979a, S. 169.

81 Vgl. EG, Kommission 1984a, S. 170, und 1985a, S. 166, sowie Hummel 1985, S. 18, und Geister 1984, S. 156f. Frankreich versuchte dennoch später erneut, für solche Beihilfen eine Genehmigung zu erhalten, die jedoch wiederum versagt wurde. Vgl. EG, Kommission 1987a, S. 142 .

82 Vgl. EG, Kommission 1987a, S. 160f., und 1988a, S. 164-166, sowie 1991a, S. 190.

83 Vgl. Ehlermann 1994, S. 416.

84 Vgl. EG, Kommission 1973a, S. 102-106, 1976a, S. 108, und 1977a, S. 138-141, sowie 1982a, S. 127 , und 1987a, S. 152, 166. 
sortiums ersetzt wurde, wobei die Kommission Beihilfen hierfür genehmigte ${ }^{85}$. Im Flugzeugbau wurde das Gemeinschaftsunternehmen Airbus-Industrie mit erheblichen Subventionen unterstützt. In dieser Branche plante die Kommission Anfang der 80er Jahre sogar den Erlaß eines Gemeinschaftsrahmens ${ }^{86}$, allerdings ohne Erfolg. Warnecke 87 sieht in dieser Politik vor allem während der 70er Jahre eine Konzession an Planungsideen, die in DG III zirkulierten. Nach 1986 wurden Beihilfen an diese Branchen aufgrund ihres Charakters vor allem durch den Gemeinschaftsrahmen für FuE-Beihilfen erfaßt (s. unten 4.1.4) und von der Kommission ebenfalls wohlwollend behandelt.

\subsubsection{Die Entwicklung von Regeln für regionale Beihilfen}

\subsubsection{Problemstellung und erste Kontrollansätze}

Bereits gegen Ende der 60er Jahre sah sich die Kommission vor das Problem gestellt, daß die MS vermehrt regionale Förderprogramme aufstellten, um den im Wirtschaftsaufschwung zurückbleibenden Gebieten über die Attrahierung von Investitionen den Anschluß an die allgemeine Entwicklung zu ermöglichen. Neben den italienischen Maßnahmen für den Mezzogiorno betraf dies zunächst Gesetze in Frankreich und den Niederlanden zur Förderung der Umstellung der alten Industriegebiete, v.a. der Bergbau- und Stahlregionen 88 . Da DG IV noch keine Kriterien zum Vergleich der wirtschaftlichen Situation einzelner Regionen in den verschiedenen MS entwickelt hatte, fiel die Beurteilung der Adäquanz der in den jeweiligen Gesetzen vorgesehenen Förderintensitäten schwer, auch wenn die Kommission in den beiden genannten Fällen den Verdacht äußerte, daß die geplanten Intensitäten zu hoch seien. Zudem befürchtete sie einen Beihilfenwettlauf zwischen den MS bzw. ihren Regionen um Industrieansiedlungen, bei dem die umworbenen Unternehmen Renten abschöpfen konnten, ohne daß das Investitionsvolumen entsprechend stark steigen würde, und den am Ende nur die schwächsten Regionen verlieren konnten ${ }^{89}$. Unter dem Deckmantel der Regionalförderung bestand darüber hinaus die Gefahr, daß die MS mittels im Vergleich zu den jeweiligen Regionalproblemen überhöhter Beihilfen

\footnotetext{
85 Vgl. EG, Kommission 1977a, S. 139f., und Curzon Price 1990, S. 168.

86 Vgl. EG, Kommission 1983a, S. $119 f$.

87 1978, S. $163 \mathrm{f}$.

88 Vgl. EG, Kommission 1968, S. 73f.

89 Vgl. EG, Kommission 1970b, S. 270, und Swann 1988, S. 139.
} 
für einzelne Investitionsprojekte eine gezielte sektorale Industriepolitik mit entsprechenden Handels- und Wettbewerbsverzerrungen betreiben würden 90 .

Wiederum stellte sich für die Kommission das Problem der Durchsetzung ihres Rechts zur Prüfung einzelner Anwendungsfälle der genehmigten Rahmenpläne, um so eine effektive Kontrolle und Transparenz sowie die induktive Entwicklung von Beurteilungskriterien zu gewährleisten 91 . Angesichts des Widerstandes der MS akzeptierte die Kommission die Beschränkung dieser Prüfung auf größere Anwendungsfälle bei Hinzuziehung nationaler Sachverständiger ${ }^{92}$. In Sitzungen mit diesen wurden dann technische Aspekte einer geplanten gemeinschaftlichen Überwachung, wie z.B. die Messung der Subventionsintensität, diskutiert. In dieser Vorbereitungsphase einer Gemeinschaftsregelung erhöhte die Kommission durch die vermehrte Eröffnung von Prüfungsverfahren nach Art. 93,II den Druck auf die MS93.

\subsubsection{Die Entwicklung und Anwendung detaillierter Beurteilungsregeln}

Den nächsten Schritt zur Entwicklung einer systematischen Politik für die verschiedenen Probleme stellte dann 1971 die Verabschiedung einer Mitteilung an den Rat durch die Kommission dar, in der sie Koordinierungsgrundsätze für Regionalbeihilfen festlegte, die vom Rat auf Wunsch der Kommission in einer formellen Entschließung unterstützt wurden ${ }^{94}$. Diese Regeln galten ab 1972 zunächst nur für Beihilfen in den sog. Zentralregionen der Gemeinschaft, in denen die maximale Förderintensität aus allen kumulierten regionalen Beihilfen auf $20 \%$ Nettosubventionsäquivalent (NSÄ) 95 bezogen auf das Investitionsvolumen festgelegt wurde, während

90 Vgl. Warnecke 1978, S. 154, sowie EG, Kommission 1968, S. 74, und 1972a, S. 130f., und Schina 1987, S. 65.

$91 \mathrm{Vgl}$. Warnecke 1978, S. 155.

92 Vgl. EG, Kommission 1969, S. 62, und 1970, S. 76f. Alternativ konnten die MS ihre Rahmengesetze transparenter in bezug auf ihre sektorale oder regionale Anwendung umgestalten. Diese Option wurde vor allem auf Drängen Frankreichs und Italiens eingeführt, die für eine enge Koordination der Rahmengesetze eintraten. Vgl. Schina 1987, S. 66, und EG, Kommission 1971b, S. 7-13.

93 Vgl. z.B. EG, Kommission 1971, S. 36f., und 1972a, S. 138f., 143f.

94 Vgl. EG, Kommission 1971b, S. 7-13, und EG, Rat 1971, S. 1-6, sowie EG, Kommission 1972a, S. 133.

95 Bei dieser Berechnungsmethode soll die Förderintensität nach Zahlung der jeweiligen Gewinnsteuer ermittelt werden, wobei unterstellt wird, daß diese bereits im ersten Jahr des Projekts mit dem maximalen Steuersatz des betreffenden MS erhoben wird. Da dies i.d.R. bei Investitionsprojekten nicht der Fall ist, liegt die tatsächliche Förderhöchstgrenze erheblich über den festgesetzten $20 \%$. Selbst diese "heruntergerechnete" Größe wurde damals von den Fördermöglich- 
den MS für die peripheren Regionen 96 keine Beschränkungen auferlegt wurden 97. Da die Zentralregionen der Gemeinschaft geographisch eng zusammenliegen und verkehrsmäßig gut verbunden sind, war hier die eben beschriebene Gefahr eines Überbietungswettbewerbs am größten und die Notwendigkeit einer Regelung am dringlichsten 98 . Eine Beschränkung war auch deswegen geboten, um einen Förderabstand zu den peripheren Regionen zu erhalten, die auch diesen Industrieansiedlungen ermöglichten 99 . Da jedoch auch diese Regionen einen unterschiedlichen Grad von Rückständigkeit aufwiesen, war zwischen ihnen eine weitere Differenzierung angebracht, über die eine politische Einigung jedoch erst 1975 erreicht werden konnte 100 . Dabei wurden Intensitätsstufen von $25 \%$ und $30 \%$ eingeführt, während für die ärmsten Regionen der erweiterten Gemeinschaft weiterhin die Anfang 1975 in den nationalen Systemen vorgesehenen Fördersätze erlaubt blieben, deren Höhe dann im Laufe des Jahres 1976 mit den MS ermittelt wurde101. Einige Regionen Nord- und Mittelitaliens wurden zudem nunmehr der 30\%-Stufe zugeordnet, und die Regionen der Neumitglieder wurden ebenfalls in diese vier Stufen eingeteilt.

keiten in Frankreich und Italien in den Zentralgebieten überschritten. Vgl. Franzmeyer/Seidel 1976, S. 70. Weitere Vereinfachungen bei der Intensitätsberechnung betreffen die Aufteilung auf Grundstücke, Gebäude und Maschinen sowie Zahlungszeitpunkt und Abzinsungssatz der Beihilfe, die teils zu einer Erhöhung, teils zu einer Senkung der gemessenen Förderintensität führen. Für den verwandten Zinssatz existieren nationale Referenzzinssätze, die sich am Zinssatz für mittelfristige Kredite an Unternehmen orientieren. Vgl. EG, Rat 1971, S. 1-6, sowie Schina 1987, S. 67, und OECD 1983, S. 234f.

96 Dies waren West-Berlin, das Zonenrandgebiet, der Mezzogiorno und einige Regionen in Westund Südwestfrankreich, die zu jener Zeit Entwicklungsprämien erhielten.

97 Auf Antrag des MS konnte die Kommission eine Überschreitung dieser Grenze genehmigen. Die MS, deren Förderintensitäten unterhalb der Höchstgrenze lagen, durften diese allerdings nicht erhöhen. Vgl. EG, Rat 1971, S. 2.

98 Vgl. Warnecke 1978, S. 156, und EG, Kommission 1972a, S. 134.

99 Vgl. Franzmeyer/Seidel 1976, S. 70f. Dies wurde auch dadurch unterstützt, daß nun auf Gemeinschaftsebene Maßnahmen zur Förderung dieser Regionen entwickelt wurden, insbesondere ab 1975 der EFRE. Vgl. Wallace 1977, S. 143.

100 Vgl. EG, Kommission 1975a, S. 102.

101 Vgl. EG, Kommission 1977a, S. 114, 118, 122. Hierbei handelte es sich um West-Berlin, Nordirland, die Republik Irland, den Mezzogiorno und Grönland, wobei innerhalb Irlands und des Mezzogiorno noch eine Differenzierung der Intensität vereinbart wurde. Für diese Gebiete mit Ausnahme von West-Berlin wurde jedoch den MS eine Ex-ante-Meldepflicht für all Investitionsvorhaben über 25 Mio. RE und mit mehr als $35 \%$ NSÄ auferlegt, um hier der Kommission eine Überprüfung möglicher sektoraler Verzerrungen zu erlauben. Vgl. EG, Kommission 1976a, S. 85f. 
Neben der quantitativen Beschränkung der nationalen Regionalförderung gingen die Koordinierungsgrundsätze auch die anderen Probleme bei der Kontrolle der regionalen Beihilfensysteme an 102 :

- Entscheidende Voraussetzung einer effektiven Überwachung der Höchstgrenze war die eindeutige Meßbarkeit der Beihilfenintensität in bezug auf die geförderte Investition, von der Kommission als Transparenz bezeichnet. Die Grundsätze verpflichteten die MS, alle nichttransparenten Beihilfen entweder umzugestalten, d.h. an das Investitionsvolumen zu binden, oder innerhalb eines Jahres abzuschaffen 103 . Diese Regelung erwies sich für die Zentralgebiete als unproblematisch. Bei der Übertragung der Koordinierungsgrundsätze auf die Randregionen zeigte sich jedoch, daß hier die Beihilfen häufig auf die Anzahl der geschaffenen Arbeitsplätze bezogen wurden 104 . Die Entwicklung entsprechender Alternativobergrenzen gelang jedoch erst mit der Verabschiedung der neuen Grundsätze von 1979 (s.u.).

- Notwendig zur Sicherung der Wirksamkeit einer Regionalförderung war ihre Konzentration auf die benachteiligten Gebiete eines Landes (Regionale Spezifität). Daher enthalten die Grundsätze ein Verbot des Einsatzes der Regionalförderung für das gesamte Staatsgebiet eines MS (mit Ausnahme Luxemburgs und später Irlands), eine Verpflichtung zur klaren Abgrenzung der verschiedenen Förderzonen und zur Differenzierung der Förderintensität zwischen ihnen, so daß nicht überall die maximale Intensität gewährt werden konnte bzw. entwickelte Regionen überhaupt nicht gefördert werden durften. Zudem konnten die Beihilfen nicht punktuell an bestimmten Orten, sondern nur für ganze Regionen gewährt werden, da man sonst eine Wirkungslosigkeit der Förderung befürchtete. Ausnahmen galten für Entwicklungsschwerpunkte105.

- Da sich in den benachteiligten Regionen der Gemeinschaft auch einige Krisenbranchen konzentrierten, bestand hier die Gefahr, daß über regionale Beihilfen die sektorale Kontrolle ausgehebelt werden könnte und damit Wettbewerbsverzerrungen und ein Export von Arbeitslosigkeit auftreten konnten (Sektorale Auswirkungen). Die Bedeutung dieses Problems sollte zunächst statistisch untersucht werden ${ }^{106}$. Vorab enthielten die Grundsätze jedoch ein Kumulierungsverbot für

102 Vgl. EG, Rat 1971, S. 1-6.

103 Vgl. EG, Rat 1971, S. 1-6, und EG, Kommission 1971a, S. 135f.

104 Vgl. EG, Kommission 1976a, S. 84f.

105 Letztere waren als zentrale Orte definiert, von denen Wachstumswirkungen auf das Umland ausstrahlen würden. Vgl. Schina 1987, S. 68.

106 Vgl. EG, Kommission 1973a, S. 90f. 
regionale und sektorale Beihilfen bzw. ab 1979 ein Verbot der Überschreitung der regionalen Höchstgrenzen bei Kumulierung107. Ab 1985 wurde zudem eine Meldepflicht für bedeutende Anwendungsfälle der Kumulierung verschiedener Beihilfetypen für Investitionen erlassen, um so die Kontrollmöglichkeit und damit die Transparenz zu verbessern 108 .

- Neben der Ex-ante-Kontrolle der Rahmengesetze sollte die Überwachung noch zusätzlich durch die Ex-post-Meldung der wichtigsten Anwendungsfälle (über 4 Mio. RE für Gründungs- und Erweiterungsinvestitionen, 3 Mio. RE für andere geförderte Investitionen) erfolgen 109 . Regelmäßige Diskussionen mit Vertretern der MS zur Anwendung der Grundsätze rundeten die Überwachung ab.

Mit der Einführung dieser Grundsätze wurden nun erstmals die MS bei ihrer Regionalförderung zunächst in den Zentral-, später auch in den Randgebieten beschränkt, was zunächst Widerstände vor allem in Großbritannien auslöste, das im Rahmen der Beitrittsverhandlungen und auch nach dem Beitritt versuchte, einen möglichst großen Teil des Staatsgebietes als periphere Region zu definieren, um so zunächst einer Beschränkung zu entkommen 110 . Indem ein Teil des britischen Staatsgebiets, das die Kommission als zentrale Region hatte einordnen wollen, nach erheblichem politischem Druck zunächst überhaupt nicht klassifiziert wurde, gelang dies auch. Durch diese Konzession unterlagen jene Gebiete weder der 20\%-Grenze der Zentralregionen noch den Transparenz- und Spezifitätskriterien der Regionalförderung, wodurch sie zunächst de facto völlig aus der Kontrolle herausfielen. Nach der Ausdehnung der Klassifizierung auf die Randregionen 1975 wurden diese Regionen dann dort eingeordnet 111 .

Bei der Anwendung der Grundsätze von 1971/1975 genehmigte die Kommission häufig Änderungen bestehender Beihilfesysteme vorläufig, ohne sich damit über die Vereinbarkeit der Gesamtsysteme zu äußern, deren Beurteilung sie zunächst zurückstellte, bzw. wesentliche Änderungen wurden beschlossen, bevor die Kommission

\footnotetext{
107 Vgl. EG, Kommission 1979d, S. 10.

108 Als Schwellenwerte galten ein Investitionsvolumen von mindestens 12 MECU oder eine kumulierte Beihilfenintensität von $25 \%$ NSÄ, wobei Fälle geringer Intensität $(<10 \%)$ oder Höhe ( $<3$ MECU) selbst bei Überschreitung einer der Grenzen von der Notifizierungspflicht aus109 Vgl. EG, Kommission 1973a, S. 88f.

110 Vgl. Wallace 1977, S. 143, 146 und $151 \mathrm{f}$.

111 Vgl. Warnecke 1978, S. 157, Swann 1983, S. 48, und EG, Kommission 1974a, S. 79.
} 
die ursprüngliche Regelung beurteilt hatte12. Eine direkte Ablehnung einer nationalen Regionalfördermaßnahme fand nicht statt, allerdings setzte die Kommission bspw. in einigen Fällen in Deutschland, Dänemark, Frankreichs und den Niederlanden durch, daß bestimmte Regionen aus der Förderung herausgenommen wurden bzw. nur für kürzere Fristen förderfähig bleiben konnten; zudem forderte sie von den MS jährliche Berichte113. Spezielle Probleme traten vor allem hinsichtlich der Transparenz und damit zusammenhängend der einheitlichen Höchstgrenze auf:

Was die Höchstgrenze anbetraf, so versuchte die Kommission in mehreren Fällen bspw. in Italien, Belgien und Dänemark zu verhindern, daß durch Kumulierung mehrerer Fördersysteme die Grenzen überschritten wurden. Regelmäßig erhielt sie hierzu die Zusagen der Regierungen ${ }^{114}$.

Hinsichtlich des Transparenzaspekts beklagte die Kommission 1977, daß ca. 50\% des Regionalbeihilfevolumens in den MS nicht transparent sei115. Dies war vor allem auf Regionalsubventionen zur Arbeitsplatzschaffung zurückzuführen, die mit den ab 1975 zunehmenden Arbeitsmarktproblemen immer mehr an Bedeutung gewannen 116. Um auch hier eine Koordinierung zu ermöglichen, wurde, auch auf Druck aus Italien und Großbritannien 117, in den neuen Grundsätzen von 1979 eine Alternativhöchstgrenze in ERE je neugeschaffenen Arbeitsplatz für jeden der 4 Regionentypen eingeführt. Da diese Höchstgrenzen relativ großzügig gewählt worden waren, wurde jedoch zusätzlich für alle Regionen außer den ärmsten eine zusätzliche Höchstgrenze in Prozent des Investitionsvolumens eingeführt, die auch bei arbeitsplatzgebundenen Investitionen nicht überschritten werden durfte118. Da diese Grenze oberhalb des "normalen" Limits dieser Region lag, konnten die MS

112 Vgl. EG, Kommission 1974a, S. 81, 1976a, S. 87, 1977a, S. 121, 125, und 1978a, S. 148, 161 .

113 Vgl. EG, Kommission 1972a, S. 140f., und 1978a, S. 151f., 158f. Die niederländische Regierung führte dann jedoch eine neue Regelung ein, die für einen Teil der ausgenommenen Gebiete enger begrenzte Fördermöglichkeiten wieder einführte.

114 Vgl. EG, Kommission 1973a, S. 96, 1976a, S. 92, und 1978a, S. 151.

115 Vgl. EG, Kommission 1977a, S. 115.

116 Vgl. Yuill/Allen/Hull 1981, S. 308, Schina 1987, S. 71, und EG, Kommission 1976a, S.91, sowie 1977a, S. 116. Besonders deutlich wird diese Tendenz auch an der Vielzahl neuer Programme, mit denen die Kommission 1977 befaßt wurde. Vgl. EG, Kommission 1978a, S. 147162.

117 Vgl. Swann 1983, S. 49f.

118 Diese weitere Grenze galt nicht für Investitionen im Dienstleistungssektor. Vgl. EG, Kommission 1979d, S. 10. 
arbeitsintensive Branchen nunmehr stärker als zuvor fördern ${ }^{119}$. Sie unterlagen dennoch einer gewissen Beschränkung, damit der Anreiz zur Förderung dieser Bereiche, die häufig technologisch weniger fortgeschritten und damit für das langfristige Entwicklungspotential einer Region weniger hilfreich waren, nicht zu groß wurde120. Zudem sollte sie sicherstellen, "daß Investitionen zu einem Teil wenigstens vom Investor getätigt werden und nicht nur durch staatliche Beihilfen erfolgen." 121 Die prozentualen Höchstgrenzen wurden auch für die Verlagerung von Betrieben in Förderregionen angewandt, wobei der Staat alternativ die gesamten Umsiedlungskosten übernehmen konnte ${ }^{122}$. Weiterhin wurden für zusätzliche Typen von Subventionen, wie etwa Bürgschaften und Mietzuschüsse, Methoden zur Intensitätsmessung entwickelt, um auch diese in die Höchstgrenzen einbeziehen zu können. Wird ein Teil der Hilfen erst nachträglich gewährt, z.B. steuerliche Beihilfen, so wird zunächst von der jeweiligen Höchstgrenze der Betrag der sofort gezahlten Subventionen abgezogen, wobei der Restbetrag dann die maximal später zahlbaren Hilfen wiedergibt 123 .

Die Höchstgrenzen blieben für die wohlhabenderen Regionen (Regionalkategorien 2 bis 4) unverändert bei 20,25 und $30 \%$, während nunmehr auch für die Randregionen (1. Kategorie) eine Höchstgrenze von $75 \%$ NSÄ eingeführt wurde, wobei hierzu noch sonstige Hilfen aus anderen Töpfen von bis zu $25 \%$ treten konnten, wenn diese mindestens über 5 Jahre verteilt wurden 124 . In diesen Regionen, zu denen jetzt auch die französischen Überseedepartements traten, konnte der Staat also die gesamten Investitionskosten (einschl. der erhöhten Gewinnsteuern aufgrund der beihilfenbedingt geringeren Abschreibungen aus der Investition) übernehmen 125 . Aufgrund der 1975 erfolgten Einrichtung des EFRE wurde im Rahmen der regionalen Spezifität nunmehr von den MS gefordert, daß sie ihre Regionalhilfen in den Förderregionen des EFRE in das Regionalentwicklungsprogramm einpaßten, das die Fondsverordnung forderte.

\footnotetext{
119 Vgl. Mutti 1982, S. 11.

120 Vgl. EG, Kommission 1983e, S. 402.

121 EG, Kommission 1979a, S. 123.

122 Vgl. EG, Kommission 1979d, S. 11.

123 Vgl. EG, Kommission 1979d, S. 12.

124 Vgl. EG, Kommission 1979d, S. 10.
}

125 Bei der Berechnung des NSÄ wird berücksichtigt, daß die Beihilfe den abschreibungsfähigen Investitionsbetrag mindert und damit zu einer im Vergleich zur Investition ohne Beihilfe höheren Steuerbelastung führt. Da bei dieser Berechnung des NSÄ eine sofortige Belastung mit dem jeweiligen Gewinnsteuerhöchstsatz unterstellt wird, kann der Fördersatz tatsächlich über $100 \%$ liegen, wenn das Unternehmen keine Gewinne macht! 
Ein weiteres von der Kommission nun erstmals aufgegriffenes Problem stellten die von einigen MS darüber hinaus gewährten Betriebsbeihilfen in bestimmten Regionen dar. Da diese i.d.R. ein Zeichen von Fehlinvestitionen sind, die nicht zur regionalen Entwicklung beitragen, wäre ihre Abschaffung angebracht gewesen, auch um die nationalen Behörden zu einer größeren Sorgfalt bei der Projektauswahl anzuhalten. Dies konnte die Kommission jedoch nicht durchsetzen. Lediglich die regionale oder intensitätsmäßige Ausweitung dieser Beihilfen wurde nunmehr verboten. Zudem wurden sie auf die Höchstgrenzen angerechnet 126 . Nachdem jedoch schon 1979/80 in Irland und Großbritannien auf Initiative der Kommission einige Regelungen, die bspw. über die Förderung von Ersatzinvestitionen ohne zusätzlichen Beschäftigungseffekt zu Betriebsbeihilfen führen konnten, abgeschafft oder umgestaltet worden waren 127 , erhöhte sie den Druck auf die anderen MS und erreichte die Aufhebung oder Beschränkung derartiger Regelungen auch in Italien und Deutschland, während für Nordirland eine Ausnahmegenehmigung aufgrund der besonderen Schwäche der Wirtschaftsstruktur dieser Region bedingt auch durch die politischen Unruhen erteilt wurde ${ }^{128}$.

Der sich verschärfenden Wirtschaftskrise nach dem 2. Ölpreisschock mit dem folgenden massiven Anstieg der Arbeitslosigkeit begannen die MS nunmehr, mit einer Ausweitung des Volumens und der räumlichen Breite ihrer Regionalförderung entgegenzutreten ${ }^{129}$. Dieser auch in den reicheren MS verstärkt auftretenden Tendenz trat die Kommission zunächst nicht energisch entgegen. Vielmehr genehmigte sie diese Ausweitung und auch die Verlängerung der Regionalförderung in eigentlich nicht mehr rückständigen Gebieten und gestattete auch in mehreren Fällen die Überschreitung der festgelegten Höchstgrenzen 130 . Mit der Konzentration der Regionalpolitik auf die Unterstützung der Schaffung von Arbeitsplätzen verlagerte sich gerade in den nördlichen MS der regionale Schwerpunkt von den ländlichen Regionen zu den "alten Industriegebieten", in denen Werften und Stahlindustrie dominierten, und die nun unter massiven Entlassungen zu leiden hatten. Die Kommission stimmte der Hereinnahme solcher Regionen in die Förderkulisse der MS mittels Sonderprogrammen i.d.R. zu131. Durch die allgemeine Ausweitung der Regionalförderung einerseits und die Hereinnnahme der alten Industrieregionen andererseits, in denen

126 Vgl. EG, Kommission 1979a, S. 125, und 1979d, S. 10f.

127 Vgl. Swann 1988, S. 140, EG, Kommission 1979a, S. 130, und 1981a, S. 125, 133.

128 Vgl. EG, Kommission 1984a, S. 183, 1985a, S. 190, und 1986a, S. 196.

129 Vgl. EG, Kommission 1980a, S. 104.

130 Vgl. z.B. EG, Kommission 1980a, S. 107-109, 111, 1981a, S. 134f., und 1982a, S. 161.

131 Vgl. z.B. EG, Kommission 1981a, S. 134, und 1983a, S. 152f. 
häufig das Pro-Kopf-Einkommen relativ hoch lag, bestand jedoch die Gefahr, daß der Fördervorsprung der rückständigsten Gebiete der Gemeinschaft reduziert und damit ihre Entwicklungsmöglichkeiten gehemmt wurden. Dieser Gefahr trat die Kommission ab 1981 verstärkt entgegen, indem sie gegen die vorgelegten Regionalförderprogramme für die entwickelteren Regionen der MS häufig das formelle Prüfverfahren nach Art. 93,II mit dem Ziel eröffnete, insbesondere in den reicheren MS den Anteil der geförderten Gebiete und der Bevölkerung zu verringern bzw. die Förderintensität zu reduzieren ${ }^{132}$. So ging sie u.a. gegen mehrere Rahmenpläne der GA in Deutschland und einige Länderprogramme vor sowie gegen die Festlegung der Förderregionen in Belgien, den Niederlanden, Dänemark und später auch Frankreich ${ }^{133}$. Zwar wurden die Förderpläne in den weniger entwickelten MS weiterhin großzügig behandelt, jedoch achtete die Kommission darauf, daß zum einen bei Kumulierungen dennoch die Höchstgrenzen eingehalten wurden, zum anderen bspw. beim Mezzogiorno, daß Gebiete mit eher durchschnittlicher Wirtschaftsentwicklung, wie in diesem Falle in Mittelitalien, nicht in diese Förderung eingeschlossen wurden und dadurch die Chancen der am wenigsten entwickelten Regionen verminderten ${ }^{134}$. Bei dieser Politik kamen der Kommission sicherlich die Haushaltsprobleme in den betroffenen MS sowie die grundsätzlich geringere Bereitschaft der neuen konservativen Regierungen in Großbritannien und Deutschland zur Beibehaltung einer intensiven Regionalförderung entgegen, so daß in diesen MS bereits aus eigenem Antrieb der Umfang der Förderregionen vermindert wurde 135. Weitere Reduzierungen wurden dann im Laufe der Verfahrenseröffnungen in Kompromissen mit den MS, die vor allem Übergangsfristen vorsahen, erreicht, z.T. allerdings auch durch negative Entscheidungen erzwungen 136 . Bzgl. der Gemeinschaftsaufgabe in

132 Vgl. EG, Kommission 1983a, S. 151, 155, und 1985a, S. 189.

133 Vgl. EG, Kommission 1982a, S. 158-68, 1983a, S. 154-156, 1986a, S. 194f., sowie 1987a, S. 174. Zur Entscheidung über die französische Regionalförderung vgl. EG, Kommission 19851, S. 28-33.

134 Vgl. EG, Kommission 1989a, S. 197. Die gleiche Vorgehensweise verwandte die Kommission 135 in der Region Friaul-Julisch Venetien. Vgl. EG, Kommission 1992a, S. 197f

Vgl. EG, Kommission 1980a, S. 111, und 1982a, S. 158. Dies galt später auch für die Niederlande, wo in mehreren Schritten die Zahl der förderfähigen Regionen, der Umfang der beihilfefähigen Investitionen und die Förderintensität gesenkt wurden. Vgl. EG, Kommission 1986a, S. 199f., 1987a, S. 181f., und 1989a, S. 198. In Großbritannien war jedoch ab 1986, insbesondere wegen der anhaltend hohen Arbeitslosigkeit in Nordengland, Wales und Schottland eine Umkehrung dieser Tendenz durch erneute Ausweitung der Fördergebiete zu beobachten. Dies wurde von der Kommission in Anbetracht der Probleme dieser Regionen jedoch genehmigt. Vgl. EG, Kommission 1987a, S. 177.

136 Vgl. EG, Kommission 1984a, S. 182-185, 1985a, S. 194, 1987a, S. 179f., und 1988a, S. 179. 
Deutschland kam es Ende 1987 bspw. zum sog. Bangemann-Sutherland-Kompromiß, mit dem der Anteil der in den Fördergebieten lebenden Bevölkerung von 45\% auf $38 \%$ gesenkt wurde bei gleichzeitiger Verminderung der Intensität und einer vorgesehenen weiteren Reduktion des Bevölkerungsanteils für das Jahr 1991137.

Tab. 4.1-2

Regionale Beihilferegelungen

(Anteil der Bevölkerung in den Fördergebieten und entsprechende Flächen am 1.1.1985)

\begin{tabular}{l|rr|rr} 
Land & $\begin{array}{r}\text { Anteil der Bevölkerung } \\
\text { in } 1000\end{array}$ & $\begin{array}{r}\text { \% der Gesamt- } \\
\text { bevölkerung }\end{array}$ & \multicolumn{1}{|c}{$\begin{array}{c}\text { Fläche } \\
\mathrm{km}^{2}\end{array}$} & $\begin{array}{r}\text { \% der Ge- } \\
\text { samtfläche }\end{array}$ \\
\hline D & 27.577 & 45,1 & 156.943 & 63,1 \\
F & 22.402 & 40,2 & 424.566 & 78,0 \\
I & 27.773 & 48,9 & 204.791 & 67,9 \\
NL & 3.914 & 27,1 & 12.885 & 31,0 \\
B & 3.264 & 33,1 & 16.230 & 53,2 \\
L & 291 & 79,7 & 1.487 & 57,5 \\
UK & 21.279 & 37,7 & 97.706 & 21,6 \\
DK & 1.233 & 24,1 & 14.223 & 33,0 \\
IRL & 3.508 & 100,0 & 70.285 & 100,0 \\
GR & 6.390 & 65,6 & 126.550 & 95,9
\end{tabular}

Quelle: EG, Kommission 1986a, S. 193.

Tab. 4.1-2 zeigt das Resultat dieser Arbeiten zum Stand 1.1.1985, wobei auffällt, daß in einigen reichen MS (F, D, L) immer noch ein verhältnismäßig hoher Teil der Fläche und Bevölkerung förderungsfähig ist.

\subsubsection{Ein differenzierterer und systematischerer Ansatz}

Ein wesentliches Element der Grundsätze von 1971/1975 und 1979 hatte der Versuch der Kommission dargestellt, alle in den MS existierenden regionalen Beihilfesysteme zu erfassen und zu quantifizieren, um so die Intensität der jeweiligen Förderung beurteilen zu können. Dies gelang mit Hilfe des im Laufe der Zeit entwickelten Instrumentariums immer besser, auch wenn dabei z.T. auf grobe Schät-

137 Vgl. EG, Kommission 1988a, S. 181, und Eser 1989, S. 205. Die Kommission hatte ursprünglich eine sofortige Reduktion auf $31 \%$ der Bevölkerung gefordert. Die Bestimmung der wegfallenden Regionen erfolgte nach dem deutschen Auswahlverfahren. Da dies vorwiegend auf Kosten der separaten Förderung durch die Länder ging, die vorher Regionen, die aus der GA herausfielen, für eine Übergangszeit weiterförderten, bestand hier zunächst großer Widerstand, der jedoch aus Furcht vor einer Niederlage vor dem EuGH wie im Falle Philip Morris (s.u.) aufgegeben wurde. 
zungen zurückgegriffen werden mußte138. Die Einteilung der Regionen in verschiedene Kategorien und die Festlegung der jeweiligen Höchstfördersätze hingegen war relativ grob und nicht an quantitative Wohlstandsindikatoren gebunden, sondern weitgehend an dem bei Einführung der Grundsätze existenten Niveau in den MS ausgerichtet ${ }^{139}$, was wohl auch an der mangelnden Verfügbarkeit vergleichbarer Statistiken für alle MS lag140. Diesem Mangel begann die Kommission nun im Laufe der 80er Jahre Abhilfe zu schaffen. Dabei nutzte sie auch die eigentlich schon durch den EGV vorgegebene Unterscheidung zwischen stark benachteiligten Regionen (Art. 92,IIIa) und solchen mit geringeren Regionalproblemen (Art. 92,IIIc). Bewertungsmethoden für beide Kategorien wurden ab 1987 bzw. 1983 angewandt und 1988 publiziert ${ }^{141}$.

Das grundsätzliche Problem für die Kommission bestand dabei in der Vereinbarkeit von nationaler und gemeinschaftlicher Perspektive. Letztere würde verlangen, daß nur die im Verhältnis zum EG-Durchschnitt armen Regionen eine Förderung verdienen, um ihnen den Anschluß an das Gemeinschaftsniveau zu ermöglichen. Andererseits sind innerhalb der EG die nationalen Regierungen noch immer Hauptentscheidungsträger der Wirtschaftspolitik. Aus ihrer Sicht ist auch eine Förderung ihrer benachteiligten Regionen notwendig, selbst wenn deren Pro-Kopf-Einkommen oberhalb des EG-Durchschnitts liegt, da die nationale Perspektive für die meisten Bürger dominiert und da sonst der Spielraum der nationalen Regionalpolitik zu sehr eingeschränkt würde ${ }^{142}$. Dies gilt nach der Süderweiterung der EG um die relativ armen MS Griechenland, Spanien und Portugal, die den gemeinschaftlichen Wohlstandsdurchschnitt senkte und damit die Kriterien für die reichen MS verschärfte, aus deren Sicht sicher noch stärker als zuvor ${ }^{143}$. Andererseits läßt sich

138 Allerdings äußern Yuill/Allen/Hull (1981, S. 311) die Befürchtung, daß aufgrund der relativ starren Rechenregeln und der geringen Flexibilität von DG IV die MS versucht gewesen waren, Umgehungsmöglichkeiten der Kontrolle zu suchen.

139 Vgl. Yuill/Allen/Hull 1981, S. 310.

140 Vgl. EG, Kommission 1977a, S. 117.

141 Vgl. EG, Kommission 1988f, S. 2-10.

142 Vgl. Biehl 1988, S. 91f., Rolfes 1991, S. 161, und Harden 1993, S. 15f. In Deutschland bspw. ist die Regionalförderung sogar verfassungsrechtlich verankert (Art. 91a GG).

143 Eine partielle Lösung dieses Problems ergäbe sich durch eine Verlagerung der Regionalpolitik von der nationalen auf die Gemeinschafts- bzw. zumindest eine intergouvernementale Ebene, um so mittels grenzübergreifender Maßnahmen in Regionen verschiedener MS mit ähnlichen Problemen eine effizientere Regionalförderung zu betreiben. Ein derartiges Konzept wurde von Frankreich, Belgien und Luxemburg im gemeinsamen Grenzgebiet als sog. Europäischer Entwicklungspol durchgeführt, um die Umstellung der alten Stahlregionen zu erleichtern. 
durch die Marktöffnung dieser neuen MS, die für die Unternehmen der alten MS Vorteile bringt und damit möglicherweise das Wohlstandsgefälle zu den neuen MS noch vergrößert, eine ungehemmte Förderung durch die alten MS nur noch schwer rechtfertigen 144 .

Doch bereits bei der Umsetzung der Grundsätze von 1979 trat diese Problematik auf. So hatte die Kommission die zusätzliche Förderung einer Investition von Philip Morris in der niederländischen Region Bergen op Zoom durch allgemeine Beihilfen in Ergänzung der normalen Regionalbeihilfen abgelehnt, da diese sich im Gemeinschaftsdurchschnitt in einer relativ günstigen Lage befand und zudem die Investition aufgrund der Marktkräfte auch ohne die zusätzlichen Beihilfen erfolgt wäre145. Die Klage des Unternehmens gegen diese Entscheidung, bei der auch andere Aspekte der Beihilfenkontrolle eine Rolle spielten, wurde vom EuGH abgewiesen, der den Ermessensspielraum der Kommission und ihr Recht, den EG-Maßstab anzuwenden, ausdrücklich bestätigte ${ }^{146}$. Eser ${ }^{147}$ sieht hierin eine im EGV nicht vorgesehene Kompetenzerweiterung der Kommission, bei der zur Wettbewerbssicherung nun die wirtschaftsgestaltende Aufgabe der Verfolgung des Konvergenzziels tritt. Die Trennung zwischen beiden Aspekten ist sicherlich außerordentlich schwierig, insbesondere bei Aspekten der Regionalpolitik, deren Zielsetzung explizit wirtschaftsgestaltend ist, so daß ihre Kontrolle zwangsläufig auch zu einem gewissen Grade lenkenden Charakter hat ${ }^{148}$. Zudem hat die EEA (Art. 130A) das Konvergenzziel für die Gemeinschaft stark in den Vordergrund gestellt, und auch dieses gewann nach der Süderweiterung erheblich an Bedeutung 149 .

Die Beurteilungskriterien der Kommission tragen in einer Art von "Compromis Communautaire" beiden Betrachtungsweisen Rechnung 150 :

Um für eine Beurteilung nach Art. 92,IIIa in Betracht zu kommen, muß das ProKopf-Einkommen der meisten Gebiete einer Region unterhalb von $75 \%$ des Gemeinschaftsdurchschnitts liegen. Dieser wird dabei in Kaufkraftstandards gemessen, um

Dieses Projekt wurde von der Kommission unterstützt, die eine höhere Grenze für Regionalbeihilfen genehmigte; es blieb jedoch der einzige Ansatz dieser Art. Vgl. EG, Kommission 1987a, S. 176.

144 Vgl. Rolfes 1991, S. 149.

145 Vgl. Swann 1983, S. 54f.

146 Vgl. EuGH 1980, S. 2691f., Rolfes 1991, S. 162f., und Schina 1987, S. $57 f$.

147 1989, S. 204.

148 Ähnlich Wallace 1977, S. 143.

149 Vgl. EG, Kommission 1987a, S. 173.

150 Vgl. auch Schina 1987, S. 53. 
Unterschiede in den Lebenshaltungskosten zu eliminieren. Förderungswürdig aufgrund dieses Indikators sind die MS Griechenland, Irland und Portugal, ein großer Teil Spaniens, der Mezzogiorno, Nordirland und die französischen Überseedepartements, also neben den neuen MS vor allem die Gebiete, die aufgrund der alten Einteilung in der Kategorie 1 der Förderwürdigkeit lagen 151 . Die dort festgelegte Beihilfenobergrenze von $75 \%$ NSÄ wurde auch übernommen. Allerdings fordert die Kommission von den betroffenen MS innerhalb der genannten Gebiete eine Differenzierung der Beihilfen je nach Schwere der Regionalprobleme unterhalb der Grenze von 75\%. Der in Art. 92,IIIa ebenfalls geforderte erhebliche Grad an Unterbeschäftigung wird in diesen Regionen auch bei geringer statistisch erfaßter Arbeitslosigkeit als gegeben angesehen, da in ihnen als vorwiegend ländlichen Regionen verdeckte Arbeitslosigkeit auftritt. Zudem dienen die niedrigen Pro-KopfBSP-Werte als Indikator für eine Unterausnutzung des Faktors Arbeit.

Ausschließlich für diese Regionen bleiben Betriebsbeihilfen auch weiterhin erlaubt. Dies wird damit gerechtfertigt, daß Investoren in diesen Regionen aufgrund ihrer geographischen Lage bzw. der mangelnden Infrastruktur so gravierende laufende Nachteile entstehen, daß sie einer permanenten Unterstützung bedürfen, um im europäischen Wettbewerb bestehen bleiben zu können ${ }^{152}$. Dabei steht die Hoffnung im Hintergrund, durch die Aufrechterhaltung bestehender Betriebsstätten quasi Kristallisationspunkte für die Heranführung weiterer Investoren zu schaffen, die der Region langfristig eine eigenständige Entwicklung gestatten ${ }^{153}$. Daher müssen diese Beihilfen von Anfang an zeitlich begrenzt sein. Beihilfen für den Export in andere MS sind jedoch verboten; ebenso müssen die Regeln für Unternehmen in Schwierigkeiten und die sektoralen Beihilferegeln (s. Abschn. 4.1.2 und 4.2-4.4) beachtet werden, um hier Überkapazitätsprobleme zu verhindern ${ }^{154}$. In den anderen Regionen der EG bekämpfte die Kommission Systeme, die Betriebsbeihilfenelemente enthielten, wie bspw. die britischen Regional Development Grants, die Beihilfen auch für Ersatzinvestitionen ohne zusätzlichen Beschäftigungseffekt vorsahen. Nach

151 Hierbei liegen Nordirland und Teruel (Aragon) aufgrund der Berechnungsmethode eigentlich oberhalb des Schwellenwertes, wurden aber wegen ihrer spezifischen ökonomischen Probleme ebenfalls einbezogen. Vgl. EG, Kommission 1988f, S. 3.

152 Derartige Hilfen wurden dann bspw. für Irland genehmigt. Vgl. EG, Kommission 1990a, S. 180.

153 Vgl. EG, Kommission 1988f, S. 3f.

154 Vgl. ebenda. 
Diskussionen mit der Kommission gestaltete die britische Regierung das System um und eliminierte die Betriebsbeihilfenelemente ${ }^{155}$.

Bei der Beurteilung von Regionalsubventionen nach Art. 92,IIIc stützt sich bereits die Kommission sowohl auf gemeinschaftliche als auch auf nationale Wohlstandsmaßstäbe und betrachtet kleinere Regionen als bei der Prüfung nach Art. 92,IIIa 156 . Dies bedingt ein mehrstufiges Beurteilungsverfahren. Zunächst wird der Entwicklungsstand einer Region im nationalen Rahmen beurteilt. Liegt ihr Pro-Kopf-BIP (bzw. die Pro-Kopf-Bruttowertschöpfung zu Faktorkosten) um mindestens 15\% unter und/oder ihre strukturelle Arbeitslosigkeit um wenigstens $10 \%$ über dem Landesdurchschnitt, so wird die Region im nationalen Rahmen als rückständig angesehen 157 . Diese Auswahl wird jedoch in einem zweiten Schritt durch die Einbeziehung der Gemeinschaftsperspektive derart korrigiert, daß in MS mit überdurchschnittlichen Pro-Kopf-Einkommen bzw. unterdurchschnittlicher Arbeitslosigkeit höhere Abweichungen auftreten müssen, um eine Region förderwürdig zu machen 158 . Aus diesem doppelten Kriterium ergibt sich für jeden MS eine Liste der Regionen, für die die Kommission Regionalfördermaßnahmen akzeptiert ${ }^{159}$. Diese

155 Vgl. Swann 1983, S. 50.

156 Die Analyse erfolgt hier auf der NUTS-III-Ebene (in Deutschland die Kreise), während bei der Prüfung nach Art. 92,IIIa die NUTS-II-Ebene (in Deutschland die Regierungsbezirke) als Beurteilungseinheit dienen. Vgl. Lehner/Meiklejohn/Reichenbach 1991, S. 58.

157 Dieses System ähnelt den Beurteilungskriterien im Rahmen der GA Förderung der regionalen Wirtschaftsstruktur in Deutschland, die hier erstmals 1975 angewandt worden waren. Vgl. EG, Kommission 1976a, S. 88.

158 Zunächst wird das Verhältnis des nationalen Durchschnittswertes zum Gemeinschaftsdurchschnitt für jeden der beiden Indikatoren anhand eines gleitenden Fünfjahreswertes berechnet. Dann wird der Schwellenwert, beim Pro-Kopf-Einkommen wie gesagt 85\%, durch dieses Verhältnis dividiert, so daß bei MS mit überdurchschnittlichem Einkommen der Prozentsatz fällt, sprich die notwendige Mindestabweichung für eine Förderwürdigkeit zunimmt. Diese Zunahme wird allerdings dann halbiert, indem aus dem Ausgangsschwellenwert und dem neuen Schwellenwert der Durchschnitt gebildet wird, so daß die durch die Gemeinschaftsperspektive ausgelöste Beschränkung der nationalen Regionalpolitiken in den reichen MS nur gedämpft auftritt. Zudem wird für den Arbeitslosigkeitsindikator bei $145 \%$ gekappt, was für Luxemburg relevant ist, dessen Arbeitslosigkeit im EG-Durchschnitt sehr gering ist. Vgl. EG, Kommission 1988f, S. $4 \mathrm{f}$.

159 Probleme können sich hierbei ergeben, wenn die MS andere Kriterien zur Auswahl ihrer Regionen verwenden, so daß die Rangfolgen der Förderungswürdigkeit voneinander abweichen. Verlangt die Kommission dann die Herausnahme bestimmter Regionen aufgrund ihrer Kriterien, so sind dies nicht unbedingt die marginal förderwürdigen nach den nationalen Kriterien, was zu Unstetigkeiten in der nationalen Förderung führen kann. Vgl. Rolfes 1991, S. 158f. Eser (1989) demonstriert für Deutschland die dabei auftretenden Unterschiede. 
nach objektiven Kriterien erstellte Liste wird allerdings in einem weiteren Schritt nochmals korrigiert, indem zusätzliche Indikatoren wie Struktur der Arbeitslosigkeit, Wanderbewegungen, Produktivität und Wirtschaftsstruktur aber auch geographische Lage und Infrastrukturangebot berücksichtigt werden. Aufgrund dieses letzten Prüfschrittes können sowohl Regionen aus der Liste herausfallen als auch neue aufgenommen werden, so daß sich hier die Möglichkeit größerer Flexibilität, aber auch intransparenter Verhandlungslösungen ergibt. Die von der Kommission akzeptierten Beihilfehöchstgrenzen liegen nun nicht mehr wie 1979 bei $20 \%$, 25\%, und $30 \%$, sondern variieren je nach MS und Meßmethode, da in einigen MS Brutto-, in anderen Nettosubventionsäquivalente angesetzt werden. Im Anhang zu den Koordinierungsgrundsätzen von 1988 werden für alle MS die förderfähigen Regionen mit der jeweils akzeptierten Förderhöchstgrenze aufgeführt. Hier wird auf sehr kleine Gebietseinheiten Bezug genommen, in Deutschland bspw. auf die Arbeitsmarktregionen, in Frankreich auf Départements, wobei innerhalb dieser Regionen häufig nur Teilgebiete förderfähig sind ${ }^{160}$. Obwohl diese Liste bei der periodischen Überprüfung der nationalen Regionalfördersysteme jeweils korrigiert wird, erfolgte seitdem keine neue Gesamtveröffentlichung.

Der oben angesprochene "Compromis Communautaire" manifestiert sich somit in einer Vermischung von nationalen Ausgleichs- und gemeinschaftlichen Kohäsionszielen bei der Definition der Förderfähigkeitsschwellen. Eine konzeptionelle Trennung dieser Ziele und ihre Umsetzung durch zwei Instrumente würde den nationalen Regionalbeihilfen allein das nationale Ausgleichsziel zuweisen und damit für alle MS gleiche Schwellenwerte für Arbeitslosigkeit und Pro-Kopf-BIP festlegen. Unterschiedliche Stärken der regionalen Probleme würden sich dabei in unterschiedlichen Intensitäten ausdrücken. Das gemeinschaftliche Kohäsionsziel wäre dann über einen EG-Finanzausgleich mittels des EFRE und der anderen Strukturfonds zu verfolgen. Das in der Gemeinschaft gewählte Verfahren vermischt die Verfolgung beider Ziele im Instrument nationaler Regionalbeihilfen durch die Festlegung höherer Abweichungsschwellen für die reicheren MS. Dies ist wohl v.a. Ausdruck der Tatsache, daß das "Finanzausgleichsvolumen" über die gemeinschaftlichen Strukturfonds allein für die Verwirklichung des Kohäsionsziels nicht ausreicht.

Bei der Umsetzung der Grundsätze im Genehmigungsverfahren für nationale Regionalbeihilfeprogramme nutzte die Kommission ihren Entscheidungsspielraum, um vor allem für die Regionen nach Art. 92,IIIc die tatsächlichen Fördersätze weiter

160 EG, Kommission 1988f, S. 7-10. Die Arbeitsmarktregionen erscheinen als Abgrenzungskriterium besser geeignet als die Kreise. 
zu senken 161 und in den reichen MS den Umfang der förderfähigen Regionen zu vermindern. So setzte sie nach der Wiedervereinigung Deutschlands hier insbesondere die Reduzierung der Fördergebietskulisse in Westdeutschland durch und verhinderte die Einbeziehung West-Berlins in die speziellen Förderprogramme (Investitionszulagengesetz, Fördergebietsgesetz, ERP-Programme) für Ostdeutschland, während eine Erweiterung der Fördermöglichkeiten für Ostdeutschland akzeptiert wurde162. In Italien wurden insbesondere Beschränkungen der Förderung in den Gebieten in Norditalien erreicht 163 .

Aber auch in den nach Art. 92,IIIa förderfähigen Regionen setzte sie eine deutliche Differenzierung der Beihilfenintensität durch, um so dem auch hier stark unterschiedlichen Entwicklungsstand gerecht zu werden, so z.B. in Spanien und Irland 164 . Dieser Vorgehensweise liegt das Kohäsionsziel zugrunde, das schon Bestandteil der EEA war (s.o.) und im Vertrag von Maastricht nochmals akzentuiert wird. Hier versucht die Kommission zudem, eine bessere Abstimmung mit der gemeinschaftlichen Regionalförderung aus den Strukturfonds zu erreichen, sowohl was die Abgrenzung der Förderregionen als auch was die Intensitäten angeht 165 . Die Förderung der ärmsten Regionen der Gemeinschaft aus dem EFRE und damit indirekt über Transfers der reicheren MS soll zudem eine Versöhnung des Gegensatzes zwischen nationaler und Gemeinschaftsperspektive erlauben, indem einerseits die bestehenden Fördermöglichkeiten in den reicheren MS nicht gänzlich beseitigt werden, andererseits die ärmeren MS einen Zuschlag zu den eigenen Anstrengungen erhalten, um so für die letzteren Regionen einen Fördervorsprung zu erreichen. Dies ist wichtig, da die ärmeren MS aufgrund ihrer Haushaltsprobleme häufig die von der Kommission genehmigten hohen Obergrenzen de facto bei weitem nicht erreichen;

161 Vgl. Eser 1989, S. 203.

162 Vgl. EG, Kommission 1993a, S. 267-269.

163 Vgl. ebenda, S. 270-273.

164 So leben im Falle Spaniens $65 \%$ der Bevölkerung in Fördergebieten, von denen allerdings einige nur nach Art. 92,IIIc förderfähig sind. Auch für die Art. 92,IIIa-Gebiete wurde eine Differenzierung der Förderintensität auf $75 \%, 45 \%$ und 30\% durchgesetzt, die dann später auf $50 \%$ bzw. $40 \%$ gesenkt wurde, wobei allerdings durch Kumulierung mit anderen Hilfen dennoch weiterhin die alten Werte erreicht werden konnten. In Irland, das insgesamt eine Art. 92,IIIa-Region ist, variieren die genehmigten Höchstsätze einschl. Kumulierungen zwischen $57,3 \%$ und $75 \%$ NSÄ, in Griechenland gewährt die Regierung in einigen Gebieten keine Regionalhilfen. Vgl. EG, Kommission 1988a, S. 180, 1989a, S. 192, und 196f., sowie 1990a, S. 177, und 1991a, S. 213f.

165 Vgl. EG, Kommission 1992a, S. 52f., 191. 
sie fördern i.d.R. mit Intensitäten zwischen 20 und $25 \%$, was den Intensitäten in den Fördergebieten der reicheren MS nahekommt 166.

Während die Kommission in den ersten Phasen der Regionalbeihilfenkontrolle auf die Neueinführung und Umgestaltung nationaler Programme lediglich reagiert hatte, um diese mit den Gemeinschaftsregeln kompatibel zu gestalten, machte sie nun, nachdem die Ausgestaltung der nationalen Förderprogramme und des Regelwerks zu ihrer Prüfung weitgehend abgeschlossen waren, im Rahmen der laufenden Prüfung die bestehenden Programme nach Art. 93,I Vorschläge zu deren Umgestaltung. Sie begann 1989/90 mit Frankreich und schlug umfangreiche Änderungen des bestehenden Systems vor, so bspw. den Ausschluß einiger Fördergebiete, die Begrenzung von Steuerbefreiungen und eine präzise Abgrenzung der Regionen, die für Umstellungshilfen wegen des Niedergangs der Stahlindustrie in Frage kommen. Über die Umsetzung der Vorschläge durch Frankreich berichtete die Kommission bisher allerdings nicht. Ähnliche Prüfungen fanden für Italien, Belgien und Deutschland statt 167 .

\subsubsection{Die Entwicklung von Regeln für horizontale Beihilfen}

Der Begriff "horizontale Beihilfen" besitzt eine doppelte Bedeutung. Er kann sich zum einen auf allgemeine Rahmengesetze, auf deren Basis Investitionssubventionen, Kredite oder Bürgschaften ohne sektorale oder regionale Spezifikation vergeben werden können, beziehen, zum anderen auf solche horizontale Maßnahmen der MS, die spezielle Investitionsarten der Unternehmen fördern, wie z.B. Beihilfen für FuE oder Umweltschutzmaßnahmen. Aber auch Regeln zur Kontrolle von Beihilfen in der Form staatlicher Beteiligungen können hierunter erfaßt werden.

\subsubsection{Allgemeine Investitions- und Beschäftigungsbeihilfen}

Während allgemeine kurzfristige Konjunkturprogramme, wie oben (vgl. Abschn. 3.1) erläutert, nicht unter die Art. 92-94 fallen, verursachen Rahmengesetzte allgemeiner Art, deren Anwendung dann später in sektoralen oder anders definierten Durchführungsprogrammen konkretisiert wird, große Probleme, da sie aufgrund ihrer sektoralen Unbestimmtheit eine a-priori Analyse ihrer möglichen Wettbewerbsund Handelswirkungen nicht zulassen und durch die Möglichkeit, Investitionshilfen

\footnotetext{
166 Vgl. Petersen 1993, S. 25. Man darf jedoch das Gewicht der gemeinschaftlichen Regionalförderung nicht überschätzen. Während der Jahre 1988-90 lag das nationale Fördervolumen beim Siebzehnfachen der Gemeinschaftsmittel.

167 Vgl. EG, Kommission 1991a, S. 211, 215-218.
} 
in Regionen, die nicht Regionalfördergebiete sind, zu vergeben, die Regionalpolitik von Kommission und MS unterlaufen 168 . Zudem besteht hier durch den großen diskretionären Spielraum, den solche Gesetze der Exekutive bieten, die Gefahr einer selektiven Anwendung zugunsten einiger Unternehmen, die in Schwierigkeiten geraten sind, wodurch die potentiellen Wettbewerbsverzerrungen und Abschrekkungseffekte auf Konkurrenten größer sind als bei klar definierten Subventionsprogrammen, deren Ausmaß und Ausrichtung bekannt sind 169 . Die Bedeutung dieser Art von Beihilfen war vor allem in Belgien, den Niederlanden, Frankreich (verschiedene Investitionsfonds) sowie Großbritannien und anfänglich in Italien sehr hoch ${ }^{170}$. Zunächst setzte die Kommission hier bis Ende 1975 (häufig unter Nutzung des Prüfverfahrens nach Art. 93,II) eine vorherige Mitteilung aller sektoralen oder regionalen Anwendungsprogramme auf der Basis dieser Regelungen bzw. einzelner Anwendungsfälle oberhalb bestimmter Schwellenwerte bezüglich Intensität und Investitionsbetrag ebenso durch wie die Erstellung eines Jahresberichts durch die MS, in dem diese dann auch die Fälle geringeren Umfangs aufzulisten hatten ${ }^{171}$. Auf diese Weise erhielt die Kommission die Möglichkeit, mögliche versteckte regionale oder sektorale Konzentrationen zu erkennen ${ }^{172}$, v.a. da die MS durch Teilung von Programmen Beihilfen "per Salamitaktik" 173 an der Meldepflicht vorbeischleusten. Einzelne Anwendungsfälle dieser allgemeinen Beihilfesysteme wurden im Rahmen dieser Kontrolle dann auch untersagt, vor allem dann, wenn sie Betriebsbeihilfencharakter hatten oder in Problemsektoren zum Aufbau weiterer Überkapazitäten führten 174 .

168 Zum ersten Mal wurde dieses Problem bereits 1972 erwähnt. Vgl. EG, Kommission 1972a, S. 144, und Warnecke 1978, S. 158.

169 Vgl. EG, Kommission 1991a, S. 147, Holmes 1991, S. 34, und Zippel 1984, S. 9.

170 Vgl. Franzmeyer 1981, S. 500. In der Rezession 1974/75 griffen dann alle MS auf Investitionsfördermaßnahmen und/oder Liquiditätshilfen für gefährdete Betriebe zurück, um den Anstieg der Arbeitslosigkeit zu bekämpfen. Dabei wurden z.T. bestehende allgemeine Beihilfensysteme genutzt und u.U. erweitert. Die Kommission genehmigte solche Programme i.d.R. nach Art. 92,IIlb als Maßnahmen "zur Behebung einer beträchtlichen Störung im Wirtschaftsleben". Allerdings verlangte sie bei Investitionshilfen in Krisenbranchen und bei Liquiditätshilfen eine Einzelfallnotifizierung. Vgl. EG, Kommission 1976a, S. 114-116 und 118-124.

171 Vgl. EG, Kommission 1973a, S. 117f., 1976a, S. 117, 1980a, S. 132f., und Caspari 1985, S.

59f. Die hier festgelegten Sch
$172 \mathrm{Vgl}$. EG, Kommission 1979e.

173 Hanke 1989, S. 44.

174 Vgl. Schlieder/Schröter 1981, S. 509, und EG, Kommission 1975a, S. 116, sowie 1978a, S. $186 f$. 
Einen ähnlichen Unbestimmtheitsgrad haben auch Beschäftigungsbeihilfen, die vor allem in den 70er Jahren zunehmende Popularität in den MS gewannen. Angesichts der steigenden Arbeitslosigkeit stimmte die Kommission denjenigen Systemen zu, die Prämien für Neueinstellungen, vor allem für Problemgruppen, gewährten und akzeptierte auch Beihilfen für Ausbildungsvorhaben in allen Regionen der Gemeinschaft 175 . Gegenüber der britischen Temporary Employment Subsidy (TES), die laufende Beschäftigungsbeihilfen beinhaltete, schritt die Kommission nach deren anfänglicher Genehmigung aufgrund ihrer laufenden Verlängerung und Klagen anderer MS dann doch ein. Zum einen wurde die Beihilfe konzentriert in einigen Krisenbranchen wie der Textilindustrie eingesetzt, zum anderen entwickelte sie sich zur Betriebsbeihilfe, die die Arbeitskosten der Unternehmen bleibend verminderte und damit ihre Wettbewerbsposition ohne jeden Umstrukturierungsanreiz verbesserte. Daher empfahl die Kommission nach Art. 93,I zweckdienliche Maßnahmen, um diese negativen Wirkungen auf die Gemeinschaft aufzuheben, was dann zu einer Reduktion der Mittel (überproportional in den Krisensektoren), ihrer zeitlichen Verkürzung und einer Kopplung ihrer längerfristigen Gewährung an Umstrukturierungsprogramme sowie Einzelfallnotifizierung bei größeren Unternehmen führte176. Im März 1979 wurde die TES eingestellt ${ }^{177}$.

In den letzten Jahren seit 1990 hat die Kommission die allgemeinen Beihilfeermächtigungen nach Art. 93,I überprüft und den MS empfohlen, solche Regelungen gänzlich abzuschaffen bzw. in regional- oder anderweit spezifische Systeme zu überführen oder bei Generalermächtigungen der Regierungen durch nationale Gesetze, wie bspw. den britischen Industry Act, alle Einzelfälle außerhalb von Regionalfördergebieten zu melden ${ }^{178}$. Die MS haben diesen Empfehlungen nach und nach entsprochen 179 ; mit der Aufhebung der allgemeinen Beihilfen aus den entsprechenden luxemburgischen und belgischen Gesetzen im Jahr 1991 ist die Umgestaltung dieser Beihilfensysteme weitgehend erreicht 180 .

\footnotetext{
175 Vgl. bspw. EG, Kommission 1979a, S. 186-188, und 1993a, S. 263.

176 Vgl. EG, Kommission 1978a, S. 196-199, und 1979a, S. 181-183. Die Problematik der TES wird daran deutlich, daß sich Irland gezwungen sah, eine Retorsionsbeihilfe ähnlicher Form einzuführen, die nach Intervention der Kommission dann auf die Förderung von Umstrukturie-

177 Vgl. EG, Kommission 1980a, S. 150. rungen beschränkt wurde. Vgl. EG, Kommission 1979a, S. 184f.

$178 \mathrm{Vgl}$. Lehner/Meiklejohn/Reichenbach 1991, S. 61, und Swann 1988, S. 143, sowie EG, Kommission 1992a, S. 174.

179 Vgl. Lehner/Meiklejohn/Reichenbach 1991, S. 71, und EG, Kommission 1991a, S. 180.

180 Vgl. EG, Kommission 1992a, S. 176, und 1993a, S. 258, sowie Ehlermann 1994, S. 419.
} 
Mit dem "Gemeinschaftsrahmen für staatliche Beihilfen an kleine und mittlere Unternehmen" 181 wurde diese ablehnende Haltung noch einmal bekräftigt und lediglich Ausnahmen für KMU akzeptiert. Nur diese Unternehmen dürfen weiterhin Investitionsbeihilfen außerhalb von Fördergebieten von bis zu 7,5\% brutto erhalten, wenn sie weniger als 250 Arbeitnehmer beschäftigen und entweder einen Umsatz unterhalb $20 \mathrm{MECU}$ oder eine Bilanzsumme bis zu $10 \mathrm{MECU}$ haben 182. Zudem sind hier Beihilfen für Beratung, Ausbildung u.ä. von bis zu 50\% der Kosten gestattet. Entsprechend einer de-minimis-Regelung 183 dürfen allerdings alle Unternehmen weiterhin Investitionsbeihilfen von bis zu 50.000 ECU sowie weitere Beihilfen bis zu einem Gesamtbetrag von nochmals 50.000 ECU über einen Dreijahreszeitraum erhalten, ohne daß hierfür die Notifizierungspflicht gilt. Bei Kumulierungen mit genehmigten Beihilfeprogrammen sind diese Beträge jeweils anzurechnen ${ }^{184}$. Auch solche Beihilfen kommen wohl vorwiegend den KMU zugute. Während diese Regelung unter dem Aspekt der Konzentration der administrativen Ressourcen auf wesentliche Fälle verständlich ist, so ist doch mit der Freistellung von der Notifizierungspflicht ein Überwachungsproblem für die Kommission geschaffen, da sie nun keine Möglichkeit mehr besitzt, selbst die Einhaltung des Schwellenwertes zu kontrollieren und auf die korrekte Durchführung durch die MS angewiesen ist 185 .

\subsubsection{Beihilfen für FuE- und Umweltschutzmaßnahmen}

Auf dem Gebiet der FuE-Beihilfen machte die Kommission bereits sehr frühzeitig deutlich, daß Subventionen für universitäre Grundlagenforschung, deren Ergebnisse allgemein zugänglich gemacht werden, nicht unter die Beihilfenkontrolle nach Art. 92f. fallen 186 . Eine effektive Überwachung der anderen Forschungsbeihilfen fand jedoch lange Zeit nicht statt, da noch nicht einmal die Notifizierung durchgesetzt werden konnte ${ }^{187}$. Detaillierte Kriterien für die Behandlung solcher Beihilfen an Industrieunternehmen wurden erst 1986 in einem Gemeinschaftsrahmen auf-

181 Vgl. EG, Kommission 1992c, S. 2-9, hier S.6.

182 Liegen diese Werte unterhalb 50 Arbeitnehmern und 5 bzw. 2 MECU, so darf die Intensität bis zu $15 \%$ betragen. Eine solch großzügigere Haltung gegenüber KMU hatte die Kommission in Grundzügen bereits 1976 entworfen. Vgl. Cownie 1986, S. 260.

183 Vgl. EG, Kommission 1992c, S. 4f. Der Grundgedanke einer solchen Regelung wurde in der Kommission bereits 1976 diskutiert. Vgl. EG, Kommission 1977a, S. 153.

184 Vgl. EG, Kommission 1993b, S. 1f.

$185 \mathrm{Vgl}$. bspw. die Anleitungen für britische Behörden in DTI 1993, S. 25.

186 Vgl. EWG, Kommission 1963, S. 81. Diese Betrachtung wird dann im Gemeinschaftsrahmen bestätigt. Vgl. EG, Kommission 1986g, S. 2-6.

187 Vgl. Caspari 1990, S. 25, daneben EG, Kommission 1985a, S. 185. 
gestellt $^{188}$. Die hohe Bedeutung dieser Beihilfenkategorie in allen MS und die mangelnde Einhaltung der Meldepflicht, d.h. die potentiell hohe Wettbewerbsverzerrung verbunden mit der geringen Transparenz, boten den Anlaß für dessen Verabschiedung 189 .

Im Gegensatz zu den Regeln für sektorale und z.T. auch regionale Beihilfen, die vorwiegend Beschränkungen und Grenzen für Beihilfen definieren, steht hier jedoch der unterstützende und anreizgebende Aspekt im Vordergrund, d.h. in Verbindung mit den gemeinschaftlichen Forschungsförderprogrammen soll die nationale FuESubventionierung zur Erhöhung der Wettbewerbsfähigkeit der Gemeinschaftsindustrie beitragen 190 . Im Gemeinschaftsrahmen wird sogar explizit gefordert, daß hierbei bestimmte Industrien bevorzugt werden, die dieses Ziel am besten erfüllen 191 . Hier wird der Ansatz einer selektiven Industriepolitik deutlich, bei der der Staat im Sinne eines "picking the winners" die geeigneten Branchen auswählen soll. Die Problematik einer solchen Vorgehensweise liegt darin, daß diese Strategie voraussetzt, daß der Staat über die besseren Informationen darüber verfügt, welches diese Wachstumsindustrien sind 192 .

Der Rahmen enthält eine Meldepflicht für FuE-Beihilferegelungen, wobei Zielsetzungen und Inhalt (z.B. förderfähige Kosten und Intensitäten) detailliert anzugeben sind. Nach Genehmigung einer solchen Regelung durch die Kommission sind Einzelanwendungsfälle nur dann meldepflichtig, wenn das Projekt mehr als 20 MECU umfaßt bei Beteiligung von Forschungsinstituten (für Eureka-Projekte gilt eine Schwelle von $30 \mathrm{MECU}$, wobei die Meldepflicht der MS oberhalb eines Anteils von $4 \mathrm{MECU}$ einsetzt); forscht das Unternehmen allein, so können niedrigere Schwellen zur Anwendung kommen. Zur Überwachung der Durchführung der Programme verlangt die Kommission von den MS Jahresberichte, um bspw. eine versteckte Sektorförderung über nominal allgemeine Programme zu verhindern.

Um genehmigungsfähig zu sein, müssen Beihilfeprogramme zu zusätzlichen Forschungsprojekten der Unternehmen führen (Kriterium der Additionalität) bzw. Großprojekte ermöglichen, zu denen die Mittel der Unternehmen nicht ausreichen

188 Vgl. EG, Kommission 1986g, S. 2-6.

189 Vgl. EG, Kommission 1987a, S. 162.

190 Vgl. Lehner/Meiklejohn/Reichenbach 1991, S. 59, und Geister 1985, S. 160.

191 Vgl. EG, Kommission 1986g, S. 2-6.

192 Vgl. Hummel/Knörndel 1985, S. 168, 170. Eine Alternative besteht in einer allgemeinen, bspw. steuerlichen, FuE-Förderung ohne sektorale Beschränkungen oder Bevorzugungen, die solche Gefahren nicht in sich birgt. 
würden. Sie sollen somit zusätzliche Risiken und Kosten abdecken, die bei Forschungsprojekten, deren Ertrag oft in fernerer Zukunft liegt, auftreten193. Allerdings wird das Problem gesehen, daß bei den Unternehmen eine Subventionsmentalität geschaffen wird, die dazu führt, daß Projekte mehr nach der Möglichkeit, Fördermittel zu erhalten, ausgesucht werden, als nach den Chancen, diese im Markt umzusetzen ${ }^{194}$. Mitnahmeeffekte sollen also vermieden werden, ebenso wie die Unterstützung der laufenden Produktionstätigkeit mittels getarnter Modernisierungsoder Betriebsbeihilfen ${ }^{195}$. Gerade bei diesen beiden Aspekten waren vorher erhebliche Probleme aufgetreten, indem die MS ihre Forschungsförderung massiv ausgeweitet und die Kriterien der Förderfähigkeit, insbesondere den Innovationsbegriff, immer stärker aufgeweicht hatten, wodurch ein regelrechter Subventionswettbewerb in diesem Bereich entstanden war 196.

Bei der Entscheidung über die maximal zulässige Förderintensität legt die Kommission zunächst generell die beihilfefähigen Kostenkategorien fest und berücksichtigt dann die Risiken für das betreffende Unternehmen 197 und die Marktnähe der Projekte, die als Indikator für mögliche Wettbewerbsverzerrungen dienen. Sie unterscheidet zwischen industrieller Grundlagenforschung, die auf ein "besseres Verständnis der Gesetze von Wissenschaft und Technik" ausgerichtet ist, von angewandter Forschung, die die Ergebnisse der Grundlagenforschung auf spezifisch praktische Probleme der Entwicklung neuer Produkte und Verfahen anwendet. Sie endet mit der Erstellung eines Prototyps, dessen Weiterentwicklung bis hin zur Serienreife dann der Stufe Entwicklung zuzurechnen ist. Während für Grundlagenforschung Beihilfen bis zu $50 \%$ der Bruttokosten zulässig sind, werden für die angewandte Forschung i.d.R. nur bis zu $25 \%$ genehmigt 198 ; für Entwicklung gilt der gleiche Prozentsatz, allerdings nur, wenn das Produkt oder Verfahren auf Gemeinschaftsebene innovativ ist. Kommt die Förderung unmittelbar einem KMU

\footnotetext{
193 Vgl. EG, Kommission 1987a, S. 162.

194 Vgl. Thies 1989, S. 9.

195 Vgl. EG, Kommission 1987a, S. 163.

196 Vgl. Hummel 1985, S. 14f., und EG, Kommission 1984a, S. 148f.

197 Ritzen (1990, S. 79f.) läßt das Risikoargument allerdings nur für KMU gelten, da bei größeren Unternehmen, deren Aktien öffentlich gehandelt werden, die Besitzer durch Diversifizierung ihrer Portefeuilles eine Risikostreuung erreichen können.

Als Argument für eine solche Begrenzung, die u.U. strenger ist, als es das Externalitätenargument fordern würde, wird auch die Entscheidungsfreiheit der Unternehmen über ihre Forschungsprojekte angeführt, die bei einer überwiegenden Staatsbeteiligung als gefährdet angesehen wird. Vgl. Caspari 1990, S. 31, und Lehner/Meiklejohn/Reichenbach 1991, S. 60.
} 
zugute, so können die Höchstsätze um bis zu $10 \%$ punkte erhöht werden ${ }^{199}$, ebenso sind Erhöhungen in benachteiligten Gebieten der Gemeinschaft und bei einer Verknüpfung mit wichtigen gemeinschaftlichen Vorhaben möglich.

In der Literatur wird die Förderung von angewandter Forschung oder Entwicklung kritisch gesehen, da hier der Externalitätsgrad gering sei, und eine Konzentration auf die Unterstützung der Grundlagenforschung gefordert. Der Externalitätsbzw. Risikograd wäre dann im Einzelfall zu untersuchen 200 . FuE-Förderung konzentriere sich zudem häufig auf Großunternehmen und auf Projekte, die ohnehin durchgeführt wordern wären, während andere nichtgeförderte Projekte verdrängt würden. Hier käme es also zu massiven Mitnahmeeffekten ${ }^{201}$, die auch durch die Definition des Additionalitätskonzepts gefördert werden. Hierbei orientiert sich die Kommission nämlich am FuE-Volumen der Vorjahre, es wird also die Flucht in den intertemporalen Vergleich 202 vorgenommen.

Bedeutende Möglichkeiten der Umgehung der Regeln bestehen einerseits in Forschungsarbeiten an Forschungsinstituten, deren Kosten voll vom Staat getragen, deren Nutzen den Unternehmen aber unter Kosten zugutekommt, andererseits in der Vergabe von staatlichen Forschungsgroßaufträgen an private Gesellschaften, die die so erworbenen Erkenntnisse gewinnbringend verwenden können ${ }^{203}$. Zur Frage des Beihilfecharakters solcher Regelungen gab die Kommission eine Studie in Auftrag, die einen solchen bei vielen Verträgen bejahte und Vergaberegeln ähnlich denen für öffentliche Aufträge forderte204.

Der Rahmen wurde zunächst für fünf Jahre beschlossen, und seine Kriterien wurden bereits ab 1985 zur Beurteilung von Beihilfeprogrammen herangezogen205. Entsprechend der positiven Haltung der Kommission wurden die Programme dabei i.d.R. genehmigt. In einigen Fällen mußte jedoch das Verfahren nach Art. 93,II eröffnet werden, um Modifikationen der Programme zu erreichen, da die MS normale Modernisierungsinvestitionen der Unternehmen als FuE fördern wollten. Negative Entscheidungen ergingen jedoch nicht ${ }^{206}$. Einige der bestehenden Regelungen wurden aufgrund von Interventionen der Kommission nach Art. 93,I geän-

\footnotetext{
199 Vgl. EG, Kommission 1992c, S. 7.

$200 \mathrm{Vgl}$. Hummel/Knörndel 1985, S. 164f., 167.

201 Vgl. Gilchrist/Deacon 1990, S. $48 \mathrm{f}$

202 Vgl. Andel 1992, S. 103.

203 Vgl. Caspari 1990, S. 25, und Cownie 1986, S. 259.

204 Vgl. EG, Kommission 1991a, S. 278f.

205 Vgl. EG, Kommission 1986a, S. 183-188.

206 Vgl. EG, Kommission 1992a, S. 147.
} 
dert, da sie ursprünglich über die Intensitätshöchstgrenzen hinausgingen 207. Die relativ hohe Bedeutung dieser Beihilfenkategorie zeigt sich in der Zahl der jährlichen Notifizierungen nach Einführung des Rahmens und in ihrem Anteil an den Gesamtnotifizierungen, wobei diese Notifizierungen im FuE-Bereich auch einen hohen Anteil von Projekten im Rahmen der europäischen Kooperationsprogramme, wie z.B. Eureka, enthalten 208 .

Tab. 4.1-3

FuE-Beihilfen unter dem Gemeinschaftsrahmen

\begin{tabular}{c|ccc} 
Jahr & Anmeldungen & in \% aller Anm. & Entscheidungen \\
\hline 1986 & 26 & 21,0 & 23 \\
1987 & 68 & 20,9 & 46 \\
1988 & 64 & 17,1 & 42 \\
1989 & 48 & 16,2 & 59 \\
1990 & 53 & 12,4 & 53 \\
1991 & 91 & 21,8 & 82
\end{tabular}

Quelle: EG, Kommission 1987a-1992a. Für die Zeit ab 1992 liegen keine Veröffentlichungen vor.

Als zu Beginn der 70er Jahre der Umweltschutz im öffentlichen Bewußtsein der MS an Bedeutung gewann, wurden dementsprechend die Umweltschutzauflagen für Unternehmen verschärft. Um diesen die Anpassung an die neuen Normen zu erleichtern, begannen viele MS hierfür Beihilfen zu vergeben. Zur Regulierung dieser Beihilfen entwickelte die Kommission 1974 einige Regeln ${ }^{209}$. Als Endziel der Umweltpolitik wurde die Verwirklichung des Verursacherprinzips angesehen, für eine Übergangszeit sollten jedoch Beihilfen erlaubt werden, ohne daß diese unbedingt durch eine Gefährdung einzelner Unternehmen oder auch bestimmter Regionen durch die neuen Belastungen gerechtfertigt wären ${ }^{210}$. Diese temporäre und partielle Anwendung des Gemeinlastprinzips sollte also verhindern, daß ein Gegensatz zwischen Umweltschutz und Arbeitsplätzen aufgebaut wurde, der zu Lasten des ersteren ging. Zudem galt es zu vermeiden, daß die Furcht vor Wettbewerbsnachteilen für die eigenen Firmen die MS davon abhielt, Maßnahmen zur Umweltverbesserung zu beschließen oder durchzusetzen ${ }^{211}$. Der Externalitätencharakter von Umweltschutzinvestitionen hätte allerdings im Falle bedeutender grenzüberschreitender Effekte

\footnotetext{
207 Vgl. z.B. EG, Kommission 1987a, S. 163f., 1989a, S. 156f. und 159, sowie 1991a, S. 159.

208 Vgl. EG, Kommission 1988a, S. 144.

209 Vgl. EG, Kommission 1974b.

210 Vgl. EG, Kommission 1977a, S. 146.

211 Vgl. Cownie 1986, S. 257.
} 
eher dafür gesprochen, derartige Investititionen aus Gemeinschaftsmitteln zu bezuschussen bzw. Transfers zwischen den MS zu organisieren, wofür damals allerdings wohl der Konsens fehlte. Beihilfen waren jedoch nur für Investitionen in die Umstellung bestehender Anlagen oder Verfahren erlaubt, die von den Unternehmen auf der Basis früherer weniger strenger Normen errichtet worden waren. Sie mußten außerdem aufgrund neuer Regeln erforderlich sein, die den Unternehmen bedeutende neue Verpflichtungen auferlegten. Während den Altanlagen also eine Art Vertrauensschutz gewährt wurde, sollte verhindert werden, daß auf dem Umweg über Umweltschutzbeihilfen für neue Fabriken zusätzliche Investitionsbeihilfen gewährt wurden. Dem gleichen Ziel diente auch die Regel, daß für Kapazitätserweiterungsinvestitionen keine solchen Beihilfen gewährt werden durften. Allerdings war eine Ausnahme von dieser Regel möglich, wenn aufgrund niedrigerer Umweltstandards in anderen Ländern den Gemeinschaftsunternehmen ein Wettbewerbsnachteil entstehen sollte. Während für die den Rahmenregeln entsprechenden Beihilfen lediglich eine jährliche Berichtspflicht der MS besteht, galt für Beihilfen, die diesen Regeln nicht entsprachen, also bspw. die Intensitätshöchstgrenzen überschritten, das normale Prüfverfahren für jeden Einzelfall. Sie sind jedoch genehmigungsfähig, wenn sie z.B. Umweltforschungsmaßnahmen unterstützen oder eine Verminderung der Umweltverschmutzung über das gesetzlich vorgeschriebene Maß hinaus fördern 212 . Die genehmigungsfähige Beihilfenintensität sollte von 45\% 1975 auf 15\% NSÄ 1980 fallen. Danach war geplant, auf das Verursacherprinzip überzugehen. Sofort nach Verabschiedung des Rahmens begann die Kommission mit der Prüfung der nationalen Programme und erreichte jeweils ihre Anpassung an diese Regeln 213.

Zum geplanten Übergang zum Verursacherprinzip nach 1980 kam es jedoch nicht. Stattdessen wurde die Möglichkeit zur Vergabe solcher Beihilfen von bis zu $15 \%$ NSÄ bis Ende 1986 verlängert ${ }^{214}$, wobei die weitere Verschärfung der Umweltnormen und die rezessionsbedingt nur zögerliche Umsetzung der Möglichkeiten des ersten Rahmens durch die MS als Rechtfertigung dienten. Gleichzeitig wurde festgelegt, daß die förderungsfähigen Anlagen jeweils mindestens zwei Jahre vor Inkraftsetzung der neuen Umweltnormen in Betrieb sein mußten ${ }^{215}$. Weitere Verlängerungen wurde 1986 für den Zeitraum bis 1992 und 1992 bis Ende 1993

\footnotetext{
212 Vgl. hierzu die Genehmigung einer französischen Maßnahme zur Förderung der Luftreinhaltung in EG, Kommission 1991, S. 202.

213 Vgl. EG, Kommission 1977a, S. 146-151.

214 Für KMU dürfen in Fördergebieten Beihilfen bis zur Höhe des maximalen regionalen Förder-

215 höchstsatzes gewährt werden.
} 
beschlossen. Zudem waren jetzt für Maßnahmen, die eine Emissionsverminderung über das gesetzlich verlangte Niveau hinaus erreichten, höhere Fördersätze möglich 216. Nachdem der Umweltschutz als Gemeinschaftsziel in die EEA aufgenommen worden war (Art. 130r-t EGV), wäre eine Aufhebung der Möglichkeit zur Vergabe von Umweltschutzbeihilfen politisch kaum zu rechtfertigen gewesen 217 . Ende 1993 wurde ein neuer Gemeinschaftsrahmen mit einer Laufzeit von 6 Jahren verabschiedet, der die Förderhöchstgrenze auf 15\% BSÄ (bzw. 30\% BSÄ bei Überschreitung der geltenden Normen) senkte. Höhere Sätze sind für KMU und in Regionalfördergebieten möglich 218 .

\subsubsection{Beihilfen an öffentliche Unternehmen}

Zwar garantiert Art. 222 EGV den MS die Wahl der Eigentumsordnung und damit auch das Recht zu Verstaatlichungen, jedoch verpflichtet Art. 90 sie auch für öffentliche Unternehmen zur Respektierung der Wettbewerbsvorschriften des Vertrages einschließlich der Beihilfenbeschränkung219. Die Überwachung der Einhaltung dieser Regeln ist allerdings bei öffentlichen Unternehmen wegen der engen Beziehungen zu ihren staatlichen Eignern, staatlichen Investitionsfonds oder öffentlichen Banken deutlich schwerer als für Privatfirmen, da die Möglichkeiten zur Vergabe intransparenter Subventionen dadurch erhöht sind 220 . Verzicht auf Dividendenausschüttung, Verlustausgleiche, Kapitalerhöhung, Vergabe günstiger Kredite durch staatliche Banken, Umwandlung von Krediten in Eigenkapital z.B. beim Erwerb durch staatliche Industrieholdings oder Forderungsverzicht bei Privatisierung sind dabei Förderformen, die bei Privatunternehmen i.d.R. nicht auftreten. Lange Zeit gelang es der Kommission hier nicht, eine effektive Kontrolle zu etablieren. Die Notifizierungspflicht wurde von den MS ignoriert, und es war weder rechtlich noch politisch klar, ob die Kommission die Offenlegung der Finanzbeziehungen zwischen MS und ihren öffentlichen Unternehmen verlangen und dieses Verlangen auch durchsetzen können würde 221 . Nach ersten Ansätzen einer Kontrolle, die die italienischen Industrieholdings und den britischen National Enterprise Board betrafen und Jahresberichte sowie (beim NEB) eine Notifizierungspflicht bei Eingriffen, die direkt

\footnotetext{
216 Vgl. EG, Kommission 1991a, S. 201f.

217 Vgl. EG, Kommission 1987a, S. 171f.

218 Vgl. EG, Kommission 1994a, S. 256f.

219 Vgl. Pelkmans 1984, S. 266f., und Ehlermann 1994, S. 423.

220 Vgl. Lehner/Meiklejohn/Reichenbach 1991, S. 57.

221 Vgl. Pelkmans 1984, S. 267.
} 
durch das Industrieministerium veranlaßt waren, vorsahen 222 , stellte die "Richtlinie der Kommission zur Transparenz der finanziellen Beziehungen zwischen den Mitgliedstaaten und den öffentlichen Unternehmen" von $1980^{223}$ den ersten Schritt zu einer umfassenden Kontrolle dar.

Diese Richtlinie enthält eine umfassende Aufzeichnungspflicht der MS über einen breiten Bereich möglicher Finanzbeziehungen zu öffentlichen Unternehmen 224 mit einem Umsatz oberhalb von $40 \mathrm{MECU}$, die der Kommission auf Anfrage mitgeteilt werden müssen. Nicht alle Transaktionen werden dabei von der Kommission als Beihilfen angesehen; ihre Möglichkeit jedoch, Informationen zu erhalten, gestatten ihr erst eine Prüfung der Transaktionen, wobei es allerdings zunächst noch an der Definition eines Beurteilungskriteriums fehlte. Ein solches Vorgehen der Kommission war angesichts der großen Bedeutung öffentlicher Unternehmen in einigen MS (v.a. F, I, UK) notwendig, um die Gleichbehandlung der MS in der Beihilfenkontrolle zu sichern, da die genannten MS in konjunkturellen Krisenphasen vermehrt auf Kapitalzuführungen an ihre Unternehmen als getarnte Subventionen auswichen.

Die drei genannten MS erhoben dann allerdings Klage vor dem EuGH gegen diese Richtlinie unter dem Vorwurf der Kompetenzüberschreitung durch die Kommission, da eine solche Maßnahme nur durch den Rat nach Art. 94 hätte erlassen werden können, und der Diskriminierung öffentlicher Unternehmen, wobei D und NL die Kommission unterstützten. Der EuGH wies die Klage jedoch in allen Punkten ab225 und erklärte, daß die RL durch die Überwachungserfordernisse der Kommission gerechtfertigt sei und den Rat nicht daran hindere, eine Regelung dieses Bereiches nach Art. 94 EGV zu erlassen. Angesichts der Ungleichheit der Situationen privater und öffentlicher Unternehmen, insbesondere der unterschiedlichen Notwendigkeit einer gewinnorientierten Geschäftsstrategie und des Zugangs zu neuem Eigenkapital sei auch eine Ungleichbehandlung gerechtfertigt 226.

Nach dem Erlaß dieses Urteils begann die Kommission, diese RL anzuwenden, wobei sie sich zunächst schwerpunktmäßig auf fünf Sektoren beschränkte, in denen besondere Gefahren für den Wettbewerb aus staatlichen Interventionen in öffent-

\footnotetext{
222 Vgl. Swann 1983, S. 52, und EG, Kommission 1973a, S. 123f., sowie 1978a, S. 190-193.

223 Vgl. EG, Kommission 1980h, S. 35-37.

224 Öffentliche Unternehmen sind dabei als solche Unternehmen definiert, auf die öffentlche Stellen einen dominierenden Einfluß ausüben, indem sie die Mehrheit des Aktienkapitals, der Stimmrechte oder der Aufsichtsratsmandate halten.

$225 \mathrm{Vgl}$. EuGH 1982, Urteil in den RS 188 bis 190/80.

226 Vgl. ebenda, RN 21, und EG, Kommission 1983a, S. 167-169, sowie Ehlermann 1992, S. $617 \mathrm{f}$.
} 
lichen Unternehmen gesehen wurden; hierbei handelte es sich um die Kfz- und Kunstfaserindustrien, Schiffbau, Tabakwaren und Textilmaschinenbau 227. Der Widerstand der MS, die gegen die RL geklagt hatten, setzte sich dann dergestalt fort, daß sie zunächst nur unvollständige Informationen übermittelten bzw. bestritten, daß bestimmte staatliche Unternehmen der Definition der RL entsprachen, so daß diese gegen Frankreich und Italien Vertragsverletzungsverfahren einleiten mußte, die dann zu Urteilen des EuGH im Sinne der Kommissionsposition führten 228 .

Nach der Umgestaltung der Transparenzrichtlinie $1985^{229}$ wurden dann auch die öffentlichen Versorgungsunternehmen und der verstaatlichte Bankenapparat in die Überwachung einbezogen. Gerade der letzte Bereich kann dabei eine hohe Bedeutung angesichts seiner doppelten Funktion haben: Er kann einerseits Empfänger von Beihilfen des staatlichen Eigners sein, die er andererseits zur Vergabe von Vorzugskrediten an Industrieunternehmen nutzt ${ }^{230}$. Aber auch die Versorgungsunternehmen können bspw. über spezielle Tarife an bestimmte Unternehmen Beihilfen vergeben 231 und über staatliche Zuschüsse refinanziert werden.

Die weitgehende Beschränkung der Überwachung durch die Kommission auf eine Informationspflicht der MS mag als eher vorsichtiges Taktieren angesehen werden. Sie erlaubte es der Kommission erst ex-post-facto festzustellen, ob eine bestimmte Kapitaltransaktion Beihilfencharakter besaß, so daß dann erst für zukünftige vergleichbare Transaktionen Ex-ante-Eingriffe zur Verhinderung solcher Beihilfen möglich wurden 232. Sie war aber ebenso wie die Klage einiger MS gegen die RL Ausdruck der Tatsache, daß Beschränkungen des Handlungsspielraums öffentlicher Unternehmen insbesondere in den Ländern, in denen solche Unternehmen eine bedeutende Rolle innerhalb der Wirtschaftspolitik spielen, als zu weitgehende Eingriffe in die nationale Souveränität über die Aushebelung der Eigentumsordnungsneutralität des Art. $222 \mathrm{EGV}$ angesehen und daher bekämpft wurden 233 .

\footnotetext{
227 Vgl. Caspari 1984, S. 33. Zum Vorgehen im Stahlbereich vgl. unten Abschnitt 4.3.

228 Vgl. EG, Kommission 1984a, S. 190, und 1985a, S. 204f., sowie 1988a, S. 209.

229 Vgl. EG, Kommission 1985k.

230 Vgl. Caspari 1982, S. 4.

231 Vgl. hierzu den Fall spezieller Gaspreise für niederländische Ammoniakhersteller in: EG, Kommission 1986a, S. 160t.

232 Vgl. dazu EG, Kommission 1978a, S. 192f.

233 Vgl. Geister 1981, S. 78f.
} 
Mit der Veröffentlichung von Leitlinien 1984234, die auch den MS als Brief übermittelt wurden, legte die Kommission ihren Grundansatz in der Frage dar, welche dieser staatlichen Beteiligungen als Beihilfen anzusehen seien 235 . Generell dient ihr zur Feststellung und Messung der Beihilfen das Verhalten eines privaten Kapitalgebers "unter normalen marktwirtschaftlichen Bedingungen" mit einer längerfristigen Perspektive als Vergleichsmaßstab, d.h. die Frage, ob ein Privater auf der Basis eines normalen Rentabilitätskalküls Kapital bereitgestellt hätte. Ist eine solche Rendite auf absehbare Zeit nicht zu erwarten oder wäre das Unternehmen aufgrund seiner schlechten Finanzsituation nicht in der Lage, auf dem Kapitalmarkt Fremdmittel aufzunehmen, so sieht die Kommission die Kapitalzuführung als Beihilfe an 236. Dies gilt auch bei gemischtwirtschaftlichen Unternehmen, wenn bei einer Kapitalerhöhung der staatliche Anteil erheblich höher ausfällt als der ursprüngliche Kapitalanteil. Durch die finanziell außerordentlich starke Position des Staates ist zudem das Potential für Wettbewerbsverzerrungen hier sehr groß237. Keine Beihilfe wird hingegen im einfachen Beteiligungserwerb durch den Staat gesehen, außer wenn dieser vorübergehender Natur ist und der Wiederverkaufspreis ex ante so festgelegt wird, daß der Staat keine normale Marktrendite erhält.

Die Leitlinien enthalten nun auch Verfahrensfestlegungen für die Prüfung. Während staatliche Beteiligungen mit Subventionscharakter unter die normalen Regeln der Art. 92/93 EGV fallen ${ }^{238}$, verlangt die Kommission bei "normalen" staatlichen Beteiligungen lediglich Jahresberichte, um so den Überblick über das Handeln der MS zu behalten. Diese Mitteilungspflicht gilt nicht für Beteiligungen an KMU239.

234 Vgl. EG, Bulletin 1984a, S. 98-100.

235 Zuführungen von Beteiligungsfonds oder ähnlichen Einrichtungen, die zum Zwecke der Beihilfenverwaltung oder -verteilung vom Staat eingerichtet wurden, sind hierbei eingeschlossen, um zu verhindern, daß die MS der Kontrolle durch die Errichtung solcher Institutionen ausweichen. Vgl. Bernitsas 1993, S. 113.

236 Vgl. EG, Bulletin 1984a, S. 98-100. Das Prinzip wurde vom Rat bei der Verabschiedung der Beihilfekodizes für Schiffbau und Stahl übernommen (s.u. Abschnitte 4.2 und 4.3). Die Auffassung der Kommission wurde auch vom EuGH ausdrücklich bestätigt. Vgl. EG, Kommission 1991g, S. 6f. Direkten Kapitalzuführungen gleichgestellt sind Instrumente ähnlicher Wirkungen, wie z.B. Wandelschuldverschreibungen oder Darlehen, deren Rendite von den Unter237 Vgl. Hellingman 1986, S. 111.

238 Dies gilt auch für Bürgschaftsregelungen der MS, die ebenso der Notifizierungspflicht unterliegen und die die Kommission nur genehmigt, wenn diese strikte Regeln der Inanspruchnahme der begünstigten Unternehmen enthalten, die bis zu deren Vergleich bzw. Konkurs reichen können. Vgl. EG, Kommission 1989h und 1989i.

239 Vgl. EG, Bulletin 1984a, S. 98-100. 
"Normale" Beteiligungen in Krisensektoren oder die Kombination von Kapitalbeteiligungen mit anderen Interventionen betrachtet die Kommission quasi als grauen Bereich, in dem sie Beihilfen lediglich vermutet. Hier verlangt sie Informationen und entscheidet innerhalb von 15 Arbeitstagen, ob diese als Notifizierung, sprich die Transaktion als Beihilfe, anzusehen ist 240 . In den Beihilfekodizes für den Schiffbau und die Stahlindustrie werden Kapitalbereitstellungen hingegen grundsätzlich als Beihilfen definiert ${ }^{241}$. In diesen Krisenbranchen, in denen die Kommission über detaillierte Beihilferegelungen eine stärkere Kontrolle auszuüben versucht (s.u. Abschn. 4.2 und 4.3), ist der Anreiz für die MS nämlich besonders groß, diese Kontrolle durch Kapitalzuführungen zu umgehen.

Zwar ist die Wirkungsrichtung dieser Leitlinien eng verwandt mit derjenigen der Transparenzrichtlinien von 1980 und 1985. Während aber die Transparenzrichtlinie lediglich die Pflicht zur Aufbewahrung und möglichen Zurverfügungstellung von Informationen festlegt, verlangen die Leitlinien Jahresberichte und unter bestimmten Bedingungen die Meldepflicht 242 .

Die rechtliche Bindungswirkung der Leitlinien und ihr juristischer Status werden in der rechtlichen Literatur angezweifelt, da sie im Unterschied zur Transparenzrichtlinie nicht auf speziellen Verpflichtungen der MS aus dem EGV basieren. Zudem wurde für den "grauen Bereich" mit der 15 Tage dauernden Vorprüfung ein Konstrukt geschaffen, das nicht den normalen Beihilfeprüfungsregeln entspricht und keinerlei rechtliche Basis besitzt. Sowohl bezüglich der Beurteilung des Beihilfencharakters von Beteiligungen als auch hinsichtlich des Verfahrens wird von dieser Seite eine Verordnung nach Art. 94 präferiert 243.

Schon vor Veröffentlichung ihrer Leitlinien griff die Kommission gegen subventionsenthaltende Kapitalbeteiligungen in zwei Fällen aus dem Papierwarensektor ein und erließ negative Entscheidungen. Dies betraf eine Beteiligung Walloniens an Intermills und einer niederländischen Entwicklungsgesellschaft an der Leeuwarder Papierwarenfabriek. Obwohl der EuGH den Klagen gegen beide Entscheidungen stattgab und diese annullierte 244 , bestätigte er doch die Position der Kommission im Prinzip 245 und erklärte dabei auch, daß kein Verstoß gegen Art. 222 EGV vorlag.

\footnotetext{
240 Vgl. EG, Bulletin 1984a, Punkte 3.4 und 4.4.

241 Vgl. Hellingman 1986, S. 111f. und im Detail unten Abschnitt 4.2 und 4.3.

242 Vgl. Hellingman 1986, S. 122 und 126.

243 Vgl. Hellingman 1986, S. 126-128.

244 Vgl. EuGH 1984 und 1985, Urteile in den RS C-323/82 und 296+318/82.

245 Vgl. EuGH 1984, S. 3810, Swann 1988, S. 142, und Caspari 1985, S. 56.
} 
Die Annullierung erfolgte, da die Kommission die notwendige Analyse der möglichen Erfüllung der Ausnahmemöglichkeiten nicht sorgfältig durchgeführt hatte 246 .

Nach Veröffentlichung der Leitlinien wandte die Kommission diese zunächst nicht an 247. In einem ersten Fall in Griechenland, bei dem eine staatliche Organisation zur Sanierung von Unternehmen in finanziellen Schwierigkeiten über staatliche Beteiligungen geschaffen worden war, genehmigte sie diese Beihilfen nach Art. 92,IIIb, da sie eine gesamtwirtschaftliche Krise in Griechenland diagnostizierte. Die Genehmigung wurde allerdings an eine Einzelfallnotifizierung für Großunternehmen, die Vermeidung von Kapazitätserhöhungen und die Beachtung der sektoralen Kodizes geknüpft 248 . In der Folgezeit untersucht die Kommission allerdings dann regelmäßig auch Fälle staatlicher Kapitalzuführungen vor allem in sensiblen Sektoren, klassifizierte sie immer dann als Beihilfen, wenn das betroffene Unternehmen aufgrund hoher Verluste o.ä. von privaten Kapitalgebern am Markt keine weiteren Zuführungen erhalten hätte, und erließ in einigen Fällen auch Verbotsentscheidungen 249. Andere Formen öffentlicher Finanzierung und Kapitalzuführungen an profitable Unternehmen unterlagen allerdings keiner Kontrolle 250 . Die Tatsache, daß unter den Entscheidungen im Zeitraum 1985-90 36 nichtnotifizierte Beihilfen an öffentliche Unternehmen im Umfang von 5 Mrd. ECU waren, von denen die Kommission z.T. erst Jahre nach der Zahlung Kenntnis erhielt 251 , machen auch die quantitative Problematik in diesem Bereich deutlich ${ }^{252}$ ( $\mathrm{Zu}$ einigen Anwendungsfällen im KfzSektor vgl. unten Abschnitt 4.4). Eine neue Unterstützungsmethode in Frankreich ist dabei die sog. "Endogamie", eine Technik buchmäßiger Kapitalerhöhungen öffentlicher Unternehmen durch Schachtelbeteiligungen anderer öffentlicher

246 Vgl. Hellingman 1986, S. 112f., 117, und EG, Kommission 1985a, S. 145.

247 Vgl. Hellingman 1986, S. 114.

248 Vgl. EG, Kommission 1987a, S. 134f., und 1988a, S. 150, sowie Bernitsas 1993, S. 117f. Die Überwachung der Einhaltung der Entscheidungsbedingungen erfolgte jedoch nur sehr lückenhaft.

249 Das Prinzip des marktwirtschaftlichen Investors wurde also konsistent angewandt. Vgl. EG, Kommission 1991g, S. 6, mit Beispielen.

250 Vgl. EG, Kommission 1991g, S. 2.

251 Vgl. EG, Kommission 1992a, S. 142.

252 Im gleichen Zeitraum traten im Privatsektor 35 derartige Fälle, allerdings lediglich mit einem Beihilfevolumen von 1,8 Mrd. ECU auf. Da gleichzeitig die Wertschöpfung privater Unternehmen in der Gemeinschaft fünt bis zehnmal höher liegt als die der öffentlichen Betriebe, ist die Inzidenz der Umgehung der Notifizierungspflicht bei Staatsunternehmen um ein Vielfaches höher, was die Notwendigkeit einer verschärften Kontrolle dieser Unternehmen nur um so stärker unterstreicht. Vgl. Ehlermann 1992, S. 618. 
Unternehmen, wie bspw. die Übernahme von Anteilen des Computerkonzerns Bull durch France Télécom. Diese Technik der Quersubventionierung, die zudem noch den Vorteil besitzt, den Staatshaushalt nicht unmittelbar zu beanspruchen, wird allerdings von der Kommission nicht als Beihilfe qualifiziert 253 .

Als Reaktion auf diese Entwicklung verlangte die Kommission in einer auf die Richtlinie von 1980 gestützten Mitteilung254 ab dem Wirtschaftsjahr 1989 von den MS, Jahresberichte (einschließlich Bilanzen und GuV) und Informationen zu allen finanziellen Transaktionen, wie z.B. Kapitalerhöhungen, Zuschüsse, Darlehensgewährungen und Bürgschaften, mit ihren öffentlichen Unternehmen im verarbeitenden Gewerbe mit einem Umsatz von mehr als 250 MECU nachträglich zu übermitteln 255 . Gegen diese neue Anforderung legte Frankreich beim EuGH wiederum Beschwerde ein 256 . Diese wurde vom Gerichtshof akzeptiert, da die Kommission hier den MS eine neue Verpflichtung auferlegt hatte, ohne dies mit einem angemessenen Rechtsinstrument, in diesem Fall einer RL nach Art. 90, zu tun. Die Mitteilung der Kommission wurde daher annulliert 257 . Dieselben Vorschriften wurden nunmehr als Änderung der RL kodifiziert und gelten ab dem Wirtschaftsjahr 1992258. Sie betreffen ungefähr 90 Unternehmen 259 und erlauben damit eine umfassendere und frühzeitigere Kontrolle der Finanztransaktionen, insbesondere solcher öffentlicher Unternehmen, die keiner Verlustausgleiche bedürfen 260 . Dies gilt v.a. für Italien, wo öffentliche Unternehmen etwa $19 \%$ der Wertschöpfung aller nichtlandwirtschaftlichen Unternehmen erstellen 261.

Mit der Publikation ihrer Beurteilungskriterien hat die Kommission gleichzeitig die Transparenz der Kontrolle erhöht ${ }^{262}$. So werden auch Darlehens- und Bürgschaftsbedingungen dahingehend beurteilt, ob sie denen, die ein privatwirtschaftlich handelndes Unternehmen erhalten könnte, entsprechen 263 . Bei Kapitalzuführungen

253 Vgl. Färber 1993, S. 148.

254 Vgl. EG, Kommission 1991g, S. 2-17.

255 Ursprünglich war hier eine Ex-ante-Notifizierung vorgesehen, die jedoch nach dem Widerstand der MS aufgegeben wurde. Vgl. Rawlinson 1993, S. 60.

256 Widerstand gegen die Kommissionsmitteilung gab es auch in Italien und Spanien. Vgl. Ehlermann 1992, S. 613.

$257 \mathrm{Vgl}$. EuGH 1993b, v.a. RN 17 und 27.

258 Vgl. EG, Kommission 1993c, S. 16-18.

259 Vgl. Petersen 1993, S. 29.

260 Vgl. Ehlermann 1992, S. 618.

261 Vgl. Ehlermann 1992, S. 614.

262 Vgl. EG, Kommission 1993d, S. 3.

263 Vgl. EG, Kommission 1991g, S. 12f. 
wird gefragt, ob sie ex ante eine Kapitalverzinsung erwarten lassen, die für einen privaten Investor akzeptabel wäre. Hierbei zieht die Kommission Kennzahlen über die finanzielle Lage des Unternehmens und die erwartete Marktentwicklung in Betracht ${ }^{264}$. In einigen MS werden die aus den Richtlinien entstehenden Informationspflichten und Prüfungsmöglichkeiten auch die Transparenz auf nationaler Ebene erhöhen, was im demokratischen Sinne nur zu begrüßen ist 265 .

Einen bedeutenden Anwendungsbereich der Beihilferegeln für öffentliche Unternehmen stellt die Tätigkeit der Treuhandanstalt in Ostdeutschland dar, und zwar sowohl bezüglich der Privatisierung als auch der Weiterführung von Unternehmen 266 .

Man mag die Orientierung am Verhalten eines privaten Investors als ungeeignetes Kriterium zur Einstufung einer staatlichen Beteiligung als Beihilfe ansehen, da die wirtschaftspolitische Ausrichtung und Verantwortung des Staates grundlegend von der privater Unternehmen verschieden ist. So intervenieren staatliche Einrichtungen über Kapitalbeteiligungen häufig mit dem Ziel, schwere Regionalprobleme mit evtl. sozialen Unruhen als Folge des Zusammenbruchs eines bedeutenden regionalen Arbeitgebers zu verhindern. Auch wird die NKA eines staatlichen Eigners bzgl. einer Beteiligung bei Einbeziehung von bspw. Steuerausfällen oder notwendigen Sozialtransfers anders aussehen als die eines Privaten. Dennoch bietet das Vergleichskriterium "privater Investor" wohl den einzig operationalisierbaren wettbewerbspolitischen Maßstab für die Kommission, um überhaupt eine Beurteilung des Subventionscharakters staatlicher Beteiligungen zu erlauben und damit eine Umgehung der Beihilfenkontrolle einzuschränken. Der Spielraum der MS für ihre Wirtschaftspolitik bleibt sicherlich groß genug, zumal weitere Ausnahmen für Beteiligungen an Unternehmen mit bedeutenden Innovationsmöglichkeiten oder für strategische Investitionen bspw. zur Versorgungssicherheit zugelassen bleiben. Allerdings ist gerade für die Bereitstellung von Eigenkapital der Vergleichsmaßstab "privater Investor" und damit die Existenz und die Höhe einer Beihilfe schwer festzulegen, da auch bei Privatinvestoren bspw. unterschiedliche Zeithorizonte und Risikoeinstellungen vorliegen 267 . Die Kommission vergleicht hierbei mit dem Verhalten eines Inve-

264 Vgl. EG, Kommission 1991g, S. 12f.

265 Vgl. Harden 1993, S. 18.

266 Dieser Aspekt soll an dieser Stelle jedoch nicht vertieft werden. Hierzu liegt eine detaillierte Monographie vor: Vgl. Schütz 1993.

$267 \mathrm{Vgl}$. Hellingman 1986, S. 119. Dies gilt auch für die Beurteilung von Quersubventionen in Gestalt von Verlustausgleichen oder Kapitalerhöhungen innerhalb öffentlicher Konglomerate, da solche Transfers auch in privaten diversifizierten Unternehmen vorkommen. Dies ist aller- 
stors mit einem langfristigen Zeithorizont, der bereit ist, kurzfristige Verluste hinzunehmen 268 . Daher bleibt ihr Handeln hier wohl auf die offensichtlichen Fälle beschränkt, in denen ex ante keine objektiven Gründe vorliegen, Gewinne aus der Kapitalzuführung zu erwarten 269 .

dings dort i.d.R. mit Umstrukturierungen verbunden. Finden diese in kapitalempfangenden öffentlichen Unternehmen nicht statt und wird Kapital über einen längeren Zeitraum hinweg zugeführt, so ist davon auszugehen, daß es sich um Beihilfen handelt. Die Möglichkeit solcher Quersubventionen ist vor allem dann gegeben, wenn ein Unternehmen im Konglomerat durch 268 eine Monopolstellung Extraprofite erwirtschaften kann.

268 Vgl. Harden 1993, S. 17f.

269 Vgl. Ehlermann 1992, S. 619f. 


\subsection{Subventionen für die Schiffbauindustrie}

\subsubsection{Situation und Entwicklung der Schiffbauindustrie nach 1945}

Die Schiffbauindustrie stellte nach dem Zweiten Weltkrieg zunächst eine sehr dynamische Wachstumsindustrie dar. Aufgrund des starken Wachstums der Weltwirtschaft und des Welthandels in den 50er und 60er Jahren, unterstützt noch durch die Zusatzbedarfe an Transportkapazität durch den Korea-Krieg und später durch die Schließung des Suez-Kanals, die den Transportweg für das immer stärker nachgefragte Nahost-Öl erheblich verlängerte, verdoppelte sich die Weltproduktion in BRT zwischen 1952 und 1958 und nach einer Stagnationsphase 1959-62 noch einmal bis 19691 . Fortschritte in der Schiffs- und Ladetechnik führten zu einer beschleunigten Ersetzung alter Schiffe und verstärkten diesen Boom noch ${ }^{2}$.

Während die Werften der EG-6 in der 1. Phase des Booms in hohem Maße am Marktwachstum teilhatten und ihren Anteil u.a. auf Kosten des stagnierenden britischen Schiffbaus auf bis zu 40\% (1958 immerhin noch 33\%) steigerten ${ }^{3}$, konnten sie an der zweiten Aufschwungsphase nur noch unterdurchschnittlich partizipieren, so daß ihr Weltmarktanteil auf ca. $20 \%$ fiel.

Diese Entwicklung ging mit einer ungebrochenen Expansion des japanischen Schiffbaus einher, für die mehrere Ursachen verantwortlich sind:

Nachdem die japanischen Werften zunächst für den Neuaufbau der eigenen Handelsflotte geliefert hatten, erfolgte nach 1955 eine verstärkte Exportorientierung. Die gleichzeitig durchgeführte Umstellung auf Serienfertigung von Massengutfrachtern, die das am stärksten wachsende Marktsegment darstellten, senkten den Entwicklungsaufwand und erhöhten die Produktivität massiv, so daß die japanischen Werften bei relativ niedrigen Lohnkosten ihren Konkurrenten im Wettbewerb überlegen waren und ihre Kapazitäten und die Produktion stark ausbauen konnten ${ }^{4}$.

Gleichzeitig wurde in Japan die bis dahin übliche Begleichung des Kaufpreises durch die Reeder in 5 Raten entsprechend dem Baufortschritt durch langfristige staatliche oder staatlich subventionierte Kredite an ausländische Reeder zu niedrigen Zinsen für bis zu $70 \%$ des Kaufpreises abgelöst, wodurch die Attraktivität japanischer Werften außerordentlich erhöht wurde 5 . Aufgrund der dominierenden Stel-

\footnotetext{
1 Vgl. Lammers 1984, S. 1-2, und Kolbe 1962, S. I.

2 Vgl. Fante 1983, S. 227.

3 Vgl. Kolbe 1962, S. I.

4 Vgl. Rother 1984, S. 132.

5 Vgl. Fante 1967, S. 120.
} 
lung der japanischen Werften setzte sich diese Zahlungsweise weltweit durch und führte in den folgenden Jahren zu einem regelrechten Kreditkonditionenwettlauf, in der BR Deutschland bspw. durch die Einführung verschiedener Werfthilfeprogramme mit zinsgünstigen Krediten der KfW seit 1962, allerdings erst ab 1971 für Intra-EG-Exporte und ab 1973 für Inlandslieferungen. Ähnliche Systeme existierten in Frankreich, Dänemark, Italien und Großbritannien, dazu gab es auch Finanzierungshilfen für inländische Reeder ${ }^{6}$.

\subsubsection{Reaktionen der Mitgliedstaaten}

Die hohe Bedeutung der Kreditkonditionen für die Kaufentscheidung der Reeder und die mit Subventionen verbundene mögliche massive internationale Wettbewerbsverzerrung führten auf OECD-Ebene ab 1963 zu Gesprächen über eine mögliche Harmonisierung der Kreditvergabebedingungen, die nach einem vorläufigen Abkommen einiger Mitgliedstaaten 1968 schließlich 1969 zu einem Schiffbauexportfinanzierungsabkommen führten, das Mindestverzinsung, Höchstlaufzeit und eine maximale Kreditsumme in Prozent des Kaufpreises festlegte ${ }^{7}$. Dieses Abkommen und seine Nachfolger, denen zunächst die EG-MS, ab 1980 dann die EG als solche beitraten, nahm quasi einen Aspekt der Schiffbauförderung aus der Subventionskontrolle durch die EG-Kommission heraus und verlagerte ihn auf eine übergeordnete Ebene. Aus diesem Grunde wird auf die Diskussion der Entwicklung dieser Abkommen hier zunächst verzichtet; dieser Aspekt wird jedoch in Abschnitt 4.2.4 wieder aufgenommen.

Die Internationalität des Schiffbau- und Schiffahrtsmarktes und insbesondere die Möglichkeit der Reeder, auf fremde Flaggen auszuweichen, machen die Einführung von Zöllen als Mittel zur Protektion der Schiffbauindustrie ungeeignet. Dies führt dazu, daß die Förderung des Schiffbaus international fast ausschließlich über verschiedene Formen der Subventionierung erfolgt ${ }^{8}$. Diesem Gesichtspunkt trug auch Art. 92,III c EWGV Rechnung, der Subventionen, die bereits 1957 bestanden und nur einen fehlenden Zollschutz kompensierten, mit der Maßgabe sanktionierte, daß diese entsprechend dem Zollabbau zwischen den MS ebenfalls abzubauen seien ${ }^{9}$. Für die Prüfung der Schiffbausubventionen wurde bereits 1959 eine Arbeitsgruppe von Regierungssachverständigen eingerichtet. Dennoch scheiterte der Versuch, den

\footnotetext{
6 Vgl. Gutowski/Thiel/Weilepp 1984, S. 27/28.

7 Vgl. Pfeiffer 1971, S. 531, und Gutowski/Thiel/Weilepp 1984, S. 28.

8 Vgl. Soltwedel et al. 1988, S. 160, Fn 1.

9 Vgl. Wallenberg 1992, S. 17.
} 
Subventionsabbau zeitgleich mit dem Zollabbau zu beginnen, da die Abstimmung mit den Vertretern der MS noch nicht erfolgt war ${ }^{10}$.

$\mathrm{Zu}$ diesen Subventionen gehörten neben Steuerbefreiungen für importierte Teile und Umsatzsteuerbefreiungen von Beginn der EG an auch direkte Baukostensubventionen in Frankreich und Italien. Diese Baukostensubventionen, die die mangelnde Wettbewerbsfähigkeit der Werften aufgrund hoher Materialkosten inländischer Zulieferer und geringer Arbeitsproduktivität ausgleichen sollten, betrugen bis zu $30 \%$ bzw. $27 \%$ der gesamten Schiffbaukosten ${ }^{11}$. In beiden Ländern wurde mit begrenztem Erfolg versucht, über Stillegungen, Fusionen und Modernisierung eine Angleichung an das Produktivitätsniveau der führenden Schiffbauländer zu erreichen und die Schrumpfung der eigenen Werften aus beschäftigungspolitischen und regionalen Gründen abzufedern ${ }^{12}$. In diesem Zusammenhang genehmigte die Kommission die Weiterführung der Beihilfen allerdings auf einem niedrigeren Niveau (nur F) und zunächst befristet und degressiv bis 1964 (Italien) in der Vorstellung, die direkten Baukostensubventionen danach abschaffen zu können ${ }^{13}$.

Zunehmende Schwierigkeiten der italienischen Werften führten allerdings dort 1961 zu einer Erhöhung der Beihilfen auf das Niveau von 195714. Diese Maßnahme wurde der Kommission notifiziert und von ihr auch genehmigt. Die Entscheidung 15 basierte auf Art. 92, III c (Entwicklung eines Wirtschaftszweiges) und war an die nachträgliche (!) Vorlage eines Sanierungsprogrammes gebunden, die 1962 in "großen Linien" erfolgte ${ }^{16}$. Trotz der damaligen Stagnationsphase im Weltschiffbau wurde eine Beeinträchtigung des gemeinschaftlichen Interesses verneint - wohl im Hinblick auf die damals allgemein günstigen Prognosen zur Zukunft des Schiffbaus.

Tatsächlich lag das Subventionsniveau nach einigen Senkungen in beiden Ländern 1964 ohne die Kreditsubventionen bei etwa 15-17\%, wobei die Subventionierung in der Stagnationsphase nach 1958 beiden Ländern erlaubte, eine größere Kapazität aufrechtzuerhalten und deutsche Werften in einigen Fällen auch zu unterbieten ${ }^{17}$.

\footnotetext{
10 Vgl. EWG, Kommission 1959, S. 92/93.

11 Vgl. Kolbe 1962, S. III-VIII.

12 Vgl. Kuhnert 1969, S. 168, Kolbe 1962, S. III-IV, und McLachlan/Swann 1967, S. 53f.

13 Vgl. EWG, Kommission 1963, S. 78/79. Ebenso wurden die oben erwähnten deutschen Export-

kreditsubventionen genehmigt.

14 Vgl. McLachlan/Swann 1967, S. 54.

15 Vgl. EWG, Kommission 1961a, S. 582/583.

16 Vgl. EWG, Kommission 1962, S. 87.

17 Vgl. Voltz 1966, S. 471/472, und Kuhnert 1969, S. 144.
} 


\subsubsection{Harmonisierungsarbeiten der Kommission}

\subsubsection{Erste Ansätze zur Subventionskontrolle während des Schiffbaubooms}

Nach diesen ersten ad-hoc Entscheidungen begann die Kommission, ein generelles Konzept zur Lösung der Subventionsproblematik zu entwickeln. Dieses zielte einmal parallel zu den laufenden Gesprächen innerhalb der OECD auf einen Ausgleich der Wettbewerbsnachteile der EG-Werften gegenüber Japan, zum anderen auf eine Harmonisierung der Förderung innerhalb der EG; ein schneller Subventionsabbau stand nicht mehr im Vordergrund 18 . Eine Arbeitsgruppe der Kommission und der MS hatte den Subventionswert der japanischen Exportkredithilfen auf durchschnittlich $10 \% 19$ des Vertragspreises geschätzt, und so wurde von der Kommission eine sog. "Gemeinschaftsbeihilfe" in gleicher Höhe vorgeschlagen, die allerdings von den MS aus nationalen Haushaltsmitteln gewährt werden und sowohl Inlands- als auch Exportaufträgen zugute kommen sollte. Die Form der Subventionierung wurde bewußt offengelassen, jedoch nannte der Vorschlag explizit Krediterleichterungen als Beispiel. Die Frist zwischen der Publikation des Vorschlags (April 1965) und seinem geplanten Inkrafttreten (Januar 1967) sollte von Frankreich und Italien zur Durchführung ihrer subventionierten Rationalisierungs- und Umstrukturierungspläne genutzt werden sowie zur Umstellung der Förderung auf die noch zu beschließende Art der Gemeinschaftshilfe 20 . Während der vorgesehene Satz von $10 \%$ Frankreich und Italien zur Senkung ihres Subventionsniveaus gezwungen hätte, ergab sich für Deutschland ein Subventionserhöhungsspielraum von 3-4\%, der von den deutschen Verbandsvertetern auch entsprechend eingefordert wurde 21 .

Der Vorschlag wurde von der Kommission als Reaktion auf die japanische Exportkreditförderung und die damals noch als gering angesehenen Chancen zur Erreichung von Wettbewerbsgleichheit in der OECD dargestellt, gleichzeitig jedoch als Element einer Verhandlungsmasse angesehen 22 . Die Subvention sollte jedoch ausdrücklich nicht die "natürlichen" Wettbewerbsdivergenzen ausgleichen; die hier existierenden strukturellen Rückstände sollten das Thema einer angekündigten strukturpolitischen Initiative sein, die auch weitere Umstrukturierungshilfen vorsehen würde. Dementsprechend läßt der RL-Vorschlag auch solche weiteren Subventionen

\footnotetext{
18 Vgl. Eußner 1983a, S. 51, und Swann 1983, S. 159-160.

19 Laut Kuhnert (1969, S. 169) wurde ein Subventionsgrad von 7,7-15,1\% festgestellt.

20 Vgl. EWG, Kommission 1965a, S. 5, 7f.

21 Vgl. Voltz 1966a, S. 1941, und Hansa 1968a, S. 961.

22 Vgl. Hansa 1965a, S. 1257.
} 
ausdrücklich zu, deren Prüfung entsprechend dem normalen Verfahren ablaufen soll (Art. 5, II).

Schon während der Phase der Diskussion des Kommissionsvorschlages in den MS legte diese in ihren Entscheidungen zur Subventionspolitik diese Werte zugrunde: So wurden die französischen Subventionen nach vorübergehender Einleitung des repressiven Verfahrens 23 zunächst 1967 auf $14 \%$ und ab 1.1 .1969 auf $10 \%$ des Kaufpreises gesenkt; gleichzeitig (1967) wurden für Italien $15 \%$ der Baukosten abnehmend auf $10 \%$ bis 1971 und ab 1972 auf $10 \%$ des um die Subventionen niedriger liegenden Kaufpreises genehmigt. Auch die deutschen und niederländischen (später noch die belgischen) Krediterleichterungen wurden im Hinblick auf die 10\%-Grenze geprüft und genehmigt 24 .

Die Diskussionen im Ministerrat ab 1965 zeigten einerseits deutsches und niederländisches Drängen auf einen Abbau der Werftsubventionen 25 , andererseits die Abneigung der MS gegen ein obligatorisches Subventionssystem mit zwingenden finanziellen Verpflichtungen und stattdessen eine Präferenz für einen EG-weiten Höchstsatz mit einheitlichen Vergabebestimmungen 26.

Dementsprechend eröffnete die im Juli 1969 verabschiedete RL27 den MS die Möglichkeit, ohne Durchlaufen des normalen Prüfungsvorgangs nach Art. 93 spezifische Schiffbausubventionen bis zu 10\% des Vertragspreises zu gewähren (Art. 2,II). Gleichzeitig wurden in Abweichung zum Vorschlag wesentlich kleinere Schiffe (100 statt 3000 BRT als Mindestgrenze) in die Regelung einbezogen.

Ihren ursprünglichen RL-Vorschlag hatte die Kommission auf Art. 235 EGV gestützt, da der EGV eine nationale Subventionsverpflichtung durch EG-Recht nicht vorsah 28 . Der nun verabschiedeten RL konnte dagegen Art. 92, III d (alte Fassung) zugrunde gelegt werden 29 . Die Initiative zur Subventionsgewährung verblieb also bei den MS, der erste Versuch der Kommission zum industriepolitisch motivierten direkten Durchgriff auf die Kassen der MS war somit gescheitert.

Ein Problem dieser RL lag in der Beschränkung der Kontrolle auf schiffbauspezifische Beihilfen, d.h. allgemeine Exportfördersysteme oder verschiedenste

23 Vgl. EWG, Kommission 1967, S. 113.

24 Vgl. Kuhnert 1969, S. 101-103, EG, Kommission 1968, S. 75, und Hansa 1968, S. 388.

25 Vgl. Heeckt 1965, S. 353.

26 Vgl. EG, Kommission 1968, S. 58.

27 Vgl. EG, Rat 1969, S. 25-26.

28 Vgl. EWG, Kommission 1965a, S. 9.

29 Vgl. Kap. 3.1 und Wallenberg 1992, S. 17/18. 
Methoden der Finanzierungshilfen für Reeder wurden nicht in die Höchstgrenze einberechnet ${ }^{30}$.

Die Kommission betrachtete diese 1. RL dennoch als Erfolg, da der Anteil der EG-6 am Weltschiffbau gehalten und eine stärkere Konzentration auf höherwertige Schiffe, bei denen die Arbeitskostennachteile der EG-Länder nicht so gravierend durchschlugen, erreicht werden konnte 31 . Dennoch muß man sagen, daß die RL nur diejenigen Obergrenzen kodifizierte, die bereits vor ihrer Verabschiedung, allerdings unter dem Einfluß des vorliegenden Vorschlages, erreicht worden waren.

Wegen der sehr guten Schiffbaukonjunktur, die aufgrund eines spekulativen Tankerbooms auch die Auslastung der weniger wettbewerbsfähigen Werften sicherte, gelang schon während der Laufzeit der 1. RL eine Reduktion der direkten nationalen Subventionen außer in Italien (dort 10\%) auf im Durchschnit 5\% 197132. Dieser Wert wurde nun in der 2. RL für 1972 wiederum kodifiziert, während für 1973 eine Höchstgrenze von $4 \%$ vorgesehen $\operatorname{war}^{33}$.

Die neue RL macht in Art. 3 die Begrenztheit der gefundenen Regelung sehr deutlich: Kreditsubventionen unter den Bedingungen des OECD-Abkommens für Exporte, aber auch für Inlandsaufträge sind von der Höchstgrenze ausgenommen, obwohl die Subventionen für den Schiffbau ursprünglich genau mit diesen Kreditsubventionen dritter Länder begründet worden waren. Auch indirekte Subventionen wie Reederhilfen sowie Systeme der Kostensteigerungsversicherung, die in Frankreich (ab 1972) und Großbritannien (ab 1975) den Werften gegen eine geringe Prämie einen staatlichen Ausgleich von Kostenerhöhungen und damit in einem inflationären Klima eine Lieferung zu Festpreisen ermöglichten, fielen nicht unter die Höchstgrenze, obwohl die Kommission diese Versicherung ebenso wie Ausfuhrkreditsubventionen in ihrem ursprünglichen Vorschlag in die Höchstgrenze hatte einbeziehen wollen ${ }^{34}$. Ebensowenig beschloß man Beschränkungen der Beihilfen für die irische (die 2. RL enthielt in Art. 6 bereits Regelungen für die Neumitglieder) und die italienische Schiffbauindustrie. Für Italien wurde lediglich eine Degression der ca. 10\%igen Beihilfen und tatsächliche Durchführung eines Sanierungsprogramms mit dem Ziel, 1976 das EG-Niveau an Wettbewerbsfähigkeit zu

\footnotetext{
30 Vgl. Pfeiffer 1971, S. 531f.

31 Vgl. EG, Bulletin 1972, S. 45.

32 Vgl. Soltwedel 1988, S. 157, und EG, Kommission 1972a, S. 150.

33 Vgl. EG, Rat 1972, S. 28-29, hier Art. 3,I.

34 Vgl. EG, Bulletin 1972, S. 47.
} 
erreichen, vorgeschrieben (Art. 3, II). Ein entsprechendes Programm der Regierung wurde von der Kommission dann auch 1973 genehmigt 35 .

Bei der Anwendung der französischen Kostensteigerungsversicherung ergab sich das zusätzliche Problem, daß der Ausgleich für 3,6\% übersteigende Kostenerhöhungen nur für inländische Vorprodukte galt und somit Importe unter Verstoß gegen die 2. RL diskriminierte. Die daraufhin eingereichte Klage der Kommission gegen Frankreich wegen Vertragsverletzung wurde 1974 zurückgezogen, da sich Frankreich bereit erklärte, Importe aus MS in die Regelung einzubeziehen 36 .

Summa summarum war die Subventionskontrolle durch die 2. RL eher weich und unvollständig, zudem traten Probleme mit den Neumitgliedern auf: So wurde die Absicht Dänemarks, Zollvergütungen für importierte Motorenteile auf im Inland produzierte Motorenteile auszudehnen, von den anderen MS ebenso abgelehnt wie die britische Absicht einer Subventionierung von Kriegsschiffexporten 37.

Der Fortschritt der 2. RL wurde schließlich nur "in der Vorbereitung einer dritten RL" gesehen, "die eine Koordinierung sämtlicher direkten sowie indirekten Beihilfen ... vornehmen soll"38. Gelänge dies nicht, so sahen Kommissionsexperten es schon im Mai 1973 als notwendig an, die Obergrenze der direkten Subventionen nach 1973 von 4 auf $6 \%$ zu erhöhen ${ }^{39}$.

Da der Vorschlag zu dieser dritten RL vom 5.11.1973 im Rat zunächst keine Akzeptanz fand, wurde die 2. RL insgesamt dreimal um jeweils ein halbes Jahr bis 30.6.1975 verlängert 40 .

Der ursprüngliche Vorschlag einer 3. RL 41 war gekoppelt mit einem Kommissionsprogramm zur Sektorpolitik im Schiffbau, das u.a. Elemente eines Plandatensystems zur Investitionskonzertierung, eine partielle Investitionslenkung zur Umstrukturierung und Modernisierung durch eine gemeinschaftliche Forschungsund Beihilfepolitik sowie einen permanenten Diskussionsausschuß mit den Sozialpartnern vorsah 42 . Außerdem strebte die Kommission statt der Produktionssubventionen eine verstärkte Förderung von Anpassungsinvestitionen an, da sie

\footnotetext{
35 Vgl. EG, Kommission 1974a, S. 87/88.

36 Vgl. Langer 1974, S. 210/211, und EG, Kommission 1975a, S. 104.

$37 \mathrm{Vgl}$. Journal de la Marine Marchande 1973, S. 1075.

38 Langer 1974, S. 207.

$39 \mathrm{Vgl}$. Journal de la Marine Marchande 1973, S. 1075.

40 Vgl. Schina 1987, S. 86.

41 Vgl. EG, Kommission 1973b, S. 23-27.

42 Vgl. Fendel 1981, S. 506.
} 
gegen Ende der 70er Jahre (!) Überkapazitäten und einen verschärften Wettbewerb erwartete 43 .

Der eigentliche Richtlinienentwurf versuchte auf mehreren Ebenen, die Kontrollmöglichkeiten aufgrund der 2. RL zu erweitern. So sollte der Vorteil der Hochinflations- und -zinsländer aus der Mindestzinssatzregelung der OECD-Exportkreditvereinbarungen begrenzt werden (Art. 4, s. auch Abschnitt 4.2.4.1.). Außerdem wurden für Investitionsbeihilfen (für Invest. $>4$ Mio. RE) und Beihilfen zur Rettung von Unternehmen oder Arbeitsplätzen ein Ex-ante-Meldeverfahren mit dreimonatiger Prüfungsfrist für die Kommission vorgesehen (Art. 6). Diese Regelung geht eigentlich nicht über die Vertragsregeln hinaus, ihre explizite Erwähnung legt nahe, daß die MS die Regeln vorher nicht beachteten. Schließlich wurden als Höchstsätze für die Subventionierung von Aufträgen die Werte von $5 \%$ bzw. $4 \%$ für 1974 und 1975 vorgeschlagen; für die folgenden Jahre war ein weiterer Abbau um $1 \%$-Punkt p.a. vorgesehen (Art. 4). Da die Auszahlung der Beihilfen i.d.R. wesentlich später als der Vertragsabschluß erfolgte (der Vorschlag setzte eine Maximalfrist von 5 Jahren) und der Subventionsbetrag mit 8\% p.a. auf den Zeitpunkt des Vertragsabschlusses abzuzinsen war, betrug die effektive Höchstgrenze für 1974 7,3\%. Den Ländern, deren Subventionshöhe unterhalb des Limits lag, war eine Erhöhung nur bei einem "stichhaltigen Grund" und erst nach Zustimmung der Kommission erlaubt (Art. 5), was zu einer Diskriminierung dieser Länder geführt hätte, die allerdings bei erfolgreichem Abbau der Höchstgrenzen nur von geringer Bedeutung gewesen wäre.

Die Rechtfertigung der Subventionierung erfolgte nunmehr nicht mehr primär mit internationalen Wettbewerbsverzerrungen, sondern mit regional- und beschäftigungspolitischen Argumenten, nichtökonomischem Unabhängigkeitsstreben im Seeverkehr und der Behauptung, daß der Schiffbau Hochtechnologie entwickle ${ }^{44}$, also quasi mit positiven Externalitäten.

Die Verhandlungen im Rat zeigten, daß nur Frankreich und Italien der Sektorpolitik der EG zuneigten und Großbritannien die Subventionsrichtlinie nicht befürwortete, da seine Schiffbausubventionen bisher als regionalpolitische Maßnahmen kaum einer Kontrolle unterlagen 45 . Zudem lehnten die MS z.T. eine vorherige

\footnotetext{
43 Vgl. EG, Kommission 1974a, S. 84/85, auch Friz 1976, S. 384.

44 Vgl. EG, Kommission 1973b, S. 25. Vgl. zur Rechtfertigung der deutschen Subventionen und Wandel auch Lammers (1984, S. 17)

45 Vgl. hierzu das Beispiel der Hilfen für Govan Shipbuilders in Field/Hills 1976, S. 14, 16, und Fendel 1981, S. 508/509.
} 
Prüfung von Subventionen für Investitionen ab, da sie Eingriffe in ihre wirtschaftspolitische Autonomie und eine zentrale Investitionslenkung durch die Kommission befürchteten, was die Kommission wohl auch beabsichtigte 46 . Diese Streitigkeiten führten zu den o.a. Verzögerungen und der dreimaligen Verlängerung der 2. RL. Zudem fällt in diese Diskussionsphase der Ausbruch der 1. Ölkrise. Der darauffolgende starke Rückgang der Schiffs-, insbesondere der Tankernachfrage ließ nach Abarbeitung der Auftragsbestände in allen MS erhebliche Überkapazitäten befürchten, was den Willen der MS zu einer umfassenden Kontrolle der Subventionen sowohl für Aufträge als auch für (Anpassungs-) Investitionen erheblich reduzierte und den vorherigen Rückgang der direkten Beihilfen stoppte 47 .

Im Februar 1975 forderte COREPER die Kommission zur Abgabe eines neuen RL-Vorschlages auf, den diese im Mai abgab. Die endgültige Richtlinie 48 wurde dann im Juli beschlossen.

Beihilfen für den Bau von Schiffen waren danach in der bisherigen Höhe bis Ende 1975 erlaubt, dem Datum, das auch in der OECD für die Abschaffung aller direkten Beihilfen angestrebt wurde 49 . Über diesen Termin hinaus wurden Subventionen für irische und italienische Werften in Verbindung mit Sanierungsprogrammen erlaubt, ebenso die französischen Preisgarantieregelungen, sofern ihre Bedingungen schrittweise verschärft wurden (Art. 2). Daneben waren Kredithilfen (auch für den Inlandsabsatz) entsprechend den OECD-Bedingungen weiterhin erlaubt (Art. 3). Für Beihilfen zum Erhalt eines Unternehmens galt zwar das übliche Melde- und Prüfungsverfahren des EGV, aber keine Höchstgrenze, für Investitionsbeihilfen wurde lediglich eine Meldepflicht, aber keine Prüfungsmöglichkeit der Kommission festgelegt (Art. 4 und 5). Hier sollte eine multilaterale Erörterung im Rat Transparenz und Koordination fördern 50 .

Insgesamt war nicht nur der zweite Anlauf zu einer umfassenden sektoralen Strukturpolitik gescheitert, sondern auch der Versuch einer Einbeziehung aller auch indirekten Subventionen für den Schiffbau in eine strikte und umfassende Kontrolle 51 . Es blieb eine breite Mitteilungspflicht an die Kommission, für die die RL Tabellenschemata enthielt, jedoch war eine Publikation dieser Daten zur Erhöhung

\footnotetext{
46 Vgl. EG, Kommission 1976a, S. 94/95.

47 Vgl. Fante 1975, S. 177.

48 EG, Rat 1975, S. 27-29.

49 Vgl. EG, Rat 1975, S. 27, und Abschnitt 4.2.5.2.

50 Vgl. EG, Kommission 1976, S. 95.

51 Vgl. Fendel 1981, S. 511/512.
} 
der Transparenz der Subventionsvergabe ausdrücklich nicht vorgesehen (Art. 2,III). In einer Anlage zum RL-Vorschlag vom Mai 1975 gab die Kommission eine recht resignativ wirkende Erklärung ab, in der sie die vorgesehenen Beihilfen als ausreichend bezeichnete und auf ihr vorrangiges Prüfungsrecht nach Art. 93 EGV verwies 52 .

Der in Großbritannien 1975 analog dem französischen Modell eingeführte Preisgarantiemechanismus wurde 1976 in die Ausnahmen der 3. RL eingeschlossen. Zunächst hatten sich bei der britischen Regelung dieselben Probleme wie im französischen Fall ergeben 53 . Diese Regelungen bewirkten in den damaligen inflationären Zeiten ein relativ hohes Subventionsniveau, das im Falle Frankreichs nach Schätzungen des VDS 1976 ca. $20 \%$ bezogen auf den Preis ausmachte 54.

\subsubsection{Harmonisierungsrückschritte in der Krise}

Die Anwendung der 3. RL wurde nun durch die rasch einsetzende Schiffahrtsund Schiffbaukrise als Folge der 1. Ölkrise und der folgenden Rezession beeinträchtigt. Schon von 1973, dem Höhepunkt des spekulativen Tankerbooms, auf 1974 waren die Weltauftragseingänge um ca. $60 \%$ (von 73 Mio. auf 28 Mio. BRT) gefallen; der Auftragsbestand erreichte seinen Höhepunkt 1974 und fiel dann, wegen der üblicherweise 2-3 jährigen Bauzeit eines Schiffes entsprechend verzögert, erreichte jedoch 1976 nur noch $49 \%$ und 1977 gar nur 33\% seines Höchststandes (dazu trugen Annullierungen bei55). Die Ablieferungen schließlich erhöhten sich 1975 noch einmal und fielen dann nach einem leichten Rückgang 1976 im Jahre 1977 auf $80 \%$ des Wertes von 1975 (vgl. Tab. 4.2-1). Da viele Länder, auch die EG-Länder, in Erwartung eines anhaltenden Expansionstrends ihre Kapazitäten gerade im Großtankerbau erheblich erweitert hatten 56 und da Schwellenländer wie Südkorea, Taiwan und Brasilien mit Hilfe staatlicher Unterstützung gerade im Tankermarkt, in dem sie wegen der geringen technischen Anforderungen ihre Lohnkostenvorteile voll ausspielen konnten, sehr stark eingestiegen waren, hatte der Weltschiffbau nun mit massiven Überkapazitäten zu kämpfen 57 , die auch wegen des fallenden Welttrans-

52 Vgl. EG, Kommission 1975b, Anlage II.

53 Vgl. EG, Kommission 1977a, S. 128/129.

54 Vgl. Fante 1976, S. 77.

55 Vgl. EG, Kommission 1976b, S. 1, 4, Anlage V. Diese Annullierungen betrugen allein 197518 Mio. BRT.

$56 \mathrm{Vgl}$. Nölling 1976, S. 240.

57 Vgl. hierzu EG, Kommission 1976b, S. 1, 3-4. Hier wurden die Überkapazitäten für den Zeitraum 1976-80 auf ca. $40 \%$ geschätzt, für Tanker sogar auf $60 \%$, wobei allerdings ein Ölpreis 


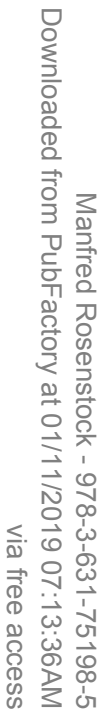

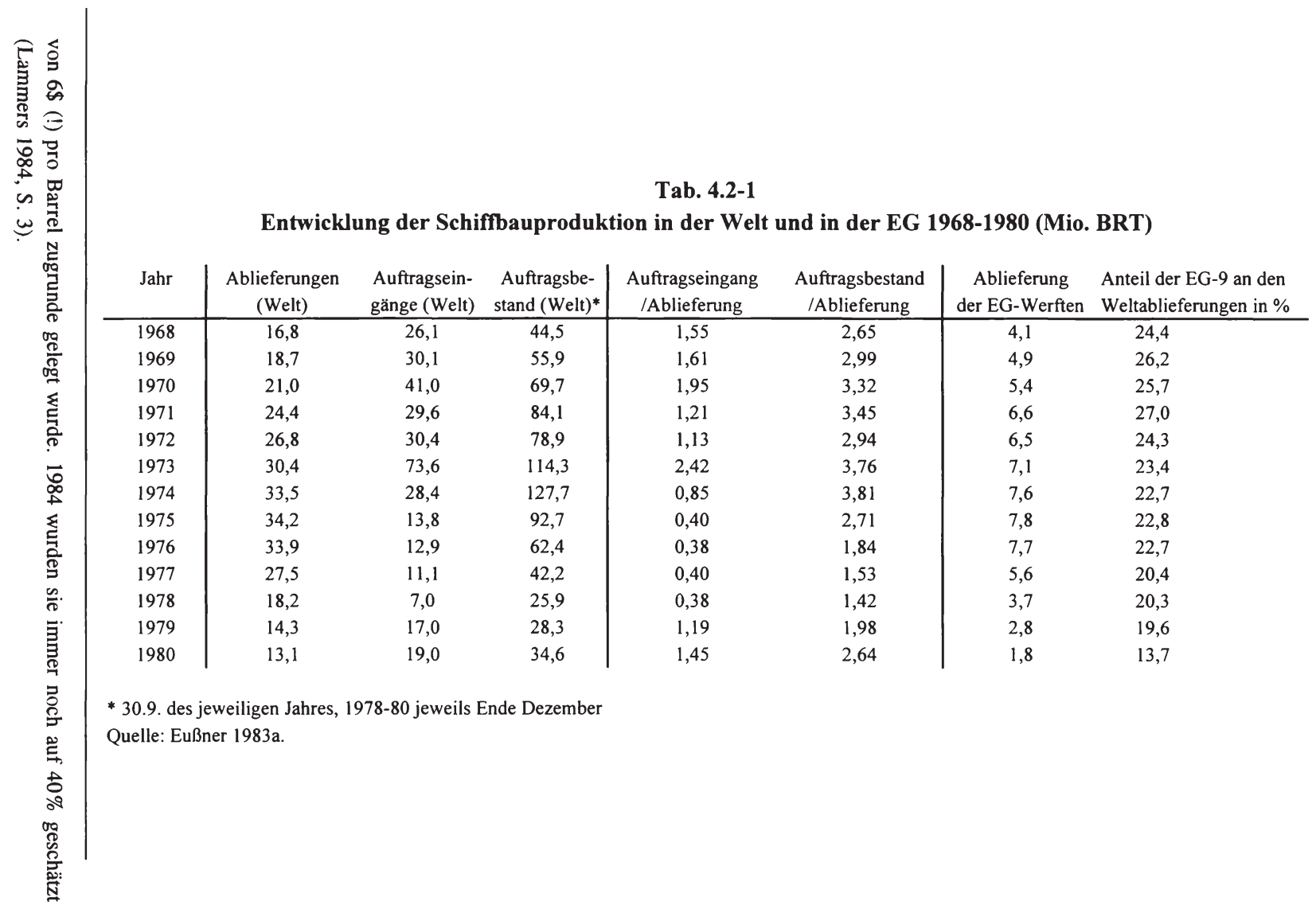


portaufkommens, somit sinkender Frachtraten und abnehmender Zahlungsfähigkeit der Reeder zu einem stark verschärften Preiswettbewerb führten, dem die MS wegen ihrer z.T. veralteten Anlagen nicht gewachsen waren 58 . Auf die Gefahren solcher Überkapazitäten war bereits 1968 warnend hingewiesen worden ${ }^{59}$, und während die EG-Kommission in einer Antwort auf eine parlamentarische Anfrage Anfang 197260 das Problem noch etwas heruntergespielt hatte, waren ihre o.a. industriepolitischen Vorschläge von 1973 doch auch auf die Bewältigung dieser Kapazitätsprobleme ausgerichtet gewesen. Trotz des Scheiterns ihrer Initiative wies die Kommission auch 1976 wieder auf die Notwendigkeit eines koordinierten Kapaziätsabbaus hin, da auch die nationalen Hilfen nicht vermocht hatten, die Konkurrenzfähigkeit der Werften der EG zu verbessern61. Dennoch zwang die Krise mit ihren insbesondere regionalen Beschäftigungsproblemen die Kommission unter dem Druck der MS insbesondere ab 1977 zu einer noch großzügigeren Subventionskontrollpolitik und der Genehmigung höherer Fördersätze, wobei "der Rahmen der 3. EG-Richtlinie ... gesprengt" wurde 62 .

Zwar wurden die direkten Baukostensubventionen in Italien nach einer Senkung von $9 \%$ auf $4 \%$ von 1972-76 auch für 1977 nochmals auf 3,8\% zurückgenommen, doch genehmigte die Kommission staatliche Investitionskredite an die Werften zu 5\% Zinsen ebenso wie Beihilfen für die Schiffsreparatur, obwohl letztere nach der 3. RL verboten waren 63 .

Die ausbrechende Krise führte auch in Deutschland zu Forderungen der Küstenländer und der Verbände nach Erhöhung der Unterstützung durch Kumulation von Werft- und Reederhilfen, OECD-Kredithilfen in voller Höhe und Ausdehnung der Fördersumme, wobei die erste Forderung auch umgesetzt wurde 64 .

Im Falle Großbritanniens wurden pauschale Hilfen von bis zu 30\% für Aufträge der 1977 verstaatlichten Werften zwar abgelehnt und stattdessen Einzelbefassung der Kommission gefordert; die Genehmigung dieser Hilfen sollte von Fortschritten bei den Umstrukturierungsplänen abhängig gemacht werden, jedoch wurden 1977 alle 14 Subventionsanträge mit dem Argument genehmigt, daß die Aufträge sonst an

\footnotetext{
58 Vgl. EG, Kommission 1977b, S. 5/6.

59 Vgl. Beplat 1968, S. 661.

60 Vgl. EG, Kommission 1972b, S. 6.

$61 \mathrm{Vgl}$. EG, Kommission 1976b, S. 18.

62 Dohnanyi 1978, S. 302.

63 Vgl. EG, Kommission 1977a, S. 127.

64 Vgl. Nölling 1976, S. 241/242.
} 
Drittländer gegangen wären65. Dies stellt zwar eine vollkommene Negierung des Prinzips der internationalen Arbeitsteilung dar, ist aber angesichts des begrenzten Auftrages der Beihilfenkontrolle, Verzerrungen zwischen den $M S$ zu vermeiden, aus dieser engen Sicht nicht zu kritisieren. Auch für die niederländischen Werften, die von der Krise besonders heftig (v.a durch Exportverluste) betroffen waren, wurden Subventionen bis zu 30\% des Auftragspreises genehmigt, sofern die Beihilfen 20\% des Jahresumsatzes der Werft insgesamt nicht überschritten, wobei die Subventionen z.T. als Kredithilfen oder Beiträge des Staates zu Abfindungen an entlassene Arbeitnehmer, z.T. als $75 \%$ iger Verlustausgleich für die Werften gegeben wurden. Auch die nach einer vorübergehenden Abschaffung 1976 in 1977 wieder eingeführten französischen Auftragssubventionen von 13-20\% wurden von der Kommission genehmigt 66 .

Als weitere Möglichkeit zur Förderung der eigenen Werften unter "legaler Umgehung" der OECD-Regeln diente der subventionierte Export von Schiffen in Entwicklungsländer als Entwicklungshilfe. Diese Art der Hilfe war durch die OECDRegeln gedeckt, wenn der Subventionswert mindestens 25\% der Kosten ausmachte 67 , um so ein signifikantes Hilfselement aufzuweisen, und wurde v.a. von Deutschland (ab 1976) und den Niederlanden genutzt, wobei die Subventionshöhen i.d.R. zwischen $25 \%$ und $30 \%$, in zwei Fällen jedoch über $60 \%$ lagen 68 .

65 Vgl. EG, Kommission 1978a, S. 166.

66 Vgl. EG, Kommission 1978a, S. 168/169.

67 Vgl. Lammers 1989, S. 120

68 Vgl. EP 1978, S. 12 und 24. Nachdem die "normale" Kapazitätsauslastung 1977 fiel, wurde die Förderung in diesen Bereich umgelenkt. Vgl. Lammers 1984, S. 10.

In Deutschland geht die Initiative zu einer solchen Beihilfe von der jeweiligen deutschen Werft aus, die sich, sobald sie einen entsprechenden Kunden hat, zum Erhalt einer günstigen Finanzierung an die KfW wendet. Diese verwaltet als Mandatar die Mittel für Werftsubventionen im Auftrag des Bundes. Sie prüft die Förderungswürdigkeit des Auftrages anhand der Kriterien der EG-Richtlinie und des Bundes (Schiff höherer technischer Qualität), stellt fest, ob noch ausreichende Fördermittel vorhanden sind und ob für das betreffende Land eine Hermes-Bürgschaft möglich ist, und genehmigt dann nach Zustimmung der Bundesregierung den zinsgünstigen Kredit. Dieser Beihilfentyp ist in Deutschland auch deswegen verbreitet, da hier im Verhältnis zu anderen MS ein höherer Anteil der Produktion auf hochwertige Spezialschiffe entfällt. Diese Schiffe können dann mit signifikanten Subventionen an Entwicklungsländer verkauft werden, während sich letztere einfachere Schiffe in Ländern wie Südkorea auch ohne Entwicklungshilfesubventionen preisgünstiger beschaffen können. (Der Verfasser dankt Herrn Prof. Dr. Werner Fassing, KfW, für diese Auskünfte.) 
In dieser Genehmigungspraxis manifestiert sich auch ein Konflikt zwischen der zuständigen DG IV Wettbewerb und der DG III für Industrie ${ }^{69}$. Letztere drängte darauf, die Subventionen für Großbritannien und die Niederlande freizugeben, um die Stimmung in diesen MS bzgl. der industriepolitischen Konzepte der DG III zu verbessern. Das Sanierungsprogramm für den Schiffbau vom Oktober 197770 verfolgte das Ziel, einen maßgeblichen Einfluß der Kommission bei der Sanierung des Sektors zu sichern über die Einsetzung eines Schiffbauausschusses aus Kommission und MS, der Orientierungen für den Kapazitätsabbau vorgeben sollte, über eine Verknüpfung von Subventionen mit Umstellungsinvestitionen, die der Kommission eine indirekte Investitionslenkung über die Genehmigungspflicht dieser Beihilfen ermöglichen sollten und über die Ausgabe von EG-Mitteln des EFRE und des ESF für Umschulungs- und Sanierungsmaßnahmen sowie schließlich über nachfrageerhöhende Maßnahmen (höhere Umwelt- und Sicherheitsauflagen). Die Kosten dieses Programms, das zu einer Kapazitätsreduktion der EG-Werften von 46\% auf 2,4 Mio. GBRT für 1980 führen sollte ${ }^{71}$, schätzte die Kommission auf 1 Mrd. RE jährlich für 5 Jahre, von denen ein Teil aus dem Gemeinschaftshaushalt bestritten werden sollte. 1979 schob die Kommission noch den Vorschlag einer subventionierten Abwrack- und Neubauaktion im Verhältnis von 2:1 bezogen auf GBRT nach, mit dem sowohl die Werftenauslastung verbessert als auch die Flottenüberkapazität vermindert werden sollte, und dessen zusätzliche Kosten sie auf 145 Mio. ERE pro Jahr schätzte $^{72}$. Die Kommission strebte dabei eine Teilfinanzierung durch die MS an, während sie die Genehmigungskompetenz für die Gesamtmittel und die Überwachung der Durchführung bekommen sollte. Die Unterschiede in der Altersstruktur und Größe der Flotten der MS, u.a. die große und überaltete griechische Flotte, hätten jedoch das Programm erheblich verteuert und die Kosten den MS mit jüngeren Flotten aufgebürdet, was nicht akzeptabel war. So wurde der Vorschlag 1981 auf Eis gelegt ${ }^{73}$.

Auch diese Versuche der Kommission, direkte Kompetenzen zur Sanierung dieses Krisensektors zu erhalten, scheiterten somit. Der Rat verabschiedete lediglich eine Entschließung zur Sanierung des Schiffbaus 74 mit allgemein gehaltenen Empfeh-

69 Vgl. hierzu und zum folgenden Fendel 1981, S. 525/526.

70 EG, Kommission 1977b, S. 12-16.

71 Eine Zahl, die im übrigen fast genau auch tatsächlich erreicht wurde!

72 Vgl. EG, Kommission 1979b, S. 25-27.

73 Vgl. Eußner 1983, S. 155, 169. Stattdessen existierte in Italien und auch in Japan ein nationales

74 Programm dieser Art. Vgl. 
lungen an Industrie und nationale Regierungen sowie der Zuteilung der Aufgabe an die Kommission, Vorschläge zur Strukturanpassung und Nachfrageerhöhung zu machen sowie regelmäßige Berichte zur Lage der Schiffbauindustrie zu erstellen.

Als Ergebnis des Kommissionshandelns in dieser Ausbruchsphase der Krise läßt sich festhalten, daß die vorher versuchte Rückführung und Harmonisierung der direkten Baukostensubventionen zusammenbrach, daß durch die Subventionserhöhungen sogar die 3. RL explizit verletzt wurde und die Gefahr von Wettbewerbsverzerrungen durch die divergierenden Subventionsniveaus stark anstieg75. Im Falle Dänemarks, wo die Schiffbauförderung über Reedersubventionen erfolgte und 1977-79 deutlich erhöht wurde ${ }^{76}$, erreichte die Kommission zumindest, daß diese Hilfen auch bei Aufträgen an Werften in anderen MS gezahlt wurden 77 .

Die weichere Haltung der Kommission wurde auch im Entwurf und dem endgültigen Text der 4. RL deutlich 78 . In den Erwägungen der RL wird anerkannt, daß die 3. RL nur in ihrer Anlaufzeit zu einem Subventionsabbau beigetragen hatte. Produktionsbeihilfen wurden nun als Krisenmaßnahmen grundsätzlich gestattet (Art. 6), wobei sie degressiv und an Umstrukturierungsmaßnahmen gebunden sein mußten. Die Kommission sollte zudem einen Höchstsatz veranschlagen. Sie konnte jedoch sowohl bezüglich der Degression als auch der Maximalhöhe bei besonders starker Betroffenheit von der Krise Ausnahmen zulassen und mußte bei konkurrierenden Angeboten aus mehreren MS die gebotenen Subventionen im Einzelfall vorher prüfen. Zusätzlich waren Subventionen zur Rettung von Unternehmen genehmigungsfähig, ebenso Reederhilfen, sofern sie nicht den Kauf in anderen MS diskriminierten, sowie die Preisgarantiesysteme einiger MS, sofern sie degressiv waren (Art. 5, 7, 8). Da für die Rettungshilfen kein quantitatives Limit vorgesehen war, erlaubten sie den MS, in der Krise ihre Werften in der von ihnen gewünschten Höhe zu unterstützen 79 . Versuche der Bundesregierung, hier Höchstgrenzen festzuschreiben, scheiterten am Widerstand der Partner 80.

Erstmals enthielt die RL Regeln zu Investitionshilfen (Art. 4). Sie wurden in spezifischer Form verboten, wenn sie kapazitätserhöhend wirkten; auch war zu vermei-

\footnotetext{
75 Diese Ansicht vertritt auch das EP. Vgl. EP 1978, S. 8/9, 15.

76 Vgl. Weilepp 1989, S. 65.

77 Vgl. EG, Kommission 1978a, S. 170/171.

78 Vgl. EG, Kommission 1977c, S. 4-7 und EG, Rat 1978a, S. 19-25. Da der Entwurf von der DG IV in Kooperation mit den MS erarbeitet worden war, wurde er innerhalb von 5 Monaten ohne 79 größere Änderungen

80 Vgl. Fante 1978, S. 108.
} 
den, daß regionale oder allgemeine Beihilfen diese Wirkung haben. Zur Kontrolle war hier eine Ex-ante-Meldung an die Kommission vorgesehen. Im ursprünglichen Entwurf hatte die Kommission hier eine Ex-ante-Meldung aller kapazitätserhöhenden Investitionsbeihilfen vorgesehen, die dann von ihr nach regionalpolitischen Gesichtspunkten und danach, ob die Gesamtkapazität in einem MS erhöht worden wäre, beurteilt werden sollten 81 . Dieses Konzept wurde im Rat nicht akzeptiert, da insbesondere Deutschland und Großbritannien hier einen Ansatzpunkt für Investitionskontrolle und -lenkung durch die Kommission befürchteten, was in der Tat den Intentionen der Vertreter der DG III für Industrie entsprach 82.

Neben dem üblichen Verweis auf die OECD-Kreditabkommen (Art. 2) wurde wiederum eine umfassende Berichtspflicht der MS an die Kommission festgelegt. Die daraus von der Kommission zu erstellenden Gesamtberichte sollten der Diskussion mit den Sachverständigen der MS dienen (Art. 6). Hierin steckte ein Ansatz, die alleinige Entscheidungskompetenz der Kommission in Subventionsfragen an ein Kollegium von Vertretern der MS zu verlieren, welches eine ausgezeichnete Basis für politische Tauschhändel schuf. Durch die Verpflichtung der Kommission, bei der Beurteilung der Subventionen auch die Ziele des vom Rat zu verabschiedenden Sanierungsprogramms zu berücksichtigen, wäre ihr diskretionärer Spielraum noch weiter eingeschränkt worden, wenn dieses oben erwähnte Programm konkrete Vorgaben enthalten hätte.

Durch diese Kompetenzeinschränkung und die Erlaubnis "vorübergehender oder degressiver" 83 - d.h. bei geringem Degressionsgrad quasi permanenter - Subventionen unter Verzicht auf explizite Höchstgrenzen war die ursprüngliche Absicht der ersten beiden RL einer vorübergehenden Subventionierung mit dem Ziel einer Harmonisierung "nach unten" im Blick auf eine kurzfristige Abschaffung völlig aufgegeben worden 84 . Im Gegenteil, der weitere Rahmen für Subventionen führte von Seiten der deutschen Schiffbauvertreter zu Forderungen nach Baukostensubventionen für deutsche Werften 85 , die auch erfüllt wurden (s.u.).

In Anwendung der RL setzte die Kommission eine Höchstgrenze für die Produktionssubventionen von $30 \%$ des Vertragspreises, was bei einem Wertschöpfungsanteil von ca. $40-50 \%$ im Schiffbau einer mehr als doppelt so hohen Subventio-

81 Vgl. EG, Kommission 1977c, S. 6, Art. 4.

82 Vgl. Fendel 1981, S. 527, und Butt Philip 1986, S. 16.

83 EG, Rat 1978, S. 19.

84 Vgl. Swann 1983, S. 160.

85 Vgl. Bartels 1978, S. 633. 
nierung der Wertschöpfung und damit nach Aussagen der Kommission 86 einer quasi völligen Übernahme der Lohnkosten durch den Staat entsprach.

In dieser Größenordnung wurden dementsprechend die Subventionsprogramme der MS genehmigt, wobei die Art der Unterstützung zwischen den MS variierte: Während Frankreich, Italien und Großbritannien (vorübergehend auch Deutschland) direkte Produktionssubventionen anwandten und in diesen drei Ländern zudem noch Preisgarantiemechanismen existierten, lag der Schwerpunkt in Holland und Irland auf Verlustausgleichen für die Werften 87.

In Frankreich 88 lag die direkte Hilfe zunächst 1978 bei $25 \%$, die Auswirkung der Preisgarantie wurde von der Kommission auf unter $4 \%$ geschätzt. Das neue Hilfsprogramm, das höhere Subventionen bis zu $30 \%$, allerdings nur für Großwerften, vorsah, wurde von der Kommission zunächst nicht genehmigt; der Maximalsatz wurde schließlich auf $25 \%$ festgelegt (incl. Preisgarantie), wobei jedoch die Möglichkeit, in Ausnahmefällen 30\% zu genehmigen, gegeben wurde. 1980 wurde eine solche Ausnahmegenehmigung für den Export von vier Schiffen nach Polen erteilt. In Großbritannien89, wo die Subventionierung durch einen separaten Schiffbaufonds erfolgte, lag die Höchstgrenze zunächst bei 30\%, ab 1980 für den neuen Fonds bei $25 \%$ mit der Möglichkeit von Ausnahmegenehmigungen für höhere Sätze. Die Kommission prüfte jeweils die Einzelfälle der Subventionsvergabe und konnte Subventionsvorhaben von mehr als $30 \%$ stoppen, wobei für die Werft Harland and Wolff in Belfast Ausnahmen genehmigt wurden. In beiden Ländern waren die Subventionen mit Umstrukturierungsprogrammen verbunden, die Kapazitäts- und Arbeitsplatzabbau und auch eine Limitierung des förderfähigen Auftragsvolumens vorsahen. Große Probleme in dieser Beziehung hatte die Kommission mit Italien, da die ihr vorgelegten Subventionsgesetze 1978 und 1980 mit Umstrukturierungsprogrammen verbunden werden sollten, die aber im Parlament noch nicht verabschiedet worden waren und sich verzögerten 90 . Gleichzeitig lag bei den weitaus meisten Aufträgen (51 von 66 im Jahr 1980) der Subventionssatz über $30 \%$, so daß die Kommission das Prüfungsverfahren einleiten mußte. 30\% wurden schließlich genehmigt; das Ansinnen der italienischen Regierung, den überschießenden Subventionsbetrag als Sanierungshilfe genehmigen zu lassen, wurde von der Kommission

\footnotetext{
86 Vgl. EG, Kommission 1979a, S. 144.

87 Vgl. Dohnanyi 1978, S. 302.

88 Vgl. EG, Kommission 1979a, S. 145, 1980a, S. 113/114 und 1981a, S. 139-141.

89 Vgl. EG, Kommission 1979a, S. 148f., und 1980a, S. 116/117.

90 Vgl. EG, Kommission 1980c, S. 20.
} 
hier, ebenso wie im Falle Frankreichs, abgelehnt ${ }^{91}$. Schließlich wurden die Subventionsvorhaben der Kommission z.T. erst zwei Jahre nach Vertragsabschluß gemeldet, was eine Prüfung der Marktbeeinflussung so gut wie unmöglich machte. Auch wurden von den italienischen Reedern fast niemals Werften aus anderen MS zur Abgabe von Angeboten aufgefordert und von den staatlichen Werften in Eigeninitiative bereits mit dem Bau von Schiffen in Erwartung des Subventionsgesetzes begonnen und dann später eine Hilfe beantragt, so daß hierdurch die der Kommission bei Verabschiedung der Gesetze mitgeteilten Haushaltsansätze für Subventionen weit überschritten wurden92. Anfang 1979 wurden rückwirkend für Dezember 1978 auch in Deutschland erstmals direkte Baukostensubventionen in Höhe von bis zu $20 \%$ für technisch höherwertige Schiffe eingeführt; jedoch durften die Subventionen für die Werften maximal 10\% (7,5\%) des Jahresumsatzes 1979/80 (1981) ausmachen. Diese sog. Auftragshilfen mußten nicht zurückgezahlt werden, wenn die Werften zwischen 1979 und 1988 Umstrukturierungsinvestitionen durchführten 93 - diese Bindung wurde neben der Degression von der Kommission als Begründung der Genehmigung genannt. Bei allen Ländern wurden von der Kommission bei Subventionen für kleine Schiffe schärfere Überwachungsmaßnahmen gefordert, da hier noch ein intensiverer Intra-EG-Wettbewerb herrschte 94 .

In allen MS außer Irland existierten noch Subventionen für nationale Reeder zum Kauf von Schiffen, die fast ausschließlich dem Kauf bei Inlandswerften zugutekamen und somit indirekt den heimischen Schiffbau subventionierten 95 . Ihre Höhe schwankte zwischen 2 und $16 \%$. Da sie zusätzlich zu den eigentlichen Werftsubventionen gewährt wurden, ergab sich hier, wie die Kommission auch zugestand 96 , eine Umgehungsmöglichkeit der 4. RL, ebenso wie durch Kapitalspritzen des Staates für verstaatlichte Werften, so z.B. in Italien, Großbritannien und den Niederlanden.

Dem Fazit des EP97, daß die Ziele der RL nicht erreicht wurden und stattdessen "die unterschiedlichen Beihilferegelungen ... nach Zahl und Umfang noch zuge-

91 Vgl. EG, Kommission 1981a, S. 141/142.

92 Vgl. EG, Kommission 1981a, S. 142/143.

93 Vgl. Flieshardt/Sablotny 1981, S. 460/461; laut Lammers (1989, S. 122) waren bis 1989 noch keine Rückzahlungen erfolgt, obwohl ihr Beginn für 1983 vorgesehen gewesen war. Umstrukturierungsinvestitionen sind dabei solche Investitionen, die nicht kapazitätserweiternd wirken und andererseits keine reinen Ersatzinvestitionen sind. Vgl. Lammers 1984.

94 Vgl. z.B. EG, Kommission 1980a, S.
95 Vgl. EG, Kommission 1980c, S. 10.

96 Vgl. EG, Kommission 1981a, S. 138/139.

97 1980, S. 6. 
nommen haben", ist für diese Phase der Krise nichts hinzuzufügen. Es wird sogar von der Kommission anerkannt 98 , die eine Erhöhung bzw. Ausweitung der Subventionen 1979 bestätigt, die vor allem in Deutschland zu einer Zunahme der Aufträge, die vorher zurückgehalten wurden, geführt habe - es handelt sich hier bei mehrperiodischer Betrachtung also um einen vollen Mitnahmeeffekt aufgrund der Beihilfen ohne eine anhaltende Wirkung auf die Produktion.

Als beliebte Methode zur Förderung der heimischen Werften erwies sich in einigen MS der verstärkte Bau von Kriegsschiffen, wobei entweder vorgesehene Aufträge vorgezogen oder das Bauvolumen insgesamt mit dem Ziel der Beschäftigungssicherung erhöht wurde 99 ; finanzielle Nachteile für die öffentliche Hand (d.h. Subventionen) wurden dabei in Kauf genommen ${ }^{100}$, wobei, wie in Kap. 3.1 erläutert, Subventionen im Rüstungsbereich aus der strengen Beihilfenkontrolle ohnehin herausfallen.

Das krasse Mißverhältnis zwischen der langsamen Entwicklung des Weltseehandels und dem noch durch vorher vergebene Aufträge verursachten Anwachsen der Schiffstonnage hielt auch während der Gültigkeitsdauer der 4. RL an und wurde durch einen vorübergehenden Auftragsboom 1980 und Anfang 1981 noch akzentuiert ${ }^{101}$; so überrascht es nicht, daß trotz der enormen Subventionen die Produktion auf den Werften der EG auch im Lauf der Jahre 1978-80 weiter abnahm und 1980 weniger als 50\% der Produktion von 1976 ausmachte.

Dementsprechend ähnelte die 5. RL 102, die im April 1981 aufgrund eines Kommissionsvorschlages vom September 1980103 und nach Verlängerung der 4. RL um drei Monate verabschiedet wurde, in ihrer Struktur der 4. RL. So blieb es für Kredit- und Investitionssubventionen (Art. 2, 3) bei der alten Regelung. Auch Beihilfen zur Rettung von Unternehmen (Art. 4) wurden weiterhin in jeder Form prinzipiell erlaubt. Der Kommissionsentwurf (Art. 4) enthielt ein Verbot, diese als Produktionshilfen zu vergeben, um Kumulierungen mit Produktionshilfen zu verhindern. Im endgültigen Text ist lediglich eine Prüfung vorgesehen, ob diese Subventionen die Regelung für Produktionssubventionen gefährden. Die Regelung für letztere sah

98 Vgl. EG, Kommission 1980c, S. 9.

99 Vgl. EG, Kommission 1981a, S. 137. Der Anteil der Werftbeschäftigten im Militärschiftbau stieg dabei von 1976 bis 1985 von 4,4\% auf 10,8\%. Vgl. EG, Kommission 1986c, Anhang, S.

100 Vgl. Matthöfer 1978, S. 463, und Lammers 1989, S. 135.

101 Vgl. EG, Kommission 1982b, S. 2.

102 Vgl. EG, Rat 1981, S. 39-43.

103 Vgl. EG, Kommission 1980b, S. 3-7. 
wiederum Degressivität und Bindung an Umstrukturierung vor (Art. 6), wobei der Begriff der Umstrukturierung jetzt weiter gefaßt wurde und Maßnahmen wie Modernisierung, Rationalisierung und Fusionen statt lediglich Kapazitäts- und Arbeitsplatzabbau einschließen sollte, da durch vorherige Reduktionen z.T. die Untergrenze der Funktionsfähigkeit der Werften erreicht worden war. Zudem konnten die MS solche Verpflichtungen noch dadurch umgehen, daß sie die Subventionen als Rettungshilfen in einer akuten Krise definierten 104 . Die RL schrieb erneut keinen Subventionshöchstsatz vor, sondern gab der Kommission die Aufgabe, einen solchen zu veranschlagen, wobei Überschreitungen in Ausnahmefällen genehmigungsfähig waren unter Berücksichtigung der besonderen Lage der Werften und der relativen Anpassungsanstrengungen - hier bestand also die Möglichkeit, bei Ländern, in denen die Modernisierung nicht voranschritt, restriktiver zu verfahren bzw. bei Werften, die die Untergrenzen einer überlebensfähigen Kapazität erreicht hatten, eine Schließung zu verhindern.

Einen Fortschritt gegenüber der 4. RL stellte die Einbeziehung der Preisgarantiemechanismen (Art. 7) in die Höchstgrenze dar, eine gewisse Orientierung der Reederhilfen (Art. 8) an dieser Höchstgrenze mit einer Prüfungspflicht der Kommission bei deren Überschreitung, aber keine Pflicht zur Voranmeldung105, und die explizite Klassifizierung von Kapitalzuführungen des Staates als mögliche Quelle von Subventionen (Art. 1e). Bei den Reederhilfen wäre schon hier eine volle Einbeziehung wünschenswert gewesen, da sie, wie das EP bereits 1980106 bemerkt, i.d.R. zur Auftragsvergabe an Inlandswerften führten. Jedoch bestand de facto weiterhin die Möglichkeit ihrer Kumulierung mit Produktionshilfen, so daß die Aussage der Kommission ${ }^{107}$, daß bei den indirekten Beihilfen v.a. an die Reeder, "sich die Auswirkungen der RL in engeren Grenzen" hielten, eher untertrieben wirkt. Auch eine Einbeziehung der Verlustausgleiche für Staatswerften, die von Deutschland gefordert wurde, gelang nicht ${ }^{108}$.

Einen neuen Aspekt stellen Subventionen zur Abfederung der sozialen und regionalen Kosten von Werftschließungen und Umstellungen auf andere Tätigkeiten dar (Art. 5); hier ist wohl vor allem an Sozialpläne und Kosten der Umschulung zu denken. Diese Art von Beihilfen wurde nun erstmals erlaubt.

\footnotetext{
104 Vgl. Eußner 1983a, S. 52, 54/55.

105 Vgl. Schina 1987, S. 92.

106 Vgl. EP 1980, S. 9.

107 1983c, S. 10. Vgl. zur Kumulierung auch EG, Kommission 1984c, S. 2.

108 Vgl. Hansa 1981, S. 890.
} 
Die RL sollte zunächst bis Ende 1982 gelten, wurde dann aber zunächst unverändert bis Ende 1984 verlängert ${ }^{109}$.

In diesen Jahren gelang es der Kommission zunächst nicht, in den Hochsubventionsländern Großbritannien, Frankreich und Italien die direkten Subventionen signifikant zu vermindern. Zwar wurden 1981 die maximalen Beihilfesätze in Frankreich, Großbritannien und Italien (dort nach Intervention der Kommission) zunächst auf $20-27,5 \%$ gesenkt 110 , doch stiegen im Laufe des Jahres 1982 die durchschnittlichen Fördersätze bei konstanten Obergrenzen wieder an. Zudem wurde dieses Unterstützungsniveau noch durch indirekte Beihilfen, v.a. an Reeder, erhöht ${ }^{111}$. Für die letzte irische Werft in Cork wurden dagegen nochmals $30 \%$ genehmigt, um die Schließung des Unternehmens zu vermeiden ${ }^{112}$, die dann aber 1984 doch erfolgte113. In den Niederlanden, Deutschland und Belgien lagen die Subventionsniveaus niedriger, jedoch wurden in Deutschland 1982 die Reederhilfen zum zweiten Mal nach 1977/78 um Sonderzuschüsse von 5\% erhöht, während insbesondere in Holland und Belgien Investitionshilfen zur Unterstützung von Modernisierungen und Fusionen von Unternehmen bei gleichzeitigem Kapazitäts- und Arbeitsplatzabbau eine wichtige Rolle spielten 114 .

Als 1983 und 1984 die weitere Stagnation bzw. der Rückgang der Auftragseingänge in der EG (bei zunehmenden Weltauftragseingängen) deutlich wurde, dem hohe Überkapazitäten und mangelnde Finanzmittel der Werften gegenüberstanden, so daß Investitionen in Umstrukturierung und Kapaziätsabbau nicht in ausreichendem Maße stattfanden 115 , konstatierte auch die Kommission das Scheitern der 5. RL und schlug ihre Verlängerung um 2 Jahre bei veränderter Strategie vor: So sollte auf eine Senkung des Subventionsniveaus, die die Kommission noch 1983 möglichst schnell hatte erreichen wollen ${ }^{116}$, zugunsten einer Bindung der Hilfen an einen Kapazitätsabbau verzichtet werden ${ }^{117}$. Diese Verlängerung erfolgte dann auch.

109 Vgl. EG, Rat 1982, S. 46.

110 Vgl. EG, Kommission 1982a, S. 144/145.

111 Vgl. EG, Kommission 1983a, S. 134.

112 Vgl. EG, Kommission 1984a, S. 165.

113 Vgl. EG, Kommission 1986c, Anhang S. 12.

114 Vgl. EG, Kommission 1983a, S. 135f. und EG, Bulletin 1982b, S. 29 mit einem Fallbeispiel, sowie Weilepp 1989, S. 72, 133.

115 Vgl. EG, Kommission 1984d, S. 8/9.

116 Vgl. EG, Kommission 1983c, S. 21.

117 Vgl. EG, Kommission 1984b, S. 4, und 1985c, S. 2. 
Obwohl die Kommission von einer Konstanz des Beihilfeniveaus für 1985/86 im Vergleich zu 1983/84 spricht ${ }^{118}$, wurden die direkten Beihilfen jedoch sogar erhöht, so auf $22,5 \%$ (Nordirland $27,5 \%$ ) in Großbritannien, $25-30 \%$ in Italien, von $8 \%$ auf maximal $11 \%$ in den Niederlanden 119 ; sie verharrten auf $10-20 \%$ je nach Werftgröße für Frankreich. In allen vier Ländern hatte die Kommission zunächst gegen die vorgeschlagenen noch höheren Subventionsprogramme (in UK bis 35\%) das Verfahren eröffnet. Aufgrund der schlechten früheren Erfahrungen limitierte die Kommission in ihrer Genehmigung für Italien zumindest die auf den Klein- und Mittelwerften förderfähige Tonnage120. Gegen zusätzliche Subventionen für die Vorratshaltung von Material eröffnete die Kommission 1986 das Verfahren und erließ im November 1987 eine ablehnende Entscheidung 121.

Wiederum waren die Hilfen an Umstrukturierungsauflagen gebunden, die vor allem auch die Verluste der Werften vermindern sollten. Diese Verluste und ihr nachträglicher Ausgleich durch den Staat als Werfteigner in Großbritannien und Italien hatte das Beihilfeniveau für 1983/84 umgerechnet auf das Auftragsvolumen um 7\% bzw. 5\% erhöht und damit die Subventionskontrolle der Kommission nachträglich entwertet ${ }^{122}$. Gleichzeitig korrigiert dies zunächst den aufgrund der obigen Zahlen aufgetretenen Eindruck, daß die Unterstützungsniveaus für 1985/86 erhöht worden waren - allerdings wurde für 1986 in Großbritannien wieder ein Ausgleich bezahlt und von der Kommission genehmigt ${ }^{123}$.

\subsubsection{Ein neuer Anlauf zur umfassenden Kontrolle}

Angesichts der weiterbestehenden Krise im gemeinschaftlichen Schiffbau und der offensichtlichen Unmöglichkeit, einen schnellen Abbau der Subventionen bis zum Auslaufen der 5. RL wie angestrebt zu erreichen ${ }^{124}$, da dies die regionalen Arbeitsmarktprobleme nur noch weiter verschärft hätte, versuchte die 6. RL, die nach einem Kommissionsvorschlag vom Oktober 1986 im Januar 1987 gegen die Stimme

118 Vgl. EG, Kommission 1986a, S. 164

119 Vgl. Hansa 1985, S. 1430.

120 Vgl. EG, Kommission 1986a, S. 165/166.

121 Vgl. EG, Kommission 1989b, S. 8.

122 Vgl. EG, Kommission 1986a, S. 164f. und Weilepp 1989, S. 82.

123 Vgl. EG, Kommission 1988a, S. 156.

124 Vgl. EG, Bulletin 1986, S. 10. Zwar hatte sich die Bundesregierung gegen eine Verlängerung des Subventionssystems mit reinen Produktionshilfen ausgesprochen, insbesondere Frankreich, Italien und Belgien waren jedoch dafür. Vgl. hierzu Hansa 1986, S. 371. 
Italiens verabschiedet wurde ${ }^{125}$, zum einen, die Kontrolle der Betriebsbeihilfen transparenter und gleichmäßiger zu gestalten, zum anderen durch präzisierte Regelungen über Umstrukturierungssubventionen einen gewissen Lenkungseffekt zu erreichen.

Dem ersten Ziel dient die Wiedereinführung einer expliziten Beihilfehöchstgrenze ${ }^{126}$, wobei als Kriterium die Kostendifferenz zwischen den wettbewerbsfähigsten EG-Werften und den Marktführern vor allem in den Bereichen benutzt wurde, in denen EG-Werften noch relativ wettbewerbsfähig sind (Art. 4). Die Grenze war jährlich zu überprüfen und zu senken, wobei für kleinere Schiffe ( $<6$ Mio. ECU), die vorwiegend von Kleinwerften gebaut werden und bei denen ein besser funktionierender Intra-EG-Wettbewerb besteht, niedrigere Grenzen galten. Die festzulegende Grenze, der Bezug auf die Kostendifferenz zum Weltmarkt und das Ziel der schrittweisen Senkung des Subventionsniveaus erinnern an den Ansatz der ersten beiden Richtlinien ${ }^{127}$, und doch bestehen zwei signifikante Unterschiede: Während in den ersten Richtlinien das Subventionsniveau der Kompensation des Vorteils durch Beihilfen in den Konkurrenzländern dienen sollte, wird nun klargestellt, daß die Beihilfen die mangelnde Wettbewerbsfähigkeit der Werften ausgleichen und ihren Erhalt sichern sollten. Auf der anderen Seite bestimmt Art. 4, iv der RL, daß in diese Höchstgrenze alle Produktionshilfen, also auch solche aus regionalen und allgemeinen Programmen, alle Reederhilfen und Verlustausgleiche sowie sog. Rettungsbeihilfen einzubeziehen sind, während die ersten RL sich allein auf die Auftragshilfen bezogen. Der Subventionswert staatlicher Bürgschaften wird dabei mit $10 \%$ des Nennbetrages angesetzt ${ }^{128}$. Ausgeschlossen von der Höchstgrenze bleiben lediglich die OECD-Kredithilfen und Subventionen in der Form von Krediterleichterungen für Exporte in Entwicklungsländer als Entwicklungshilfe, für die der oben erwähnte Mindestsubventionssatz von $25 \%$ einzuhalten war (Art. 4, vi und vii). Während für die letzte Beihilfekategorie eine Ex-ante-Prüfung des Einzelfalles vorgeschrieben war, mußte die Kommission bei den Produktionssubventionen lediglich das Programm im vorhinein genehmigen, die Anwendung im Einzelfall war dann genehmigungsfrei. Eine Ausnahme exisitierte nur für Aufträge, bei denen ein Intra-

125 Vgl. Hansa 1987, S. 98. Vorschlag: EG, Kommission 1986b, S. 4-8; Richtlinie: EG, Rat 1987, S. 55-64.

126 Vgl. BMWi 1987, S. 2.

127 Die in den folgenden RL vorgegebene Ausrichtung der Betriebsbeihilfen auf Umstrukturierungen wurde also aufgegeben - ein gewisser Gewinn an Ehrlichkeit. Vgl. EP 1986, S. 18, auch 128 EG, Kommission 1986c, S. 9.

Vgl. Weilepp 1989, S. 138. 
EG-Wettbewerb herrscht. Hier mußte die Kommission auf Antrag eines MS den Einzelfall prüfen. Zur Protektion der Werften in Spanien und Portugal wurden Übergangsregelungen ohne Anwendung der Höchstgrenze vereinbart (Art. 9). Eine wohl ursprünglich in der Kommission überlegte Festlegung der Subventionsform auf subventionierte Kredite für inländische Reeder (sog. Home Credit Schemes) in Anlehnung an die OECD-Regeln für Exportkredite wurde nach Widerstand der MS aufgegeben 129 .

Als Höchstsatz für 1987 und 1988 legte die Kommission $28 \%$ fest ${ }^{130}$. Dieser Satz wurde um $2 \%$-Punkte höher festgesetzt, als von der Kommission ursprünglich geplant ${ }^{131}$, um die volle Einbeziehung der Reederhilfen konsensfähig zu machen. Hier gab es zunächst Vorbehalte der MS, die argumentierten, daß die Reederhilfen einerseits auch für Aufträge bei ausländischen Werften verwendet werden könnten, andererseits häufig mit der Verpflichtung verbunden seien, das Schiff unter inländischer Flagge mit dementsprechend höheren Kosten fahren zu lassen, so daß es sich hier um Schiffahrtshilfen handele. Da eine Aufteilung der Subventionsbeträge aber nicht durchführbar war, wurde die Vollanrechnung beschlossen, auch deshalb, weil die MS eine transparentere Zahlung des Betrages, der zum Ausgleich der höheren Flaggenkosten dient, in mehreren Jahresraten nicht durchführten ${ }^{132}$. Der Satz von $28 \%$ mag zunächst im Vergleich zu Werten bis zu $30 \%$ in früheren Jahren als Fortschritt wirken, zumal jetzt in diese Höchstgrenze weitere Subventionsformen eingeschlossen wurden. Doch hier ist in zweifacher Hinsicht Vorsicht geboten: Zum einen bezieht sich die Höchstgrenze auf den sog. "Vertragswert (vor Beihilfe)" (Art. 1e), d.h. die Summe aus Vertragspreis und Subventionen, während die früheren Höchstgrenzen sich allein auf den Vertragspreis bezogen. Rechnet man die $28 \%$ auf diese Basis um, so erhält man ein vergleichbares Limit von 38,9\%133. Zum anderen bezieht sich diese Höchstgrenze bei Zahlung von Rettungshilfen und Verlustausgleichen auf den Jahresumsatz der jeweiligen Werft an Handelsschiffen (Art. 5), so daß hier niedrigere Subventionen für einzelne Aufträge durch nachträglich de facto höhere für andere Aufträge kompensiert werden können. Selbst dieser Satz wurde vom $\mathrm{EP}^{134}$ noch für zu niedrig gehalten; es schlug eine variable Höchstgrenze zwi-

\footnotetext{
129 Vgl. EG, Kommission 1986c, S. 11.

130 Vgl. EG, Kommission 1989b, S. 3.

131 Vgl. FAZ 1986.

132 Vgl. EG, Kommission 1990b, S. 14.

133 Vgl. VSM 1989, S. 2.

134 1986, S. 14, 20. Auch die Kommission (1988b, S. 2) spricht davon, daß die Subventionen zu niedrig seien, um die Preisunterschiede zum Weltmarkt auszugleichen.
} 
schen $26 \%$ und $35 \%$ je nach Schiffstyp vor, um in weiteren Marktsegmenten EGWerften wettbewerbsfähig zu erhalten, die durch die vorherige unvollständige Kontrolle und die damit gegebenen Kumulationsmöglichkeiten mit noch höheren Werten überlebt hatten.

Was das zweite o.g. Ziel betrifft, so enthielt die RL ein explizites Verbot jeder Subventionierung kapazitätserweiternder Investitionen (Art. 6). Ausnahmen galten nur für MS, in denen bisher keine oder nur eine Werft mit geringen Auswirkungen auf den Gemeinschaftsmarkt bestand - diese Regelung paßt auf die Situation in Irland und führte dann 1990 auch zur Genehmigung von Beihilfen für die Wiedereröffnung der einzigen irischen Werft, die 1984 stillgelegt worden war, durch einen neuen Eigner 135. Bei der Prüfung anderer Investitionssubventionen waren Kriterien wie Umstrukturierungsgrad, Innovation, Spezialisierung sowie soziale Ziele heranzuziehen. Bei der totalen oder partiellen Schließung von Werften wurden Subventionen für Abfindungen, Beratung und Umschulung der Arbeitnehmer sowie für die Ansiedlung anderer Betriebe und die Entschädigung der Eigner für den Restbuchwert erlaubt, wobei sich die Subventionshöhe an Regionalproblemen orientierte (Art. 7). Subventionen für Grundlagenforschung und angewandte Forschung im Sinne des Gemeinschaftsrahmens FuE (s. Abschnitt 4.1.4) waren ebenfalls gestattet (Art. 8). Auch die Wahl der Höchstgrenze von $28 \%$ hat einen gewissen Lenkungseffekt, da dadurch den Werften der EG der Bau von Öltankern und Massengutfrachtern, bei denen ihre preisliche Unterlegenheit im Durchschnitt bei $50 \%$ liegt, unmöglich gemacht wurde 136. Dementsprechend sank trotz einer Belebung des Tankermarktes ab 1987 ihr Anteil an den beihilfefähigen Aufträgen auf 12\%137.

Schließlich schrieb die 6. RL verschärfte und präzisierte Regeln für die Meldung und Überwachung der Subventionen sowie eine umfassende Berichtspflicht der MS vor (Art. 10, 11), wobei der Anhang wiederum Formularmuster für diese Berichte enthält. Die Ex-ante-Meldepflicht mit Anwendungssperre erstreckte sich ausdrücklich auf neue Regelungen, die Anwendung genehmigter regionaler und allgemeiner Subventionsprogramme, Subventionen für Entwicklungshilfeexporte und Fälle von Intra-EG-Auftragskonkurrenz. Auch hier zeigen sich die früheren Schwierigkeiten

\footnotetext{
135 Vgl. EG, Kommission 1991a, S. 172.

136 Vgl. EP 1986, S. 16, 19, EG, Kommission 1986c, S. 4 und Anhang S. 7. Bei Frachtern lag der Abstand bei $10-20 \%$, bei Nichtfrachtschiffen bei 0 .

137 Vgl. EG, Kommission 1989b, S. 11.
} 
der Kommission, die vertragliche Notifizierungspflicht durchzusetzen, worauf auch das $\mathrm{EP}$ in seinem Entschließungsantrag hinweist 138 .

Bei allen Regelungen der 6. RL wird das Bestreben deutlich, über bessere Erfassung und Transparenz der Subventionen mehr Vergleichbarkeit und damit einen weniger verzerrten Wettbewerb auf EG-Ebene zu erreichen. Aus allokativer Sicht ist die Orientierung des zulässigen Beihilfeniveaus an der Kostendifferenz zur asiatischen Konkurrenz fragwürdig. Eine solche wäre nur zum Ausgleich von Dumping vertretbar, nicht jedoch zur Kompensation produktivitäts- und lohnniveaubedingter Wettbewerbsvorteile ${ }^{139}$. Im Unterschied zu früheren Regelungen werden hierdurch allerdings nur noch die effizientesten EG-Werften wirksam geschützt, was als Fortschritt $\mathrm{zu}$ werten ist. Betrachtet man den Bericht der Kommission für die Jahre $1987 / 88^{140}$, so sind zumindest eine verbesserte Transparenz und Vergleichbarkeit erreicht worden.

Die neue Regelung zwang die Hochsubventionsländer Frankreich, Italien und Großbritannien zu einer Verminderung ihrer hohen Subventionsniveaus, die bspw. durch die Kumulierung von Reeder- und Werfthilfen in Frankreich und von Baukostenzuschüssen und Verlustausgleichen in Großbritannien bedingt waren ${ }^{141}$. Im Falle Italiens ergab sich das Problem, daß es zum Ende der Gültigkeitsdauer der 5. RL noch die Genehmigung für Refinanzierungsbeihilfen für den Schiffbau in Großwerften, für den Ende 1986 noch ein Großauftrag vergeben wurde, erlangte ${ }^{142}$. Dieser Auftrag aufgrund des Finmare-Gesetzes diente der Erneuerung der staatlichen italienischen Handelsflotte und war mit Produktionsbeihilfen von $25-30 \%$ sowie zusätzlichen Reederhilfen von knapp 30\% verbunden, die "natürlich nicht unmittelbar unter die 5. RL"143 fielen. Er gestattete den italienischen Werften eine mittelfristige Auslastung außerhalb der strengeren Regeln der 6. RL und erhöhte die Auftragsbestände 1987 um 86\%144. Als Italien dann 1989 einen neuen Gesetzentwurf über Schiffbausubventionen vorlegt, mußte die Kommission u.a. wiederum wegen Überschreitung der Höchstgrenzen durch Beihilfenkumulierung für Werften und Reeder das Verfahren eröffnen. Da die Verlustausgleichszahlungen des Staates an

\footnotetext{
138 Vgl. EP 1986, S. 13, 18, auch Hansa 1986a, S. 533.

139 Vgl. Franzmeyer 1987, S. 169.

140 EG, Kommission 1989b.

141 Vgl. VSM 1989, S. 9.

142 Vgl. EG, Kommission 1989a, S. 165.

143 EG, Kommission 1989b, S. 8/9.

144 Vgl. EG, Kommission 1988c, S. 15.
} 
Fincantieri nicht gemeldet worden waren, schloß das Verfahren auch diese ein 145. Nach verschiedenen Änderungen des Gesetzes wurde das Verfahren 1990 eingestellt ${ }^{146}$.

In Deutschland wurden mit der 6. RL sog. Wettbewerbshilfen von bis zu $20 \%$ eingeführt, die die bisherigen Reederhilfen von ca. $12,5 \%$ ersetzten und damit eine umfassende und signifikante Baukostensubventionierung erbrachten, auch wenn das Hilfsvolumen keine Förderung aller Aufträge erlaubte ${ }^{147}$.

Das tatsächliche Förderniveau lag in den meisten MS in den Jahren 1987/88 im Durchschnitt deutlich unterhalb des Limits von 28\% (bzw. 20\% für kleine Schiffe) trotz der Krise im Weltschiffbau, lediglich in Frankreich wurden 27,3\% erreicht (vgl. Tab. 4.2-2). Bei einem Durchschnittsniveau innerhalb der Gemeinschaft von 18,5\% zeigt eine Aufschlüsselung nach Schiffstypen, daß bei den Low-tech-Schiffen, wie Tankern und Massengutfrachtern, bei denen die Lohnkostennachteile europäischer Werften bedeutsam durchschlagen, das Subventionsniveau über diesem Durchschnitt lag, während technisch aufwendigere Typen wie Fahrgastschiffe tendenziell niedrigere Fördersätze aufwiesen ${ }^{148}$.

Für 1989 und 1990 konnten aufgrund der ansteigenden Schiffbaukonjunktur als Folge der Zunahme des Seeverkehrs und des Ersatzbedarfes sowie vorherigen krisenbedingten Kapaziätsabbaus in Ostasien die Subventionssätze auf 26\% (16\%) bzw. 20\% (14\%) gesenkt werden. Dementsprechend wurde der deutsche Fördersatz für 1990 dann auch auf $14 \%$ der Auftragssumme gekürzt ${ }^{149}$. Dies galt nicht für die ehemalige DDR, für deren Werften die Kommission höhere Betriebsbeihilfen als $20 \%$ gestattete, da hier Verpflichtungen aus Aufträgen für die UdSSR zu Festpreisen bestehen 150 . Die Tendenz zur Senkung der Obergrenzen drückte sich auch in fallenden tatsächlichen Beihilfeintensitäten aus, die wiederum, abgesehen von Belgien, wo mehrere Verfahren nach Artikel 93,II eröffnet wurden ${ }^{151}$, unterhalb der Obergrenzen lagen. In Fällen, in denen die MS höhere Beihilfeintensitäten gewähren wollten, lehnte die Kommission das Projekt ab. Eine Klage Belgiens gegen eine solche negative Entscheidung 152 lehnte der Gerichtshof ab und legte fest, daß eine Überschrei-

\footnotetext{
145 Vgl. EG, Kommission 1989c, S. 3, und 1990a, S. 148.

146 Vgl. EG, Kommission 1991a, S. 172.

147 Vgl. BMF 1987, S. 38.

148 Vgl. EG, Kommission 1989b, S. 5-10, 45/46.

149 Vgl. VSM 1990, S. 16-19, 28/29, sowie EG, Kommission 1990a, S. 133

150 Vgl. EG, Kommission 1991, S. 117, und Wirtschaftsdienst 1990, S. 493

151 Vgl. EG, Kommission 1990a, S. 147, und 1991a, S. 169f.

152 Vgl. EG, Kommission 1992a, S. 152.
} 
Tab. 4.2-2

Produktionsbeihilfen (incl. Preisgarantie, Verlustausgleich und Shipbuilders Relief in \%)

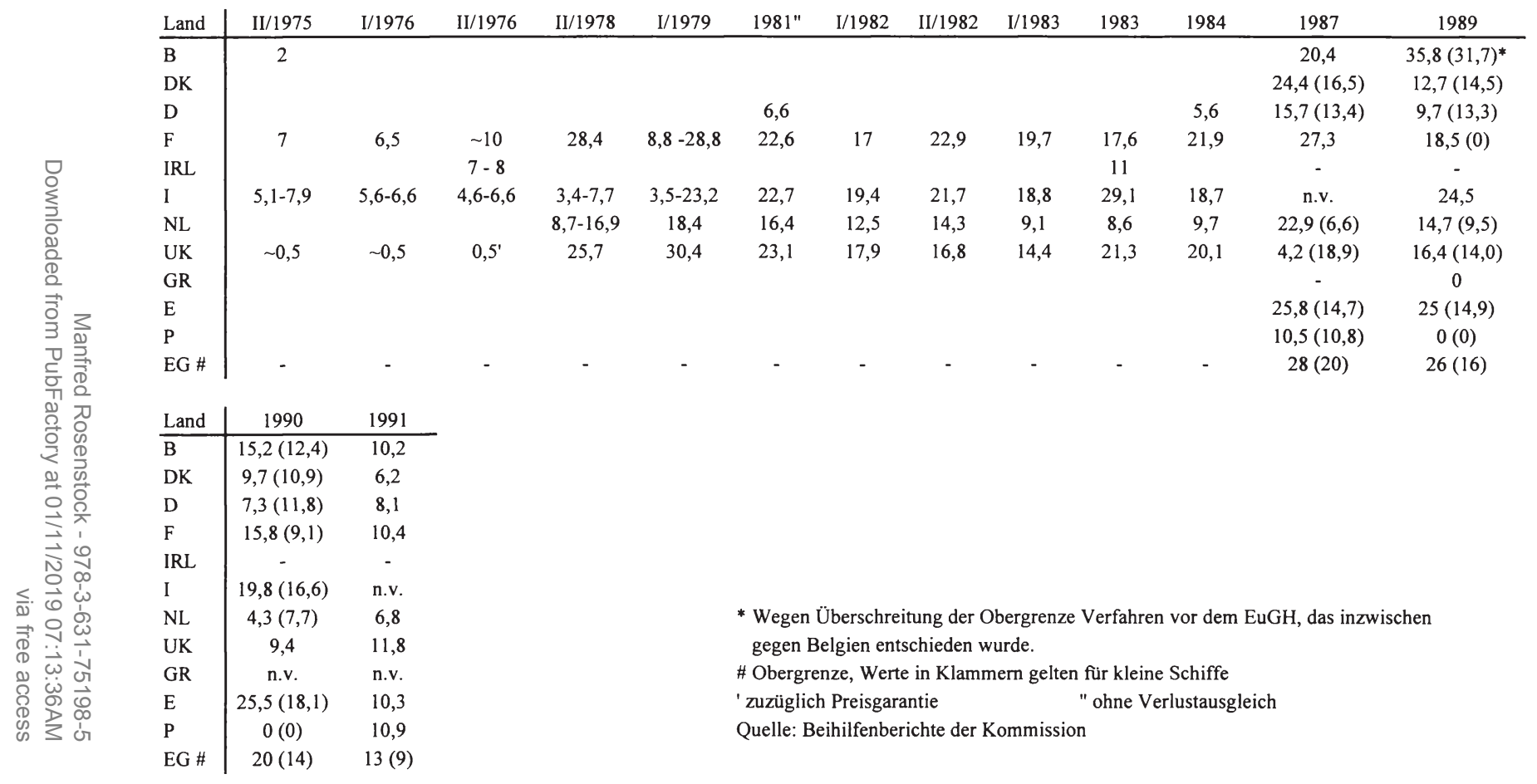


tung der festgelegten Grenze eine Beihilfe an sich unvereinbar macht und somit der Kommission keinen weiteren Spielraum bietet 153 .

Erstmalig rechnete die Kommission auch gezahlte Verlustzuweisungen oder Kapitalspritzen in Belgien, Deutschland und Großbritannien auf die Subventionshöchstgrenzen voll an ${ }^{154}$.

Tab. 4.2-2(a)

\section{Reederhilfen (Durchschnittsinzidenz in \%)}

\begin{tabular}{l|rrrrr} 
Land & 1978 & 1981 & 1982 & 1983 & 1984 \\
\hline B & & ca. 60 & n.a. & 17 & 17 \\
DK & 2,5 & 27,6 & 12,6 & & OECD + 3,6 \\
D & 16,4 & $<12,5$ & 15,8 & 12,2 & 12,5 \\
F & $14,1^{*}$ & 10,8 & 12,9 & $11,3-12,5$ & \\
IRL & & 18,9 & & 1,75 & \\
I & 2 & ca. 38 & n. vgl. & & $2,8-3,2 \#$ \\
NL & $1,1^{* *}$ & $<5,4$ & $2,3 * *$ & & $2,1^{* *}$ \\
UK & & 23 & $8-15.2$ & $8-11$ & $4-8$
\end{tabular}

* $10 \%$ bei Extra-EG-Bestellungen \# halbjährliche Zuschüsse für 12 Jahre

** Jährliche Hilfe für 5 Jahre

Quellen: Beihilfenberichte der Kommission, Hansa 1981a.

In 23 Fällen mußte die Kommission 1987/88 aufgrund der Beschwerde eines Mitgliedstaates bei einem Wettbewerb subventionierter Aufträge zwischen Werften aus mehreren MS tätig werden, wobei 14 der Beschwerden aus den Niederlanden kamen. Hierbei entschied die Kommission in 11 Fällen, daß entweder keine Beihilfe oder kein Intra-EG-Wettbewerb vorlag. In anderen Fällen erreichte sie eine Angleichung auf das niedrigste Subventionsniveau, in drei Fällen wurden sogar Beihilfevorhaben einzelner MS als zu hoch explizit abgelehnt. In drei Fällen wurde dagegen das höhere Niveau genehmigt, um den Auftrag gegen Extra-EG-Konkurrenz zu sichern 155 . Hier zeigt sich erneut eine bedenkliche merkantilistische Haltung, die eine Wettbewerbsverzerrung nach außen aus industriepolitischen Überlegungen toleriert ${ }^{156}$. Unter den 8 Fällen dieser Kategorie 1989/90 wurde dieses Prinzip dennoch

$153 \mathrm{Vgl}$. Europe 1993, S. 11.

154 EG, Kommission 1989b, S. 6, 7, 10.

155 Vgl. EG, Kommission 1989b, S. 11-12.

156 Sicherlich liegt die Motivation hierfür nicht, wie im ursprünglichen Merkantilismus in zahlungsbilanzpolitischen Überlegungen. Dennoch wird staatlicherseits derselbe Politikansatz verfolgt, d.h. Schutz vor Importen bei gleichzeitiger Förderung von Exporten zum Erhalt bzw. Ausbau der eigenen Industrie. 
in einem Fall erneut angewandt 157 . In anderen Fällen wurden jedoch aufgrund der Intervention der Kommission Beihilfeprojekte zurückgezogen und auch eine negative Entscheidung erlassen 158 .

In 17 Fällen wurden von der Kommission Entwicklungsbeihilfen für den Schiffbau genehmigt, wobei das Subventionselement der gegebenen Krediterleichterungen zwischen $25,4 \%$ und $100 \%$ lag. Daß dieses Instrument zur Schiffbauförderung vor allem in Deutschland eine wichtige Rolle spielt, zeigt sich daran, daß allein 15 dieser Fälle deutsche Werften betrafen, die anderen beiden kamen aus Großbritannien 159 . Die Regelung der RL wurde auch vom BMWi160 ausdrücklich als Möglichkeit für deutsche Werften gelobt, hier von Zinszuschüssen "in beträchtlichem Maße zu profitieren". Ab 1989 präzisierte die Kommission die Regeln für diesen Beihilfentyp: So durften die Schiffe nicht unter einer Billigflagge fahren, und der tatsächliche Eigner mußte in einem Entwicklungsland niedergelassen sein, um hier getarnte Beihilfen an EG-Reeder zu verhindern ${ }^{161}$. Ferner ersetzte die Kommission das für diese Beihilfen gültige Länderverzeichnis des DAC der OECD durch eine eigene Liste, die diejenigen Länder ausschloß, die "höheres mittleres Pro-Kopf-Einkommen" besaßen, um hier eine versteckte Exportförderung an nicht-bedürftige Länder zu vermeiden 162 . Aufgrund dieser Änderung wurden zwei deutsche Vorhaben 1989 beanstandet und von der Bundesregierung auch zurückgezogen 163 . Die Bedeutung dieser Beihilfekategorie war 1989/90 jedoch gering 164 .

Neben der Tatsache, daß Spanien und Portugal de jure, Italien wegen der Großaufträge aufgrund der 5 . RL de facto zunächst nicht der strengeren Kontrolle der 6 . RL unterlagen, lag das größte Problem der Kommission in der mangelnden Erfüllung der Berichterstattungspflicht durch die MS. So beklagt die Kommission in ihrem Zwischenbericht, daß nicht einmal die Berichte über Schiffbauaufträge regelmäßig eingereicht wurden, so daß Mitte 1989 noch keine Zahlen für 1988 vorgelegt werden konnten. Dieser Unwillen bzw. die Nachlässigkeit der MS erschwert die Kontrolle der Kommission und damit die angestrebte Transparenz, so daß die

\footnotetext{
157 Vgl. EG, Kommission 1990a, S. 145-147, 1991a, S. 169.

158 Vgl. EG, Kommission 1990a, S. 145.

159 Vgl. EG, Kommission 1989b, S. 14.

1601987 , S. 2.

161 Vgl. EG, Kommission 1993e.

162 Vgl. EG, Kommission 1989b, S. 14.

163 Vgl. EG, Kommission 1990a, S. 147.

164 Vgl. ebenda und 1991a, S. 169.
} 
Drohung der Kommission mit einem Vertragsverletzungsverfahren gegen die MS nicht überrascht 165 .

Aufgrund der Genehmigungspflicht für Umstrukturierungs- und Schließungssubventionen wurde die Kommission auch vermehrt mit diesen Vorhaben befaßt ${ }^{166}$, die vor allem Frankreich, Großbritannien und Deutschland betrafen und von der Kommission gebilligt wurden. Wiederum stellte Italien den Problemfall dar, da hier keine Umstrukturierungen durchgeführt wurden. Dasselbe gilt aufgrund sozialer Unruhen für Spanien, wobei hier die Kommission im Juli 1989 das Verfahren einleitete, da Umstrukturierung und Kapazitätsabbau ihr nicht ausreichend erschienen 167 .

Seit 1991 ist die 7. RL168 in Kraft, die zunächst bis Ende 1993 galt, dann aber um ein Jahr verlängert wurde ${ }^{169}$. Sie verfolgt im wesentlichen den Ansatz der 6. RL weiter, versucht jedoch in einigen Bereichen eine Präzisierung bzw. Verschärfung der Subventionsregeln, um Umgehungsmöglichkeiten zu erschweren und im Zuge der Vollendung des Binnenmarktes die Wettbewerbsverzerrungen deutlich zu vermindern. Sie soll auch Vorbildfunktion für die OECD-Verhandlungen um einen Subventionsabbau haben 170 . So wurde der Bereich der "kleinen Schiffe", für die niedrigere Subventionshöchstgrenzen gelten, auf solche bis zu einem Auftragswert von 10 Mio. ECU (bisher 6 Mio. ECU) erweitert, da im Preisbereich zwischen 6 und 10 Mio. ECU ein starker Intra-EG-Wettbewerb herrscht, dessen Verzerrung verringert werden soll ${ }^{171}$. Da die Herabsetzung der zulässigen Subventionssätze vorgesehen ist und der jeweilige Höchstsatz bei Vertragsabschluß maßgebend ist, wurde eine maximale Zeitspanne von drei Jahren bis zum Auslieferungstermin festgelegt, um eine Umgehung der Beihilfendegression durch sehr lange Lieferfristen auszuschalten 172 . Erfolgt die Lieferung nun nach dieser Frist, so gilt der Subventionshöchstsatz des Zeitpunktes drei Jahre vor der Auslieferung, wobei die Kommission allerdings in Ausnahmefällen die Frist verlängern kann (Art. 4, III). Bei den Schließungsbeihilfen hatte die Kommission bereits im Ratsprotokoll zur 6. RL auf

\footnotetext{
165 Vgl. EG, Kommission 1989b, S. 5/6, 23.

166 Vgl. EG, Kommission 1989b, S. 16/18, und 1991a, S. 170f. sowie 173; zu einem Fallbeispiel Hansa 1988, S. 376.

167 Vgl. EG, Kommission 1990a, S. 148/149.

168 Vgl. EG, Rat 1990, S. 27-36.

169 Vgl. Hill 1993b, S. 2, und EG, Kommission 1994a, S. 307.

170 Vgl. FAZ 1990.

171 Vgl. EG, Kommission 1990b, S. 15.

172 Vgl. Ebenda, S. 16.
} 
einer Mindestschließungsdauer von 5 Jahren bestanden, um in der Hoffnung auf technische Veraltung der Anlagen eine Umgehung der Regeln zu Produktions- und Investitionshilfen zu verhindern. In der Anfang der 90er Jahre verbesserten Marktlage fanden sich jedoch Interessenten, die solche Werften wiedereröffnen wollten, was dem Kapazitätsabbaukonzept der Kommission widersprach 173 . Deshalb wurde die Mindestschließungsdauer in der neuen RL mit der Verpflichtung verknüpft, die Anlagen während dieser Zeit nicht für schiffbauähnliche Zwecke oder für Wiederaufbau oder Erhaltung zu nutzen. Eine Wiederinbetriebnahme im Zeitraum von 5-10 Jahren nach der Schließung wurde außerdem von der Genehmigung der Kommission abhängig gemacht, die sich dabei an der Weltmarktlage orientieren soll (Art. 7,I).

Ferner wurde die Befreiung Spaniens von der Höchstgrenze um 1 Jahr unter der Bedingung verlängert, daß bis Ende 1992 ein Umstrukturierungsprogramm durchgeführt werden sollte, das den spanischen Werften danach erlaubt, mit den normalen Beihilfen im Wettbewerb zu bestehen. Für Griechenland wurde die Anrechnung von Rettungshilfen und Verlustausgleichen für $1 \mathrm{Jahr}$ ausgesetzt, um eine subventionierte partielle Privatisierung der griechischen Werften zu erlauben (Art. 9, 10). Diese Privatisierung erfolgte dann auch partiell im Jahre 1992, und die Kommission genehmigte Beihilfen in Form von Schuldabschreibungen174. Für Spanien kam ein unabhängiger Berater zu dem Schluß, daß trotz der Durchführung des Planes einige Werften mit der gemeinschaftlichen Beihilfenhöchstgrenze noch nicht wettbewerbsfähig sein würden. Hier werden z.Zt. zusätzliche Maßnahmen der spanischen Regierung mit der Kommission diskutiert ${ }^{175}$.

Schließlich will die Kommission der Nachlässigkeit der MS bei der Meldung von Daten dadurch beikommen, daß sie nach Konsultation und Mitteilung den MS die Auszahlung bereits genehmigter Beihilfen bis zum Eingang aller fälligen Berichte verbieten kann (Art. 12,III).

In Anwendung dieser 7. RL wurden die Höchstsätze für Produktionssubventionen wiederum in Absprache mit den MS für 1991 auf $13 \%$ bzw. für kleine Schiffe auf 9\% und für 1992 sowie 1993 und 1994 auf $9 \%$ (4,5\%) festgesetzt ${ }^{176}$.

$173 \mathrm{Vgl}$. Ebenda, S. 17/18. Inzwischen verläuft die Schiffbaukonjunktur wieder gedämpfter. Zur jüngsten Entwicklung des Schiffbaus in der Gemeinschaft vgl. EG, Kommission 1993h, S. 7-9.

174 Vgl. EG, Kommission 1993a, S. 226, und Bernitsas 1993, S. 122.

175 Vgl. EG, Kommission 1994a, S. 309.

176 Vgl. EG, Kommission 1991, S. 118, 1992a, S. 151, 1993a, S. 225, sowie 1994a, S. 307. 
Für die Werften der ehemaligen DDR wurden durch eine Ergänzung der 7. RL erheblich höhere Beihilfen von $36 \%$ erlaubt 177 . Diese waren alllerdings an massive Kapazitätskürzungen um $40 \%$ gegenüber 1990 gebunden, deren Aufteilung auf die einzelnen Werften von Bundesregierung und THA zu vereinbaren waren. Die gefundene Lösung (vgl. Tab. 4.2-3) zeigt, daß die Kapazitätskürzungen nicht gleichmäßig auf die Werften verteilt wurden. Zwei Werften können sogar ihre Kapazitäten ausbauen, während zwei weitere (Neptun und Roßlau) gänzlich geschlossen werden. Der Beihilfesatz von $36 \%$ wird hier nicht auf die einzelnen Auftragswerte bezogen, sondern auf einen künstlichen Umsatz, der sich aus der geplanten Zahl der Arbeitnehmer nach der Umstrukturierung multipliziert mit einer EG-durchschnittlichen Arbeitsproduktivität ergibt 178 . Die Beihilfen dürfen dabei zur Annullierung von Altschulden, als Liquiditätshilfe und zum Ausgleich von Verlusten während der Umstrukturierung gewährt werden. Die maximale Intensität von $36 \%$ darf dabei allerdings nicht pro Jahr, sondern lediglich während der gesamten Umstrukturierungsphase bis Ende 1995 erreicht werden und muß bis Ende 1993 ausgezahlt sein.

Tab. 4.2-3

Beihilfen für ostdeutsche Werften (in Mio. DM)

\begin{tabular}{|c|c|c|c|c|c|c|}
\hline Werft & $\begin{array}{l}\text { Betriebs- } \\
\text { beihilfen }\end{array}$ & $\begin{array}{r}\text { Investitions- } \\
\text { beihilfen }\end{array}$ & $\begin{array}{r}\text { Stillegungs- } \\
\text { beihilfen }\end{array}$ & $\begin{array}{r}\text { Gesamt- } \\
\text { beihilfen }\end{array}$ & $\begin{array}{r}\text { Restkapaz. } \\
1995^{* *}\end{array}$ & $\begin{array}{l}\text { Ausgangska- } \\
\text { paz. } 1990^{* *}\end{array}$ \\
\hline Elbe-Boizenburg & 110,1 & 4,0 & 0,0 & 114,1 & 22.000 & 38.228 \\
\hline Volkswerft Stralsund & 680,5 & 16,0 & 2,6 & 699,1 & 85.000 & 183.030 \\
\hline Peene-Wolgast & 157,7 & 69,2 & 32,2 & 259,1 & 35.000 & $0^{*}$ \\
\hline Warnow-Warnemünde & 745,0 & 127,5 & 27,0 & 899,5 & 85.000 & 133.804 \\
\hline MTW-Wismar & 191,2 & 94,8 & 18,0 & 304,0 & 100.000 & 87.275 \\
\hline Summe & 1884,5 & 311,5 & 79,8 & 2275,8 & 327.000 & $545.041 \#$ \\
\hline $\begin{array}{l}{ }^{*} \text { Nur Militärschiffbau } \\
\text { Quelle: Krüger } 1992\end{array}$ & & einschl. Neptu & werft und Rol & & ** in GBRT & \\
\hline
\end{tabular}

Nach Vorlage entsprechender Daten zu den geplanten Kapazitätsabbauten und verbleibenden Kapazitäten für die fünf ostdeutschen Werften genehmigte die Kommission Investitions-, Betriebs- und Stillegungsbeihilfen in mehreren Tranchen. Tab. 4.2-3 zeigt das genehmigte Beihilfevolumen. Ein Problemaspekt aus der Verbindung

177 Vgl. EG, Rat 1992, S. 54f., und zum folgenden: Krüger 1992, S. 598-600.

178 Hinter dieser Berechnung steht die Prämisse, daß die Produktivität der ostdeutschen Werftarbeiter nach der Umstrukturierung dem Gemeinschaftsdurchschnitt entsprechen wird. Da diese Produktivität nach der Umstrukturierung/Modernisierung möglicherweise überschritten wird, liegt die effektive Obergrenze niedriger. 
dieser hohen Beihilfebeträge mit der gleichzeitigen Privatisierung der Werften, der auch von Werften in anderen MS kritisiert wird, besteht darin, daß die neuen Erwerber möglicherweise Investitionen zu geringeren Kosten durchführen und einen Teil der erhaltenen Beihilfen zur Quersubventionierung ihrer anderen Werften benutzen können ${ }^{179}$. Zur Sicherstellung der tatsächlichen Durchführung der Investitionen und des Kapazitätsabbaus beauftragte die Kommission daher eine unabhängige Consultingfirma mit der Überprüfung 180 .

In Anwendung der Regeln für Entwicklungsbeihilfen wurden wiederum vorwiegend deutsche Beihilfen überprüft, wobei in einigen Fällen aufgrund von Zweifeln am Entwicklungsförderungscharakter das Prüfverfahren eröffnet werden mußte und in einem Fall sogar eine negative Entscheidung erging 181. Auch einige Fälle des innergemeinschaftlichen Wettbewerbs unterlagen wieder der Überprüfung 182 . Der größte Teil der geprüften Beihilfefälle und Beihilferegelungen betraf jedoch Betriebsbeihilfen, die von der Kommission bei Einhaltung der jeweiligen Obergrenzen genehmigt wurden ${ }^{183}$.

\subsubsection{Außenwirkungen der Subventionen und außenwirtschaftliche Absiche- rung der Subventionspolitik}

Angesichts des globalen Charakters des Weltschiffbaumarktes mit einer hohen Bedeutung von Exportaufträgen einerseits und des abnehmenden Weltmarktanteils der EG schon im Laufe der 60er Jahre andererseits mußte die EG ihre Subventionskontrollpolitik nach außen absichern, um sie nach innen durchsetzen zu können. Dies betraf zum einen die Subventionierung der Exportkreditkonditionen, bei der Japan aufgrund seiner dominierenden Marktstellung eine bestimmende Rolle hatte, und zum anderen die Frage der Kapazitätsanpassungen, die ebenfalls unter dem Druck ausländischer Konkurrenz stattfand. Bei beiden Aspekten konnten internationale Vereinbarungen den Anreiz für die MS mindern, durch nationale Alleingänge die Subventionskontrolle politisch zu unterlaufen und den innergemeinschaftlichen Wettbewerb aufzuheben 184 . Forum für derartige Verhandlungen war die OECD, in der zunächst noch alle bedeutenden Schiffbaunationen der Welt vertreten waren.

\footnotetext{
179 Vgl. Moreau 1993.

180 Vgl. EG, Kommission 1993g.

181 Vgl. EG, Kommission 1992a, S. 418 und 422, sowie 1993a, S. 225.

182 Vgl. EG, Kommission 1992a, S. 423.

183 Vgl. bspw. EG, Kommission 1993f zu der deutschen Wettbewerbshilfe.

184 Vgl. EP 1976, S. 25, 31.
} 


\subsubsection{Die OECD-Exportkreditabkommen}

Das erste OECD-Exportkreditabkommen vom Mai 1969 ebenso wie alle weiteren Vereinbarungen dieser Art legte drei Größen für Exportkredite fest: die maximale Kreditsumme in Prozent des Baupreises, die maximale Kreditlaufzeit und die Mindestverzinsung. Die Konditionen wurden mehrfach geändert, um sie der Zinsentwicklung an den Kapitalmärkten und der Stärke der Schiffbaukrise anzupassen ${ }^{185}$.

Tab. 4.2-4

OECD-Exportkreditbedingungen

\begin{tabular}{|c|c|c|c|}
\hline Jahr & Laufzeit & Zins & Mindestanzahlung \\
\hline vor 1969 & $8-10$ & 5,5 & 20 \\
\hline $5 / 1969$ & 8 (evtl. 10) & 6 & 20 \\
\hline $1 / 1971$ & 8 & 7,5 & 20 \\
\hline $7 / 1974$ & 7 & 8 & 30 \\
\hline Seit $12 / 1979$ & 8,5 & 8 & 20 \\
\hline
\end{tabular}

So brachten die Modifikationen 1971 und 1974 eine Verschärfung der Konditionen in einer Periode stark steigender Zinsen und eines anhaltenden Schiffbaubooms, während 1980 wieder eine Erleichterung in Kraft trat, was mit der inzwischen eingetretenen Schiffbau- und Schiffahrtskrise erklärbar ist, in der man die finanzielle Situation der Reeder verbessern wollte ${ }^{186}$.

Das erste Abkommen von 1969 stellte lediglich eine Empfehlung dar und besaß für die Signatarstaaten weder Verbindlichkeit noch existierten Kontrollmechanismen ${ }^{187}$. Jedoch erleichterte die Transparenz des Weltschiffbaumarktes die Kontrolle des Abkommens und schuf somit Anreize für seine Einhaltung ${ }^{188}$. Die späteren Abkommen waren rechtlich verbindlicher.

Die Harmonisierung der Subventionen in diesem Teilbereich durch die Vereinheitlichung der Kreditkonditionen behandelt die Signatarstaaten jedoch nur scheinbar gleich: So galten bereits im Abkommen von 1974 Ausnahmeregelungen für einige MS (Belgien, Frankreich, Italien, Großbritannien), die es ihnen erlaubten, in den Mindestzinssatz von $8 \%$ gewisse Kosten, insbesondere die Prämien für die Exportkreditversicherung einzubeziehen, so daß der tatsächliche Nettozinssatz für

185 Vgl. Gutowski/Thiel/Weilepp 1984, S. 28/29.

186 Vgl. Eußner 1983a, S. 55.

187 Vgl. Pfeiffer 1971, S. 531.

188 Vgl. Borggrefe 1980, S. 319. 
ihre Exportkredite nochmals niedriger lag ${ }^{189}$. Dieses Privileg wurde auch 1980 beibehalten, allerdings auf eine maximale Zinsverbilligung auf 7,5\% limitiert 190 .

Eine wesentlich gravierendere Wettbewerbsverzerrung entsteht jedoch durch den einheitlichen Mindestzinssatz, der Ländern mit hoher Inflation - also geringerer Stabilitätsorientierung der Wirtschaftspolitik - und entspechend höheren Nominalzinsen einen wesentlich stärkeren Grad der Subventionierung gestattet als den stabilitätsorientierten Ländern ${ }^{191}$. Der Versuch der EG-Kommission, diese Verzerrung mit der 3. RL 1973 im Innenverhältnis der MS durch Kappung des Zinsvorteils auf 5\%Punkte bezogen auf einen modifizierten nationalen Anleihezinssatz mit Ausnahmen bei Drittlandskonkurrenz zu beschränken ${ }^{192}$, scheiterte wohl v.a. am Widerstand der MS mit hohen Inflationsraten und ebensolchen Zinssätzen. Weil Seetransportgeschäfte i.d.R. auf Dollarbasis abgewickelt werden, besteht bei Finanzierung in Weichwährung für die Reeder bei gleichem Zins noch der Vorteil möglicher Abwertungsgewinne ${ }^{193}$. Da bei einer Laufzeit von 8,5 Jahren bei 17 gleichen Rückzahlungsraten eine einprozentige Zinsverbilligung einem Subventionsäquivalent von 3,6\% des Baupreises entspricht, überrascht es nicht, daß bspw. 1984 innerhalb der EG der Subventionsgrad zwischen $26,7 \%$ in Italien und 5,4\% in den Niederlanden schwankte oder in den Niedrigzinsphasen wie 1978 Länder wie Deutschland oder Holland überhaupt keine Zinsverbilligung geben konnten ${ }^{194}$. Auch in Zeiten höherer Zinsen beschränkten die letztgenannten Länder ihre Kreditsubvention auf maximal 22,5\% des Verkaufspreises, während die anderen MS dieses Instrument unlimitiert bis zur OECD-Grenze einsetzten ${ }^{195}$.

Ein weiteres Problem des OECD-Ansatzes besteht darin, daß einige aufstrebende Schiffbauländer wie Taiwan oder Südkorea als Nichtmitglieder dem Abkommen nicht unterworfen sind, daß auch einige OECD-Mitglieder wie die USA dem Abkommen nicht beigetreten sind, andere wie z.B. Spanien 1979-84 austraten, so daß eine Reihe wichtiger Länder die Mindestkonditionen unterbieten können. Dem tragen die beiden jüngsten OECD-Abkommen dadurch Rechnung, daß eine Matching-Klausel den Signatarstaaten eine Anpassung ihrer Konditionen an solche

189 Vgl. Langer 1974, S. 211.

$190 \mathrm{Vgl}$. Borggrefe 1980, S. 321.

$191 \mathrm{Vgl}$. Gutowski/Thiel/Weilepp 1984, S. 29.

192 Vgl. EG, Kommission 1973b, S. 23-27, Art. 4.

193 Vgl. Eußner 1983a, S. 56.

194 Vgl. Hansa 1984, S. 2235.

195 Vgl. Fante 1983b, S. 2151. 
externer Wettbewerber nach vorheriger Meldung an die OECD erlaubt, was auch mehrfach genutzt wurde ${ }^{196}$.

Schließlich begrenzt das OECD-Abkommen auch nicht die Kreditsubventionen an Werften für Inlandslieferungen, so daß hier ausländische Konkurrenten, die an die OECD-Regeln gebunden sind, unterboten werden können ${ }^{197}$. Hier hat die EG seit der 2. RL eine Begrenzung eingeführt, indem die OECD-Limits auch für Inlandslieferungen festgesetzt wurden, wobei allerdings die o.g. Ausnahmen bestehen.

\subsubsection{Verhandlungen zur Überwindung der Schiffbaukrise}

Schon in den 60er Jahren wurden in einer OECD-Arbeitsgruppe Fragen des Subventionsabbaus, der Kapazitätsbeschränkung und von Exportquoten diskutiert, die Gespräche scheiterten jedoch zunächst am Widerstand Japans und dem parallen Subventionsausbau in anderen Ländern ${ }^{198}$, so daß lediglich eine Einigung über die Kreditkonditionen zustande kam.

Bereits im November 1972 trat dann aber eine OECD-Resolution in Kraft, die den MS das Ziel eines vollständigen progressiven Abbaus der spezifischen Subventionen bis 1.11.1975 setzte ${ }^{199}$. Da Großbritannien noch kurz vor Verabschiedung dieser Entschließung neue Subventionen eingeführt hatte und Frankreich und Deutschland ihre Bereitschaft zur Einhaltung des Abkommens an das Verhalten anderer Länder und die Entwicklung der allgemeinen Marktlage knüpften, erschien der völlige Subventionsabbau bereits 1974 als "unrealistische Zielsetzung" 200. Dennoch wurde sowohl in den beiden Entwürfen zur 3. RL als auch in ihrer endgültigen Fassung auf diesen Abbauplan Bezug genommen und dementsprechend die Gültigkeit der Regeln für Produktionsbeihilfen mit Ausnahme derjenigen für Italien, Irland und der französischen Kostensteigerungsversicherung bis Ende 1975 befristet (vgl. Abschn. 4.2.3.1).

Die ausbrechende Schiffbaukrise machte jedoch die o.g. OECD-Resolution zur Makulatur und führte zu ihrer Ersetzung durch einige unverbindliche Leitlinien im Mai 1976201: Sie sahen einen Kapazitätsabbau unter Berücksichtigung der regionalen und sozialen Probleme vor, hielten die Mitglieder dazu an, keine Hilfen für einen

\footnotetext{
196 Vgl. ebenda.

$197 \mathrm{Vgl}$. ebenda.

198 Vgl. Kuhnert 1969, S. 159-161.

199 Vgl. Hansa 1972, S. 2115.

200 Langer 1974, S. 213.

201 Vgl. Nölling 1976, S. 241.
} 
Kapazitätsausbau oder für Maßnahmen zu geben, die die Anpassung stören könnten, und verpflichteten die Regierungen, für einen fairen Preiswettbewerb der Werften zu sorgen $^{202}$. Insbesondere für den Kapazitätsabbau enthielten die Leitlinien weder zeitliche noch quantitative Fixierungen, dennoch konnten sich einige EG-MS selbst auf das Prinzip des Abbaus nicht klar festlegen ${ }^{203}$. Diese mangelnde Einigkeit der MS erschwerte die Position der EG in den OECD-Verhandlungen, in denen die Kommission einen koordinierten Kapazitätsabbau (um ca. $40 \%$ für die EG) entsprechend den Anteilen der Staaten am Bau von Krisenschiffstypen (Tankern und Massengutfrachtern) sowie eine kartellartige Auftragsaufteilung zwischen Japan und der EG entsprechend den Marktanteilen 1974/75 hatte durchsetzen wollen ${ }^{204}$. Diesen merkantilistisch-planwirtschaftlichen Ansatz zur partiellen Abwälzung der Anpassungslasten vertrat die Kommission, obwohl sie implizit anerkannt hatte ${ }^{205}$, daß der Erfolg der japanischen Werften auf natürlichen Wettbewerbsvorteilen beruhte und auf der Zugehörigkeit der Werften in Japan zu großen Konzernen, die eine Umlegung der Gemeinkosten erlaubte ${ }^{206}$. Er ist wohl damit zu erklären, daß ein offener Wettbewerb von den MS nicht geduldet worden wäre (wegen evtl. Werftzusammenbrüche) und daß die Kommission bei Beschluß eines koordinierten Kapazitätsabbauprogramms in der OECD dessen Aufteilung auf die MS hätte ausarbeiten und überwachen können, um so ihr sektorpolitisches Konzept durchzusetzen $^{207}$.

Nachdem die Kartellierungsvorschläge der EG, die auch in den direkten Verhandlungen zwischen AWES und SAJ unterbreitet worden waren ${ }^{208}$, von Japan abgelehnt worden waren, drohte die Gemeinschaft mit EG-Subventionen und anderen Abschottungsmaßnahmen. Dies führte zu einer Zusage Japans, die Ausfuhrpreise für Schiffe um $5 \%$ zu erhöhen, seine Beschäftigung zu senken und Selbstbeschränkungsmaßnahmen in bezug auf solche EG-Teilmärkte zu ergreifen, in denen japanische Werften stark vorgedrungen waren ${ }^{209}$. Letzteres betraf vor allem die deutschen Reeder, von denen japanische Werften 1978 keine Aufträge

\footnotetext{
202 Vgl. EG, Kommission 1976b, S. 11.

203 Vgl. Fendel 1981, S. 520, Eußner 1983a, S. 58.

204 Vgl. EG, Kommission 1976b, S. 15.

205 Vgl. EG, Kommission 1976b, S. 15, und 1986c, S. 7 Anhang.

206 Vgl. EP 1976, S. 23.

207 Vgl. zu den Ideen EG, Kommission 1976b, S. 14.

208 Vgl. EP 1976, S. 26, Fante 1976a, S. 244.

209 Vgl. EG, Kommission 1977b, S. 8.
} 
annahmen $^{210}$. In der Folge konnten die AWES-Werften 1978 ihren Marktanteil und die Auftragsbestände signifikant erhöhen ${ }^{211}$. Weitere Absprachen zur Reglementierung im Sinne der EG-Vorschläge kamen nicht zustande. Stattdessen konzentrierten sich nunmehr sowohl die EG als auch Japan auf interne Sanierungsprogramme. Nachdem die japanischen Werften ihr staatlich gefördertes Kapazitätsabbauprogramm mit Werftenschließungen 1979 abgeschlossen hatten 212 und in einer sich stetig verschlechternden Konjunktur nach Aufhebung der Produktionsquoten des Antikrisenkartells 1981 größere Anteile am Weltauftragseingang an sich zogen, versuchte die Kommission, im Rahmen der OECD Japan zu weiterer Selbstbeschränkung zu drängen ${ }^{213}$. Dies gelang auch zum Teil, indem unter stillschweigender staatlicher Lenkung das Preis- und Mengenkartell der japanischen Werften schon Anfang 1983 wieder eingeführt wurde ${ }^{214}$. Hier wurde also mangels konkreter industriepolitischer Kompetenzen nach innen die Zuflucht zu einer protektionistischen Handelspolitik nach außen genommen, wobei normale marktwirtschaftliche Strukturverschiebungen zum Anlaß von Gegenmaßnahmen genommen wurden 215 .

Ein neues OECD-Abkommen zum internationalen Subventionsabbau vom Februar 1983 legte keine festen Zeitpläne und Abbauvorschriften fest ${ }^{216}$. Trotz seiner vagen Formulierungen trug es zu einer Entspannung der Beziehungen zwischen AWES und japanischen Werften bei - 1988 wurden sogar Gespräche über eine Zusammenarbeit bei der Lösung der Probleme geführt ${ }^{217}$, auch wenn die Kommission 218 noch zu Verhandlungen bzgl. einer Marktaufteilung und kartellmäßigen Preisanhebung mit Japan kommen wollte und beim Scheitern mit Schutzmaßnahmen, insbesondere einem "EG-Hafenzoll" beim Einlaufen eines in Drittländern billig gekauften Schiffes in einen Hafen der Gemeinschaft, drohte, wobei der "Zoll" abhängig vom Subventionsgrad sein sollte (also eher den Charakter einer Abschöpfung hätte). Zudem wurden in Japan weitere Umstrukturierungsprogramme mit Kapazitätsabbau (beim Bau

210 Vgl. Dohnanyi 1978, S. 302.

211 Vgl. Curzon Price 1981, S. 99.

212 Vgl. Rother 1984, S. 143.

213 Vgl. EG, Kommission 1982b, S. 8, 22.

214 Vgl. EG, Kommission 1983c, S. 9, 14, 22.

215 Vgl. Geister 1984, S. 159.

216 Vgl. VSM 1989, S. 8.

217 Vgl. Rother 1988, S. 478.

218 1988b, S. 2/3. 
von Großschiffen um fast $25 \%$ zwischen 1988 und 1991) und Auslastungsbeschränkungen durchgeführt 219 .

Seit 1990 wurde über einen stufenweisen Abbau der Subventionen in der OECD erneut diskutiert ${ }^{220}$. Südkorea beteiligt sich an diesen Diskussionen im Rahmen einer Verbindungsgruppe zur WP 6 der OECD; seine Bereitschaft zu Kapazitätsreduktionen ist jedoch nach wie vor gering 221 , vielmehr existieren hier Pläne zu massiven Erhöhungen der Kapazitäten 222 . Das im Juli 1994 unterzeichnete Abkommen zwischen den wichtigsten Schiffbaunationen im Rahmen der OECD sieht ein Auslaufen aller Betriebsbeihilfen und kapazitätserhöhender oder -erhaltender Investitionsbeihilfen bei gleichzeitiger Einführung effektiver Anti-dumping-Regeln und bei Einschränkung diskriminierender Vorschriften in anderen Staaten, wie dem JonesAct in den USA (s.u. Abschn. 4.2.5.3) vor. Das Abkommen soll 1996 in Kraft treten $^{223}$. Danach werden nur noch FuE-, Umweltschutz- und Ausbildungsbeihilfen erlaubt sein sowie Home-credit-schemes für inländische Reeder, deren Konditionen den OECD-Exportkreditkonditionen entsprechen. Belgien, Spanien und Portugal wurde eine längere Übergangsphase zum Subventionsabbau im Gegenzug zu weiterem Kapazitätsabbau zugestanden. Frankreich leistete gegen das Abkommen lange Zeit Widerstand, da wegen der geringen Größe seiner inländischen Flotte die Homecredits den inländischen Werften weniger als die bisherigen Betriebsbeihilfen nützen werden, und erhält nunmehr auch eine Übergangszeit gewährt ${ }^{224}$. Inzwischen herrscht Sorge vor dem Heranwachsen neuer Konkurrenten mit extrem niedrigen Kosten in Rußland und der Ukraine, wo die bisherigen Marinewerft-Kapazitäten auf den Bau von Handelsschiffen umgerüstet werden könnten 225 .

Insgesamt läßt sich feststellen, daß die internationalen Verhandlungen im Rahmen der OECD zur Lösung der Schiffbaukrise und der Subventionsproblematik, abgesehen von den Exportkreditabkommen, lange Zeit wenig erfolgreich waren, was wohl vor allem darauf zurückzuführen ist, daß der OECD als lockerem Kooperations- und Gesprächsgremium die Sanktionsmöglichkeiten zu Erzwingung gemeinsamen Verhaltens fehlen.

\footnotetext{
219 Vgl. VSM 1990, S. 27, und Petersen 1991, S. 7.

220 Vgl. Haussmann 1990, S. 14.

221 Vgl. EG, Kommission 1987, S. 155, VSM 1990, S. 28.

222 Vgl. Petersen 1991, S. 8, und Lipinski 1994.

223 Vgl. Ridding 1994. Dies hängt allerdings noch von seiner Ratifizierung durch die USA und Südkorea ab. Vgl. Robert 1994.

224 Vgl. Buchan 1994, und Robert 1994.

225 Vgl. FAZ 1993.
} 


\subsubsection{Beurteilung der Subventionskontrollpolitik}

\subsubsection{Der Weltschiffbau in der Krisenphase}

Die Entwicklung der Schiffbauindustrie ist eine Funktion der Entwicklung des Weltgüterverkehrs über See, der wiederum von der Entwicklung der Weltwirtschaft und des Welthandels sowie von dessen Regionalstrukturen bestimmt wird. Vor 1973 machte der Transport von Mineralöl und dessen Derivaten 2/3 der Transportleistung der Weltflotte aus 226. Dessen Stagnation nach der 1. Ölkrise 1973 und scharfer Rückgang nach der 2. Ölkrise 1979, bedingt auch durch den Bedeutungszuwachs des Nordseeöls mit seinen kurzen Transportwegen, konnte auch durch das Wachstum anderer Frachten nicht aufgefangen werden, so daß die Gesamttransportleistung der Weltflotte bis 1983 rückläufig war (Tab. 4.2-5). Da vor 1973 in Erwartung eines anhaltenden Booms die Reeder große Neubauaufträge vergeben hatten 227 , wuchs jedoch die Weltflotte zunächst bis 1977 kräftig und danach bis 1981 langsam an (Tab. 4.2-5), wodurch die Frachtraten für Seetransporte deutlich fielen und damit die Liquidität der Reeder sich erheblich reduzierte. Dies wiederum verminderte die Nachfrage nach neuen Schiffen um so stärker, obwohl zunächst die fallenden Schiffspreise noch eine spekulative Nachfrage im Vorgriff auf späteren Bedarf aufrechterhielten 228 .

Diese Entwicklung spiegelt sich auch deutlich in der Entwicklung der Weltstapelläufe wider (s. Tab. 4.2-6), die einen rapiden Anstieg bis 1975 und dann einen ebenso scharfen Rückgang um ca. 2/3 bis 1979 zeigt. Nimmt man die abgewrackten Schiffe, z.T. als Folge der schlechten Schiffahrtskonjunktur, in die Betrachtung hinein, so zeigt sich von 1983-86 sogar ein Nettorückgang der Weltflotte. Diese Zahlen überzeichnen den Rückgang der Beschäftigung im Weltschiffbau allerdings, da der Arbeitsaufwand für den am stärksten schrumpfenden Bereich, den Tankerbau, pro BRT geringer ist als für höherentwickelte Schiffe, wie z.B. Container- und Passagierschiffe. Dem trägt die Maßzahl GBRT Rechnung, die den Input an Arbeitsstunden pro BRT berücksichtigt. Derartig korrigierte Werte (Tab. 4.2-6a) zeigen einen Rückgang des Weltschiffbaus um lediglich 50\% von 1976-80, danach jedoch eine parallele Entwicklung zu den BRT-Zahlen. Die Situation des Schiffbaus in der EG wurde noch dadurch verschärft, daß der Anteil der Gemeinschaft am schrumpfenden Weltschiffbauvolumen deutlich abnahm (Tab. 4.2-6b) bei konstantem Anteil Japans und einem starken Zuwachs vor allem Südkoreas, wo der Aufbau von Werften durch

226 Vgl. Lammers 1984, S. 1.

227 Vgl. EG, Kommission 1976b, S. 3.

228 Vgl. EG, Kommission 1977b, S. 18; erneut 1984d, S. 8. 
Tab. 4.2-5

Weltgüterverkehr über See und Frachtertonnage

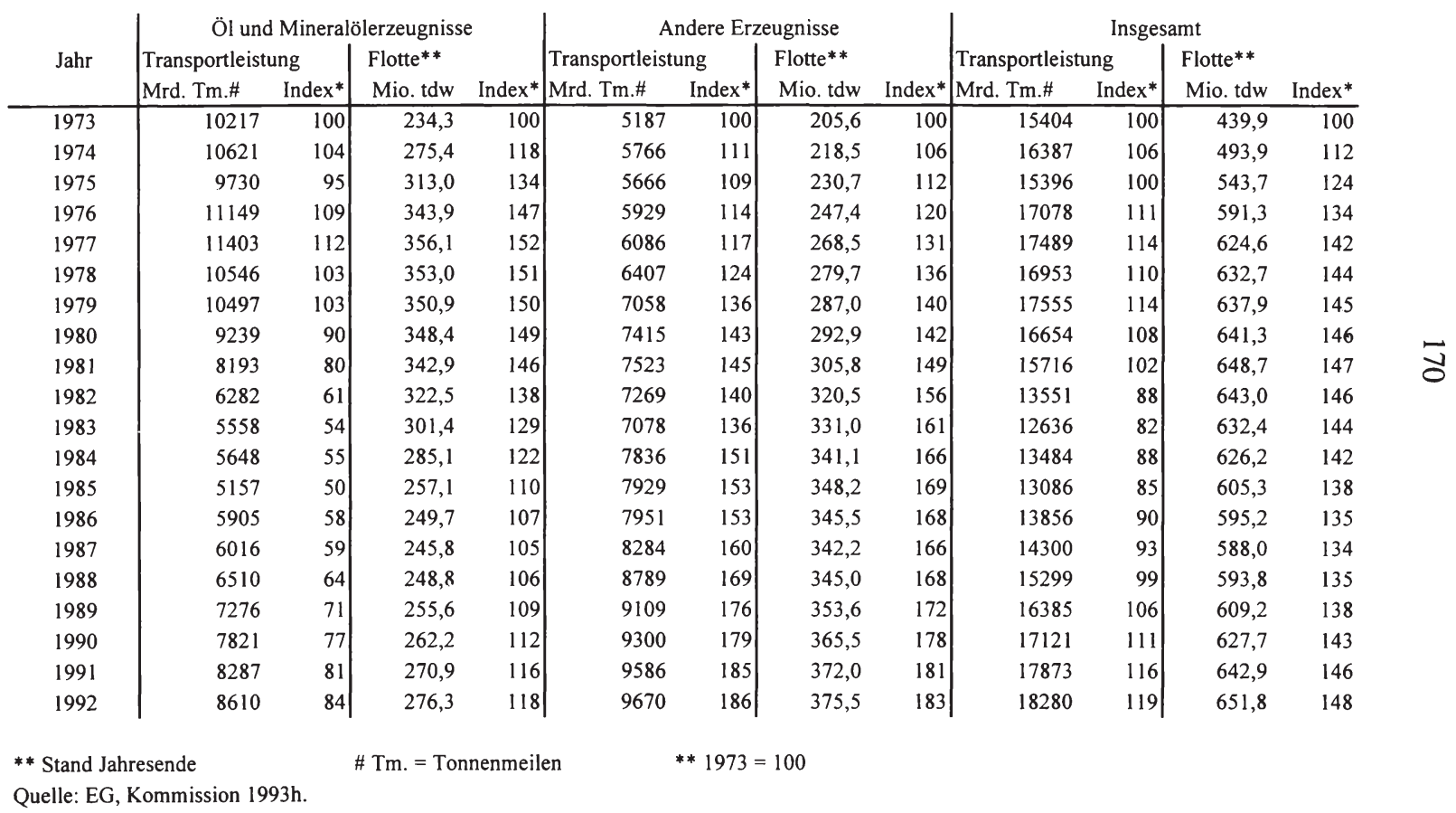


Tab. 4.2-6

Entwicklung des Weltschiffbaus

\begin{tabular}{|c|c|c|}
\hline Jahr & $\begin{array}{l}\text { Weltstapelläufe } \\
\text { in Mio. BRT/BRZ }\end{array}$ & $\begin{array}{l}\text { Abgewrackte und ver- } \\
\text { lorengegangene Schiffe } \\
\text { in Mio. BRT/BRZ }\end{array}$ \\
\hline 1937 & 2,691 & 1,026 \\
\hline 1950 & 3,489 & 1,174 \\
\hline 1955 & 5,315 & 1,175 \\
\hline 1960 & 8,356 & 3,643 \\
\hline 1965 & 12,216 & 3,262 \\
\hline 1970 & 21,690 & 4,923 \\
\hline 1971 & 24,860 & 5,297 \\
\hline 1972 & 26,714 & 5,903 \\
\hline 1973 & 31,520 & 4,498 \\
\hline 1974 & 34,624 & 3,829 \\
\hline 1975 & 35,898 & 6,073 \\
\hline 1976 & 31,047 & 7,771 \\
\hline 1977 & 24,167 & 7,166 \\
\hline 1978 & 15,220 & 11,781 \\
\hline 1979 & 11,788 & 8,875 \\
\hline 1980 & 13,935 & 7,826 \\
\hline 1981 & 17,066 & 8,490 \\
\hline 1982 & 17,290 & 15,256 \\
\hline 1983 & 14,888 & 18,231 \\
\hline 1984 & 17,732 & 20,105 \\
\hline 1985 & 17,247 & 23,881 \\
\hline 1986 & 14,914 & 22,896 \\
\hline 1987 & 9,770 & 13,293 \\
\hline 1988 & 11,997 & 5,879 \\
\hline 1989 & 13,041 & 3,145 \\
\hline 1990 & 14,894 & 2,933 \\
\hline 1991 & 16,860 & 3,914 \\
\hline 1992 & 20,992 & 7,792 \\
\hline 1993 & 18,699 & $11,50^{*}$ \\
\hline
\end{tabular}


staatliche Hilfen massiv forciert wurde 229 . Diese Tendenz konnte erst in jüngerer Zeit auf einem wieder leicht wachsenden Markt mit steigenden Preisen umgekehrt werden, so daß der EG-Anteil wieder auf rund $23 \%$ stieg 230 .

Im folgenden soll der Erfolg der gemeinschaftlichen Subventionskontrolle anhand von vier Fragestellungen untersucht werden:

- Gelang es, das Subventionsniveau im Schiffbau abzubauen, um so die Verzerrungen gegenüber anderen Industriezweigen zu vermindern?

- Wurde, unabhängig von einer Senkung des Subventionsniveaus, zumindest dessen Harmonisierung zwischen den MS erreicht, um eine Intra-EG-Wettbewerbsverzerrung zu verhindern?

- Welches waren die Auswirkungen der Subventionen und ihrer Kontrolle auf den Intra-EG-Handel und Wettbewerb?

- Wurde schließlich mit Hilfe der Subventionen das Ziel der Umstrukturierung und technischen Modernisierung der EG-Werftindustrie erreicht?

\subsubsection{Die Entwicklung des Subventionsniveaus}

Versucht man, den Erfolg der gemeinschaftlichen Subventionskontrolle zu beurteilen, so stellt sich zunächst die Frage, ob es gelang, das Subventionsniveau im Schiffbau abzubauen, um so die Verzerrungen gegenüber anderen Industriezweigen zu vermindern. Diese Frage muß mit einem Nein beantwortet werden. Die Subventionsintensität folgt relativ klar der wirtschaftlichen Lage der Schiffbauindustrie, d.h. im Laufe der Boomjahre bis 1975 gelang es, das Beihilfeniveau abzubauen, während es in den folgenden Krisenjahren massiv erhöht wurde und erst wieder in jüngster Zeit aufgrund der Erholung der Branche abnahm; der ineffizienzfördernde Subventionswettlauf wurde also im politischen Prozeß nicht gestoppt 231 . So weist Lammers 232 darauf hin, daß von 1973-84 der Subventionsgrad im Schiffbau stärker gestiegen sei als in allen anderen Zweigen des verarbeitenden Gewerbes.

Der hohe Subventionsgrad für Schiffsneubauten perpetuierte die Krise zudem, da sich der Kauf neuer Schiffe für die Reeder dadurch gegenüber dem Erwerb gebrauchter Schiffe erheblich verbilligte, was die Weltflotte vergrößerte, ihre Aus-

\footnotetext{
229 Vgl. BDI 1986, S. 74.

230 Vgl. Petersen 1991, S. 8, und EG, Kommission 1993h, S. 9

231 Vgl. Curzon Price 1981, S. 99/100.

232 1984, S. 10.
} 
Tab. 4.2-6(a)

Fertiggestellte Schiffe im Weltschiffbau

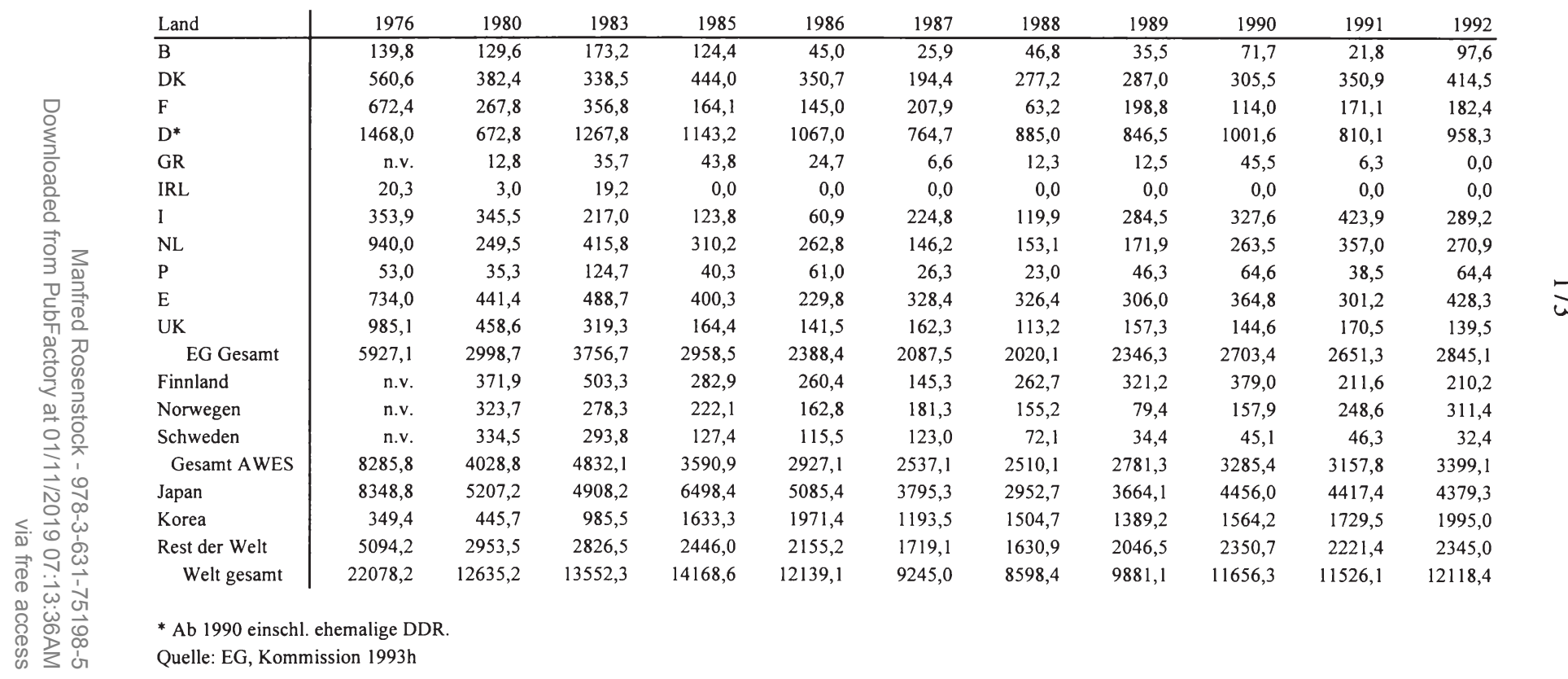


Tab. 4.2-6(b)

Prozentualer Anteil der Länder am Weltschiffbau (in \% GBRT)

\begin{tabular}{|c|c|c|c|c|c|c|c|c|c|c|c|}
\hline Land & 1976 & 1980 & 1983 & 1985 & 1986 & 1987 & 1988 & 1989 & 1990 & 1991 & 1992 \\
\hline B & 0,6 & 1,0 & 1,3 & 0,9 & 0,4 & 0,3 & 0,5 & 0,4 & 0,6 & 0,2 & 0,8 \\
\hline DK & 2,5 & 3,0 & 2,5 & 3,1 & 2,9 & 2,1 & 3,2 & 2,9 & 2,6 & 3,0 & 3,4 \\
\hline $\mathrm{F}$ & 3,0 & 2,1 & 2,6 & 1,2 & 1,2 & 2,2 & 0,7 & 2,0 & 1,0 & 1,5 & 1,5 \\
\hline $\mathrm{D}^{*}$ & 6,6 & 5,3 & 9,4 & 8,1 & 8,8 & 8,3 & 10,3 & 8,6 & 8,6 & 7,0 & 7,9 \\
\hline GR & n.v. & 0,1 & 0,3 & 0,3 & 0,2 & 0,1 & 0,1 & 0,1 & 0,4 & 0,1 & 0,0 \\
\hline IRL & 0,1 & 0,0 & 0,1 & 0,0 & 0,0 & 0,0 & 0,0 & 0,0 & 0,0 & 0,0 & 0,0 \\
\hline I & 1,6 & 2,7 & 1,6 & 0,9 & 0,5 & 2,4 & 1,4 & 2,9 & 2,8 & 3,7 & 2,4 \\
\hline NL & 4,3 & 2,0 & 3,1 & 2,2 & 2,2 & 1,6 & 1,8 & 1,7 & 2,3 & 3,1 & 2,2 \\
\hline$P$ & 0,2 & 0,3 & 0,9 & 0,3 & 0,5 & 0,3 & 0,3 & 0,5 & 0,6 & 0,3 & 0,5 \\
\hline $\mathrm{E}$ & 3,3 & 3,5 & 3,6 & 2,8 & 1,9 & 3,6 & 3,8 & 3,1 & 3,1 & 2,6 & 3,5 \\
\hline UK & 4,5 & 3,6 & 2,4 & 1,2 & 1,2 & 1,8 & 1,3 & 1,6 & 1,2 & 1,5 & 1,2 \\
\hline EG Gesamt & 26,8 & 23,7 & 27,7 & 20,9 & 19,7 & 22,6 & 23,5 & 23,7 & 23,2 & 23,0 & 23,5 \\
\hline Finnland & n.v. & 2,9 & 3,7 & 2,0 & 2,1 & 1,6 & 3,1 & 3,3 & 3,3 & 1,8 & 1,7 \\
\hline Norwegen & n.v. & 2,6 & 2,1 & 1,6 & 1,3 & 2,0 & 1,8 & 0,8 & 1,4 & 2,2 & 2,6 \\
\hline Schweden & n.v. & 2,6 & 2,2 & 0,9 & 1,0 & 1,3 & 0,8 & 0,3 & 0,4 & 0,4 & 0,3 \\
\hline Japan & 37,8 & 41,2 & 36,2 & 45,9 & 41,9 & 41,1 & 34,3 & 37,1 & 38,2 & 38,3 & 36,1 \\
\hline Korea & 1,6 & 3,5 & 7,3 & 11,5 & 16,2 & 12,9 & 17,5 & 14,1 & 13,4 & 15,0 & 16,5 \\
\hline Rest der Welt & 23,1 & 23,4 & 20,9 & 17,3 & 17,8 & 18,6 & 19,0 & 20,7 & 20,2 & 19,3 & 19,4 \\
\hline Welt gesamt & 100,0 & 100,0 & 100,0 & 100,0 & 100,0 & 100,0 & 100,0 & 100,0 & 100,0 & 100,0 & 100,0 \\
\hline
\end{tabular}

* Ab 1990 einschl. ehemalige DDR

Quelle: EG, Kommission 1993h. 
lastung und die Frachtraten, somit die Liquidität der Reeder und deren Fähigkeit und Willen zur Entrichtung kostendeckender Preise weiter minderte 233.

Betrachtet man die Tabellen 4.2-2, 4.2-2a und 4.2-7, so zeigt sich, daß die traditionellen Schiffbausubventionsländer der EG, also Frankreich und Italien, aber auch Großbritannien (später die NL) während der ganzen Zeit seit Ausbruch der Krise Produktionshilfen in z.T. beträchtlichem Ausmaß gezahlt haben. Dies ist z.T. wohl auch darauf zurückzuführen, daß diese Länder Anfang der 70er Jahre ihre Produktion weniger stark modernisiert und rationalisiert hatten als die Partnerländer und somit Produktivitätsrückstände aufwiesen 234 . Belgien, Dänemark und Deutschland konzentrierten ihre Schiffbauförderung, die einen geringeren Grad einnahm, auf Reederhilfen, die bei Frankreich, Italien und Großbritannien noch zusätzlich gezahlt wurden.

Ein Erklärungsansatz für die unterschiedliche Subventionsintensität ließe sich in einer höheren regionalen Konzentration der Werften in den Hochsubventionsländern vermuten. Die vorliegenden Zahlen 235 zeigen jedoch im Gegenteil eine höhere Regionalkonzentration in Deutschland im Vergleich zu Großbritannien und Frankreich und z.T. auch zu Italien.

Stattdessen hatten wohl die unterschiedlichen wirtschaftspolitischen Leitbilder und Eigentumsorganisationen der MS einen großen Einfluß. Während Deutschland, aber auch die Niederlande und Dänemark, die marktwirtschaftlich ausgerichtet sind und deren Werften sich größtenteils in Privatbesitz befinden, für einen Subventionsabbau eintraten, galt das für Länder mit indikativer Planung wie in Frankreich und staatlichen Werften wie in Großbritannien, Italien und z.T. Frankreich nicht. Sie traten für eine weitere Subventionierung ein, höchstens für eine Konzertierung236. Hieran zeigen sich die möglichen Schwierigkeiten der Durchsetzung der Wettbewerbsregeln des EGV bei einem hohen Staatsanteil an der Wirtschaft und auch die Möglichkeit des Staates, über die subventionistische Kapitalzuführung oder den Verzicht auf

233 Vgl. Sohmen 1983, S. 21/22.

234 Vgl. Weilepp 1989, S. 59/60.

235 Vgl. Soltwedel 1988, S. 181, der einen sog. Lokalisationskoeffizient berechnet. Zu dessen Ermittlung wird der Anteil der im Schiffbau Beschäftigten in einer Region durch den jeweiligen Anteil für den MS als Ganzes dividiert. Diese Werte liegen für die deutschen Schiffbauregionen zwischen 6.9 und 23.5, während sie in den entsprechenden Regionen des UK nur zwischen 2.6 und 3.0 und in $\mathrm{F}$ zwischen 2.6 und 9.9 liegen.

236 Vgl. Fante 1983, S. 229/230. 
Tab. 4.2-7

Staatliche Hilfen für den Neubau von Schiffen in den EG-Ländern 1974-86 (\% der Baupreise)

(für inländische Reeder bzw. für exportierte Schiffe)

\begin{tabular}{|c|c|c|c|c|c|c|c|c|c|c|c|c|c|c|}
\hline \multirow[t]{2}{*}{ Jahr } & \multicolumn{2}{|c|}{ Belgien } & \multicolumn{2}{|c|}{ Deutschland } & \multicolumn{2}{|c|}{ Dänemark } & \multicolumn{2}{|c|}{ Frankreich } & \multicolumn{2}{|l|}{ Italien } & \multicolumn{2}{|c|}{ Niederlande } & \multicolumn{2}{|c|}{ Großbritannien } \\
\hline & Inlanc & Export & Inland & Export & Inland & Export & Inland & Export & Inland & Export & Inland & Export & Inland & Export \\
\hline 1974 & n.v & 6 & 10 & 4 & n.v & 13 & n.v. & n.v. & n.v. & 14 & n.v. & 4 & 17 & 17 \\
\hline 1975 & n.v & 6 & 10 & 4 & n.v & 9 & n.v. & n.v. & n.v. & 14 & n.v. & 4 & 14 & 14 \\
\hline 1976 & 15 & 4 & 10 & 4 & n.v & 4 & $6-19$ & 4 & n.v. & 14 & n.v. & n.v. & 10 & 10 \\
\hline 1977 & 15 & 4 & 19 & 4 & n.v & 4 & n.v. & n.v. & n.v. & n.v. & n.v. & n.v. & n.v. & n.v. \\
\hline 1978 & 15 & 4 & 20 & 4 & n.v & 4 & n.v. & n.v. & n.v. & $8-11$ & $15-36$ & $10-31$ & $14-32$ & $14-32$ \\
\hline 1979 & 19 & 4 & 26 & 14 & 15 & 6 & $28-48$ & $14-34$ & $19-28$ & $19-28$ & n.v. & n.v. & n.v. & n.v. \\
\hline 1980 & 42 & 5 & 27 & 15 & 60 & 32 & $34-48$ & $23-37$ & $38-45$ & $38-45$ & n.v. & n.v. & n.v. & n.v. \\
\hline 1981 & 47 & 5 & 25 & 13 & 61 & 33 & $44-57$ & 42 & 56 & 56 & 32 & 22 & 39 & 39 \\
\hline 1982 & 36 & 5 & 22 & 7 & 59 & 38 & $41-54$ & 39 & 52 & 52 & 28 & 18 & 31 & 31 \\
\hline 1983 & 24 & 7 & 18 & 7 & 29 & 19 & 47 & 35 & 52 & 52 & 24 & 14 & 22 & 23 \\
\hline 1984 & 27 & 10 & 23 & 12 & 29 & 18 & $39-52$ & 37 & 39 & 39 & 25 & 15 & 19 & 20 \\
\hline 1985 & $19-2$ & 7 & 22 & 10 & 16 & 10 & $20-45$ & $20-30$ & n.v. & n.v. & n.v. & n.v. & n.v. & n.v. \\
\hline 1986 & $18-23$ & 7 & 18 & 7 & $30-31$ & 7 & $15-40$ & $15-40$ & $31-53$ & $21-40$ & $30-35$ & $12-17$ & 26 & 27 \\
\hline
\end{tabular}

Die angegebenen Fördersätze für B, D, F, NL und UK unterstellen in allen Jahren die höchstmögliche Zinsverbilligung im Rahmen von Finanzierungshilfen von 2 Prozentpunkten. Da in mehreren Jahren die Kapitalmarktzinssätze in diesen Ländern um weniger als 2 Prozentpunkte über dem OECD-Limit von 8\% lagen, ist nicht ausgeschlossen, daß der tatsächliche Fördersatz geringfügig niedriger war.

Für Irland lagen nur für 1983 Werte vor. Sie betrugen 27\% für inländische Lieferungen und 25\% für Exporte.

Quelle: Soltwedel et al. 1988. 
Gewinnausschüttungen der Werften deren Kapitalbasis und damit ihre Möglichkeit, durch niedrigere Preiskalkulationen Verluste hinzunehmen, zu stärken 237.

\subsubsection{Erfolge bei der Harmonisierung und Kontrolle?}

Die zweite Frage, die sich zur Beurteilung der Subventionskontrolle stellt, ist: Wenn schon eine Senkung des Subventionsgrades scheiterte, gelang dann zumindest eine Harmonisierung des Niveaus zwischen den MS, um eine Intra-EG-Wettbewerbsverzerrung zu verhindern? Auch hier muß die Antwort eher skeptisch ausfallen. Wie die Tabellen 4.2-2, 4.2-2a und 4.2-7 zeigen, variierten sowohl die Form als auch die Intensität der Beihilfen zwischen den MS während der gesamten Betrachtungsperiode stark. Zudem ergibt sich als Resultat der Darlegungen aus Kap. 4.2.3, daß die in den jeweiligen RL oder von der Kommission in ihren Entscheidungen festgelegten Subventionshöchstgrenzen i.d.R. dem Niveau entsprachen, das die Länder mit dem höchsten Subventionsniveau und der geringsten Wettbewerbsfähigkeit verkraften konnten. Die Kontrolle der Kommission hatte also stärker konstatierenden als regulierenden Charakter. Diese Politik führte sogar eher dazu, daß die Regierungen der niedrig subventionierenden Länder, wie Deutschland und z.T. auch die Niederlande, unter dem Druck ihrer Werftenlobbies alte Beihilfen erhöhten oder neue einführten, so daß eine Subventionsharmonisierung, wenn überhaupt, dann eher nach oben erfolgte 238 . Diese Tendenz konnte erst in den Jahren seit Verabschiedung der 6. RL gestoppt und dann umgekehrt werden, so daß die drastische Reduktion der Obergrenzen auch von einer ähnlich starken Abnahme der tatsächlichen Förderung begleitet wurde, die in den Hochsubventionsländern noch stärker ausgeprägt war. Diese Tendenz wird zukünftig durch das jüngste OECD-Abkommen über einen Subventionsabbau unterstützt werden.

Hier, ebenso wie bei der Beurteilung zur 1. Frage, stellt sich zudem das Problem, wie die Subventionierung ohne die Kommissionskontrolle ausgefallen wäre angesichts der harten Debatten um die RL. Einen Anhaltspunkt hierfür könnte die Entwicklung der Subventionierung in Staaten außerhalb der EG geben, wobei die Betrachtung auf das Verhalten anderer Industrieländer, wie Norwegen, Schweden,

237 Vgl. Lammers 1988, S. 5-7. Auch in D taten dies die Länder. Vgl. Lammers 1989, S. 128/129. Der Anteil der Staatswerften stieg von $16 \%$ auf $40 \%$ in der Dekade bis 1983; vgl. Fante 1983a, S. 2262

238 So war es 1987/88 in allen MS außer Belgien möglich, durch Kumulation verschiedenener Subventionssysteme den Höchstsatz von $28 \%$ zu erreichen. Vgl. EG, Kommission 1989b, S. 4. In Deutschland wurden die Subventionen einschließlich der Exportförderung von $12 \%$ auf $20 \%$ erhöht. Vgl. EG, Kommission 1988c, S. 15. 
Japan und die USA mit etablierten Werftindustrien und vergleichbaren Lohnkosten konzentriert werden soll. Hierbei stellen die USA 239 einen Sonderfall dar, da ihre Subventionen (Baukostensubventionen als Preisnachteilsausgleich, Kreditbürgschaften, Betriebskostensubventionen) völlig auf Inlandsaufträge abgestellt waren (Exportanteil unter 5\%) und ein Betriebsverbot für Importschiffe auf inneramerikanischen Routen besteht (Jones Act). Diese Vorgehensweise führte zu einer starken Abschottung der USA vom Weltmarkt sowie zum Erhalt eines ineffizienten Industriezweiges mit weit überhöhter Belegschaft, wohl vorwiegend aus militärischen Gründen.

In ähnlicher Weise wie in der EG eskalierte auch in Norwegen, Schweden und Japan 240 nach Ausbruch der Krise die Subventionierung des Schiffbaus, wobei alle in der EG benutzten Instrumente auch in diesen Ländern auftraten. So wurden in Norwegen 1978 Baukostenzuschüsse von $20 \%$ eingeführt, die allerdings bis 1982 auf $5 \%$ reduziert und danach abgeschafft wurden. Sie wurden dann durch Zinszuschüsse ersetzt, deren Subventionswert aber nur bis zu 2,8\% betrug, und durch Zollrückvergütungen für Importe von Komponenten sowie Finanzierungshilfen für Reeder

Tab. 4.2-8

Koeffizient der Produktionsstruktur*

\begin{tabular}{l|rrrrrrrrr} 
Land & 1975 & 1980 & 1981 & 1982 & 1983 & 1984 & 1985 & 1986 & 1987 \\
\hline DK & 0,53 & 1,84 & 0,98 & 0,73 & 0,76 & 0,75 & 0,97 & 0,97 & 0,79 \\
D & 0,56 & 1,59 & 1,24 & 1,23 & 1,02 & 1,28 & 1,14 & 1,12 & 1,19 \\
F & 0,64 & 0,95 & 0,88 & 1,33 & 1,16 & 1,13 & 0,82 & 0,92 & 1,23 \\
UK & 0,65 & 1,07 & 1,14 & 0,91 & 0,64 & 0,69 & 0,96 & 1,43 & 0,84 \\
I & 0,61 & 1,39 & 1,33 & 0,88 & 0,85 & 0,66 & 1,41 & 1,79 & 0,68 \\
NL & 0,74 & 2,05 & 1,97 & 1,84 & 1,79 & 1,68 & 1,72 & 1,74 & 2,50 \\
E & n.v. & n.v. & n.v. & 1,05 & 0,98 & 0,97 & 0,73 & 1,38 & 1,01 \\
Finnland & n.v. & n.v. & n.v. & 1,63 & 1,94 & 1,20 & 1,33 & 1,13 & 0,86 \\
Norwegen & n.v. & n.v. & n.v. & 1,29 & 1,53 & 1,57 & 1,82 & 1,92 & 2,60 \\
Schweden & n.v. & n.v. & n.v. & 0,88 & 0,90 & 0,64 & 0,63 & 1,43 & 1,60 \\
Brasilien & 0,62 & 0,57 & 0,58 & 0,68 & 0,68 & 0,69 & 0,52 & 0,53 & 0,45 \\
Japan & 0,51 & 0,85 & 0,66 & 0,71 & 0,74 & 0,75 & 0,68 & 0,62 & 0,66 \\
Südkorea & 0,45 & 0,85 & 0,55 & 0,63 & 0,64 & 0,70 & 0,62 & 0,54 & 0,57 \\
Taiwan & n.a. & 1,03 & 0,53 & 0,53 & 0,69 & 0,53 & 0,70 & 0,54 & 0,55 \\
USA & 0,95 & 0,95 & 1,32 & 1,86 & 1,14 & 1,30 & 1,02 & 0,60 & 0,56 \\
Welt gesamt & 0,60 & 0,96 & 0,82 & 0,87 & 0,85 & 0,84 & 0,78 & 0,72 & 0,74
\end{tabular}

* Verhältnis fertiggestellter Tonnage in GBRT zu fertiggestellter Tonnage in BRT Quelle: Weilepp 1989.

239 Vgl. Weilepp 1989, S. 117-120.

240 Vgl. Weilepp 1989, S. 96-104, 108-112. 
ergänzt. Auch in Schweden wurden 1977 solche Finanzierungshilfen eingeführt. Direkte Baukostenzuschüsse hatten hingegen eine sehr geringe Bedeutung. Stattdessen wurden alle Großwerften verstaatlicht, was dann zu umfangreichen Verlustausgleichen durch den Staat führte (in Höhe von ca. 10,3 Mrd SKR zwischen 1977 und 1985). In Japan gewährte der Staat ebenfalls keine direkten Baukostensubventionen; die Förderung erfolgte v.a. durch subventionierte Kredite für den Export wie auch für inländische Reeder. Daneben übernahm der Staat die Stillegungskosten der Werften bei Kapazitätsabbauten und zahlte dazu noch Abwrackprämien241.

Obwohl sich in den beiden skandinavischen Ländern die Subventionen auf die Förderung von Aufträgen konzentrierten, gelang es auch hier nicht, das Produktionsvolumen zu halten. Die starke Produktionsschrumpfung ging allerdings mit einer deutlichen Verbesserung der Produktionsstruktur einher (vgl. Tab. 4.2-8), und die sozialen Probleme aufgrund von Werftschließungen konnten in Schweden durch eine allerdings teure aktive regionale Industrieansiedlungspolitik abgefedert werden 242 . In Japan konzentrierten sich die Hilfen, wie eben erläutert, stärker auf Umstrukturierungen und Schließungen; durch die hohe Produktivität und die Einbindung der Werften in Großkonzerne konnten jedoch der Kapazitätsabbau und seine sozialen Folgen in Grenzen gehalten werden.

Insgesamt bleibt der Eindruck, daß auch Industrieländer außerhalb der EG-Subventionskontrolle in ähnlicher Weise wie die MS auf die Schiffbaukrise reagiert haben, wobei ihr Verhalten in bezug auf Umstrukturierung und Kapazitätsabbau eher dem der niedrig subventionierenden MS entsprach, was vor allem bei Schweden mit seinem verstaatlichten Werftensektor bemerkenswert ist.

Einen weiteren Mangel bei den Harmonisierungsanstrengungen stellen die fehlende Einbeziehung aller Subventionsformen und damit die Umgehungsmöglichkeiten für die MS dar. Anfänglich (1. und 2. RL) unterlagen nur die direkten Baukostensubventionen der Kommissionskontrolle, eine Einbeziehung der Preissteigerungsgarantien und Steuerrückerstattungen für die Werften gelang erst mit der 4. RL (schärfer ab der 5. RL) und die konsequente Einbeziehung auch der Reederhilfen erst mit der 6. RL. Schwierig ist auch die Erfassung von indirekten Hilfen (z.B. FuE) und von informellen Abmachungen mit Staatsunternehmen243. Im Bereich der Reederhilfen besteht heute noch Widerstand der MS, den die Kommis-

241 Vgl. zu diesem Abschnitt Weilepp 1989, S. 96-104 und 108-112.

242 Vgl. Rother 1984, S. 142.

243 Vgl. Eußner 1983, S. 158. 
sion in ihrem Entwurf zur 7. RL anspricht 244 - einige MS versuchten, die Reederhilfen nur partiell in der Höchstgrenze zu erfassen, da ihre Inzidenz unklar sei und sie zum Teil auch Werften in anderen Ländern zugutekamen. Zum ersten Argument läßt sich sagen, daß bei unklarer oder partieller Begünstigungswirkung eine Einbeziehung nur eines Teils lediglich einer pauschalen Erhöhung der Förderung entsprochen hätte und über eine Variation des Einbeziehungssatzes nur weitere Subventionserhöhungsmöglichkeiten geboten hätte. Die Kommission kam ersterem Aspekt durch einen höheren Subventionssatz 1987 entgegen und konnte so der Gefahr des 2. Aspektes ausweichen. Die Umgehung des italienischen Widerstandes gegen die 6. RL durch die Beurteilung des Handelsflottenerneuerungsprogrammes unter der 5. RL mit entsprechend höheren Fördersätzen aufgrund der Nichteinbeziehung der Reederhilfen in die Kontrolle illustriert ebenfalls den mangelnden Erfolg bei der Harmonisierung der Subventionen und der Gleichbehandlung der Länder. Angesichts der positiven Erfahrungen der jüngeren Vergangenheit mit einer erheblichen Rückführung der Förderungsintensitäten kann man jedoch argumentieren, daß die Akzeptanz der 6. RL durch alle MS, d.h. die Vermeidung eines italienischen Vetos, mit der Einbeziehung aller Subventionsformen in die Kontrolle und der damit zukünftig größeren Handhabe der Kommission ein Gewinn war, der diesen letzten Preis rechtfertigte.

Was die Begünstigung von Werften anderer Staaten durch die Reederhilfen betrifft, so zeigen die Beihilfenberichte der Kommission, daß von den meisten MS keine und von den anderen nur sehr geringe Prozentsätze der mit Reederhilfen geförderten Aufträge an Werften anderer Staaten vergeben wurden245. Die Werften der Gemeinschaft sind insoweit also auf nationaler, nicht auf EG-Ebene geschützt.

\subsubsection{Wettbewerbs- und Handelswirkungen der Subventionskontrollpolitik}

Dieser Aspekt leitet über zu einer dritten Frage: Welches sind die Auswirkungen der Subventionen und ihrer Kontrolle auf den Intra-EG-Handel und Wettbewerb gewesen? Hier sind die Zahlen aus Tab. 4.2-9 sehr instruktiv. Sie zeigen einen recht intensiven Intra-EG-Handel mit Schiffen während der Boomphase des Schiffbaus und einen fast völligen Zusammenbruch in der Krise ab 1977 und verstärkt ab 1979246, in den Worten der Kommission "eine sofortige, vollständige und anhaltende Auf-

244 Vgl. EG, Kommission 1990b, S. 13.

245 Vgl. ebenso EG, Kommission 1980c, S. 10, und 1982b, S. 13 mit Zahlen.

246 Vgl. EG, Kommission 1986c, S. 13 Anhang, und Soltwedel et al. 1988, S. 176. 
splitterung des Gemeinschaftsmarktes in Einzelmärkte"247. Diese Entwicklung ist vor allem Ausdruck der mangelnden Kontrolle der Reeder- und Finanzierungshilfen. Während die Bedingungen für Exportkredite durch die OECD-Abkommen geregelt sind, unterlagen die Finanzierungshilfen für inländische Reeder z.T. nicht diesen Beschränkungen. Dies gilt v.a. für Belgien und Dänemark, wo diese Finanzierungshilfen an Reeder für inländische Lieferungen anstelle direkter Baukostenzuschüsse existierten und seit 1979 bzw. 1977 deutlich günstigere Konditionen als in den OECD-Abkommen boten. Für die Werften in diesen beiden Ländern bestand also ein starker Anreiz, vermehrt für den Inlandsmarkt zu produzieren, was in Belgien zu einem völligen Verschwinden der Exporte seit 1981, in Dänemark zu einem im Vergleich zum Produktionsanteil deutlich geringeren Exportanteil geführt hat (Tab. 4.210) 248 .

In den anderen MS erreichen die an die Werften ausgezahlten Finanzierungshilfen zwar nur die OECD-Limits, jedoch bestehen direkt an die Reeder gezahlte Investitionshilfen in Deutschland, Frankreich und Holland, die de facto fast ausschließlich

Tab. 4.2-9(a)

Produzierte Schiffe der EG-Länder ohne Irland nach Bestimmungsregionen 1970-86 (Anteile an BRT in \%)

\begin{tabular}{c|rrr} 
Jahr & Inland & Andere EG & Drittländer \\
\hline 1970 & 57,1 & 13,4 & 29,5 \\
1971 & 55,8 & 16,9 & 27,3 \\
1972 & 52,5 & 16,4 & 31,1 \\
1973 & 45,1 & 20,8 & 34,1 \\
1974 & 56,5 & 18,2 & 25,3 \\
1975 & 47,0 & 17,4 & 35,6 \\
1976 & 50,5 & 12,6 & 36,9 \\
1977 & 51,3 & 6,5 & 42,2 \\
1978 & 62,2 & 5,7 & 32,1 \\
1979 & 67,1 & 0,8 & 32,1 \\
1980 & 65,8 & 3,8 & 30,4 \\
1981 & 47,9 & 2,0 & 50,1 \\
1982 & 61,2 & 4,3 & 34,5 \\
1983 & 60,4 & 4,7 & 34,9 \\
1984 & 68,7 & 1,8 & 29,5 \\
1985 & 67,0 & 1,0 & 32,0 \\
1986 & 73,1 & 1,7 & 25,2
\end{tabular}

Quelle: Soltwedel et al. 1988.

247 EG, Kommission 1987b, S. 16.

248 Vgl. Soltwedel et al. 1988, S. 162-164, 169. 
für im Inland georderte Schiffe gewährt werden, auch wenn diese Bedingung formal nicht existiert 249 .

Tab. 4.2-9(b)

Produzierte Schiffe ausgewählter EG-Länder nach Bestimmungsregionen 1970-86 (BRT in \%)

\begin{tabular}{c|rrr|rrr|} 
Land & \multicolumn{2}{|c|}{$1970-74$} & \multicolumn{2}{|c}{$1975-79$} & \\
& Inland & Andere EG & Drittländer & Inland & Andere EG & Drittländer \\
\hline D & 45,9 & 18,0 & 36,1 & 33,4 & 11,5 & 55,1 \\
DK & 46,0 & 17,2 & 36,8 & 55,0 & 36,9 & 8,1 \\
F & 54,2 & 19,6 & 26,2 & 47,4 & 5,8 & 46,8 \\
I & 84,7 & 2,9 & 12,4 & 89,7 & 2,9 & 7,4 \\
NL & 13,5 & 47,3 & 39,2 & 38,2 & 13,7 & 48,1 \\
UK & 74,2 & 3,3 & 22,5 & 65,2 & 1,1 & 33,7
\end{tabular}

\begin{tabular}{c|rrr|rrr|} 
Land & \multicolumn{2}{|c|}{$1980-84$} & \multicolumn{2}{|c|}{$1985 / 86$} & \\
& Inland & Andere EG & Drittländer & Inland & Andere EG & Drittländer \\
\hline D & 62,5 & 4,2 & 33,3 & 69,8 & - & 30,2 \\
DK & 58,1 & 1,9 & 40,0 & 66,1 & 1,3 & 32,6 \\
F & 31,1 & 4,0 & 64,9 & 60,1 & - & 39,9 \\
I & 66,8 & 7,8 & 25,4 & 75,4 & 0,8 & 23,8 \\
NL & 69,8 & 8,6 & 23,4 & 78,9 & 9,1 & 12,0 \\
UK & 57,8 & 0,1 & 42,1 & 54,0 & - & 46,0
\end{tabular}

Quelle: Soltwedel et al. 1988.

Die finanziellen Vorteile der Inlandsbestellungen für die Reeder, in Großbritannien auch durch den weitergewälzten Shipbuilders relief 250 , sowie ein gewisser Druck der MS bei ihrer Vergabeentscheidung bzgl. der Finanzierungshilfen 251 bewirkten somit diese massive Beeinträchtigung des Intra-EG-Handels, die den Zielen der Regeln des EGV diametral widerspricht. Diese Probleme wurden in Italien noch durch starke administrative Importhemmnisse, die der Kommission bekannt waren, verschärft 252 . Besonders betroffen von diesem Zusammenbruch waren die Niederlande, in zweiter Linie auch Deutschland und Dänemark, für die der IntraEG-Export in den Vorkrisenjahren eine signifikante Rolle gespielt hatte 253 . Ent-

249 Vgl. ebenda, S. 162-164.

250 Beim Shipbuilders relief handelt es sich um eine pauschale Rückerstattung von auf Vorprodukte gezahlten indirekten Steuern in Höhe von $2 \%$ des Baupreises des Schiffes. Vgl. Sinclair Scott 1966, S. 477.

251 Vgl. schon Heeckt 1965, S. 328/329; später Flieshardt/Sablotny 1981, S. 460, Boie 1978, S. 144, und EG, Kommission 1983b, S. 2.

$252 \mathrm{Vgl}$. Eußner 1983, S. 158.

253 Vgl. Soltwedel et al. 1988, S. 176/177. 
Tab. 4.2-10

Länderanteile an der Produktion von Seeschiffen innerhalb der EG 1970-86

(Anteile in GBRT in \%, EG ohne Irland =100)

\begin{tabular}{r|rrrrrrr} 
Jahr & B & D & DK & F & I & NL & UK \\
\hline 1970 & 5,4 & 33,4 & 6,5 & 12,9 & 9,8 & 9,4 & 22,6 \\
1971 & 3,5 & 33,3 & 7,1 & 18,3 & 10,0 & 9,3 & 18,5 \\
1972 & 4,9 & 33,5 & 10,1 & 14,5 & 10,5 & 10,8 & 15,7 \\
1973 & 2,8 & 36,8 & 6,8 & 16,9 & 8,4 & 10,8 & 17,4 \\
1974 & 3,3 & 26,6 & 11,4 & 18,6 & 10,8 & 11,7 & 17,6 \\
1975 & 3,2 & 27,3 & 10,4 & 25,6 & 7,1 & 11,8 & 14,7 \\
1976 & 2,9 & 33,1 & 8,6 & 22,1 & 6,4 & 10,3 & 16,7 \\
1977 & 1,7 & 33,3 & 9,1 & 18,8 & 9,9 & 11,4 & 15,8 \\
1978 & 4,7 & 30,9 & 9,9 & 13,7 & 8,3 & 13,3 & 19,3 \\
1979 & 5,0 & 23,0 & 10,0 & 18,9 & 8,7 & 15,1 & 19,3 \\
1980 & 5,6 & 27,3 & 10,8 & 14,1 & 11,2 & 10,6 & 20,4 \\
1981 & 3,9 & 36,2 & 12,9 & 18,8 & 9,6 & 10,0 & 9,0 \\
1982 & 3,8 & 33,7 & 12,5 & 11,4 & 6,6 & 16,1 & 15,8 \\
1983 & 5,9 & 35,6 & 12,8 & 14,6 & 4,7 & 14,7 & 11,8 \\
1984 & 4,0 & 32,5 & 14,5 & 16,3 & 7,7 & 13,6 & 11,3 \\
1985 & 5,3 & 40,8 & 18,9 & 8,7 & 4,2 & 14,8 & 7,3 \\
1986 & 2,8 & 40,4 & 19,8 & 11,0 & 3,3 & 14,7 & 8,0
\end{tabular}

Länderanteile an den Exporten von Seeschiffen innerhalb der EG 1970-86

(Anteile in GBRT in \%, EG ohne Irland = 100)

\begin{tabular}{c|rrrrrrr}
\multicolumn{1}{r}{ Jahr } & B & D & DK & F & I & NL & UK \\
\hline 1970 & 9,7 & 32,6 & 12,7 & 14,8 & 0,9 & 18,8 & 10,4 \\
1971 & 3,6 & 39,0 & 8,3 & 15,8 & 7,9 & 15,0 & 10,6 \\
1972 & 6,7 & 36,9 & 5,8 & 16,0 & 9,4 & 17,1 & 8,1 \\
1973 & 2,6 & 47,6 & 5,7 & 18,9 & 0,8 & 16,7 & 7,7 \\
1974 & 2,0 & 26,4 & 12,5 & 25,2 & 1,1 & 20,1 & 12,8 \\
1975 & 2,0 & 34,1 & 12,2 & 29,9 & 0,0 & 14,6 & 6,4 \\
1976 & 2,9 & 42,0 & 7,0 & 23,6 & 0,4 & 13,9 & 10,3 \\
1977 & 0,5 & 40,6 & 7,5 & 23,8 & 1,8 & 8,8 & 17,1 \\
1978 & 0,3 & 43,4 & 4,3 & 19,8 & 2,4 & 8,9 & 21,0 \\
1979 & 0,0 & 23,3 & 5,3 & 34,8 & 8,0 & 9,0 & 19,6 \\
1980 & 7,1 & 27,1 & 8,2 & 12,0 & 8,0 & 9,2 & 28,5 \\
1981 & 0,0 & 34,6 & 6,7 & 31,9 & 5,5 & 13,0 & 8,3 \\
1982 & 0,0 & 30,1 & 11,1 & 28,1 & 6,2 & 16,5 & 8,1 \\
1983 & 0,0 & 31,6 & 17,3 & 22,8 & 6,9 & 7,1 & 14,3 \\
1984 & 0,0 & 29,7 & 15,3 & 27,1 & 3,1 & 8,2 & 16,6 \\
1985 & 0,0 & 33,3 & 29,4 & 8,0 & 4,1 & 13,6 & 11,6 \\
1986 & 0,0 & 39,1 & 12,2 & 23,6 & 0,0 & 17,6 & 7,6
\end{tabular}

Quelle: Soltwedel et al. 1988. 
sprechend waren die Niederlande von der Schiffbaukrise auch besonders hart betroffen. Die Kommission versucht, diese Entwicklung seit der 6. RL zumindest partiell umzukehren, indem für kleine Schiffe mit einem Wert unter 10 Mio. ECU (anfangs 6 Mio. ECU) deutlich geringere Beihilfeniveaus festgelegt wurden, da in diesem Marktsegment noch ein funktionierender innergemeinschaftlicher Wettbewerb existiert.

\subsubsection{Subventionskontrolle als Mittel der Industriepolitik}

Schließlich bleibt noch die Frage, ob die massive Subventionierung zumindest das Ziel der Umstrukturierung und technischen Modernisierung der EG-Werftindustrie erreicht hat. Dieser Ansatz, der schon im 2. Programm zur mittelfristigen Wirtschaftspolitik von 1967 anklang254, den die Kommission dann wieder in ihrem Umstrukturierungsprogramm von 1977 betont hatte 255 , und der dann ab der 4. RL in allen RL auftaucht, strebte angesichts der Konkurrenz Japans und der Schwellenländer mit geringeren Lohnstückkosten einen Ausstieg der Gemeinschaftswerften aus dem Bau von Tankern und einfachen Frachtschiffen, in denen noch 1983 ca. 30\% der Werftbeschäftigten arbeiteten 256 , und eine Konzentration auf technisch hochwertige Schiffe mit hoher Wertschöpfung an. Wie Tabelle 4.2-8 zeigt, ist zwar das Verhältnis GBRT zu BRT im Vergleich zur Vorkrisenphase in den MS angestiegen, aber die Jahre seit 1980 zeigen doch eine stark schwankende Entwicklung des Quotienten ohne einen klaren Trend.

Zudem spiegelt der oben diskutierte hohe Subventionsgrad in Frankreich und Italien den Versuch wider, den Weltmarktanteil zu halten und den wegen der geringen Wettbewerbsfähigkeit notwendigen Kapazitätsabbau aufzuhalten. So wurden hier die Neubaukapazitäten 1975-86 um weniger als 30\% abgebaut bei einem EG-Durchschnitt von 45\%; nur in Großbritannien, Deutschland und den Niederlanden erfolgte ein Abbau um mehr als $40 \%$. Der hohe Kapazitätsabbau ermöglichte Deutschland und Holland eine Auslastung der Restkapazitäten von über $70 \%$, während sie in Großbritannien ebenso wie in Frankreich und Italien unter $40 \%$ lag257. Trotz des

\footnotetext{
254 Vgl. Eußner 1983a, S. 26.

255 Vgl. EG, Kommission 1977b.

256 Vgl. EG, Kommission 1983c, S. 5.

257 Vgl. EG, Kommission 1986c, S. 3/4 Anhang.
} 
hohen Subventionsniveaus konnten also Frankreich, Italien und Großbritannien ihre Positionen nicht halten 258 .

Tab. 4.2-11

\section{Verfügbare Kapazitäten im Welthandelsschiffbau}

(in Mio. GBRT)

\begin{tabular}{l|rrrr} 
Land & $1975 / 76$ & 1980 & 1985 & 1993 \\
\hline DK & 0,6 & 0,6 & 0,5 & 0,4 \\
D* & 1,5 & 0,9 & 0,8 & 1,1 \\
F & 0,8 & 0,5 & 0,3 & 0,2 \\
UK & 0,8 & 0,7 & 0,3 & 0,2 \\
I & 0,5 & 0,3 & 0,3 & 0,3 \\
NL & 0,6 & 0,3 & 0,2 & 0,3 \\
E & 1,0 & 1,0 & 0,5 & 0,4 \\
EG - 12 & 6,3 & 4,3 & 3,4 & 3,0 \\
Finnland & 0,3 & 0,5 & 0,3 & n.v. \\
Norwegen & 0,7 & 0,4 & 0,3 & n.v. \\
Schweden & 1,1 & 0,4 & 0,2 & n.v. \\
$\quad$ Westeuropa & 8,5 & 5,6 & 4,4 & n.v. \\
Staatshdlsldr. & 2,8 & 2,5 & 2,7 & n.v. \\
Brasilien & n.v. & 0,4 & 0,3 & n.v. \\
Japan & 9,0 & 7,0 & 7,0 & n.v. \\
Südkorea & 0,4 & 0,6 & 1,8 & n.v. \\
Taiwan & n.v. & 0,4 & 0,4 & n.v. \\
USA & n.v. & 0,9 & 0,4 & n.v. \\
$\quad$ Welt & 22,4 & 18,4 & 17,8 & n.v.
\end{tabular}

Quellen: Weilepp 1989 und Robert 1994.

* 1993 einschl. ehemalige DDR.

Die zu geringe Senkung der Produktionskapazität (vgl. auch Tab. 4.2-11), somit steigende Kapitalintensität der Produktion mit Unterauslastung und hoher Fixkostenbelastung, machte trotz der Arbeitsproduktivitätsgewinne durch Modernisierung die Werften dennoch nicht rentabel. Der Arbeitsplatzabbau überstieg dabei den Kapazitätsabbau ${ }^{259}$. Ein weiterer Aspekt der Ineffizienz der Umstrukturierungsweise neben

258 Vgl. Weilepp 1989, S. 77, 81-83, 85/86 und 130/131. Generell wies die Kommission darauf hin, daß die Länder mit geringeren Subventionsniveaus bei der Umstrukturierung größere Fortschritte machten. Vgl. EG, Kommission 1985c, S. 13.

259 Vgl. EG, Kommission 1986c, S. 5 Anhang, und Kwasniewski 1983, S. 160. Der Arbeitskräfteabbau erfolgte allerdings z.T. langsamer als der Produktionsrückgang wegen der Notwendigkeit einer Mindestbelegschaft für bestimmte Arbeiten und weil zuerst ein Abbau von Überstunden erfolgte. Vgl. EG, Kommission 1981b, S. 16. Dies wiederum machte Produktivitätsgewinne zunichte. 
dem unzureichenden Kapazitätsabbau zeigt sich in der zunächst bis 1980, abgesehen von Großbritannien und den Niederlanden, sehr geringen Abnahme der Zahl der Werften 260 (Tab. 4.2-12). Da angesichts des absoluten Rückgangs insbesondere des Tankermarktes auch die Konkurrenzländer ihre Produktionsstrukturen veränderten und in höherwertige Marktsegmente wanderten, wurde der Anpassungsdruck auf die EG-Werften nicht geringer 261 .

Tab. 4.2-12

Anzahl der Werften in der Gemeinschaft

\begin{tabular}{l|rrrr} 
Land & 1975 & 1980 & 1985 & 1993 \\
\hline B & 8 & 8 & 8 & 11 \\
DK & 22 & 21 & 19 & 23 \\
D* & 45 & 41 & 38 & 47 \\
F & 16 & 14 & 14 & 11 \\
GR & 2 & 2 & 2 & 2 \\
IRL & 1 & 1 & 0 & 0 \\
I\# & 11 & 11 & 10 & 45 \\
NL & 65 & 54 & 45 & 34 \\
UK & 45 & 29 & 19 & 23 \\
EG-10 & 214 & 182 & 153 & 196 \\
E & 45 & 44 & 31 & 25 \\
P & 13 & 13 & 13 & 10 \\
EG-12 & 272 & 239 & 197 & 231
\end{tabular}

* In den Werten für 1993 sind die Werften der ehemaligen DDR enthalten \# Verzerrung des Wertes für 1993 durch Hereinnahme von Konversionswerften Quelle: EG, Kommission 1986c und neuere Angaben.

Die in Kapitel 2.1.2 als Subventionsrechtfertigung vorgebrachte Argumentation der Notwendigkeit der Vermittlung von Informationen zur Umstrukturierung paßt also im Falle Schiffbau nur sehr begrenzt, da eine solche Politik erst sehr spät einsetzte $^{262}$. So wurde ein grundlegender Plan zur subventionierten Neustrukturierung der französischen Werftindustrie in zwei Werftgruppen erst 1982 vorgelegt ${ }^{263}$, und auch die anderen MS führten subventionierte Schließungen, Fusionen und Spezialisierungen zur Erhaltung notwendiger Mindestkapazitäten für eine effiziente Produk-

\footnotetext{
260 Vgl. EG, Kommission 1986c, S. 11 Anhang, und 1983d, S. 20. Aus Sicht der Werften ist eine Schließung wegen des Totalverlustes an Kapital auch unattraktiv. Vgl. Weilepp 1989, S. 123.

261 Vgl. Eußner 1983a, S. 41.

262 Vgl. Rother 1984, S. 131.

263 Vgl. Hansa 1982, S. 1560. Vorherige Pläne dieser Art waren weitgehend gescheitert.
} 
tion erst ab Mitte der 80er Jahre durch 264 . Hier wurde durch die strikteren Regeln der 6. und 7. RL die Bereitschaft zu Schließungen erhöht 265 . Dementsprechend gelang es den Werften der MS trotz ihrer Subventionierung lange Zeit auch nicht, ihre Produktions- und Beschäftigungsniveaus oder ihren Weltmarktanteil zu halten.

Dieser sehr langsame und angesichts des gesamten Beihilfevolumens sehr teure Umstrukturierungsprozess erklärt sich aus mehreren Faktoren. Zum einen sahen nach Beginn der Krise viele Marktprognosen regelmäßig einen Wiederaufschwung innerhalb von 5 Jahren voraus, was den Umstrukturierungswillen eher bremste 266 . So wurde auch der zu erwartende Arbeitsplatzverlust noch 1978 mit ca. 50.000 für die EG weit unterschätzt ${ }^{267}$ (vgl. dagegen Tab. 4.2-13). Weiterhin war der größte Anteil der Subventionen klar auftragsbezogen und nicht direkt an Modernisierungsmaßnahmen gebunden 268 . Die dadurch scheinbar bewahrte Konkurrenzfähigkeit hat den Anreiz zu drastischem Kapazitätsabbau wohl eher behindert.

Auch die oben diskutierte Tatsache, daß sich in einigen MS die Werften in Staatseigentum befinden, sowie der starke Einfluß der gutorganisierten Werftabeitergewerkschaften und militärische Überlegungen erklären die zögernde Umstellung269. Schließlich war der wohl notwendige massive Arbeitsplatzabbau bei Konzentration auf wenige Spezialschiffe in einer Phase allgemein hoher Arbeitslosigkeit nicht sofort durchsetzbar 270 . Die schnelle Schließung von Werften, die sich in nur wenigen Regionen der MS (u.a. Loire-Atlantique, Tyne and Wear, Ligurien, Belfast, Kiel) konzentrierten, die z.T. bereits vorher Förderzonen des EFRE waren, hätte einen Zusammenbruch der regionalen Arbeitsmärkte zur Folge gehabt und damit möglicherweise soziale Unruhen, da die Bereitstellung von Ersatzarbeitsplätzen nur langsam gelang. In dieser Situation der Krise genehmigte die Kommission i.d.R. nach einigen Diskussionen und Modifikationen die vorgelegten Programme der MS 271 . Dennoch hat die hohe Subventionierung den aufgrund der mangelnden

\footnotetext{
264 Vgl. EG, Kommission 1989b, S. 17/18.

265 Vgl. Petersen 1991, S. 13.

266 Vgl. z.B. Sohmen 1983, S. 7-8, EG, Kommission 1986d, S. 1.

267 Vgl. EG, Kommission 1978a, S. 162.

268 Vgl. EG, Kommission 1983b, S. 2.

269 Vgl. Eußner 1983a, S. 53/54, 176.

270 Vgl. Soltwedel et al. 1988, S. 159, Diebold 1978, S. 184/185, 187.

271 Vgl. Eußner 1983, S. 150, 158. Zu den sozialen Problemen der Umstrukturierung am Beispiel Spaniens vgl. den kurzen Hinweis in EG, Kommission 1989b, S. 18.
} 
Tab. 4.2-13

Beschäftigung im Schiffsneubau der Gemeinschaft

\begin{tabular}{|c|c|c|c|c|c|c|c|c|c|}
\hline Land & 1975 & 1978 & 1980 & 1983 & 1986 & 1988 & 1990 & 1991 & 1992 \\
\hline B & 7.467 & 6.614 & 6.523 & 4.104 & 2.995 & 2.270 & 2.377 & 2.418 & 2.391 \\
\hline DK & 16.630 & 12.000 & 11.400 & 11.200 & 7.000 & 7.300 & 8.400 & 8.600 & 8.300 \\
\hline$F(1)$ & 32.500 & 25.300 & 22.200 & 21.000 & 13.700 & 6.850 & 6.600 & 6.100 & 6.040 \\
\hline $\mathrm{D}(2)$ & 46.839 & 31.113 & 24.784 & 25.966 & 18.184 & 14.845 & 15.297 & 27.763 & 28.146 \\
\hline GR & 2.316 & n.v. & 2.672 & 2.812 & 1.709 & 1.855 & 550 & 0 & 0 \\
\hline IRL & 869 & 840 & 750 & 550 & 0 & 0 & 0 & 0 & 0 \\
\hline$P$ & n.v. & n.v. & n.v. & n.v. & 5.087 & 4.412 & 3.845 & 3.820 & 3.520 \\
\hline $\mathrm{E}$ & n.v. & n.v. & n.v. & n.v. & 18.000 & 14.000 & 11.940 & 11.440 & 10.735 \\
\hline UK & 54.550 & 41.050 & 24.800 & 20.486 & 12.500 & 9.000 & 6.126 & 5.984 & 5.820 \\
\hline Gesamt EG & 208.833 & 154.457 & 124.229 & 110.168 & 96.145 & 72.460 & 68.875 & 78.424 & 77.152 \\
\hline
\end{tabular}

(1) Ab 1986 enthalten die Zahlen den Schiffsneubau für militärische und quasi-militärische Zwecke (Konversion, Kriegsschiffe und Offshore). Vergleichbare Zahlen für frühere Jahre sind: $1975-32.500,1980-23.700,1985-17700$.

(2) Ab 1991 einschl. Beschäftigte in den Werften der ehemaligen DDR. 1991 - 11.700, 1992 - 12441.

(3) Von 1975-1984 einschl. Militärschiffbau mit folgenden Beschäftigtenzahlen: 1975 - 1800, 1978 - 3200, 1980 - 3400,

1983 - 2800. Zu den Werten für die Jahre ab 1988 müssen Arbeitslose addierte werden, die ab 1991 strukturelle

Überkapazitäten darstellen und deren Abbau vorgesehen ist. 1988 - 2850, 1990 - 1838, 1991 - 1321, 1992 - 700.

Quelle: EG, Kommission 1993h. 
Konkurrenzfähigkeit notwendigen Kapazitätsabbau lediglich verzögern können, verhindern konnten sie ihn nicht 272 .

Was den Aspekt des innergemeinschaftlichen Wettbewerbs betrifft, so wären Investitionsbeihilfen zur Umstrukturierung nur im Rahmen einer gemeinsamen Strategie unbedenklich gewesen 273 . Da diese jedoch nicht zustande kam, bedeutete die unterschiedlich starke Förderung eine weitere Verzerrung der Positionen der Werften - auch wenn Investitionen und Investitionsbeihilfen zunächst nur eine untergeordnete Rolle spielten 274 . Dies gilt vor allem, wenn von einer Obergrenze nicht betroffene Umstrukturierungshilfen dazu benutzt werden, Werften so zu modernisieren, daß sie danach im Rahmen der Höchstgrenze für Betriebsbeihilfen wettbewerbsfähig sind, da dann die Umstrukturierungssubventionen quasi vorweggenommene pauschale Produktionshilfen darstellen. Zudem bedeutete dies eine Umlenkung bzw. Bindung zu vieler Ressourcen in einem wenig produktiven Bereich.

Schließlich war auch der Versuch der Kommission, über ihre Vorschläge zu Umstrukturierungsprogrammen und zur Einsetzung eines Schiffbauausschusses größere industriepolitische Kompetenzen an sich zu ziehen und unter Umgehung der nationalen Behörden direkter Ansprechpartner der Interessengruppen und Konkurrenzländer zu werden, nur wenig erfolgreich. Zwar fanden regelmäßige Konsultationen mit den Sozialpartnern bereits 1968/69 und später auch mit den Reedern als Kunden statt ${ }^{275}$, zudem handelt die Kommission für die gesamte EG im Schiffbauausschuß der OECD (WP6), doch wurden die genannten weitergehenden Initiativen von den MS allesamt abgeblockt und Geldmittel für eine Industriepolitik der Gemeinschaft nur in sehr geringem Umfang gewährt 276 . Im Gegenteil, die Kommission hat sogar durch die Vorgehensweise über Subventionsrichtlinien insoweit Kompetenzen bei der Beihilfenkontrolle verloren, als der Rat die RL verabschiedet und die Kommission ihre Genehmigungspraxis jeweils anhand der Berichte der MS mit nationalen Sachverständigen diskutieren muß. Schließlich erfolgt die Festlegung des Subventionshöchstsatzes seit der 6. RL auch nach Absprache mit den MS277, und es gibt weiterhin keine Einzelfallprüfung der Subventionsfälle nach Art. 93, obwohl die Kommission 1986 die Rückkehr hierzu überlegt hatte278.

272 Vgl. Lammers 1984, S. 19-21.

273 Vgl. EP 1978, S. 13.

274 Vgl. EG, Kommission 1985b, S. 5.

275 Vgl. EG, Kommission 1983c, S. 16, und 1969, S. 192.

276 Vgl. Eußner 1983, S. 155, 158/159.

277 Vgl. EG, Kommission 1986c, S. 7.

278 Vgl. Hansa 1986a, S. 533. 
Es handelt sich hier um den einzigen Fall, in dem der Rat seine Kompetenz aus Art. 92,III e genutzt hat, Beihilfearten als mit dem EG-Vertrag vereinbar zu erklären, die ansonsten verboten wären, d.h. vor allem die permanenten Betriebsbeihilfen. Da dies jeweils nur auf Vorschlag der Kommission geschehen kann, hat letztere hierbei allerdings mitgewirkt. Dies ist zum einen historisch aus den oben erwähnten Übergangsvorschriften des Art. 92,III c zu erklären (vgl. Abschn. 4.2.2), die Betriebsbeihilfen gestatteten und somit entsprechende Rahmenbedingungen schufen, zum anderen aus dem Versuch, eine gestaltende gemeinschaftliche Industriepolitik in diesem Sektor zu etablieren (vgl. auch oben Abschn. 4.2.3.2), die einen Erhalt dieses Sektors bedingte, der bei plötzlichem Entzug der Subventionen gefährdet gewesen wäre. Vor allem der letzte Aspekt führte auch zu einem Druck der MS zur Fortsetzung der Subventionierung, der eine Weigerung der Kommission, Vorschläge für RL zu unterbreiten, nur als sehr theoretische Möglichkeit erscheinen läßt. Im Bereich Schiffbau haben somit die weitgehenden Kompetenzen der Kommission aus dem EGV eine erhebliche Einschränkung erfahren. Gegenüber Drittländern erfolgte zudem die Koordination weitgehend im Rahmen von OECD und AWES, die den Einschluß anderer bedeutender Schiffbaunationen erlaubten 279 .

279 Vgl. Butt Philip 1986, S. 16, und Ehlermann 1994, S. 415. 
There was a joke in Brussels about Viscount Davignon being refused entry into heaven and being sent to hell. A few days later the devil visits St Peter and begs him to change his mind. "Etienne", says the devil, "has been with us only a short time but he has already closed half our furnaces."

Loukas Tsoukalis/Robert Strauss 1

\subsection{Subventionen für die Stahlindustrie}

\subsubsection{Situation und Entwicklung bis zum Krisenausbruch}

In ähnlicher Weise wie die Werftindustrie, für die die Stahlproduzenten ja auch ein wesentlicher Zulieferer sind, profitierte die Stahlindustrie vom europa- und weltweiten Wiederaufbau und massiven Welthandelswachstum nach dem Ende des Zweiten Weltkrieges. Im Vergleich zur Basis 1954 verdoppelte sich die Weltrohstahlerzeugung bis 1964 und verdreifachte sich bis 1973, und auch die Produktion der EG-Staaten stieg nach Bildung der Montanunion 1952 bis 1973 auf das 2,5fache des Wertes von 1954 (Vgl. Tab. 4.3-1).

Trotz gewisser Nachfragestrukturveränderungen der Investitionsgüterindustrie weg vom Stahl bereits in den $60 \mathrm{er} \mathrm{Jahren}^{2}$, trotz der steigenden Rohstahlkapazitäten und -erzeugung in den Entwicklungsländern, die diese wenig humankapitalintensive Branche als Weg zur Industrialisierung ansahen, bei dem sie aufgrund ihrer niedrigen Löhne und auch der wachsenden Eigennachfrage nach Stahl Wettbewerbsvorteile hatten ${ }^{3}$, und schließlich trotz vorübergehender Stagnationsphasen in der europäischen Stahlproduktion 1961/62, 1966 und 1971 blieb die Stahlindustrie aufgrund der guten Gesamtkonjunktur optimistisch und investierte auch am Ende der 60er und Anfang der 70er Jahre in Kapazitätserweiterungen ${ }^{4}$.

Die Entwicklung der Jahre 1972-74 schien dieser Einschätzung auch zunächst Recht zu geben, und selbst die Ölkrise förderte anfänglich den Stahlverbrauch, da nunmehr einerseits verstärkt in Ölfördereinrichtungen wie Bohrinseln oder Pipelines, zum anderen in den Ölförderländern vermehrt in Infrastruktureinrichtungen inve-

1 1985, S. 223.

2 Vgl. Hausner 1987, S. 5.

3 Vgl. Stotz 1983, S. 31/32, Tsoukalis/Strauss 1985, S. 211, und Krägenau 1986, S. 14-16.

4 Vgl. Krägenau 1986, S. 27, und Jürgensen 1984, S. 113. 
Tab. 4.3-1

Weltrohstahlerzeugung 1954-1993 in $1000 \mathrm{t}$

\begin{tabular}{l|rrrrr} 
Jahr & EU & Japan & USA & Übrige & Welt \\
\hline 1954 & 62.992 & 7.750 & 80.115 & 72.543 & 223.400 \\
1957 & 82.326 & 12.570 & 102.250 & 95.254 & 292.400 \\
& & & & & \\
1960 & 98.118 & 22.138 & 91.920 & 135.724 & 347.900 \\
1961 & 96.303 & 28.268 & 90.453 & 137.276 & 352.300 \\
1962 & 94.216 & 27.546 & 91.171 & 148.867 & 361.800 \\
1963 & 96.479 & 31.501 & 101.477 & 159.343 & 388.800 \\
1964 & 109.956 & 39.799 & 117.993 & 170.352 & 438.100 \\
1965 & 113.896 & 41.161 & 122.490 & 181.353 & 458.900 \\
1966 & 110.273 & 47.784 & 124.700 & 192.143 & 474.900 \\
1967 & 114.630 & 62.154 & 118.020 & 203.696 & 498.500 \\
1968 & 125.433 & 66.893 & 121.900 & 216.574 & 530.800 \\
1969 & 134.722 & 82.166 & 131.175 & 227.937 & 576.000 \\
& & & & & \\
1970 & 138.034 & 93.322 & 122.120 & 244.124 & 597.600 \\
1971 & 128.073 & 88.557 & 111.780 & 254.890 & 583.300 \\
1972 & 139.005 & 96.916 & 123.530 & 273.349 & 632.800 \\
1973 & 150.015 & 119.322 & 139.300 & 289.563 & 698.200 \\
1974 & 155.534 & 117.131 & 135.235 & 301.900 & 709.800 \\
1975 & 125.559 & 102.313 & 108.250 & 311.178 & 647.300 \\
1976 & 134.156 & 107.399 & 118.960 & 318.785 & 679.300 \\
1977 & 126.121 & 102.405 & 115.997 & 332.077 & 676.600 \\
1978 & 132.587 & 102.100 & 127.171 & 357.842 & 719.700 \\
1979 & 140.195 & 111.748 & 126.087 & 371.870 & 749.900 \\
1980 & 127.738 & 111.395 & 104.036 & 376.331 & 719.500 \\
1981 & 126.105 & 101.676 & 111.285 & 370.934 & 710.000 \\
1982 & 111.442 & 99.548 & 68.578 & 367.432 & 647.000 \\
1983 & 109.524 & 97.169 & 76.762 & 379.545 & 663.000 \\
1984 & 120.131 & 105.584 & 83.940 & 400.345 & 710.000 \\
1985 & 135.525 & 105.281 & 80.067 & 398.588 & 719.461 \\
1986 & 125.596 & 98.275 & 74.032 & 416.586 & 714.489 \\
1987 & 126.054 & 98.513 & 80.860 & 430.634 & 736.061 \\
1988 & 137.426 & 105.681 & 90.631 & 445.830 & 779.568 \\
1989 & 139.461 & 107.909 & 88.834 & 449.611 & 785.815 \\
1990 & 136.853 & 110.339 & 89.723 & 433.584 & 770.499 \\
1991 & 137.418 & 109.649 & 79.738 & 409.698 & 736.503 \\
1992 & 132.138 & 98.132 & 84.305 & 408.351 & 722.926 \\
1993 & 132.249 & 99.623 & 87.142 & 406.821 & 725.835
\end{tabular}


Tab. 4.3-1 (Forts.)

Herstellung von Walzstahlfertigerzeugnissen in der EG nach Ländern (in 1000 t)

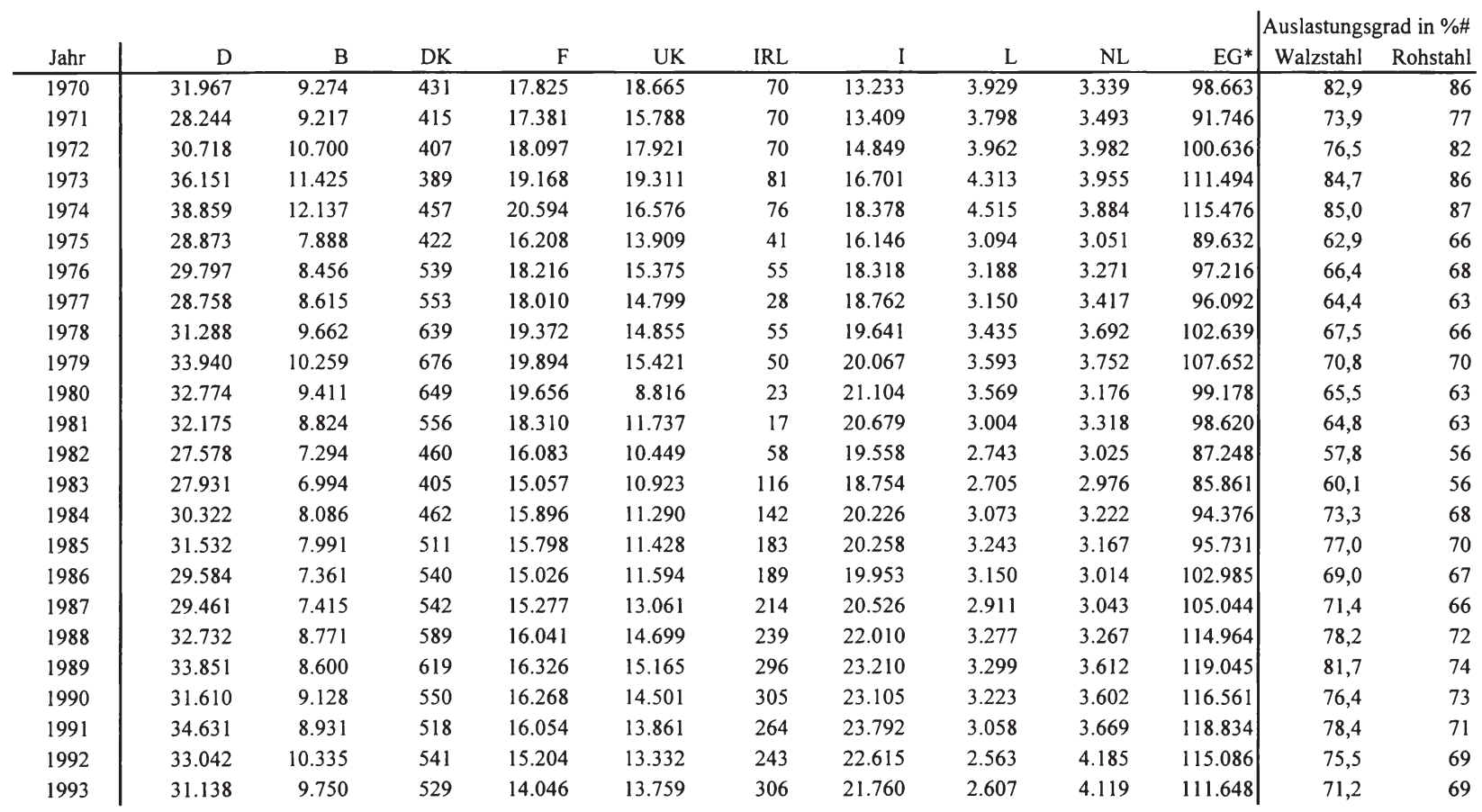

*EG-9, ab 1984 EG-10, ab 1986 EG-12.

\# 1970-72 EG-6, danach entsprechend Gesamtproduktion

Quelle für die gesamte Tab. 4.3-1: WV Eisen- und Stahlindustrie 1994, S. 84f., 89, 92, 331, sowie 1978, S. 90 , $96,99$. 
stiert wurde 5 . Dieser Nachfrageboom führte 1974 zu einem Produktionsrekord im Bereich der EG und gleichzeitig zu einer annähernden Verdopplung der Preise gegenüber 19736. Obwohl diese Expansion fast ausschließlich auf ein Wachstum der Exporte zurückzuführen war, während sich auf dem Binnenmarkt der EG bereits die Auswirkungen der Rezession v.a. in der Bauwirtschaft und der Autoindustrie in einer Stagnation des Stahlbedarfs äußerten 7 , rechnete man noch auf der Konferenz des Internationalen Eisen- und Stahlinstituts im Oktober 1974 nicht mit einem Einbruch der Stahlnachfrage, und die Kapazitätsausbaupläne in Frankreich, Deutschland und Italien wurden nicht gestoppt ${ }^{8}$.

Dennoch fielen die Auftragseingänge bereits Ende 1974, und die Stahlproduktion in der EG sank 1975 im Vorjahresvergleich um 20\%, wobei die Rückgänge im 2. Halbjahr noch ausgeprägter waren ${ }^{9}$. Dieser Nachfragerückgang machte auch den Preisanstieg von 1974 wieder zunichte, die Inlandspreise fielen um 35-40\%, die Exportpreise gar um 50\% 10 , und der Auslastungsgrad der Werke in der EG sank von $87 \%$ auf $66 \%$ (Vgl. Tab. 4.3-1). Ein Versuch der deutschen Stahlproduzenten, noch Anfang 1975 Preiserhöhungen durchzusetzen, scheiterte dementsprechend, worauf diese mit Produktionsverringerungen reagierten. Die drastischen Preis- und Mengenreduzierungen führten zu erheblichen Verlusten der Stahlproduzenten, da gleichzeitig die Inputpreise für Rohstoffe und Energie sowie die Löhne stiegen 11 .

Die Ursachen dieses Einbruchs waren sowohl konjunktureller als auch struktureller Natur: Die Rezession als Folge der 1. Ölkrise drückte das Investitionsvolumen und somit die Stahlnachfrage bei gleichzeitig weiter wachsendem Angebot und führte auch zur Substitution des energieintensiven Produktes Stahl durch andere Werkstoffe bzw. durch leichtere Stähle, so z.B. beim Automobilbau, um hier den Benzinverbrauch zu reduzieren ${ }^{12}$. Der o.e. zunehmende Wettbewerb durch Entwicklungsund Schwellenländer sowie auch durch Japan wirkte als struktureller Faktor ebenso

5 Vgl. Stotz 1983, S. 23/24, Curzon Price 1981, S. 85, Heusdens/de Horn 1980, S. 32

6 Vgl. Hausner 1987, S. 3

7 Vgl. Stotz 1983, S. 24, Hausner 1987, S. 4.

8 Vgl. Esser et al. 1982, S. 280/281. Die Kapazitäten in der Gemeinschaft wuchsen noch bis 1979, in Italien sogar bis 1982 an. Vgl. Tsoukalis/Strauss 1985, S. 221, und Bartling 1984, S. 444.

9 Vgl. Heusdens/de Horn 1980, S. 32, Stotz 1983, S. 26.

10 Vgl. Bartling 1984, S. 447. Hierbei spielte die Preispolitik der kleinen norditalienischen Produzenten (Bresciani), die über moderne Ministahlwerke verfügten, eine wichtige Rolle. Vgl. Fendel 1981, S. 377.

11 Vgl. Stotz 1983, S. 25f., Heusdens/de Horn 1980, S. 33, Curzon Price 1990, S. 171.

12 Vgl. Neumann 1984, S. 15/16, und Jürgensen 1984, S. 115. 
wie die Tatsache, daß mit dem Abschluß des Wiederaufbaus der Infrastruktur und der nachlassenden Bautätigkeit in Europa der Stahlbedarf pro Einheit des BSP säkular sank ${ }^{13}$.

Dennoch wurde die Krise 1975 fälschlicherweise als rein konjunkturelles Phänomen eingeschätzt ${ }^{14}$, was auch an der massiven Überschätzung der zukünftigen Stahlnachfrage durch die Kommission in ihren Vorausschätzungsprogrammen Stahl vom Dezember 1974 und April 1975 deutlich wird, aufgrund derer ein weiterer Kapazitätsausbau als notwendig angesehen wurde 15 .

\subsubsection{Kommissionshandeln in der 1 . Krisenphase $1975-80$}

\subsubsection{Die Krisenpläne}

Die weitere Entwicklung sollte jedoch zeigen, daß die Stahlindustrie mit einer langanhaltenden Strukturkrise zu kämpfen haben würde. Zwar stieg die Walzstahlerzeugung in der EG nach dem Einbruch von 1975 zunächst 1976 und nach einem leichten Rückgang 1977 auch 1978/79 wieder an, doch erreichte sie auch nicht annähernd wieder das Niveau von 1974 (vgl. Tab. 4.3-1). Bei leicht steigenden Kapazitäten fiel der Auslastungsgrad daher auf 63-69\% (1972-74: 81-87\%), und alle großen Stahlproduzenten erlitten erhebliche Verluste, die sich 1977 allein auf ca. 3 Mrd. US\$ beliefen 16 .

Die Ursachen hierfür waren z.T. in gesamtwirtschaftlichen Phänomenen zu suchen: So ließ der langsame Aufschwung nach der 1. Ölkrise die Investitionsbereitschaft anderer Industrien und damit den Stahlverbrauch sinken, besonders ausgeprägt war dies im Schiffbau (vgl. oben 4.2.3). Weiterhin schwächte die Abwertung des US-Dollar die Wettbewerbsfähigkeit der EG-Stahlindustrie, die ohnehin in einigen MS aufgrund veralteter Anlagen gering war. Die Tendenz zu fallenden Preisen aufgrund dieser Konstellation wurde noch durch die Erhöhung der Kapazitäten aufgrund früherer Investitionsentscheidungen verschärft, so daß ein regelrechter Preiskampf mit der Gefahr eines Marktzusammenbruches drohte ${ }^{17}$. In dieser Situation griff die Kommission zu immer stärkeren Instrumenten der Marktlenkung und Planung.

13 Vgl. Curzon Price 1981, S. 85/86.

14 Vgl. Kokalj/Albach 1987, S. 272, und Wienert 1988, S. 139.

15 Vgl. Tsoukalis/Strauss 1985, S. 215. Diese Überschätzung war weit verbreitet. Vgl. Krägenau 1986, S. 18.

16 Vgl. Curzon Price 1981, S. 86/87.

17 Im Stahlmarkt bestehen sehr hohe Marktaustrittsschranken. Diese entstehen durch den hohen Anteil fixer und den niedrigen Anteil variabler Kosten, der im Falle einer Krise zu einer ruinösen 
Eine Nutzung des harten Eingriffsinstrumentariums des EGKSV, z.B. die Erklärung der offensichtlichen Krise nach Art. 58 mit der Möglichkeit der Einführung von Produktionsquoten, wurde jedoch zunächst als zu kompliziert abgelehnt; man hoffte auf die Selbstheilungskräfte und nationale Maßnahmen zur Konjunkturbelebung 18 .

Die ersten Aktionen der Kommission zielten daher auf eine Verbesserung ihres eigenen Informationsstandes durch Verpflichtung der Unternehmen zur monatlichen Meldung ihrer Produktion und einer Prognose für den nächsten Monat, mit denen die Kommission dann vierteljährliche Absatzvorausschätzungen erstellte, die allerdings für die Unternehmen nicht bindend waren. Auch die Einhaltung der Preissetzungsregeln des EGKSV sollte stärker überwacht werden 19 .

Den ersten wirklichen Ansatz zur Krisenbekämpfung enthielt dann der SimonetPlan vom Juli 197620. Er sah neben einer Beeinflussung der Stahlinvestitionen über evtl. negative Stellungnahmen der Kommission, neben Konzepten zur Marktaufteilung mit Drittländern und neben Vorschlägen für regionalpolitische Eingriffe die sog. Krisenmaßnahmen vor: Diese bedeuteten, daß sich die Stahlproduzenten individuell oder in Gruppen der Kommission gegenüber verpflichten sollten, die von ihr aufgrund der Meldungen der Unternehmen aufgestellten detaillierten Vorausschätzungen für ihre Intra-EG-Lieferungen für jedes Quartal ebenso einzuhalten wie (allerdings nicht bindende) Richtpreise. Dabei begrüßte und unterstützte die

Unterbietungskonkurrenz führte, bei der die Anbieter das alte Produktionsvolumen auch bei fallenden Preisen bis hin zu Grenzkosten zu halten versuchen, die aber aufgrund kurzfristig sehr niedriger Nachfrageelastizitäten dennoch nicht zu einem Marktausgleich führen, da zwar ein einzelner Hersteller durch Preissenkungen Nachfrage auf Kosten der Konkurrenten auf sich ziehen kann, letztere aber wegen steigender Durchschnittskosten mit fallender Kapazitätsauslastung gezwungen werden, ebenfalls ihre Preise zu senken, ohne daß sich dadurch die Gesamtnachfrage erhöht. Die entstehenden Verluste entziehen den Firmen die notwendigen Mittel für Modernisierungsinvestitionen, so daß zum einen eine Anpassung an das Weltniveau unterbleibt und zum anderen die finanzstärksten, d.h. diversifizierten bzw. subventionierten, Unternehmen, nicht aber notwendigerweise die effizientesten überleben. Vgl. Krägenau 1986, S.

18 Vgl. Stotz 1983, S. 35, und Heusdens/de Horn 1980, S. 42. 38f., Tsoukalis/Strauss 1985, S. 212, Pelkmans 1984, S. 263f., und Bartling 1984, S. 445-448.

19 Vgl. Heusdens/de Horn 1980, S. 41/42, Bartling 1984a, S. 488. Diese Regeln nach Art. 60 EGKSV untersagen Preisdiskriminierungen zwischen verschiedenen Abnehmern für vergleichbare Geschäfte sowie Preissenkungen (vor allem lokal begrenzte) zur Verdrängung von Konkurrenten. Sie sehen die Veröffentlichung von Preislisten vor und erlauben von diesen nur sehr begrenzte Abweichungen.

20 Vgl. Tsoukalis/Strauss 1985, S. 215/216. Henri Simonet war zu jener Zeit Industriekommissar und somit auch zuständig für die Stahlpolitik. 
Kommission die Gründung des EUROFER-Verbandes der Stahlproduzenten, der ca. 90\% der EG-Stahlproduktion kontrollierte, da sie hierin einen "wertvollen Mittler" sah, um die Produktions- und Preisdisziplin durchsetzen zu können ${ }^{21}$. Steigende Importe zu niedrigen Preisen ebenso wie Preisunterbietungen durch nicht in EUROFER organisierte Produzenten, insbesondere die Gruppe der Bresciani, ca. 80 kleine italienische Hersteller von Betonstahl für Bauzwecke, bewirkten, daß auch die Kartellmitglieder häufiger die Orientierungspreise der Kommission unterboten und somit die fehlende Wirksamkeit des Simonet-Planes demonstrierten 22.

Dementsprechend intensivierte der Davignon-Plan von 1977 das Interventionsinstrumentarium weiter ${ }^{23}$. Erstmalig wurden Umstrukturierungs- und Modernisierungsziele für die Stahlindustrie formuliert, die von der Kommission überwacht und auch finanziell unterstützt werden sollten24. Das System der "freiwilligen" Lieferquoten wurde aufrechterhalten, das der Orientierungspreise auf weitere Erzeugnisse ausgedehnt; zudem wurden diese Preise im Zeitablauf mehrfach erhöht. Um die Preispolitik der Bresciani zu unterbinden, wurden für Betonstahl verpflichtende Mindestpreise eingeführt ${ }^{25}$. Eine Verletzung dieser Mindestpreise durch vier der Firmen ahndete die Kommission mit Geldstrafen. Zudem gelang es ihr, die Bresciani zur Errichtung einer gemeinsamen Exportagentur, in der EGBeamte mitarbeiteten, zu bringen und schließlich auch Exportbeschränkungen in andere MS durchzusetzen ${ }^{26}$. Um Billigimporte zu beschränken, führte man zunächst (automatische) Importlizenzen zur Preisüberwachung sowie Antidumpingverfahren ein, später Importbasispreise und variable Importzölle, die dann durch bilaterale Selbstbeschränkungsabkommen mit anderen Lieferländern abgelöst wurden 27.

Die kurze Darstellung zeigt, wie im Falle des Vorhandenseins eines protektionistischen Instrumentariums dieses beim Auftreten einer Krise eskalierend ein-

21 EUROFER war im Dez. 1976 entstanden, nachdem die DENELUX-Vereinbarung der deutschen, niederländischen, belgischen und luxemburgischen Stahlproduzenten auf lautstarken Widerstand der französischen Produzenten gestoßen war. Ab Anfang 1978 betrieb EUROFER in eigener Verantwortung ein Mengenkartell zur Durchsetzung der Vorgaben der Kommission. Auch dieses Kartell fand die Unterstützung der Kommission im Widerspruch zum EGKSV. Vgl. Tsoukalis/Strauss 1985, S. 216, und Krägenau 1986, S. 41/42, sowie Bartling 1984a, S. 488.

22 Vgl. Curzon Price 1981, S. 88/89.

23 Zum Prozeß der Beschlußfassung in Kommission und Rat vgl. Fendel 1981, S. 410-414.

24 Vicomte Etienne Davignon trat ab 1977 die Nachfolge von Simonet an.

24 Vgl. Stotz 1983, S. 59/60, und Tsoukalis/Strauss 1985, S. 217.

25 Vgl. Fendel 1981, S. 416, und Tsoukalis/Strauss 1985, S. 217.

26 Vgl. Curzon Price 1981, S. 89.

${ }^{27}$ Vgl. unten Abschn. 4.3.5 und Gerstenberger et al. 1985, S. 64. 
gesetzt wird (Ölfleckentheorie), wie aber auch das Aushebeln des Marktmechanismus an einer Stelle weitere Löcher schafft, die dann durch weitere dirigistische Maßnahmen zu stopfen sind, wobei die Einführung von Zwangslieferquoten als letzter Schritt dann Mitte 1980 erfolgte (s. unten Abschn. 4.3.6.1)28.

Als Gegengewicht zu diesen Maßnahmen der Marktabschottung und -aufteilung, die den ineffizienten Unternehmen das Überleben sicherten und Anreize zur Umstrukturierung nahmen, versuchte die Kommission nun jedoch, die rasant um sich greifende massive staatliche Subventionierung, die insbesondere in Verlustausgleichen für die Staatsunternehmen in einigen MS bestand, verstärkt zu kontrollieren oder zumindest an Umstrukturierungsmaßnahmen zu koppeln.

\subsubsection{Erste Ansätze zu verstärkter Subventionskontrolle}

In den Jahren des Stahlbooms von der Gründung der Montanunion bis zum Krisenausbruch 1975 war es der Kommission nicht gelungen, das kategorische Subventionsverbot des Art. 4c EGKSV auch durchzusetzen ${ }^{29}$. Die im Vergleich zum EGV mangelnde Gestaltungsmöglichkeit und die fehlenden Kontrollmechanismen ähnlich Art. 93 EGV erwiesen sich nun als Nachteil, da die MS nicht bereit waren, eine so gravierende Beschränkung ihres Handlungsspielraums hinzunehmen 30 . In dieser Expansionsphase, in der vor allem die Unterstützung der Ausweitung und Modernisierung der Anlagen im Vordergrund stand 31 , waren die Perspektiven der Stahlindustrie in jedem MS so gut, daß er die Subventionierung in anderen MS zu tolerieren bereit war. Symptomatisch dafür ist, daß in den Gesamtberichten der EGKS $^{32}$ im Gegensatz zum Kohlebereich keine einzige Passage zur Subventionskontrolle bei Stahl auftaucht.

Für die Beurteilung wurde die in Abschnitt 3.3 dargelegte Interpretation entwickelt und angewandt, nach der sich das Verbot des Art. 4c nur auf spezifische

28 Vgl. Krägenau 1986, S. 70, und Curzon Price 1981, S. 90, 98.

29 Krägenau (1986, S. 27-37) zeigt für die vier größten Stahlerzeugerländer der EG die Subventionsformen und -volumina in dieser Phase auf.

30 Vgl. Mény/Wright 1987, S. 51/52, 58. Die Autoren weisen darauf hin, daß die französische Regierung auch das eigene Parlament nicht über Subventionen an die Stahlindustrie informierte,

31 Vgl. Wienert 1988, S. 137 um so zu vermeiden, daß ihre EGKS-vertragswidriges Handeln an die Öffentlichkeit kam.

32 Vgl. EGKS, Hohe Behörde 1953-1966. McLachlan und Swann (1967, S. 42-53) gehen in ihrem Kapitel über das Problem staatlicher Beihilfen in der EGKS dementsprechend nur auf Beispiele aus dem Kohlebergbau ein. 
Subventionen beziehe, während regionale oder horizontale Subventionen, die z.B. aus allgemeinen Entwicklungsfonds stammen und zu gleichen Bedingungen auch anderen Sektoren zugutekommen können, unter Art. 67 fallen und dort tolerierbar sind, solange durch sie keine "schwere Störung des Gleichgewichts" 33 entsteht. In diesem Sinne wurde bereits 1968 das französische Subventionsprogramm für Stahlinvestitionen und -exporte genehmigt, das aus zinsvergünstigten Darlehen des staatlichen Entwicklungsfonds FDES bestand ${ }^{34}$. Im Nachgang zur Abweisung einer gegen diese Entscheidung gerichteten Klage der niederländischen Regierung durch den $\mathrm{EuGH}^{35}$ legte die Kommission ihre Abgrenzung nochmals dar ${ }^{36}$. Sie forderte außerdem die MS auf, alle möglichen Anwendungsfälle von Art. 4c und 67 ex ante zu melden und leitete wegen Nichtnotifizierung zunächst gegen Belgien und Italien das Verstoßverfahren ein, das nach entsprechenden Auskünften der MS dann 1973 eingestellt werden konnte 37 . Die im 2. Wettbewerbsbericht 197338 enthaltene Aufforderung an die MS, ihre Subventionen für 1971 (sic!) zu melden, zeigt jedoch, daß diese Ex-ante-Meldepflicht nicht eingehalten wurde.

Dieses Problem verschärfte sich in der nun ausbrechenden Stahlkrise noch ${ }^{39}$. Auch den massiven Subventionsanstieg in dieser Phase versuchte die Kommission zunächst mit der Art. 4c-Art. 67-Abgrenzung zu bewältigen und genehmigte entsprechend 1976 Investitionssubventionen von bis zu 50\% des Investitionsvolumens und staatliche Kapitalbeteiligungen in Belgien, Frankreich und Großbritannien 40 , was natürlich die MS dazu animierte, sektorspezifische Hilfen vermehrt in regionale oder horizontale Systeme einzukleiden, um so die Genehmigung zu erhalten ${ }^{41}$.

Als Anfang 1977 französische Pläne zur Subventionierung der Stahlindustrie in Lothringen in Höhe von 2,5 Mrd. FF bekannt wurden, sah sich die Kommission angesichts der neuen Massivität der Unterstützung veranlaßt, allgemeine Grundsätze

33 EG, Kommission 1969, S. 59. Caspari (1990, S. 18) spricht hier von einer "Notzüchtigung des Art. 67 EGKSV".

34 Vgl. EG, Kommission 1969, S. 58/59. Zur Gestaltung des Fonds vgl. Hausner 1987, S. 9.

35 Vgl. hierzu mit deutlicher Kritik an EuGH, Kommission und dem Generalanwalt: Stotz 1983, S. 103-107.

36 Vgl. EG, Kommission 1972a, S. $162 \mathrm{f}$.

37 Vgl. EG, Kommission 1973a, S. 125/126, und 1974a, S. 104.

38 Vgl. EG, Kommission 1973a, S. 126.

39 Vgl. Wirtschaftsvereinigung Eisen- und Stahlindustrie 1982, S. 2.

40 Vgl. EG, Kommission 1977a, S. 156/157.

41 Vgl. Hausner 1987, S. 8, und Wirtschaftsvereinigung Eisen- und Stahlindustrie 1982, S. 2. Der rechtlichen Form des Subventionsverbots nach Art. 4c wurde somit Genüge getan, dem ökonomischen Inhalt jedoch nicht. Vgl. SVR 1983, S. 230. 
zur Beurteilung von Stahlsubventionen aufzustellen ${ }^{42}$, die sie den MS mit einer Erinnerung an ihre Ex-ante-Meldepflicht schriftlich am 20.4.1977 mitteilte ${ }^{43}$ : Danach waren reine Erhaltungsbeihilfen verboten ebenso wie solche Modernisierungs-, Rationalisierungs- und Umstrukturierungshilfen, die zu Kapazitätserweiterungen in Bereichen mit Überkapazitäten führten. Rettungsbeihilfen sollten zeitlich streng begrenzt und an Strukturänderungen gebunden sein, und schließlich waren Form und Höhe der Subventionen an ihren Zielen und der Art der zu lösenden Probleme auszurichten.

Da spezifische Subventionen nach Art. 4c verboten waren, hätten sich aus juristischer Sicht diese Regeln nur auf regionale und allgemeine Hilfen beziehen dürfen 44 . Aus Sicht der Kommission 45 waren sie jedoch auf alle Beihilfen anzuwenden, wobei sie die MS über die Art und Weise der Anwendung der Vertragsregeln in der Krise unterrichten wollte. Hier handelte es sich also um eine massive Uminterpretation der Regeln - der Vorwurf des "gradual whittling away" 46 des Verbots des Art. $4 \mathrm{c}$ ist daher nur zu berechtigt. Zudem verpflichtete sich die Kommission auf Aufforderung des Rates, diesen bzgl. der Durchführung ihrer Beihilfenkontrollpolitik anzuhören; sie unterwarf sich also einer zusätzlichen Beschränkung und Kontrolle, um wie es offiziell hieß - die "Erreichung der vereinbarten Umstrukturierungs- und Umstellungsziele" 47 durch ihre Politik zu gewährleisten.

In einer ersten Anwendung der neuen Grundsätze wurden belgische Kreditgarantien und Zinsverbilligungen für kurzfristige Liquiditätskredite von 12 Mio. BFR genehmigt. Die Zustimmung der Kommission wurde damit begründet, daß die Unternehmen kapazitätserweiternde Investitionen und Massenentlassungen verschoben sowie sich zur Beteiligung an einem noch zu erarbeitendem Umstrukturierungsplan verpflichteten ${ }^{48}$. Die Genehmigung der Kommission erscheint auch im Hinblick auf ihre Grundsätze recht dubios, da der Inhalt des Umstrukturierungsplans noch unbekannt war, die Unternehmen wohl ohnehin nicht investiert hät-

42 Vgl. Stotz 1983, S. 60/61.

43 Vgl. EG, Kommission 1978a, S. 213, und auch Stotz 1983, S. 60/61. Diese Grundsätze entsprachen in etwa den später generell für Krisensektoren aufgestellten Subventionsgrundsätzen. Vgl. zu diesen EG, Kommission 1979a, S. 139-141. Die Wirksamkeit dieser einseitigen Aktion der Kommission war wohl sehr gering. Vgl. Fendel 1981, S. 431.

44 Vgl. Stotz 1983, S. 241.

45 1978a, S. 213.

46 Heusdens/de Horn 1980, S. 70.

47 EG, Kommission 1978, S. 97.

48 Vgl. EG, Kommission 1978a, S. 214. 
ten und der Verzicht auf Entlassungen der Effizienzerreichung wohl nicht förderlich war.

Auch Subventionen anderer Länder während dieser Phase wurden von der Kommission nach multilateralen Diskussionen mit Vertretern der MS toleriert ${ }^{49}$. Hierbei handelte es sich um eine partielle Verstaatlichung der zahlungsunfähigen französischen Stahlindustrie, um Eigentümerkapitalhilfen in Italien und Großbritannien und um deutsche Hilfen für ARBED-Saarstahl 50 . Tabelle 4.3-2 vermittelt einen Eindruck über die Höhe der in dieser Phase gezahlten Subventionen, deren Gesamtvolumen von 1975-79 auf 24,1 Mrd. DM geschätzt wird.

\subsubsection{Der Weg zum 1. Beihilfekodex}

Nachdem die Kommission nun auch quasi offiziell das vorhandene klare Verbot des Art. 4c zu den Akten gelegt hatte, benötigte sie paradoxerweise neue rechtliche Instrumente zur Kontrolle der wuchernden nationalen Subventionen, da auch sie selbst die Grundsätze von 1977 nur als ersten, zur Wettbewerbssicherung nicht ausreichenden Schritt ansah 51 . Dieses neue Instrument sollte ihr gestatten, "die Gewährung von Beihilfen und Subventionen genehmigen zu können, die andernfalls durch Artikel 4 Buchstabe $c$ des Vertrages untersagt wären." 52 In dieser Krisenlage suchte die Kommission also eine Regelung zur flexibleren Handhabung der Subventionsregeln. Die Lage wurde als ein im EGKS-Vertrag nicht vorgesehener Fall definiert, der nach Art. 95 Kommission und Rat zum Erlaß von zweckdienlichen Entscheidungen ermächtigte 53 .

Dementsprechend legte die Kommission dem Rat im Mai 1978 einen Entscheidungsentwurf vor ${ }^{54}$, der gleiche Ex-ante-Meldepflichten und Beurteilungskriterien

49 Die Kommission verzichtete auf eine konkrete Stellungnahme, da sie den Beschluß des Rates zu ihrem Entwurf einer Entscheidung über Stahlsubventionen abwarten wollte (s.u. Abschnitt 4.3.3.). Vgl. EG, Kommission 1979a, S. 155

50 Vgl. Krägenau 1986, S. 43/44. Ein spezieller Fonds des Finanzministeriums übernahm 1978 einen großen Teil der langfristigen Schulden der französischen Stahlunternehmen, was quasi einer Nationalisierung entsprach. Vgl. Le Monde 1984, S. 24.

52 EG, Kommission 1979a, S. 152. Vgl. auch Dominick 1984, S. 392.

$53 \mathrm{Vgl}$. EG, Kommission 1978b, S. 2/3. Hierbei ist zu kritisieren, daß der EGKSV ja eine Regelung zu Subventionen enthielt. Als nicht vorgesehen wurde hier durch Kommission und MS "der Eintritt einer durch Überkapazitäten bedingten langen Krise" definiert. Vgl. Kutscher 1989a, S. 95. In der juristischen Literatur wird die Verwendung dieses Vertragsartikels als äußerst fragwürdig angesehen. Vgl. Stotz 1983, S. 254-274.

Vgl. EG, Kommission 1978 b. 
Tab. 4.3-2

Staatliche Beihilfen für die Stahlindustrie in der EG 1975-85

\begin{tabular}{|c|c|c|c|c|c|c|c|c|c|c|}
\hline \multirow{3}{*}{$\begin{array}{l}\text { Land/ } \\
\text { Unternehmen }\end{array}$} & \multicolumn{4}{|c|}{ Beihilfen in Mio. DM* } & \multicolumn{6}{|c|}{ Beihilfen in DM pro Tonne Erzeugung im Jahresdurchschnitt } \\
\hline & $1975-79$ & $1980-85$ & Summe, & davon 1985 & \multicolumn{3}{|c|}{ Rohstahlerzeugung } & \multicolumn{3}{|c|}{ Walzstahlfertigerzeugung } \\
\hline & & & & & $1975-79$ & $1980-85$ & Summe & $1975-79$ & $1980-85$ & Summe \\
\hline Belgien & 2.725 & 10.017 & 12.742 & 746 & 45 & 150 & 100 & 61 & 206 & 136 \\
\hline Cockerill-Sambre & & 9.285 & & 704 & & 291 & & & 365 & \\
\hline Übrige & & 732 & & 42 & & 21 & & & 47 & \\
\hline Frankreich\# & 2.060 & 21.515 & 23.575 & 6.672 & 18 & 183 & 102 & 22 & 213 & 122 \\
\hline Usinor & & 10.756 & & 3.335 & & 184 & & & 231 & \\
\hline Sacilor & & 10.759 & & 3.337 & & 213 & & & 267 & \\
\hline Großbritannien & 13.852 & 13.275 & 27.127 & 2.549 & 133 & 154 & 142 & 186 & 205 & 195 \\
\hline British Steel & & 13.119 & & 2.502 & & 183 & & & 268 & \\
\hline Übrige & & 155 & & 47 & & 11 & & & 10 & \\
\hline Italien & 4.327 & 28.317 & 32.644 & 16.068 & 37 & 195 & 124 & 47 & 235 & 153 \\
\hline Finsider & & 25.756 & & 15.626 & & 316 & & & 428 & \\
\hline Übrige & & 2.561 & & 442 & & 40 & & & 42 & \\
\hline Deutschland & 922 & 6.320 & 7.242 & 755 & 4 & 27 & 16 & 6 & 35 & 22 \\
\hline Saarstahl & 891 & 2.378 & & 628 & 48 & 128 & 88 & 68 & 164 & 118 \\
\hline Übrige & 31 & 3.942 & & 127 & 0 & 18 & 10 & 0 & 23 & 13 \\
\hline Luxembg-Arbed & 33 & 1.485 & 1.518 & 245 & 1 & 64 & 33 & 2 & 81 & 44 \\
\hline Niederlande & 22 & 1.073 & 1.095 & 0 & 1 & 35 & 19 & 1 & 57 & 30 \\
\hline Hoogovens & & 1.054 & & 0 & & 36 & & & 60 & \\
\hline Übrige & & 19 & & 0 & & 13 & & & 13 & \\
\hline DK-Danish Steel & 115 & 191 & 306 & 0 & 32 & 55 & 43 & 41 & 63 & 52 \\
\hline IRL-Irish Steel & 76 & 621 & 697 & 78 & 233 & 1.025 & 748 & 330 & 1.138 & 906 \\
\hline Griechenland & 0 & 0 & 0 & 0 & 0 & 0 & 0 & 0 & 0 & 0 \\
\hline EG-10 & 24.132 & 82.814 & 106.946 & 27.113 & 36 & 116 & 78 & 48 & 146 & 100 \\
\hline EG-10 ohne D & 23.210 & 76.494 & 99.704 & 26.358 & 51 & 159 & 107 & 67 & 199 & 136 \\
\hline
\end{tabular}

*Von der Kommission freigegeben; für D nach 1980 tatsächlich ausgezahlte Beträge (freigegeben waren 9,047 Mrd. DM); von den Beihilfen nach 1980 sind 2,8 Mrd. DM bedingt rückzahlbar.

\# Gesamtbetrag hälftig aufgeteilt.

Quelle: WV Eisen- und Stahlindustrie 1987a. 
für alle Arten von Beihilfen enthielt und somit die intransparente Flucht der MS in formell regionale oder allgemeine Subventionen aufgrund der konstruierten Dichotomie von Art. 4c und Art. 67 beenden sollte 55. Auch das Recht der Kommission zur Rückforderung illegal gewährter Beihilfen wurde festgeschrieben. Es überrascht nicht, daß ein solch weitgehender Regulierungsversuch auf den Widerstand insbesondere Großbritanniens und Italiens stieß, wobei diese beiden MS vor allem die Kontrolle von Regionalbeihilfen für den Ausbau von Kapazitäten und von Hilfen für ihre Staatsbetriebe vermeiden wollten 56 . Diesem Widerstand wurde nachgegeben, so daß die Kommission gezwungen war, einen neuen Entwurf vorzulegen, der dann zur Grundlage des nach mehreren Beratungen durch COREPER 57 im Februar 1980 endgültig beschlossenen ersten Beihilfekodex wurde.

\subsubsection{Beihilfenkontrolle unter den beiden ersten Beihilfekodizes}

\subsubsection{Der 1. Beihilfenkodex von 1980}

Die Notwendigkeit dieses ersten Kodex 58 wurde aus der krisenhaften Situation der Industrie abgeleitet, die Investitionen zur Modernisierung und Kapazitätsanpassung erfordere, denen die Unternehmen mit ihren eigenen Finanzmitteln nicht gewachsen seien. Staatliche Beihilfen wurden deshalb als notwendig und auch vertragskonform angesehen, indem das Beihilfenverbot des Art. 4c als nur auf einseitige Maßnahmen der MS anwendbar definiert wurde, die nicht der Verwirklichung einer gemeinsamen Stahlpolitik dienen. Die Regeln dieser gemeinsamen Politik definiere u.a. der Kodex, so daß nach ihm genehmigte Beihilfen das Verbot des Art. 4c nicht verletzten. Die staatlich unterstützte Umstrukturierung des Sektors sollte also den Vorrang vor einer strikten Wettbewerbspolitik erhalten ${ }^{59}$.

Neben allgemeinen Grundsätzen für die Beihilfenvergabe, wie Transparenz, zeitliche und intensitätsmäßige Begrenzung, weitgehende Vermeidung von Wettbewerbsverzerrungen und Umstrukturierungsförderung sowie Erfassung von Sub-

$55 \mathrm{Vgl}$. ebenda, Artikel 7.

56 Vgl. Heusdens/de Horn 1980, S. 71/72, und Stotz 1983, S. 64. Diese MS legten im Rat zunächst ihr Veto ein. Hingegen drängte die deutsche Regierung auf eine Verabschiedung des Kodex, um so eine Kontrolle der Subventionen und einen Schutz der deutschen Stahlindustrie zu erreichen, und drohte anderenfalls mit einer Verweigerung ihrer Zustimmung zu der Verlängerung der übrigen Krisenmaßnahmen. Vgl. Fendel 1981, S. 432, 452, 457, 465/466, 481/482, sowie Tsoukalis/Strauss 1985, S. 218.

57 Vgl. EG, Kommission 1979c und Heusdens/de Horn 1980, S. 71.

58 Vgl. EG, Kommission 1980e, S. 5-8.

59 Vgl. EG, Kommission 1981e, S. 1. 
ventionen aller Gebietskörperschaften ${ }^{60}$, legte der Kodex Beurteilungskriterien für Subventionen verschiedener Zweckbestimmungen fest. Diese galten allerdings nur für spezifische Beihilfen zugunsten der Stahlindustrie, während bspw. regionale Beihilfen, die auch Stahlunternehmen zugutekommen können, weiterhin nach den normalen Regeln der Art. 92/93 EGV zu beurteilen waren61. Da die Kommission hier aber i.d.R. nur die Rahmenpläne zur Genehmigung vorgelegt bekommt, ohne die spätere Vergabe der Mittel für bestimmte Branchen zu kennen, wären durch diese Regelung regionale und allgemeine Beihilfen de facto von der Kontrolle ausgenommen gewesen. Daher forderte die Kommission die MS auf, ihr alle einzelnen Anwendungsfälle solcher Beihilferegelungen ex ante zu melden, was die MS auch zusicherten 62 .

Für die spezifischen Subventionen wurden folgende Kriterien festgelegt 63 :

- Beihilfen für Umstrukturierungsinvestitionen im Sinne der Allgemeinen Ziele Stahl waren entsprechend dem Grad der Umstrukturierung und der Regionalprobleme bei vorheriger Meldung der Investitionsprogramme genehmigungsfähig.

- Schließungsbeihilfen waren für Arbeitnehmerabfindungen, Zahlungen an Dritte zur Beendigung von Lieferverträgen und Erschließungsaufwendungen für die Fabrikgelände und -gebäude zulässig, wobei die MS über diesen Beihilfentyp halbjährlich zu berichten hatten.

- Betriebsbeihilfen waren bei Kopplung an ein Umstrukturierungsprogramm, das das Unternehmen zur Wettbewerbsfähigkeit zurückführt, für begrenzte Dauer oder bei degressiver Gestaltung in der Höhe genehmigungsfähig, die das Überleben des Betriebes sichert ${ }^{64}$. Auch hier wurden Regionalprobleme bei der Beurteilung berücksichtigt.

- Rettungsbeihilfen "zur Überwindung schwerwiegender sozialer Schwierigkeiten", die man vermutlich auch als regionale Probleme aufgrund von Massenentlassungen in monostrukturierten Gebieten verstehen muß, waren ebenfalls genehmigungsfähig. Eine im hier Entscheidungsentwurf von 1978 noch vorgesehene

60 Diese explizite Festlegung, die im Entwurf noch gefehlt hatte, war wohl aufgenommen worden, um hier ein Ausweichen der MS zu verhindern.

61 Vgl. EG, Kommission 1980e, S. 5.

62 Vgl. EG, Kommission 1980a, S. 124.

63 Vgl. EG, Kommission 1980e, S. 6/7.

64 De facto wurde hierdurch nationales Konkursrecht sektoral außer Kraft gesetzt. Vgl. Herdmann/Weiss 1985, S. 102. 
Beschränkung dieses Beihilfentyps auf Bürgschaften und marktgerecht verzinste Anleihen 65 war fallengelassen worden.

Analog den Regeln des EGV legte der Kodex eine Ex-ante-Meldepflicht aller Beihilfevorhaben, eine Stillhaltepflicht der MS während des Prüfverfahrens bzw. bei fehlender Äußerung der Kommission für einen Zeitraum von zwei Monaten nach der Meldung fest.

Man mag es als Fortschritt ansehen, daß nach einer quasi gesetzlosen Phase nun erstmals überhaupt Beurteilungskriterien für Subventionen festgelegt wurden. Jedoch waren die Kriterien, insbesondere für Rettungsbeihilfen, so weich und unbestimmt, daß eine tatsächliche Einschränkung der Subventionierung durch den Kodex insbesondere in einer Krisenphase kaum gegeben war. Dieses Urteil wird noch durch die Nichteinbeziehung der regionalen und allgemeinen Beihilfen sowie die Tatsache verstärkt, daß auch bei den spezifischen Beihilfen die Kommission i.d.R. nur Programme und nicht einzelne Anwendungsfälle prüfen sollte66, obwohl gerade letzteres zur Beurteilung von Umstrukturierungshilfen notwendig gewesen wäre.

Dementsprechend erwies sich der Kodex als Instrument zur Beihilfenkontrolle in der sich durch den zweiten Ölpreisschock und die folgende Rezession, insbesondere bei den großen Stahlverbrauchern Kfz- und Maschinenbauindustrie, verschärfenden Krisensituation als weitgehend erfolglos 67 . So hatte die Kommission schon Schwierigkeiten, allein die Ex-ante-Meldepflicht der MS durchzusetzen68. Zwar wurde sie dann im Laufe des Jahres 1980 und in der ersten Jahreshälfte 1981 mit Beihilfeanträgen aus allen MS, abgesehen von Irland und Griechenland, befaßt, doch genehmigte sie diese, ggf. nach Einholung weiterer Informationen, zumeist ohne Einleitung des formellen Verfahrens und auch ohne Kürzung des Beihilfevolumens, wobei für Investitionsbeihilfen Intensitäten zwischen 6 und $20 \%$ akzeptiert wurden69. Dies

65 Vgl. EG, Kommission 1978b, S. 4.

66 Vgl. EG, Kommission 1980e, S. 7.

67 Die Umsetzung seiner Regeln verblieb in den Worten von Curzon Price (1981, S. 91) "safely in the zone of wishful thinking".

68 Vgl. EG, Kommission 1981e, S. 5. Bezüglich der vor dem Inkrafttreten des Kodex 1978/79 gewährten Beihilfen erteilte die Kommission zudem trotz ihres unvollkommenen Informationsstandes über deren Höhe quasi eine Ex-post-Absolution, indem sie diese als mit den Zielen der neuen Regelung vereinbar erklärte. Vgl. ebenda, S. 6bis, und Wirtschaftsvereinigung Eisen- und Stahlindustrie 1982, S. 4.

69 Vgl. EG, Kommission 1981a, S. 148-153, und 1982a, S. 131-143. Lediglich FuE-Beihilfen für die Maxhütte in Bayern kürzte die Kommission von 38 auf 29 Mio. DM. Vgl. EG, Kommission 1982c, S. 2-5. 
geschah, obwohl, abgesehen von den deutschen Beihilfen für Hoesch und die Maxhütte und den dänischen Beihilfen, keine Zusagen für einen signifikanten Kapazitätsabbau gemacht wurden bzw. diese Zusagen ausgesprochen zweifelhaft waren. Bei den Beihilfen für die Umstrukturierung und Modernisierung eines Stahlwerkes in Bagnoli bei Neapel, das aus regionalpolitischen Überlegungen sogar mit einem NSÄ von $38 \%$ gefördert wurde, war sogar von einer deutlichen Kapazitätserhöhung auszugehen 70 .

Ein umfangreicheres Prüfverfahren nach Art. 93,II EGV leitete die Kommission gegen belgische Investitionsbeihilfen und Rettungsbeihilfen ein. Bei den Investitionsbeihilfen kamen Befürchtungen einer Netto-Kapazitätsausweitung mit Zweifeln über die Wirksamkeit des vorgesehenen Umstrukturierungsplanes zusammen, während die Verfahrenseröffnung bei den Rettungsbeihilfen auch wegen der fehlenden vorherigen Notifizierung geschah ${ }^{71}$. Da Belgien diese Rettungsbeihilfen in Höhe von 1,5 Mrd. BFR für Firmen im Dreieck von Charleroi zudem noch gewährte, bevor das Prüfverfahren abgeschlossen war, leitete die Kommission außerdem ein Vertragsverstoßverfahren gegen Belgien ein, in das weitere Rettungsbeihilfen von 6,5 Mrd. BFR aus dem gleichen Grunde eingeschlossen wurden 72. Auch gegen Frankreich und Italien wurden Verstoßverfahren eingeleitet, da hier Beihilfen bereits vor ihrer Anmeldung gewährt worden waren ${ }^{73}$. Eine derartige Konsequenz ließ die Kommission jedoch nicht immer walten, da sie weitere belgische Rettungsbeihilfen, die bei ihrer Meldung bereits gewährt worden waren, nachträglich genehmigte ${ }^{74}$. Doch auch in den Fällen, in denen ein Verfahren eingeleitet worden war, wurden im Laufe der Jahre 1984/85 praktisch alle Beihilfen freigegeben, da sie materiell gerechtfertigt erschienen, d.h. die Kodexbedingungen erfüllten ${ }^{75}$. Der Verstoß

70 Immerhin gelang es durch den Widerstand der anderen MS, den Neubau eines weiteren Stahlwerkes im Mezzogiorno durch Finsider zu verhindern. Im Falle von British Steel hatte die Kommission zunächst das Prüfverfahren eröffnet, da ihr die angebotene Kapazitätsverminderung von 0,9 Mio t Rohstahl als zu gering erschien, genehmigte dann aber doch die Subventionen in Tranchen z.T. noch vor der Vorlage des Umstruktierungsplanes, nachdem nicht spezifizierte Reduktionen der Kapazitäten der privaten Stahlindustrie zugesagt wurden. Vgl. Hausner 1987, S. 32-34, 42, und EG, Kommission 1982c, S. 8-9.

71 Vgl. EG, Kommission 1981a, S. 151-153.

72 Vgl. EG, Kommission 1982a, S. 143, und 1982c, S. 10. Hier handelte es sich um Fälle, in denen an dasselbe Unternehmen zum wiederholten Male Rettungsbeihilfen gewährt wurden.

73 Vgl. EG, Kommission 1982c, S. 20. Weitere derartige Verfahren wurden im April 1983 gegen B, D, F, I, L und UK eingeleitet. Vgl. EG, Kommission 1984e, S. 5.

74 Vgl. EG, Kommission 1981a, S. 151f.

75 Vgl. EG, Kommission 1986e, S. 9/10, und Kutscher 1989b, S. 120. 
gegen die Verfahrensregeln blieb somit für die beteiligten MS folgenlos, und die Autorität der Kommission bei der Durchsetzung der Kontrolle wurde beschädigt.

Insgesamt hatte die Subventionskontrolle in dieser Phase also eher konstatierenden Charakter, so daß die Bundesregierung bei den weiter ansteigenden Subventionsvolumina mit Kompensationsabgaben auf Stahleinfuhren drohte und energisch eine Beendigung der Stahlsubventionen forderte 76 . Angesichts dieser Drohung beschloß der Ministerrat im März 1981 eine Verschärfung der Kontrolle, ihre Kopplung an tatsächliche Umstrukturierung und eine zeitliche Begrenzung der Subventionierung der EG-Stahlindustrie. Die Kommission wurde aufgefordert, in diesem Sinne eine neue Entscheidung zu erarbeiten 77 . Dieser Aufforderung kam die Kommission bereits zwei Monate später nach, so daß nach Zustimmung des Rates der zweite Beihilfenkodex im August 1981 - und damit vor dem eigentlichen Ablauf des ersten - erlassen werden konnte.

\subsubsection{Der zweite Beihilfenkodex von 1981}

Gegenüber dem ersten Kodex brachte die neue Entscheidung78 in mehreren Bereichen Verschärfungen: Zunächst einmal wurde die Gültigkeit sowohl der Verfahrens- als auch der inhaltlichen Regelungen nunmehr uneingeschränkt auf regionale und allgemeine Beihilfen an Stahlunternehmen ausgedehnt ${ }^{79}$. Weiterhin waren in einem neuen Artikel 2 wesentlich präzisere allgemeine Kriterien zur Beurteilung der Genehmigungsfähigkeit von Beihilfen festgelegt. So wurde konkret ein Kapazitätsabbau ebenso zur Bedingung gemacht wie die zeitlich degressive Staffelung der Beihilfen - beide Elemente sollten Bestandteil eines vorzulegenden Umstrukturierungsprogramms sein. Weiterhin definierte die Entscheidung die Bereitstellung von Beteiligungskapital an Staatsunternehmen ebenso wie Verlustausgleiche und Verzicht auf Dividenden seitens des staatlichen Eigners als Beihilfen. Zudem wurden die Meldefrist für Beihilfen auf den 30.9.1982, die Genehmigungsfrist auf den 1.7.1983 und die letztmalige Auszahlung auf den 31.12.1985 terminiert. Eine Ausnahme von der Genehmigungsfrist gab es lediglich für Schließungsbeihilfen. Hingegen wurden Rettungsbeihilfen auf maximal 6 Monate beschränkt und durften nach 1981 nicht mehr gewährt werden; für Betriebsbeihilfen waren die entsprechenden Fristen 2

\footnotetext{
76 Vgl. Meny/Wright 1987, S. 43, Hausner 1987, S. 35, und Stotz 1983, S. 64.

77 Vgl. EG, Bulletin 1981, S. 95-96, und Hausner 1987, S. 35.

78 Vgl. EG, Kommission 1981d, S. 14-18.

79 Vgl. Stotz 1983, S. 277, und Dominick 1984, S. 393.
} 
Jahre und das Jahresende 1984, wobei jedoch Ausnahmen nach Anhörung der MS möglich sein sollten.

Während die Kommission also durch strikte Terminfestsetzung und verschärfte Verfahrensregeln das Beihilfeproblem in diesem Sektor besser in den Griff bekommen und in seiner zeitlichen Dauer begrenzen wollte80, enthielten die inhaltlichen Vorschriften für die verschiedenen Subventionstypen neben der weitgehenden Übernahme der Regeln des 1. Kodex zwei mögliche neue Schlupflöcher: Zum einen konnte die Kommission bei der Beurteilung von subventionierten Investitionen deren Beitrag zu Innovation, Energieeinsparung und Umweltschutz berücksichtigen. Zum anderen wurde ein neuer Artikel 7 zu Forschungs- und Entwicklungsbeihilfen eingefügt, der eine Höchstförderung von 50\% für Projekte erlaubte, die bspw. zur Senkung der Produktionskosten, Verbesserung der Produktivität oder der Warenqualität beitrugen - allesamt Ziele, die zu den normalen Aufgaben eines Unternehmens gehören und eigentlich keine spezielle Förderung verdienen.

Schließlich setzte die Kommission sich eine Entscheidungsfrist von drei Monaten für jeden Fall und verpflichtete sich zur Konsultation der MS vor einer Entscheidung. Mit der relativen langen Gültigkeitsdauer der Entscheidung bis Ende 1985 verband sich die Hoffnung, danach das Problem der Stahlindustrie gelöst zu haben 81 .

\subsubsection{Die Umsetzung des zweiten Kodex}

Trotz der nun schärfer und präziser formulierten Subventionskontrollgrundsätze gelang es der Kommission in der sich zuspitzenden Krise - 1981, 1982 und 1983 sanken die Roh- und Walzstahlproduktionsvolumina jeweils gegenüber dem Vorjahr und die Preise fielen erheblich82 (vgl. Tab. 4.3-1) - nicht, die Beihilfengewährung der MS signifikant einzudämmen; das Gegenteil war eher der Fall!

Während bspw. im Laufe des Jahres 1981 die Kommission 8 Beihilfeprogramme genehmigte und weitere 14 prüfte, von denen bei 10 das förmliche Verfahren ein-

\footnotetext{
80 Art. 12,I erlaubte allerdings mit Zustimmung des Rates eine Änderung dieser Fristen. Diese geschah dann auch 1985; s. unten.

81 Vgl. Krägenau 1986, S. 49.

82 Vgl. Hausner 1987, S. 44.
} 
geleitet wurde, erreichte die Zahl der Stellungnahmen 1982 schon den Wert von 92 und die Zahl der Verfahrenseröffnungen 6183 .

Kernstück der Politik der Kommission während der Laufzeit des zweiten Kodex war die Kopplung der Genehmigung von Subventionen an Verpflichtungen der begünstigten Unternehmen zum Abbau eines Teils ihrer Produktionskapazitäten 84 . Hiermit sollte in einer Situation sinkenden Bedarfs verhindert werden, daß Unternehmen, die durch staatliche Hilfe am Leben erhalten wurden, durch eine Ausweitung ihrer Produktion und evtl. Preissenkungen ihre Kapazitätsauslastung und Rentabilität zu verbessern suchten. Dieses individuell rationale Verhalten war kollektiv als irrational zu betrachten, da hierdurch ein weiterer drastischer Preisverfall mit weiter sinkender Rentabilität und wachsendem Subventionsbedarf vorprogrammiert gewesen wäre85. Eine Senkung verbunden mit gleichzeitiger Modernisierung der Kapazitäten sollte dies verhindern und zugleich den Unternehmen erlauben, auch bei niedrigerem Ausstoß rentabel zu arbeiten. Diese direkte Einflußmöglichkeit auf die Produktionsmöglichkeiten der Unternehmen, die die Regeln des EGKSV der Kommission nicht boten, erhielt sie nun also auf dem Umweg über die Subventionskontrolle 86.

Dem sektoralen Gesamtziel wurden dann auch die veschiedenen Beihilfekategorien der Kodizes untergeordnet. Während noch 1981 die Kommission 87 die von ihr behandelten Beihilfeanträge entsprechend der verschiedenen Beihilfetypen abhandelte, betonte sie $1983^{88}$, daß sie alle Beihilfen zunächst den gleichen sektoralen Kriterien unterwerfen werde und erst bei der Intensitätsbemessung regionale und andere Gemeinschaftsziele berücksichtigen werde. Der diskretionäre Spielraum der Kommission stieg hierdurch noch weiter an, die Transparenz ihrer Entscheidungen wurde hingegen nicht gefördert 89 .

Schon 1981 versuchte die Kommission, diese Kopplung zu verwirklichen und erreichte bis Mitte 1982 Zusagen bzw. Umsetzungen von Kapazitätsverminderungen

83 Vgl. EG, Kommission 1982c, S. 2, und 1983f, S. 1 und Anhang 2. Dementsprechend nahm die Informationstiefe der Beihilfenberichte der Kommission ab und konzentrierte sich immer mehr auf Globalzahlen.

84 Vgl. EG, Kommission 1983f, S. 1.

85 Vgl. zu den spezifïschen Bedingungen der Industrie oben Abschn. 4.3.2.1. Zunächst war einem

solchen Verhalten durch das Quotensystem ein Riegel vorgeschoben. S. unten Abschn. 4.3.6.1.

86 Vgl. Kutscher 1989, S. 81.

87 Vgl. EG, Kommission 1981a, S. 147-153.

88 Vgl. EG, Kommission 1983a, S. 129/130.

89 Vgl. Dominick 1984, S. 394, 400. 
über 4 Mio. Tonnen 90 , was sich allerdings als völlig unzureichend erwies 91 . Gegen belgische Beihilfen anläßlich der Fusion von Cockerill und Hainaut-Sambre mußte sie das Verfahren eröffnen, obwohl hier ein Kapazitätsabbau von 1 Mio. t Warmwalzkapazität vorgesehen war. Die Zweifel der Kommission richteten sich einerseits auf die hohe Beihilfenintensität von $40 \%$ der Investitionen, andererseits auf die Ausreichendheit der Umstrukturierungen zur Wiedergewinnung der Rentabilität des neuen Unternehmens 92 .

Zur Systematisierung und Verbesserung der Durchsetzung ihrer Subventionskontrolle versuchte die Kommission nun im Laufe des Jahres 1982, ein Gesamtkonzept zur Beurteilung der Beihilfe- und Umstrukturierungspläne zu entwickeln. Auf Basis ihrer eigenen Vorausschätzungen in den Allgemeinen Zielen Stahl sah sie bis 1986 einen Kapazitätsabbau von 30-35 Mio. $t$ als zum Marktausgleich notwendig an. In diesen Globalwert sollten sich die entsprechenden Pläne der MS einfügen, wobei der Kapazitätsabbau nicht nur alte, unrentable und verlustbringende Anlagen treffen sollte, sondern auch andere Unternehmen, selbst solche, die keine Beihilfen erhalten hatten, da von einer Erholung des Marktes alle profitieren würden93. Hier wurde also der wettbewerblich-marktliche Ansatz z.T. durch eine Art von Gerechtigkeitsdenken ersetzt, nach dem alle MS einen Teil der Lasten tragen sollten ${ }^{94}$. Dahinter steht quasi eine Externalitätenbetrachtung, bei der die Nutznießer der Schließungen in einem Unternehmen - alle anderen Unternehmen - eine Entschädigung in Form eigener Schließungen leisten sollten. Dubios hierbei ist, daß quasi allen Marktteilnehmern ein Eigentumsrecht an ihren Marktanteilen eingeräumt wird, was marktwirtschaftlichem Denken widerspricht. Eine solche Lösung steht zudem im Widerspruch zu Art. 2 EGKSV, der von der Gemeinschaft die Sicherung der "rationellste(n) Verteilung der Erzeugung auf dem höchsten Leistungsstandard" fordert, war aber sicherlich der politischen Durchsetzbarkeit förderlich. So weist Kutscher 95 darauf hin, daß aufgrund der stark divergierenden Produktivitäten eine Marktlösung in einigen MS zum fast völligen Verlust ihrer Stahlindustrie geführt

90 Vgl. EG, Kommission 1982d, S. 1.

$91 \mathrm{Vgl}$. Wirtschaftsvereinigung Eisen- und Stahlindustrie 1982, S. II.

92 Vgl. EG, Kommission 1982c, S. 11/12. Eine vorgesehene Kapitalzeichnung der Regierung für das Unternehmen mußte auf Druck der Kommission in eine Bürgschaft des Staates für ein Darlehen zu Marktkonditionen umgewandelt werden. Die Genehmigung erfolgte schließlich in Tran-

chen und unter Reduktion des Beihilfevolumens und der -typen. Vgl. EG, Bulletin 1982, S. 40.

93 Vgl. EG, Kommission 1982e, S. 1.

94 Vgl. Krägenau 1986, S. 49.

95 1989, S. 82. 
hätte, was von diesen nicht akzeptiert worden wäre. Auch der Verzicht auf eine strikte Kopplung des Beihilfevolumens an die abgebaute Kapazitätsmenge - stattdessen sollten Modernisierungsmaßnahmen sowie regional- und beschäftigungspolitische Aspekte einbezogen werden - weist in dieselbe Richtung, wobei allerdings diese Aspekte den MS nicht als Entschuldigung für den Verzicht auf die Schaffung von Ersatzarbeitsplätzen dienen sollten 96 .

Angesichts der akuten Krisenlage war die Kommission jedoch im Widerspruch zu ihrem Gesamtkonzept häufig gezwungen, Teilbeträge vorgesehener Beihilfen (z.B. Notbeihilfen) gegen moderate Kapazitätsreduktionen zu genehmigen, noch bevor Regierung und Unternehmen einen endgültigen Sanierungsplan vorgelegt hatten und z.T. auch vor Abschluß des vorgesehenen Anhörungsverfahrens 97.

Auch zum Zeitpunkt des eigentlichen Ablaufs der Meldefrist für alle Beihilfeprogramme am 30.9.1982 hatten die MS zum Teil nur vorläufige Umstrukturierungspläne vorgelegt. Da diese Pläne mit einem geplanten Abbau von 14 Mio. $t$ zudem weit unter dem Zielwert blieben, eröffnete die Kommission im Herbst 1982 gegen sie das Prüfverfahren ${ }^{98}$. Im Laufe dieses Verfahrens erinnerte die Kommission die MS mehrmals an ihre Pflicht zur Vorlage eines Beihilfe- und Umstrukturierungsplanes. Während erstere von allen MS schließlich vor dem 1.7.1983 vorgelegt wurden, waren einige Umstrukturierungspläne immer noch vorläufig. Hierin zeigte sich also, daß die von einer verbindlichen Fristsetzung erhoffte Disziplinierung der MS letzten Endes in einer tiefen Krise nicht durchsetzbar war 99 . Dasselbe gilt für die im Kodex festgesetzte zeitliche Begrenzung der Betriebsbeihilfen auf 2 Jahre. Auch sie wurde durch Ratsbeschluß für $6 \mathrm{MS}$ aufgehoben 100 .

Trotz der weiterhin nicht vollständig geklärten Gesamtsituation erließ die Kommission am 29.6.1983 neun bedingte Entscheidungen, in denen für alle MS außer Dänemark umfangreiche Beihilfeprogramme unter Auflagen genehmigt wurden101.

96 Vgl. EG, Kommission 1983f, S. 5-6, Krägenau 1986, S. 51, und Kutscher 1989, S. 81.

97 Vgl. z.B. EG, Kommission 1982c, S. 12/13, 15, 17/18a, 1983f, S. 4, und Wirtschaftsvereinigung Eisen- und Stahlindustrie 1982, S. 11, sowie Stotz 1983, S. 66.

98 Vgl. EG, Kommission 1982e, S. 1, und 1983f, S. 1.

99 Vgl. Hausner 1987, S. 49.

100 Vgl. EG, Kommission 1984e, S. 1/2. Dabei handelte es sich um B, D, F, IRL, I, UK.

$101 \mathrm{Vgl}$. EG, Kommission 1983g, S. 1-40. Formell handelte es sich für Griechenland und Irland sowie in Einzelfällen in Belgien und Großbritannien um bedingt negative Entscheidungen, bei denen die geplanten Beihilfen als mit dem GM unvereinbar erklärt wurden, falls die MS nicht die vorgegebenen Auflagen erfüllten. Da jedoch die Auflagen mit denen der positiven Entscheidungen übereinstimmten, bestand de facto kein Unterschied. Im Gegensatz zu den anderen 
Noch einmal wurde den MS eine Fristverlängerung für die Vorlage eines Umstrukturierungsplanes bis zum 31.1.1984 gewährt. Bis dahin durften sie die zum Überleben der jeweiligen Unternehmen nötigen Subventionen gewähren, wenn ein Kapazitätsabbau im Gegenzug angeboten wurde 102 .

Tab. 4.3-3

Abbau der Kapazität für warmgewalzte Erzeugnisse aufgrund des Beihilfenkodexes 1980-1985 (in 1000 t)

\begin{tabular}{|c|c|c|c|c|c|c|c|}
\hline Land & $\begin{array}{r}\text { Kapazität } \\
1980\end{array}$ & $\begin{array}{r}\text { Kapazität } \\
12 / 1985\end{array}$ & $\begin{array}{c}\text { Kapazitäts- } \\
\text { abbau } \\
12 / 1985\end{array}$ & $\begin{array}{r}\text { hiervon } \\
\text { aufgrund } \\
1018 / 85 / \\
\text { EGKS* }\end{array}$ & $\begin{array}{r}\text { Geforderter } \\
\text { Mindest- } \\
\text { abbau\#\# } \\
6 / 1983\end{array}$ & $\begin{array}{l}\text { Geforder- } \\
\text { ter Abbau } \\
\text { für 1986\# }\end{array}$ & $\begin{array}{r}\text { Gesamtabbau } \\
\text { bei Ablauf der } \\
\text { Stahlbeihilfen- } \\
\text { regelung }\end{array}$ \\
\hline B & 16.028 & 13.098 & 3.180 & - & 3.155 & 256 & 3.436 \\
\hline DK & 941 & 875 & 66 & - & 66 & - & 66 \\
\hline $\mathrm{D}^{\prime}$ & 51.869 & 45.176 & 6.693 & 110 & 6.010 & 36 & 6.729 \\
\hline GR & 4.317 & 4.710 & -393 & - & - & - & -393 \\
\hline $\mathrm{F}$ & 26.869 & 21.469 & 5.400 & - & 5.311 & 745 & 6.145 \\
\hline IRL & 57 & 333 & -276 & - & - & - & -276 \\
\hline I & 36.294 & 29.894 & 6.400 & 350 & 5.834 & 800 & 7.200 \\
\hline $\mathrm{L}$ & 5.215 & 3.920 & 1.045 & 85 & 960 & - & 1.045 \\
\hline $\mathrm{NL}^{* *}$ & 7.597 & 5.865 & 1.732 & - & 950 & - & 1.732 \\
\hline UK & 22.840 & 18.064 & 4.776 & - & 4.500 & 655 & 5.431 \\
\hline EG-10 & 172.027 & 143.404 & 28.623 & 545 & 26.786 & 2.492 & 31.115 \\
\hline
\end{tabular}

* Als Gegenleistung für zusätzliche Beihilfen lt Kommissionsentscheidung.

\# Aufgrund der Entscheidung 1018/85/EGKS und/oder aus Rentabilitätsgründen. Der Kapazitätabbau bei Belgien enthält $250 \mathrm{kt}$, die von Luxemburg ausgeliehen wurden und dort abgezogen wurden.

' Kapazitätswerte nach Berichtigungen bei Klöckner. Mindestabbau enthält nicht Verringerungen als Gegenleistung für Beihilfen an ein Unternehmen.

** Kapazität nach Berichtigung aufgrund der EuGH Entscheidung.

\#\# Laut Kommissionsentscheidungen.

Quelle: EG, Kommission 1986a, S. 159.

Die eigentlichen Kernbedingungen für die Gewährung weiterer Beihilfen bestanden in einem zusätzlichen Kapazitätsabbau und im Nachweis der Erreichung der

Fällen wurde jedoch der Abbau im Falle Griechenlands nicht spezifiziert; er sollte lediglich "angemessen" sein. Im Falle Irlands, das nur ein kleines Stahlwerk besitzt, verzichtete die Kommission unter Heranziehung der Ausnahmevorschrift in Art. 2,III des Kodex auf die Forderung nach einem Kapazitätsabbau. Vgl. EG, Kommission 1983g, S. 19, 22.

102 Hausner (1987, S. 49) spricht hier von einer Umkehrung der im Kodex festgelegten "Entscheidungsleiter - erst notifizieren, dann prüfen und danach genehmigen - in das exakte Gegenteil ... erst genehmigen, dann notifizieren." 
finanziellen Rentabilität der Unternehmen bis Ende 1985 durch Umstrukturierung. Tab. 4.3-3 zeigt die von der Kommission den MS auferlegten Kapazitätsabbauvolumina, die größtenteils deutlich über die von den MS im Zusammenhang mit ihren Plänen angebotenen Volumina hinausgehen. Somit lag der für die $\mathrm{Ge}$ meinschaft im Zeitraum 1980-85 vorgesehene Kapazitätsabbau bei 26,7 Mio. t und damit nahe bei dem von der Kommission als notwendig angesehenen Zielwert von 30-35 Mio. t. Die Kommission hoffte, daß die ökonomischen Notwendigkeiten einige Unternehmen zwingen würden, weitere Anlagen zu schließen, um so die Differenz zum Zielwert wettzumachen 103 .

Im Gegenzug zu diesen Auflagen autorisierte sie die MS zur Vergabe umfangreicher Beihilfen, deren Höhe und Aufteilung auf Subventionstypen Tab. 4.3-4 deutlich macht ${ }^{104}$. Die Summen entsprachen den von den MS beantragten. Ihre Größenordnung wird aus einem Vergleich mit den von 1980 bis zu dieser Entscheidung gezahlten Hilfen deutlich (Tab. 4.3-5), die im Durchschnitt weniger als die Hälfte der jetzt genehmigten Beträge ausmachten ${ }^{105}$. Die Auszahlung der Subventionen durch die MS bedurfte jedoch noch der Freigabe durch die Kommission, die jeweils nur in Tranchen bis Ende 1985 erfolgte. Während die Beihilfen in den Entscheidungen präzise einzelnen Unternehmen zugeordnet wurden, galten die Kapazitätsabbauauflagen pauschal für jeden MS, so daß die MS eine gewisse Freiheit hatten, die Schließung unrentabler oder auch regionalpolitisch unbedenklicher Anlagen vorzunehmen. Dies geschah, obwohl die Kommission in ihren Entscheidungen große Zweifel bzgl. der Überlebensfähigkeit einzelner Unternehmen geäußert hatte, so daß hier davon ausgegangen werden muß, daß die Beihilfengenehmigung den Marktaus-

103 Vgl. EG, Kommission 1984e, S. 3, und Kutscher 1989, S. 82.

104 Problematisch wirkt hier zunächst bei der Addition der verschiedenen Typen ihre Gleichgewichtung, da zinsverbilligte Kredite oder Bürgschaften i.d.R. nicht zum vollen Betrag eine Begünstigung des Unternehmens darstellen, wie dies umgekehrt bei Verlustausgleichen der Fall ist. Vgl. BMF 1983, S. 55. Jedoch gilt im speziellen Fall der Stahlindustrie, daß angesichts der Krisenlage der Branche bspw. staatliche Bürgschaften nicht lediglich eine Zinsreduktion für die Kreditnehmer erbrachten, sondern sie überhaupt erst kreditwürdig machten. Unter diesem Gesichtspunkt haben auch staatliche Darlehen zu Marktkonditionen Beihilfecharakter. Daher wird an allen Stellen in diesem Kapitel mit Bruttobeihilfen und Absolutbeträgen gerechnet. Außerdem kam es häufig zur vollen Übernahme der verbürgten Kredite bzw. der Verschuldung der Unternehmen durch den Staat, so daß auch die Wirtschaftsvereinigung Eisen- und Stahlindustrie (1982, S. 17) die Gleichgewichtung vornimmt.

105 Hinzu kamen noch Hilfen aus EGKS-Mitteln zur Umschulung der entlassenen Arbeitnehmer. Vgl. Kutscher 1989, S. 82/83. 
Tab. 4.3-4

Beihilfen an die Stahlindustrie, die am 29.6.1983 als mit dem

Gemeinsamen Markt unvereinbar angesehen wurden, sofern nicht bestimmte Bedingungen erfüllt waren (in MECU*)

\begin{tabular}{|c|c|c|c|c|c|}
\hline $\begin{array}{l}\text { Land/ } \\
\text { Unternehmen }\end{array}$ & $\begin{array}{r}\text { Zuschüsse/ } \\
\text { Zinszu- } \\
\text { schüsse }\end{array}$ & $\begin{array}{r}\text { Kapital/Be- } \\
\text { teiligungs- } \\
\text { darlehen }\end{array}$ & $\begin{array}{r}\text { Umwandlung } \\
\text { von Schulden } \\
\text { in Kapital }\end{array}$ & $\begin{array}{r}\text { Zinsver- } \\
\text { billigte } \\
\text { Darlehen }\end{array}$ & $\begin{array}{l}\text { Bürgschaften/ } \\
\text { Darlehen zum } \\
\text { Marktzinssatz }\end{array}$ \\
\hline \multicolumn{6}{|l|}{ Belgien } \\
\hline Sidmar & - & 77 & 245 & - & \\
\hline Sonstige & 36 & 31 & 25 & - & \\
\hline \multicolumn{6}{|l|}{ Griechenland } \\
\hline Metall. Halyps & 4 & - & - & - & \\
\hline Sidenor & 2 & - & - & - & \\
\hline \multicolumn{6}{|l|}{ Irland } \\
\hline Irish Steel & - & 129 & - & - & 26 \\
\hline \multicolumn{6}{|l|}{ Großbritannien } \\
\hline Sheerness Steel & 9 & - & - & - & \\
\hline EG-10 & 51 & 237 & 270 & - & 26 \\
\hline
\end{tabular}

Am 29.6.1983 bedingt genehmigte Beihilfen an die Stahlindustrie (in $\mathrm{MECU}^{*}$ )

\begin{tabular}{|c|c|c|c|c|c|}
\hline $\begin{array}{l}\text { Land/ } \\
\text { Unternehmen }\end{array}$ & $\begin{array}{r}\text { Zuschüsse/ } \\
\text { Zinszu- } \\
\text { schüsse } \\
\end{array}$ & $\begin{array}{r}\text { Kapital/Be- } \\
\text { teiligungs- } \\
\text { darlehen } \\
\end{array}$ & $\begin{array}{r}\text { Umwandlung } \\
\text { von Schulden } \\
\text { in Kapital } \\
\end{array}$ & $\begin{array}{r}\text { Zinsver- } \\
\text { billigte } \\
\text { Darlehen } \\
\end{array}$ & $\begin{array}{c}\text { Bürgschaften/ } \\
\text { Darlehen zum } \\
\text { Marktzinssatz }\end{array}$ \\
\hline \multicolumn{6}{|l|}{ Belgien } \\
\hline Cockerill-Sambre & 38 & 493 & 1122 & - & 608 \\
\hline Sonstige & 5 & 30 & 33 & - & 1 \\
\hline \multicolumn{6}{|l|}{ Deutschland } \\
\hline Arbed Saarstahl & 484 & - & - & - & - \\
\hline Sonstige & 2205 & - & - & 8 & 917 \\
\hline \multicolumn{6}{|l|}{ Frankreich } \\
\hline Sacilor/Usinor & - & 3943 & - & - & \\
\hline \multicolumn{6}{|l|}{ Italien } \\
\hline Finsider & 2156 & 4488 & - & 1512 & - \\
\hline Sonstige & 416 & 37 & - & - & - \\
\hline \multicolumn{6}{|l|}{ Luxemburg } \\
\hline Arbed & 154 & 59 & - & 1 & 182 \\
\hline \multicolumn{6}{|l|}{ Niederlande } \\
\hline Hoogovens & 74 & 272 & - & 8 & 58 \\
\hline Nedstaal & 8 & - & - & - & - \\
\hline \multicolumn{6}{|l|}{ Großbritannien } \\
\hline British Steel & 200 & 2474 & - & - & - \\
\hline EG-10 & 5740 & 11796 & 1155 & 1529 & 1766 \\
\hline
\end{tabular}

* Umrechnung zu den Wechselkursen vom 30.9.1982

Quelle: EG, Kommission 1984e. 
tritt der Unternehmen verhinderte und damit den Wettbewerb und den Intra-EGHandel beeinflußte106.

Tab. 4.3-5

Im Rahmen des 1. und 2. Beihilfenkodex bis zum 29.6.1983 genehmigte Beihilfenzahlungen an die Stahlindustrie der Gemeinschaft (in $\mathrm{MECU}^{*}$ )

\begin{tabular}{|c|c|c|c|c|c|c|}
\hline $\begin{array}{l}\text { Land/ } \\
\text { Unternehmen }\end{array}$ & $\begin{array}{r}\text { Zuschüsse/ } \\
\text { Zinszu- } \\
\text { schüsse }\end{array}$ & $\begin{array}{r}\text { Kapital/Be- } \\
\text { teiligungs- } \\
\text { darlehen }\end{array}$ & $\begin{array}{r}\text { Umwandlung } \\
\text { v. Schulden } \\
\text { in Kapital }\end{array}$ & $\begin{array}{r}\text { Zinsver- } \\
\text { billigte } \\
\text { Darlehen }\end{array}$ & $\begin{array}{l}\text { Bürgschaften/ } \\
\text { Darlehen zum } \\
\text { Marktzinssatz }\end{array}$ & Sonstige \\
\hline \multicolumn{7}{|l|}{ Belgien } \\
\hline Cockerill-Sambre & - & 493 & 548 & 77 & 270 & - \\
\hline Sonstige & 33 & - & - & - & 136 & - \\
\hline Dänemark & - & 39 & - & - & - & 42 \\
\hline \multicolumn{7}{|l|}{ Deutschland } \\
\hline Arbed Saarst. & 442 & - & - & 1 & 89 & 29 \\
\hline Hoesch & 40 & - & - & 52 & - & - \\
\hline Klöckner/Maxh. & 31 & - & - & - & - & - \\
\hline Sonstige & 10 & - & - & 4 & 2 & - \\
\hline \multicolumn{7}{|l|}{ Frankreich } \\
\hline Sacilor & 2 & 1455 & - & - & 340 & - \\
\hline Usinor & 2 & 1518 & - & - & 353 & - \\
\hline Irland & 44 & - & - & - & 32 & - \\
\hline \multicolumn{7}{|l|}{ Italien } \\
\hline Finsider & 123 & 265 & - & 307 & - & - \\
\hline Sonstige & 912 & - & - & 54 & - & - \\
\hline \multicolumn{7}{|l|}{ Luxemburg } \\
\hline Arbed & 70 & 2 & - & 26 & 44 & 2 \\
\hline \multicolumn{7}{|l|}{ Niederlande } \\
\hline Hoogovens & 15 & - & - & - & 79 & - \\
\hline \multicolumn{7}{|l|}{ Großbritannien } \\
\hline British Steel & - & 3055 & - & - & - & - \\
\hline Sonstige & 33 & - & - & 1 & - & - \\
\hline EG-10 & 1757 & 6827 & 548 & 522 & 1345 & 73 \\
\hline
\end{tabular}

* Umrechnung zu den Wechselkursen vom 30.9.1982

Quelle: EG, Kommission 1984e.

106 Es handelt sich hierbei um Sacilor, ARBED Saarstahl, Finsider und British Steel. Vgl. EG, Kommission 1983g, S. 10, 15, 26, 36, und Wienert 1990, S. 208. 
Auch wenn die MS in der Vergangenheit einige Male überzeugt werden konnten, die geplanten Beihilfenintensitäten für einzelne Projekte zu reduzieren, bzw. die Genehmigung von Programmen mit der Forderung der Meldung von Einzelfällen gekoppelt wurde 107 , so hatte die Kommission doch grundsätzliche Probleme bei der Durchsetzung der Beihilfendisziplin. So kam es offensichtlich zum Mißbrauch genehmigter Investitionsbeihilfen zur Deckung von Verlusten. Deshalb verpflichtete die Kommission in diesen Entscheidungen die MS zu vierteljährlichen Meldungen über ausgezahlte Investitionshilfen und die mit ihrer Hilfe durchgeführten Investitionen, um so eine Pro-rata-temporis-Zahlung zu sichern ${ }^{108}$. Dem Mißbrauch von Betriebsbeihilfen zur Unterbietung der EG-weit verbindlichen Richtpreise wollte die Kommission durch eine Beschränkung der Verlustausgleiche auf monatliche Raten bei gleichzeitiger Überprüfung der Einhaltung der Preisregeln Herr werden, wobei sie bei Verstößen die Aussetzung der Zahlung anordnen konnte ${ }^{109}$. Schließlich versuchten die MS, die Kontrolle der Kommission über ihre Subventionsgewährung $\mathrm{zu}$ erschweren, indem sie die Subventionsvergabe dezentralisierten und auf Kapitaldotationen auswichen 110 .

Gegen die Entscheidungen vom Juni 1983 kam es zu mehreren Anfechtungsklagen vor dem EuGH. Im Falle einiger luxemburgischer Gemeinden wurde diese wegen Nichtberechtigung zur Klage abgewiesen 111 . Auch die separaten Klagen des niederländischen Produzenten Hoogovens und der Bundesrepublik Deutschland gegen die genehmigten Beihilfen für Belgien, Frankreich, Italien und Großbritannien, die sich auf das divergierende Verhältnis von Beihilfen und Stillegungen stützten, wurden schließlich abgewiesen. Der EuGH vertrat die Auffassung, daß die Kommission bei der Verteilung der Umstrukturierungslasten ihr Ermessen entsprechend den Grundsätzen der Verhältnismäßigkeit, Gleichbehandlung und Nichtdiskriminierung rechtmäßig genutzt hatte und daß eine feste Kopplung von Beihilfen und Kapazitätsabbau nicht zwingend sei. Der EuGH interpretierte also Gleichbehandlung und Nichtdiskriminierung weniger in einem allokativen als vielmehr in einem distributiven Sinn und gewährte der Kommission einen außerordentlich weiten Spielraum bei der

107 Dies galt für Deutschland und Großbritannien. Vgl. EG, Kommission 1982d, S. 2-10, und 1983f, S. 6/7.

108 Vgl. auch Dominick 1984, S. 395.

109 Vgl. z.B. EG, Kommission 1983g, S. 12/13 (Art. 5-7), und 1984e, S. 3/4. Diese Vorgehensweise war bereits vorher angekündigt worden. Vgl. EG, Kommission 1982e, S. 2, und 1983f, S. 7.

$110 \mathrm{Vgl}$. Hausner 1987, S. 44/45.

111 Vgl. EG, Kommission 1986e, Teil I, S. 10. 
Anwendung ihrer Kriterien. Dominick ${ }^{112}$ argumentiert, daß hierdurch die Möglichkeit einer juristischen Prüfung des Kommissionshandelns lediglich auf einen Willkürausschluß reduziert wurde, während eine Nachprüfbarkeit der ökonomischen Beurteilungskriterien ausgeschlossen wurde, was angesichts der Schwere und Dauer der Krise kaum zu rechtfertigen ist. Lediglich für Hoogovens verpflichtete der EuGH die Kommission, eine neue Berechnung des vorzunehmenden Kapazitätsabbaus vorzunehmen 113 .

\subsubsection{Verlängerung des Kodex und Fazit}

In der Folgezeit gab die Kommission schrittweise die genehmigten Beihilfen zur Auszahlung frei. Teilweise erfolgte die Freigabe, bevor die Kapazitätsabbauten nachgewiesen wurden (italienische private Stahlindustrie) bzw. bevor der endgültige Umstrukturierungsplan vorlag (BSC) ${ }^{114}$. Angesichts der nur langsamen Erholung des Stahlmarktes - eine Kapazitätsauslastung von $70 \%$, die im allgemeinen als absolutes Rentabilitätsminimum angesehen wird ${ }^{115}$, wurde erst 1985 knapp erreicht und im Folgejahr bereits wieder unterschritten; zudem hatte der trotz der administrierten Mindestpreise gegenüber 1981 eingetretene Preisverfall die Kostenrechnungen der Unternehmen zur Makulatur gemacht 116 - forderte die Kommission von den Unternehmen die Erstellung detaillierter Finanzpläne, um die Möglichkeit der Wiedergewinnung ihrer Rentabilität einschließlich einer Mindestkapitalrendite zu prüfen 117. Hierbei zeigte sich die Notwendigkeit weiterer Unterstützung insbesondere der staatlichen Unternehmen, und so meldeten vier MS, daß sie zusätzliche Beihilfen gewähren müßten; zwei weitere MS sahen es als notwendig an, auch 1985 Betriebsbeihilfen zu gewähren 118 . Um dies zu legalisieren, wurden schließlich durch eine vom Rat einstimmig gebilligte Kommissionsentscheidung 119 die Fristen des zweiten Beihilfekodex wie folgt geändert: Meldefrist 31.5.85, Genehmigungsfrist 1.8.85, letzte Zahlung von Betriebsbeihilfen 31.12.85. Eine Bindung zusätzlicher Beihilfen an

\section{1986, S. 604/605, 616.}

113 Vgl. Dominick 1986, S. 599/600, und EG, Kommission 1986e, Teil II, S. 4/5. Letzteres führte

die Kommission dann auch durch. Vgl
114 Vgl. EG, Kommission 1986e, S. 3.

115 Für die langfristige Lebensfähigkeit ist eine Auslastung von mindestens $80 \%$ nötig. Vgl. Bartling 1984, S. 445.

116 Vgl. Hausner 1987, S. 44.

117 Vgl. EG, Kommission 1986e, S. 3-5.

118 Vgl. EG, Kommission 1986e, S. 9/10. Schon 1984 hatte sich die Notwendigkeit weiterer Kapi-

119 talzuführungen an Finsider abgezeich 
neue Kapazitätsabbauten wurde aufgegeben, die Kosten eines möglichen Abbaus konnten aber vom Staat übernommen werden 120 . Zudem waren staatliche Entschuldungen der Unternehmen so weit gestattet, bis die Belastungen aus dem Schuldendienst denen der 1984 rentablen Unternehmen entsprachen (ca. 4\% des Umsatzes) ${ }^{121}$. Vor allem durch die letzte Vorschrift wurde der marktwirtschaftliche Selektionsmechanismus nunmehr völlig außer Kraft gesetzt.

Fast alle MS führten folglich ihre Regelungen für Betriebsbeihilfen auch 1985 weiter. Zudem notifizierten 6 MS (B, F, D, IRL, I und L) zusätzliche Beihilfen zur Entschuldung der Stahlproduzenten, die von der Kommission nach Überprüfung der Einhaltung der 4\%-Grenze auch genehmigt wurden. Das Volumen dieser zusätzlichen Beihilfen betrug 4,3 Mrd. ECU, von denen allein 2,2 Mrd. bzw. 1,4 Mrd. ECU auf Italien und Frankreich entfielen. Im Gegenzug erhielt die Kommission Versprechen zum Abbau weiterer 2,4 Mio. t Warmwalzkapazität bis Ende 1986 (zur Verteilung auf die MS vgl. Tab. 4.3-3)122.

Insgesamt hatte die Kommission somit während der Geltungsdauer der ersten beiden Beihilfekodizes (einschl. der Modifizierung 1985) Beihilfen in Höhe von 36,4 Mrd. ECU genehmigt, denen ein Nettokapazitätsabbau von 28,6 Mio. t gegenüberstand, zu denen noch die eben erwähnten 2,4 Mio. t zu addieren sind. Dieser Abbau war mit einem Verlust von 250.000 Arbeitsplätzen, d.h. 37\% des Standes von 1980, verbunden ${ }^{123}$. Die Aufgliederung der Beihilfen auf die verschiedenen im Kodex erwähnten Typen zeigt eine deutliche Dominanz der Betriebsbeihilfen, während das befürchtete neue Schlupfloch der FuE-Beihilfen nur eine außerordentlich untergeordnete Rolle einnahm (Tab. 4.3-6), das lediglich in Deutschland in größerem Maße genutzt wurde.

Trotz dieses massiven Schrumpfungsprozesses waren die Probleme der Industrie zum Ende des 2. Beihilfekodex nicht gelöst, was auch daran deutlich wird, daß die geplante Degressivität der Beihilfen nicht erreicht wurde124. Die Hoffnung, die Unternehmen könnten nunmehr die weitere Umstrukturierung allein aus eigenen

\footnotetext{
120 Diese Regelung, die einen verzögerten Abbau erlaubte, wenn sonst die Umstrukturierung des Unternehmens gefährdet worden wäre, kam auf Druck Frankreichs zustande. Vgl. BMF 1985, S. 47.

121 Vgl. EG, Kommission 1985f, S. 5/6, und 1986e, Teil 2, S. 2. Trotz dieser Hilfen betrug bei einigen französischen und italienischen Unternehmen diese Belastung bereits 1987 wieder 9$15 \%$. Vgl. Vondran 1987, S. 7-9.

122 Vgl. EG, Kommission 1986a, S. 151, und 1986e, Teil 2, S. 2/3.

$123 \mathrm{Vgl}$. Gerstenberger et al. 1985, S. 68/69, und EG, Kommission 1986e, Teil 2, S. 5/6.

124 Vgl. Wirtschaftsvereinigung Eisen- und Stahlindustrie 1982, S. 7.
} 
Mitteln bestreiten, erwies sich als trügerisch. Nach Schätzungen bestand weiterhin eine Überkapazität von 20-25 Mio. t, und auch eine ausreichende Rentabilität war nicht gegeben 125 .

Tab. 4.3-6

Gesamtbetrag der Beihilfen an die Stahlindustrie nach Zielsetzungen freigegeben zwischen 1.2.1980 und Ende 1985 (in MECU)

\begin{tabular}{l|rrrrr|r} 
Land & Investition & FuE & Stillegungen & Betriebsbeih. & Notbeih. & Gesamt \\
\hline B & 719 & - & 118 & 3408 & 12 & 4257 \\
DK & 13 & - & - & 68 & - & 81 \\
D & 1120 & 163 & 619 & 1942 & - & 3844 \\
GR & - & - & - & - & - & 0 \\
F & 3039 & - & 302 & 5111 & 689 & 9141 \\
IRL & - & - & - & 264 & - & 264 \\
I & 1791 & 54 & 1053 & 9171 & - & 12069 \\
L & 440 & - & 15 & 176 & - & 631 \\
NL & 234 & - & - & 222 & - & 456 \\
UK & 1788 & 49 & 1036 & 2767 & - & 5640 \\
EG-10 & 9144 & 266 & 3143 & 23129 & 701 & 36383
\end{tabular}

Quelle: EG, Kommission 1986e.

\subsubsection{Subventionskontrolle nach der Krise}

\subsubsection{Der 3. Kodex - Einengung der Subventionierungsmöglichkeiten?}

Dementsprechend begann eine Diskussion um die mögliche Verlängerung des Subventionskodex. Auch wenn auf der Ratstagung Ende 1984 noch kein MS eine Verlängerung beantragt hatte ${ }^{126}$, Anfang 1985 noch eine große Mehrheit gegen eine solche Verlängerung bestand und die Gegenleistung der MS für die oben erwähnte Modifizierung der Fristen des Kodex in der Verpflichtung bestanden hatte, ab 1986 auf jegliche Subventionen zu verzichten, war damit noch nicht das letzte Wort gesprochen. Der Forderung Belgiens, Frankreichs und Italiens nach einer Verlängerung des Beihilfenregimes schloß sich auch Kommissionspräsident Delors an, und so legte die Kommission einen Entwurf zur Verlängerung des Kodex vor. Der deutsche Widerstand, insbesondere gegen eine Fortführung der Schließungsbeihilfen, führte

\footnotetext{
125 Vgl. EG, Kommission 1986e, Teil 1, S. 3/4, und von Freyend/Linkohr 1986, S. 9. Die herrschende Unsicherheit wird auch daran deutlich, daß Krägenau (1986, S. 55, 70) an zwei verschiedenen Stellen seiner Schrift hierzu jeweils abweichende Zahlen nennt.

126 Vgl. EG, Bulletin 1984, S. 63.
} 
schließlich zu einem Kompromiß, der einige Vorschriften aus dem Kommissionsentwurf verschärfte ${ }^{127}$. So wurde zunächst das Subventionsregime nur für drei statt der geplanten fünf Jahre verlängert 128 .

- Schließungsbeihilfen waren zwar weiterhin gestattet, ihre Einsatzmöglichkeiten wurden jedoch beschränkt. Zahlungen wegen der vorzeitigen Beendigung von Verträgen und zur Geländesanierung waren im Gegensatz zum 2. Kodex und dem Kommissionsentwurf nur noch bei einer endgültigen Produktionseinstellung eines vor Inkrafttreten des Kodex bestehenden Unternehmens unter Auflagen bis zum Restwert der Anlagen bzw. dem Ertragswert des Unternehmens über drei Jahre beihilfefähig 129. In anderen Fällen durften nur noch Abfindungen an entlassene Arbeiter zu lediglich $50 \%$ durch staatliche Hilfen abgedeckt werden 130 .

- Beihilfen für FuE-Vorhaben blieben unter den gleichen Voraussetzungen wie im 2. Kodex beihilfefähig, ihre Intensität wurde allerdings auf $35 \%$ bei Grundlagenforschung und $25 \%$ bei angewandter FuE reduziert, wobei die Abgrenzung zwischen beiden Kategorien im Kodex definiert wurde und Kosten der industriellen Verwertung nicht beihilfefähig waren.

- Umweltschutzbeihilfen wurden als neues Element eingeführt, wobei Subventionen für die Anpassung an neue Normen lediglich für mindestens zwei Jahre alte Anlagen gewährt werden durften. Ihre Intensität wurde auf $15 \%$ begrenzt, wobei sich diese bei gleichzeitiger Erhöhung der Kapazität nur auf Investitionen in die bisherigen Kapazitäten beziehen durften.

Bei den letzten beiden Beihilfetypen wurde also die Stahlindustrie nunmehr weitgehend wie alle anderen Industrien behandelt.

Da die Kommission die mit dem 2. Kodex angestrebten Umstrukturierungs- und Sanierungsziele als weitgehend erreicht ansah, waren weitere Anpassungen nunmehr von den Unternehmen selbst zu tragen ${ }^{131}$. Daher wurden Rettungs-, Betriebs- und

127 Vgl. Becker 1989, S. 111, Hausner 1987, S. 49-52, und EG, Kommission 1985g. Der deutsche Widerstand wird noch im 10. Subventionsbericht deutlich. Vgl. BMF 1985, S. 47.

$128 \mathrm{Vgl}$. zum folgenden EG, Kommission 1985h.

129 Die Möglichkeit von Beihilfen für Teilstillegungen wurde auf deutsches Drängen ausgeschlossen. Vgl. Geister 1986, S. 169.

130 Auch der SVR (1983, S. 229) erkennt an, daß Stillegungen für Unternehmen teuer sind und daß ihnen nach den Krisenjahren die finanziellen Mittel fehlten.

131 In gewissem Widerspruch hierzu steht die Feststellung, daß weiterhin Überkapazitäten bestanden, weshalb es sich bestenfalls um ein labiles Gleichgewicht handeln kann. Im Entscheidungs- 
Investitionsbeihilfen als nicht mehr notwendig und damit auch nicht genehmigungsfähig angesehen 132 , wobei regionale Investitionshilfen noch in solchen MS zulässig sein sollten, die unter den ersten beiden Kodizes keine staatliche Unterstützung erhalten hatten. Letztere Regelung war lediglich auf Griechenland anwendbar, da die Neumitglieder Spanien und Portugal ausdrücklich von den Regeln des Kodex ausgeschlossen blieben. Letztere durften für einen Übergangszeitraum von $3 \mathrm{bzw}$. 5 Jahren Betriebs-, aber auch Investitions-, Stillegungs- und FuE-Beihilfen gewähren, wenn diese von der Kommission entsprechend den Kriterien des 2. Kodexes - also einschließlich eines Kapazitätsabbaus - genehmigt worden waren 133 .

Tab. 4.3-7

\section{Beihilfen für die Stahlindustrie unter dem 3. Kodex} (in MECU)

\begin{tabular}{l|rrrrrrr|r} 
Typ & $\mathrm{D}$ & $\mathrm{F}$ & $\mathrm{I}^{* * *}$ & $\mathrm{~L}^{*}$ & $\mathrm{UK}$ & $\mathrm{E}$ & $\mathrm{P}$ & Summe ** \\
\hline FuE & 12,1 & 20,4 & - & 5,6 & 0,2 & - & - & 38,3 \\
Umweltschutz & 0,3 & - & - & - & - & 1,1 & - & 1,4 \\
Schließung & 117,4 & - & 3357,0 & - & - & 292,4 & - & 3766,8 \\
Investitionen & - & - & - & - & - & 1559,0 & 511,4 & 2070,4 \\
Summe & 129,8 & 20,4 & 3357,0 & 5,6 & 0,2 & 1852,5 & 511,4 & 5876,9
\end{tabular}

* Im Falle Luxemburg kommen zu dem angegebenen Wert noch zinsbegünstigte Darlehen in Höhe von 4,9 MECU hinzu.

** Für die anderen MS wurden keine Beihilfen notifiziert.

*** Nur $4 \%$ der genehmigten Beihilfen sind echte Schließungsbeihilfen

Quelle: EG, Kommission 1990c und 1990a, S. 153.

Nochmals betonte die Kommission die Gleichsetzung staatlicher Kapitalzuführungen mit anderen Beihilfen, sowohl was die inhaltliche Beurteilung als auch was die Verfahrensregeln betrifft. Letztere entsprachen den Regeln des 2. Kodex, wobei durch die erneute Festlegung einer letzten Meldefrist (auf den 30.6.1988)134 ein zweiter Versuch unternommen wurde, die Subventionierung der Stahlindustrie auf Sicht völlig zu beenden.

entwurf wird ehrlicherweise zugegeben, daß diese aufgrund sozialer und regionaler Rücksichten akzeptiert wurden. Vgl. EG, Kommission 1985h, S. 1/2, und 1985g, S. 1.

Interessanterweise betont die Kommission explizit, daß solche Beihilfen auch "keinesfalls durch Artikel 67 gerechtfertigt wären" und folglich aufgrund von Art. 4c EGKSV verboten seien. Das alte Dichotomiekonzept aus der Vor-Kodex-Phase (s.o. Abschn. 4.3.2.2) wurde also hier 133 Vgl. EG, Kommission 1990c, S. 3/4. endgültig zu Grabe getragen. Vgl. EG, Kommission 1985h, S. 1.

134 Vgl. EG, Kommission 1985h, S. 4. 
Wie Tab. 4.3-7 zeigt, lag das genehmigte Subventionsvolumen während der Laufzeit des 3. Kodex mit knapp 5,9 Mrd. ECU weit unter den Beträgen des 2. Kodex. Dies lag neben den während der Laufzeit des 2 . Kodex durchgeführten, massiv subventionierten Umstrukturierungen und Modernisierungen, die die Wettbewerbsfähigkeit der Industrie deutlich verbessert hatten ${ }^{135}$, vor allem an der allgemeinen Erholung des Stahlmarktes, die den EG-Produzenten eine stetige Erhöhung der Produktion erlaubte und 1988 die höchste Auslastung seit 1974 brachte (Tab. 4.3-1). Hierdurch verstummte die noch in der Anfangsphase des Kodex bestehende Diskussion um die Notwendigkeit weiteren Kapazitätsabbaus ${ }^{136}$. Die verbesserte Finanzlage ermöglichte den Unternehmen zudem, auch ohne Betriebsbeihilfen zu überleben.

Dies galt nicht für die Stahlerzeuger der Neumitglieder Spanien und Portugal. Hier genehmigte die Kommission die vorgelegten Betriebs-, Umstrukturierungs- und Investitionsbeihilfen (40\% des EG-Gesamtvolumens) im Falle Spaniens gegen Kapazitätsabbauauflagen. Während die Beitrittsakte hier ursprünglich einen Abbau von 21 auf 18 Mio. Tonnen Warmwalzkapazität vorgesehen hatte, führten die Umstrukturierungen bis Anfang 1989 sogar zu einer Verminderung auf 16,24 Mio. $\mathrm{t}^{137}$.

Fast das gesamte restliche Beihilfevolumen entfiel auf die staatliche italienische Stahlindustrie. Trotz umfangreicher Subventionen von insgesamt ca. 25 Mrd. $\mathrm{DM}^{138}$ und kapazitäts- und beschäftigungsreduzierender Umstrukturierungen zwischen 1980 und 1985 verschlechterte sich selbst in der günstigen Konjunkturlage die Situation des Unternehmens Finsider weiter, was "vor allem auf nicht wettbewerbsfähige industrielle und kommerzielle Strukturen, auf Verzögerungen bei der Durchführung von Investitionen und auf Schwächen in der Betriebsführung zurückzuführen war." 139 Die anhaltenden Verluste wurden durch immer neue Darlehen staatlicher Kreditinstitute ausgeglichen, so daß die Verschuldung des Unternehmens Ende 1987 104\% des Umsatzes betrug 140. Schon gegen diese Kredite, die

\footnotetext{
135 Siehe hierzu unten Abschnitt 4.3.6.5.

136 Vgl. Wienert 1990, S. 209.

137 Vgl. EG, Kommission 1990c, S. 11-13.

138 Vgl. Woche im Bundestag 1988, S. 38.

139 EG, Kommission 1989e, S. 76. Im Widerspruch hierzu sehen Gerstenberger et al. (1985, S. 90f.) bereits 1985 die italienische Stahlindustrie als den hinter Deutschland wettbewerbsfähigsten europäischen Produzenten an. Dies spricht dafür, daß v.a. der letzte im Zitat genannte Aspekt von hoher Bedeutung ist. In diese Richtung argumentieren auch Meny/Wright 1987, S.

140 Vgl. EG, Kommission 1989e, S. 76.
} 
bei üblichen Kreditwürdigkeitsprüfungen kaum gewährt worden wären ${ }^{141}$, hatte die Kommission ein Prüfverfahren eröffnet, das nach der Liquidation des Unternehmens auf die staatliche Bürgschaft zugunsten der Gläubiger ausgedehnt wurde.

Die italienische Regierung plante nunmehr die Übertragung der leistungsfähigsten Teile des Unternehmens auf den neu zu gründenden ILVA-Konzern, wobei die weiteren Betriebsteile entweder stillgelegt oder an Privatunternehmen verkauft werden sollten. Die Stillegung von 1,18 Mio. t Warmwalzkapazität entsprach $8 \%$ der Gesamtkapazität; hinzu kamen weitere Stillegungen im Kaltwalz- und Rohstahlbereich. Im Gegenzug waren Beihilfen in Höhe von knapp $5 \mathrm{Mrd}$. ECU zur Schuldentilgung, zum Verlustausgleich, als Drohverlustrückstellungen und für Schließungskosten vorgesehen 142 .

Obwohl dieser Plan den strengen Subventionsregeln des 3. Kodex diametral widersprach, genehmigte die Kommission nach einstimmiger Zustimmung des Rates $2 / 3$ der vorgesehenen Beihilfen, von denen lediglich $4 \%$ echte Schließungs-, der Rest jedoch Betriebsbeihilfen darstellten ${ }^{143}$. Die Möglichkeit einer späteren Genehmigung des restlichen Drittels blieb offen. Als Gegenleistung wurden die geplanten Schließungen und Verkäufe festgeschrieben, lediglich der Zeitplan wurde etwas verkürzt. Weitere Auflagen sowie Kontrollrechte sollten die Verwendung der Veräußerungserlöse zur Schuldentilgung sichern sowie ein Sinken des Nettozinsaufwandes unter 5,5\% des Umsatzes verhindern (ein höherer Wert als der oben genannte) ${ }^{144}$. Die vorgesehene Freigabe der Beihilfen in Tranchen bis Ende 1990 erwies sich aufgrund der guten Lage des Sektors zunächst als nicht in vollem Umfange nötig. Lediglich 58\% der genehmigten Summe wurden im April 1990 freigegeben, weitere $37 \%$ erst erst im Juli 1991, während der Restbetrag zunächst nicht genutzt werden mußte ${ }^{145}$. Aus dem gleichen Grund genehmigte die Kommission allerdings auch einen Aufschub der vorgesehenen Stillegungen für ein Viertel der stillzulegenden Warmwalz- und die gesamte Kaltwalz- und Rohstahlkapazität um 6, 21 bzw. 9 Monate146.

141 Vgl. Colombo/Friderichs/Mayoux 1987, S. 7, und unten Abschnitt 4.3.6.3.

142 Vgl. EG, Kommission 1989e, S. 76/77.

143 In der Literatur wird der Verdacht geäußert, daß die deutsche Akzeptanz dieser Beihilfe im Gegenzug zur Zustimmung der anderen MS zu Beihilfen für den deutschen Steinkohlenbergbau im Rahmen des Jahrhundervertrages erfolgte. Vgl. Franzmeyer 1992, S. 159.

144 Vgl. EG, Kommission 1989e, S. 79-81.

145 Vgl. EG, Kommission 1991a, S. 175/76, und 1992a, S. 141.

146 Vgl. EG, Kommission 1990a, S. 150. Zu den von den "drei Stahlweisen" vorgeschlagenen "umfangreichen Stillegungen ... nach einem strengen Terminplan" bei einer Auszahlung der 
Obwohl also die strengeren Regeln des 3. Kodex in einer allerdings günstigen Konjunktur- und Branchenlage weitgehend akzeptiert und durchgesetzt wurden, demonstriert das Beispiel Finsider/ILVA doch, daß im Falle einer existentiellen Krise eines großen Unternehmens die MS weiterhin bereit waren, eine Aufweichung bzw. gar Aufhebung dieser Regeln zu tolerieren, um einen Marktaustritt des Unternehmen mit den entsprechenden regionalen und sozialen Folgen zu vermeiden.

\subsubsection{Konvergenz mit den EG-Vorschriften: Die 4. und 5. Kodizes und der Gemeinschaftsrahmen}

Trotz allem stimmten die MS zu, die spezifische Beihilferegelung zu verlängern, so daß die Kommission nach Zustimmung des Rates den 4. Kodex im Februar 1989 erlassen konnte ${ }^{147}$. Angesichts der relativ guten Lage der Branche wäre eine Aufweichung der Regeln nicht zu verantworten gewesen, im Gegenteil, das endgültige Auslaufen der Quotenregelung Mitte 1988 (s.u. Abschn. 4.3.6.1) hätte eher eine noch strengere Regelung nahegelegt, um zu verhindern, daß subventionierte Unternehmen nunmehr zu Lasten der nichtsubventionierten Marktanteile gewinnen. Solchen Überlegungen wurde jedoch nicht gefolgt. Stattdessen übernahm der 4. Kodex unverändert die Regeln seines Vorgängers, wenn man von den Fristen absieht, die nunmehr auf den 30.6.1991 (Meldung) bzw. 31.12.1991 (letzte Zahlung) festgelegt wurden. Außerdem wurden die Bestimmungen sofort auf Spanien und ab 1.1.1991 auch auf Portugal angewandt. Nach der deutschen Vereinigung wurde die ursprünglich für Griechenland entworfene Sonderregelung, die regionale Investitionsbeihilfen ohne Kapazitätserhöhung erlaubte, nunmehr auch auf die ehemalige DDR ausgedehnt ${ }^{148}$.

Im Zusammenhang mit der Verabschiedung des 4 . Kodex wurde allerdings eine Lücke in der gemeinschaftlichen Stahlbeihilfenkontrolle geschlossen: Diese bestand darin, daß die Kodizes nur sog. EGKS-Stahltätigkeiten erfassen und die Stahlweiterverarbeitung, wie z.B. die Röhrenherstellung oder die Drahtproduktion, nicht der strengen Kontrolle unterliegt, sondern den normalen Regeln des EG-Vertrages ${ }^{149}$. $\mathrm{Da}$ in einigen Subsektoren der Stahlverarbeitung eine Integration mit EGKS-Stahltätigkeiten in einem Unternehmen dominiert, bestand hier die Gefahr einer unternehmensinternen Quersubventionierung, die die Beihilfendisziplin der Kodizes aus-

Beihilfen erst nach der Umstrukturierung kam es also nicht. Vgl. Colombo/Friderichs/Mayoux 1987, S. 11 .

147 Vgl. EG, Kommission 1989f, S. 8-11.

148 Vgl. EG, Kommission 1991b, S. 2.

149 Vgl. EG, Kommission 1988e, S. 1. 
hebeln konnte 150 . Dies gilt insbesondere für regionale oder allgemeine Beihilfen an solche Unternehmen im Rahmen genehmigter Regelungen, die generell bzw. unterhalb bestimmter Schwellen keiner Ex-ante-Meldepflicht unterliegen. Aus diesem Grunde führte die Kommission Ende 1988 einen Gemeinschaftsrahmen für NichtEGKS-Stahltätigkeiten ein 151 , der für die Hersteller nahtloser und großer geschweißter Röhren ab 1989 eine Ex-ante-Meldepflicht für alle Beihilfefälle einführte und die MS für einige weitere Subsektoren zur jährlichen Ex-post-Meldung aller Subventionen verpflichtete ${ }^{152}$.

Tab. 4.3-8

Beihilfen für die Stahlindustrie unter dem 4. Kodex

(in MECU)

\begin{tabular}{l|rrrrrrr|r} 
Typ & $\mathrm{D}$ & $\mathrm{F}$ & $\mathrm{GR}^{*}$ & $\mathrm{I}^{*}$ & $\mathrm{~L}^{*}$ & $\mathrm{E}$ & $\mathrm{P}$ & Summe ** \\
\hline FuE & 7,3 & - & - & 2,5 & 14,0 & - & - & 23,8 \\
Umweltschutz & - & - & - & - & - & 3,6 & - & 3,6 \\
Schließung & - & 72,2 & - & - & - & 19,1 & - & 91,3 \\
Investitionen & - & - & 0,6 & - & - & - & 483,0 & 483,6 \\
Summe & 7,3 & 72,2 & 0,6 & 2,5 & 14,0 & 22,7 & 483,0 & 602,3
\end{tabular}

* Bei folgenden Ländern kommen zu dem angegebenen Wert noch zinsbegünstigte Darlehen hinzu:

Luxemburg 11,1 MECU, Griechenland 0,7 MECU, Italien 2,5 MECU.

** Für die anderen MS wurden keine Beihilfen notifiziert.

Quelle: EG, Kommission 1991b und 1992a, S. 159-162.

Wie Tab. 4.3-8 im Vergleich zu Tab. 4.3-7 zeigt, sanken die genehmigten Beihilfevolumina gegenüber der Gültigkeitsdauer des 3. Kodex noch einmal deutlich; dies gilt vor allem für die italienische und spanische Stahlindustrie. Wie oben erwähnt, fielen jedoch die Auszahlungen der für ILVA genehmigten Beihilfen weitgehend in die Periode des 4. Kodex, so daß das von 1989-91 ausgezahlte Subventionsvolumen deutlich über dem Gesamtwert aus der Tabelle liegt.

150 Vgl. Wirtschaftsvereinigung Eisen- und Stahlindustrie 1987a, S. 5.

151 Vgl. EG, Kommission 1988d, S. 3-7.

152 Die beiden der Ex-ante-Meldepflicht unterliegenden Teilbereiche sind zudem aufgrund ihrer Abhängigkeit von der Lage in der Öl- und Gasindustrie, ihrem Hauptabnehmer, krisen- und damit auch subventionsanfällig, wodurch sich die schärfere Überwachung noch zusätzlich rechtfertigte. Zusätzlich zur Meldepflicht sieht der Rahmen natürlich auch eine Stillhaltepflicht der MS während der Prüfung vor. Vgl. EG, Kommission 1988d, S. 6/7. Zum rechtlichen Status des Instituts Gemeinschaftsrahmen vgl. unten Abschnitt 4.4.6. 
Zwar genehmigte die Kommission die überwiegende Mehrzahl der Beihilfeanträge bzw. sah staatliche Kapitalzuführungen als marktwirtschaftlich zu rechtfertigen und damit beihilfenfrei an, doch führte ihre Kontrolltätigkeit jetzt auch zu einigen Einschränkungen der staatlichen Subventionierung. So wurden mehrere Subventionsanträge Italiens im Gesamtvolumen von 6,7 MECU in dieser Zeit von der Kommission abgelehnt, da es sich um einfache Investitionsbeihilfen bzw. um solche Umweltschutzbeihilfen handelte, die die Bedingungen des Kodex nicht erfüllten 153. Im Falle spanischer Umweltschutzbeihilfen erreichte die Kommission nach Eröffnung des Prüfverfahrens, daß sowohl das förderfähige Investitionsvolumen enger gefaßt als auch die Beihilfeintensität gesenkt wurde, so daß der Subventionsbetrag sich auf ein Drittel des ursprünglich geplanten Volumens reduzierte 154.

Inzwischen gilt der 5. Kodex, dessen Laufzeit mit 5 Jahren (bis Ende 1996) sehr lang bemessen ist. Diese Geltungsdauer ist im Zusammenhang mit dem Auslaufen des EGKS-Vertrages im Jahre 2002 zu sehen, wodurch die Notwendigkeit einer Angleichung der Beihilfevorschriften an diejenigen des EG-Vertrages entsteht 155. Dementsprechend wäre dann nur noch eine weitere Verlängerung des Kodex nötig. Alternativ wird diskutiert, den EGKSV vorzeitig Ende 1996 auslaufen zu lassen 156.

Die stufenweise Anpassung an die EG-Regeln wird auch in einer Änderung der Vorschriften sichtbar. So wurde die detaillierte Darlegung der beihilfefähigen FuETätigkeiten durch einen einfachen Verweis auf den augenblicklichen Gemeinschaftsrahmen für FuE-Beihilfen ersetzt. Der Verweis führt zu einem Übergang der Intensitätsmessung von Netto- auf Bruttobeihilfenäquivalente. Eine entsprechende Änderung des Artikels zu Umweltschutzbeihilfen unterblieb. In beiden Fällen ist festgelegt, daß bei Änderungen der allgemeinen Beihilfendisziplin die Kommission dem Rat Vorschläge zur Änderung des Kodex unterbreitet 157. Dies geschah wohl, weil der Rat nicht akzeptieren wollte, daß die Kompetenz zur Änderung der Regeln

153 Vgl. EG, Kommission 1988d, S. 6-8. Eine Beihilfe von 1,17 MECU an ein sardisches Stahlunternehmen zur Wiederverwendung von einheimischem Schrott wurde zwar im Rahmen eines Umweltschutzgesetzes gewährt, führte jedoch lediglich zur Diskriminierung anderen Schrotts gegenüber dem sardischen und zu einer Bevorzugung des Unternehmens. Da die Kommission zudem bei ihrer Genehmigung des Gesetzes dessen Anwendung auf den EGKS-Stahlbereich ausdrücklich untersagt hatte, erklärte sie die - nicht angemeldete - Beihilfe für illegal und forderte die Rückzahlung. Vgl. EG, Kommission 1991d, S. 1-3.

154 Vgl. ebenda, S. 11, und EG, Kommission 1991c, S. 2.

155 Vgl. EG, Kommission 1992a, S. 157.

156 Vgl. Handelsblatt 1992.

157 Vgl. EG, Kommission 1991e, S. 57/58. 
allein auf die Kommission übergeht, deren Subventionskontrolle im FuE-Bereich und im Umweltschutzbereich auf einem Gemeinschaftsrahmen beruht; zum Zeitpunkt der Verabschiedung des 5. Kodex basierte die Kontrolle im Umweltbereich sogar nur auf von der Kommission in Schreiben an die MS dargelegten Kriterien. Die Einführung von $\mathrm{CO}_{2}$ /Energie-Abgaben in Dänemark und den Niederlanden führte zu einer Änderung des Kodex, mit der die Freistellung der Stahlunternehmen von diesen Abgaben ermöglicht wurde, um so eine Benachteiligung dieser Unternehmen aufgrund der in diesen MS strengeren Umweltgesetzgebung zu verhindern 158.

Eine weitere Änderung betrifft die regionalen Investitionsbeihilfen. Sie sind nun neben Griechenland und Unternehmen in der ehemaligen DDR auch für KMU in Portugal erlaubt. Die Investitionen dürfen weiterhin zu keiner Kapazitätserhöhung führen, für die neuen Länder ist sogar eine Kapazitätssenkung von $10 \%$ für Warmwalzerzeugnisse vorgeschrieben; dafür darf dieser Subventionstyp hier bis Ende 1995 gewährt werden, in den beiden anderen Ländern dagegeben nur bis Ende 1994159. Für alle anderen MS bleiben Regionalbeihilfen weiterhin untersagt 160 .

In Anwendung dieser Regeln genehmigte die Kommission die Ausweitung der deutschen Regionalbeihilferegelungen auf die ostdeutsche Stahlindustrie und akzeptierte in fünf Beihilfefällen Investitionsbeihilfen von insgesamt 167,2 Mio. DM (ohne EKO und Freital). Für die Einhaltung der Kapazitätsschließungsbedingung wurde dabei die gesamte ehemalige DDR-Produktion als Referenzgröße betrachtet, so daß Beihilfen an ein (privatisiertes) Werk durch Schließungen an anderen Standorten bspw. durch die THA ermöglicht wurden 161 .

Angesichts der erneuten Krise der Stahlindustrie mit einem Preisverfall und hohen Verlusten einiger Produzenten sieht die Kommission die erneute Notwendigkeit eines deutlichen Kapazitätsabbaus durch alle Produzenten, wobei Subventionen aus dem EGKS-Haushalt in Höhe von 240 MECU die Unternehmen v.a. von sozialen Kosten

158 Vgl. EG, Kommission 1993a, S. 227f. Vom umweltpolitischen Gesichtspunkt ist diese Ausnahmeregelung sehr zweifelhaft.

159 Vgl. ebenda, S. 59/60, und 1993a, S. 227. Diese Beihilfen oberhalb eines Jahresvolumens von $10 \mathrm{MECU}$ werden in das Konsultationsverfahren mit den MS vor einer evtl. Genehmigung einbezogen.

160 Vgl. Schaub 1993, S. 36.

161 Vgl. EG, Kommission 1993a, S. 228f. Diese Vorgehensweise unterscheidet sich von der in der Automobilindustrie angewandten Unternehmensbetrachtung, ist angesichts des starken staatlichen Einflusses in der Stahlindustrie und der starken Präsenz von öffentlichen Unternehmen sowie der techischen Integration aller Stahlstandorte in der ehemaligen DDR dort auch eher angebracht. 
dieses Abbaus, wie bspw. für Frühpensionierungen, entlasten sollen 162 . Weitere Kosten sollen über EGKS-Anleihen zwischenfinanziert werden. Eine erneute Lenkung über Quoten nach Art. 58 EGKSV soll jedoch vermieden werden ${ }^{163}$. Von seiten einiger Unternehmen wurde zusätzlich die Genehmigung eines Krisenkartells der Produzenten gefordert, das jedoch von der Kommission abgelehnt wurde, sowie ein erneutes gemeinschaftsweites Konversionsförderprogramm in Anlehnung an das frühere Resider-Programm ${ }^{164}$.

Gleichzeitig wurden jedoch wiederum für einige Staatsunternehmen nach der Ausnahmeregel des Art. 95 EGKSV erhebliche Umstrukturierungsbeihilfen beantragt. Dies betraf erneut ILVA, jedoch auch EKO-Eisenhüttenstadt und Freital in den neuen Bundesländern sowie CSI und Sidenor in Spanien. Nachdem die Kommission die ursprünglichen Konzepte für ILVA, EKO-Stahl und CSI abgelehnt hatte, wurden sie nach Reduktionen der Beihilfen und Erhöhungen des angebotenen Kapazitätsabbaus im Rahmen einer politischen Paketlösung im Dezember 1993 genehmigt 165 (vgl. Tab. 4.3-9). Gleichzeitig wurde ein umfassender Überwachungsmechanismus beschlossen, der die Umsetzung der Kapazitätsabbauauflagen sichern und bei Verletzungen zu Rückzahlungen der Beihilfen führen soll. Aufgrund dieses Mechanismus erstellte die Kommission zwei Berichte, in denen sie eine Einhaltung der Auflagen und Verbesserung der Wettbewerbsfähigkeit der Unternehmen konstatierte 166. Zudem beschlossen die Minister, auf zukünftige Ausnahmegenehmigungen für Beihilfen bei fehlender Rückkehr der Unternehmen zur Profitabilität zu verzichten 167 . Erneut erwies es sich als schwierig, bei diesen Unternehmen signifikante Kapazitätsschließungen im Gegenzug zu den erheblichen Beihilfen durchzusetzen ${ }^{168}$. EKO und CSI wollen sogar neue Warmwalzanlagen erstellen, die durch höhere Schließungen andernorts ausgeglichen werden sollen 169 . Zudem bestritt die italienische Regierung im Falle ILVA lange Zeit, daß der zunächst vorgesehene Schuldenerlaß von ca. 4 Mrd. ECU vor der geplanten Privatisierung eine Beihilfe darstellte und mußte durch

\footnotetext{
162 Die gleiche Summe wäre noch einmal von den MS aufzubringen.

163 Vgl. Schaub 1993, S. 37f.

164 Vgl. Radzio 1993 und Leuthner 1993.

165 Vgl. Europe 1993a, und Hill 1993a sowie EG, Kommission 1994a, S. 303-306.

166 Vgl. EG, Kommission 1994f.

167 Vgl. Hill 1993a, und EG, Kommission 1994a, S. 300f.

168 Vgl. EG, Kommission 1993a, S. 230.

169 Nach dem Scheitern der Übernahme von EKO durch den italienischen Riva-Konzern und der Übernahme durch Cockerill-Sambre mußte das ursprüngliche Förderkonzept modifiziert und erneut von Rat und Kommission genehmigt werden. Dies geschah im Dezember 1994. Vgl. EG, Kommission 1994e.
} 
eine einstweilige Anordnung der Kommission an der Ausführung gehindert werden 170 ; sie blockierte später noch einmal eine Entscheidung durch ihre Weigerung, dem Kapazitätsabbau zuzustimmen 171 . Die staatlichen Stahlunternehmen erreichten also durch die Beihilfengenehmigung eine günstigere Sonderbehandlung, die nach anfänglichem Widerstand schließlich von allen MS akzeptiert wurde, wobei regionalpolitische Argumente (Arbeitsplatzsicherung in den Krisenregionen neue Bundesländer und Baskenland) über wettbewerbspolitische Überlegungen dominierten. Von den privaten Produzenten wird zudem bezweifelt, daß der von der Kommission angestrebte "um so deutlichere(r) Kapazitätsschnitt"172 für diese Produzenten erreicht wurde und daß alle zugesagten Schließungen auch tatsächliche Reduktionen darstellen 173 . Aus diesem Grund und auch wegen der zwischenzeitlichen Verbesserung der Stahlkonjunktur ist der von den privaten Produzenten dem von der Kommission eingesetzten Beauftragten F. Braun in Aussicht gestellte Kapazitätsabbau von knapp 13 Mio. Tonnen Warmwalzkapazität mit geschätzten $6 \mathrm{Mrd}$. ECU Umstrukturierungskosten, der ohnehin als unzureichend angesehen wurde, gescheitert ${ }^{174}$. Angesichts der wiederholten Erfahrungen mit Beihilfen an staatliche Stahlunternehmen muß zudem der Wert der politischen Selbstverpflichtung zur zukünftigen Beihilfenabstinenz bezweifelt werden.

170 Vgl. Schaub 1993, S. 38-40, und EG, Kommission 1993a, S. 230f., sowie 1994a, S. 251. Die Argumentation der italienischen Regierung basierte darauf, daß ILVA über die Börse teilprivatisiert werden sollte und somit private Investoren dem Unternehmen auch Kapital zuführen würden. Da ILVA jedoch 1991 Verluste erwirtschaftet hatte, wurde die Börseneinführung aufgrund des italienischen Aktienrechts unmöglich und die Argumentation der Regierung hinfällig.

171 Vgl. Hill/Graham/Genillard 1993, S. 18.

172 Schaub 1993, S. 39.

173 Vgl. Rodger/Genillard/Graham 1994, S. 1f.

174 Vgl. Lemaitre 1993 und Rodger/Genillard/Graham 1994, S. 1f., sowie EUROPE 1994. Stattdessen drohen einige private Stahlproduzenten mit einer Klage vor dem EuGH gegen die Beihilfegenehmigungen für ihre staatlichen Konkurrenten. Vgl. Tucker/Peel/Baxter 1994, S. 2. Zur Rettung des Kapazitätsabbauplanes wurden zwischenzeitlich zusätzliche Beihilfen für private italienische Produzenten im Gegenzug für partielle Schließungen einzelner Werke diskutiert, obwohl dies in Konflikt zum Stahlkodex zu stehen schien. Vgl. Tucker 1994, S. 2. 
Tab. 4.3-9

Beihilfen für staatliche Stahlunternehmen 1993

\begin{tabular}{lc|rr|r} 
Unternehmen & MS & $\begin{array}{r}\text { Beihilfe } \\
\text { in MECU }\end{array}$ & $\begin{array}{r}\text { Kapaz.reduktion } \\
\text { in Tsd. Tonnen }\end{array}$ & $\begin{array}{r}\text { Relation Schließung } \\
\text { zu Beihilfe T/MECU }\end{array}$ \\
\hline EKO-Stahl** & $\mathrm{D}$ & 474 & 361 & 761,60 \\
Freital & $\mathrm{D}$ & 140 & 160 & 1142,86 \\
CSI & $\mathrm{E}$ & 2817 & 2300 & 816,47 \\
Sidenor & $\mathrm{E}$ & 515 & 439 & 852,43 \\
ILVA* $_{\text {Sider. Nacion. }}$ & $\mathrm{I}$ & 2585 & 2000 & 773,69 \\
Summe & $\mathrm{P}$ & 306 & 140 & 457,52 \\
& & 6837 & 5400 & 789,82
\end{tabular}

* Basiert auf Stillegungen von 1,2 Mio. $\mathrm{T}$ in Taranto, weiteren $500.000 \mathrm{~T}$ durch den zukünftigen Erwerber von Taranto und weiteren $300.000 \mathrm{~T}$ (von der Kommission angesetzter Wert) für das derzeit ruhende Werk in Bagnoli.

** Neues Konzept nach der Übernahme durch Cockerill-Sambre. Zusätzlich erhält EKO regionale Investitionsbeihilfen.

Quellen: Hill 1993, und EG, Kommmission 1994e.

\subsubsection{Außenwirtschaftliche Absicherung der Subventionspolitik}

\subsubsection{Importrestriktionen der Gemeinschaft}

Ziel der verschiedenen Krisenmaßnahmen der Gemeinschaft und auch der Subventionskodizes war die Sicherung der Lebensfähigkeit der gemeinschaftlichen Stahlindustrie über eine Reduktion der Angebotsmengen mittels Kapazitätsabbau und über administrativ verfügte Preiserhöhungen. Diese Strategie wäre bei offener außenwirtschaftlicher Flanke zum Scheitern verurteilt gewesen 175 . Daher wurden nach ersten informellen Vereinbarungen zwischen den japanischen und europäischen Stahlproduzenten in den Jahren 1975/76176 bereits im Gefolge des Davignon-Planes ab Januar 1978 mit den 15 wichtigsten Lieferländern, u.a. Japan, sog. freiwillige Selbstbeschränkungsabkommen (voluntary export restraint - VER) geschlossen. Diese verpflichteten die Länder, einerseits ihre Exporte in die EG zu beschränken, andererseits nicht unterhalb der Intra-EG-Referenzpreise anzubieten 177. Produkte aus Ländern, die diese VERs nicht unterzeichneten, wurden durch eine variable

175 Vgl. Krägenau 1986, S. 43.

176 Vgl. Malmgren 1978, S. 215.

177 Vgl. Bartling 1984a, S. 489, und Krägenau 1986, S. 42/43. Als Anreiz zur Einhaltung der Preisregeln mußten die ausländischen Lieferanten Garantiebeträge hinterlegen, die bei Verstoß gegen die Vorschriften verfielen. Vgl. Lösch 1984, S. 53. Zum Verhandlungsablauf vgl. Fendel 1981, S. 442-444. 
Importabgabe auf den sog. Basispreis hochgeschleust, der weit über den Referenzpreisen lag und somit de facto zu einem Ausschluß dieser Importe führte ${ }^{178}$. Hinzu kamen erfolgreiche Dumping-Klagen von EUROFER ${ }^{179}$. Auf diese Weise konnte der Anstieg des Importanteils gedämpft werden, gleichzeitig verminderte sich jedoch der Umstrukturierungsanreiz für die Gemeinschaftsproduzenten. Zudem wurden die Preise für Stahlverbraucher künstlich erhöht und damit ihre Wettbewerbsfähigkeit gemindert 180 ; Emerson et al. ${ }^{181}$ machen allerdings darauf aufmerksam, daß dennoch die Stahlpreise innerhalb der EG deutlich unter denen in den USA und Japan lagen. Schließlich konnten potentielle Lieferländer in die EG entweder ihre Exporte auf andere Märkte umlenken und dort Gemeinschaftsproduzenten verdrängen oder, falls ihnen dies nicht gelang, aufgrund ihrer fallenden Exporte auch weniger aus der EG importieren ${ }^{182}$. Trotz dieser Nachteile wurden die Importbeschränkungen beibehalten und in der Krisenphase der frühen $80 \mathrm{er}$ Jahre noch verschärft ${ }^{183}$. In den vergangenen Jahren kam es zu stufenweisen Lockerungen für einzelne Länder, doch sollten erst Ende 1992 alle diese Abkommen auslaufen, einschließlich der Quotierungen, die auf einzelne MS bezogen sind, die in einem Binnenmarkt ohnehin nicht gehalten werden könnten 184 . Aufgrund der aktuellen Krisensituation und der sprunghaft ansteigenden Importe aus Osteuropa wurde nunmehr jedoch beschlossen, Importe aus der Tschechischen Republik und der Slowakei Einfuhrquoten zu unterwerfen und mit den anderen osteuropäischen Stahlproduzenten, v.a. in Ungarn, Polen und Rußland, Selbstbeschränkungen zu vereinbaren, indem mit Anti-dumpingZöllen gedroht wird 185 .

\subsubsection{Beschränkungen der EG-Stahlexporte}

Neben einer Beschränkung der Importe zur Absicherung des höheren Preisniveaus in der EG erwies sich im Zuge des zunehmenden Interventionismus auch eine Kontrolle des Stahlexports als notwendig. Die durch die Quotenregelung (s.u. Abschn. 4.3.6.1) künstlich verknappten Inlandsmengen erlaubten den Unternehmen nämlich,

178 Vgl. Tsoukalis/Strauss 1985, S. 211, 217, 219, Herdmann/Weiss 1985, S. 106, und Curzon Price 1981, S. 88/89.

179 Vgl. Kriwet 1987, S. 42

180 Vgl. Krägenau 1986, S. 72f.; s. auch Abschn. 4.3.6.5.

181 1988, S. 92/93. Ebenso Tsoukalis/Strauss 1985, S. 223.

182 Vgl. Curzon Price 1981, S. 94, und Dicke et al. 1987, S. 69.

183 Vgl. Gerstenberger et al. 1985, S. 64/65, Krägenau 1986, S. 56.

184 Vgl. EG, Kommission 1992, S. 358f

185 Vgl. Paoloni 1993, und The Economist 1992e, S. 91, sowie 1992b, S. 79. Die Preise dieser Produzenten liegen im Durchschnitt um ca. 20\% unter den EGKS-Preisen. 
hier höhere Preise zu erheben, um so eine Abdeckung der Kapitalkosten zu sichern. Auf den Exportmärkten konnte hingegen fast zu Grenzkosten angeboten werden, um so eine höhere Auslastung und damit fallende Durchschnittskosten zu erreichen. Eventuell auftretende Verluste aus Exportgeschäften konnten dann im Rahmen des 2. Kodex über Betriebsbeihilfen wieder ausgeglichen werden. Da hierdurch zum einen die Umstrukturierung weiter verzögert worden wäre, zum anderen sich der Beihilfenwettbewerb lediglich auf den Weltmarkt verlagert hätte, trat die Kommission diesem Problem mit einer integrierten Quotenregelung unter Einschluß der Exporte entgegen 186.

Diese Vorgehensweise war jedoch nicht allein intern motiviert, sondern erwies sich auch durch den Druck der Hauptexportmärkte der EG, vor allem der USA, als notwendig187. Aufgrund der extrem veralteten Strukturen der US-Stahlindustrie (z.T. existierten noch Anlagen aus dem Jahre 1890188) traf die Stahlkrise die USProduzenten besonders hart, so daß bereits Ende der 70er Jahre Gespräche über eine Reduktion der EG- und japanischen Exporte in die USA stattfanden, die allerdings ohne Ergebnis blieben ${ }^{189}$. Nachdem von 1981 auf 1982 die Rohstahlerzeugung in den USA um $40 \%$ gefallen war (vgl. Tab. 4.3-1), nahm der Druck der US-Stahlindustrie auf die eigene Regierung mittels Dumping- und Subventionsklagen gegen Importe zu. Im Gegenzug zu einem Rückzug dieser Klagen unterzeichnete die EG 1982 ein VER, das ihren Marktanteil bei 10 Produktgruppen auf durchschnittlich $5,75 \%$ beschränkte und einer Reduktion der Exporte um $9 \%$ gleichkam ${ }^{190}$. Diese VERs wurden im Laufe der Krise noch auf weitere Produkte ausgedehnt ${ }^{191}$, wobei

186 Vgl. Herdmann/Weiss 1985, S. 104, 110f., und Tsoukalis/Strauss 1985, S. 212.

187

Vgl. Krägenau 1986, S. 45, und Herdmann/Weiss 1985, S. 104. Dieser Druck erhöhte sich noch dadurch, daß die EG sich gegen Importe aus diesen Ländern abschottete. Vgl. oben Abschn. 4.3.5.1 und Curzon Price 1981, S. 92.

$188 \mathrm{Vgl}$. Fendel 1981, S. 421. Diese veralteten Strukturen erklären Geroski/Jacquemin (1985, S. 181, 183-86) mit den bestehenden Marktzugangsbarrieren in den USA und den existierenden Preiskoordinationsmechanismen, die den Firmen eine gewisse Profitabilität garantierten, ohne Anreize zur Innovation zu setzen.

189 Bereits von 1969-1974 hatten VERs für Exporte in die USA existiert. Vgl. Krägenau 1986, S. 58/59, und Anjaria et al. 1982, S. 19.

190 Vgl. EG, Kommission 1983, S. 100, EG, Bulletin 1982a, S. 14/15, und Tsoukalis/Strauss 1985, S. 219. Ursprünglich hatten die USA differenzierte Strafzölle je nach Subventionsgrad erheben wollen, der die Niedrigsubventionsländer der EG, wie z.B. Deutschland und die Niederlande, weniger getroffen hätte. Das VER führte also zu einer Umverteilung der Opfer innerhalb der EG zu den Niedrigsubventionsländern! Vgl. Krägenau 1986, S. 54, 60f., und zu den vorgesehenen Strafzöllen Anjaria et al. 1982, S. 20, sowie Müller 1983, S. 239.

191 Vgl. Lösch 1984, S. 53f. Die EG führte im Gegenzug Vergeltungsmaßnahmen ein. 
der Importrestriktionseffekt z.T. durch zusätzliche Importe aus nicht kontingentierten Lieferländern unterlaufen wurde 192. Dennoch wurden sie mehrfach verlängert und erst in Etappen bis zum 31.3.1992 abgeschafft ${ }^{193}$. Auf Beschwerden der amerikanischen Stahlproduzenten hatte die US-Regierung im vergangenen Jahr vorläufige Anti-Subventionszölle gegen Stahlimporte aus einigen MS eingeführt, deren Höhe aufgrund der Beihilfen der letzten 15 (!) Jahre berechnet worden waren. Gegen diese Zölle beantragte die Gemeinschaft die Ingangsetzung des Konsultationsund Beschwerdeverfahrens im GATT; die meisten dieser Zölle wurden jedoch von den USA nach Prüfung der Beschwerden ohnehin aufgehoben 194.

\subsubsection{Internationale Ansätze zur Subventionskontrolle}

Mit dem Auslaufen der mengenmäßigen Importbeschränkungen auf den beiden größten Stahlverbrauchsmärkten, USA und EG, bestand nunmehr die erneute Gefahr, daß im Falle krisenhafter Entwicklungen der Branche die Industrieverbände über Anti-Subventionsklagen versuchen würden, eine Protektion der inländischen Produzenten zu erreichen. Diesem Risiko traten die USA und die EG entgegen, indem sie 1989 eine bilaterale Vereinbarung über die Zulässigkeit verschiedener Typen staatlicher Beihilfen vereinbarten, die auf der Grundlage des 3. und 4. Kodex der Gemeinschaft erfolgte. Ihr Auslaufen am 31.3.1992 führte bereits 1990 zur Aufnahme von Verhandlungen am Rande der GATT-Gespräche mit dem Ziel, ein multilaterales Stahlabkommen unter Einschluß von 12 weiteren Stahlproduzenten zu erreichen. Hierbei sollen die GATT-Subventionsregeln für den Stahlsektor verschärft werden, wobei wiederum der EG-Stahlbeihilfenkodex als Vorbild gilt 195 . So sollen lediglich Beihilfen für Forschungszwecke196, Schließungsbeihilfen einschl. Abfindungszahlungen und Umweltschutzbeihilfen unter Bedingungen erlaubt sein, die denen des aktuellen Kodex ähnlich sind. Zudem sollen staatliche Exportbürgschaften und -versicherungen gestattet sein. Im Gegenzug sollen Zölle und nicht-tarifäre Han-

192 GATT 1987, S. 53-56.

193 Vgl. The Economist 1992, S. 101/102. In diesem Artikel wird auf die erfolgreiche Umstrukturierung der US-Stahlindustrie hingewiesen, ihre Ursache aber in inneramerikanischer Konkurrenz und der Unattraktivität des US-Marktes für ausländische Konkurrenten aufgrund des schwachen Dollars gesehen. Der letzte Aspekt führte dazu, daß nach 1985 Ausländer ihre Quoten nicht mehr ausfüllten.

195 Vgl. EG, Kommission 1992a, S. 140, und 1992, S. 358f.

196 Gegen den Einschluß von Beihilfen für Entwicklungszwecke bestand zunächst heftiger Widerstand der USA. Schließlich wurde ein Kompromiß diskutiert, der diesen Beihilfentyp unter sehr restriktiven Bedingungen genehmigte. 
delshemmnisse stufenweise abgebaut werden. Wie oben dargelegt, spielten vor allem letztere eine dominante Rolle im Welt-Stahlhandel. Auch Verfahren zur Streitbeilegung sind Teil des Konsenses. Eine Verabschiedung des Konsens nähme der Kommission die Möglichkeit der Gewährung von Ausnahmegenehmigungen wie im Fall ILVA/Finsider und verstärkte somit extern die Beihilfendisziplin. Auf der anderen Seite würden die Subventionen klar in akzeptable und verbotene gegliedert, so daß es keine Kategorie "unter Umständen erlaubter" Beihilfen gibt, die den Regierungen diskretionären Handlungsspielraum und damit auch Mißbrauchsmöglichkeiten bieten. Somit erhöhte sich die Rechtssicherheit. Die Verhandlungen zu diesem Konsens scheiterten jedoch zunächst im März 1992 an der Forderung der USA, auch gegen akzeptable Subventionen Gegenmaßnahmen ergreifen zu können. Danach führten die USA, wie oben erläutert, vor allem auf Druck der Produzenten zeitweise Sonderzölle für Stahlimporte ein 197 . Die Wiederaufnahme der Verhandlungen führte bis jetzt zu keinem Ergebnis 198 .

Im EWR-Abkommen mit den EFTA-Staaten ist eine Übernahme der EGKS-Beihilferegeln durch die EFTA vorgesehen, während die Abkommen mit Ungarn, Polen und den Tschechischen und Slowakischen Republiken eine dreijährige Übergangsfrist für diese Staaten vor der Einführung der Wettbewerbsregeln der Gemeinschaft vorsehen und sogar für weitere 5 Jahre diesen Staaten gestatten, Umstrukturierungsbeihilfen zu gewähren 199 .

\subsubsection{Beurteilung der Subventionskontrollpolitik}

\subsubsection{Die Entwicklung der EG-Stahlindustrie seit dem Krisenausbruch}

Wie Tab. 4.3-1 zeigt, fiel die Walzstahlproduktion der EG nach dem ersten Einbruch 1975 von ihrem Zwischenhoch 1979 zunächst aufgrund der erneuten Rezession mit sinkender Stahlnachfrage im Gefolge des 2. Ölpreisschubs rapide $a b^{200}$ und erreichte 1983 ihren Tiefpunkt, der um mehr als 20\% unter dem Wert von 1979 und um mehr als $25 \%$ unter dem absoluten Spitzenwert von 1974 lag. Im folgenden Aufschwung wurden die Produktionsmengen von 1979 und 1974 erst 1988 bzw. 1989 wieder überschritten. Trotz dieser massiven Schwankungen der Gesamterzeugung

\footnotetext{
197 Vgl. The Economist 1992c, S. 74. Tatsächlich sind die jüngsten Probleme amerikanischer Stahlhersteller v.a. auf die Inlandskonkurrenz kleiner Produzenten zurückzuführen, während 198 Vgl. Williams 1993, S. 6, und EG, Kommission 1994a, S. 253.

199 Vgl. EG, Kommission 1992a, S. 140/141.

200 Vgl. Krägenau 1986, S. 45.
} 
blieben die Anteile der MS während der gesamten Phase fast konstant (vgl. auch Tab. 4.3-10). Neben der dargelegten hohen Subventionierung der schwächeren Unternehmen durch die jeweiligen MS (hierzu beurteilend die folgenden Abschn. 4.3.6.2-4) ist dies vor allem auf das schon mehrfach erwähnte, 1980 eingeführte Quotensystem zurückzuführen.

Tab. 4.3-10

Anteile einzelner MS an der EG-Walzstahlerzeugung* (in \%)

\begin{tabular}{c|ccccccc} 
Jahr & D & B & F & UK & I & L & NL \\
\hline 1984 & 32,7 & 8,7 & 17,1 & 12,2 & 21,8 & 3,3 & 3,5 \\
1985 & 33,5 & 8,5 & 16,8 & 12,1 & 21,5 & 3,4 & 3,4 \\
1986 & 32,7 & 8,1 & 16,6 & 12,8 & 22,1 & 3,5 & 3,3 \\
1987 & 31,9 & 8,0 & 16,5 & 14,1 & 22,2 & 3,1 & 3,3 \\
1988 & 32,2 & 8,6 & 15,8 & 14,5 & 21,7 & 3,2 & 3,2 \\
1989 & 32,2 & 8,2 & 15,6 & 14,4 & 22,1 & 3,1 & 3,4 \\
1990 & 30,9 & 8,9 & 15,9 & 14,2 & 22,6 & 3,2 & 3,5 \\
1991 & 33,1 & 8,5 & 15,3 & 13,2 & 22,7 & 2,9 & 3,5 \\
1992 & 32,4 & 10,1 & 14,9 & 13,1 & 22,2 & 2,5 & 4,1 \\
1993 & 31,8 & 9,9 & 14,3 & 14,0 & 22,2 & 2,7 & 4,2
\end{tabular}

* Prozentwert jeweils bezogen auf Summe der EG-9, also ohne GR, E und P.

Quelle: Wirtschaftsvereinigung Eisen- und Stahlindustrie 1994, S. 92.

Wie bereits oben (vgl. Abschn. 4.3.2.1.) erläutert, hatte die Kommission zunächst versucht, mit dem weicheren Instrumentarium des EGKS-Vertrages (Orientierungspreise und freiwillige Lieferquoten) den Stahlmarkt zu stabilisieren.

Nachdem aber das EUROFER-Kartell, das diese Politik unterstützt hatte, im Streit der Mitglieder über die Verteilung der Produktionsmengen mit dem Ausscheiden der Klöckner-Werke und auch von Italsider zerbrochen war ${ }^{201}$ und ein erneuter Preiskrieg einsetzte, der die gesamten Verluste der EG-Stahlindustrie auf 20 Mio. \$ pro Tag steigen ließ202, erklärte die Kommission zum 31.10.1980 mit Zustimmung des Rates nach Überwindung des anfänglichen deutschen Widerstandes durch Zugeständnisse bei Spezialstählen die "offensichtliche Krise" nach Art. 58 EGKSV, was die Zuteilung von Zwangsquoten einschloß203. Die Quoten wurden quartalsweise festgelegt, schlossen eine Kontrolle der Exporte ein und basierten auf der Durch-

201 Vgl. Geister 1981, S. 146, sowie Bartling 1984a, S. 489.

$202 \mathrm{Vgl}$. Curzon Price 1981, S. 89f.

203 Vgl. Curzon Price 1981, S. 89/90, und 1990, S. 171, sowie Tsoukalis/Strauss 1985, S. 218. 
schnittsproduktion der Jahre 1977-80. Ihre Überschreitung wurde mit Geldbußen geahndet ${ }^{204}$. Während das System ursprünglich auf 8 Monate begrenzt und auf Rohstahl und einige Walzstahlprodukte beschränkt war, wurde es in der Folgezeit angesichts der Krisenverschärfung und der Unfähigkeit der Stahlindustrie, eine freiwillige Regelung zu vereinbaren, parallel zur Erneuerung der Beihilfekodizes mehrfach verlängert, um verpflichtende Mindestpreise ergänzt und auf fast alle Walzstahlprodukte ausgedehnt, so daß zeitweise 70\% der EG-Walzstahlproduktion der Quotierung unterlagen ${ }^{205}$. Erst mit der deutlichen Verbesserung der Marktlage ab 1986 kam es zur stufenweisen Herausnahme einzelner Produktgruppen aus der Quotenregelung206. Schließlich machten Rat und Kommission ihre Zustimmung zu einer weiteren Verlängerung von Umstrukturierungs- und Schließungszusagen der Unternehmen abhängig, deren notwendige Höhe von den drei Stahlweisen auf 16 Mio. $t$ geschätzt wurde 207. Da diese in der günstigen Marktlage des Jahres 1988 nicht mehr in aus Sicht der Kommission ausreichender Höhe erfolgten, hob sie das Quotensystem zum 30.6.1988 endgültig auf208.

In der Krisenphase bis Mitte der 80er Jahre stellte das Quotensystem für die MS und Stahlunternehmen eine Art Garantie dafür dar, daß Kapazitätsabbau nicht zu einem Verlust an Marktanteilen führen würde, da eine Expansion der Konkurrenten durch die Quotierung unterbunden wurde 209 . Der Umstrukturierungswille wurde so möglicherweise erhöht. Auf der anderen Seite führten die durch Quoten und Importrestriktionen bedingten Preis- und Marktanteilserhöhungen in der Gemeinschaft zu einer Verbesserung der Finanzlage der Unternehmen, die ihnen ein Durchhalten der Überkapazitäten für die Zeit nach dem Quotensystem erlaubte210.

\footnotetext{
204 Vgl. Bartling 1984a, S. 489, und Stotz 1983, S. 69-71. Diese Geldbußen wurden jedoch nicht konsequent eingetrieben. Vgl. Jürgensen 1984, S. 130, und Colombo/Friderichs/Mayoux 1987, S. 7.

205 Die restlichen Produktbereiche wurden vom sog. EUROFER-Il-Kartell kontrolliert. Vgl. Bartling 1984a, S. 490, und Tsoukalis/Strauss 1985, S. 218. 1983 wurden auf deutsche Intervention vorübergehend sogar regionale Intra-EG-Lieferquoten festgesetzt und der GM somit aufgehoben. Vgl. Dicke et al. 1987, S. 66, und Wirtschaftsvereinigung Eisen- und Stahlindustrie 1984, S. 7f. Zum Teil wurden die Quoten auf politischen Druck hin auch zugunsten einiger Produzenten v.a. in Italien geändert, wodurch das System seiner angestrebten Objektivität und Transparenz beraubt wurde. Vgl. Jürgensen 1984, S. 130.

206 Vgl. EG, Kommission 1986, S. 144, und 1988, S. 135/36.

207 Vgl. Colombo/Friderichs/Mayoux 1987, S. 8.

208 Vgl. EG, Kommission 1989, S. 150/151, und Kriwet 1987, S. 42.

209 Vgl. Colombo/Friderichs/Mayoux 1987, S. 5.

210 Vgl. Neumann 1984, S. 17, und Colombo/Friderichs/Mayoux 1987, S. 6.
} 
Die Quoten gaben aber auch den wenig subventionierten Produzenten, wie etwa den deutschen und niederländischen, die Sicherheit, durch die Subventionen der anderen MS nicht vom Markt verdrängt zu werden211. Dies minderte zwar ihren Widerstand gegen Beihilfen, auf der anderen Seite erhielten jedoch die Hochsubventionierer zwar eine Überlebensgarantie, wurden aber um den "Ertrag" ihrer Beihilfen gebracht, was möglicherweise deren Begrenzung und vor allem die Begrenzung der Verzerrung von Wettbewerb und Intra-EG-Handel erleichterte 212. Angesichts dennoch weiterbestehender Beihilfen in einigen MS überrascht es jedoch nicht, daß gerade die deutschen Stahlunternehmen der Aufhebung der Quoten bis zuletzt den stärksten Widerstand entgegenstellten, da sie um ihre Position fürchteten 213 , insbesondere dann, wenn die Konkurrenzunternehmen mit Hilfe ihrer höheren Beihilfen durch Investitionen ihren Wettbewerbsrückstand aufholen konnten 214 .

Die Befürchtungen der weniger stark subventionierten Stahlunternehmen, daß in der Krise der frühen 80er Jahre ohne das Quotensystem ein Verdrängungswettbewerb zu ihren Lasten stattgefunden hätte, waren in jener Phase sicherlich berechtigt gewesen; die Aufhebung des Quotensystems 1988 in einer günstigeren Lage und bei strengeren Beihilfevorschriften bestätigte diese Befürchtungen jedoch nicht. Vielmehr gewann die deutsche Stahlindustrie 1988, 1989 und 1991 im Vergleich zu 1987 leicht an Marktanteilen, während sich bei den anderen Ländern, abgesehen von Frankreich, wenig veränderte (Tab. 4.3-10). Gleichzeitig blieb bis 1992 das Walzstahlproduktionsniveau in der Gemeinschaft auf hohem Niveau stabil, und die Auslastung hielt sich oberhalb der kritischen 70\%-Marke.

Auch die Aufhebung der Krisenmaßnahmen brachte allerdings keine völlige Liberalisierung: Zwar werden im Rahmen des Binnenmarktprogramms Wettbewerbshemmnisse bei der Energieversorgung, im Transport- und Versicherungsbereich sowie auf den Kapitalmärkten aufgehoben, wodurch auch den Stahlproduzenten Kostenersparnisse zuwachsen, jedoch besteht weiterhin eine Überwachung bzgl. Einfuhren, Preisen und Produktionsmengen ${ }^{215}$. Curzon Price 216 spricht hier im Zusammenhang mit dem Widerstand der EG-Stahlproduzenten gegen eine Aufhebung des Importschutzes von einem klassischen Fall von Rent seeking. Zudem

211 Vgl. Krägenau 1986, S. 53.

212 Vgl. Kriwet 1989, S. 39, und Dicke et al. 1987, S. 68.

213 Vgl. Kriwet 1987, S. 42, und Wirtschaftsvereinigung Eisen- und Stahlindustrie 1987a, S. 5.

214 Vgl. Krägenau 1986, S. 53, 72, und unten Abschn. 4.3.6.4.

215 Vgl. EG, Bulletin 1988, S. 20.

216 1990, S. 172. 
konstatiert auch die Kommission 217 immer noch bestehende potentielle Überkapazitäten und die Notwendigkeit von Strukturanpassungen für einige Unternehmen. Ihre Prognosen für 1995 sehen die Auslastung der Walzstahlkapazität zwar über der kritischen 70\%-Marke, doch läßt die augenblickliche Krise der Branche in wichtigen Industriestaaten daran eher Zweifel aufkommen. Gegenwärtig bewegen sich u.a. wegen des Preisverfalls um 30\% die meisten großen Stahlproduzenten wieder in der Verlustzone, und es wird davon ausgegangen, daß noch einmal 50.000 Arbeitsplätze und 30-40 Mio. $\mathrm{t}$ Überkapazitäten abgebaut werden müssen. In Deutschland sind der Konkurs von Saarstahl, der Vergleichsantrag von Klöckner, das überschuldet ist und unter Standortnachteilen leidet, da das Stahlwerk in Bremen vergleichsweise weit von den Kokereien im Ruhrgebiet entfernt liegt, von denen die deutschen Produzenten einen Teil ihres Koksbedarfs decken müssen, und die Fusion von Krupp und Hoesch Zeichen der Probleme218, auf der europäischen Ebene zeigen die erneut beschlossenen hohen Beihilfen (vgl. Abschn. 4.3.4.2) das Ausmaß der erneuten Krise.

\subsubsection{Die Entwicklung des Subventionsniveaus}

Analog zur Vorgehensweise beim Schiffbau soll die Analyse der gemeinschaftlichen Subventionskontrolle mit der Frage begonnen werden, ob es mittels eines Abbaus der Subventionen gelang, Verzerrungen gegenüber anderen Branchen zu vermindern. Wiederum muß die Antwort eher skeptisch ausfallen. Auch in diesem Industriezweig waren die Subventionvolumina stark mit der generellen und der Branchenkonjunktur korreliert. In den Krisenphasen 1975-79 und 1980-85 wiesen die Beihilfen mit 10,2 Mrd. ECU und 36,4 Mrd. ECU ein enormes Volumen auf. Erst ab 1986 zeigt sich mit dem Abflauen der Stahlkrise auch ein gewisser Rückgang der Subventionsbereitschaft, so daß von 1986-91 lediglich 6,5 Mrd. ECU beantragt und genehmigt wurden. Auch hier gelang es also im innergemeinschaftlichen politischen Prozeß nicht, den ineffizienzfördernden Subventionswettlauf in der Krise anzuhalten 219 .

Bei der Betrachtung der Tabellen 4.3-6 bis 4.3-8 zeigt sich, daß sich die Subventionierung der Industrie vor allem auf die Länder Frankreich, Italien, Großbritannien

217 Vgl. EG, Kommission 1990d, S. 22. Problematisch ist hierbei, daß die Produzenten wohl tendenziell ihre Kapazitäten überschätzen, da dies unter dem Quotenregime und bei Umstrukturierungsauflagen für sie günstig war. Vgl. Vondran 1987, S. 11.

219 Gerstenberger et al. (1985, S. 63, 148) sprechen davon, daß der Wettbewerb der Unternehmen durch einen solchen der Staatskassen ersetzt wurde. 
und (im Verhältnis zur Produktionskapazität) auch Belgien konzentrierte. Dies ist sicherlich nicht zuletzt darauf zurückzuführen, daß in diesen Ländern große Stahlwerke eines relativ niedrigen Modernitätsgrades dominierten, die wiederum Produktivitätsrückstände aufwiesen. Die daraus resultierenden Verluste auf dem Markt für ein relativ homogenes Produkt wurden dann durch hohe Betriebsbeihilfen ausgeglichen, die strukturkonservierend wirken und den Großteil der insgesamt gezahlten Hilfen ausmachen 220 . Dies gilt nicht für Länder wie Deutschland und Luxemburg, in denen Schließungs- und Investitionsbeihilfen dominierten, also wesentlich stärker auf Umstrukturierung und Rationalisierung gesetzt wurde. In geringerem Maße gilt dies auch für die Niederlande und Großbritannien (s. Tab. 4.3-6).

Die immer noch hohe industrielle Bedeutung der Branche und ihre Verflechtung mit anderen Industriezweigen sowie ihre z.T. regional hochkonzentrierte Rolle als Arbeitgeber erklären auch einen Teil der staatlichen Interventionsbereitschaft 221 . Erneut ist auch hier der hohe Organisationsgrad der Arbeitnehmer als Einflußfaktor zu nennen.

Wiederum spielt die Eigentümerstruktur eine wichtige Rolle bei der Festlegung der Haltung einzelner MS zur Subventionierung. Während in den erstgenannten MS die Stahlwerke bereits vor Ausbruch der Krise in staatlichem Besitz waren oder in ihrer Frühphase verstaatlicht wurden 222 , handelte es sich in den anderen MS um Privatbetriebe. Die staatlichen Eigner waren stets bereit, "ihre" Unternehmen weiter zu unterstützen 223 . Hierbei wurden vor allem Kapitalzuführungen, Umwandlung von Krediten in Eigenkapital, Verzicht auf Dividenden und Kreditgarantien eingesetzt $^{224}$. Dabei spielten unterschiedliche Leitbilder und traditionelle Interventionsintensitäten in den einzelnen Ländern eine Rolle225; staatliche Lenkung der Wirtschaftsstruktur mit der Betrachtung der Stahlindustrie als strategische Branche zur Unterstützung der Entwicklung eines Landes und auch die militärische Rolle der

220 Vgl. Krägenau 1986, S. 53.

221 Vgl. Tsoukalis/Strauss 1985, S. 213, Esser et al. 1982, S. 285, und Meny/Wright 1987, S. 20 , 24-26. Den Extremfall stellte sicherlich Luxemburg dar, wo der ARBED-Konzern allein 10\% des BSP erwirtschaftete und die Regierung für ein Hilfsprogramm an das Unternehmen sogar umfassende Steuererhöhungen beschloß.

222 Vgl. Esser et al. 1982, S. 281, Krägenau 1986, S. 43f., und Tsoukalis/Strauss 1985, S. 213.

223 Vgl. Curzon Price 1981, S. 90f.

224 Vgl. dazu im Detail Mutti 1982, S. 27-30.

225 Meny/Wright (1987, S. 40-42) illustrieren und kontrastieren diese. Krägenau (1986, S. 27-37) zeigt ihre Wirkung in der Phase bis zum Krisenausbruch. 
Stahlindustrie sind hier zu nennen 226 . MS mit anderer ordnungspolitischer Ausrichtung und privaten Stahlunternehmen hingegen, wie z.B. Deutschland und die Niederlande, standen einer großzügigen Förderung eher ablehnend gegenüber, wobei im Falle Deutschlands diese Position nach 1981 aufgeweicht wurde und zudem aufgrund der massiven Hilfen für ARBED Saarstahl und in jüngster Zeit für die ostdeutschen Stahlunternehmen an Glaubwürdigkeit einbüßte227.

Das ordnungspolitische Grundkonzept einer Regierung reicht jedoch als Erklärung des Subventionsverhaltens nicht aus, denn häufig standen viel direktere politökonomische Motivationen hinter einzelnen Subventionsentscheidungen: So führten anstehende Wahlen mit einem erwarteten knappen Ausgang häufiger zu Hilfsprogrammen der Regierungen, so z.B. in Großbritannien 1983, Deutschland 1980, Belgien und Frankreich 1978228. Selbst im Großbritannien der Thatcher-Ära wurde also die ordnungspolitische Grundposition der Regierung wahltaktischen Kalkülen geopfert und der Staatskonzern BSC mit hohen Betriebsbeihilfen unterstützt und schließlich vor der Privatisierung noch entschuldet, so daß er schließlich einen Eigenkapitalanteil an der Bilanzsumme von $70 \%$ aufwies, wodurch seine Zinslast diejenigen der Konkurrenten erheblich unterschritt 229 .

In einigen MS gingen jedoch die politökonomischen Motive zur Subventionierung der Industrie noch weit über das unmittelbare wahltaktische Kalkül hinaus, da in diesen Ländern Industrien wie Stahl eine wichtige Rolle beim "Erhalt einer prekären nationalen Stabilität spielen"230. Dies bedeutet, daß hier regionalwirtschaftlich wichtige Stahlwerke in politisch unruhigen oder potentiell instabilen Regionen am Leben gehalten wurden, um so eine mögliche Staatskrise abzuwenden. Als Beispiele

226 Vgl. Curzon Price 1981, S. 91, und Tsoukalis/Strauss 1985, S. 212f. Meny/Wright (1987, S. 23f.) sprechen hier von psycho-nationalen Gründen, die allerdings in allen MS wirksam waren und auch eine lange historische Tradition besaßen.

227 Vgl. Fendel 1981, S. 452, und Wienert 1988, S. 139, sowie Abschnitt 4.3.4.2. Diese Unternehmen befanden sich allerdings auch zum Teil in Staatsbesitz. Letztlich ist Meny/Wright (1987, S. 38f.) sicherlich zuzustimmen, daß Großunternehmen in einem derartigen Sektor 228 Vgl. Meny/Wright 1987, S. 28f.

229 Vgl. Kriwet 1987, S. 42, und Wirtschaftsvereinigung Eisen- und Stahlindustrie 1987, Anl. 14. Eine gegen die Kommissionsentscheidung zur Akzeptanz dieser Beihilfen erhobene Klage der Wirtschaftsvereinigung Eisen- und Stahlindustrie, die die Beihilfen im Sinne der Regeln des Kodex als überhöht ansah und auch die Zahlung ungenehmigter Beihilfen monierte, wurde vom EuGH wegen Fristversäumnissen der Anfechtung als unzulässig abgewiesen. Vgl. EuGH 1990, S. 4413-4443, insbesondere 4436-4443.

230 Warnecke 1978a, S. 152. (Übersetzung des Verfassers) 
seien hier Belgien (Wallonie), Schottland (Ravenscraig) oder der Mezzogiorno (Stahlwerk Bagnoli/Neapel) genannt, wo sich dann auch regionale Koalitionen über Parteigrenzen hinweg bildeten 231 . Da ein solches Vorgehen den Unternehmensinteressen z.T. widersprach, war es natürlich wesentlich leichter gegenüber Staatsbetrieben durchzusetzen (Bsp. Taranto, Italien), wo Regierungen bspw. das Management auswechseln konnten und dies auch taten, was den Erfolg der Betriebe häufig eher zusätzlich behinderte232.

\subsubsection{Erfolge bei der Harmonisierung und Kontrolle?}

Zieht man das absolute Subventionsverbot des Art. 4c EGKS-Vertrag als Maßstab zur Beurteilung der Kontrolltätigkeit der Kommission heran, so muß diese sicherlich als weitgehend gescheitert betrachtet werden, da das Verbot ab Ausbruch der Krise massiv umgangen wurde und diese Umgehung dann auch noch durch die Kodizes legalisiert wurde 233 .

Diese Betrachtungsweise wird jedoch m.E. der Problematik nicht gerecht. Zum einen können gewisse Subventionen, wie z.B. FuE- oder Umweltschutzbeihilfen, aus allokativer Sicht wegen vorhandener externer Effekte unabhängig vom betroffenen Sektor gerechtfertigt werden; im Umweltbereich impliziert dies dann die Anwendung des Gemeinlastprinzips. Die Aufgabe der Kontrolle besteht hier darin, die MS daran zu hindern, andere Subventionen unter diesen Kategorien zu deklarieren. Zum anderen zeigte die politökonomische Analyse im vorherigen Abschnitt, daß es unrealistisch ist, anzunehmen, daß unter den spezifischen Bedingungen dieser Branche eine Behörde wie die Kommission ein absolutes Subventionsverbot in einer tiefen Krise gegen die von den diversen Lobbies beeinflußten nationalen Regierungen durchsetzen kann 234 . Dieser Aspekt fällt bei verstaatlichten Unternehmen, in denen der Staat die Arbeitgeberrolle einnimmt, noch stärker ins Gewicht. Eine einigermaßen erfolgreiche Subventionskontrolle verlangt hier sicherlich eine größere Flexibilität, als sie der EGKSV bietet, wobei gleichzeitig jedoch die Gleichbehandlung der MS zu sichern ist.

Betrachtet man die Tätigkeit der Kommission unter diesem eingeschränkten Maßstab, so fällt die Beurteilung differenzierter aus. Die konstruierte Dichotomie zwischen Art. 4c und Art. 67 EGKSV, auf der die Kontrolle vor dem 1. Kodex beruhte,

231 Vgl. Meny/Wright 1987, S. 29-31, 59f., Caspari 1981, S. 5, sowie Jürgensen 1984, S. 130.

$232 \mathrm{Vgl}$. Meny/Wright 1987, S. 36.

233 Vgl. Kokalj/Albach 1987, S. 274.

234 Vgl. Kutscher 1989a, S. 94f. 
ist aus mehreren Gründen sehr negativ zu beurteilen: So förderte sie zunächst das Ausweichen der MS auf formell regionale und allgemeine Beihilfensysteme, die aber de facto, bspw. aufgrund der Auswahl der Regionen oder der Gewährungsbedingungen, v.a. dem Stahlsektor zugutekamen, und verminderte damit die Beihilfentransparenz und Kontrollmöglichkeit massiv 235. Selbst wenn diese nicht-spezifischen Beihilfen dann jedoch einer Überprüfung nach den Regeln des EGV unterzogen werden konnten, führt dies zu sektoral unerwünschten Ergebnissen. Die Unterstützung einer Erweiterungsinvestition in einer Problemregion, die zur Schaffung neuer Arbeitsplätze führt, mag zwar regionalwirtschaftlich außerordentlich erwünscht sein, findet sie jedoch in einem Krisensektor mit erheblichen Überkapazitäten statt, so verschärft sie lediglich die sektoralen Probleme, verlagert sie bestenfalls in andere MS und führt zu neuem Subventionsbedarf. Diese Inadäquanz wurde auch durch die Regeln des 1. Kodex nicht aufgehoben, der sich ja auf sektorale Subventionen beschränkte und die übrigen weiter der Kontrolle nach dem EGV überließ, zudem auch erst 5 Jahre nach Krisenbeginn und damit sehr spät erlassen wurde236.

Erst mit dem 2. Kodex gelang der Kommission die Einbeziehung aller Beihilfen in ein einheitliches Regelwerk, die sie schon in ihren Vorschlägen für den 1. Kodex angestrebt hatte 237 . Es bedurfte jedoch des Versagens der Kontrolle unter dem 1. Kodex, um den Widerstand der MS gegen eine solche Einschränkung ihrer Handlungsfähigkeit aufzubrechen 238 . Im Gegenzug blieben jedoch die Regeln sehr weich und ließen alle Arten der Subventionierung mit nur geringen Beschränkungen zu239. Ein wirkliches Konzept zur Lösung der Strukturkrise mit Hilfe der Subventionskontrolle entwickelte die Kommission auch erst im Laufe der Anwendung des 2. Kodex, indem sie Beihilfegenehmigungen an vorgegebene Kapazitätsabbauten koppelte und damit die sektoralen Wirkungen in den Vordergrund stellte240. Doch auch hier kam es zu erheblichen Konflikten zwischen den Beteiligten, wie die oben diskutierten Klagen vor dem EuGH zeigten. Zudem spricht die Einführung von Stahl-

235 Vgl. Bartling 1984a, S. 490f.

236 Vgl. Krägenau 1986, S. 48. Bünnagel (1984, S. 96) bezeichnet den 1. Kodex hinsichtich seiner Wirkung lediglich als Transparenzrichtlinie.

237 Vgl. Jürgensen 1984, S. 129.

238 Vgl. Tsoukalis/Strauss 1985, S. 219, 222.

239 Vgl. Krägenau 1986, S. 50. Letztendlich handelte es sich um einen politischen Kompromiß, bei dem Deutschland die Legalisierung der Subventionen und die Hochsubventionsländer gewisse

240 Vgl. Bartling 1984a, S. 492. 
subventionsprogrammen in Deutschland ab 1982 dafür, daß die relativ weichen Regeln des Kodex eher eine Subventionsharmonisierung nach oben förderten 241 .

Eine wirkliche Beschränkung der Subventionierung gelang erst ab dem 3. Kodex, der die genehmigungsfähigen Beihilfen sowohl qualitativ als auch intensitätsmäßig klar begrenzte. Hier kam der Kommission die zunehmend marktwirtschaftliche Orientierung der Regierungen der wichtigsten MS entgegen 242 , allerdings auch die deutliche Verbesserung der Branchenlage, die die regionalen Krisen abschwächte und die während des 2. Kodex erreichten Kapazitätsabbauten wider Erwarten als ausreichend erscheinen ließ.

Jedoch beweist auch die Nach-Krisen-Zeit ab 1986, daß selbst das Vorhandensein strenger und zugleich praktikabler Regeln sowie der Wille der Kommission zu deren Anwendung ihre Durchsetzung nicht immer sichern kann. So wurden im Fall Finsider/ILVA die Regeln des Kodex durch einstimmigen Ratsbeschluß zweimal quasi außer Kraft gesetzt, um das Überleben des Konzerns zu sichern. Zudem bewies die erneute Subventionsnotwendigkeit für dieses Unternehmen auch, daß die Kommission bei der Gewährung umfangreicher Hilfen 1983 ihr eigenes Kriterium, nämlich Erreichung der Rentabilität bis 1985 , nicht sorgfältig angewandt hatte 243 . Die krisenhafte Entwicklung des Sektors 1992/93 führt außerdem bereits wieder zu einer Aufweichung dieses Konsens für eine Beschränkung der Subventionierung, wie die jüngsten Beihilfenentscheidungen des Rates nach Art. 95 EGKSV zeigen.

Dennoch ist eine Wiederholung des Subventionswettlaufs der frühen 80er Jahre trotz der jüngsten Beihilfegenehmigungen eher unwahrscheinlich. Zwei Gründe sprechen für diese Einschätzung. Zum einen ist die Zahl der in der Stahlindustrie in 7 MS Beschäftigten von 740.000 1976 auf nur noch 306.0001992 gefallen $^{244}$, so daß der Druck auf die nationalen Regierungen, hier in großem Umfang rettend einzugrei-

\footnotetext{
241 Vgl. Krägenau 1986, S. 54. Diese Vorgehensweise der Bundesregierung wurde aber selbst vom SVR in der gegebenen Lage akzeptiert, da eine reine Marktlösung unrealistisch erschien. Vgl. SVR 1983, S. 231.

242 Vgl. Krägenau 1986, S. 73f.

243 Dies wird indirekt auch von Caspari (1984a, S. 97f.) bestätigt, der auch im Hinblick auf den in Italien länger als in den anderen MS betriebenen Kapazitätsausbau davon spricht, daß "das große Problem in der Gemeinschaft .. eigentlich nur Italien" sei.

244 Es sind dies die traditionellen großen Stahlländer der Gemeinschaft, also B, D, F, I, L, NL und UK, die den Großteil der Arbeitnehmer beschäftigen. In den anderen MS gab es 199241.300 Beschäftigte in der Stahlindustrie. Insgesamt sind heute lediglich noch 1,5\% der industriellen Arbeitnehmer in der Stahlbranche beschäftigt. Vgl. Wirtschaftsvereinigung Eisen- und Stahlindustrie 1993, S. 98f. und 330, sowie Hitiris 1991, S. 304.
} 
fen, geringer sein wird. Zum anderen bestünde durch die Übernahme der EGSubventionskontrollregeln in einen multilateralen Konsensus eine externe Beschränkung für die Politik der Gemeinschaft, da solche Abkommen schwerer zu ändern sind als EG-Beihilfekodizes. Die Verhandlungen hierzu sind allerdings noch nicht erfolgreich abgeschlossen 245 .

Auch im Falle der Staatskonzerne außerhalb Italiens wurde scharfe Kritik daran geübt, daß sie durch Verlustausgleiche, Kapitalzuführungen und die Umwandlung von Schulden in Kapital unterstützt wurden und somit die Gleichbehandlung der Unternehmen grob verletzt wurde246. Staatliche Beteiligungen wurden wohl häufig von vornherein als nicht ertragbringend "abgeschrieben". Dies gilt neben Italien vor allem für Frankreich, Großbritannien und Belgien247. Zwar wird in den Kodizes stets betont, daß angesichts der Krisenlage des Sektors jede Kapitalzuführung als Beihilfe anzusehen und somit entsprechend den Regeln zu beurteilen sei, doch bereitete die Umsetzung des Grundsatzes wohl erhebliche Probleme. So weist das Gutachten der "drei Stahlweisen"248 darauf hin, daß einige der Staatsunternehmen sehr geringe oder keine Finanzierungskosten zu tragen hatten 249 oder daß die Gesamtkonzerne, zu denen die Stahlunternehmen gehörten, Jahresüberschüsse von genau Null auswiesen. Die Kontrollprobleme der Kommission erklären sich einerseits daraus, daß die betreffenden MS Kapitalzuschüsse an Nicht-EGKS-Betriebe innerhalb von Stahlkonzernen leisteten, die dann innerhalb der Konzerne transferiert wurden. Hier griff die Kommission erst spät ein und erließ erstmals 1987 eine negative Entscheidung gegen Frankreich 250 . Inzwischen konnte durch den Erlaß eines Gemeinschaftsrahmens für Nicht-EGKS-Stahltätigkeiten eine gewisse Abhilfe geschaffen werden. Ein andererseits vor allem in Italien genutztes Verfahren zur Umgehung der Beihilfenkontrolle waren hohe Kredite öffentlicher Banken an Stahlkonzerne, die ohne adäquate Prüfungen der Kreditwürdigkeit gewährt wurden und bei denen eine eventuelle Ablösung durch den Staat möglicherweise schon bei der Gewährung in Betracht gezogen worden war 251 . Hier griff die Kommission erstmals

245 Vgl. Abschn. 4.3.5.3.

246 Vgl. Tsoukalis/Strauss 1985, S. 224, und Bartling 1984a, S. 491.

247 Vgl. Gerstenberger et al. 1985, S. 42-45; s. auch oben FN 104.

248 Vgl. Colombo/Friderichs/Mayoux 1987, S. 6/7.

249 Dies gilt, wie oben in Abschn. 4.3.6.2 erläutert, bspw. für BSC.

250 Vgl. EG, Kommission 1988a, S. 159.

251 Vgl. Colombo/Friderichs/Mayoux 1987, S. 7. 
1988 ein, das Verfahren gegen Finsider fand dann jedoch die oben erläuterte Ausnahmelösung 252 .

\subsubsection{Wettbewerbs- und Handelswirkungen der Subventionskontrollpolitik}

Ziel der gemeinschaftlichen Beihilfenkontrolle muß es sein, durch die Gleichbehandlung der Unternehmen aus verschiedenen MS Wettbewerbsverzerrungen und Verlagerungen im Intra-EG-Handel zu verhindern. Schon die Darlegungen im vorhergehenden Abschnitt legen eine implizite Begünstigung der verstaatlichten Unternehmen in einigen MS aufgrund von Erfassungs- und Kontrollproblemen bei bestimmten Beihilfetypen nahe. Wie ist nun aber die explizite Politik der Kommission bei den von ihr erfaßten Hilfen zu beurteilen?

Im Zentrum der Diskussion steht hierbei insbesondere ihr Vorgehen während der Gültigkeit des 2. Kodex, da hier die höchsten Beihilfen genehmigt und im Gegenzug umfangreiche Umstrukturierungen gefordert wurden. Wie bereits in Abschn. 4.3.3.3 erläutert, lehnte die Kommission eine feste Kopplung von Beihilfebeträgen an Kapazitätsabbauvolumina $a b$ und verpflichtete auch Unternehmen, die keine Beihilfen erhalten hatten, zum Abbau. Gerechtfertigt wurde diese Strategie des annäherend gleichen proportionalen Opfers mit der erwähnten dubiosen Externalitätenbetrachtung253. Die rückwirkende "Amnestie" für alle Beihilfen vor dem 1. Kodex verzerrte die Situation weiter zuungunsten der Unternehmen, die die ersten Krisenjahre durch eigene Anstrengung überstanden hatten 254 . Selbst wenn man diese Beihilfen jedoch ausklammert, zeigt sich in Tab. 4.3-2 die starke Streuung der Beihilfevolumina pro Tonne Walzstahlfertigung, die selbst bei Vernachlässigung Irlands zwischen $35 \mathrm{DM} / \mathrm{t}$ in Deutschland und $235 \mathrm{DM} / \mathrm{t}$ in Italien schwankte. Die Streuung liegt noch höher, wenn man unternehmensbezogene Vergleiche anstellt. Hierbei weisen in Großbritannien, Italien und Belgien die staatlichen Konzerne wesentlich

252 Vgl. EG, Kommission 1989a, S. 168/169, 1990a, S. 149/150.

253 Bei den ursprünglich von der Kommission für die Zeit nach 1986 geplanten Kapazitätsreduktionen durch Schließung ganzer Warmbreitbandstraßen, die dann nicht durchgeführt wurden, war eine ähnliche proportionale Aufteilung der Lasten vorgesehen. Vgl. Wirtschaftsvereinigung Eisen- und Stahlindustrie 1987, Anl. 15.

254 Vgl. Tsoukalis/Strauss 1985, S. 223, Wienert 1988, S. 139, und Bartling 1984a, S. 492; vgl. auch FN 68. Die ungleiche Verteilung dieser Beihilfen auf die einzelnen MS demonstriert Tab. 4.3-2. Eine Klage von Thyssen und Krupp gegen die Verteilung von Produktionsquoten, in der auch diese Frage eine Rolle spielte, wurde auch in diesem Punkt vom EuGH abgewiesen, der die Festsetzung des Jahres 1980 als Referenzdatum damit rechtfertigte, daß dies Teil der gemeinsamen Stahlpolitik war. Vgl. Dominick 1986, S. 613. 
höhere Subventionierungsgrade als ihre privaten inländischen Konkurrenten auf 255 . Bezieht man, was für die Frage der Gleichbehandlung im Rahmen des Kommissionskonzepts wichtiger ist, die Beihilfen auf die Kapazitätsabbauforderungen, so erkennt man auch hier (Tab. 4.3-11) die klare Besserstellung der Länder mit staatlichen Stahlwerken (B, F, UK, I), die im Durchschnitt nur 295.500 t pro Mrd. DM Subventionen stillegen mußten, während es für die Länder mit vorwiegend privaten Stahlwerken (D, L, NL, DK) 906.000 t/Mrd. DM waren 256.

Bei der Interpretation der Daten sind jedoch zwei Einschränkungen zu machen: Die Subventionsbeträge beziehen sich für Deutschland auf tatsächlich gezahlte, in den anderen Ländern auf freigegebene Beihilfen. Da in Deutschland nur ca. 2/3 der genehmigten Hilfen ausgezahlt wurden und die deutschen Zahlen den Wert der zweiten Ländergruppe dominieren, kann dies zu Verzerrungen führen, wenn die Auszahlungsquote in den Ländern der ersten Gruppe ähnlich liegt. Rechnet man mit den genehmigten Beträgen für die Bundesrepublik, so liegt der Wert für die zweite Gruppe bei $696.600 \mathrm{t} / \mathrm{Mrd}$. DM, damit jedoch immer noch deutlich über dem der ersten Gruppe 257 . Zum anderen zeigt Spalte 9 derselben Tabelle, daß von allen gröBeren Stahlproduktionsländern Deutschland der geringste Kapazitätsabbau im Verhältnis zur Gesamtkapazität auferlegt wurde, so daß hier der Aspekt der relativen Wettbewerbsfähigkeit auch zum Tragen kam und nicht vom Prinzip des gleichen relativen Opfers völlig dominiert wurde 258 . Dennoch ist das Stillegungsverhältnis zwischen dem effizientesten EG-Stahlproduzenten Deutschland und der notorisch ineffizienten italienischen Stahlindustrie völlig unzureichend differenziert 259.

\footnotetext{
255 Vgl. Wirtschaftsvereinigung Eisen- und Stahlindustrie 1987a, Anl. 1, Tab. 4. Bspw. wurden im Durchschnitt der Jahre 1980-85 an Finsider 428 DM/t und an Cockerill-Sambre $365 \mathrm{DM} / \mathrm{t}$ gezahlt. Vgl. Wirtschaftsvereinigung Eisen- und Stahlindustrie 1987, Anlage 6. Dies entsprach z.T. mehr als $25 \%$ der Erzeugungskosten. Vgl. Bartling 1984a, S. 491. Einen griffigen Vergleichsmaßstab liefert die Wirtschaftsvereinigung Eisen- und Stahlindustrie (1987, Anl. 4), die darlegt, daß die deutsche Stahlindustrie bei einem Produktionsanteil innerhalb der Gemeinschaft von ca. $33 \%$ nur etwa $7 \%$ aller Subventionen erhalten habe.

256 Ähnliche Rechnungen stellt Curzon Price (1990, S. 172) an. Das betriebswirtschaftliche Institut der Eisenhüttenindustrie errechnete für die deutsche Stahlindustrie daraus Ausgleichsforderungen von ca. 1,4 Mio. t Zusatzproduktion, um diese Werte einander anzugleichen. Vgl. Wirtschaftsvereinigung Eisen- und Stahlindustrie 1985, S. 18.

257 Ähnliche Berechnung bei Kriwet 1989a, S. 53.

$258 \mathrm{Vgl}$. Kutscher 1989a, S. 87, 94.

259 Vgl. Curzon Price 1990, S. 172.
} 
Tab. 4.3-11

Geforderter Nettoabbau von Warmwalzkapazität und das Verhältnis zu den freigegebenen Subventionen (EG-10)

\begin{tabular}{|c|c|c|c|c|c|c|c|c|}
\hline Land & $\begin{array}{r}\text { Ausgangs- } \\
\text { kapazität } \\
1980 \# \\
\end{array}$ & $\begin{array}{r}\text { Geforderter } \\
\text { Gesamtabbau } \\
\text { Ende 1985 \# } \\
\end{array}$ & $\begin{array}{r}\text { Erwarteter } \\
\text { Abbau } \\
\text { Ende 1985 \# }\end{array}$ & $\begin{array}{r}\text { Beihilfen/ } \\
\text { Stillegungs- } \\
\text { forderungen* }\end{array}$ & $\begin{array}{r}\text { Ant } \\
\text { am Netto- } \\
\text { abbau \% }\end{array}$ & $\begin{array}{l}\text { il der Länder } \\
\text { an den Bei- } \\
\text { hilfen \% }\end{array}$ & $\begin{array}{l}980-85 \\
\text { an Warmwalz- } \\
\text { erzeugung \% }\end{array}$ & $\begin{array}{l}\text { Kapazitätsabbau } \\
1985 \text { vs. } 1980 \\
(-=\text { Aufbau })\end{array}$ \\
\hline $\bar{B}$ & 16.028 & 3.411 & 3.436 & 341 & 11,4 & 12,1 & 9,6 & 21,4 \\
\hline $\mathrm{F}$ & 26.869 & 6.056 & 6.145 & 281 & 20,3 & 26,0 & 17,5 & 22,9 \\
\hline UK & 22.840 & 5.155 & 5.431 & 388 & 17,3 & 16,0 & 11,6 & 23,8 \\
\hline I & 36.294 & 6.984 & 7.200 & 247 & 23,4 & 34,2 & 20,9 & 19,8 \\
\hline $\mathrm{D}$ & 51.869 & 6.156 & 6.729 & 974 & 20,6 & 7,6 & 31,4 & 13,0 \\
\hline Saarstahl & 4.274 & 504 & 504 & 212 & 1,7 & 2,9 & 2,6 & 11,8 \\
\hline Übrige Unt. & 47.595 & 5.652 & 6.225 & 1434 & 19,0 & 4,8 & 28,8 & 13,1 \\
\hline $\mathrm{L}$ & 5.215 & 1.045 & 1.045 & 704 & 3,5 & 1,8 & 3,2 & 20,0 \\
\hline NL & 7.597 & 950 & 1.732 & 885 & 3,2 & 1,3 & 3,9 & 22,8 \\
\hline DK & 941 & 66 & 66 & 346 & 0,2 & 0,2 & 0,5 & 7,0 \\
\hline IRL & 57 & 0 & -276 & 0 & 0,0 & 0,8 & 0,1 & $-484,2$ \\
\hline GR & 4.317 & 0 & -393 & 0 & 0,0 & 0,0 & 1,3 & $-9,1$ \\
\hline EG-10 & 172.027 & 29.823 & 31.115 & 360 & 100,0 & 100,0 & 100 & 18,1 \\
\hline EG-10 ohne D & 120.158 & 23.667 & 24.386 & 309 & 79,4 & 92,4 & 68,6 & 20,3 \\
\hline
\end{tabular}

* In 1000 t/Mrd. DM. Von der Kommission freigegebene Hilfen; für D tatsächlich ausgezahlte Beträge (freigegeben waren 9,047 Mrd. DM); von den Beihilfen sind 2,8 Mrd. DM bedingt rückzahlbar.

\# jeweils in $1000 \mathrm{t}$.

Quelle: WV Eisen- und Stahlindustrie 1987a. 
Tab. 4.3-12

Verluste ausgewählter Stahlunternehmen und Beihilfen an die Stahlindustrie in ausgewählten Ländern der EG 1975-83 (in Mrd. DM)

\begin{tabular}{|c|c|c|c|c|c|}
\hline Land & $\begin{array}{l}\text { Notifizierte } \\
\text { Beihilfen }\end{array}$ & Unternehmen & Verluste & $\begin{array}{l}\text { Verluste in \% } \\
\text { der Umsatz- } \\
\text { erlöse }\end{array}$ & $\begin{array}{l}\text { Beihilfen für Unter- } \\
\text { nehmen 1980-85 } \\
\text { in \% der Gesamt- } \\
\text { beih. des MS }\end{array}$ \\
\hline $\bar{B}$ & 12,9 & Cockerill-Sambre & 5,1 & 14,0 & 92,7 \\
\hline \multirow[t]{2}{*}{$\mathrm{F}$} & 20,1 & Usinor & 10,5 & 19,8 & $100^{*}$ \\
\hline & & Sacilor & 7,8 & 21,0 & \\
\hline UK & 27,4 & British Steel & 23,0 & 19,8 & 98,8 \\
\hline I & 29,9 & Italsider & 12,1 & 21,4 & 91,0 \\
\hline$\overline{\text { Summe }}$ & 90,3 & & 58,5 & & \\
\hline
\end{tabular}

Auch wenn hier Aspekte der Wettbewerbsfähigkeit berücksichtigt wurden, muß man doch davon ausgehen, daß bei strengerer Beihilfenkontrolle und stärkerer Gleichbehandlung das Verhältnis der relativen Stillegungen noch extremer ausgefallen wäre260. Dies legt Tab. 4.3-12 nahe, die die Verluste der großen staatlichen Stahlunternehmen in absoluten Zahlen und im Verhältnis zum Umsatz den an sie gezahlten Subventionen gegenüberstellt. Eine Beschränkung der Beihilfen bspw. auf die Kategorien der 3. und weiteren Kodizes und damit der Ausschluß von Betriebsbeihilfen hätte diesen Unternehmen ein Überleben nur bei massiven Schließungen (Schließungsbeihilfen) erlaubt und ihren Anteil an der Gesamtkapazität in der Gemeinschaft vermindert. Allerdings muß man berücksichtigen, daß bei einem strengeren Subventionskontrollregime und weniger restriktiven Importhemmnissen die Stahlindustrie in der Gemeinschaft insgesamt stärker geschrumpft wäre261, so daß die Produktion der anderen EGKS-Stahlunternehmen nicht notwendigerweise gestiegen wäre. Dennoch führte die Politik der Kommission, wie oben dargelegt, zum Erhalt von Standorten und zur Verhinderung von Marktaustritten, die unter rein wettbewerblichen Gesichtspunkten hätten erfolgen müssen 262 . Die Probleme der

\footnotetext{
260 Vgl. Gerstenberger et al. 1985, S. 63f., Kutscher 1989a, S. 86/87, und Wirtschaftsvereinigung Eisen- und Stahlindustrie 1984, S. 1.

261 Vgl. Wienert 1988, S. 137, 141, und Dicke et al. 1987, S. 67.

$262 \mathrm{Zu}$ den Problemen dabei aufgrund der strukturellen Besonderheiten dieses Industriezweiges s. oben FN 17 und unten Abschn. 4.3.6.5.
} 
gesunden Unternehmen wurden dadurch noch verschärft. Hierzu trugen neben den Betriebsbeihilfen auch die Quoten und Mindestpreise bei263. Die Kommission veränderte damit die Wettbewerbs- und Handelsbedingungen und wurde in dieser Vorgehensweise durch den EuGH noch unterstützt, der ihr keine Verpflichtungen zu mehr Transparenz und Nachprüfbarkeit auferlegte264. Der Vorteil der hochsubventionierten Unternehmen hieraus war allerdings geringer zu veranschlagen, da sie zum Teil nur zum Ausgleich der den Unternehmen durch ihre staatlichen Eigner aus regional-, konjunktur- und arbeitsmarktpolitischen Gründen auferlegten Zusatzkosten, wie z.B. Schließungs- und Preiserhöhungsverbote in Frankreich dienten 265. Mittels des Quotensystems konnten die Auswirkungen der unterschiedlichen Subventionshöhen auf den Intra-EG-Wettbewerb weiter eingedämmt werden. Über die Vergabe von Exportquoten konnte die Kommission zudem verhindern, daß der Beihilfenwettbewerb zwischen EGKS-Unternehmen über Drittmärkte ablief. Jedoch führten die allseitigen VERs zu einer massiven Verzerrung des Weltstahlhandels.

Angesichts der extrem hohen Subventionsbereitschaft in einigen MS läßt sich allerdings vermuten, daß ohne die Kontrolle seitens der Kommission der Subventionswettlauf noch härter ausgefallen und die Produktionsstrukturen noch stärker verzerrt worden wären. Dies gilt wohl auch für die Nach-Krisen-Phase, in der ohne die verschärfte Kontrolle die staatlichen Produzenten noch stärker gefördert worden wären.

Im Ergebnis führte die relative Ungleichbehandlung dazu, daß am Ende des Umstrukturierungsprozesses in etwa gleich moderne und wettbewerbsfähige Produktionsanlagen bei allen Produzenten vorhanden waren, daß dieses Ergebnis aber durch stark unterschiedliche Beihilfevolumina erreicht wurde266. Der Ablauf dieses Prozesses läßt sich gut anhand der Investitionsvolumina pro Tonne Rohstahlproduktion in den verschiedenen MS illustrieren (Tab. 4.3-13). Hier zeigt sich, daß die hohen Beihilfen den Produzenten in F, I, B und UK deutlich höhere Investitionen und damit ein Aufholen des Produktivitätsrückstandes durch den vermehrten Einsatz moderner Produktionsverfahren erlaubten ${ }^{267}$. Der Widerstand der wenig subventio-

263 Vgl. Wienert 1988, S. 139, und 1990, S. 208, sowie Kokalj/Albach 1987, S. 298, und Herdmann/Weiss 1985, S. 106.

264 Vgl. Dominick 1986, S. 602f., 616 und FN 46.

265 Vgl. Wienert 1990, S. 208, und Ulrich 1989, S. 36f., 42.

266 Vgl. Wienert 1988, S. 141, und 1990, S. 209, sowie Herdmann/Weiss 1985, S. 106.

267 Vgl. Gerstenberger et al. 1985, S. 61-63, Kriwet 1989, S. 40, und Wirtschaftsvereinigung Eisen- und Stahlindustrie 1987, Anl. 8. 
nierenden MS, wie Deutschland, dagegen war jahrelang sehr gering268. Statt rein wettbewerbspolitischen Zwecken zu dienen, stellte die Subventionskontrolle also ein wesentliches Element einer industriepolitisch motivierten Beeinflussung der Kapazitätshöhe und -verteilung auf Gemeinschaftsebene dar.

Tab. 4.3-13

\section{Investitionen der EG-Stahlindustrie in ECU je Tonne Rohstahlproduktion}

\begin{tabular}{l|c} 
Land & $\begin{array}{c}\text { Durchschnitt } \\
1975-83\end{array}$ \\
\hline Deutschland & 16 \\
Frankreich & 20 \\
Italien & 23 \\
Niederlande & 18 \\
Belgien & 21 \\
Luxemburg & 17 \\
Großbritannien & 28 \\
Irland/Dänemark & 31 \\
\hline EG-9 & 21
\end{tabular}

Quelle: Gerstenberger et al. 1985

\subsubsection{Subventionskontrolle als Mittel der Industriepolitik}

Welche Auswirkungen hatte nun diese industriepolitische Lenkung, deren Ziele Rationalisierung und Umstrukturierung der Stahlindustrie sowie die finanzielle Gesundung der Unternehmen waren und zu deren Instrumenten neben den Beihilfekontrollregeln auch Produktionsquoten, Mindestpreise, Investitionslenkungsmaßnahmen und Außenhandelsprotektionismus gehörten ${ }^{269}$, auf die gemeinschaftliche Stahlindustrie, und wie sind diese Wirkungen zu bewerten?

Erst im Zuge der Verschärfung der Stahlkrise während der Laufzeit des 2. Kodex, insbesondere in den Jahren 1982/83, erkannte die Kommission die massiven Überkapazitäten als eine Hauptursache der Probleme der Unternehmen in der Gemeinschaft und entwickelte deshalb die Strategie, weitere Beihilfengenehmigungen an

268 Vgl. Jürgensen 1984, S. 119, $121 \mathrm{f}$.

269 Vgl. Tsoukalis/Strauss 1985, S. 220. 
Kapazitätsabbauzusagen zu koppeln270. Der notwendige Abbau wurde von der Kommission in ihren Allgemeinen Zielen Stahl bis Ende 1985 mit mindestens 30 Mio t prognostiziert 271 . Während der Laufzeit des 2 . Kodex und seiner Verlängerung wurde dieser Wert bis Ende 1986 dann auch erreicht. Doch erschien zu jenem Zeitpunkt aufgrund der im Vergleich zu den ursprünglichen Erwartungen langsameren Erholung der Industrie die erreichte Kapazität als immer noch um über 20 Mio. $\mathrm{t} z \mathrm{u}$ hoch 272. Da jedoch im 3. Kodex keine Regeln vorgesehen waren, die eine weitere Kopplung von Beihilfen an Schließungen erlaubten, kam der systematische Abbau zum Stillstand, und Kapazitätsverringerungen für 1986/87 von 3,8 Mio. $t$ in Deutschland, Großbritannien und den Niederlanden standen Erweiterungen in Italien und Frankreich um 2,3 Mio. $\mathrm{t}$ gegenüber, obwohl die Unternehmen in diesen Ländern weiterhin hohe Verluste erlitten 273 . Der unerwartete Aufschwung der Stahlnachfrage ab 1988 führte jedoch die Prognosen der Kommission ad absurdum, löste dabei allerdings zunächst das Problem des Kapazitätsüberhangs 274 .

Neben der Kapazitätsverringerung stellte die Verbesserung der Produktivität der Stahlunternehmen durch Modernisierungsinvestitionen ein weiteres Hauptziel der industriepolitischen Intervention dar. Auch hier sind durchaus positive Ergebnisse zu verzeichnen. Zum einen stieg die Beschäftigtenproduktivität seit 1980 um jahresdurchschnittlich 5,6\%, die Zahl der geleisteten Arbeiterstunden pro Tonne Rohstahl fiel sogar um 7,1\% p.a.; zum anderen konnte auch der Energiebedarf erheblich gesenkt werden. Der Koks- und Ölverbrauch fiel im Zeitraum 1980-87 pro Jahr um durchschnittlich 2\%; lediglich der Stromverbrauch stieg leicht an. Letzteres erklärt sich durch die Ersetzung des energieintensiven Siemens-Martin-Verfahrens durch das Elektrostahlverfahren 275 . Durch die zunehmende Verwendung des

270 Hierbei wurde die Warmwalz- und nicht die Rohstahlkapazität als Maßstab gewählt, um zu verhindern, daß die Unternehmen lediglich die erste Produktionsstufe abbauten und dann über Rohstahlzukäufe ihren Walzstahlausstoß konstant hielten und so die Marktprobleme perpetuierten.

271 Vgl. EG, Kommission 1983a, S. 123.

272 Vgl. EG, Kommission 1986f, Tab. 7. Wie im Schiffbau kam es also zu einer Unterschätzung der Schwere der Probleme, die zunächst in den 70er Jahren als rein konjunkturelles Phänomen begriffen und somit überhaupt nicht angegangen wurden, in den frühen 80er Jahren dann nicht konsequent genug. Im Gegensatz zum Schiffbau rettete der Konjunkturaufschwung das industriepolitische Konzept.

273 Vgl. Wirtschaftsvereinigung Eisen- und Stahlindustrie 1987, Anlage 11, und Kriwet 1988, S. 34.

274 Vgl. Wienert 1990, S. 208, 211.

275 Vgl. Wienert 1990, S. 209. 
Stranggußverfahrens sank auch der Rohstahlverbrauch pro Tonne Walzstahl um 15\% während dieses Zeitraums. Diese Entwicklungen erhöhten natürlich die Rentabilität und Wettbewerbsfähigkeit der europäischen Stahlindustrie erheblich und brachten sie damit wieder auf ein leistungsfähiges Niveau, allerdings auf Kosten eines besonders starken Arbeitsplatzabbaus in den Ländern mit geringer Produktivität (F, B, UK) 276.

Diesem an sich recht positiv erscheinenden Bild einer erfolgreichen industriepolitischen Intervention auf der Basis eines - im Unterschied zum Schiffbau - gemeinschaftlich akzeptierten Umstrukturierungsprogramms 277 müssen allerdings für eine adäquate Beurteilung die Methoden der Zielerreichung und ihre Kosten gegenübergestellt werden. Die Interventionsintensität in der Stahlindustrie war vermutlich höher als in jedem anderen Industriezweig in der EG (abgesehen vielleicht vom Bergbau), und das verfügbare Instrumentarium dazu bot auch lediglich der EGKS-Vertrag278.

Importbeschränkungen, Produktionsquoten und Mindestpreise stabilisierten zwar den EG-Stahlmarkt, erhöhten jedoch gleichzeitig die Inlandspreise für Stahl, somit die Inputkosten der Stahlverbraucher und verminderten ihre Wettbewerbsfähigkeit 279 . Gleichzeitig wurde die sektorale Struktur der Wirtschaft verzerrt, da durch die hohen Beihilfen, deren Aufbringung noch zusätzliche allokative Verzerrungen verursacht haben dürfte280, ein im Vergleich zu einer Marktlösung deutlich größerer Stahlbereich erhalten wurde281. Diese Tendenz einer zu geringen Schrumpfung wurde durch die Mindestpreisregelungen noch verschärft. Gleichzeitig sank hierdurch und durch die Subventionen der Anreiz zu effizientem Handeln282. Da

276 Vgl. Wienert 1988, S. 141.

277 Eine derartige positive Beurteilung vertritt z.B. von Freyend (in von Freyend/Linkohr 1986, S. 9) vom BDI.

278 Vgl. Esser et al. 1982, S. 284, Tsoukalis/Strauss 1985, S. 226, und Stotz 1983, S. 106.

279 Vgl. Curzon Price 1981, S. 91f., und 1990, S. 172, sowie Abschn. 4.3.5.1. Dicke et al. (1987, S. 69f.) schätzen diese Zusatzkosten allein in Deutschland für 1983 auf 4,3 Mrd. DM. Dieses Argument gilt nicht für die Phasen, in denen die Preisvorschriften nicht eingehalten wurden. Hier dürften die Stahlverarbeiter über Weiterwälzung sogar von den Subventionen profitiert haben. Vgl. Wienert 1990, S. 210. Durch den partiellen Ausschluß externer Anbieter vom EGMarkt dürfte das Angebot auf dem Weltmarkt zusätzlich gestiegen und der Weltmarktpreis gefallen sein, so daß Stahlabnehmer im Ausland durch die EG-Politik begünstigt wurden. Vgl.

280 Herdmann/Weiss 1985, S. 111

280 Vgl. Krägenau 1986, S. 44.

281 Vgl. Tomann 1984, S. 53f.

282 Vgl. Wienert 1990, S. 210. Eine Wohlfahrtsanalyse der sozialen Kosten der Interventionen nahmen Herdmann/Weiss (1985, S. 107-111) vor. 
allerdings im Stahlsektor weltweit massive staatliche Eingriffe vorherrschen, bleibt die Frage, ob eine reine Marktlösung angesichts des immensen Problemdrucks eine relevante Alternative darstellte oder ob nicht vielmehr unkoordinierte nationale Protektionsmaßnahmen bei höheren gesamtwirtschaftlichen Kosten einen mindestens ebenso großen Stahlsektor erhalten hätten 283 .

Tab. 4.3-14

Konzentrationsgrad der Stahlerzeugung in der EG 1988

\begin{tabular}{lc|r|r} 
Konzern & Land & $\begin{array}{r}\text { Rohstahl- } \\
\text { erzeugung } \\
\text { in Mio. T Teil an der Stahl- }\end{array}$ & $\begin{array}{l}\text { Anter } \\
\text { erzeugung des jewei- } \\
\text { ligen Landes in \% }\end{array}$ \\
\hline Usinor-Sacilor & F & 17,6 & 92,1 \\
British Steel & UK & 14,7 & 77,4 \\
ILVA (Finsider) & I & 11,8 & 49,8 \\
Thyssen & D & 11,8 & 28,8 \\
ARBED-Sidmar* & L/B & 7,2 & 48,3 \\
Hoogovens & NL & 5,3 & 96,4 \\
Cockerill-Sambre & B & 4,5 & 40,2 \\
Peine-Salzgitter & D & 4,3 & 10,5 \\
Krupp & D & 4,3 & 10,5 \\
Mannesmann & D & 4,3 & 10,5 \\
Hoesch & D & 4,1 & 10,0 \\
Klöckner & D & 3,6 & 8,9 \\
ENSIDESA & E & 3,3 & 28,0 \\
Saarstahl & D & 2,8 & 6,8 \\
& & & \\
* Anteil an der Summe B/L. In Luxemburg beträgt der Anteil \\
100\%, in Belgien 31,3\%. & \\
Quelle: Kutscher 1989. &
\end{tabular}

Einen weiteren Preis der gelenkten Modernisierung stellte die Verstärkung der industriellen Konzentration in einem ohnehin schon durch wenige Großunternehmen dominierten Sektor dar284. So fusionierten Cockerill und Hainaut-Sambre in Belgien, Usinor und Sacilor in Frankreich, und in Italien und Großbritannien übernahmen die staatlichen Konzerne Finsider/ILVA und BSC weitere kleinere Produ-

283 Vgl. Tsoukalis/Strauss 1985, S. 220, 223, und SVR 1983, S. 231, sowie Esser et al. 1982, S. 285. Eine solche Marktlösung wurde wohl von allen Beteiligten wegen der hohen Marktaus284 trittsschranken nie ernsthaft in Erwägung gezogen. Vgl. FN 17.

Sie besaßen und modernisierten zudem große und inflexible Anlagen, die eine neue Subventionsgefahr darstellten. Vgl. Tomann 1984, S. 54. 
zenten 285 . Während diese Konzentration z.T. technisch bedingt gewesen sein mag, lag die Verantwortung in Frankreich, Großbritannien, Belgien und Italien bei den jeweiligen Regierungen als Eigentümer der Unternehmen286, die die Großunternehmen stärker subventionierten als die kleineren privaten Produzenten ${ }^{287}$. Die Fusionen und Übernahmen waren dabei ein Teil der Strategie, den Marktaustritt der jeweils schwächeren Partner zu verhindern, da Konkurse für die MS nicht akzeptabel waren 288 . So gesehen handelte es sich sicherlich nicht um eine effiziente Umstrukturierung. Diese hätte auch angesichts der speziellen Charakteristika der Branche (s.o. FN 17) darin bestanden, das Ausscheiden der ineffizientesten Produzenten durch Schließungsbeihilfen zu erreichen, anstatt Ressourcen dafür zu verschwenden, sie am Leben zu erhalten, danach zu modernisieren und dann anschließend bei allen Produzenten anteilig zu kürzen. Das Quotensystem verhinderte ebenfalls eine solche Selektion, da es auch den ineffizientesten Herstellern Schutz gewährte und sie ermutigte, in Erwartung eines früheren Ausscheidens ihrer Konkurrenten die Kapazitäten nicht zu vermindern ${ }^{289}$. Allerdings verhinderte das System zumindest eine Verschärfung der ruinösen Branchenkonkurrenz. Ineffizient war die Umstrukturierung um so mehr, als die Fusionen praktisch ausschließlich auf nationaler Ebene erfolgten und eine mögliche europäische Dimension ignoriert wurde290. Hier standen wieder die Interessen der nationalen Regierungen im Vordergrund, den notwendigen Schrumpfungsprozeß, v.a. den Arbeitsplatzabbau, zu verzögern und regional gleichmäßiger zu verteilen ${ }^{291}$. Durch die Verzögerung dieses Abbaus wurden sicherlich die sozialen Kosten des Strukturwandels gedämpft, aus allokativer Sicht wurden jedoch Res-

285 Zum Ergebnis des Konzentrationsprozesses bis 1988 vgl. Tab. 4.3-14. Aufgrund mangelnder Integration der fusionierten Unternehmensteile blieben erhoffte Effizienzgewinne jedoch häufig aus. Vgl. Meny/Wright 1987, S. 38.

286 Vgl. Wienert 1990, S. 208. Ähnliche Konzepte, u.a. zur Bildung von zwei großen Stahlgruppen, unter strukturpolitischer Lenkung und finanzieller Förderung des Staates wurden auch in Deutschland diskutiert, dann aber aufgrund eines fehlenden Konsens der Beteiligten nicht umgesetzt. Vgl. Kokalj/Albach 1987, S. 278f., Esser et al. 1982, S. 280.

$287 \mathrm{Vgl}$. Herdmann/Weiss 1985, S. 107.

288 Vgl. Ulrich 1989, S. 38.

289 Vgl. Cox 1984, S. 24f.

290 Vgl. Tsoukalis/Strauss 1985, S. 224f. Dies gilt, obwohl die zunehmende Internationalisierung der Industrie solche Strategien erfordert hätte. Einzelne Versuche hierzu scheiterten jedoch. Vgl. Meny/Wright 1987, S. 32f., 37.

291 Vgl. Wienert 1988, S. 138, und 1990, S. 208-211, sowie Tsoukalis/Strauss 1985, S. 221. Hier bleibt natürlich zu fragen, ob gezielte regionalpolitische Maßnahmen nicht größeren Erfolg gezeitigt hätten. Vgl. Kokalj/Albach 1987, S. 274, 298. 
sourcen länger als effizient im Stahlsektor gebunden. Wienert292 argumentiert hingegen, daß allein durch die Subventionen der Preisverfall und das Modernisierungstempo verstärkt und somit der Abbau von Arbeitsplätzen eher beschleunigt wurde. Dem wirkten jedoch die anderen Krisenmaßnahmen entgegen.

Der intensive staatliche Eingriff in die Unternehmensentscheidungen hat in den jeweiligen Ländern wohl auch die Unternehmensstrukturen erheblich beeinflußt. Während nämlich in den Ländern mit privaten Stahlunternehmen diese eine Strategie der Diversifizierung betrieben, um die Abhängigkeit von der Stahlkonjunktur und damit die Krisenanfälligkeit zu reduzieren, blieben die staatlichen Unternehmen reine Stahlkonzerne, was in jeder neuen Krise ihren Subventionsbedarf wieder wachsen läß ${ }^{293}$. Auf diesen Aspekt hatte die Kommission allerdings keinen direkten Einfluß, da ihre industriepolitische Kompetenz selbst nach dem EGKSV nicht so weit geht. Dennoch kann man argumentieren, daß die Marktstabilisierung durch die diversen Krisenmaßnahmen eher einen Anreiz gegen eine Diversifizierung und für einen Erhalt der eigenen Kapazitäten darstellte.

Diese mangelnde Diversifizierung, d.h. der zu geringe Umstrukturierungsdruck auf einige Unternehmen, insbesondere die zu großzügige Akzeptanz von Subventionen in Italien (Fall ILVA/Finsider) und in Spanien (unter dem Übergangsregime) ohne adäquate Schließungsauflagen, werden für die wiederaufflammende Krise verantwortlich gemacht, zu deren Lösung nun wieder Hilfsprogramme verabschiedet wurden 294 . Nach Ansicht von Experten hätten aus reinen Wettbewerbsgesichtspunkten ohne diese Beihilfen fast die gesamte spanische Stahlindustrie sowie das größte ILVA-Werk in Taranto und EKO-Stahl schließen müssen295. Bei einer Durchführung der Beihilfenprogramme muß allerdings mit neuen handelspolitischen Konflikten gerechnet werden. Diese erneute Fehlprognose bedingt eine eher noch negativere Beurteilung der bisherigen Industriepolitik.

292 1988, S. 141.

293 Vgl. Wienert 1990, S. 209, und Jürgensen 1984, S. 123f. mit Beispielen. Insbesondere Usinor/Sacilor und ILVA kauften sich mit erheblichen Investitionen bei kleineren Herstellern ein. Vgl. Student 1991, S. 174. Allerdings ist Diversifizierung allein sicherlich kein Patentrezept, da sich dann für das Unternehmen das Problem der Integration der verschiedenen Bereiche stellt. Auf Negativbeispiele weisen Meny/Wright (1987, S. 37) hin.

294 Verluste mußten v.a. die reinen Stahlkonzerne tragen, während es bei diversifizierten Konzernen wie Thyssen lediglich zu Dividendenkürzungen kam. Vgl. The Economist 1992e, S. 91, und FNP 1992, S. 5. Ein derartiges Wiederaufflammen der Krisenerscheinungen hatten die drei Stahlweisen bereits 1987 prognostiziert. Vgl. Colombo/Friderichs/Mayoux 1987 .
295 Vgl. Baxter 1993 und zu den Verlusten dieser Unternehmen Handelsblatt 1993. 
Was schließlich den Versuch der Kommission angeht, mittels der Beihilfekodizes, der auf ihnen aufbauenden bedingten Entscheidungen und der anderen Krisenmaßnahmen ihre industriepolitischen Kompetenzen zu erweitern, so waren diese nur z.T. von Erfolg gekrönt.

Meny/Wright 296 argumentieren, daß die Kommission generell von den sehr ineffizienten Entscheidungsstrukturen und internen Rivalitäten auf nationaler Ebene profitierte, die dort z.T. zu inkonsistenten nationalen Entscheidungen führten und es der Kommission erlaubten, als "policy broker" zu agieren. Dazu verfügte sie im Vergleich zu den nationalen Administrationen über bessere Informationen und damit über ein größeres Expertenwissen aufgrund ihrer Überwachungsrechte und der Berichtspflichten der Unternehmen 297.

Speziell in bezug auf die Beihilfenkontrolle gewann die Kommission durch die Verabschiedung der Kodizes signifikante neue Kompetenzen hinzu, nachdem sie vorher v.a. in der "gesetzlosen" 1. Krisenphase, in der sie trotz des kategorischen Verbots erhebliche Subventionen hatte dulden müssen, zunächst an Einfluß eingebüßt hatte. Der Druck zum Erlaß solcher Regeln ging allerdings v.a. von der deutschen Regierung und Industrie aus, jedoch konnte die Kommission diesen Druck zu ihren Gunsten nutzen, dies auch deswegen, weil die MS einen Zusammenbruch des Systems am meisten fürchteten 298 . So bieten die Regeln der Kodizes im Vergleich zur strikten Regelung des EGKS-Vertrages mehr diskretionären Spielraum, und die Kapazitätsabbauauflagen sowie Preislenkungsmaßnahmen ermöglichten nach Zustimmung des Rates zu den Regeln einen direkten Durchgriff auf die Stahlunternehmen der Gemeinschaft, den der EGKSV allein nicht gestattet hätte299.

Bei der Nutzung dieser Kompetenzen wurde die Kommission massiv durch den EuGH unterstützt, der sie durch die Aufstellung außerordentlich hoher Beweishürden für Kläger in ihren Entscheidungen de facto einer richterlichen Kontrolle entzog 300 . Allerdings hat das weitgesteckte Ermessen auch den Nachteil, daß die Kommission dadurch immensen Pressionen ausgesetzt ist ${ }^{301}$, deren Existenz wohl auch die z.T. nicht befriedigende Umsetzung ihrer Kompetenzen in Einzelentscheidungen erklärt (s.o. Abschn. 4.3.6.4.).

296 1987, S. 45-49, 52f.

297 Vgl. ebenda, sowie Tsoukalis/Strauss 1985, S. 224f.

298 Vgl. Meny/Wright 1987, S. 53f., Fendel 1981, S. 432, 452, 457.

299 Vgl. Kutscher 1989, S. 81.

300 Vgl. Dominick 1986, S. 603-605, 616.

301 Vgl. Wirtschaftsvereinigung Eisen- und Stahlindustrie 1982, S. 7. 
Daneben unterliegen die Handlungsmöglichkeiten der Kommission auch spürbaren rechtlichen Einschränkungen. Zunächst einmal sind die Kodizes als Entscheidungen nach Art. 95 EGKSV von der einstimmigen Zustimmung des Rates abhängig, so daß die Kommission hier ihre eigenen Vorstellungen nicht autonom durchsetzen kann, was z.B. bei den langen Diskussionen mit den folgenden Verwässerungen des 1 . Kodex deutlich wurde 302 . Selbst innerhalb des Rahmens, den die Kodizes setzen, besteht für sie zumindest eine Konsultationspflicht gegenüber den MS. So muß sie bei allen vorgesehenen Schließungs- und bedeutenden regionalen Investitionsbeihilfen sowie anderen wichtigen Subventionsvorhaben vor einer Entscheidung die Stellungnahme der MS einholen und danach die MS über ihre Entscheidung unterrichten ${ }^{303}$. Zudem diskutiert die Kommission ihre Jahresberichte zur Anwendung des jeweiligen Kodex mit den MS. Ein großer Teil ihrer Handlungen im Beihilfenkontrollbereich durchläuft also quasi einen Filter aller MS, bevor sie rechtskräftig werden.

Für eine eigenständig gestaltende Industriepolitik stehen der Kommission über den EGKS-Funktionshaushalt, die gemeinschaftlichen Forschungsprogramme und die Genehmigung von Investitionen 304 sicherlich wesentlich mehr Mittel zur Verfügung als im Schiffbau, dennoch übten die MS über die nationalen Beihilfen und z.T. als Anteilseigner einen größeren Einfluß auf die Entwicklung der Industrie aus als die Kommission 305 .

302 Vgl. Fendel 1981, S. 483f.

303 Vgl. dazu im neuesten Kodex (EG, Kommission 1991e) den Art. 6,III.

304 Vgl. Narjes 1988, S. 8f., und Fendel 1981, S. 477f. Die Mittel aus dem Funktionshaushalt wurden v.a. für sozialpolitische Maßnahmen eingesetzt.

$305 \mathrm{Vgl}$. Tsoukalis/Strauss 1985 , S. $225 \mathrm{f}$. 


\subsection{Subventionen für die Automobilindustrie}

\subsubsection{Entwicklung des Industriezweiges}

Seit den dreißiger Jahren spielt die Automobilindustrie in allen größeren Industriestaaten eine bedeutende und noch wachsende Rolle gemessen an ihrem Anteil an der industriellen Wertschöpfung, an den Arbeitsplätzen in der Industrie sowie am Außenhandel ${ }^{1}$. Diese Bedeutung wird in noch stärkerem Maße deutlich, wenn man die Zulieferindustrie und die mit dem Produkt verbundenen Dienstleistungen in die Betrachtung einbezieht und außerdem bedenkt, daß die Kfz-Produzenten selbst Großfirmen mit häufig noch regional konzentrierter Produktion sind. Hierdurch erklärt sich das starke Interesse der nationalen Regierungen am Wohlergehen der ansässigen Autoproduzenten auch in der EG, in der in sechs MS eigene Produzenten existieren und in vier weiteren MS ausländische Produzenten Montageeinrichtungen unterhalten ${ }^{2}$.

Nach dem Zweiten Weltkrieg verstaatlichten daher einige MS einzelne Automobilfirmen direkt oder übernahmen zumindest Kapitalanteile über staatliche Industrieholdings ${ }^{3}$. Diese Beteiligungen führten z.T. anfänglich zu erheblichen staatlichen Kapitalzuführungen; im bald einsetzenden Automobilboom in Westeuropa erwirtschafteten diese Betriebe für ihre staatlichen Eigner jedoch Gewinne ${ }^{4}$. Die rasante Entwicklung der Kfz-Industrie ab dem Ende der 50er Jahre wird an den Produktions- und Absatzzahlen deutlich (vgl. Abb. 4.4-1). Gleichzeitig erhöhte die Entwicklung zur Massenproduktion die Bedeutung der Erzielung von Economies of scale und führte zu einem Konzentrationsprozeß, der viele kleinere Marken vom

${ }^{1}$ Vgl. Für die EG betrugen die Werte 1985 für Wertschöpfung und Arbeitsplätze 6\% und 7\%. 27\% der Produktion gingen in den Export, davon knapp 90\% in andere MS. Damit betrug der Anteil der Kfz-Industrie am Intra-EG-Handel $12,3 \%$ bei einem Volumen von $60 \mathrm{Mrd}$. ECU (1987) Vgl. Emerson et al. 1988, S. 75, sowie EG, Kommission 1989r, S. 5.

2 Vgl. Bhaskar/MIRU 1990, S. 1

3 Es handelt sich hierbei um Renault (Frankreich), ENASA und SEAT (Spanien) sowie Alfa Romeo (Italien), später auch DAF (Niederlande). Vgl. Bhaskar/MIRU 1990, S. 2-4, 6. Bei Renault spielten auch politische Aspekte eine Rolle (Kollaboration des Privateigners mit der deutschen Besatzungsmacht während des Krieges). Der Erhalt des staatlichen Eigentums war jedoch v.a. industriepolitisch motiviert. VW war als Staatsunternehmen gegründet worden und dann von der britischen Besatzungsmacht an den Bund und das Land Niedersachsen übertragen worden. Die Präsenz v.a. des Landes im Aufsichtsrat dient immer auch der Verfolgung regional- und industriepolitischer Ziele.

4 Dies gilt z.B. für Renault. Vgl. Bhaskar/MIRU 1990, S. 2 
Markt verschwinden ließ ${ }^{5}$. Die dadurch entstandene oligopolistische Marktstruktur, in der Investitionen oder preispolitische Maßnahmen einzelner Marktteilnehmer eine spürbare Auswirkung auf die Wettbewerbsstellung der Konkurrenten haben, bedeutet, daß staatliche Eingriffe zugunsten einheimischer Produzenten einer noch intensiveren Kontrolle als in anderen Sektoren bedürfen.

Abb. 4.4-1 Angebot und Nachfrage an Pkw in Westeuropa 6

(+ Produktion, Zulassungen)

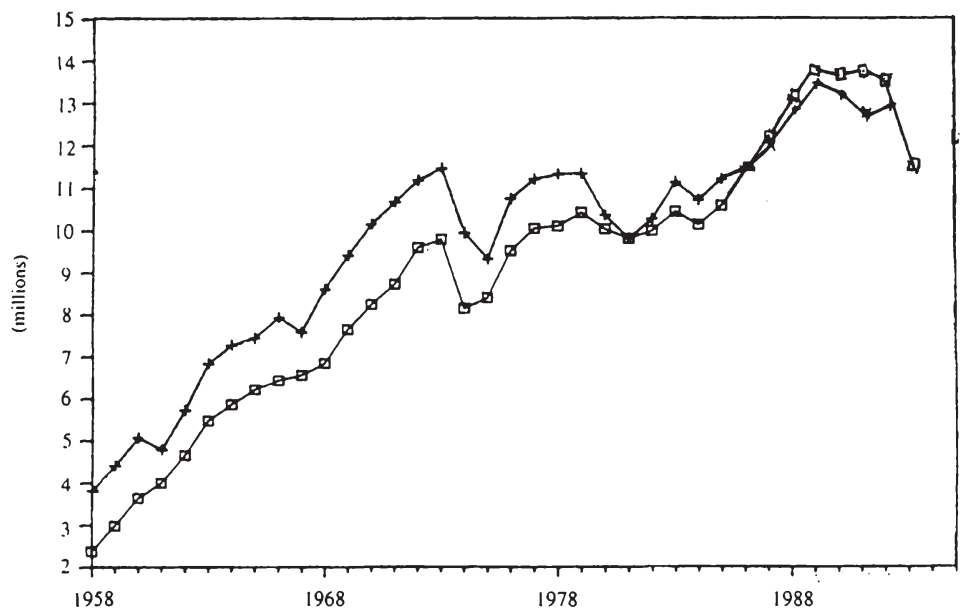

Aufgrund der guten konjunkturellen und sektoralen Lage, die den Firmen eine Ausweitung ihrer Produktion bei gleichzeitiger Erhöhung der Preise und auch der Löhne erlaubte, spielten in dieser Phase Subventionen an die Autoproduzenten nur eine geringe Rolle. Lediglich zum Zweck der Regionalentwicklung wurde eine Mischung aus Druck und finanziellen Anreizen eingesetzt, um die Firmen zum Aufbau neuer Anlagen in Problemgebieten zu veranlassen7. Jedoch fand hier seitens der Kommission keine Prüfung oder Beanstandung dieser Vorhaben statt, und es liegen in den Archiven auch keine Unterlagen vor. Eine indirekte Beihilfe für die Auto-

5 Vgl. Bhaskar/MIRU 1990, S. 5.

6 Westeuropa entspricht den MS der EG und der EFTA. Quellen: MIRU 1987, fortgeführt anhand von VDA-Statistiken.

7 Dies war z.T. ein genereller Aspekt staatlicher Regionalpolitik, der insbesondere gegenüber Unternehmen mit staatlicher Beteiligung eingesetzt wurde. Er betraf z.B. Alfa Romeo (Pomigliano/Neapel) und DAF (Born/Limburg). Vgl. Bhaskar/MIRU 1990, S. 4-6, und Franzmeyer/Seidel 1976, S. 76. 
mobilindustrie in Italien, die in steuerlichen Vorteilen für den Kauf italienischer Fahrzeuge bestand, schaffte die italienische Regierung nach entsprechenden Vorschlägen der Kommission nach Art. 93,I EWGV $1961 \mathrm{ab}^{8}$.

Die 1. Ölkrise ab 1973 mit den folgenden massiven Benzinpreiserhöhungen, Geschwindigkeitsbegrenzungen und vorübergehenden Fahrverboten traf die Autoindustrie jedoch sehr hart. Es kam zu Produktions- und Absatzrückgängen (vgl. Abb. 4.4-1), Entlassungen und Verlusten, die die Liquidität einiger Unternehmen stark gefährdeten ${ }^{9}$.

\subsubsection{Erste Ansätze zur Subventionskontrolle}

Als Folge sahen sich die französische (Citroen), britische (Chrysler UK, British Leyland) und deutsche (VW) Regierung veranlaßt, zur Stützung der Industrie mit Subventionen einzugreifen: Diese umfaßten in den ersten drei Fällen zinsgünstige langfristige Darlehen und Kreditbürgschaften, Kapitalaufstockungen und Verlustausgleiche sowie bei VW Regionalhilfen im Rahmen eines Sonderprogramms zur Schaffung von Ersatzarbeitsplätzen (vgl. auch Tab. 4.4-1) ${ }^{10}$. Obwohl es sich hier (abgesehen von VW) eindeutig um Hilfen handelte, die einzelne Unternehmen in einem Sektor bevorzugten, in dem starker innergemeinschaftlicher Handel herrschte und somit Wettbewerbsverzerrungen zu befürchten waren - im Fall BL erklärt die Kommission sogar explizit, daß die Subventionen dazu dienen sollten, "die Stellung (von BL) auf dem Binnenmarkt zu behaupten und seine Ausfuhren zu erhöhen"11 wurden alle Hilfen genehmigt. Dies wurde damit begründet, daß die Unternehmen nach den vorgesehenen Umstrukturierungen, über die die Kommission unterrichtet werden wollte, wieder allein lebensfähig sein würden, wobei dies im Falle Citroen (und später dann auch Chrysler UK) mittels einer Übernahme durch Peugeot

8 Vgl. EWG, Kommission 1961, S. 76.

9 Vgl. EG, Kommission 1976a, S. 103.

10 Vgl. ebenda, S. 103-105, und Mutti 1982, S. 33-35. Ein weiteres Subventionselement für VW bestand im Verzicht der Bundes- und Landesregierung auf Dividendenzahlungen in den Jahren 1973 und 1974.

11 EG, Kommission 1976a, S. 104. Mutti (1982, S. 35) weist darauf hin, daß BL, um die gleiche Rendite für seine Aktionäre wie der Konkurrent Ford UK zu erzielen, 1978 um 6-7\% höhere Preise hätte verlangen müssen. Durch die Kapitalzuführung wurde der Staat bei BL zum Mehrheitsaktionär. Vgl. Carmoy 1978, S. 40. 
geschah. Bei den britischen Fällen dienten zudem arbeitsmarkt- und regionalpolitische Überlegungen sowie Handelsbilanzprobleme zur Rechtfertigung 12 .

Tab. 4.4-1

Subventionsfälle 1975 (in MECU)

\begin{tabular}{l|rrrr} 
Firma & Darlehen & $\begin{array}{r}\text { Kapitalzuschuß/ } \\
\text { Verlustausgleich }\end{array}$ & Garantien & $\begin{array}{r}\text { Regional- } \\
\text { beihilfen }\end{array}$ \\
\hline Citroen/PSA & 42,0 & - & - & - \\
Renault/Berliet & 84,6 & - & - & - \\
Brit. Leyland & 892,8 & 357,1 & 357,1 & - \\
Chrysler UK & 98,2 & 129,5 & 62,5 & - \\
VW & - & - & - & 6,6
\end{tabular}

Quellen: EG, Kommission 1975a, und MIRU 1987.

Diese ersten größeren Subventionsfälle waren jedoch gleichzeitig der Auslöser für Überlegungen zur Entwicklung spezifischer Regeln für die Subventionskontrolle im Automobilbereich, da in einem stagnierenden oder schrumpfenden Markt die Auswirkungen von Wettbewerbsverzerrungen durch Subventionierung stärker empfunden wurden ${ }^{13}$. Die Krise war dabei durch eine Mischung von konjunkturellen und strukturellen Problemen verursacht, wobei die Kommission in ihren Dokumenten ${ }^{14}$ die strukturellen Probleme der Industrie in der folgenden Dekade und die daraus resultierenden Anpassungszwänge besonders betonte.

In dem Arbeitsdokument über Akzeptanzkriterien für Automobilsubventionen 15 wurde keine Unterscheidung zwischen beiden Faktoren vorgenommen. Stattdessen waren zwei Grundsätze zur Beurteilung von Subventionsanträgen vorgesehen: Zum einen sollten Beihilfen untersagt werden, die die mittelfristige Anpassung an die Marktbedingungen hinauszögerten, zum anderen sollten die begünstigten Unter-

12 Vgl. Mutti 1982, S. 35, und Swann 1984, S. 150. Bei den britischen Beihilfen spielte auch die Überlegung eine Rolle, das anstehende Referendum in diesem MS über den EG-Verbleib nicht negativ zu beeinflussen. Dementsprechend wurde auch die ablehnende Haltung des Wettbewerbskommissars Borschette zu den Chrysler-Beihilfen im Kollegium der Kommissare überstimmt. Die Motivation zur Vergabe der Beihilfen war hier hochgradig politisch beeinflußt, da die Labour-Regierung mit der Rettung von Chrysler auch die Rettung eines Tochterunternehmens in Schottland bezweckte, um so den Verlust von Wählerstimmen an nationalistische Parteien zu verhindern. Vgl. Warnecke 1978, S. 165, 169.

13 Vgl. EG, Kommission 1975c, S. 12.

14 Vgl. z.B. EG, Kommission 1976a, S. 102f., und 1976c, S. 2-9, 13

15 Vgl. EG, Kommission 1975d. Das Dokument war ursprünglich lediglich als erster Entwurf gedacht, wurde jedoch nie revidiert. 
nehmen aus ihren Beihilfen keinen Vorteil im innergemeinschaftlichen Handel ziehen. Als operative Merkmale für die Erfüllung der ersten Bedingung sollten gelten: Kapazitätsanpassungen einschl. externer Diversifizierung (Vermeidung von Beggarthy-neighbour-policies), Produktanpassungen, Erhöhung der Wettbewerbsfähigkeit gegenüber Drittländerkonkurrenz durch Produktivitätserhöhung oder Rationalisierung einschl. Zusammenschlüssen oder Kooperationen zwischen Unternehmen sowie Reformen in der Geschäftsführung, die eine finanzielle Gesundung des Unternehmens erwarten lassen. Für das Handelskriterium sah es die Kommission als entscheidend an, daß die Beihilfe nicht mittels einer Entschuldung des begünstigten Unternehmens diesem Preissenkungen unter diejenigen der Konkurrenten am Markt erlaubte und daß sie nicht zur Erhaltung von Überkapazitäten und damit zur Überwälzung der Strukturprobleme auf Konkurrenten sowie Handelsverlagerungen führte.

Weiterhin wurden Beihilfen für Produkte, die vorwiegend in Drittstaaten exportiert werden, als weniger problematisch angesehen, da ihr Effekt auf den Binnenmarkt geringer sei und sie außerdem zum Ausgleich der Handelsbilanz beitrügen. Schließlich waren auch Beihilfen zur Beschäftigungssicherung in benachteiligten Gebieten akzeptabel.

Insbesondere die zwei Hauptkriterien bedürfen einer Vorstellung über die Marktentwicklung, die in diesem Arbeitsdokument und ausführlicher in einer späteren Studie zur Zukunft der Automobilindustrie 16 dargelegt wurde. Sie beinhaltete eine Prognose von $3 \%$ p.a. für das Wachstum den Binnen- wie des Weltmarktes ab 1976 bei Verlagerung der Nachfrage von mittelgroßen auf kleine Modelle und einer zunehmenden Konkurrenz durch Produzenten in der dritten Welt.

Ein Problem des Arbeitsdokuments ist das Fehlen jeglicher Definition der von ihm erfaßten Subventionstypen sowie von quantitativen Kriterien für ihre höchstzulässige Intensität. Die Anwendung der Regeln und Kriterien im Dokument bezieht sich zudem nur auf direkte sektorale Subventionen, da wohl im Einklang mit theoretischen Überlegungen regionale und horizontale Beihilfen (z.B. Förderung der Schaffung von Alternativarbeitsplätzen) als weniger stark verzerrend angesehen wurden. Dementsprechend werden Regionalbeihilfen auch pauschal als positiv angesehen, ohne allerdings auf mögliche negative sektorale Nebeneffekte einzugehen. Daneben besteht auch ein möglicher Widerspruch zwischen der gewünschten Erhöhung der Wettbewerbsfähigkeit nach außen und den zu

16 Vgl. EG, Kommission 1976c, S. 6-7, 11-13. 
verhindernden Wirkungen auf den Binnenhandel. Da es de facto keine Produkte im Pkw-Bereich gibt, die ausschließlich innerhalb der Gemeinschaft oder ausschließlich auf Drittmärkte exportiert werden, wird jede Produktivitätserhöhung, die durch Beihilfen gefördert wird, dem Unternehmen die Möglichkeit zu Preissenkungen geben bzw. seine Produktionsmöglichkeiten, d.h. die Kapazität, erhöhen, wobei beide Effekte auf allen Märkten auftreten werden. Eine Auflösung dieses Widerspruchs gelänge nur durch (Gemeinschafts-) Beihilfen an alle Hersteller oder Subventionen für Kooperationsprojekte. Schließlich ist auch das Handelskriterium selbst zu weich gefaßt, da bereits der Verbleib der an sich bankrotten Unternehmen im Markt zu Auswirkungen auf die Konkurrenten und damit zu Handelsverzerrungen führt.

\subsubsection{Versuche der Entwicklung eines umfassenderen Kontrollkonzepts}

Dieser rudimentäre Subventionskontrollrahmen sollte in ein industriepolitisches Gesamtkonzept eingebettet werden, das folgende weitere Elemente enthielt: zumindest wohlwollende Duldung eines Konzentrationsprozesses, Förderung von Forschungskooperation auch aus EG-Mitteln, handelspolitische Maßnahmen zur Erleichterung von Exporten und Beseitigung von innergemeinschaftlichen technischen Handelshemmnissen. Zu diesem Zweck strebte die Kommission die Bildung von zwei Arbeitsgruppen an, zum einen die interne Inter-Services-Group Automobilindustrie, zum anderen eine Ad-hoc-Gruppe mit Vertretern der MS ${ }^{17}$.

Die Inter-Services-Group Automobilindustrie bereitete unter Federführung von DG III eine Studie zur Lage und Zukunft der europäischen Automobilindustrie vor, die auch Passagen zur Frage der Beihilfenkontrolle enthielt. Hierbei traten Meinungsverschiedenheiten auf zwischen der eher industriepolitischen Konzeption der DG III, die gemeinschaftliche Finanzierungsinstrumente und nationale Beihilfen zur Förderung der Wettbewerbsfähigkeit der europäischen Industrie auf dem Weltmarkt gegen japanische und US-Konkurrenz u.a. mittels Kapazitätslenkung sowie Fusionen und Kooperationen unter Zurückstellung der wettbewerbspolitischen Konsequenzen innerhalb der EG (Weltmarktbetrachtung) einsetzen wollte, und der gegenüber Interventionen und einer Aushöhlung bzw. Umfunktionierung der Beihilfenkontrolle eher skeptischen DG IV. Die Überlegung, einen Gemeinschaftsrahmen für Autosubventionen zu erstellen, wurde von DG IV zunächst eher skeptisch beurteilt, da ein solches Vorgehen nur in wirklichen Krisensektoren (mit struktureller Überkapazität) angebracht sei und wenn alle Beteiligten sich über die Ziele und die notwendigen

17 Vgl. EG, Kommission 1976c, S. 14-22. 
sektorspezifischen Maßnahmen einig seien, was hier noch nicht der Fall war; dies auch deshalb, weil die Problemlage zwischen den einzelnen Unternehmen doch stark variierte. Auch einige MS standen einem Gemeinschaftsrahmen, der alle Subventionen einschließlich der Regionalbeihilfen, die anderen Zielen dienten, einheitlicher strenger Kontrolle unterworfen hätte, ablehnend gegenüber.

Als Maßnahmen zur Verbesserung der Beihilfenkontrolle strebte die Kommission zum einen eine Ex-post-Meldepflicht der MS nach Art. 93,I für alle den Automobilunternehmen zugutekommenden Beihilfen einschließlich regionaler und allgemeiner Maßnahmen im Rahmen genehmigter Beihilfenprogramme an, um so einen besseren Überblick als Basis für Diskussionen mit den MS - auch zur möglichen Vorbereitung eines Gemeinschaftsrahmens - zu gewinnen 18. Dieser Überblick sollte ihr dann ermöglichen, im Falle der Entstehung struktureller Überkapazitäten durch subventionierte Investitionen die "Notbremse" zu ziehen 19. Zum anderen nahm die Kommission eine differenzierte Haltung zu verschiedenen Beihilfekategorien ein. So sollten reine Erhaltungssubventionen verboten werden, Hilfen zum Ausbau von Unternehmen außerhalb gemeinsamer Politiken nur sehr beschränkt genehmigt werden und Anpassungs- und Umstrukturierungshilfen in Dauer und Intensität begrenzt werden. Positiv stellt sich die Kommission zu FuE-Subventionen, z.B. zur Energieeinsparung und zum Umweltschutz, wobei erstere in der einsetzenden 2. Ölkrise besondere Bedeutung gewannen 20 .

In der eigentlichen Studie 21 wurde im Kapitel über staatliche Interventionen zunächst auf staatliche Förderung in den Konkurrenzländern USA (Fall Chrysler) und Japan (durch das MITI) hingewiesen. Staatliche Beihilfen (und EG-Mittel) wurden als Instrument der Verbesserung der Wettbewerbsfähigkeit der EG-Autoindustrie insgesamt angesehen, wobei die Gemeinschaftswirkungen zu beachten seien. Während der letzte Aspekt die eigentliche Zielrichtung der Beihilfenkontrolle ausmacht, erklärte sich die Kommission doch auch bereit, bei dieser die Lage auf dem Weltmarkt insgesamt $\mathrm{zu}$ berücksichtigen, wobei ihr eine gemeinschaftlich abgestimmte Anpassungsstrategie vorschwebte, die sich z.B. in den Vergabekriterien von EGFördermitteln ausdrückt. Das Vorhaben der Ex-post-Beihilfenkontrolle wurde

18 Vgl. Cownie 1986, S. 258.

19 Vgl. EG, Kommission 1981g, S. 2, und 1981f, S. 50.

20 Vgl. auch EG, Kommission 1981f, S. 50.

21 Vgl. EG, Kommission 1981f, S. 49-51. 
bekräftigt. Insgesamt wirkt das Konzept wie eine Mischung aus industriepolitischer Steuerung und wettbewerbspolitischer Kontrolle22.

\subsubsection{Die Umsetzung des Konzepts in der Genehmigungspraxis}

\subsubsection{Einige Anwendungsfälle}

Diese Mischung aus industrieller Förderung und wettbewerbsorientierter Kontrolle bestimmte auch das Handeln der Kommission in konkreten Beihilfefällen während dieser Periode der Herausbildung einer Politik. Während in den Jahren 1978/79 Kfz-Beihilfen als Ausprägungen allgemeiner Beihilferegeln genehmigt wurden 23 , ging es in der ab 1980 verschlechterten konjunkturellen Lage, in der die Produktion in der EG sank und die finanzielle Lage der großen europäischen Produzenten sich rapide verschlechterte, um die Beurteilung größerer Einzelfälle, die alle genehmigt wurden.

Dies galt mit einer Beschränkung auf Umweltschutzbeihilfen für die GeneralMotors-Europe Anlage in Antwerpen (Reduktion des beihilfefähigen Investitionsvolumens auf $40 \%$ der ursprünglich geplanten Summen, Subventionsgrad $15 \% 24$ ), während massive Kapitalerhöhungen für Volvo Car BV (Niederlande) und British Leyland voll akzeptiert wurden, wobei erneut die Beschleunigung bzw. Ermöglichung einer Rationalisierung der Unternehmen als Begründung genannt wurden 25 .

22 Viele der anderen in der Studie angesprochenen Aspekte sind heute noch aktuell bzw. erst in jüngster Zeit umgesetzt worden, zeigen also die lange Zeit bestehende relative Erfolglosigkeit der Kommission bei der Umsetzung ihrer Positionen: So wird der Produktivitätsrückstand gegenüber der japanischen Konkurrenz beleuchtet, der u.U. durch Fusionen der Firmen (Economies of scale), v.a. aber durch - z.T. von der EG subventionierte - Forschungskooperation, wettgemacht werden soll. Im Binnenmarktbereich ging es der Kommission um den Abbau technischer Handelshemmnisse (Typenzulassung) und die Harmonisierung der Besteuerung von $\mathrm{Kfz}$ und Treibstoff sowie von Umweltschutzauflagen, um hier Marktverzerrungen und Nachteile von EG-Produzenten aufgrund der Notwendigkeit unterschiedlicher Modellspezifikationen für die Einzelmärkte abzubauen. Außenhandelspolitisch wird das Ziel der Aufhebung einzelstaatlicher Importkontrollen für japanische Autos und ihre Ersetzung durch Gemeinschaftsregelungen angesprochen. Vgl. zum aktuellen Stand die Abschnitte 4.4.10 und 4.4.11.

23 Vgl. EG, Kommission 1979a, S. 169/70, und 1980a, S. 131.

24 Vgl. EG, Kommission 1981a, S. 157.

25 Vgl. EG, Kommission 1981a, S. 156-158. Die Genehmigung für Volvo Car BV, bei der es sich um einen revolvierenden zinsfreien Investitionsfonds handelt, verursachte für die Beihilfenkontrollpolitik der Kommission im Automobilbereich noch bis in die jüngste Vergangenheit Probleme. Siehe unten Abschnitt 4.4.7.3. 
Außerdem beteiligte sich im Falle Volvo die schwedische Muttergesellschaft entsprechend ihrem Anteilsbesitz an der Kapitalerhöhung26, so daß die Kommission hier kein Beihilfeelement nachweisen konnte. Dasselbe galt für weitere Einschüsse durch die beiden Aktionäre für zusätzliche Investitionen 1982 und 1983, auch wenn zwischenzeitlich der Staatsanteil durch einseitige Kapitalerhöhung auf $70 \%$ gestiegen war. Im Falle BL wurde für die zweite Tranche dieser Kapitalerhöhung (insges. 990 Mio. $£$ incl. 1980) zwar zunächst das Prüfverfahren eröffnet, später jedoch eingestellt, obwohl die Kommission noch Zweifel am Erfolg der subventionierten Umstrukturierung hatte. Zur Kontrolle verlangte sie Berichte über die Umstrukturierungsfortschritte sowie die tatsächliche Durchführung der geplanten Investitionen und die Schließung der verlustträchtigen Unternehmensbereiche27. Für das VWWerk in Brüssel wurde 1979 eine Beihilfe für Modernisierungsinvestitionen mit einem Nettosubventionsäquivalent von $4 \%$ genehmigt, da keine Kapazitätserhöhung oder Handelsbeeinträchtigung auftrat. Ein zweites Projekt von 1981, das Investitionshilfen für die Modernisierung einer Montagestraße und die Einführung eines neuen Modells vorsah, wurde nach Widerstand der Kommissionsdienststellen aufgrund der direkten Verknüpfung mit üblichen unternehmerischen Produktionsentscheidungen 1982 von den belgischen Behörden zurückgezogen.

In der Folgezeit versuchte die Kommission, das Projekt der Ex-post-Kontrolle umzusetzen und dafür die Kooperation der MS zu gewinnen ${ }^{28}$. Es gelang auch, eine Liste der regionalen und allgemeinen Beihilfeprogramme aufzustellen, die der Autoindustrie zugutekommen konnten, daneben wurde von DG IV ein Musteranmeldebogen entwickelt. Dennoch traten bei den Diskussionen mit den Mitgliedstaaten Probleme technischer Art ebenso wie grundsätzliche Widerstände zutage. Erstere betrafen u.a. die Abgrenzung des Sektors (Frage des Einschlusses der Komponentenzulieferer), die einzubeziehenden Beihilferegelungen, die Verfügbarkeit von Daten und damit die Vergleichbarkeit der Ergebnisse, die Informationstiefe und ihre Nutzung durch die Kommission einschl. Vertraulichkeits- und Datenschutzfragen sowie die Häufigkeit der Berichterstattung. Grundsätzliche Widerstände kamen v.a. von deutscher Seite, die den relativen Nutzen der Maßnahme im Verhältnis zu den Erfassungskosten als gering ansah und insbesondere die sektorale Analyse auch allgemeiner Subventionen analog den Krisenbranchen Schiffbau und Stahl als in diesem Sektor unangebracht ablehnte, wobei die Befürchtung

\footnotetext{
26 Vgl. EG, Kommission 1981a, S. 158.

27 Vgl. EG, Kommission 1982a, S. 151/152.

28 Vgl. EG, Kommission 1983a, S. 142.
} 
der Entwicklung einer dirigistischen europäischen Industriepolitik im Hintergrund stand. Dieser Widerstand der wichtigsten autoproduzierenden MS, neben D waren dies auch UK, I und F, wobei letztere auf das Ersuchen der Kommission nach einem Expertentreffen erst gar nicht reagierten, während die ersten beiden den Ausschluß von FuE-Beihilfen von der Mitteilungspflicht wünschten, ließen auch die Kommission an der Nützlichkeit und Durchführbarkeit des Vorhabens zweifeln. Dementsprechend enthält der Umsetzungsbericht ${ }^{29}$ zur Studie 1981 auch nur eine Feststellung der Notwendigkeit weiterer Diskussionen. Im weiteren Verlauf wurde dann die Ex-post-Kontrolle stillschweigend aufgegeben; dieser Versuch einer umfassenden sektoralen Kontrolle war also am Widerstand der MS gescheitert.

Allerdings sollte zumindest die Richtlinie über die Transparenz der finanziellen Beziehungen zwischen den MS und ihren öffentlichen Unternehmen ${ }^{30}$ vorrangig auf die Automobilindustrie, in der diese Beziehungen eine wichtige Rolle spielen, angewandt werden.

Auch die im Jahre 1983 gemeldeten Beihilfen in Form von Zinssubventionen und zinsgünstigen Krediten für FIAT, Alfa Romeo und einige Zulieferer wurden schließlich im Mezzogiorno voll (1200 Mrd. Lira) und in Norditalien in verminderter Höhe (ca. 35\% des geplanten Niveaus, d.h. zu 315 Mrd. Lira) genehmigt, nachdem zunächst für die Projekte in Norditalien das Prüfverfahren eröffnet worden war ${ }^{31}$. Während die italienische Seite die Lage im Automobilsektor als krisenhaft ansah und die vorgesehenen Hilfen als notwendigen Teil eines Umstrukturierungsprogramms erachtete, das mit den industrie- und wettbewerbspolitischen Leitlinien der Kommission übereinstimmte, betrachtete die Kommission die Lage des Sektors als nicht überdurchschnittlich krisenhaft und die mangelnde Wettbewerbsfähigkeit der italienischen Firmen als durch eigene Fehler verursacht, während der Modernisierungscharakter der Investitionen, das Fehlen eines klaren Umstrukturierungsprogramms und der de facto nur geringe Kapazitätsabbau keine massiven Subventionen rechtfertigten. Die Änderung der Kommissionsposition wurde durch die oben erwähnte Verminderung der Beihilfen und die Zusage weiterer Kapazitätsreduktionen erreicht.

Gegen weitere Subventionen für BL $(100 \mathrm{~m} \mathfrak{f})$ zum Abschluß der Umstrukturierung wurde zunächst das Verfahren eröffnet, dann zog UK dieses Projekt ebenso wie

\footnotetext{
29 Vgl. EG, Kommission 1983i, S. 37-38.

30 Vgl. EG, Kommission 1980h, und 1984a, S. 189, sowie oben Abschnitt 4.1.4.3.

31 Vgl. EG, Kommission 1984a, S. 175, und 1985a, S. 174f.
} 
die Zahlung der letzten Rate der 1981 genehmigten Hilfen von 740 Mio. $£$ aufgrund der verbesserten finanziellen Lage des Unternehmens zurück ${ }^{32}$.

Zur gleichen Zeit untersuchte die Kommission die Darlehensvergabepraxis des neugeschaffenen Fonds industriel de modernisation (FIM) in Frankreich, der mittels Steuerbefreiungen nominell niedrig verzinsliche Spareinlagen attrahierte und diese in zinsgünstige und staatlich verbürgte Darlehen an vom Staat ausgewählte Unternehmen zur Anwendung neuer Technologien u.ä. transformierte. Die Kommission wertete diese Darlehen als Subvention und verlangte die Ex-ante-Meldung wichtiger Einzelanwendungsfälle zur Überprüfung ihrer Kompatibilität, die Frankreich auch zusagte $^{33}$. Die FIM-Darlehen sind für den hier betrachteten Sektor relevant, da sie ausdrücklich auch zur Entwicklung sehr wirtschaftlicher Fahrzeuge gewährt werden konnten und an Renault und Peugeot gewährt wurden 34 . Beide Produzenten litten 1983/84 unter deutlichen Absatzrückgängen und hohen Verlusten aufgrund niedriger Produktivität bei gleichzeitigen staatlichen Preiserhöhungssperren, was zu großen Entlassungen zu führen drohte, die staatlicherseits zunächst unterbunden wurden. Im Falle Renaults glich der französische Staat als Alleinaktionär weiterhin - und von der Kommission zunächst unbeanstandet - die Verluste durch jährliche Kapitalzuführungen aus ${ }^{35}$. Schließlich wurden im Falle Peugeots von der Kommission entgegen der Empfehlung von DG IV EIB-Kredite für Modernisierungen genehmigt, obwohl gleichzeitig gegen staatliche Beihilfen für ebensolche Modernisierungsinvestitionen an dasselbe Unternehmen das Prüfverfahren lief. Hier zeigt sich eine gewisse Inkonsistenz der Regeln, da Art. 130 EWG-Vertrag der EIB explizit gestattete, Kredite für Modernisierungen zu vergeben, während staatliche Beihilfen für derartige Investitionen regelmäßig nach Art. 92 beanstandet wurden.

32 Vgl. EG, Kommission 1985a, S. 175, und 1984f, S. 3.

33 Vgl. EG, Kommission 1985a, S. 175, und 1985m, S. 18.

34 So erhielten 1984-86 Peugeot 1,75 Mrd. FF und Renault 1,25 Mrd. FF Kredite aus dem FIM, die im Jahre 1984 ca. 30\% der gesamten Ausleihungen des Fonds entsprachen. Dazu erhielt der Zulieferer Jaeger noch 60 Mio. FF. Gegen alle Kredite wurde das Prüfungsverfahren eröffnet. Vgl. hierzu EG, Kommission 1986a, S. 175f., Les Echos 1985 und Financial Times 1984. Zu den Ergebnissen siehe unten Abschnitt 4.4.7.1.

Dies gilt für Zuführungen in Höhe von 4,2 Mrd. FF für 1980-84. Der französische Wirtschaftsund Sozialausschuß und die von der Regierung eingesetzte Dalle-Kommission befürworteten darüberhinaus staatliche Liquiditäts- und Investitionshilfen (Beteiligungsdarlehen) in Milliardenhöhe über mehrere Jahre. Vgl. Le Nouveau Journal 1984, S. 8, und 1984a, S. 1f., sowie Le Monde 1984, S. 1, 24. Gegen spätere Zuführungen eröffnete die Kommission dann das Prüfungsverfahren. Vgl. Bhaskar/MIRU 1990, S. 16, und unten Abschnitt 4.4.7.1. 
Gegen eine Beihilfe im Rahmen eines Sonderprogramms der Gemeinschaftsaufgabe in Höhe von 51 Mio. DM für Investitionen von 582,1 Mio. DM von Daimler Benz in Bremen eröffnete die Kommission Ende 1985 das Verfahren, da nach ihrer Ansicht die Investition von der Firma bereits beschlossen worden war, bevor Bremen zu einer beihilfefähigen Region wurde, und somit Daimler-Benz hier einen Windfall profit machte. Dennoch genehmigte sie die Beihilfe mit einem NSÄ von $8,31 \%$, die zur Schaffung von 3000 Arbeitsplätzen beitrug, dann aber aufgrund der Arbeitsmarktprobleme in der Region 36.

Auch gegen eine Kapitalhilfe der britischen Regierung von 680 Mio. £ (979 MECU) zur Entschuldung und Umstrukturierung der LKW- und Busproduktion von British Leyland im Zuge der Privatisierung dieser Teilbereiche hatte die Kommission zunächst das Prüfverfahren eröffnet ${ }^{37}$, dieses jedoch später gegen die Zusicherung eines Kapazitätsabbaus in beiden Bereichen von je $60 \%$ eingestellt. Angesichts der Überkapazitäten in Europa wurde dieser Abbau als im Sinne der Gemeinschaft angesehen, während eine Beeinträchtigung der Handelsbedingungen nicht bestehe ${ }^{38}$.

\subsubsection{Fazit - Der Stand 1987}

Angesichts der zunehmenden Häufigkeit und des steigenden Umfangs staatlicher Hilfen an die nationalen Automobilfirmen, die auf einem 1984/85 stagnierenden Markt zum Erhalt von Überkapazitäten und einem staatlich verzerrten Preiskampf zu führen drohten ${ }^{39}$, widmete sich die Kommission nun einer gründlicheren und strengeren Untersuchung der Beihilfen in diesem Sektor.

Im Rahmen der bestehenden Regeln wurde sie von jeder spezifisch sektoralen Beihilfe im vorhinein unterrichtet, jedoch (nach dem Scheitern der Ex-post-Beihilfenkontrolle) von den Anwendungsfällen allgemeiner und regionaler Hilfen nur, wenn diese die festgelegten Schwellen bzgl. Volumen und Intensität überschritten. Da für den Sektor in keinem MS spezifische Beihilfeprogramme existierten ${ }^{40}$, war die

36 Vgl. EG, Kommission 1986a, S. 195, und 1987a, S. 181, sowie MIRU 1987, S. 12, 49.

37 Vgl. EG, Kommission 1987a, S. 148.

38 Vgl. EG, Kommission 1987f, S. 7, und 1988a, S. 172.

39 Vgl. Gooding 1985, S. 9. Dies wurde z.B. vom VDA beklagt, der auch auf die mangelnde Transparenz der Subventionierung staatseigener Firmen in Italien, Frankreich, Großbritannien und dem Beitrittsland Spanien hinwies und eine strengere Genehmigungspraxis der Kommission forderte. Vgl. VDA 1985, S. 1-2. Die Höhe der Überkapazität wurde auf ca. $20 \%$ geschätzt. Vgl. The Economist 1985, S. 14.

40 Eine Auflistung der in den MS für den Sektor verfügbaren Beihilfeprogramme regionaler und allgemeiner Art liefert MIRU (1987, S. 40-80). 
Kontrolle lediglich auf die bedeutenden Anwendungsfälle der anderen genannten Programme beschränkt. Um hier ein übermäßiges Ausweichen der MS zu verhindern, hatte die Kommission in einzelnen Fällen, wie bei den o.a. italienischen Projekten die Notifizierungspflicht auf alle Anwendungsfälle ausgedehnt; schließlich verlangte sie auch die Notifizierung aller Rettungsbeihilfen an Unternehmen ${ }^{41}$.

Selbst diese Hilfen konnten jedoch aus Sicht der Kommission akzeptiert werden, wenn sie Umstrukturierungen mit Kapazitäts- und Arbeitsplatzabbau kombinierten (Bsp. Volvo 1978, BL 1975) ${ }^{42}$. Ähnlichen Charakter besaßen die Beihilfen der britischen und französischen Regierung an Peugeot für die Übernahmen von Chrysler UK und Citroen, die auch das Überleben der übernommenen Firmen sicherten und ihre Umstrukturierung erlaubten, anstatt ihren Marktaustritt zu erzwingen. Vergleichbare Umstrukturierungs- und Kapazitätsabbauargumente wurden auch für die Hilfen an Fiat und Alfa Romeo vorgebracht (s.o.), wobei auch der Regionalaspekt (Transfer von Kapazität in den Mezzogiorno) zur Rechtfertigung diente. Solche Umstrukturierungsbeihilfen für staatliche Unternehmen machten den Großteil des Gesamtbeihilfevolumens in dieser Phase aus ${ }^{43}$. Eine systematische Ex-post-Kontrolle der Durchführung der genehmigten Umstrukturierungspläne durch die Kommission wurde jedoch nicht durchgesetzt.

Regionalbeihilfen wurden als neutral in bezug auf die Kapazitätsentwicklung angesehen, da sie auf die Standortwahl des Unternehmens, nicht aber die Investitionsentscheidung an sich Auswirkungen hätten. Zur Regionalentwicklung wurden Hilfen an die Autoindustrie dabei als besonders nützlich betrachtet, da sie stabile Arbeitsplätze in einem nicht-schrumpfenden Sektor schufen. Aus diesen Gründen hielt die Kommission solche Beihilfen für akzeptabel und genehmigte sie i.d.R. nach Art. 92,IIIa oder c bzw. für das Zonenrandgebiet und Berlin nach Art. 92,IIc. Diese Beihilfenkategorie machte wohl neben Rettungs- und Umstrukturierungshilfen den Großteil der gezahlten Beihilfen aus. Auch hier gelang keine ausreichende Kontrolle darüber, daß diese Hilfen wirklich für Zwecke der Regionalentwicklung und nicht etwa für normale Modernisierungs- und Ersatzinvestitionen eingesetzt wurden. Zudem wurde die sektorale Problematik von Wettbewerbsvorteilen einzelner Unternehmen bei Überkompensation der regionalen Standortnachteile durch Beihilfen nicht angegangen.

41 Vgl. EG, Kommission 1979, S. 176-78.

42 Vgl. Bhaskar/MIRU 1990, S. 6.

43 Vgl. EG, Kommission 1988a, S. 149. 
Schließlich wurden Beihilfen für Umweltschutzmaßnahmen, Energieeinsparung und FuE vorwiegend nach Art. 92,IIIb genehmigt, wobei hier die Gefahr auftrat, daß die MS Beihilfen anderer Provenienz unter diesen Kategorien präsentierten, um von der positiveren Haltung der Kommission zu ihnen zu profitieren. Eine Beurteilung von Grenzfällen verlangt hier häufig detaillierte Kenntnis technischer Gegebenheiten der Automobilproduktion.

Insgesamt waren daher trotz einer zunehmend strengeren Anwendung der Beihilferegeln in den Jahren 1977-87 Beihilfen in Höhe von geschätzten 26 Mrd. ECU an die Produzenten in der EG geflossen ${ }^{44}$, und es hatte bis Ende 1987 trotz häufiger Eröffnungen des Prüfverfahrens in keinem einzigen Fall eine negative Entscheidung der Kommission gegeben. Dies lag wohl auch an der strategischen Bedeutung, die die MS "ihren" Autoproduzenten beimaßen 45 und die sie dazu bewogen, in kritischen Grenzfällen Druck auf die Kommission im Sinne einer positiven Entscheidung auszuüben. So war dann auch trotz aller weltwirtschaftlichen Umbrüche seit Anfang der 60er Jahre kein einziger europäischer Produzent aus dem Markt gegangen; schwerwiegende Krisen wurden durch Übernahmen gelöst (Chrysler UK, Citroen, Berliet) ${ }^{46}$. Dennoch erwähnt die Kommission in dieser Zeit in keinem Fall eine Beschwerde eines Produzenten wegen übermäßiger Hilfen für Konkurrenten. Die Aussicht, bei ähnlichen eigenen Problemen auch die Unterstützung der eigenen Regierung ohne Widerstand der Konkurrenten in Anspruch nehmen zu können, hielt die Firmen wohl davon ab und ließ sie die Verschlechterung der eigenen Wettbewerbsposition hinnehmen. Zudem könnte die Befürchtung eine Rolle gespielt haben, daß ein Widerstand eines Unternehmens gegen Subventionsprojekte anderer MS diesem evtl. Schwierigkeiten bei der technischen Zulassung seiner Modelle in jenem MS bringen könnte, da den MS noch die Verantwortung für die Typenzulassung oblag. Schließlich könnte die Überlegung eine Rolle gespielt haben, daß bspw. für zukünftige Forschungsprojekte Kooperationen mit anderen Produzenten nötig werden könnten, so daß eine Verschlechterung der Beziehungen zu diesen aufgrund von Beschwerden über Beihilfen kontraproduktiv wären. Ein weiterer, als weniger negativ zu betrachtender Aspekt kann darin bestanden haben, daß die Konkurrenten fürchteten, mit dem Ausscheiden eines bedeutenden Produzenten könnte die Zulie-

\footnotetext{
44 Vgl. Bhaskar/MIRU 1990, S. 57.

45 Als Beispiel sei hier Alfa Romeo genannt, dessen Fabrik bei Neapel die italienische Regierung aus Beschäftigungsgründen trotz einer Kapazitätsauslastung von lediglich $38 \%$ in Betrieb halten wollte. Vgl. MIRU 1987, S. 58-59.

46 Vgl. Bhaskar/MIRU 1990, S. 76.
} 
fererindustrie aufgrund der auf sie überschwappenden Probleme an Leistungsfähigkeit verlieren. Dieser Aspekt wird bspw. auf die Beihilfen an BL bezogen 47 .

\subsubsection{Die Entwicklung des Gemeinschaftsrahmens}

Angesichts der eben skizzierten Probleme, des intensiven Intra-EG-Handels und des immensen Investitionsbedarfs in der Industrie zur Modernisierung im Zuge der Verwirklichung des Binnenmarktes und eines Abbaus der Außenprotektion sah die Kommission hier die Gefahr eines verschärften Subventionswettlaufs mit zunehmenden Wettbewerbsverzerrungen und strebte eine strengere Beihilfenkontrolle an. Dieser Wettlauf konnte vor allem um die zunehmenden Ansiedlungen japanischer Produzenten in der Gemeinschaft entstehen 48 . Die Kontrolle sollte eine allgemein höhere Transparenz der Subventionsprogramme und strengere Notifizierungsverpflichtungen enthalten. Bei letzterem Aspekt ging es vor allem um eine Ex-anteNotifizierungspflicht aller Anwendungsfälle genehmigter Beihilfeprogramme, da die Beschränkung auf eine Ex-post-Kontrolle, wie sie 1981 angestrebt worden war, der Kommission die Möglichkeit nahm, bei Verzerrungen die gezahlten Hilfen zurückzufordern. Weitere Ziele waren die Zurverfügungstellung detailierterer Umstrukturierungspläne durch die Beihilfeempfänger und deren spätere Überprüfung durch DG IV sowie strengere "Qualitätskontrollen" bei der Vergabe von Regionalbeihilfen (Tatsächlicher Beitrag zur regionalen Entwicklung?) und Umstrukturierungshilfen (Reduktion von Überkapazitäten zur Marktstabilisierung). Schließlich galt es auch zu vermeiden, daß Mittel aus Gemeinschaftsfonds für Projekte vergeben wurden, deren nationales Beihilfeelement noch der Prüfung durch DG IV unterlag bzw. von ihr abgelehnt worden war 49 .

Ein Entwurf für einen Gemeinschaftsrahmen für Beihilfen an die Kfz-Industrie wurde von der Kommission im Juli 1988 verabschiedet. Nach Durchführung der notwendigen Konsultationen mit den anderen betroffenen Generaldirektionen und einer multilateralen Diskussionsrunde mit allen MS beschloß die Kommission den Rahmen endgültig im Dezember $1988^{50}$ und setzte ihn im folgenden Monat für zunächst zwei Jahre in Kraft.

\footnotetext{
47 Vgl. Caspari 1981, S. 9.

48 Vgl. Hanke 1989, S. 44

49 Vgl. EG, Kommission 1989m, S. 4. Hier trat der Übergang von der Projekt- zur Programmtinanzierung als erschwerender Faktor aus Sicht der Beihilfenkontrolle hinzu, da hierdurch in $50 \mathrm{Vgl}$. EG, Kommission 1989m, S. 3-11, und 1989a, S. 149f.
} 
Die Diskussion des Vorhabens rankte sich um mehrere Aspekte: Zunächst wurde von einigen MS, v.a. Deutschland, die Notwendigkeit eines solchen Gemeinschaftsrahmens überhaupt angezweifelt, da ein solches Vorgehen in der Vergangenheit ausschließlich in Krisensektoren angewandt worden war, um hier mittels einer strengeren Disziplin die MS von einer Beggar-thy-neighbour-policy abzuhalten. Eine solche Krisensituation lag angesichts der verbesserten Absatz- und Gewinnlage aller großen Produzenten augenscheinlich nicht vor ${ }^{51}$. Demgegenüber verwies DG IV auf die oben erwähnten Herausforderungen an den Sektor, die - quasi präventiv - eine strengere Kontrolle rechtfertigten 52 . Weitere Aspekte der Diskussion waren die Frage der Verknüpfung des Gemeinschaftsrahmens mit einer umfassenden Industriepolitik (siehe hierzu unten Abschnitt 4.4.11.5.), die Höhe der Meldeschwelle und das Problem des Einschlusses der Zulieferer:

An sich wäre es gerechtfertigt gewesen, auch Beihilfen an Zulieferer der Disziplin des Gemeinschaftsrahmens zu unterwerfen, nicht zuletzt wegen der Möglichkeit des Beihilfentransfers über niedrigere Preise an ihre Abnehmer, die Autoproduzenten. Jedoch entschloß man sich am Ende nur zum Einschluß von Beihilfen für Projekte in Werken zur Komponentenherstellung, die im Eigentum der Autoproduzenten selbst sind, da hier diese Transfermöglichkeit am größten war. Hier wäre schon eine klare Trennung der Tätigkeitsbereiche äußerst schwierig gewesen. Auf einen Einschluß aller Zulieferbetriebe wurde wohl vor allem aufgrund der praktischen Probleme bei der Abgrenzung des Sektors verzichtet und aufgrund des hohen administrativen Aufwands durch die hohe Zahl von Klein- und Mittelbetrieben in diesem Bereich (Überwachung, große Zahl von Notifizierungen, vor allem bei niedriger Meldeschwelle). Jedoch wurden die Hersteller von Motoren als der wichtigsten Einzelkomponente in $\mathrm{Kfz}$ in die Disziplin des Rahmens eingeschlossen. Zudem wurde die Ex-ante-Meldepflicht bei Anwendungsfällen genehmigter Beihilfesysteme auf Investitionsvorhaben mit einem Volumen von mehr als 12 Mio. ECU beschränkt, während nicht an Investitionen gebundene Hilfen und Ad-hoc-Subventionen in jedem Fall zu melden waren. In einem von den MS zu erstellenden Jahresbericht, für den der Rahmen detaillierte Formulare enthält, sollten jedoch auch die nicht-meldepflichtigen Subventionen enthalten sein 53 .

Schließlich beschloß die Kommission, auch beantragte Hilfen aus Gemeinschaftsmitteln (Strukturfonds, EIB) mittels einer Kooperation der Dienststellen an

51 S. unten Abschnitt 4.4.6.

52 Vgl. EG, Kommission 1989m, S. 3.

53 Vgl. EG, Kommission 1989m, S. 3f. 
den Wettbewerbsregeln zu messen. Ziel dieser Kooperation war die Durchsetzung eines internen parallelen Prüfungsverfahren für nationale und EG-Hilfen, da letztere i.d.R. nur bei nationaler Kofinanzierung genehmigt werden, und somit eine Konsistenz des Kommissionshandelns 54 .

Der Gemeinschaftsrahmen enthält dann nach Subventionstypen gegliederte Beurteilungskriterien 55 :

- Rettungs- und Umstrukturierungshilfen sollen nur in Ausnahmefällen akzeptabel sein, wenn ein umfassender Umstrukturierungsplan vorliegt und das Fortbestehen und die Sanierung des Unternehmens im gemeinschaftlichen Interesse ist. Generell ist eine Erhöhung des Marktanteils des Subventionsempfängers zu verhindern, bei Kapazitätsüberschüssen (z.B. bei Nutzfahrzeugen) kann sogar ein Kapazitätsabbau verlangt werden.

- Bei Regionalbeihilfen zur Investitionsförderung erkennt die Kommission das Konvergenzziel an, will dieses aber gegen mögliche nachteilige sektorale Wirkungen auf die Konkurrenten durch subventionierte Kapazitätserhöhungen des geförderten Unternehmens abwägen. Dies kann dazu führen, daß in unterstützungsfähigen Regionen die genehmigte Beihilfeintensität einzelner Projekte unter der jeweiligen Höchstgrenze des Rahmens für Regionalbeihilfen bleibt.

- Innovations-, Modernisierungs- und Rationalisierungsinvestitionen sollten nach Ansicht der Kommission generell von den Unternehmen selbst oder über den Kreditmarkt finanziert werden. Selbst bei regionalpolitischen Nebenzielen will die Kommission hier über Beihilfen restriktiv urteilen. Nur umfangreiche Rationalisierungsinvestitionen zu einer grundlegenden Strukturänderung des Unternehmens sollen subventionsfähig sein, während für Innovationshilfen der letzte technische Stand auf Gemeinschaftsebene als Beurteilungskriterium maßgebend sein soll.

- Im Einklang mit dem Gemeinschaftsrahmen für FuE-Beihilfen befürwortet die Kommission solche Hilfen auf der dem Markt vorgelagerten Stufe, sieht jedoch das Problem der Abgrenzung zu den vorher betrachteten Modernisierungsinvestitionen zur betrieblichen Einführung solcher Neuentwicklungen, für die geringere Obergrenzen angebracht sind. Im Vergleich zum FuE-Gemeinschaftsrahmen ist der Kfz-Rahmen insofern strenger, als seine Meldeschwelle mit 12 Mio. ECU um 8 Mio. ECU unter der Grenze im ersteren liegt.

\footnotetext{
54 Vgl. auch EG, Kommission 1989m, S. 4.

55 Vgl. EG, Kommission 1989 m, S. 4/5.
} 
- Beihilfen für den Umweltschutz und die Energieeinsparung sollen nicht dazu mißbraucht werden, die Entwicklung schadstoffarmer und energiesparender Fahrzeuge zu unterstützen, da dies eine Grundaufgabe der Industrie selbst darstellt. Allgemeine Umweltschutzhilfen, z.B. für umweltschonendere Produktionsverfahren, sind jedoch im Einzelfall entsprechend den Regeln des entsprechenden Gemeinschaftsrahmens weiterhin genehmigungsfähig.

- Bei Ausbildungs- und Umschulungssubventionen trennt der Rahmen zwischen solchen, die mit Sachinvestitionen verbunden sind, und anderen. Letztere können zur Sicherung alter oder Schaffung neuer Arbeitsplätze genehmigt werden. Erstere finden nur dann eine separate Berücksichtigung, wenn ihre Intensität begrenzt bleibt und die Investitionen grundlegende Änderungen in den beruflichen Anforderungen an die Beschäftigten mit sich bringen, die die Umschulungen zur Sicherung von Arbeitsplätzen notwendig machen. Bei Nichterfüllung dieser Voraussetzungen gelten die Umschulungsausgaben als Bestandteil der Investition mit entsprechend strengeren Beurteilungskriterien für die gewährten Beihilfen.

- Betriebsbeihilfen schließlich sollen wegen ihrer direkt verzerrenden Wirkung nicht mehr genehmigt und die bisher zulässigen und akzeptierten Subventionen in benachteiligten Regionen nach Art. 92,IIIa und im Zonenrandgebiet progressiv abgebaut werden.

Sicherlich bleiben die Kriterien in vielen Aspekten sehr allgemein und auch unscharf, insbesondere gilt dies für die wichtige Kategorie der Rettungs- und Umstrukturierungshilfen 56 . Hier ist wohl i.d.R. eine Wettbewerbsverzerrung bereits dann gegeben, wenn die unterstützte Firma ihren Marktanteil halten kann, und nicht erst bei Anteilserhöhungen. Auch fehlt es an Hinweisen zur Behandlung von Entschuldungen als Element der finanziellen Umstrukturierung, was insbesondere bei der Privatisierung staatseigener Betriebe eine wichtige Rolle spielt. Angesichts der Tatsache, daß subventionierte Umstrukturierungspläne in der Vergangenheit nicht eingehalten wurden bzw. nicht zu einer Gesundung des Unternehmens führten, wäre auch eine Behandlung der Frage, inwieweit solche Beihilfen mehrfach genehmigungsfähig sein könnten, angebracht gewesen. Auf der anderen Seite könnte eine zu starre Handhabung der Kapazitätsabbauforderung dazu führen, daß in einem temporären (konjunkturellen) Abschwung Kapazitäten permanent (und unter hohen

56 Auch die Unterscheidung der letzteren von Rationalisierungshilfen ist nicht klar. Vgl. Bhaskar/MIRU 1990, S. 45/46. 
Kosten) vermindert werden, deren Wiederaufbau im Aufschwung schwierig sein wird 57 .

Ein weiteres Problem stellt die mögliche Akzeptanz von Beihilfen für Rationalisierungsinvestitionen dar. Im Vergleich zu den Umstrukturierungsbeihilfen, die ein sehr ähnliches Problem betreffen, fehlt die Verknüpfung mit Kapazitätsabbauverpflichtungen. Gegenüber Regionalbeihilfen fehlt der regionale Entwicklungs- und Beschäftigungseffekt, zudem sind solche Hilfen auch außerhalb von Fördergebieten nicht a-priori ausgeschlossen. Üblicherweise sind solche Beihilfen in anderen Sektoren nicht genehmigungsfähig, da angesichts der für die Unternehmen permanenten Rationalisierungsnotwendigkeit die Gefahr besteht, daß sie Betriebsbeihilfencharakter annehmen.

Eine bemerkenswerte Neuerung stellt die quasi-nochmalige Prüfung von Anwendungsfällen genehmigter regionaler Beihilfenprogramme dar. Diese Vorgehensweise ist angesichts ihrer Bedeutung für den Sektor ${ }^{58}$ und der oben diskutierten Überwachungsprobleme einsichtig, führte jedoch zu Befürchtungen, u.a. bei den Regierungen einiger $\mathrm{MS}^{59}$, daß hierdurch die Entwicklung rückständiger Regionen über die Ansiedlung von (Automobil-)Industriebetrieben behindert werden könnte.

Positiv ist jedoch die Tatsache zu werten, daß die zunehmend strenger gewordenen Beurteilungskriterien für Subventionen an diesen Sektor nun durch Kodifizierung festgeschrieben wurden 60 und daß durch ihre Veröffentlichung die Transparenz erhöht wurde mit der Möglichkeit, einen Lenkungseffekt für zukünftige Beihilfeprojekte der MS zu erzielen. Auch die Aufstellung einer Hierarchie der Beihilfetypen, wobei Subventionen um so eher genehmigungsfähig sind, je marktferner die unterstützten Ausgaben oder je weiter entfernt sie von den üblichen betrieblichen Aufwendungen sind, ist zu begrüßen. Der verbleibende diskretionäre Spielraum der Kommission entspricht der Konzeption der Verträge und ist für eine adäquate Einzelbeurteilung unerläßlich. Der Verzicht auf quantitative Kriterien und Vorgaben, z.B. für Produktivitätsverbesserungen, zum Zwecke der Auswahl zu genehmigender Projekte und einer späteren Erfolgskontrolle entspricht der auch im Gemeinschaftsrahmen 61 selbst deutlich gemachten Zielsetzung, dem Sektor keine industriepoli-

\footnotetext{
57 Vgl. Bhaskar/MIRU 1990, S. 43.

58 Diese wird in Zahlen bei MIRU (1987, S. 40-80) demonstriert.

59 S. unten Abschnitt 4.4.6.

60 Vgl. Dawkins 1988a.

61 Vgl. EG, Kommission 1989m, S. 4.
} 
tische Strategie aufzuerlegen62. Hierzu paßt auch der Verzicht auf diskriminierend strengere Kontrollen bei Investitionen ausländischer, insbesondere japanischer, Produzenten in der EG zum Aufbau von Automobilfabriken. Eine solche Diskriminierung war von mehreren MS, so u.a von französischer und griechischer Seite, gefordert worden 63 , da man einerseits eine Umgehung bestehender quantitativer Importbeschränkungen durch solche "Transplants" befürchtete und andererseits vermutete, daß die Japaner nur Produktionsstufen niedriger technologischer Stufe (Schraubenzieherfabriken) in die EG verlagern und keinen technologischen Spillover zulassen würden.

\subsubsection{Durchsetzungsprobleme}

Im Unterschied zu einigen der früher beschlossenen Gemeinschaftsrahmen64 stützte die Kommission den Kfz-Rahmen explizit auf die rechtliche Basis des Art. 93,I, der ihr ermöglichte, im Zusammenhang mit der Überprüfung bestehender Beihilferegelungen den MS zweckdienliche Maßnahmen vorzuschlagen, die durch die Entwicklung und für das Funktionieren des GM notwendig werden(zur Erläuterung des Verfahrens vgl. oben Abschn. 3.2). Dementsprechend ersuchte sie alle MS um ihre Zustimmung zu dem Regelwerk, um es danach dann rechtsverbindlich anwenden zu können. Diese Zustimmung erhielt sie dann im Laufe des 1. Halbjahres 1989 (geplant war 1 Monat), z.T. nach nochmaligen Konsultationen, von allen MS außer Deutschland und Spanien65.

Die deutsche Weigerung basierte auf mehreren Gründen66: Zunächst wurde der Gemeinschaftsrahmen an sich, wie bereits oben diskutiert, als überflüssig und im Lichte früherer, möglicherweise als Präzedenzfälle dienender, Entscheidungen eher noch subventionsfördernd angesehen. Weiterhin befürchtete die Bundesregierung einen Mißbrauch des Rahmens für industriepolitische Ziele67, d.h. in diesem Falle

62 Die Frage der industriepolitischen Strategie für den Sektor stellte sich zu jener Zeit, da parallel zu den Arbeiten am Gemeinschaftsrahmen DG III ein Dokument zur Situation und Zukunft der Automobilindustrie im Binnenmarkt erarbeitete, in dem auch handelspolitische Fragen erörtert wurden. Vgl. hierzu unten Abschn. 4.4.10.1 und 4.4.11.5.

63 Vgl. Dawkins 1988, S. 1.

64 Vgl. oben Abschn. 4.1.

65 Vgl. Bhaskar/MIRU 1990, S. 12.

66 Vgl. zum folgenden auch EG, Kommission 1989s, S. 6-7.

67 Sie konnte sich dabei auf Passagen aus dem Gemeinschaftsrahmen stützen, die eine industriepolitische Interpretation zulassen. So wird die Industrie als "von strategischer Bedeutung" bezeichnet. Ferner will "die Kommission ... zur gedeihlichen Entwicklung dieses Sektors beitragen und die Unternehmen veranlassen, sich rechtzeitig auf veränderte Marktbedingungen einzu- 
für Zwecke der Investitionslenkung, die sie aus ordnungspolitischen Gründen ablehnt. Insbesondere wurde ein zusätzlicher sektoral motivierter Eingriff in die deutsche Regionalförderung befürchtet, die nach Ansicht der Bundesregierung von relativ geringer Intensität und zudem sektorneutral ausgestaltet war, so daß eine nochmalige Überprüfung der Kfz-Beihilfen zu einer generellen Gefährdung der Ziele der deutschen Regionalpolitik mittels einer Aufhebung ihrer Kontinuität und Vorhersehbarkeit (auch durch längere Prüfungsdauern) 68 und einer Diskriminierung dieses Sektors führen würde, die angesichts einer fehlenden Krisensituation in der KfzIndustrie unangebracht sei69. Als praktisches Argument gegen den Rahmen wurde angeführt, daß für eine Umsetzung der Ex-ante-Meldepflicht die Änderung von ca. 160 existierenden Beihilferegelungen im Bundestag notwendig werden würde, da viele Subventionsprogramme (insbesondere das Berlin-FG) aus automatisch gewährten Steuervergünstigungen bestanden, von denen die Finanzämter erst nach Vornahme der Investitionen Kenntnis erhalten 70 . Zudem wurde die Anwendbarkeit des Gemeinschaftsrahmens bzgl. der sog. 92,IIc-Gebiete, d.h. des Zonenrandgebietes und West-Berlins bestritten. Hier sei die Frage der Wettbewerbsverzerrung durch Beihilfen irrelevant; DG IV habe lediglich zu prüfen, ob die Beihilfen nötig zum Ausgleich der Teilungseffekte seien. Ist dies nicht der Fall, kann die Kommission geeignete Maßnahmen vorschlagen und bei Weigerung des MS eine negative Entscheidung treffen. Der Erhalt dieser politisch sensiblen Sonderstellung, insbesondere Berlins ${ }^{71}$, auch im Kfz-Bereich war eines der Hauptziele Deutschlands.

Die Begründung der spanischen Weigerung, den Gemeinschaftsrahmen anzuwenden, rechtfertigt in einer gewissen Hinsicht die deutschen Befürchtungen. Die spanische Regierung forderte nämlich die Berücksichtigung industriepolitischer Globalziele bei der Beurteilung einzelner Beihilfevorhaben, insbesondere der Förderung der technologischen Modernisierung und der finanziellen Sanierung der großen europäischen Automobilhersteller, und war nur bereit, den Rahmen anzuwenden,

stellen." Vgl. EG, Kommission 1989m, S. 3. Diese Kritik wird auch vom VDA geteilt. Vgl. Emmerich 1992, S. 1f.

68 Vgl. EG, Kommission 1989s, S. 7, daneben 1990i, S. 56.

69 Vgl. ebenda: 1989s, S. 7, und 1990i, S. 56.

70 Dieses Argument ist allerdings wenig stichhaltig, da seine Akzeptanz geradezu einen Anreiz für die MS darstellen würde, derartige Beihilfesysteme zu konzipieren, um so die Ex-ante-Notifizierungspflicht des Art. 93 EGV auszuhebeln. Vgl. EG, Kommission 1990i, S. 57, 59, wo zudem

71 Vgl. EG, Kommission 1990i, S. 57. die Vorrangigkeit des Gemeinschaftsrechts betont wird. 
wenn ein solches industriepolitisches Gesamtkonzept vorlag72. Daneben befürchtete sie wohl auch eine zusätzliche Beschränkung der spanischen Regionalpolitik.

Nachdem Konsultationen mit beiden Regierungen nicht zu einer Bereitschaft zur Akzeptanz des Gemeinschaftsrahmens geführt hatten, beschloß die Kommission die Eröffnung des Prüfungsverfahrens gegen beide MS, da sie die Verweigerung der Anwendung als Forderung nach einer besonderen Ausnahme von der Beihilfenkontrolle für die beiden MS ansah, die nach ihrer Auffassung unangebracht war. Dieses Verfahren bezog sich auf alle Beihilferegelungen, die auch der Automobilindustrie zugute kommen können ${ }^{73}$.

In bezug auf der deutschen Argumente bestritt die Kommission, wie bereits oben erläutert, in der Verfahrenseröffnung wie auch im Gemeinschaftsrahmen selbst ${ }^{74}$ strikt, daß sie die Absicht habe, eine industriepolitische Strategie durchzusetzen. Vielmehr sollten die durch nationale industriepolitische Maßnahmen, vor allem Subventionen, in der Vergangenheit verursachten Wettbewerbsverzerrungen in Zukunft durch eine strenge wettbewerbspolitische Kontrolle vermieden werden, die die unternehmerische Investitionsentscheidung allein von den Marktgegebenheiten abhängig macht ${ }^{75}$. In dieser Hinsicht können auch extensive Regionalförderprogramme insbesondere in den wohlhabenderen MS Verzerrungen verursachen, wenn sie über die Kompensation der regionalspezifischen Nachteile hinausgehen und aufgrund ihrer Ausgestaltung, z.B. Bindung der Förderung an Sachinvestitionen, oder aufgrund von Prioritätensetzungen der gewährenden Stellen schwerpunktmäßig einem Sektor wie der Automobilindustrie zugute kommen 76 . Hier können dann versteckte sektorale Beihilfen auftreten 77 . Bzgl. des Zonenrandgebietes machte die Kommission deutlich, daß die Bundesregierung dessen Einschluß in andere spezielle Beihilferegelungen (Textil, Schiffbau) akzeptiert hatte, so daß dieses Argument wenig schlagkräfig sei 78 . Zudem war die Kommission

72 Vgl. Quiring 1989, S. 7, und EG, Kommission 1989t, S. 8.

73 Vgl. EG, Kommission 1989s, S. 6-7, und 1989t, S. 8-9.

74 Vgl. EG, Kommission 1989m, S. 4.

75 Mit weitgehend gleicher Argumentation wird auch die spanische Forderung nach einer Kopplung mit einer EG-Industriepolitik abgelehnt und auf die entsprechende Kompetenz des Ministerrates verwiesen. Vgl. EG, Kommission 1989t, S. 9, und auch EG, Kommission 1990i, S. 57.

76 Vgl. EG, Kommission 1989s, S. 7, und 1990i, S. 57.

77 Zudem hatte die Kommission ihre grundsätzlich positive Haltung zu Regionalsubventionen bereits im Gemeinschaftsrahmen selbst
78 Vgl. EG, Kommission 1990i, S. 58. 
bereit, die speziellen Bedingungen dieser Gebiete zu berücksichtigen ${ }^{79}$. Eine formelle Freistellung des Zonenrandgebietes war angesichts der Tatsache, daß bspw. das Wolfsburger Hauptwerk von VW in dieser Region liegt, schwer vorstellbar. Demgegenüber war die Kommission bereit, der besonderen Problemlage Berlins Rechnung zu tragen.

In Anbetracht der Weigerung Deutschlands, den Rahmen auch nach Ablauf des Prüfverfahrens anzuwenden, erließ die Kommission im Februar 1990 eine negative Entscheidung 80. Diese verpflichtete die deutschen Behörden, vom 1.5.1990 an alle Beihilfefälle im Kfz-Bereich im vorhinein zu melden; für alle vorher zur Ausführung kommenden Subventionsfälle konnten sich die Unternehmen auf Vertrauensschutz berufen 81 . Lediglich Hilfen nach dem Berlinförderungsgesetz waren von der Exante-Meldepflicht ausgenommen, mußten jedoch in den Jahresberichten aufgeführt werden 82 .

Um einer negativen Entscheidung der Kommission zuvorzukommen und angesichts der nochmaligen Versicherung der Kommission, bei der Prüfung von Regionalbeihilfen den Grad der strukturellen Probleme in bestimmten Regionen angemessen zu berücksichtigen, akzeptierte die spanische Regierung den Gemeinschaftsrahmen im Februar 1990 rückwirkend zum 1. Januar83.

Aufgrund des Empfehlungscharakters, den der Gemeinschaftsrahmen als zweckdienliche Maßnahme nach Art. 93,I besitzt, wird er für jeden MS erst mit dessen formeller Annahme durch diesen wirksam ${ }^{84}$. Daher brachte die Weigerung Spaniens und Deutschlands diesen beiden MS einen Aufschub in der Anwendung dieser strengeren Regeln bis zur formellen Entscheidung durch die Kommission bzw. bis zu der in dieser Entscheidung genannten Umsetzungsfrist ${ }^{85}$, den sie zur Vergabe bspw. von Regionalbeihilfen ohne die Einzelfallüberprüfung nutzen konnten.

\footnotetext{
79 Vgl. ebenda, S. 58f.

80 Vgl. EG, Kommission 1990i, S. 55-60.

81 Diese Frist wurde später aufgrund verzögerter offizieller Zustellung der Entscheidung an die Bundesregierung wegen kommissionsinterner Übermittlungsprobleme auf den 26.5. verschoben.

82 Vgl. EG, Kommission 1990i, S. 59-60.

83 Vgl. EG, Kommission 1990h, S. 13.

84 Siehe dazu auch oben Abschn. 3.2.

85 Vgl. EG, Kommission 1990i, S. 60.
} 


\subsubsection{Die Entscheidungspraxis während der Übergangsphase}

Während der Jahre 1987 und 1988, in der zunächst der Gemeinschaftsrahmen in DG IV erarbeitet und danach innerhalb der Kommission und mit den MS diskutiert wurde, hatte sich DG IV mit einer Reihe von z.T. großen Subventionsfällen zu beschäftigen. Zwar unterliegen diese Fälle, auch wenn die formelle Entscheidung der Kommission z.T. erst nach Inkrafttreten des Gemeinschaftsrahmens erfolgte, nicht den Regeln dieses Rahmens, doch zeigen die jeweiligen Entscheidungen bereits eine gewisse Verschärfung der Genehmigungspraxis im Sinne dieser Regeln.

\subsubsection{Der Inhalt der ursprünglichen Entscheidungen}

Dies gilt bspw. für die Hilfen des Landes Baden-Württemberg und der Stadt Rastatt für die dortige Ansiedlung von Daimler-Benz, wobei der Verkauf des Geländes zu einem günstigen Preis erfolgte und die Gebietskörperschaften auch noch die Kosten der Baulanderschließung und der Infrastruktur übernahmen 86 . Nach Berechnungen der Kommission entsprachen die Aufwendungen hierfür in Höhe von 140 (evtl. sogar 160-200) Mio. DM einem NSÄ von 7\%87. Hier wurde zunächst das Verfahren nach Art. 93,II eröffnet 88 . Es handelte sich dabei um den ersten Fall, in dem eine Infrastrukturförderung zur Erschließung eines Industriegeländes als Beihilfe betrachtet wurde und die Verfahrenseröffnung auslöste. Angesichts der Tatsache, daß Daimler-Benz hier, insbesondere bei der Baulanderschließung, die zudem noch auf die spezifischen Bedürfnisse eines Automobilherstellers ausgerichtet war, der einzige Nutznießer war, ist diese Vorgehensweise aber voll berechtigt. Nachdem die deutschen Behörden das Beihilfevorhaben so modifiziert hatten, daß staatliche Stellen lediglich die Infrastruktur bereitstellten, Daimler-Benz jedoch selbst die Baulanderschließungskosten übernehmen würde, genehmigte die Kommission das Projekt im Juli 198789.

Während es sich hierbei um einen relativ kleinen und übersichtlichen Fall handelte, beschäftigte sich die Kommission in jener Periode hauptsächlich mit vier großen Fällen, die alle eine ähnliche Problemlage aufwiesen: Es handelte sich hierbei um Alfa Romeo, Renault, Rover und ENASA (einen spanischen Hersteller von

86 Zur Finanzierung dieser Maßnahmen mußte Baden-Württemberg sogar einen Ergänzungsetat aufstellen. Vgl. Süddeutsche Zeitung 1986, S. 22.

87 Vgl. MIRU 1987, S. 13, und FAZ 1986b.

88 Vgl. EG, Kommission 1987a, S. 181, und 1986j, S. 4-5.

89 EG, Kommission 1988a, S. 168/69. Während die Kommission danach davon ausging, daß keine Beihilfe mehr vorlag, schätzen Bhaskar/MIRU (1990, S. 13), daß die Subventionen lediglich von 160 auf 120 Mio. DM gesenkt wurden. 
Tab. 4.4-2

Umstrukturierungsbeihilfen in der Übergangsphase

\begin{tabular}{|c|c|c|c|c|c|c|}
\hline Fall & $\begin{array}{r}\text { Verluste } \\
1980-86 \\
\text { (in MECU) } \\
\end{array}$ & Beihilfentyp & $\begin{array}{l}\text { Beihilfen } \\
\text { Vorges. Vol. } \\
\text { (in MECU) }\end{array}$ & $\begin{array}{r}\text { Genehm. Vol. } \\
\text { (in MECU) }\end{array}$ & $\begin{array}{c}\text { Beihilfen/ } \\
\text { Umstrukt. } \\
\text { kosten (in \%) }\end{array}$ & $\begin{array}{c}\text { Kapaz.abbau/ } \\
\text { Gesamtkapaz. } \\
\text { (in \%) }\end{array}$ \\
\hline Alfa Romeo & 1958 & Kapitalzuführung & 405 & 0 & 0 & 0 \\
\hline Rover & 3986 & Entschuldung & 1233 & 723 & 30 & 30 \\
\hline \multirow[t]{3}{*}{ Renault } & 4663 & Kapitalzuführung & 1130 & 1130 & 24 & 25 \\
\hline & & Schuldenübernahme & 1690 & 1690 & (insges.) & \\
\hline & & FIM-Darlehen & 176 & 0 & & \\
\hline ENASA* & 383 & Kapitalzuführung & 815 & 359 & 36 & 31 \\
\hline
\end{tabular}

* Bei der Eröffnung des Verfahrens war die Kommission noch von 101 Mrd. Pta. (774 MECU) ausgegangen. Im Laufe des Verfahrens ergab sich die höhere Zahl.Das Beihilfeelement der urspünglich vorgesehenen Kapitalzuschüsse war von der Kommission mit 69,7 Mrd. Pta (534 MECU) errechnet worden, das der unvereinbaren auf $23 \mathrm{Mrd}$. Pta. (176 MECU). die übrigen Elemente der staatlichen Förderung sah die Kommission nicht als Beihilfen an, da sie teils bereits vor dem EG-Beitritt Spaniens beschlossen worden waren, teils Militärprojekte betrafen und damit aus der Beihilfenkontrolle herausfielen (vgl. Kap. 3.), und schließlich zu einem weiteren Teil einfach Ausflüsse des spanischen Konzernsteuerrechts waren. 
Lkws und Bussen), also verstaatlichte Unternehmen, bei denen die jeweiligen MS unter Einsatz z.T. erheblicher Beihilfen, v.a. zur Verlustdeckung, Eigenkapitalaufstockung und Entschuldung, versuchten, eine Privatisierung zu erreichen. Tab. 4.4-2 zeigt die von den MS angestrebten Beihilfevolumina.

In allen Fällen betrachteten die jeweiligen Regierungen die Kapitalspritzen als normales Verhalten eines Aktionärs, der seine Vermögenswerte sichern will. Die Kommission sah hingegen diese Finanzspritzen angesichts der schlechten Finanzlage der Unternehmen, die über mehrere Jahre massive Verluste erwirtschaftet hatten, was bei Renault bereits zu einem negativen Eigenkapital geführt hatte, zudem unter sinkenden Marktanteilen und z.T. negativen Cash flows litten, als Beihilfen an, die ein privater Investor nicht getätigt hätte. Zudem befürchtete sie eine subventionsunterstützte Aufrechterhaltung von Überkapazitäten in diesen Marktsegmenten. Daher eröffnete sie konsequenterweise in allen Fällen das Prüfverfahren 90 .

Im Gegensatz zu den früheren Fällen erhielt die Kommission hier nach der Verfahrenseröffnung Stellungnahmen von anderen Verfahrensbeteiligten (vgl. Tab. 4.43), darunter bspw. im Falle Renault eine des französischen Konkurrenten Peugeot, der lediglich die Höhe der Schuldenübernahme beklagte 91 .

Tab. 4.4-3

Stellungnahmen anderer Beteiligter

\begin{tabular}{l|cccc} 
& Renault & Rover & Alfa Romeo & ENASA \\
\hline MS & 4 & 2 & 4 & 4 \\
Weitere Beteiligte & 2 & $>1$ & - & -
\end{tabular}

In Anbetracht der industriellen Gegebenheiten dieser Fälle erkannte die Kommission im Laufe der Verfahren, daß es sich um Rettungs- und Umstrukturierungsbeihilfen handelte, ohne die die Unternehmen hätten liquidiert werden müssen.

In den Fällen Renault, Rover und ENASA erließ sie daher sog. bedingte Entscheidungen, bei denen die Genehmigung eines Teils der Beihilfen (vgl. Tab. 4.4-2) an eine Reihe von Auflagen geknüpft wurde, deren wichtigste der Abbau von Überkapazitäten war92. Der Anteil der Beihilfen an den Umstrukturierungskosten ent-

\footnotetext{
90 Vgl. EG, Kommission 1987d, S. 5, und 1988h, S. 4, sowie 1989n, S. 9 (Alfa Romeo); 1987c, S 4-5, und 1988g, S. 4-5, sowie 1989l, S. 64 (ENASA); 1988j, S. 2 (Rover); 1986h, S. 3, 1987e, S. 10 und 19881, S. 3 (Renault).

91 Vgl. PSA 1987.

92 Vgl. EG, Kommission 1988m, S. 30-40; 19891, S. 62-70; 1989k, S. 92-100.
} 
sprach dabei in etwa dem Anteil der abzubauenden an den Gesamtkapazitäten der Unternehmen. Diese Relation ergab sich eher zufällig aus der Fähigkeit der betroffenen Unternehmen, externe Finanzierungsquellen zu erschließen. Der Kapazitätsabbau sei "ein Beitrag zur Eindämmung zukünftiger Schwierigkeiten mit Überschußkapazitäten"93 in dieser Branche. Ein weiterer Teil der Beihilfen wurde jeweils nicht genehmigt, weil er entweder nicht zu den tatsächlichen Schulden des Unternehmens zu rechnen war (Rover) oder, wie im Falle ENASA im Verhältnis zur Umstrukturierung überhöht erschien oder schließlich, wie im Falle der FIM-Darlehen an Renault, weitgehend nicht für innovative Zwecke vergeben worden war ${ }^{94}$.

Da im Falle Alfa Romeo die Beihilfen nicht mit einem kapazitätsreduzierenden Umstrukturierungsplan gekoppelt waren und auch keine signifikanten regionalwirtschaftlichen Wirkungen hatten, erklärte die Kommission sie in voller Höhe für unvereinbar mit dem GM und ordnete ihre Rückzahlung an, da sie außerdem noch ohne Anmeldung und vor einer Kommissionsentscheidung gewährt worden waren 95 . Da Fiat als Käufer keine Haftung für die Beihilfenrückzahlung auferlegt werden konnte und Alfa Romeo inzwischen liquidiert worden war, verpflichtete die Kommission die Industrieholding Finmeccanica als früheren Eigentümer zur Rückzahlung der Beihilfe, da ihr auch die Erträge aus dem Verkauf von Alfa Romeo zugeflossen waren 96 .

In den anderen Fällen stützte sich die Kommission bei der partiellen Genehmigung der Beihilfen auf Art. 92,IIIc und interpretierte den vorgesehenen Kapazitätsabbau als Förderung der Entwicklung dieses Wirtschaftszweiges in dem Sinne, daß die Rationalisierung des Sektors gefördert und die Gefahr einer krisenhaften Entwicklung aufgrund von Überkapazitäten reduziert wurde ${ }^{97}$. Im Falle Renault rekurrierte

93 Vgl. EG, Kommission 1989k, S. 98.

94 Auch gegen mehrere an die Unternehmen der PSA-Gruppe gewährten FIM-Darlehen in einer Gesamthöhe von 1,7 Mrd. FF wurden Verfahren eröffnet (vgl. EG, Kommission 1986h, S. 3, und 1988i, S. 2), bei denen ein Darlehen in Höhe von 500 Mio. FF als nicht mit dem GM vereinbar angesehen wurde, da die mit ihm geförderten Investitionen nicht innovativ seien (vgl. EG, Kommission 1989o, S. 57-58). Die Kommission forderte die Rückzahlung des Zinsvorteils an den französischen Staat und die Umwandlung in ein normalverzinsliches Darlehen bzw. die vorzeitige Rückzahlung des Kredits. Letztere Lösung wurde im Falle Peugeot schließlich durchgeführt; vgl. EG, Kommission 1989p.

Vgl. EG, Kommission 1989n, S. 14-16. Die Rettungshilfen verstießen damit auch gegen die Kompatibilitätskriterien aus dem Jahre 1979; vgl. oben 4.1.2.

96 Vgl. ebenda, S. 17/18. Dies impliziert, daß FIAT einen dem Marktwert entsprechenden Preis 97 gezahlt und damit die Beihilfe an Finmeccanica zurücktransferiert hat.

97 Vgl. EG, Kommission 1989l, S. 65, 69. 
die Kommission zudem auf die von ihr 1978 aufgestellten Regeln für sektorale Beihilfen ${ }^{98}$, die sie hier als erfüllt ansah, da durch die Beihilfen die Lebensfähigkeit des Unternehmens wiederhergestellt, zu einem großen Teil mit ihnen die sozialen Kosten der Umstrukturierung gedeckt und die Position der Konkurrenten Renaults nicht beeinträchtigt worden sei. Insbesondere der letzte Aspekt ist doch sehr zu bezweifeln (vgl. dazu unten Abschnitt 4.4.11.4).

Ein neuartiger Aspekt der bedingten Entscheidungen war die Verknüpfung der Beihilfenakzeptanz mit zusätzlichen in die Zukunft reichenden Bedingungen. Diese umfaßten für Rover z.B. eine Beschränkung zukünftiger Regionalbeihilfen auf 78 Mio. $£(120 \mathrm{MECU})$, ein Verbot weiterer Subventionen oder Verpflichtungen des britischen Staates, die Begrenzung der steuerlichen Ausnutzung der Verlustvorträge von Rover durch den neuen Eigner und eine Strafe von 400 Mio. $£$ bei Weiterverkauf von Rover durch BAe innerhalb von 5 Jahren 99 . Bei Renault sollte die Schuldenübernahme von $12 \mathrm{Mrd}$. FF erst bei Umwandlung in eine AG, die bis Ende $1988 \mathrm{zu}$ erfolgen hatte, ausgezahlt werden dürfen und dem Unternehmen keine direkte Liquidität zuführen dürfen ${ }^{100}$. Dazu sollte das Unternehmen keine weiteren Kapitalhilfen erhalten dürfen, und zukünftige Einnahmen aus dem Verkauf des Tochterunternehmens American Motors Corporation mußten an den Staat übertragen werden 101 . ENASA schließlich sollte neben dem Kapazitäts- auch einen Beschäftigungsabbau durchführen und Modernisierungsinvestitionen tätigen 102 .

Zusätzlich wurden Untersuchungen durchgeführt, ob die Verkäufe der Unternehmen an private Investoren zu Preisen unterhalb des Marktwertes erfolgt waren und damit weitere Beihilfen enthielten. Im Falle des Verkaufs von Alfa Romeo an Fiat Ende 1986 bewahrheitete sich diese Vermutung nach einem Vergleich mit dem Konkurrenzangebot von Ford nicht 103 .

98 Vgl. EG, Kommission 1979a, S. 136f., siehe auch oben Abschnitt 4.1.2.

99 Vgl. EG, Kommission 1989k, S. 99-100.

100 Vgl. EG, Kommission 1988m, S. 34. Dieses Junktim war wohl auch von der französischen Regierung angestrebt worden, weshalb sie den Beihilfencharakter der Schuldenübernahme im Gegensatz zu den anderen Kapitalhilfen nie bestritt. Vgl. Lalitch 1990, S. 14-15.

1 Bhaskar/MIRU (1990, S. 18) erwähnen, daß die Regierung ursprünglich weitere 9 Mrd. FF an Beihilfen und günstigen Krediten hatte bereitstellen wollen, die jedoch von der Kommission

102 Vgl. EG, Kommission 1989l, S. 65.

103 Vgl. EG, Kommission 1989n, S. 15. 


\subsubsection{Die Umsetzung der Entscheidungen}

Bei der Durchführung dieser Entscheidungen traten jedoch in drei Fällen große Probleme auf.

So klagte die italienische Regierung gegen die Alfa-Romeo-Entscheidung vor dem EuGH. Sie bestritt die Existenz einer Beihilfe ebenso wie ihre Unvereinbarkeit mit dem GM oder die Notwendigkeit der Rückzahlung und warf der Kommission vor, die Entscheidung nicht angemessen begründet zu haben. Der EuGH wies die Klage jedoch in allen Punkten zurück ${ }^{104}$. Er stellte fest, daß die Industrieholdings unter der Kontrolle des Staates standen, dementsprechend Beihilfen gewähren konnten und dies in den Umständen dieses Falles auch getan hatten. Eine Benachteiligung des staatlichen gegenüber anderen Privatunternehmen liege nicht vor ${ }^{105}$. Auch die Begründungen der Entscheidung der Kommission unterstützte er voll. Trotz dieses Urteils stieß die tatsächliche Rückabwicklung der Beihilfe weiter auf Schwierigkeiten. Zwar hatte die Regierung eine entsprechende Direktive an die "Sammelholding" IRI erlassen, die von jener und und ihrer Tochter Finmeccanica jedoch gerichtlich in Italien angefochten wurde. Da zudem Finmeccanica inzwischen verkauft und umbenannt worden war, nachdem sie ihr Vermögen auf eine neue Finmeccanica übertragen hatte, argumentierte die italienische Seite, daß mit den von IRI aus dem Verkauf erzielten Erlösen die Rückzahlung der Beihilfe erfolgt sei, während die neue Finmeccanica mit dem Alfa Romeo Fall nichts zu tun habe106. Da die neue Finmeccanica jedoch die Erlöse aus dem Verkauf von Alfa Romeo erhalten hat, besteht die Kommission weiterhin auf Rückzahlung durch die neue Holding. Da IRI die eigentliche Subvention aus Kapitalmarktkrediten finanziert hatte, die vom Staat ursprünglich hätten getilgt werden sollen, was dieser nun aber für die Kapitalzuführungen des Jahres 1986 ablehnte, würde die Rückzahlung durch die neue Finmeccanica an IRI deren finanzielle Position hier wieder ausgleichen, während die Rückzahlung der Zuschüsse des Jahres 1985 an den italienischen Staat zu erfolgen hätte. Die im März 1992 erfolgte Rückzahlung des Gesamtbetrages von Finmeccanica an IRI stellte somit keine ausreichende Umsetzung der Kommissionsentscheidung dar; zudem wurde der Zinsbetrag für die verspätete Rückzahlung zu gering berechnet, so daß die Kommission gezwungen ist, wiederum vor dem EuGH zu klagen 107.

$104 \mathrm{Vgl}$. EuGH 1991, S. 1607-1615, 1636-1646.

105 Vgl. ebenda, S. 1638-1641.

106 Vgl. EG, Kommission 1992e, und Simonian 1992.

107 Vgl. EG, Kommission 1992e. Das Verfahren ist noch anhängig. 
Im Falle Rover zeigte die spätere Veröffentlichung eines Berichts und eines vertraulichen Memorandums des britischen Rechnungshofs in der Presse, daß die britische Regierung Rover wesentlich unter Wert verkauft hatte und exklusiv mit British Aerospace (BAe) verhandelt hatte, obwohl vier weitere Interessenten existierten 108 . Vermögensbewertungen der beratenden Bank sowie Umsatz- und Gewinndaten und prognosen für Rover, die diese Tatsache offenkundig gemacht hätten, wurden der Kommission vorenthalten, obwohl die MS zur Erteilung vollständiger Auskünfte verpflichtet sind und die Kommission alle Informationen zur Beurteilung des Kaufpreises angefordert hatte. Nach der Kommissionsentscheidung wurden zudem Absprachen mit BAe getroffen, die die Übernahme weiterer Transaktionskosten von Rover und BAe in Höhe von 11 Mio. $£$ durch den Staat und außerdem eine zeitliche Verschiebung der Zahlung des Kaufpreises um 20 Monate mit gesparten Zinsaufwendungen von 33 Mio. $£$ (brutto vor Steuern) vorsahen, um so den Kauf für BAe trotz der von der Kommission erzwungenen Subventionskürzungen attraktiv zu erhalten. Schließlich wurde BAe in Aussicht gestellt, bei einem vorzeitigen Wiederverkauf die vorgesehene Strafe nicht zahlen zu müssen 109 . In Briefwechseln hierzu berieten der zuständige Minister und der Vorstand von BAe zudem über die besten Möglichkeiten, diese Arrangements vor der Kommission und dem britischen Parlament zu verbergen 110. Anstatt wegen dieser nachträglichen Absprachen vor dem EuGH gegen UK wegen Nichteinhaltung einer Kommissionsentscheidung zu klagen und bezüglich der zusätzlichen Beihilfen erneut das Prüfverfahren zu eröffnen, erließ die Kommission lediglich eine neue Entscheidung 111 gegen die nachträglich in Verletzung der ersten Entscheidung gewährten finanziellen Vergünstigungen von 44 Mio. £, zu deren Rückforderung sie die britische Regierung verpflichtete. Die Begründungen der Kommission dafür, daß sie die Rechtfertigung des Kaufpreises nicht mehr untersuchte, nämlich daß sie selbst in Kenntnis der ihr vorenthaltenen Bewertungen und Empfehlungen nicht anders entschieden hätte ${ }^{112}$, sind schwer nachzuprüfen. Eine Interpretation dieser Vorgehensweise besteht darin, daß die geforderte Rückzahlung der Sweeteners das Gegengewicht zur Nichtverfolgung der

108 Vgl. EG, Kommission 1991k, S. 3. Die Kommission akzeptierte die Exklusivverhandlungen in der Annahme, daß zunächst keine weiteren ernsthaften Interessenten existierten und daß bei 109 einem späteren Auftauchen mit ihnen ernsthaft verhandelt würde.

Vgl. EG, Kommission 1991k, S. 3-5. Der letzte Aspekt beruhte darauf, daß es sich hier um eine Ermessensentscheidung des Handels- und Industrieministeriums handelte. Diese Tatsache wurde der Kommission während des Verfahrens vorenthalten. Vgl. ebenda, S. 6-7.

110 Vgl. Hencke 1989, S. 1, und 1990, sowie EG, Kommission 1991k, S. 5.

111 Vgl. EG, Kommission 1991k, S. 2-10.

112 Vgl. EG, Kommission 1991k, S. 7-8. 
Frage des Kaufpreises darstellte ${ }^{113}$. Außerdem konnte so auf die publizitätsträchtige Neueröffnung des Verfahrens nach Art. 93,II verzichtet werden.

Diese Vorgehensweise erwies sich als fatal, da zwar die britische Regierung das neue Verdikt akzeptierte, BAe jedoch vor dem EuGH dagegen klagte und auch Recht bekam. Während der Gerichtshof die anderen Punkte der neuen Entscheidung akzeptierte, die im wesentlichen die britische Regierung zur Einhaltung der Vereinbarungen verpflichteten, wurde die Rückforderung der 44 Mio. $£$ wegen Formfehlern aufgehoben. Der EuGH zeigte auf, daß die Kommission zum einen selbst wegen Verletzung ihrer Entscheidung hätte klagen müssen, zum anderen bei neuen Beihilfen aus Transparenzgründen das normale Prüfverfahren hätte eröffnen müssen ${ }^{114}$. In Konsequenz dieses Urteils eröffnete die Kommission nun tatsächlich das Verfahren gegen die zusätzlich gewährten Beihilfen in Höhe von 44 Mio. $£^{115}$ und erließ schließlich eine negative Entscheidung, in der die Rückzahlung dieses Betrages einschließlich der aufgelaufenen Zinsen seit der aufgehobenen Entscheidung von 1990 angeordnet wurde ${ }^{116}$. Die Rückzahlung erfolgte dann auch in Höhe von 57,6 Mio. $£$ und stellt den ersten Fall einer ausgeführten Rückerstattung mit Zinsen dar117.

Die Umsetzung der Renault-Entscheidung wurde durch den Regierungswechsel in Frankreich im Sommer 1988 (Wahlsieg der Sozialisten) in Frage gestellt 118 . Die Veränderung der Rechtsform des Unternehmens erfolgte zunächst nur durch ein Dekret, das Renault nicht allen Regeln des Privatrechts unterwarf. Das Gesetz, das die Umwandlung im Sinne des früheren Konzepts vollständig durchführte, wurde

\footnotetext{
$113 \mathrm{Vgl.} \mathrm{Hill/Buchan} 1992$.

114 Vgl. EuGH 1992, und EG, Kommission 1991a, S. 188.

115 Vgl. EG, Kommission 1992k, S. 3-5.
}

116 Vgl. EG, Kommission 1993i, und 1993r, S. 7-16. Damit entsprach die finanzielle Situation von BAe und Rover derjenigen, die bei einer Exekution der Kommissionsentscheidung von 1990 entstanden wäre. Die zwischenzeitlich eingetretene Verschärfung der Rückforderungsregeln, die eine Zinsberechnung vom Zeitpunkt der Gewährung der Beihilfen vorsieht und deren Anwendung auch von einigen Kommissaren gefordert worden war, wurde nicht angewandt. Vgl. Hill 1993. Sie hätte ohnehin den geringeren Teil der Beihilfen betroffen, da der überwiegende Betrag eben dem Zinsvorteil aus der zu späten Entrichtung des Kaufpreises erst im Jahre 1990 entsprach.

117 Vgl. Betts 1993, und EG, Kommission 1993j. Da die britische Regierung unterstellte, daß BAe bei Nichterhalt der Sweeteners ein höheres Darlehen zum Kauf von Rover hätte aufnehmen müssen, dessen Zinsen steuerlich absetzbar gewesen wären, wurde dies bei der Rückzahlungsberechnung berücksichtigt. Die Steuerersparnisse reduzieren die Effektivbelastung für das Unternehmen auf 42,2 Mio. £.

118 Vgl. Bhaskar/MIRU 1990, S. 18. 
erst im Mai 1990 verabschiedet. Auch der der Kommission zugesagte Kapazitätsabbau wurde aufgrund des Widerstands der Gewerkschaften und der verbesserten Marktlage nur zu einem Teil durchgeführt ${ }^{119}$. Dementsprechend annullierte die Kommission ihre Entscheidung von 1988 und forderte die französische Regierung auf, Vorschläge zur Lösung des Falles zu machen ${ }^{120}$. Im Prinzip standen der Kommission hier zwei Lösungen offen: Zum einen konnte sie das genehmigte Beihilfenvolumen proportional zur nicht-durchgeführten Kapazitätsreduktion kürzen, zum anderen konnte sie die Frage der Notwendigkeit der Beihilfen neu stellen. Da die Finanzlage des Unternehmens sich seit 1988 erheblich verbessert hatte, hätte dies vermutlich zu einer völligen Ablehnung zumindest der Schuldenübernahme von 12 Mrd. FF geführt 121 . Am Ende fiel die Entscheidung, auch um einen politischen Streit mit der französischen Regierung zu umgehen, für die erste Lösung: Während die Berechnungen der Kommission zu einer Rückzahlung von 8,4 Mrd. FF geführt hätten, weigerte sich Frankreich zunächst, eine Rückzahlung von mehr als $4 \mathrm{Mrd}$. FF zu leisten ${ }^{122}$. Da sich im Kollegium der Kommissare keine Mehrheit für eine harte Haltung der Kommission und einen eventuellen Gang vor den EuGH abzeichnete, wurden Verhandlungen zwischen der Kommission, insbesondere den Kommissaren Brittan und Bangemann, und dem französischen Regierungschef Rocard aufgenommen ${ }^{123}$, die schließlich folgendes Ergebnis brachten: In einer neuen Mitteilung errechnete die Kommission eine Erfüllung der Kapazitätsabbaubedingung von $50 \% 124$ und forderte dementsprechend die französische Regierung auf, die Hälfte der Schuldenübernahme, d.h. $6 \mathrm{Mrd}$. FF rückgängig zu machen, wobei 3,5 Mrd. FF von Renault sofort zurückzuzahlen waren und weitere 2,5 Mrd. FF wieder als Verbindlichkeiten in die Bilanz aufzunehmen waren. Auch die von Renault zwischenzeitlich gesparten Zinsen waren an den Staat zu erstatten.

119 Vgl. EG, Kommission 19911, S. 4.

120 Vgl. EG, Kommission 1989q, und The Economist 1989, S. 87.

121 Vgl. The Economist 1989, S. 87. Zur Entwicklung der Finanzlage des Unternehmens, vgl. EG, Kommission 19911, S. 5.

$122 \mathrm{Vgl}$. Kellaway/Graham 1990 und Vandoorne 1990.

$123 \mathrm{Vgl}$. Jublin/Paoloni 1990, Wolf/Cornelius 1990 und Buchan/Dawkins 1990.

124 Einige der Kommission zugesagte Betriebsschließungen waren erst mit erheblicher Verspätung durchgeführt worden, wodurch es Renault ermöglicht wurde, von der guten Automobilkonjunktur durch steigenden Absatz zu profitieren, ohne größere Investitionen vornehmen zu müssen. Die französische Regierung hatte ein Consultingunternehmen mit der Erstellung einer Studie zu dieser Fragestellung beauftragt, die dennoch zum Ergebnis einer fast vollständigen Erfüllung der Kapazitätsabbaubedingung kam. Jedoch erkannte die Kommission nicht alle aufgeführten Elemente als endgültigen und irreversiblen Abbau an. Vgl. EG, Kommission 19911, S. 6-8. 
Die anderen Bedingungen der Entscheidung von 1988 blieben erhalten, wobei die Verpflichtung zum Verzicht auf weitere Kapitalzuführungen allerdings jetzt so interpretiert wurde, daß sie nur bis zum Ende des Umstrukturierungsplans, also bis Ende 1990 galt 125 . Damit wurde auch der Weg frei für gegenseitige Beteiligungen von Renault und Volvo am jeweils anderen Unternehmen, die von einer Kapitalerhöhung von über 5 Mrd. FF bei Renault begleitet waren, in die sich der französische Staat und Volvo in Verhältnis ihrer neuen Firmenanteile (80:20\%) teilten ${ }^{126}$. Diese Transaktion, die der Kommission in ihren Grundzügen bei ihrer Entscheidung bereits bekannt war und die sie quasi ex ante und informell absegnete ${ }^{127}$, machte materiell die Rückzahlung der Beihilfe zwar zum Teil wieder rückgängig, ließ sich aber formell nicht als Subvention ansehen, da das Privatunternehmen Volvo entsprechend seinem Aktienanteil an der Kapitalerhöhung teilnahm. Sie macht damit deutlich, daß eine Subventionskontrolle gegenüber staatlichen Unternehmen wesentlich größeren Schwierigkeiten gegenübersteht als gegenüber Privatunternehmen, was gerade im Zusammenhang mit der Erreichung des Binnenmarktes von Bedeutung ist 128 .

Im Falle ENASA stand der subventionierte Umstrukturierungsplan im Zusammenhang mit Verhandlungen der spanischen Regierung zum Verkauf einer Aktienmehrheit des Unternehmens an einen Privatinvestor. Nachdem ein entsprechendes Abkommen mit Daimler-Benz/MAN an einem Einspruch des Bundeskartellamtes gescheitert war, kam es schließlich zu einem Einstieg von FIAT/Iveco129. Da dieser Zusammenschluß vor dem Inkrafttreten der Fusionskontrollverordnung erfolgte, wurde hierzu keine Prüfung durch die Kommission eingeleitet. Zu der Durchführung des subventionierten Umstrukturierungsplans sind auch keine weiteren Aktionen unternommen worden, so daß man von seiner korrekten Exekution ausgehen muß.

\subsubsection{Der Fall Volvo Car BV}

In den Problemkreis der bisher betrachteten vier Fälle - Subventionen in Gestalt von staatlichen Kapitalanteilen an Kfz-Produzenten und mögliche weitere Beihilfen im Rahmen von (Teil-) Privatisierungen - fällt auch Volvo Car BV, auch wenn hier schon die Verfahrenseröffnung in die Zeit nach Inkrafttreten des Gemein-

\footnotetext{
125 Vgl. EG, Kommission 19911, S. 8.

126 Vgl. Browning 1991.

127 Vgl. Paoloni 1990, S. 3.

$128 \mathrm{Vgl}$. The Economist 1990, S. 76.

129 Vgl. EG, Kommission 1991a, S. 109.
} 
schaftsrahmens fällt. Diese Verfahrenseröffnung 130 betraf eine vorgeschlagene Änderung der Rückzahlungsmodalitäten der dem Unternehmen zinsfrei gewährten Darlehen (s. oben FN 25). Während die letzte derartige Darlehensvereinbarung aus dem Jahre 1981 die Rückzahlung in einen Fonds, dessen Mittel zur Entwicklung neuer Modelle wiederverwendet werden konnten, entsprechend einem Pauschalbetrag für jeden verkauften Pkw der 400er-Serie festlegte, sahen die früheren Darlehensvereinbarungen von 1977 und 1979 Rückzahlungen bei Überschreiten eines Jahresgewinns von 30 Mio. Hfl. bis 1989 bzw. 1994 vor. Diese frühere Regelung wollte die niederländische Regierung nun im Sinne der letzten Vereinbarung mit Pauschbeträgen und einer möglichen Wiederverwendung der Fonds umgestalten, wobei eine Verschiebung der Rückzahlung und eine Obergrenze von 300 Mio. Hfl. (ursprünglicher Kreditbetrag 524 Mio. Hfl.) festgelegt werden sollte, um die verschlechterte Gewinnsituation von VCBV zu berücksichtigen. Während die niederländische Regierung hierin keine Erhöhung der Beihilfen sah, da der Verzögerung der Rückzahlung eine angesichts der Gewinnerwartungen des Unternehmens höhere und sicherer anfallende Summe gegenüberstehen würde, sah die Kommission in der Wiederverwendbarkeit und der Tilgungsverschiebung eine zusätzliche Beihilfe und bezweifelte, daß die Rückzahlung unter den neuen Modalitäten betragsmäßig höher ausfallen würde als unter den alten ${ }^{131}$. Zudem waren die Beihilfen ursprünglich als Rettungshilfen zum unmittelbaren Erhalt des Unternehmens gebilligt worden und nicht zur fortwährenden Investitionsförderung, die den Wettbewerb weiterhin verzerrt.

Auch für die jüngsten Darlehen wollten die niederländischen Behörden eine Umgestaltung, indem die Mittel unbegrenzt und zinslos wiederverwendet werden sollten, ohne daß die Rückzahlung gesichert war. Die Kommission sah dies als Betriebsbeihilfe an 132 .

Da die Kommission die Darlehen und die Einrichtung der Fonds ursprünglich genehmigt hatte und da die Muttergesellschaft Volvo Schweden an beiden Arrangements beteiligt war, blieb die Kommission in ihrer Entscheidung jetzt darauf beschränkt, eine weitere Aufweichung der Bedingungen zu verhindern. Die Einstellung des Verfahrens erfolgte, nachdem die niederländische Regierung einige der Konditionen verschärft hatte. So wurde der Rückzahlungsbetrag pro $\mathrm{Kfz}$ für die jüngsten Darlehen erhöht und die Höchstgrenze des Rückzahlungsbetrages ge-

\footnotetext{
130 Vgl. EG, Kommission 1989r, S. 3-6.

131 Vgl. ebenda, S. 4.

132 Vgl. ebenda, S. 5.
} 
strichen. Bei zukünftigen Krediten aus dem durch diese Rückzahlungen geschaffenen Fonds muß die Beteiligung immer im Verhältnis der Anteile der Aktionäre erfolgen und der Kommission ex ante mitgeteilt werden, solange der niederländische Staat Mehrheitsaktionär an VCBV bleibt. Bei den beiden älteren Darlehen akzeptierte die Kommission die Argumentation, daß angesichts der Gewinnsituation des Unternehmens die neue Regelung eine höhere Rückzahlungssumme erbringt, wodurch die zeitliche Verzögerung ausgeglichen wird ${ }^{133}$.

Die eben erwähnte Mitteilungspflicht bei zukünftigen Krediten erwies sich jedoch schon bald als gegenstandslos, da der niederländische Staat seinen Anteil auf 33\% zurückführte, Volvo Schweden den seinigen auf die gleiche Höhe aufstockte und Mitsubishi als dritter Partner einstieg. Auch bei dieser Transaktion war die Kommission wiederum gezwungen, das Prüfungsverfahren zu eröffnen, da die Bedingungen des Vertrages den Verdacht neuer Beihilfen aufkommen ließen ${ }^{134}$. So haben sich die Niederlande verpflichtet, ihren verbliebenen Anteil an VCBV (jetzt Nedcar) 1998 zum gleichen Preis pro Anteil wie 1991 zu veräußern, obwohl sie und die beiden anderen Eigner in der Zwischenzeit dem Unternehmen einen zinslosen Kredit von je 700 Mio. Hfl. zur Entwicklung einer neuen Modellreihe geben, wobei der Anteil des Staates daran aus den Einnahmen der oben erläuterten Fonds finanziert wird. Während mögliche Gewinne aus der neuen Reihe aufgrund des fixen Exit price allein den Privataktionären zufließen, verliert der Staat Rückflüsse aus den oben diskutierten früheren Darlehen, da die Volvo 400er-Serie, aus der die Rückzahlungen finanziert werden, zwei Jahre früher eingestellt wird. Für diese verlustbringende Serie übernimmt der Neuaktionär Mitsubishi keinerlei Haftung, ohne deshalb für den Erwerb seiner Anteile einen höheren Preis als Volvo Schweden zu zahlen. Auch eine mögliche Verteilung der Gemeinkosten und Festlegung der Ab-Werk-Preise der Volvo 400er Serie zuungunsten der jetzigen Eigner kann zu indirekten Beihilfen der Niederlande an das Unternehmen führen 135. Das Verfahren konnte dann jedoch geschlossen werden, da eine Gesamtanalyse aller Bedingungen dieser Transaktion ergab, daß die Niederlande höhere Rückflüsse als bei einem Direktverkauf des Unternehmens erwarten konnten, so daß die Privatisierung nicht zu zusätzlichen Beihilfen führt. Insbesondere wurde anerkannt, daß Mitsubishi auf eigene Kosten strukturverbessernde und kostensenkende Maßnahmen durchführte, die mittels Verlustreduktionen bei der Volvo 400-Serie direkt den beiden Altaktionären zugute

\footnotetext{
133 Vgl. EG, Kommission 19910, S. 8.

134 Vgl. EG, Kommission 1992m, S. 16-21.

135 Vgl. ebenda, S. 19-20.
} 
kamen. Aufgrund dieser zusätzlichen "Sachleistungen" wurde auch akzeptiert, daß in der Haftungsfreiheit von Mitsubishi für die alte Serie bei gleichem Kaufpreis der Anteile keine Beihilfe begründet lag. Die Niederlande wurden allerdings verpflichtet, die mögliche Nutzung bestimmter Optionsklauseln der Aktionärsvereinbarung ebenso zu notifizieren wie die Verteilungsregeln für die Gemeinkosten, da in diesen die Möglichkeit der Vergabe von Beihilfen gesehen wurde136.

\subsubsection{Die Anwendung des Gemeinschaftsrahmens}

Aufgrund der Akzeptanzfrist für die MS und der Durchsetzungsprobleme in Deutschland und Spanien galt der Gemeinschaftsrahmen im Jahre 1989 de facto erst ab dem 2. Halbjahr und lediglich in 10 MS. Erst ab 1990 entfaltete er seine volle Wirkung. Nachdem die "großen" Fälle subventionierter (Teil-) Privatisierungen staatlicher Automobilproduzenten vor Inkrafttreten des Gemeinschaftsrahmens aufgetreten waren und somit auch nicht nach dessen Regeln beurteilt wurden, umfaßten die nun unter diesen Rahmen fallenden Projekte zunächst relativ geringe Subventionsvolumina, bevor dann ab 1991 wieder große subventionierte Investitionsprojekte zu beurteilen waren.

Eine der wesentlichen Neuerungen des Rahmens stellte die Ex-ante-Meldepflicht für Anwendungsfälle genehmigter Regionalbeihilfeprogramme auf Kfz-Produzenten dar, und so überrascht es nicht, daß angesichts des Fehlens spezifischer sektoraler Subventionsprogramme für die Automobilindustrie in den MS die große Mehrheit der zu behandelnden Fälle in diesen Bereich fiel. Tab. 4.4-4 zeigt eine Auflistung der Regionalbeihilfenfälle mit dem jeweiligen Subventionsvolumen, der -intensität und der maximalen Intensität nach dem Gemeinschaftsrahmen für Regionalbeihilfen 137. Es fällt auf, daß die von der Kommission genehmigten Beihilfeintensitäten in fast allen Fällen deutlich unterhalb der für diese Region zulässigen Höchstgrenzen lagen. Dies entspricht der Argumentation im Gemeinschaftsrahmen, nach der zwischen den positiven Effekten auf die Regionalentwicklung und den negativen sektoralen Effekten auf den Wettbewerb abzuwägen ist ${ }^{138}$. Den MS wird auf diese Weise die Möglichkeit, im Rahmen der Regionalpolitik eine begrenzte sektorale Industriepolitik zu betreiben, nicht völlig genommen, sie wird jedoch stärker begrenzt als in anderen Sektoren ohne spezielle Regelungen, so daß hier ein gewisser Anreiz und auch eine stärkere Fähigkeit besteht, Unternehmen aus anderen Industriebereichen in

136 Vgl. EG, Kommission 1994g.

137 Vgl. EG, Kommission 1988k, S. 2-10.

138 Vgl. ebenso in EG, Kommission 1992g, S. 10. 
Tab. 4.4-4

Fälle von Regionalsubventionen unter dem Gemeinschaftsrahmen

\begin{tabular}{l|cc|rrcc} 
Fall & MS & $\begin{array}{c}\text { Jahr der } \\
\text { Entscheidung }\end{array}$ & $\begin{array}{r}\text { Beihilfen } \\
\text { in MECU }\end{array}$ & $\begin{array}{l}\text { Beihilfen- } \\
\text { intensität } \\
\text { in (brutto) }\end{array}$ & $\begin{array}{l}\text { Maximale } \\
\text { Intensitat }\end{array}$ & $\begin{array}{l}\text { Verfahren } \\
\text { nach }\end{array}$ \\
\hline Frt. 93,II?
\end{tabular}

* Lăngere Untersuchung

** $\mathrm{b}=$ brutto, $\mathrm{n}=$ netto

\# Ursprünglicher Plan für das Werk in Ahrensdorf. Nach dem vorlaufigen Verzicht

darauf bleibt lediglich das Projekt Nutzfahrzeuge Ludwigsfelde. Siehe hierzu Tab. 4.4-5

\#\# Ursprünglicher Plan für die neuen Werke in Mosel und Chemnitz. Zu den Beihilfen für die von der THA ubernommenen Betriebe s. Tab. 4.4-5.

" Projekte zur Komponentenproduktion durch Kfz-Hersteller, die nicht der strikten Disziplin unterliegen.

Quelle: EG, Kommission 1990a-1994a. 
zurückgebliebene Regionen zu locken. Die Kritik, daß Unternehmen dennoch vorwiegend in Fördergebieten investieren und dabei von der Kommission akzeptierte Beihilfen erhalten ${ }^{139}$, spricht nicht gegen diese Analyse, da ohne die Existenz des Gemeinschaftsrahmens ohne Prüfung deutlich höhere Beihilfen hätten gezahlt werden können, was diese Tendenz eher noch verstärkt hätte. Zudem kann die Ansiedlung von Automobilfabriken in diesen Gebieten auch aufgrund möglicher sekundärer Beschäftigungseffekte regionalpolitisch ja durchaus positive Entwicklungseffekte haben, auch wenn diese aufgrund des augenblicklichen Rationalisierungsdrucks geringer als früher ausfallen werden.

Die niedrigeren Förderintensitäten sind wohl auch als ein Ergebnis der Anwendung einer strikteren ökonomischen Analysemethode auf die Fälle anzusehen. So wird im Rahmen einer detaillierten Nutzen-Kosten-Analyse der regionalspezifische Kostennachteil des Investors aus der Wahl eines förderfähigen Standorts im Vergleich zu einem Standort in einer nicht geförderten Region der Gemeinschaft ermittelt ${ }^{140}$. Hierbei werden höhere Investitionskosten, wie bspw. Infrastrukturkosten, ebenso in Betracht gezogen wie zusätzliche Betriebskosten während der ersten fünf Betriebsjahre, da in dieser Anlaufphase bis zur vollen Installation bspw. der Zulieferer gerade in entlegenen unterentwickelten Gebieten höhere Kosten z.B. für Transport und Lager auftreten. Regionalspezifische Vorteile werden gegengerechnet 141 . Die Kompensation dieses Kostennachteils durch Beihilfen wird von der Kommission in jedem Fall akzeptiert ${ }^{142}$. Auf diese Weise wird lediglich für den Investor eine Kostenneutralität zwischen der Entscheidung zwischen dem förderfähigen und einem zentralen Standort erreicht, ein tatsächlicher Anreiz zur Niederlassung im Fördergebiet im Sinne des Kohäsionsziels wird dadurch nicht gewährt. Ein solcher Anreiz, d.h. eine Förderung über die regionalen Nachteile hinaus, wird nur akzeptiert, wenn

139 Vgl. Reichert 1993, S. 138, 140.

140 Vgl. EG, Kommission 1993o, S. 18. Der Vergleichsstandort mit seinen relativen Kosten hat dabei fiktiven Charakter, auch wenn nicht auszuschließen ist, daß einzelne Unternehmen derartige Alternativstudien angestellt haben, die dann evtl. Verwendung finden könnten. Um zu einem korrekten Vergleich zu kommen, stellt die Kommission einer tatsächlichen neuen Fabrik (greenfield project) ein ebensolches hypothetisches Projekt gegenüber. Der tatsächliche Alternativstandort für die Investition hätte dagegen häufig in anderen Fördergebieten oder in Osteuropa gelegen. Seine Heranziehung würde allerdings dem Zweck der NKA widersprechen. Vgl. EG, Kommission 1993p, S. 16.

141 Vgl. EuGH 1993, Rn. 27, und EG, Kommission 1993o, S. 18, sowie 1993p, S. 19f. Die Ergebnisse der Kommissionsanalyse können dabei erheblich unter denen des Unternehmens liegen.

142 Vgl. Jallon 1993, S. 342. 
mit dem Projekt keine Überkapazitätsprobleme geschaffen oder verschärft werden. In wachsenden Marktsegmenten, wie dem der Mehrzweckfahrzeuge im Falle Ford/VW-Setubal (vgl. unten), wird nicht von der Existenz solcher Überkapazitäten ausgegangen, so daß hier höhere Beihilfen akzeptabel sind. In anderen Segmenten führen Nettokapazitätserhöhungen der Unternehmen zu einer Begrenzung der Beihilfen auf die Kostennachteile. Sowohl bei der Kapazitätsbeurteilung als auch der NKA zieht die Kommission externe Consultants zur Beratung und Analyse heran143.

Bisher wurde noch kein von den MS notifiziertes Projekt abgelehnt, was auch schwer vorstellbar wäre, da die Kommission auch bei der strikten sektoralen Analyse in ihren Entscheidungen das Kohäsionsziel und die Regeln des Gemeinschaftsrahmens für regionale Beihilfen in Betracht ziehen muß, innerhalb dessen die Programme der MS für ihre Regionalförderung genehmigt wurden, und da alle Projekte innerhalb dieser genehmigten Programme notifiziert wurden. So sind lediglich Beihilfereduktionen denkbar, wenn das geplante Volumen die regionalspezifischen Nachteile übersteigt. In allen Fällen, die nicht lediglich Projekte zur Komponentenherstellung betrafen, beruhte die Entscheidung auf der Analyse dieser Nachteile, wie sie oben dargelegt wurde. In einigen Fällen mußte dabei das formelle Prüfverfahren nach Art. 93,II EWGV eröffnet werden:

Im Fall Fiat Mezzogiorno144 hing dies zum einen mit der Größe des Projekts (förderbare Investitionen von ca. 4,15 Mrd. ECU) und seinen massiven Auswirkungen auf die Produktionskapazität zusammen. Dieses Projekt führt nämlich zu einer Ausweitung der jährlichen Produktionskapazität von Fiat um 450.000 Pkw und 800,000 Motoren, womit die klare Gefahr bestanden hätte, daß hier mit Hilfe staatlicher Unterstützung die relative Wettbewerbsposition des Unternehmens im GM massiv gestärkt wird, ohne daß die hohe Beihilfenintensität durch strukturelle Nachteile der Region gerechtfertigt wird. Die Kosten-Nutzen-Analyse ergab schließlich regionale Nachteile von knapp 30\% der förderfähigen Investitionen, während das Bruttosubventionsäquivalent bei $30,5 \%$ lag. Da Fiat jedoch gleichzeitig sich zu Kapazitätsschließungen in Norditalien bereitfand, konnte die Kommission die vorgeschlagenen Regionalbeihilfen in ihrer Gänze genehmigen, da nunmehr nicht von negativen sektoralen Effekten ausgegangen werden konnte ${ }^{145}$. Wiederum blieben die Beihilfen weit unter der regionalen Fördergrenze von 59-74\% NSÄ. Daneben enthielt das Paket auch Subventionen aus dem italienischen Innovationsfonds. Diese

\footnotetext{
143 Vgl. van Gerven 1993, S. I-8 und I-12f., sowie EG, Kommission 1993p, S. 20.

144 Vgl. EG, Kommission 1991h, S. 4-8.

145 Vgl. EG, Kommission 1993o, S. 18.
} 
wurden von der Kommission zunächst als Investitionen zur Produkterneuerung, die auch nach dem Gemeinschaftsrahmen strenger zu beurteilen sind, eingestuft ${ }^{146}$. Die genauere Untersuchung ergab jedoch, daß es sich um Innovationsausgaben handelte, die teils auf europäischer, teils auf Weltebene grundlegende Neuerungen darstellten und für das Unternehmen mit erheblichen Risiken verbunden waren. Die kombinierte Beihilfenintensität von $17 \%$ wurde daher genehmigt ${ }^{147}$. Ursprünglich vorgeschlagene Beihilfen zur Energieeinsparung hatte die italienische Regierung zurückgezogen 148 .

Eine ähnliche Situation existiert bei den Investitionen von VW, Opel und DaimlerBenz in den neuen Ländern: Diese drei Unternehmen haben die ehemaligen Pkw(VW und Opel) bzw. Lkw- (Mercedes) Produktionsstandorte in der Ex-DDR übernommen und ließen bzw. lassen dort im Rahmen von Joint ventures bzw. Lohnmontageverträgen (Mercedes) in den bestehenden Produktionsanlagen Fahrzeuge und (im Falle von VW) Motoren ihrer Produktpalette montieren. Gleichzeitig werden an diesen Standorten neue Werke errichtet, in denen nach ihrer Fertigstellung ein voller Produktionsablauf stattfinden kann ${ }^{149}$. Neben der Regionalförderung aus der Gemeinschaftsaufgabe und den Beihilfen aus dem Investitionszulagengesetz der alten $\mathrm{DDR}^{150}$, die von der Kommission grundsätzlich bis zu einer kumulierten Bruttoobergrenze von 33\% genehmigt worden sind und in diesen Fällen knapp 30\% erreichen, leistete die Treuhandanstalt als Partner in den Joint ventures bzw. als Auftragnehmer der Lohnmontage vielfältige zusätzliche Unterstützung: Diese bestand in werksnahen Infrastrukturleistungen, Investitionen in die Modernisierung der alten Werke und Verkäufen von Grund und Gebäuden sowie Anlagen zu vorher festgelegten Preisen, die aufgrund der Modernisierungsinvestitionen z.T. zu niedrig angesetzt waren. Dazu kommen Verlustübernahmegarantien für die Übergangsunternehmen in Höhe von max. 200 Mio. DM bei Nutzfahrzeuge Ludwigsfelde (Mercedes Benz) bzw. 430 Mio. DM bei der Sächsischen Automobilbau (Joint venture THA-VW) ${ }^{151}$. Aufgrund dieser zusätzlichen Beihilfen, die eine

\footnotetext{
146 Vgl. EG, Kommission 1991h, S. 7.

147 Vgl. EG, Kommission 19930, S. 19

148 Vgl. EG, Kommission 1993o, S. 16

$149 \mathrm{Zu}$ den industriellen Details der Fälle ebenso wie zum folgenden vgl. die Eröffnungen des formellen Prüfverfahrens in EG, Kommission 1992j, S. 2-7, 1992h, S. 8-13, und 1992n, S. 14-19.

150 Dazu kommen bei Opel noch Umweltschutzbeihilfen. Vgl. EG, Kommission 1992j, S. 5.

151 Vgl. EG, Kommission 1992j, S. 4-5, 1992h, S. 10-11, und 1992n, S. 16-17. Die Bewertung der festgelegten Verkaufspreise ist auch deshalb schwierig, weil die THA keine Verhandlungen mit anderen möglichen Investoren führte und somit keine alternativen Angebote vorlagen.
} 
Abschätzung der Gesamtförderintensität außerordentlich erschweren, sowie der z.T. massiven subventionierten Kapazitätsausweitungen, die den Intra-EG-Wettbewerb und -Handel erheblich verzerren können ${ }^{152}$, eröffnete die Kommission im Dezember 1991 das formelle Prüfverfahren153. Ein erschwerender Faktor lag noch in der fehlenden formellen Notifizierung durch die deutschen Behörden. Obwohl die maximal zulässige Beihilfenintensität für die Ex-DDR von $33 \%$ angesichts der massiven dortigen Umstellungsprobleme auch im Vergleich mit anderen benachteiligten Regionen wie z.B. dem Mezzogiorno oder Portugal, wo maximal $75 \%$ zulässig sind, zu niedrig erscheint, weshalb einige der zusätzlichen Investitionshilfen akzeptabel sein sollten, so sind doch die Verlustausgleiche für MercedesBenz und VW von immenser Höhe. Sie wurden zudem zunächst von der Kommission als Betriebsbeihilfen gewertet, die nach dem Gemeinschaftsrahmen unzulässig sind (s.o.), so daß sich hier die Notwendigkeit von Begrenzungen ergibt. Eine Berufung auf die Sonderregelung des Art. 92,IIc erscheint zwar formal rechtlich möglich, eine ökonomisch korrekte Evaluierung muß jedoch aus dem Vergleich mit anderen benachteiligten Gemeinschaftsregionen entstehen.

Trotz der langen Prüfungsdauer ist bis heute lediglich einer der drei Fälle vollständig abgeschlossen. Für das Opel-Eisenach-Projekt wurden die vorgesehenen Regionalbeihilfen von knapp 29\% genehmigt, da sie in etwa den regionalspezifischen Kostennachteilen entsprachen. Da das Projekt mit einer signifikanten Kapazitätsausweitung verbunden war, ließ sich eine Überkompensation der Nachteile nicht rechtfertigen ${ }^{154}$. Allerdings wurden Umweltschutzbeihilfen von 9,1 Mio. DM für Emissionsreduktionen in der Lackiererei, die über die gesetzlichen Vorschriften hinausgingen, ebenfalls genehmigt. Zusätzliche Beihilfen der Treuhand in Gestalt von zu geringen Preisen für den Landverkauf wurden durch eine Erhöhung des von Opel zu zahlenden Preises um 14,65 Mio. DM eliminiert 155.

Die Lösung der beiden anderen Fälle wurde dadurch erschwert, daß sowohl Mercedes-Benz als auch VW angesichts der schlechten Marktlage ihre Investitionspläne revidierten. So gab Mercedes-Benz den Bau des neuen Werkes auf und erhöhte

\footnotetext{
152 Dies gilt trotz der gleichzeitigen Erweiterung des Marktes um die neuen Länder und evtl. Osteuropa.

153 Die politische Sensibilität der drei Fälle zeigt sich in der ausdrücklichen Betonung in der Pressemitteilung, daß die Verfahrenseröffnung keine Änderung der wohlwollenden Politik der Kommission gegenüber Investitionsbeihilfen in den neuen Ländern darstelle. Vgl. EG, Kommission 1992i, S. 1.

154 Vgl. EG, Kommission 1993p, S. 19f.

155 Vgl. EG, Kommission 1993p, S. 17f.
} 
stattdessen die Investitionen in das ehemalige IFA-Werk, in dem in Lohnmontage Lkws für das Unternehmen hergestellt werden. Gleichzeitig wird Mercedes-Benz das Werk in Ludwigsfelde völlig übernehmen ${ }^{156}$. Die verbliebenen Beihilfen für dieses Projekt, u.a. Verlustausgleiche, werden nunmehr eher unter den Regeln für Umstrukturierungsbeihilfen zu beurteilen sein. Letzteres gilt auch für die Beihilfen für das VW-Projekt in Sachsen, soweit sie das Übergangsunternehmen Sächsische Automobilbau (SAB) betreffen. VW hat seine Pläne für das neue Werk in Mosel zeitlich erheblich gestreckt, so daß auch hier die Produktionszeit der SAB erheblich verlängert wird. Zu den Umstrukturierungsbeihilfen für die SAB erließ die Kommission eine abschließende Entscheidung, in der sie den größten Teil der vorgesehenen Hilfen (ca. 80\%) genehmigte, den Rest jedoch in Analogie zu den Fällen der Übergangsphase verbot, da diese Hilfen im Verhältnis zu den Umstrukturierungskosten und der Rückführung der alten DDR-Kapazitäten in Sachsen als überhöht angesehen wurden 157 . Da ein Teil der Beihilfen illegalerweise vor der Verfahrenseröffnung gewährt worden war, schließt die Entscheidung deren Rückforderung (einschl. Zinsen) ein. Auch der vorgesehene Verlustausgleich wurde durch die Entscheidung reduziert 158 . Die regionale Analyse für die neuen Projekte wird aufgrund der Verzögerung wohl ebenfalls wesentlich korrigiert werden müssen.

Ein wesentliches Element der beiden Entscheidungen zu Fiat und Opel stellte die Einrichtung einer umfassenden Ex-post-Kontrolle mit der Vorlage jährlicher Berichte dar, um so die Einhaltung des Investitionsprojekts und der maximal genehmigten Beihilfeintensitäten zu gewährleisten ${ }^{159}$. Diese Überwachung schließt eine Lücke der Subventionskontrolle, die in früheren Fällen (s.o.) zu Problemen geführt hatte. Obwohl in beiden Fällen das Prüfungsverfahren ohne formelle Entscheidung geschlossen werden konnte, legte die Kommission ihre Akzeptanzgründe im Amtsblatt und damit öffentlich ausführlich da, was auch im Sinne der Transparenz der Kontrolle positiv ist.

Eine solche Transparenz und Ex-post-Kontrolle sicherte die Kommission ebenfalls bei ihrer Entscheidung zu den Beihilfen an das Joint venture zwischen Ford und VW zur Herstellung von Minivans in Portugal. Hier war die Publizität allein schon auf-

156 Vgl. Aeppel 1992 und FAZ 1992a, S. 15.

157 Vgl. EG, Kommission 1994h. Aufgrund des mit der Verfahrenseröffnung verbundenen Beihilfenzahlungsstopps war die Sächsische Automobilbau zwischenzeitlich in Liquiditätsprobleme geraten, so daß die Kommission im Einklang mit ihren üblichen Bedingungen Ausfallbürg-

158 Sgl. EG, Kommission 1994h.

159 Vgl. EG, Kommission 1993o, S. 18f., und 1993p, S. 20. 
grund des Fördervolumens und der Beschwerde des Konkurrenten Matra, der für Renault das Modell Espace herstellt, geboten 160 . Zudem erfolgte hier eine zusätzliche Untersuchung der Kommission nach Art. 85 EWGV wegen möglicher Kartellprobleme, die aber auch zu einer Genehmigung führte161. Vom regionalpolitischen Standpunkt war die hier genehmigte Beihilfenintensität sicher unproblematisch, jedoch erzielen die beiden Unternehmen durch ihre Kooperation in einer vermutlich wachsenden - aber mit größerer Unsicherheit behafteten - Marktnische Kostenersparnisse und eine Risikominderung durch Senkung ihres individuellen Breakeven-Punktes. Diese Situation hätte wohl eher für eine noch niedrigere Subventionierung gesprochen, verbunden mit einem Angebot, bei getrenntem Vorgehen der beiden Firmen höhere Beihilfen zu gewähren, um so einen Anreiz zu setzen, in einem Teilmarkt mit ohnehin verminderter Wettbewerbsintensität die Konzentration nicht noch weiter voranzutreiben. Eine Klage von Matra gegen die Beihilfenentscheidung wies der EuGH in allen Punkten ab. Matra hatte sowohl die Marktanalyse als auch die Ermittlung der regionalen Nachteile für grob fehlerhaft gehalten. Dies wurde vom EuGH verworfen, wobei die Einschaltung unabhängiger Consultants als Argument für die Vertrauenswürdigkeit der Kommissionsanalyse angeführt wurde 162.

Bei den anderen Fällen unter dem Gemeinschaftsrahmen dominierten Beihilfen für FuE- und Innovationsinvestitionen (vgl. Tabelle 4.4-5). Hierbei ist zu befürchten, daß die MS Projekte als innovativ anmelden, die in Wirklichkeit normale Modernisierungsinvestitionen bzw. Produktentwicklungen darstellen. Deshalb liegt die Hauptaufgabe der Kommission darin zu prüfen, ob bestimmte Produkte oder Verfahren wirklich auf Gemeinschaftsebene neue Bereiche erforschen bzw. innovativ sind 163 . Hierfür sind technische Kenntnisse notwendig, die sie sich durch die Einschaltung von Consultants zugänglich macht. Diese technischen Untersuchungen führten im Falle VW-Bruxelles dazu, daß die Kommission gegen das ursprünglich vorgeschlagene Förderprojekt, das Beihilfen von 2,7 MECU vorgesehen hatte, das Verfahren eröffnete ${ }^{164}$. Eine eingehende technische Analyse ergab dann, daß nur etwa $10 \%$ der Investitionen innovativen Charakter besaßen, für die dann eine $8 \%$ ige

\footnotetext{
160 Vgl. EG, Kommission 1991i, S. 5-7.

161 Vgl. EG, Kommission 1993a, S. 96.

162 Vgl. EuGH 1993, Rn. 26-28 und 37. Auch das Argument, daß die Kommission angesichts der von der portugiesischen Regierung im Laufe des Vorprüfverfahrens notifizierten Modifikationen des Projekts das Hauptverfahren hätte eröffnen müssen, lehnte der EuGH ab, da sie nicht als wesentliche Änderungen angesehen werden konnten.

164 Vgl. EG, Kommission 19901.
} 
Tab. 4.4-5

Fälle von anderen Subventionen unter dem Gemeinschaftsrahmen

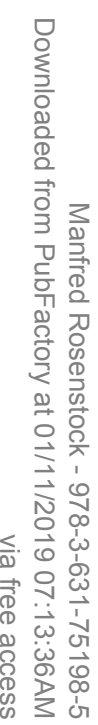

\begin{tabular}{|c|c|c|c|c|c|c|c|}
\hline Fall & MS & $\begin{array}{c}\text { Jahr der } \\
\text { Entscheidung }\end{array}$ & $\begin{array}{r}\text { Beihilfen } \\
\text { in MECU }\end{array}$ & $\begin{array}{r}\text { Beihilfen } \\
\text { intensität } \\
\text { in \% }\end{array}$ & $\begin{array}{c}\text { Subventions- } \\
\text { typ }\end{array}$ & $\begin{array}{c}\text { Verfahren } \\
\text { nach Art. } \\
\text { 93,II? }\end{array}$ & $\begin{array}{l}\text { Nicht ak- } \\
\text { zeptierte } \\
\text { Beihilfen }\end{array}$ \\
\hline VW Bruxelles & B & 1990 & 0,3 & 8 & Innovation & ja & 2,4 \\
\hline Renault/Peugeot & $\mathrm{F}$ & 1990 & 70,0 & 40 & FuE, Innovation & nein & - \\
\hline Daimler-Benz Berlin & $\mathrm{D}$ & 1992 & 26,0 & ? & Ad hoc & ja & 19,2 \\
\hline Iveco Elena & I & 1992 & $80,1^{*}$ & 17,4 & FuE & nein & - \\
\hline Fiat Mezzogiomo & I & 1992 & 175,0 & 17 & Innovation, FuE & ja\# & - \\
\hline Opel Eisenach & $\mathrm{D}$ & 1992 & 4,6 & 30 & Umwelt & ja\# & - \\
\hline Renault-Peugeot VSR & $\mathrm{F}$ & 1993 & 31,5 & 32 & FuE & nein & - \\
\hline
\end{tabular}

*Zinsgünstiges Darlehen in dieser Höhe

\# In Verbindung mit dem Prüfverfahren gegen die Regionalbeihilfen

Quelle: EG, Kommission 1990a-1994a. 
Subvention zusammen mit einer fünfjährigen Freistellung von der Grundsteuer genehmigt wurde 165 . Diese konsequente Vorgehensweise der Kommission führte dazu, daß in einem weiteren belgischen Fall (Volvo Gent) die Behörden die ursprüngliche Anmeldung zurückzogen und danach eine Genehmigung nur für die innovativen und umweltschutzfördernden Elemente des Projekts beantragten, die dann auch erteilt werden konnte ${ }^{166}$.

Einen besonderen Problemaspekt warfen die Fälle Toyota Derbyshire und Daimler-Benz Berlin auf. In beiden Fällen vertrat die Kommission die Auffassung, daß die regionalen Behörden den Firmen Grundstücke für Investitionsvorhaben zu einem zu niedrigen Preis verkauft und damit diesen eine Beihilfe hatten zukommen lassen. Diese Sichtweise wurde sowohl von den Firmen als auch den nationalen Behörden energisch bestritten, die sich zudem auf Preisschätzungen offizieller Stellen berufen konnten. Die Kommission setzte in beiden Fällen die Einschaltung unabhängiger Gutachter durch, die jeweils zu wesentlich höheren Werten kamen. Es ergingen daher negative Entscheidungen mit einer Aufforderung zur Nachzahlung der Preisdifferenz an die Firmen 167. Beide Rückzahlungen sind inzwischen erfolgt ${ }^{168}$. Mit diesen Entscheidungen konnte die Kommission etablieren, daß auch "normale" Kaufverträge zwischen dem Staat und Unternehmen indirekte Beihilfen enthalten konnten, in die ein Eingriff möglich ist, wenn sich kein Marktpreis für die entsprechenden Objekte aufgrund des Vorliegens mehrerer Angebote feststellen läßt. $\mathrm{Da}$ diese als Ad-hoc-Beihilfen außerhalb genehmigter Programme klassifiziert wurden, waren sie trotz der in Relation zum gesamten Investitionsvolumen geringen Beihilfenintensität auch nicht genehmigungsfähig 169 . Somit gelang es hier, den MS

165 Vgl. EG, Kommission 1991n, S. 46-50.

166 Vgl. EG, Kommission 1993a, S. 236.

167 Vgl. EG, Kommission 19921, S. 36-44, und 1992f, S. 15-25. Bei Daimler-Benz divergieren Beihilfenhöhe und Nachzahlungsbetrag, da die Kommission angesichts des Standortes in (West-)Berlin unter Anwendung von Art. 92,IIc eine Aufrechnung mit zusätzlichen Kosten akzeptierte, die dem Unternehmen durch den im Preis überhöhten Erwerb eines Nachbargrundstücks (Bellevue-Tower) entstanden. Zu diesem Kauf war das Unternehmen verpflichtet, um die städtebaulichen Vorgaben des Berliner Senats zu erfüllen. Seine Berücksichtigung stellte ein juristisches Problem dar, da die Kaufverpflichtung von Daimler-Benz nur ein implizites Element der Vertragsvereinbarung zwischen Berliner Senat und dem Unternehmen war.

168 Vgl. EG, Kommission 1992a, S. 172, und 1993a, S. 236f.

$169 \mathrm{Im}$ Gemeinschaftsrahmen ist auch ausdrücklich festgelegt, daß Beihilfen außerhalb einer genehmigten Regelung ohne Rücksicht auf die Meldeschwelle stets zu notifizieren sind. Vgl. EG, Kommission 1989m, S. 3. 
ein weiteres Schlupfloch zur Umgehung der strengeren Regeln des Gemeinschaftsrahmens zu verschließen und die Transparenz der Beihilfenvergabe zu erhöhen.

Angesichts der jüngsten Krise der Automobilindustrie bestand auch wieder die Gefahr, daß einzelne Unternehmen in Zahlungsschwierigkeiten gerieten und die betroffenen MS mit Rettungs- und Umstrukturierungsbeihilfen einschl. Kapitalbeteiligungen in ähnlicher Weise eingriffen, wie dies in den Fällen der Übergangsphase zu beobachten war (s. oben Abschn. 4.4.7). Einen derartigen Fall stellte die Rettung des in Konkurs geratenen Lkw-Produzenten DAF durch die niederländischen und flämischen Regierungen dar, bei der die drei o.g. Beihilfentypen gewährt wurden. Die Prüfung der Kommission ergab, daß nicht nur die Beihilfen im Zusammenhang mit der Rettungsaktion nicht gemeldet worden waren, sondern daß auch vor dem Konkurs bereits mehrfach nichtnotifizierte Beihilfen insbesondere durch die niederländische Regierung an das Unternehmen gewährt worden waren 170 . In dem nunmehr eröffneten formellen Verfahren nach Art. 93, II wird ein wichtiger Aspekt der Untersuchung darin bestehen zu klären, ob sich die beiden MS beim Beteiligungserwerb wie ein normaler privatwirtschaftlicher Investor (vgl. oben Abschnitt 4.1.4.3) verhalten haben. Des weiteren ist zu prüfen, ob nicht durch die Entschuldung des Unternehmens und einen möglichen Verkauf der Aktiva unter ihrem Marktwert an die neuen Eigner, die teilweise mit den alten identisch sind, dem neuen Unternehmen massive Wettbewerbsvorteile verschafft wurden ${ }^{171}$. Aufgrund dieser partiellen Identität der Eigner erscheint es auch notwendig, daß mögliche Restitutionsforderungen aus illegalen Beihilfen an das alte Unternehmen beim Rechtsnachfolger eingetrieben werden können, da sonst Beihilfenrückforderungen leicht durch Konkurse umgangen werden können 172 .

Was die Verpflichtung der MS nach dem Gemeinschaftsrahmen zur Erstellung von Jahresberichten betrifft, so hatte die Kommission große Schwierigkeiten, die MS zur fristgerechten Einreichung innerhalb von 3 Monaten nach Jahresende anzuhalten, und mußte regelmäßig zusätzliche Aufforderungen an die MS versenden. Neben den in den obigen Tabellen aufgeführten Fällen enthalten die Berichte Daten zu kleinen Beihilfeprojekten, die unterhalb der Meldeschwelle liegen.

170 Vgl. EG, Kommission 1994c, S. 11-14. Hierbei handelte es sich um neue zinsverbilligte Darlehen, aber auch um den Aufschub ähnlicher früher gewährter Darlehen. Die Nichtnotifizierung ist umso befremdlicher, als ähnliche Transaktionen im Falle Volvo Car BV von derselben

171 Vgl. EG, Kommission 1994b, S. 6f.
172 Vgl. dazu auch EG, Kommission 1994b, S. 8. Regierung notifiziert worden waren. 


\subsubsection{Die Verlängerungen des Gemeinschaftsrahmens}

Angesichts der o.a. starken Widerstände von seiten einiger MS bereits beim Erlaß des Gemeinschaftsrahmens war die Verlängerung des Rahmens über 1990 hinaus keineswegs gesichert.

Die Analyse eines Forschungsinstituts 173 hatte sich klar für eine solche Verlängerung ausgesprochen. Ihre Studie sah in bezug auf den Binnenmarkt sowie die Öffnung Osteuropas eine Welle von Erweiterungsinvestitionen voraus, um die vor allem zwischen kleineren Staaten, die bisher noch keine Automobilstandorte besaßen, ein heftiger Subventionswettlauf entbrennen würde. Daneben waren noch weitere subventionierte Investitionen, vor allem zur Modernisierung und Schadstoffverminderung zu erwarten. Angesichts der prognostizierten Subventionsvolumina und der Gefahr von Überkapazitäten mit daraus folgenden weiteren Subventionsanreizen bestand die Notwendigkeit strenger Subventionskontrollen unvermindert fort. Zur Erhöhung der Transparenz und der Vergleichbarkeit von Entscheidungen wurde die Festlegung definitiver Intensitätsgrenzen für einzelne Subventionstypen gemessen am Investitionsvolumen oder den geschaffenen Arbeitsplätzen vorgeschlagen.

Eine solche Einengung des Entscheidungsspielraums fand jedoch keine Unterstützung, wohl vor allem deswegen, weil man sich bei der dominierenden Kategorie der Regionalsubventionen die Möglichkeit eines gewissen "Fine tuning" bei der Gestaltung der Subventionshöhe und sonstigen Bedingungen entsprechend den spezifischen regionalen Problemen erhalten wollte. Ein weiterer Aspekt, der gegen einzelne Modifikationen sprach, war die Gefahr, daß damit eine Grundsatzdiskussion um alle Aspekte des Gemeinschaftsrahmens losgetreten worden wäre, in der dann möglicherweise die Vertreter der MS versucht hätten, Verwässerungen bspw. bei den Regionalsubventionen durchzusetzen. Allerdings wurde damit auch auf mögliche Verschärfungen und Präzisierungen, so bspw. bei den Rationalisierungs- und Modernisierungsbeihilfen, bei denen an sich keine Beihilfenrechtfertigungen vorliegen, verzichtet. So wurde dann lediglich die Ausnahme für West-Berlin aufgehoben, deren Rechtfertigung aufgrund der Wiedervereinigung hinfällig geworden war, insbesondere da die Kommission eine spezielle Ausnahme vom Gemeinschaftsrahmen für die neuen Bundesländer abgelehnt hatte174. Ansonsten wurde der Rahmen unverändert verlängert, wobei die Kommission sich verpflichtete, nach weiteren 2 Jahren eine erneute Überprüfung vorzunehmen ${ }^{175}$. Die vorgetragenen Warnungen

\footnotetext{
173 Vgl. MIRU 1990.

174 Vgl. EG, Kommission 1990k, S. 1f.

175 Vgl. EG, Kommission 1991j, S. 4.
} 
vor einem Subventionswettlauf gaben schließlich den Ausschlag, wobei diese Gefahr angesichts der ungünstigeren Prognosen für den Sektor, insbesondere den Nutzfahrzeugbereich, für die kommenden Jahre noch schärfer gesehen wurde176. Auch die Aufhebung aller Binnenrestriktionen im Zuge der Vollendung des Binnenmarktes 177 und die vorgesehene Liberalisierung der Importe aus Nicht-EG-Staaten, v.a. aus Japan, bis 1999 (s.u.) werden zu einer Intensivierung des Wettbewerbs und damit zu noch stärkeren Verzerrungen durch Subventionsmaßnahmen einzelner MS führen, womit sich eine Aufrechterhaltung der strengeren sektoralen Regelung der Beihilfenkontrolle rechtfertigen ließ. Schließlich wird wohl die Einsicht vorhanden gewesen sein, daß eine explizite Aufgabe des Gemeinschaftsrahmens nach nur zweijähriger Praxis den Eindruck erweckt hätte, diese strengere Art der Beihilfenkontrolle sei ein Fehler gewesen, was die Autorität der Kommission in dieser Frage generell geschwächt und möglicherweise ein Signal für eine erneute Erhöhung der staatlichen Unterstützung des Sektors gesetzt hätte.

Die o.e. erneute Überprüfung fand dann im Dezember 1992 in einer multilateralen Sitzung mit den MS statt, bei der zwar eine große Mehrheit für die Weiterführung des Rahmens, nicht aber für erneut diskutierte Änderungen vorhanden war. So wurde der Rahmen erneut unverändert verlängert, wobei diesmal kein präzises Datum für eine erneute Überprüfung festgelegt wurde 178 .

Da die Verlängerungen des Rahmens, wenn auch nach Konsultation der MS, von der Kommission einseitig beschlossen wurden, ohne wie bei der Einführung die explizite Zustimmung der MS einzufordern, wird die Rechtmäßigkeit dieses Vorgehens z.T. bezweifelt ${ }^{179}$.

\subsubsection{Außenwirtschaftliche Absicherung der Subventionspolitik}

Der außenwirtschaftliche Aspekt der Subventionskontrolle im Automobilbereich berührt vor allem zwei Bereiche: Dies ist zum einen die sektorale Handelspolitik gegenüber Japan, zum anderen die Anwendung der Beihilfenkontrollregeln gegenüber Ländern, mit denen die Gemeinschaft Freihandelsabkommen unterhält. Während der erste Bereich vorwiegend protektionistische Züge trägt und dem Schutz der (z.T. subventionierten) EG-Produzenten vor Importen dient, gegenüber denen der Subventionsvorwurf i.d.R. nicht erhoben wird, geht es beim zweiten Aspekt vor

\footnotetext{
176 Vgl. EG, Kommission 1990k, S. 1.

177 Hier handelt es sich vor allem um technische, umweltpolitische und steuerliche Hindernisse.

178 Vgl. EG, Kommission 1993a, S. 235f, und 1993q, S. 17.

179 Vgl. Schütterle 1993a, S. 77.
} 
allem darum, ein Ausweichen der Kfz-Hersteller vor den strengeren Subventionskontrollregeln innerhalb der Gemeinschaft durch hochsubventionierte Investitionen in den Nachbarländern zu verhindern.

\subsubsection{Die Handelspolitik der EG im Kfz-Bereich gegenüber Japan}

Obwohl seit dem Ende der Übergangszeit die handelspolitische Kompetenz allein bei der Kommission liegt, existierten in einzelnen MS noch nationale Importrestriktionen für $\mathrm{Kfz}$, insbesondere für Fahrzeuge aus Japan, die von der Kommission aufgrund der Ausnahmevorschrift des Art. 115 laufend genehmigt wurden. Diese reichten von absoluten Obergrenzen (Beispiel Italien: ursprünglich 2200 Fahrzeuge pro Jahr, mittlerweile 2,3\%) über Marktanteilsquotierungen wie in Frankreich seit 1977 (wo das Industrieministerium diese Quote von 3\% auf die japanischen Produzenten aufteilte) und in Großbritannien seit 1976 (11\% aufgrund von Absprachen zwischen den Automobilverbänden) bis zu temporären Selbstbeschränkungen der Japaner wie in Belgien und Deutschland Anfang der 80er Jahre. Die meisten dieser Beschränkungen erfolgten als Reaktion auf starke Anstiege der Importe japanischer Automobile180. Ähnliche Selbstbeschränkungszusagen gab die japanische Regierung auch in Gesprächen mit der Kommission ab. Zudem erfolgte seit 1981 aufgrund einer Ratsverordnung eine statistische Importerfassung 181. Die Auflistung zeigt die große Streubreite von Eingriffen der MS, wobei MS ohne eigene Automobilindustrie (DK, L, IRL) keine Beschränkungen erließen. Diese Divergenz der Interessen und Herangehensweisen machte in den 80er Jahren eine gemeinsame Handelspolitik in diesem Sektor unmöglich.

Von seiten der Produzenten wurde versucht, die dennoch empfundene japanische Bedrohung durch Kooperationsabkommen abzumildern und auf diese Weise gleichzeitig von den japanischen Produzenten zu lernen, um den Produktivitätsrückstand abzubauen. Die Dauerhaftigkeit dieser Kooperationen variierte stark ${ }^{182}$. Japanische Hersteller haben versucht, den bestehenden Protektionismus durch vermehrte Direktinvestitionen in der Gemeinschaft, v.a. in Großbritannien, zu umgehen, was zu Forderungen der südlichen MS nach hohen Local-content-Barrieren führte ${ }^{183}$.

180 Vgl Cohen 1983, S. 530-533, Müller 1983, S. 240f., sowie de Melo/Messerlin 1988, S. 1529f. Die Arbeit der letztgenannten Autoren untersucht die Wirkung dieser VERs auf Preise, Qualitätsstruktur der Nachfrage und auf die Entwicklung der inländischen Produktion in den jeweiligen MS.

182 Vgl. MIRU 1987, S. 83/84

183 Vgl. Herrmann 1989, S. 18. 
Im Zusammenhang mit der Erstellung des Gemeinschaftsrahmens und des Binnenmarktkonzepts für die Kfz-Industrie 184 entwickelte die Kommission erneut ein Konzept für eine gemeinsame Handelspolitik in diesem Sektor. Während Frankreich, Italien und Spanien eine strikte Marktanteilsbegrenzung für japanische Importe und eine Bindung an EG-Exporte nach Japan forderten ${ }^{185}$, strebte die Kommission eine schrittweise Liberalisierung an. Diese sollte bei Aufhebung der nationalen Restriktionen den EG-Produzenten eine Anpassungsfrist an die Herausforderungen des Binnenmarktes durch Beibehaltung einer EG-weiten vorübergehenden Beschränkung gewähren ${ }^{186}$. Andere Aspekte des sektoralen Binnenmarktprogramms, wie z.B. EGweit einheitliche Typenabnahmeregeln, würden im Gegenzug die Wettbewerbssituation der Importautos verbessern ${ }^{187} 1991$ wurde dann ein derartiges Understanding mit Japan erreicht, das den Marktanteil japanischer Hersteller bis 1999 gemeinschaftsweit beschränkt, wobei der Anteil stufenweise auf $16 \%$ wachsen soll, wovon die Hälfte aus sog. Transplants in der Gemeinschaft stammen soll. Nationale Beschränkungen in einzelnen MS und die Anwendung der Schutzklausel nach Art. 115 EWGV wurden ab 1993 aufgehoben ${ }^{188}$. Allerdings sicherte Japan eine Selbstkontrolle in Richtung auf verabredete Zielwerte für die Exporte in die o.g. MS zu, in denen bisher quantitative Restriktionen galten ${ }^{189}$. Da für diese Märkte allerdings überproportionale Steigerungen vorgesehen sind, impliziert dies einen Rückgang der Exporte in bisher nicht geschützte Märkte, die allerdings evtl. durch einen Anstieg der Importe aus Transplants ausgeglichen werden könnten. Ab 1999 sollen alle Importrestriktionen fallen 190 . Vertreter europäischer Firmen befürchten als Folge erhebliche Arbeitsplatzverluste, befürworten daher eine längere Übergangsperiode und fordern eine Übernahme der Umschulungskosten durch staatliche Stellen ${ }^{191}$. In

\footnotetext{
184 Vgl. EG, Kommission 1990j. Siehe auch unten 4.4.11.5.

185 Vgl. Herrmann 1989, S. 20.

186 Vgl. EG, Kommission 1990j, S. 13-14.

187 Vgl. Dawkins 1988, S. 1.

188 Arrangement 1991, Paragraph 2b).

189 Vgl. ebenda, Paragraph 2c).

190 Vgl. Arrangement 1991, S. 31-34, The Economist 1991, S. 42, und Preuße 1992, S. 361/62 und 370. In der Übergangsphase werden die Direktimporte langsam mit der Entwicklung des Marktes wachsen, während das Outputwachstum der Transplants informell limitiert wird.

191 Vgl. ebenda und Calvet 1992, S. 13. Das EP fordert sogar eine Reziprozität der Marktöffnungen, wobei ihr Erfolg an der Entwicklung der jeweiligen Marktanteile gemessen werden soll. Vgl. EP 1991, S. 22. Eine solche "ergebnisorientierte" sektorale Handelspolitik, die auch in der außenhandelspolitischen Diskussion in den USA augenblicklich große Bedeutung hat, würde einen weiteren Rückzug aus der multilateralen und multisektoralen Welthandelsordnung
} 
Anwendung des Abkommens wurde angesichts des starken Rückgangs der Zulassungen in der Gemeinschaft im Laufe des Jahres 1993 das Volumen der japanischen Exporte zweimal reduziert 192 .

\subsubsection{Die Ausdehnung der Subventionskontrolle auf Partnerländer mit Frei- handelsabkommen}

Der hier zu diskutierende Aspekt betrifft vor allem die EFTA-Staaten, mit denen die EG seit 1973 Freihandelsabkommen für Industriegüter unterhält, in jüngster Zeit aber auch die sog. Europa-Abkommen mit einigen Reformstaaten des ehemaligen Ostblocks.

Entsprechend den EFTA-Freihandelsabkommen sind wettbewerbsverzerrende Beihilfen, die den Handel zwischen den Vertragsparteien beeinflussen, mit dem Abkommen unvereinbar. Beide Parteien haben im Falle des Scheiterns einer gütlichen Einigung das Recht, gegen solche Beihilfen mit Schutzmaßnahmen, insbesondere der Streichung der Zollpräferenzen einzuschreiten 193. Von den Möglichkeiten dieser Regelung wurde jedoch im Kfz-Bereich erst in jüngster Zeit Gebrauch gemacht, was wohl einerseits mit der durch den Gemeinschaftsrahmen verschärften und systematisierten Beihilfenkontrolle, andererseits mit der durch die zunehmende Integration der Märkte und insbesondere den Abschluß des Vertrages über den EWR sich intensivierenden Standortkonkurrenz zusammenhängt.

Betroffen waren hiervon mehrere Projekte in Österreich, insbesondere ein Joint venture zwischen Chrysler und Steyr-Daimler-Puch zum Aufbau einer Produktionsstätte für den Voyager Minivan in Graz. Hierfür wollten die österreichischen Behörden Beihilfen von insgesamt 33\% des Investitionsvolumens bereitstellen ${ }^{194}$. Angesichts der geplanten Kapazität (max. 120.000 Einheiten p.a.) und der Ausrichtung der Produktion auf Absatzmärkte in der EG (90\% der Produktion) sah die Kommission eine Wettbewerbsverzerrung in der EG und eine Handelsverlagerung zu Lasten des Konkurrenzprodukts Renault Espace für gegeben an und begann Untersuchungen. Diese ergaben, daß für ein Projekt in einer vergleichbaren förderfähigen

des GATT bedeuten, wie er auch im Textilsektor existiert (s.o.). Er würde am Ende zu

192 Vgl. Nakamoto/Griffiths 1993, S. 1, und Handelsblatt 1993a. "managed trade" mit entsprechenden Wohlfahrtsverlusten führen.

193 Vgl. EG, Kommission 1972c, S. 5-6. In einer einseitigen Erklärung der EG machte diese deutlich, daß sie sich bei der Prüfung der Existenz von Verzerrungen an den Regeln der Art. 92-94 194 des EWGV orientieren wird. Vgl. ebenda, S. 92.

4 Vgl. Thöni/Ciresa 1990, S. 13. 
Region der Gemeinschaft lediglich maximal $16 \%$ genehmigt worden wären 195 . Angesichts der mangelnden Bereitschaft Österreichs, die Beihilfenintensität für das Projekt zu senken, beschloß die Kommission nach einigem Zögern ${ }^{196}$, dem Rat die Wiedereinführung von Schutzzöllen aufgrund des Freihandelsabkommens in Höhe von $10 \%$ vorzuschlagen. Da sich die notwendige qualifizierte Mehrheit im Rat für eine solche Entscheidung abzeichnete, lenkten Chrysler und Österreich ein und senkten den Beihilfenbetrag von 105 auf 65,5 Mio. ECU, was bei Berücksichtigung der notwendig gewordenen höheren Investitionsaufwendungen die Beihilfenintensität von $33 \%$ auf $14,4 \%$ senkte ${ }^{197}$. Weitere Beihilfenfälle betrafen den Ausbau eines Motoren- und Getriebewerks von General Motors in Aspern/Wien und eines LKWWerks der Steyr Nutzfahrzeuge in Steyr, für die jeweils $15 \%$ ige Beihilfen von Bund, Land und Gemeinde vorgesehen waren. Hier konnte die Kommission zunächst keinerlei Beihilfenrechtfertigung im Sinne der Gemeinschaftskriterien (insbesondere Regionalförderung) erkennen und verlangte die Rückzahlung198. Nach dem Scheitern von Verhandlungen wurde dem Ministerrat erneut die Erhebung von Strafzöllen vorgeschlagen, und im Falle von General Motors dann auch in Höhe von 4,9\% auf eingeführte Getriebe durchgesetzt. Im Falle der Steyr Nutzfahrzeuge wurde aufgrund neuer Daten die Regionalförderfähigkeit akzeptiert und ein Kompromiß mit Reduktion der Subventionen erreicht ${ }^{199}$. Die betrachteten Fälle zeigen, daß es der Kommission mit den Mitteln des Freihandelsabkommens gelang, ihre Beihilfenkontrollkompetenz quasi auf ein EFTA-Land zu erweitern und ihre eigenen Beurteilungskriterien durchzusetzen. Inzwischen ist nach Inkrafttreten des EWR die EFTA Surveillance Authority (ESA) für diese Länder zuständig. Sie hatte dann einen weiteren österreichischen Fall von Beihilfen für das BMW-Motorenwerk in Steyr zu beurteilen, der nach der Vereinbarung eines bilateralen Prüfungsverfahrens zunächst noch von der Kommission geprüft worden war200. Die Entscheidung der ESA

195 Vgl. EG, Kommission 1993k.

196 Die Verschiebung der Entscheidung wurde mit politischen Rücksichten auf die laufenden Beitrittsverhandlungen mit Österreich und die dortige Stimmung begründet. Vgl. The Economist 1992a, S. 61.

197 Vgl. EG, Kommission 1993a, S. 212, und 1993k. Zur Durchführung dieses Abkommens mußte Chrysler einen Teil der Beihilfen auf ein Sperrkonto einzahlen, aus dem dann entsprechend dem Investitionsfortschritt Beträge an die Firma zurücküberwiesen wurden, wobei jederzeit die 198 Vgl. Ninz 1993

$199 \mathrm{Vgl}$. Handelsblatt 1993b und Hill/Reuter 1993.

200 Vgl. Ninz 1993, und Oberösterreichische Nachrichten 1993. 
erfolgte entsprechend den Regeln des EWR-Abkommen unter Anwendung derselben Regeln, die in der Gemeinschaft gelten, d.h. hier des Gemeinschaftsrahmens 201.

Auch die Europa-Verträge (vorläufige Abkommen) mit Ungarn, Polen und den Tschechischen und Slowakischen Republiken erlauben der Kommission die Kontrolle von Beihilfen in diesen Ländern für Produkte, die unter die Freihandelsregeln dieser Verträge fallen, wobei die erlaubten Beihilfenhöchstgrenzen mit jenen der ärmsten Regionen der EG gleichgestellt werden sollen (also 75\%)202. Ein gewisser Interessenkonflikt ergibt sich daraus, daß subventionierte Industrieprojekte häufig auch von der EBRD gefördert werden, die ein Interesse daran hat, daß diese Projekte im Interesse des Wiederaufbaus in den Reformstaaten durchgeführt werden. Solche Fälle stellen ein Joint venture von GM mit dem ungarischen Produzenten RABA zur Errichtung einer Motoren- und Montagefabrik in Ungarn sowie ein weiteres Joint venture von Suzuki mit ungarischen Komponentenherstellern zur Herstellung von Kleinwagen dar, für die die Regierung vielfältige Unterstützung in Form direkter Beihilfen, einer zehnjährigen Einkommensteuerbefreiung, der Produktion in einer zollfreien Zone bei dennoch zollfreier Einfuhrmöglichkeit der Pkw nach Ungarn (nur GM) sowie eines garantierten hohen Zollschutzes auf die Einfuhr anderer Pkw zusicherte203. Diese vielfältigen Beihilfen von unsicherer Höhe, die zudem dem Charakter von Betriebsbeihilfen nahekommen, könnten zu einer Prüfung durch die Kommission führen, angesichts des Fehlens von Durchführungsbestimmungen zu den Europa-Verträgen wohl für diese Fälle nur im Rahmen der GATT-Regeln.

\subsubsection{Beurteilung der Subventionskontrollpolitik}

\subsubsection{Die jüngere Entwicklung der Automobilindustrie}

Nach einer Phase weitgehender Stagnation 1973-84, in der der zweimalige massive Ölpreisschub zu einer erheblichen Verteuerung der Kfz-Nutzung führte und sich Produktion und Absatz folglich ohne klaren Trend in einem Auf und Ab bewegten, konnte die Industrie von 1984-89 ein rasantes Wachstum verzeichnen, das 1989 im Absatz von 13,7 Mio. Fahrzeugen in Westeuropa (EG 12,3 Mio.) gipfelte (vgl. Abb. 4.4-1.). Diese Entwicklung erlaubte auch eine erhebliche Verbesserung der finanziellen Position der westeuropäischen Produzenten, die schon 1985 kollektiv wieder einen Gewinn erzielten, der 1987 Rekordhöhen erreichte. Eine ähnliche

201 Vgl. EFTA Surveillance Authority 1994, S. 3-5.

202 Vgl. EG, Kommission 1993a, S. 68f.

203 Vgl. Somai 1993, S. 10-29. 
Tab. 4.4-6

Nettogewinne der europäischen Automobilhersteller (in MECU)

\begin{tabular}{l|rrrrrrrrr} 
Unternehmen & 1977 & 1979 & 1981 & 1983 & 1984 & 1986 & 1988 & 1990 & 1992 \\
\hline Alfa-Romeo* & $-149,3$ & $-80,3$ & $-92,2$ & $-158,3$ & $-323,6$ & $-661,3$ & 0 & 0 & 0 \\
BMW & 48,2 & 70,5 & 57,4 & 128,5 & 144,8 & 162,9 & 219 & 339 & 359 \\
DAF & 10,8 & 7,9 & 0,4 & $-10,6$ & 3,9 & 14,1 & n.v. & n.v. & n.v. \\
Daimler-Benz & 221,7 & 254,0 & 328,7 & 435,1 & 493,2 & 830,4 & 820 & 753 & 1868 \\
FIAT & 55,0 & 30,0 & 71,4 & 187,7 & 453,7 & 1478,9 & 1968 & 1060 & 345 \\
Ford Europe & 533,6 & 889,4 & 258,9 & 315,7 & 186,2 & 568,0 & 1234 & 114 & -1315 \\
Gen. Motors Eur. & 243,0 & 246,7 & $-382,2$ & $-256,5$ & $-368,8$ & $-349,0$ & 1506 & 1503 & 946 \\
Jaguar & 0,0 & 0,0 & 0,0 & 0,0 & 72,1 & 124,2 & 50 & -56 & n.v. \\
MAN & 22,7 & 27,9 & 20,0 & $-65,2$ & $-50,4$ & 57,4 & n.v. & n.v. & n.v. \\
Porsche & 6,4 & 9,1 & 4,0 & 30,7 & 41,3 & 35,4 & 12 & 28 & -32 \\
PSA & 223,2 & 308,8 & $-330,0$ & $-382,5$ & $-49,6$ & 528,0 & 1257 & 1339 & 492 \\
Renault & $-20,9$ & 174,3 & $-95,9$ & $-266,3$ & $-1851,2$ & $-859,9$ & 1267 & 125 & 781 \\
Rover & $-79,4$ & $-223,5$ & $-898,6$ & $-243,4$ & 136,5 & $-1328,4$ & 99 & n.v. & n.v. \\
Saab-Scania & 35,5 & 39,6 & 70,6 & 55,6 & 104,8 & 186,7 & 280 & 47 & 50 \\
SEAT* & 4,7 & $-164,1$ & $-196,4$ & $-280,6$ & $-285,9$ & 0,0 & 0 & 0 & 0 \\
Volkswagen & 158,4 & 265,7 & 54,2 & $-94,8$ & 101,9 & 272,6 & 376 & 529 & 73 \\
Volvo Group & 38,7 & 70,9 & 80,4 & 29,9 & 240,3 & 364,7 & 682 & -136 & -441 \\
Volvo Car BV & $-7,1$ & 0,0 & $-10,5$ & 5,5 & 7,2 & 2,2 & n.v. & n.v. & n.v. \\
Summe & 134,2 & 1926,9 & $-1059,8$ & $-569,5$ & $-943,6$ & 1426,9 & 9770 & 5645 & 3126
\end{tabular}

* Nach den Übernahmen von Alfa-Romeo und SEAT durch FIAT bzw. VW sind deren Resultate bei der jeweiligen Muttergesellschaft enthalten. Die Resultate von Jaguar sind bis 1983 bei Rover enthalten.

Quellen: Bhaskar/MIRU 1990 und Marketing Systems 1993. 
Entwicklung läßt sich jedoch bei der Beschäftigung nicht beobachten. Hier ist eher eine Stagnation bzw. ein Abbau zu beobachten, der mit der v.a. japanischen Konkurrenz und dem Druck zu Kostensenkungen und Produktivitätserhöhungen zu erklären ist ${ }^{204}$ (vgl. Tab. 4.4-6 und 4.4-7).

Die Jahre ab 1990 sahen wiederum eine weitgehende Stagnation und eine drastische Schrumpfung des Marktes 1993, wobei bereits 1991 bei Eliminierung des wiedervereinigungsbedingten Booms in Ostdeutschland der Absatz in Westeuropa um $8,4 \%$ gefallen wäre 205 . Diese Zahlen reflektieren die konjunkturelle Abschwungphase in Westeuropa nach einem langen Aufschwung, wobei die Stärke der jüngsten Wiederbelebung des Absatzes bei einem evtl. Auslaufen fiskalischer Kaufanreize in einigen MS abzuwarten bleibt. Mit den in Gang befindlichen Kapazitätserweiterungen mehrerer europäischer Hersteller und der erwarteten Zunahme der Produktion japanischer Hersteller in der EG 206 besteht erneut die Gefahr signifikanter Überkapazitäten, die noch dadurch verschärft wird, daß der Ausbau der Produktionsanlagen in Osteuropa das Nachfragewachstum zunächst übertreffen wird.

Tab. 4.4-7

Beschäftigte in der Automobilindustrie (in 1000)

\begin{tabular}{c|cc} 
Jahr & Anzahl & Index $(1980=100)$ \\
\hline 1993 & 1215,5 & 74,57 \\
1992 & 1299,7 & 79,74 \\
1991 & 1337,1 & 82,03 \\
1990 & 1354,8 & 83,12 \\
1989 & 1325,1 & 81,29 \\
1988 & 1322,9 & 81,16 \\
1987 & 1329,7 & 81,58 \\
1986 & 1334,1 & 81,85 \\
1985 & 1364,1 & 83,69 \\
1984 & 1408,7 & 86,42 \\
1983 & 1438,4 & 88,25 \\
1982 & 1471,0 & 90,25 \\
1981 & 1516,6 & 93,04 \\
1980 & 1630,0 & 100,00
\end{tabular}

Quelle: Eurostat (NACE 351 und 352 ohne Komponentenherstellung)

204 Vgl. EG, Kommission 1992g, S. 2-4.

205 Vgl. Financial Times 1992, S. 2.

206 Vgl. Preuße 1992, S. 370. 


\subsubsection{Die Entwicklung des Subventionsniveaus}

A priori legt die hohe Bedeutung der Kfz-Industrie in bezug auf Wertschöpfung und Beschäftigung in einigen MS eine hohe Bereitschaft zur Förderung nahe207. Im Vergleich zur Lage im Schiffbau- oder Stahlsektor fällt die Beantwortung der Frage nach einem Erfolg beim Abbau des Subventionsniveaus in der Autoindustrie jedoch erheblich schwerer. Im Gegensatz zur Situation bei den Werften und den Stahlwerken existieren hier nämlich keine permanenten sektorspezifischen Auftragshilfenprogramme bzw. regelmäßigen staatlichen Verlustausgleiche, deren Intensitätsentwicklung sich verfolgen läßt. Stattdessen erfolgt die Subventionierung ad hoc nach Bedarf vorwiegend für Investitionsprojekte aufgrund verschiedener Beihilferegelungen zumeist regionalpolitischer Provenienz.

Doch auch hier zeigt die bisherige Analyse, daß die staatlichen Hilfen an die Industrie stark mit der allgemeinen bzw. der Branchenkonjunkturlage korreliert waren 208. So führten die Krisen Mitte der 70er und Anfang/Mitte der 80er Jahre zu einem massiven Anstieg der Subventionsfälle und -volumina, v.a der Rettungsbeihilfen, den die Kommission in der ersten Phase überhaupt nicht, in der Übergangsphase vor dem Gemeinschaftsrahmen nur bedingt beschränken konnte. Das relativ geringe Subventionsniveau der Jahre bis 1992 war sicherlich zu einem guten Teil Ausfluß der guten Automobilkonjunktur. In Anbetracht der Existenz einiger großer Subventionsprojekte (Fiat Mezzogiorno und die Fälle in den neuen Bundesländern) und einer starken Abschwächung der Autokonjunktur könnte man mit einem Wiederanstieg der Subventionsvolumina rechnen. Dies würde allerdings eine unveränderte Qualität der Beihilfenkontrolle unterstellen.

\subsubsection{Erfolge bei der Harmonisierung und Kontrolle?}

Eine solche Sicht der Dinge läßt sich jedoch m.E. aus der tatsächlichen Entwicklung der letzten Jahre nicht rechtfertigen. Während noch Anfang der 80er Jahre das relativ bescheidene Vorhaben der Ex-post-Kontrolle am Widerstand der MS scheiterte, die seine Notwendigkeit und Nützlichkeit bezweifelten und einen unangebrachten Eingriff in ihre regionalpolitischen Kompetenzen sowie die Aufoktroyierung einer gemeinschaftlichen Industriepolitik befürchteten, gelang die viel ambitioniertere Etablierung einer Ex-ante-Kontrolle mittels des Gemeinschaftsrahmens trotz des Widerstandes einiger MS, die mit den gleichen Begründungen operierten. Der Wandel erklärt sich sicherlich auch durch die Dynamik des

207 Vgl. EG, Kommission 1992g, S. 10.

208 Siehe Abb. 4.4-1 und Abschnitte 4.4.2 und 4.4.3. 
Binnenmarktprojekts, das die Notwendigkeit schärferer wettbewerbspolitischer Kontrollen schlagartig klarmachte und der Kommission für ihr Handeln auch neues Selbstbewußtsein gab.

Der Gemeinschaftsrahmen hat sicherlich dazu beigetragen, das öffentliche Bewußtsein für die Subventionsprobleme in diesem Sektor zu erhöhen. Zudem haben die detaillierte Darlegung der Beurteilungskriterien und der Aufbau einer ökonomisch orientierten Hierarchie der Akzeptanzfähigkeit der Subventionstypen vermutlich bereits im Vorfeld der Erstellung von Beihilfenprogrammen in den MS einen dämpfenden Einfluß gehabt bzw. zum Rückzug offensichtlich nicht genehmigungfähiger Programme und ihrer Überarbeitung geführt, wie z.B. bei den beiden oben erläuterten belgischen Fällen. In den Fällen, in denen die MS zu solchen Modifikationen nicht bereit waren, hat die Kommission unter dem Gemeinschaftsrahmen häufiger das Prüfungsverfahren nach Art. 93,II eröffnet und einige Male spektakuläre Rückforderungen von Beihilfen durchgesetzt. Nützlich im Sinne der Konsistenz des Kommissionshandelns ist auch die im Gemeinschaftsrahmen festgelegte Verknüpfung der Beurteilung bspw. von EIB-Krediten für staatlich geförderte Projekte mit der Beihilfenkontrolle, da man aufgrund der anders gearteten Anreizstrukturen für die EIB sonst damit rechnen könnte, daß diese das Subventionskontrollziel konterkarierte.

Im Gegensatz zur Lage im Schiffbau, wo eine in Prozenten festgelegte Obergrenze den Handlungsspielraum der MS klar eingrenzte, konnte hier die Politik der Kommission in Detailfragen erst im Zuge der Bearbeitung einzelner Anwendungsfälle klare Gestalt annehmen. Dies ergibt sich aber zwangsläufig aus der unterschiedlichen Situation beider Sektoren, denn während es sich im Schiffbau um Auftragshilfen handelt, die die Kostendifferenz eines an sich nicht wettbewerbsfähigen Sektors zum Weltmarktpreis ausgleichen sollten, wurden hier Hilfen für viele verschiedene Zwecke in ebenfalls sehr verschiedenen Formen gewährt, so daß eine eindimensionale Orientierungsgröße eine adäquate Beurteilung nicht möglich gemacht hätte. Auch hier gelang es der Kommission im Laufe ihrer Entscheidungspraxis in der Übergangsphase und unter dem Gemeinschaftsrahmen, immer mehr staatliche Eingriffe als Beihilfen zu klassifizieren und diese Sichtweise auch durchzusetzen. Hiervon waren staatliche Verlustausgleiche und Kapitalzuführungen ebenso betroffen wie zinsgünstige Kredite, staatliche Infrastrukturleistungen und Grundstücksverkäufe an Unternehmen unter Wert. Auf diese Weise konnten Schlupflöcher für die MS progressiv geschlossen werden. 
Eine zusätzliche Intensivierung der Kontrolltätigkeit brachte der vermehrte Einsatz der bedingten Entscheidungen, bei denen die Genehmigung eines gegebenen Beihilfevolumens an die Erfüllung bestimmter Auflagen gebunden wurde. Auf diese Weise erwarb sich die Kommission die Möglichkeit einer laufenden Kontrolle des Verhaltens der Firmen und auch eines späteren erneuten Eingreifens ${ }^{209}$. Jedoch zeigt der Fall Renault, daß hier im Zweifel auch Kompromisse geschlossen werden mußten, die die ökonomische Logik der ursprünglichen Entscheidung zumindest verbogen. Auch bleibt abzuwarten, ob die Kommission die Rückzahlung der zusätzlichen Einnahmen Renaults aus dem Verkauf von AMC an Chrysler, die jetzt auf ca. 145 MECU geschätzt werden 210 , tatsächlich so durchsetzen wird, wie dies die bedingte Entscheidung vorsieht.

Der Fall Renault zeigt auch, daß die Umgehungsmöglichkeiten der Beihilfenkontrolle bei Staatsunternehmen erheblich höher sind als bei privaten Produzenten: Eine massive Kapitalerhöhung, die einen privaten Minderheitsaktionär beteiligt, hebelt die Argumentation der Kommission aus, da der staatliche Eigentümer hier zeigen kann, daß er nicht anders als ein vergleichbarer privater Investor handelt. Unter diesem Aspekt ist aufgrund der weitgehenden Privatisierung der Kfz-Industrie in den MS während der letzten Jahre, wobei Renault mit einem weiterhin bestehenden Staatsanteil von über 50\% die Ausnahme bildet, die Beihilfenkontrollaufgabe der Kommission für die Zukunft sicherlich leichter geworden, wobei allerdings Umkehrungen dieses Trends bei zukünftigen Krisen einzelner Firmen nicht ausgeschlossen werden können 211; der Fall DAF stellt hier bereits das erste Beispiel dar.

Das Nachspiel mit den sog. Sweeteners im Falle Rover demonstriert natürlich auch, daß die Kommission gegen böswilliges Handeln der MS und den Willen zur Hintergehung der Kommission nicht gefeit ist und sich hier nur auf die Öffentlichkeit verlassen kann. Dies gilt auch deshalb, weil im Falle einer Verfahrenseröffnung die Erfahrung zeigt, daß mit einer Kooperation der MS und der Konkurrenzunternehmen durch Abgabe von Stellungnahmen nicht in allen Fällen gerechnet werden kann 212 .

209 Lalitch (1990, S. 43) zeigt in der Vorgehensweise der Kommission gewisse Parallelitäten zu der Regelung des Art. 88 EGKSV, der der Hohen Behörde gestattet, im Falle der Vertragsverletzung durch MS nach deren Anhörung eine erneute Entscheidung mit Fristsetzung zu erlassen. Allerdings ist die im EGKSV mit Ratszustimmung vorgesehene Sanktionsmöglichkeit nicht gegeben.

210 Vgl. Les Echos 1992.

211 Vgl. Bhaskar/MIRU 1990, S. 159.

212 Vgl. Lalitch 1990, S. 33-35. 


\subsubsection{Wettbewerbs- und Handelswirkungen der Subventionskontrollpolitik}

Auch wenn im Kfz-Bereich im Gegensatz zum Schiffbau keine Wettbewerbsverzerrungen bei einzelnen Aufträgen durch staatliche Beihilfen existierten, was in einem von privaten Käufern einzelner Pkw dominierten Markt auch schwer vorstellbar ist, so haben vor allem die staatlichen Verlustausgleiche und Kapitalzuführungen in den 70er und 80er Jahren, die von der Kommission nicht adäquat begrenzt wurden, den Wettbewerb massiv beeinflußt. Eine Studie hierzu kommt zu dem Ergebnis, daß ohne diese Beihilfen in einem unverzerrten Markt zwischen 1979 und 1985 fünf Pkw-Hersteller wegen Überschuldung aus dem Markt hätten gehen müssen. Es handelt sich hierbei um Alfa Romeo, SEAT, British Leyland (Rover), Volvo Car BV und Renault ${ }^{213}$. Anhand von zwei Szenarien, die eine unterschiedliche Aufteilung der freiwerdenden Marktanteile auf die verbleibenden europäischen und japanischen Wettbewerber unterstellen, werden die Auswirkungen dieses Rückzugs auf die Marktanteile und die Profitabilität der Produzenten untersucht 214 . Auch wenn die methodischen Annahmen z.T. eher zweifelhaft erscheinen - so wird u.a. im Jahr des Ausscheidens einzelner Firmen eine deutliche Schrumpfung der Gesamtverkäufe unterstellt, ohne daß die Konkurrenten ihre Kapazitätsreserven ausnutzen, um die Lücken zu schließen; außerdem ist es wohl wenig realistisch anzunehmen, daß Renault seinen Absatz von 1984 auf 1985 von 1,1 Mio. Fahrzeugen auf 0 zurückgefahren hätte - so ist die Grundaussage, nämlich eine signifikante Erhöhung der Marktanteile der überlebenden Wettbewerber und eine erhebliche Verbesserung ihrer Gewinnsituation, doch überzeugend. In der Erkenntnis, daß derartig radikale Lösungen aus allgemein-, beschäftigungs- und regionalpolitischen Gründen nicht durchsetzbar sind, versuchte die Kommission, die Wettbewerbsverzerrungen dadurch zu vermindern, daß sie derartige Rettungsbeihilfen mit Umstrukturierungsauflagen verknüpfte, die zu deutlichen Kapazitätsverminderungen der unterstützten Firmen führen und dadurch ihre Marktanteile fallen lassen. In den großen Fällen der Übergangsphase tat sich die Kommission jedoch schwer bei der Durchsetzung215. Dennoch wurde dieser Politikansatz partiell auf die Regionalbeihilfen übertragen, wie die

\footnotetext{
213 Vgl. Bhaskar/MIRU 1990, S. 76.

214 Vgl. ebenda, S. 76-88.
}

$215 \mathrm{Da}$ dieser Ansatz jedoch durchaus in die richtige Richtung weist und helfen kann, Wettbewerbsverzerrungen zu vermindern, zeigen die Darlegungen in MIRU (1987, S. 81-83), die demonstrieren, daß die britische Regierung aus wahltaktischen Gründen keinen Kapazitäts- und Arbeitsplatzabbau in den in den Midlands konzentrierten Produktionsstätten von Rover in Erwägung gezogen hätte, obwohl die Lage des Unternehmens sie gebot. Im Falle Renault legen die Beschwerden des Konkurrenten PSA nahe, daß die Staatshilfen bei konstanter Kapazität zur Marktanteilserhöhung in Frankreich durch Preisunterbietung ausgenutzt wurden. 
Fälle Fiat Mezzogiorno und die Projekte in den neuen Ländern beweisen. Hier kann es im Gewande der Regionalpolitik zu staatlich geförderten massiven Kapazitätserhöhungen kommen, die den Wettbewerb verzerren können, wenn es zu einer Überkompensation der regionalen Nachteile durch Beihilfen kommt. Deshalb hat die Kommission in den bisher gefällten Entscheidungen die genehmigte Beihilfenhöhe zumindest zu einem geringen Teil auch von der Kapazitätsentwicklung der Unternehmen abhängig gemacht, auch wenn damit ein industriepolitischer Eingriff höherer Intensität verbunden ist (s. auch unten).

Auch die außenhandelspolitische Wirkung des Rahmens sollte nicht unterschätzt werden. Seine Anwendung kann den Handelspartnern der EG in der EFTA oder in Osteuropa als Orientierung dafür dienen, welchen Grad staatlicher Unterstützung die Kommission für akzeptabel hält bzw. oberhalb welchen Subventionsgrades mit handelspolitischen Schutzmaßnahmen durch die Gemeinschaft zu rechnen sein würde216. Durch die explizite Übernahme solchen Sekundärrechts in das EWRAbkommen und die Klarstellung seiner Anwendungsmöglichkeit in den EuropaAbkommen ist auch die rechtliche Basis für ein Eingreifen der Kommission erheblich verbessert worden. Angesichts der wachsenden Neigung der EG-Produzenten zu Investitionen insbesondere in Osteuropa wird dieser Aspekt in Zukunft mit Sicherheit an Bedeutung gewinnen 217.

Schließlich wird auch die vereinbarte vollständige Öffnung des europäischen Marktes für japanische Fahrzeuge bis 1999 Auswirkungen auf den Intra-EG-Handel haben, da aufgrund der externen Abschottung einiger Teilmärkte bei gleichzeitiger Offenheit für nicht-nationale EG-Konkurrenten letztere dort höhere Marktanteile erzielten. Somit werden Produzenten aus nicht oder kaum abgeschotteten nationalen Märkten durch die Öffnung gegenüber Japan zumindest auf den Märkten der Partnerstaaten negativ betroffen 218 . Aus wettbewerbspolitischer Sicht wird die Kommission darauf achten müssen, daß Nachteile aus der Öffnung für die EG-Produzenten nicht durch höhere Subventionen kompensiert werden. Jedoch werden hier möglicherweise auch industriepolitische Argumente ins Spiel kommen.

\subsubsection{Subventionskontrolle als Mittel der Industriepolitik}

Auch im Kfz-Bereich hat die Kommission versucht, mittels ihrer Subventionskontrollpolitik die Umstrukturierung und technische Modernisierung der Industrie zu

216 Vgl. EG, Kommission 1992g, S. 11.

217 Vgl. z.B. Financial Times 1991, S. 12, und Diekmann 1992, S. 76.

218 Vgl. Bhaskar/MIRU 1990, S. 33. 
fördern. Dies gilt sicher noch nicht so sehr für die Genehmigungen der 70er und frühen $80 \mathrm{er}$ Jahre, wo der strukturerhaltende Aspekt dominierte und es an einer adäquaten Kontrolle fehlte. Jedoch treten strukturpolitische Ziele schon deutlich in den Entscheidungen der Übergangsphase hervor, in denen den Unternehmen Modernisierungs-, Kapazitäts- und Beschäftigungsabbauziele als Gegenleistung für Beihilfengenehmigungen aufgegeben wurden. Schließlich weist auch der Gemeinschaftsrahmen mit seiner wesentlich wohlwollenderen Einstellung gegenüber bspw. Innovations- und Forschungsbeihilfen in diese Richtung. Die zunehmende Heranziehung externer technischer Beratung zur Beurteilung einzelner Fälle in diesen Bereichen, insbesondere auch zur Erstellung von NKA in Fällen von Regionalsubventionen, unterstützt dabei die Qualität der Entscheidungsfindung ${ }^{219}$, zeigt aber auch eine eher strukturpolitische Herangehensweise.

$\mathrm{Da}$ eine strenge Beihilfenkontrolle mittels des Gemeinschaftsrahmens als wichtiger Bestandteil des Binnenmarktprogramms für den Kfz-Bereich im entsprechenden Positionspapier der Kommission 220 dargelegt wird, stärkt sicherlich die Position von DG IV auch gegenüber den MS. Andererseits ist jedoch zu befürchten, daß wettbewerbspolitische Ziele gegenüber anderen Aspekten dieses Programms, wie z.B. der Förderung von FuE oder von Umschulungsmaßnahmen 221 , die u.U. auch mehr Kooperation der Firmen beinhalten, zurücktreten müssen, da andere Generaldirektionen hier oder auch im Bereich der technischen Harmonisierung größere Möglichkeiten industriepolitischer Kompetenzzuwächse sehen. Dabei werden sie möglicherweise von Vertretern einzelner Produzenten, wenn auch aus anderen Motiven, mit dem Argument einer notwendigen Weltmarktbetrachtung Unterstützung finden 222 , die dementsprechend den Gemeinschaftsrahmen in der jetzigen Umbruchsituation im Sinne einer industriepolitschen Umstrukturierungsförderung statt einer wettbewerbspolitischen Kontrolle umgestalten wollen. Diese Umbruchsituation hat einen binnenund einen außenwirtschaftlichen Aspekt:

Binnenwirtschaftlich können Anreize zur strukturpolitischen Steuerung aus den erwarteten strukturellen Problemen des Industriezweiges im nächsten Jahrzehnt entstehen. Bei sinkender Akzeptanz des Automobils aus verkehrs- (Überfüllung der Ballungsräume) und umweltpolitischen Gründen wird lediglich mit einem Wachstum

\footnotetext{
219 So ließ die EG bspw. eine Studie zur Abgrenzung zwischen Innovationen und einfachen Modernisierungen erstellen. Vgl. Bhaskar 1988.

220 Vgl. EG, Kommission 1990j, S. 6

221 Vgl. ebenda, S. 7-11.

222 Vgl. z.B. Calvet 1992.
} 
des Marktes um 1-2\% jährlich gerechnet 223 . Dies wird vermutlich zu anwachsenden Überkapazitäten der Produzenten und einer Verschlechterung ihrer Finanzlage führen. Bei steigenden Entwicklungskosten ist daher mit zunehmender Kooperation der Firmen und möglicherweise Fusionen und Aufkäufen, aber auch Werksstillegungen und Entlassungen zu rechnen224. Hieraus kann eine wieder zunehmenden Bereitschaft der MS zu subventionistischen Eingriffen folgen, die aus wettbewerbspolitischer Sicht eine strengere Subventionskontrolle erfordert, als sie in den Krisen der Industrie Mitte der 70er und Anfang der 80er Jahre stattfand, aber aus industriepolitischer Sicht einen größeren Druck auf DG IV zur Toleranz höherer Beihilfen auslösen könnte.

Auch aus dem außenwirtschaftlichen Blickwinkel werden angesichts des weiterhin konstatierten Produktivitätsrückstandes der europäischen gegenüber der japanischen Autoindustrie 225 schon heute die Rufe nach spezifischer sektoraler Förderung, auch aus EG-Mitteln 226 , laut. Aus dieser Sicht wäre es die Aufgabe des Gemeinschaftsrahmens, in der Interimsphase bis zur Öffnung des Marktes 1999 die Modernisierung der europäischen Produzenten zu unterstützen, um sie für die globale Konkurrenz fitzumachen. In diesem Sinne müßte die Anwendung des Regimes schärfer, zielgerichteter, aber auch lenkender werden. Lebensunfähige Fabriken wären mittels Schließungsbeihilfen aus dem Markt zu nehmen, lebensfähige mittels Investitionshilfen zu sanieren und neue Fabriken, z.B. mittels Regionalhilfen, auf der grünen Wiese anzusiedeln. Eine solche Herangehensweise würde die Entwicklung operativer Kriterien zur Unterscheidung erfordern. Sie liefe allerdings einer marktorientierten Konzeption der Beihilfenkontrolle, die sich auf die Sicherstellung der Chancengleichheit der Wettbewerber beschränkt, zuwider. Zudem würde sie auch die sichtbare Macht von DG IV derartig erhöhen, daß mit scharfem Widerstand der MS zu rechnen wäre. Es mag die Angst vor solchen Entwicklungen sein, die jetzt zur Diskussion einer Ausrichtung der Subventionskontrollrahmen an eher horizontalen Ansätzen, wie z.B. durch einen Rahmen für kapitalintensive Industrien, führt, um die Beihilfenkontrolle zu vereinfachen und eine (scheinbare) Gleichbehandlung aller

223 Der Referenzwert bis zum Jahr 2000 im neuesten industriepolitischen Dokument der Kommission beträgt $1,7 \%$ p.a. Vgl. EG, Kommission 1992 g, S. 3.

224 Vgl. The Economist 1992, S. 54/55, Fisher 1992, S. 18, und EG, Kommission 1990j, S. 3, sowie Bhaskar/MIRU 1990, S. 27-28.

225 Dieser wird allerdings von Unternehmensvertretern z.T. energisch bestritten. Vgl. Calvet 1992 , S. 2-3.

226 Vgl. z.B. Calvet 1992, S. 14, FAZ 1992, sowie kritisch dazu Diekmann 1992, S. 78/79. 
Industrien zu erreichen. Zur Diskussion der Vor- und Nachteile eines solchen Ansatzes vgl. unten Abschnitt 6.5. 
Doubtless, the level of subsidization would be higher and perhaps also its structure more distorting without the Commission's activities - how deficient they may be considered.

Norbert Andel ${ }^{1}$

\section{Fazit: Erfolge und Probleme bei der supranationalen Kontrolle NATIONALER SUBVENTIONEN}

Die Untersuchung in Kap. 4 analysierte überblicksartig (Abschn. 4.1) bzw. in größerem Detail (Abschn. 4.2 - 4.4) die Subventionskontrollpolitik der Kommission und ihre Wirkungen in einzelnen Bereichen, wobei sich die Darlegungen vorwiegend auf den jeweiligen Themenbereich konzentrierten. Im folgenden Kapitel sollen nunmehr die Ergebnisse dieser Untersuchungen zusammengeführt werden, um die Gesamtentwicklung, die erzielten Erfolge und die verbliebenen Probleme sowie deren jeweilige Ursachen analysieren zu können. Dabei wird zunächst (Abschn. 5.2) der Frage nachgegangen, inwieweit die entwickelten Regeln den in Kap. 2 dargelegten theoretischen Vorgaben entsprachen. In Abschnitt 5.3 soll dann untersucht werden, ob die Durchsetzung der in Kap. 3 erläuterten Regeln des Prüfungsverfahrens gelang. Schließlich verknüpft Abschnitt 5.4 die praktische Beihilfenkontrollpolitik der Kommission mit den politökonomischen Erkenntnissen und geht auf sektorübergreifende inhaltliche Entwicklungen und Probleme ein. Um zunächst aber den Umfang des untersuchten Themas deutlich zu machen, enthält der folgende Abschnitt eine kurze statistische Analyse des Umfangs und der Struktur der von den MS vergebenen Beihilfen.

\subsection{Der heutige Stand der Subventionsvergabe durch die Mitgliedstaaten}

Dieser Abschnitt liefert einen quantitativen Gesamtüberblick über die Subventionsvergabe der MS, wie sie sich in der jüngeren Vergangenheit und damit unter dem Einfluß der Kommissionskontrolle darstellte. Zur Gewinnung eines solchen Überblicks und damit als Basis für ihre zukünftige Kontrolltätigkeit, aber auch für internationale Diskussionen, hat die Kommission seit 1989 drei Berichte über den Umfang staatlicher Beihilfen in den MS erstellt ${ }^{2}$. Diese Berichte erfassen Beihilfen aus Gemeinschaftsmitteln ebensowenig wie die meisten der nationalen Beihilfen

\footnotetext{
1 1990, S. 180.

2 Vgl. EG, Kommission 1989j, 1990g und 1992d.
} 
sozialer Art an einzelne Verbraucher nach Art. 92,IIa, wie bspw. auch Beihilfen für den sozialen Wohnungsbau. Daneben werden Beihilfen für einige Sektoren überhaupt nicht einbezogen, andere wieder nur zum Teil ${ }^{3}$. Die erfaßten Beihilfetypen sind Zuschüsse ebenso wie Steuersubventionen, zinsgünstige Kredite, staatliche Kapitalbeteiligungen und Bürgschaften mit geringeren als marktüblichen Prämien ${ }^{4}$.

Die Berichte zeigen, daß die Beihilfen selbst in dieser eingeschränkten Definition in der Periode 1988-90 2.0\%5 (1986-88 2,2\%) des BIP der Gemeinschaft und 4,3\% $(4,6 \%)$ der Staatsausgaben ausmachten, wobei die Streuung zwischen den MS enorm war (vgl. Tab. 5.1-1). Das Gesamtvolumen der Beihilfen in konstanten Preisen war dabei leicht rückläufig. Die sektorale Aufteilung offenbart, daß Bereiche, deren Anteil am BIP relativ niedrig liegt, einen hohen Anteil an den gezahlten Subventionen hatten. Es sind dies der Kohlebergbau (18\%), die Land- und Fischereiwirtschaft (13\%, wobei hier die hohen EG-Subventionen nicht enthalten sind) und das Verkehrswesen, insbesondere der Schienenverkehr (29\%). Dennoch sind Industriebeihilfen mit $40 \%$ der größte Posten, auch wenn sie sich auf viele Sektoren verteilen (vgl. Abb. 5.1-1).

Der Vergleich der Subventionsintensität zwischen den MS zeigt einige Überraschungen. So liegen die Beihilfen in Deutschland bei allen Indikatoren deutlich über dem Durchschnitt, was sich vor allem mit der starken Kohlesubventionierung (knapp ein Drittel aller Beihilfen) erklären läßt. Andere MS, wie z.B. Spanien oder Frankreich, befinden sich entgegen den üblichen Vorstellungen deutlich unter dem Mittelwert und haben ihr Subventionsniveau z.T. erheblich gesenkt ${ }^{6}$. In Relation zur Beschäftigtenzahl fällt vor allem auf, daß die ärmeren MS (GR, IRL, E, P) - wohl auch wegen Haushaltsproblemen - klar unter dem Durchschnitt liegen?.

3 Vgl. Färber 1993, S. 26f. Nicht erfaßt werden bspw. Presse und Medien, der Verteidigungssektor, öffentliche Versorgungsbetriebe, Bauwesen oder Banken und Versicherungen. Im Energiebereich beschränken sich die Berichte auf Beihilfen für den Kohlebergbau, im Verkehrswesen auf den Schienen- und Binnenschiffsverkehr. Ausgeschlossen bleiben auch grundlegende Unterschiede in den Steuer- und Sozialsystemen, die als allgemeine Maßnahmen und nicht als spezielle Vergünstigungen für bestimmte Unternehmen angesehen werden.

4 Vgl. EG, Kommission 1992d, Anhang 1, S. 3f.

5 Die Kommission analysiert gleitende Dreijahresdurchschnitte, um dadurch Verzerrungen über hohe Auszahlungen in einzelnen Jahren auszugleichen. Vgl. EG, Kommission 1992d, S. 5.

6 Aufgrund fehlender Kooperation Griechenlands bei der Erstellung der Daten sind die Angaben für diesen MS geschätzt. Vgl. EG, Kommission 1992d, S. 5.

7 Vgl. EG, Kommission 1992d, S. 41. Zur Verfolgung des Kohäsionsziels wären hier stärkere Finanztransfers mittels der Strukturfonds erforderlich. 
Tab. 5.1-1

Gesamtbetrag der nationalen Beihilfen in den Mitgliedstaaten*

\begin{tabular}{|c|c|c|c|c|c|c|}
\hline \multirow[t]{2}{*}{ Land } & \multicolumn{2}{|l|}{ In $\%$ des BIP } & \multicolumn{2}{|c|}{ In ECU je Beschäftigtem } & \multicolumn{2}{|c|}{$\begin{array}{l}\text { In \% der öffentlichen } \\
\text { Gesamtausgaben }\end{array}$} \\
\hline & 1986-88 & $1988-90$ & $1986-88$ & $1988-90$ & 1986-88 & $1988-90$ \\
\hline B & 3,2 & 2,8 & 1153 & 1040 & 6,0 & 5,4 \\
\hline DK & 1,0 & 1,1 & 385 & 409 & 1,8 & 1,9 \\
\hline D & 2,5 & 2,4 & 964 & 971 & 5,3 & 5,2 \\
\hline GR & 4,5 & 3,1 & 640 & 387 & 9,2 & 6,0 \\
\hline $\mathrm{E}$ & 2,7 & 1,8 & 668 & 480 & 6,5 & 4,2 \\
\hline $\mathrm{F}$ & 2,0 & 1,8 & 779 & 735 & 4,0 & 3,7 \\
\hline IRL & 2,7 & 2,0 & 703 & 564 & 5,2 & 4,5 \\
\hline I & 3,1 & 2,9 & 1016 & 982 & 6,2 & 5,6 \\
\hline $\mathrm{L}$ & 4,0 & 4,0 & 1390 & 1389 & 7,4 & 7,6 \\
\hline NL & 1,3 & 1,3 & 513 & 528 & 2,1 & 2,2 \\
\hline$P$ & 1,5 & 2,2 & 167 & 245 & 3,4 & 5,0 \\
\hline UK & 1,1 & 1,1 & 300 & 312 & 2,6 & 2,9 \\
\hline EG-12 & 2,2 & 2,0 & 728 & 687 & 4,6 & 4,3 \\
\hline
\end{tabular}

*Jahresdurchschnitte 1988-90 bzw. 1986-88.

Quelle: EG, Kommission 1992d.

Tab. 5.1-2

Staatliche Beihilfen im verarbeitenden Gewerbe \#

\begin{tabular}{l|rr|rr|rr} 
Land & \multicolumn{2}{|l|}{$\begin{array}{r}\text { In der Wertschöpfung } \\
1986-88\end{array}$} & \multicolumn{1}{|c|}{ In ECU je Beschäftigtem } & In Mio. ECU* \\
& 4,3 & 4,1 & 1606 & 1685 & 1175 & 1211 \\
\hline B & 1,9 & 2,1 & 593 & 634 & 316 & 333 \\
DK & 2,7 & 2,5 & 994 & 984 & 7869 & 7865 \\
D & 24,3 & 14,6 & 2983 & 1502 & 2074 & 1072 \\
GR & 6,8 & 3,6 & 1749 & 936 & 4491 & 2499 \\
E & 3,8 & 3,5 & 1437 & 1380 & 6479 & 6106 \\
F & 6,4 & 4,9 & 2114 & 1734 & 447 & 368 \\
IRL & 6,2 & 6,0 & 2139 & 2175 & 10760 & 11027 \\
I & 2,3 & 2,6 & 988 & 1270 & 37 & 48 \\
L & 3,1 & 3,1 & 1215 & 1327 & 1101 & 1225 \\
NL & 2,2 & 5,3 & 302 & 758 & 245 & 616 \\
P & 2,6 & 2,0 & 770 & 582 & 4101 & 3133 \\
UK & 4,0 & 3,5 & 1325 & 1203 & 38835 & 35503 \\
EG-12 & & & & & &
\end{tabular}

* Durchschnitte 1986-88 in Preisen von 1989

\# Jahresdurchschnitte 1988-90 und 1986-88

Quelle: EG, Kommission 1992d. 
Konzentriert man sich auf Beihilfen an die Industrie, so zeigt sich, daß die MS im Durchschnitt der Jahre 1988-90 35,5 Mrd. ECU (1986-88 38,8 Mrd. ECU) in konstanten Preisen von 1989 vergaben. Dies entsprach 3,5\% (4.0\%) der gemeinschaftlichen Wertschöpfung oder 1203 ECU (1325 ECU) pro Beschäftigten (vgl. Tab. 5.12). Alle Indikatoren zeigen somit einen signifikanten Rückgang der Beihilfenvergabe, der bei einer Jahresanalyse vor allem in den Jahren 1989 und 1990 sichtbar wird 8 . Vergleicht man die Beihilfenvergabe der MS, gemessen an ihrem Anteil an der Wertschöpfung, so zeigt sich gegenüber den Gesamtbeihilfen eine Veränderung der Rangfolge. Industriebeihilfen haben eine hohe Bedeutung in den ärmeren MS (außer Spanien) und in Italien, aber auch in Belgien. Bezogen auf die Beschäftigtenzahl liegen die Werte vor allem in Portugal aber auch in Spanien unter dem Gemeinschaftsdurchschnitt, was auch ein Ausdruck der geringeren Arbeitsproduktivität in diesen Ländern ist ${ }^{9}$. Vergleicht man die zeitliche Entwicklung zwischen den beiden Dreijahreszeiträumen, so zeigt sich, daß der Anteil der Beihilfen an der Wertschöpfung in den vier ärmeren MS stärker gefallen ist als in den vier großen MS, so daß im Gesamtvolumen der Anteil der letzteren sogar gestiegen ist 10 .

Abb. 5.1-1 Staatliche Gesamtbeihilfen in den Mitgliedstaaten

Verteilung nach Hauptsektoren 11

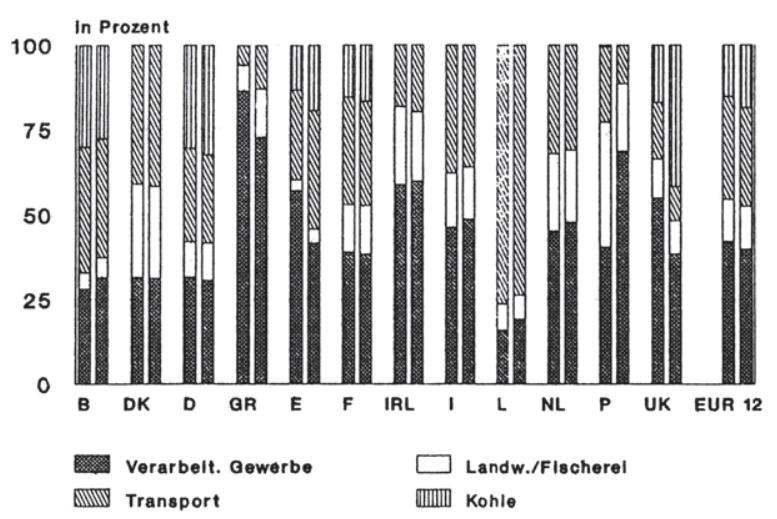

8 Vgl. EG, Kommission 1992d, S. 9f.

9 Vgl. ebenda, S. 13.

10 Vgl. ebenda, S. 14, und EG, Kommission 1993a, S. 216. Sind die Beihilfen bspw. für benachteiligte Regionen in den reicheren MS im Verhältnis zu ihren strukturellen Problemen überhöht, so führt dies zu Wettbewerbsvorteilen gegenüber allen anderen Regionen, insbesondere in den ärmeren MS.

11 Mittelwerte 1986-88 und 1988-90. Quelle: EG, Kommission 1992d. 
Eine tiefere Gliederung nach den verfolgten Zwecken der Beihilfen offenbart, daß horizontale Beihilfen in fast allen MS eine hohe Bedeutung besitzen, wobei im Durchschnitt der Gemeinschaft solche für Innovation/FuE, KMU und Exportförderung in etwa gleichrangig sind (vgl. Tab. 5.1-3). Während dabei die letztgenannte Kategorie heute eine geringere Bedeutung als in der ersten Hälfte der 80er Jahre hat, nahmen die FuE- und insbesondere die KMU-Beihilfen $\mathrm{zu}^{12}$. Bei den sektoralen Beihilfen werden solche an die Stahl- und Schiffbauindustrie getrennt ausgewiesen. Zwar ergab sich für die betrachteten Zeiträume eine Abnahme der Bedeutung der Förderung dieser Sektoren, so daß sie in den meisten MS den geringeren Teil der sektoralen Förderung ausmachen, doch hat die Detailanalyse in Kap. 4.2 und 4.3 gezeigt, daß diese Branchen in der Vergangenheit intensiv gefördert wurden und erhebliche Probleme bei der Beihilfenkontrolle verursachten. Bei den regionalen Beihilfen fällt auf, daß in der Vergangenheit solche für Berlin und das Zonenrandgebiet sowie den Mezzogiorno im Gemeinschaftskontext eindeutig dominierten und $\mathrm{da}$ daneben Regionalbeihilfen lediglich in Großbritannien noch eine signifikante Höhe besaßen. Jedoch spielten Regionalbeihilfen in Irland und Luxemburg, gemessen an ihrem Anteil an den Gesamtbeihilfen dieser MS eine bedeutende Rolle, auch wenn dies in Relation zum Gemeinschaftsniveau nicht deutlich wird. Zudem ist bei dieser Analyse zu berücksichtigen, daß Griechenland, Irland und Portugal in ihrer Gänze Regionalfördergebiete nach den Gemeinschaftskriterien sind, so daß die in diesen Ländern bedeutenden allgemeinen Beihilfesysteme eigentlich der Regionalförderung zugerechnet werden können, was doch zu einer Korrektur des Bildes führt ${ }^{13}$. Dasselbe gilt für die Einbeziehung der EG-Regionalförderung, die auch v.a. den ärmsten MS zugutekommt. Da nach den verschiedenen Reformen der Strukturfonds diese EG-Mittel stärker auf jene Staaten konzentriert werden, findet ein gewisser Finanzausgleich statt 14 . Augenblicklich erlebt die deutsche Regionalförderung eine Schwerpunktverlagerung zugunsten der neuen Länder.

\subsection{Probleme der Umsetzung theoretischer Anforderungen in konkrete Konzepte und Leitlinien}

Die Diskussion in Kap. 2 offenbarte eine Reihe von allokativen und auch nichtallokativen Begründungen für die Vergabe von Subventionen ebenso wie für die Notwendigkeit einer Kontrolle von Subventionen in einem offenen Wirtschaftsraum

\footnotetext{
12 Vgl. EG, Kommission 1992d, S. 23, und Lehner/Meiklejohn/Reichenbach 1991, S. 35-38.

$13 \mathrm{Vgl}$. Lehner/Meiklejohn/Reichenbach 1991, S. 39f.

14 Vgl. Färber 1993, S. 32.
} 
Tab. 5.1-3

Staatliche Beihilfen im verarbeitenden Gewerbe 1988-90 (in MECU)

(Aufgliederung nach Sektoren und Funktion)

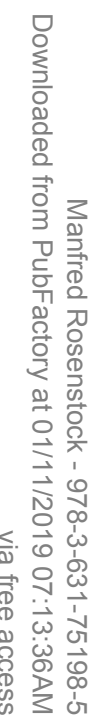

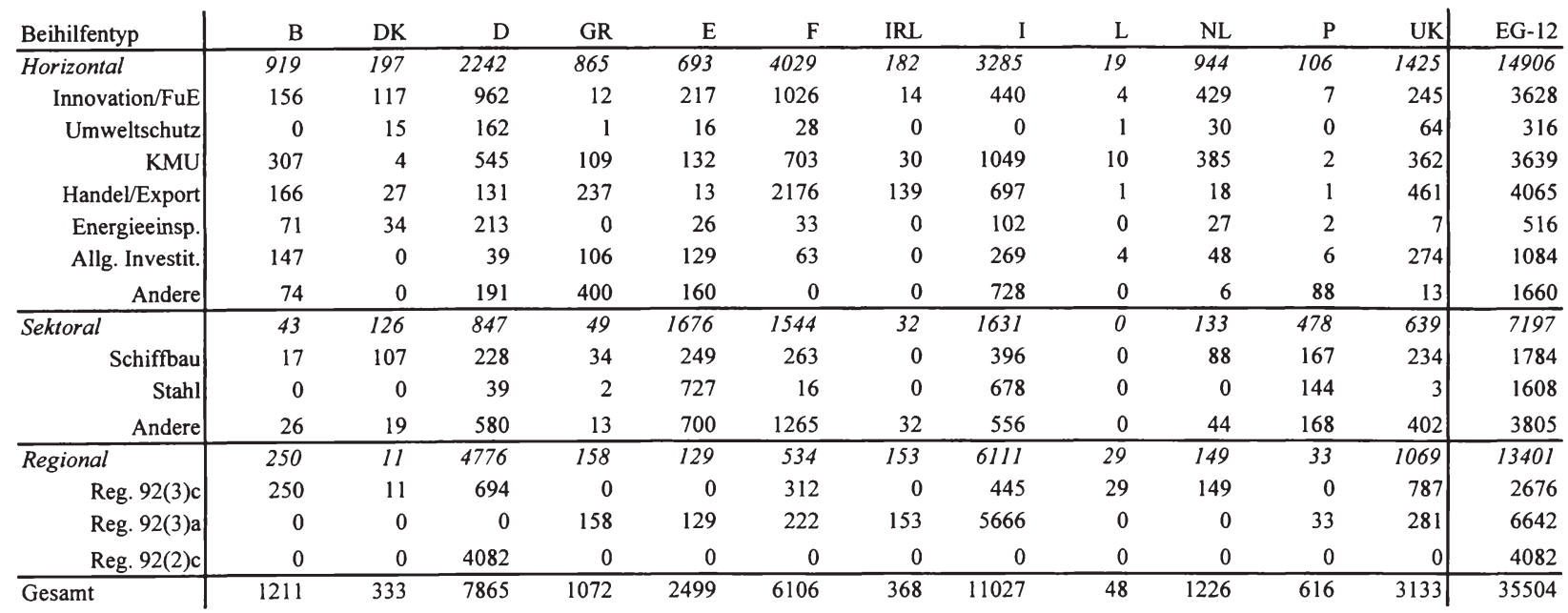

Quelle für die gesamte Tab. 5.1-3: EG, Kommission 1992d. 
Tab. 5.1-3 (Forts.)

Staatliche Beihilfen im verarbeitenden Gewerbe 1988-90

(Aufgliederung nach Sektoren und Funktion in \%)

\begin{tabular}{|c|c|c|c|c|c|c|c|c|c|c|c|c|c|}
\hline Beihilfentyp & B & DK & $\mathrm{D}$ & GR & E & $\mathbf{F}$ & IRL & I & $\mathrm{L}$ & NL & $\mathrm{P}$ & $\mathrm{UK}$ & EG-12 \\
\hline Horizontal & 76 & 59 & 29 & 81 & 28 & 66 & 50 & 30 & 39 & 77 & 17 & 45 & 42 \\
\hline Innovation/FuE & 13 & 35 & 12 & 1 & 9 & 17 & 4 & 4 & 8 & 35 & 1 & 8 & 10 \\
\hline Umweltschutz & 0 & 4 & 2 & 0 & 1 & 0 & 0 & 0 & 1 & 2 & 0 & 2 & 1 \\
\hline KMU & 25 & 1 & 7 & 10 & 5 & 11 & 8 & 10 & 21 & 31 & 0 & 12 & 10 \\
\hline Handel/Export & 14 & 8 & 2 & 22 & 1 & 36 & 38 & 6 & 2 & 1 & 0 & 15 & 11 \\
\hline Energieeinsp. & 6 & 10 & 3 & 0 & 1 & 1 & 0 & 1 & 0 & 2 & 0 & 0 & 1 \\
\hline Allg. Investit. & 12 & 0 & 0 & 10 & 5 & 1 & 0 & 2 & 8 & 4 & 1 & 9 & 3 \\
\hline Andere & 6 & 0 & 2 & 37 & 6 & 0 & 0 & 7 & 0 & 0 & 14 & 0 & 5 \\
\hline Sektoral & 4 & 38 & 11 & 5 & 67 & 25 & 9 & 15 & 0 & 11 & 78 & 20 & 20 \\
\hline Schiffbau & 1 & 32 & 3 & 3 & 10 & 4 & 0 & 4 & 0 & 7 & 27 & 7 & 5 \\
\hline Stahl & 0 & 0 & 0 & 0 & 29 & 3 & 0 & 6 & 0 & 0 & 23 & 0 & 5 \\
\hline Andere & 3 & 6 & 8 & 2 & 28 & 18 & 9 & 5 & 0 & 4 & 28 & 13 & 10 \\
\hline Regional & 21 & 3 & 61 & 15 & $5^{*}$ & 9 & 42 & 55 & 61 & 12 & 5 & 34 & 38 \\
\hline Reg. 92(3)c & 21 & 3 & 9 & - & - & 5 & - & 4 & 61 & 12 & - & 25 & 8 \\
\hline Reg. 92(3)a & - & - & - & 15 & 5 & 4 & 42 & 51 & - & - & 5 & 9 & 18 \\
\hline Reg. 92(2)c & - & - & 52 & - & - & - & - & - & - & - & - & - & 12 \\
\hline Gesamt & 100 & 100 & 100 & 100 & 100 & 100 & 100 & 100 & 100 & 100 & 100 & 100 & 100 \\
\hline
\end{tabular}

*Untergliederung nicht verfügbar. 
wie der EG. An dieser Stelle soll nun in Verknüpfung dieser Diskussion mit den Erfahrungen mit der tatsächlichen Politik der Kommission aus Kap. 4 untersucht werden, inwieweit die Kommission in der Festsetzung ihrer Regeln die wirtschaftstheoretischen Anforderungen umsetzte.

Tab. 5.1-3 (Forts.)

Staatliche Beihilfen im verarbeitenden Gewerbe 1988-90 und 1986-88

(nach Hauptzwecken in \%)

\begin{tabular}{l|rr|rr|rr} 
Land & \multicolumn{2}{|c|}{ Horizontale Zwecke } & \multicolumn{2}{|c}{ Sektorale Zwecke } & \multicolumn{2}{r}{ Regionale Zwecke } \\
& $1986-88$ & $1988-90$ & $1986-88$ & $1988-90$ & $1986-88$ & $1988-90$ \\
\hline B & 70 & 76 & 11 & 4 & 20 & 21 \\
DK & 71 & 59 & 24 & 38 & 6 & 3 \\
D & 35 & 29 & 7 & 11 & 58 & 61 \\
GR & 84 & 81 & 3 & 5 & 13 & 15 \\
E & 13 & 28 & 85 & 67 & 1 & 5 \\
F & 55 & 66 & 37 & 25 & 8 & 9 \\
IRL & 48 & 50 & 12 & 9 & 40 & 42 \\
I & 33 & 30 & 14 & 15 & 53 & 55 \\
L & 45 & 39 & 1 & 0 & 54 & 61 \\
NL & 75 & 77 & 10 & 11 & 15 & 12 \\
P & 23 & 17 & 43 & 78 & 34 & 5 \\
UK & 35 & 45 & 31 & 20 & 33 & 34 \\
EG-12 & 40 & 42 & 26 & 20 & 34 & 38
\end{tabular}

\subsubsection{Theoretische Subventionsrechtfertigungen und praktische Genehmigungs- kriterien}

Das bedeutendste allokative Subventionsargument stellen sicherlich Externalitäten dar. Hierbei ist vor allem an die Förderung von FuE-, Umwelt- oder Regionalinvestitionen zu denken. Tatsächlich hat die Kommission, wie oben erläutert, in all diesen Bereichen umfangreiche Regelwerke aufgestellt.

Die Umsetzung des Externalitätenarguments in konkrete Regeln ist insbesondere im FuE- und im Umweltbereich sehr schwierig, und so greifen beide Gemeinschaftsrahmen auf sehr pauschale Kriterien zurück. So wird bei FuE-Beihilfen in solche für Grundlagenforschung, angewandte Forschung und Entwicklung innovativer Produkte und Prozesse mit jeweils abnehmender möglicher Förderintensität unterschieden. Diese abnehmende Intensität spiegelt jedoch zunehmende Marktnähe und damit geringeren Externalitätsgrad der unternommenen FuE wider und entspricht damit 
annähernd den theoretischen Anforderungen und den Ergebnissen empirischer Studien ebenso wie die Forderung nach möglichst weiter Verbreitung der erzielten Ergebnisse 15 . Aus theoretischer Sicht wird hier wohl ein geringerer Fördersatz als $25 \%$ als optimal erachtet, um ein Überschießen des gesamtwirtschaftlichen Optimums zu verhindern ${ }^{16}$. Im Rahmen für Umweltschutzbeihilfen wird zudem das Problem zusätzlicher Markteintritte bei der Vergabe von Subventionen zur Beseitigung negativer externer Effekte (vgl. oben Abschn. 2.1.2.1) dadurch angegangen, daß Beihilfen lediglich zur Verbesserung von Anlagen eines Mindestalters von 2 Jahren gewährt werden können.

Die relativ pauschale Festsetzung von akzeptablen Fördersätzen ${ }^{17}$ und die Begrenzung der Prüfung auf Programme ermöglichen jedoch lediglich eine sehr grobe Annäherung an die Intensität externer Effekte. Hier erforderte eigentlich bspw. der FuE-Bereich eine genauere Überprüfung der Lage des Einzelfalles, um tatsächlich innovative FuE-Aktivitäten von normalen Modernisierungsprogrammen ohne externe Erträge zu unterscheiden. Das dafür notwendige technische Detailwissen würde allerdings die Heranziehung externer oder interner (DG XII) Experten erfordern, die jedoch bei der Einzelfallprüfung nur im Automobilbereich erfolgt. Die gewählte Lösung ist als Kompromiß aus erreichbarer Genauigkeit und administrativer Effizienz anzusehen und auch mit den begrenzten Humankapazitäten von DG IV zu erklären. Dasselbe gilt auch für die Messung der Additionalität des Vorhabens, d.h. die Beantwortung der Frage, ob das Unternehmen durch die Förderung zusätzliche FuE-Anstrengungen unternimmt, die es aufgrund des geringen internen Nutzens bzw. hohen Risikos sonst unterlassen hätte. Hierbei wird auf die FuE-Ausgaben des Unternehmens in den vorangehenden Jahren rekurriert und eine über den Trend hinausgehende Erhöhung in der Phase des zu prüfenden Projekts als Beweis für Additionalität gewertet. Die Flucht in den intertemporalen Vergleich ${ }^{18}$ ersetzt also die genaue Analyse der Situation ohne die Förderung. Wie in Kapitel 4.1.4 erläutert, spricht jedoch die Beschreibung der Zielsetzung des Rahmens ohnehin dafür, daß er weniger der Förderung positiver externer Effekte als einer gezielten Unterstützung bestimmter Industrien dient.

\footnotetext{
15 Vgl. Ritzen 1990, S. 78f.

16 Vgl. Klodt 1987, S. 7.

17 Bei Umweltschutzbeihilfen werden sogar generell $15 \%$ Beihilfenintensität festgesetzt unabhängig vom jeweiligen Projekt bzw.
18 Vgl. Andel 1992, S. 103.
} 
Eine relativ direkte Umsetzung eines weiteren Externalitätenarguments stellt die Regionalförderung aller MS und ihre wohlwollende Beurteilung durch die Kommission dar. Die Bindung der Förderung an das Investitionsvolumen oder alternativ die Arbeitsplatzschaffung entspricht der theoretischen Rechtfertigung sowohl für Subventionen an den Faktor Kapital als auch den Faktor Arbeit. Auch wenn die allokative Argumentation für eine Regionalpolitik zur Internalisierung der negativen externen Effekte der Ballung und damit der Verminderung von Ballungskosten ${ }^{19}$ so explizit lediglich in Frankreich im Vordergrund stand 20 und in den anderen MS vor allem distributive Argumente vorgebracht wurden (Ausgleich unterschiedlicher Wohlstandsniveaus), so sind doch die gewählten Ansätze allokativ vorteilhaft.

Regionalpolitik im Sinne des Infant-industry-Arguments wurde vor allem für die entwicklungsschwächsten Regionen der Gemeinschaft, die unter Art. 92,IIIa förderfähig sind, betrieben und von der Kommission akzeptiert. Dieses Argument diente bspw. zur Rechtfertigung der Genehmigung von Subventionen im Kfz-Bereich für die Investitionen von Fiat im Mezzogiorno und von Ford/VW in Setubal. Hier wurden insbesondere die positiven Entwicklungseffekte durch die Ausbildung von Arbeitnehmern in den neuen Werken, die dann auch bei Zulieferunternehmern ihr Wissen anwenden können, betont und besonders gefördert, u.a. auch aus Gemeinschaftsmitteln.

Die Subventionsregeln der MS im Bereich der sektoralen Beihilfen lassen sich theoretisch am besten mit dem Argument der "Einkommensverlustexternalitäten" (vgl. oben Abschn. 2.1.2.2) erfassen. Das Grundkonzept bestand dabei darin, daß Beihilfen an Unternehmen in Schwierigkeiten ganz im Sinne einer konservativen sozialen Wohlfahrtsfunktion ${ }^{21}$ zeitlich und intensitätsmäßig begrenzt zu sein hatten und an Umstrukturierungsauflagen gebunden wurden, die stets auf einer Detailanalyse des jeweiligen Falles beruhten und z.T. einen drastischen Kapazitätsabbau beinhalteten 22 . Die Beihilfen sollten dabei einen temporären Schutz der Industrien während dieser Umstrukturierungsphase bieten und diese Umstrukturierung ohne große soziale Verwerfungen erlauben, insbesondere in Zeiten großer Arbeitslosigkeit, in denen die Aufnahmefähigkeit des Arbeitsmarktes für durch Umstrukturierung freigesetzte Arbeitnehmer gering ist. Werden solche Umstrukturierungen nicht

\footnotetext{
19 Vgl. Biehl 1992, S. 72 und 75.

$20 \mathrm{Vgl}$. Carmoy 1978, S. 47.

21 Vgl. Chard/Macmillen 1979, S. 138, und Corden 1974, S. 107-112.

22 Vgl. Caspari 1984, S. 31.
} 
durchgeführt, so sollte die Beihilfe i.d.R. abgelehnt werden23. Dies gilt ebenso für Betriebsbeihilfen einschl. Beihilfen für normale Ersatzinvestitionen und Beihilfen, die Kapazitäts- und Beschäftigungsprobleme auf andere MS verlagern, da bei allen diesen Beihilfetypen kein Gemeinschaftsziel gefördert wird.

In den Krisensektoren Stahl, Schiffbau oder Textil wurden bspw. die dort beschäftigten Faktoren subventioniert, um das Schrumpfen dieser ganzen Industriebereiche unter dem Einfluß zunehmender externer Konkurrenz mit entsprechenden rapiden Einkommensverlusten zu verzögern. Das ökonomisch diktierte Tempo des Strukturwandels war also politisch nicht akzeptabel ${ }^{24}$. In Ergänzung dessen wurden bspw. im Stahlsektor unter Nutzung der Instrumente des EGKS-Vertrages Anpassungshilfen gezahlt. Die betrachteten Branchen zeigten jedoch, daß in der Regel entsprechend einer konservativen sozialen Wohlfahrtsfunktion unter unvollkommener Information die Erhaltungshilfen, wie Rettungsbeihilfen, Verlustausgleiche oder auch Auftragshilfen, eindeutig dominierten 25 . De facto mußte die Kommission bei der zeitlichen Begrenzung und der Degressivität häufig zurückstecken, indem Betriebshilfen quasi unbegrenzt verlängert wurden, so z.B. im Kohlebergbau oder im Schiffbau, bei denen die Unternehmen in der Gemeinschaft auf den internationalen Märkten nicht wettbewerbsfähig sind und es aufgrund der Marktgegebenheiten und der Konkurrenz auch in Zukunft voraussichtlich nicht sein werden. Hier hat die Kommission hohe Beihilfen bei sehr langsamen Anpassungsprozessen gestattet. Das von der Kommission zur Rechtfertigung vorgebrachte Argument, daß solche Beihilfen wenig problematisch seien, da sie in allen MS gewährt würden und gleichzeitig der Intra-EG-Handel gering sei 26 , ist allerdings nicht stichhaltig, da die Analyse in

23 Hierbei stellt sich das Problem, Umstrukturierungen, die die Lebensfähigkeit der Unternehmen wiederherstellen, von geringeren Veränderungen in Produktion und Organisation der Unternehmen zu unterscheiden, die keinen Beitrag zu dessen Gesundung leisten. Vgl. EG, Kommission 1984a, S. 148.

24 Vgl. Malmgren 1978, S. 218, und Krauss 1979, S. 65-67. Der letztgenannte Autor spricht hier von einem Widerstand gegen Anpassungen als Ausdruck einer "Revolution steigender Ansprüche", die ein Zeichen der "Erweiterung politischer Rechte in den wirtschaftlichen Bereich" sei (Übersetzung des Verfassers). Hier ist vor allem an den Gedanken eines Rechtes auf Arbeit im Sinne des Anspruchs auf den aktuellen Arbeitsplatz zu denken.

25 Peacock (1990, S. 28) vermutet, daß dabei innerhalb der Regierung unterschiedliche Informationsstände ausgenutzt werden: Die zuständigen Ministerien werden zunächst das für die Umstrukturierung nötige Subventionsvolumen unterschätzen, um eine Genehmigung dafür zu erhalten. Erweist sich dies später als unzureichend, so werden hohe Marktaustrittskosten als Argument für eine Weiterführung der Förderung angeführt.

26 Vgl. EG, Kommission 1988a, S. 149. 
Abschnitt 4.2 für den Schiffbau zeigte, daß die Beihilfeintensitäten erheblich zwischen den MS divergierten und daß der fast vollständige Zusammenbruch des innergemeinschaftlichen Handels eine direkte Folge der Art der Beihilfengewährung war.

Letzlich fehlte hier bei den MS selbst auf längere Sicht der Wille, bestimmte Industriezweige aufzugeben, da die Dauer des Strukturwandlungsprozesses mit seinen möglichen positiven Langzeitwirkungen über den politisch determinierten Zeithorizont von Legislaturperioden hinausging 27 . Dies kann lediglich mit einer kollektiven Präferenz für Industrieproduktion bzw. genauer mit einer Präferenz für die Erhaltung bestehender Industrien und Strukturen im Sinne der Darlegungen aus Kapitel 2.3.2 erklärt werden 28. Dieses Konzept ist zwar sehr unscharf und schwer meßbar und kann praktisch als Rechtfertigung für alle Arten von Subventionen dienen. Dennoch ist es als Motivation staatlicher Subventionierung sicherlich häufig vorhanden, wobei Leistungsbilanz- und Arbeitsplatzerhaltungsargumente vorgebracht werden, die allerdings langfristig allokativ unsinnig sind. Da im Sinne dieses Ansatzes bei gleichen Präferenzen der MS die Subventionsintensitäten mit sinkender Konkurrenzfähigkeit steigen müßten, erklärt dies auch gut die beobachteten Verhaltensweisen. Ebenso erklärt es den geringen Widerstand der anderen MS gerade in jenen Branchen, in denen aufgrund komparativer Nachteile der Gemeinschaft eine Verdrängung durch Drittlandsimporte zu erwarten gewesen wäre. Durch die fortlaufende Förderung schrumpfender Industrien wurde dabei eine Verzögerung des industriellen Wandels mit entsprechenden Verlusten an Einkommen in Kauf genommen 29 . Bereits in den Abschnitten 4.2 - 4.4 wurden mögliche politökonomische Erklärungen dieser Entwicklungen diskutiert, die in Abschnitt 5.4 noch einmal aufgenommen und gebündelt werden sollen.

Das Argument aus Abschnitt 2.1.2.3, nachdem Umstrukturierungsbeihilfen als eine gezielte Bereitstellung von Informationen zur Erleichterung allokativ sinnvoller Fusionen interpretiert werden können, erwies sich schon in der theoretischen Betrachtung als problematisch. Daneben kann aber auch von seiner konsequenten Anwendung in den betrachteten Sektoren nicht gesprochen werden. Generell wurden übernationale gemeinschaftsweite Fusionen eher behindert ${ }^{30}$, und auch auf nationaler Ebene wurde die Konsolidierung, bspw. im Schiffbau, eher verzögert. Bei

27 Vgl. ebenda.

28 Das modifizierte Konzept paßt auch besser auf die umfangreichen Subventionen für nichtindustrielle Bereiche, wie Landwirtschaft oder Kohlebergbau, bei denen die erläuterten politökonomischen und distributiven Erklärungsansätze dominieren.

30 Vgl. Warnecke 1978, S. 151f. 
tatsächlich stattfindenden Fusionen bspw. im Stahlbereich (BSC, Cockerill-Sambre, Usinor-Sacilor) wirkte der jeweilige MS in viel stärkerem Maße industriepolitisch lenkend als lediglich Informationsmängel überwinden helfend mit, um die Herausbildung nationaler Champions zu unterstützen. In der Hoffnung auf Effizienzgewinne durch Rationalisierung und Spezialisierung unterstützte die Kommission diese Strategie zum Teil noch, bpsw. bei der Cockerill-Sambre-Fusion $1982^{31}$.

Schließlich bleibt noch das Argument zu betrachten, daß aufgrund der Produktionstechnologie und -verfahren mit einem dominierenden Fixkostenanteil und einer sehr geringen Bedeutung der variablen Kosten die Stahlindustrie, zumindest jedoch die Massenstahlproduktion, prädestiniert für eine Entwicklung hin zu einem natürlichen Monopol (bzw. einem sehr engen Oligopol) mit entsprechender Marktmacht erscheint. Die tatsächliche Entwicklung der Branche vor allem in den Krisenphasen mit massiven Preiskämpfen bis hin zur Grenzkostenpreissetzung scheinen in dieselbe Richtung zu weisen und eine Rechtfertigung für subventionistische Eingriffe des Staates in der in Kap. 2.1.1 beschriebenen Art am Ende des Konzentrationsprozesses zu liefern. Tatsächlich waren die gezahlten Subventionen, wie in Kap. 4.3 deutlich wurde, von immenser Höhe, sie lassen sich jedoch nicht in die Kategorie "natürliches Monopol" einordnen. Anstatt bei vorhandenem Monopol über Preisfestschreibung zu Grenzkosten und Verlustsubventionierung eine Wohlfahrtsmaximierung anzustreben, wurde versucht, über Importbeschränkungen und Kartelle eine Erhöhung der Preise über Grenzkosten zu erreichen. Durch staatliche Verlustabdeckung ineffizienterer Produzenten und Produktionsquoten wurden zudem im Sinne des oben beschriebenen Averch-Johnson Effekts Innovationen eher gehemmt und dynamische Ineffizienz gefördert. Die Erfahrung mit konkurrenzfähigen Ministahlwerden liefert am Ende noch ein empirisches Argument gegen das Vorliegen über einen weiten Ausbringungsbereich fallender Durchschnittskosten.

\subsubsection{Relative Verzerrungsintensität und Intensität der Kontrolle}

Betrachtet man die in Abschnitt 2.2 herausgearbeitete Verzerrungshierarchie verschiedener Beihilfetypen, so kann man sagen, daß die Kontrollpolitik der Kommission diese Verzerrungsintensitäten in etwa widerspiegelt.

So wurden insbesondere innergemeinschaftliche Exportsubventionen, deren Ausbeutungsmöglichkeit v.a. für große MS bereits in Abschnitt 2.1.4 demonstriert

31 Vgl. Forschungsschwerpunkt Marktprozeß 1989, S. 11. 
wurde, von der Kommission besonders scharf bekämpft und selbst in Bagatellfällen verboten 32 . Auch Beihilfen, die durch parafiskalische Abgaben finanziert wurden und Importe diskriminierten oder Betriebsbeihilfencharakter besaßen, verfolgte die Kommission scharf.

Horizontale Beihilfen, etwa für FuE oder Umweltschutz ${ }^{33}$ sowie für KMU, erfuhren hingegen eine sehr wohlwollende Betrachtung mit großzügigen Genehmigungskriterien, relativ hohen Beihilfeintensitäten und einer Begrenzung auf Programmüberprüfungen ohne Einzelfalluntersuchung 34 . Hierbei wird, wie oben erläutert, auf Programmebene darauf geachtet, daß MS nicht normale Modernisierungsinvestitionen unter den ersten beiden Kategorien oder unter Innovationsmaßnahmen subsumieren35. Ähnliches gilt für Beihilfen für Weiterbildung und Umschulung, sofern sie nicht getarnte Beschäftigungsbeihilfen darstellen 36 .

Die ebenfalls relativ großzügige Behandlung nationaler Regionalbeihilfen durch die Kommission kommt darin zum Ausdruck, daß auch hier i.d.R. nur Programme geprüft werden und auf eine Einzelfallkontrolle verzichtet wird. Die Sorge allerdings vor einer doch auftretenden interregionalen Verzerrung durch einen Überbietungswettbewerb nur gering benachteiligter Regionen zeigt sich in den ständigen Anstrengungen von DG IV, bei den regelmäßigen Überprüfungen der nationalen Regionalprogramme unter der Gemeinschaftsperspektive die Zahl der geförderten Regionen insbesondere in den reichen MS zu begrenzen, um so den Fördervorsprung der armen Randregionen im Süden und Westen der Gemeinschaft zu erhalten ${ }^{37}$, der ihren strukturellen Nachteilen entspricht. Die Entwicklung der Beihilfenkontrollpolitik im Regionalbereich lief dabei notwendigerweise parallel zur Entwicklung einer eigenen EG-Regionalpolitik, da beide ein kompatibles Zielsystem verfolgen mußten 38 .

Am größten ist die Diskrepanz zwischen theoretischen Anforderungen und tatsächlicher Subventionskontrollpolitik sicherlich bei den sektoralen Beihilfen in Krisensektoren oder an Unternehmen in Schwierigkeiten, die den Schwerpunkt des

32 Vgl. Schlieder/Schröter 1981, S. 509, und Andel 1983, S. 359.

33 Die ursprünglich geplante Begrenzung dieser Beihilfen auf eine Übergangszeit (vgl. z.B. Caspari 1982, S. 7) gelang jedoch nicht.

$34 \mathrm{Vgl}$. Caspari 1984, S. 29f.

35 Vgl. Cownie 1986, S. 266, und Thies 1989, S. 9, sowie Caspari 1985, S. 61.

36 Vgl. Caspari 1984, S. 30.

37 Vgl. Thies 1989, S. 8f., und Cownie 1986, S. 262.

38 Vgl. Pelkmans 1984, S. 259. 
industrie- und wettbewerbspolitischen Handelns der Kommission bildeten 39 . Während die Theorie hier aufgrund der hohen Verzerrungsintensität strenge Maßstäbe fordert, blieben schon die allgemeinen Kriterien zur Behandlung sektoraler Subventionen von 1978 (vgl. Abschnitt 4.1.2) sehr vage. Die detaillierte Betrachtung der Politik der Kommission in drei ausgewählten Branchen zeigte zudem, daß hier insbesondere in Krisenphasen die Kontrolle zum Teil völlig außer Kraft gesetzt wurde, indem nicht nur die Prüfungskriterien außerordentlich unscharf formuliert wurden, sondern zudem noch ihre Durchbrechung toleriert wurde. Entsprechende Wettbewerbs- und Handelsverzerrungen wurden dabei in Kauf genommen. Erst in jüngster Zeit gelang es, die hier theoretisch geforderten strengen Regeln verstärkt durchzusetzen. Einige theoretische Erklärungsmöglichkeiten solcher Entwicklungen wurden bereits in diesem Abschnitt weiter oben diskutiert, eine detailliertere Untersuchung der Probleme, denen sich die Kommission gegenübersah, erfolgt im Abschnitt 5.4.

\subsection{Probleme bei der Durchsetzung des Prüfungsverfahrens}

Da die Darstellung des Ablaufs des Prüfverfahrens bereits im Abschnitt 3.2 im Detail erfolgte, soll im folgenden nur auf Durchsetzungsprobleme und auf neuere Entwicklungen bei der Umsetzung der Regeln durch die Kommission eingegangen werden.

\subsubsection{Durchsetzung der Notifizierungspflicht der Mitgliedstaaten}

Die Einhaltung der Verpflichtung der MS nach Art. 93, der Kommission alle Beihilfevorhaben rechtzeitig zu melden, ist Grundvoraussetzung für eine glaubwürdige und wirksame Subventionskontrolle durch die Kommission. Erst hierdurch kann die Kommission einen vollständigen Überblick über die Subventionstätigkeit der MS gewinnen und eine Gleichbehandlung der Firmen aus verschiedenen MS im innergemeinschaftlichen Wettbewerb gewährleisten. Die Durchsetzung dieser Verpflichtung bereitet allerdings auch die größten Probleme, da die MS natürlich einen Anreiz besitzen, gerade solche Projekte, deren Genehmigung unsicher oder unwahrscheinlich ist, nicht anzumelden. Zudem fehlen der Kommission die im Bereich von

39 Vgl. Swann 1983, S. 178. 
Kartellen und Zusammenschlüssen vorhandenen Untersuchungsrechte vor Ort ("dawn raids") 40 .

Wie die Darlegungen in Kap. 4 gezeigt haben, war die Einhaltung dieser Verpflichtung durch die MS nicht immer gewährleistet ${ }^{41}$. Insbesondere in konjunkturellen oder strukturellen Krisen, in denen einerseits aus nationaler Sicht die Notwendigkeit der Gewährung von Beihilfen zunahm ${ }^{42}$, andererseits die verzerrende Wirkung solcher Subventionen stärker spürbar wurde, unterließen die MS die Notifizierung gänzlich (Bsp. Stahl vor 1980), mißachteten nach einer Meldung die Stillhaltepflicht während der Prüfung oder meldeten erst z.T. Jahre nach der Beihilfengewährung (Bsp. Schiffbau, Abschnitt 4.2.3.2), so daß eine Verhinderung von Wettbewerbsverzerrungen durch die Kommission unmöglich wurde ${ }^{43}$. Hierin zeigt sich der Unwille der MS, insbesondere in solchen Fällen, in denen es um die unmittelbare Erhaltung gefährdeter Unternehmen und Arbeitsplätze geht, sich der externen Kontrolle durch die Kommission zu unterwerfen ${ }^{44}$. Die Position der Kommission wird dabei dadurch geschwächt, daß ihr keine Sanktionen gegenüber den MS zur Verfügung stehen 45 . Ihre Hilflosigkeit in solchen Situationen wird bspw. in der Expost-Absolution aller Stahlsubventionen vor 1980 deutlich (vgl. Abschnitt 4.3.3.1). Auch in der Stahlkrise nach 1980 gelang keine geordnete Durchsetzung der Vertragsregeln. Die Kommission sprach in diesem Zusammenhang von einer "allgemeinen Entschlossenheit ..., die fraglichen Bestimmungen nicht einzuhalten. "46 Die Durchsetzung der Meldepflicht erwies sich zudem als besonders schwierig bei Hilfen an staatliche Unternehmen, wo die jeweiligen MS, wie bspw. bei den staatlichen Stahlkonzernen oder auch im Falle Renault, selbst den Beihilfencharakter ihrer Kapitalzuführungen oder Verlustausgleiche bestritten. Eine zusätzliche Erschwerung der Kontrolle und Möglichkeit der Umgehung der Notifizierungspflicht entstand durch die Tendenz der MS in den 80er Jahren, Beihilfenvergabekompetenzen auf regionale oder lokale Ebenen zu delegieren ${ }^{47}$. Die Möglichkeit hierzu bot sich vor allem in föderalen oder sich in eine föderale Richtung entwickelnden Staa-

40 Vgl. Thies 1989, S. 4. Sie hat allerdings in der Möglichkeit, die Rückzahlung von Beihilfen zu fordern, ein Instrument zur Durchsetzung der Notifizierungspflicht. Inwieweit von diesem Gebrauch gemacht wurde, soll in Abschnitt 5.3.5 untersucht werden.

41 Vgl. auch Verreydt/Waelbroeck 1980, S. 6.

42 Vgl. Zippel 1984, S. 3.

43 Vgl. Andel 1990, S. 178, und Geister 1984, S. 156.

44 Vgl. EG, Kommission 1980g, S. 2, und 1981a, S. 124.

45 Vgl. Lalitch 1991, S. 33.

46 EG, Kommission 1981a, S. 124.

47 Vgl. EG, Kommission 1984a, S. 144, und Färber 1993, S. 37 und 140. 
ten. Besitzen die Gliedstaaten dabei eine eigene Subventionierungshoheit, so ist allerdings auch die interne Kontrolle der MS erschwert, da innerstaatlich dann i.d.R. keine Notifizierungspflicht existiert, während gegenüber der Kommission nur die MS selbst direkt notifizierungspflichtig sind.

Als Reaktion auf diese Probleme sah sich die Kommission in einem Schreiben an die MS 1980 veranlaßt, diese an ihre Pflichten zu erinnern und im Falle der Nichteinhaltung mit einer Klage vor dem EuGH zu drohen48. Der Effekt dieses Schreibens war nur vorübergehend. Zwar fiel der Anteil der nichtnotifizierten Beihilfen 1981 auf 8,3\% aller Entscheidungen, stieg aber 1982 und 1983 wieder auf $47 \%$ bzw. $42 \%$ an 49 . Daher publizierte die Kommission 1983 ein weiteres Schreiben 50 , in dem sie nochmals die Notifizierungs- und Stillhaltepflicht darlegte und potentielle Empfänger illegal gewährter Beihilfen darauf hinwies, daß sie nunmehr auch das Instrument der Rückforderung einsetzen werde (s. unten Abschnitt 5.3.5). Später wies sie noch einmal darauf hin, daß die Mitteilungspflicht bereits entsteht, wenn ein Gesetzentwurf vorgelegt wird und nicht wenn dieser bereits beschlossen ist. Dennoch hatte die Kommission mit einigen MS weiterhin Probleme. So meldeten im Zeitraum 1985-87 die folgenden fünf MS einen hohen Prozentsatz ihrer Beihilfen nicht oder nicht vor Vergabe: Frankreich (37\%), Belgien (32\%), Griechenland $(28 \%)$, Spanien $(23 \%)$ und Italien $(16 \%)^{51}$. Diese Werte sind sicherlich enttäuschend; zudem muß man hinter ihnen noch eine Dunkelziffer nicht entdeckter Beihilfen vermuten 52 . Inzwischen geht die Kommission von einer besseren Einhaltung der Notifizierungspflichten durch die MS aus ${ }^{53}$. Nach den im vergangenen Jahr (erstmalig!) veröffentlichten Daten zur Gesamtzahl nichtnotifizierter Beihilfen innerhalb eines Jahres lag deren Anteil 1993 aber immer noch bei mehr als 15\%54.

Trotz dieser Probleme kam es bereits ab Anfang der 80er Jahre zu einer massiven Zunahme der gemeldeten Fälle 55 (vgl. Tabelle 5.3-156). Die ausgesprochen hohen

48 Vgl. EG, Kommission 1980g, S. 2.

49 Vgl. Cownie 1986, S. 247.

50 Vgl. EG, Kommission 1983h, S. 3.

51 Vgl. EG, Kommission 1990a, S. 135.

52 Vgl. Färber 1993, S. 34.

53 Vgl. EG, Kommission 1989g.

54 Vgl. EG, Kommission 1994d, S. 39.

55 Dieser Anstieg war allerdings auch durch den Druck auf die MS verursacht, in den Krisenphasen die Unternehmen zu stützen und Arbeitsplätze zu erhalten sowie auf die Erweiterung der Gemeinschaft um Griechenland. Vgl. Caspari 1984, S. 27, und 1987, S. 86.

56 Bei den Zahlen in dieser Tabelle ist zu beachten, daß es sich bei den Notifizierungen sowohl um Programme als auch um Anwendungsfälle oder Ad-hoc-Beihilfen handeln kann. 
Werte in den Jahren 1982 und 1983 sind dabei zum einen durch Stahlbeihilfefälle, zum anderen durch eine große Zahl von Anwendungsfällen niederländischer und italienischer allgemeiner Beihilferegelungen bedingt, die danach ausliefen 57 . Der vorübergehende Rückgang der Anmeldungen Mitte der 80er Jahre wird weniger als Ausdruck eines erneuten Ausweichens der MS als vielmehr des Rückgangs der Beihilfen aufgrund knapper öffentlicher Kassen sowie einer kritischeren Sicht von Subventionen gesehen 58 . Mit der Erweiterung der Gemeinschaft um Portugal und Spanien 1986, der vermehrten Notifizierung regionaler und lokaler Beihilfen und der zunehmenden Einführung von Rahmenregeln mit der Pflicht zur Einzelfallnotifizierung nahmen die Meldungen ab 1986 sprunghaft zu, ohne daß dies notwendigerweise einen Anstieg der Subventionierung reflektiert ${ }^{59}$ (s. auch oben Abschnitt 5.1).

Die in den MS existierenden Regeln zur Offenlegung gewährter Subventionen divergieren stark und sind generell sehr unvollkommen 60 . So wurde bspw. in Frankreich zu Beginn der 80er Jahre, als die Intensität der Gemeinschaftskontrolle zunahm, die Subventionsberichterstattung eingestellt 61 . Daher ist die Kommission weiterhin auch auf die Nutzung öffentlich zugänglicher Informationen, wie Geschäftsberichte oder die Medien angewiesen, um Kenntnis von einzelnen Fällen zu erhalten 62 . Dies gilt auch deswegen, weil sie, wie oben erläutert, nicht immer auf Unterstützung durch Beschwerden von Konkurrenten nicht begünstigter Unternehmen rechnen kann. Hier spielt wohl z.T. Unkenntnis der Unternehmen eine Rolle, z.T. die Furcht, bei eigenen Projekten den Widerstand der anderen MS auf sich zu ziehen bzw., falls der Konkurrent im Inland beheimatet ist, die Beziehungen zur eigenen Regierung und damit die Chancen, selbst Beihilfen zu erhalten, zu verschlechtern63. Schließlich mag auch falsch verstandener Patriotismus eine Rolle

57 Vgl. EG, Kommission 1986a, S. 144. Diese Notifizierungen führten mit einjähriger Verzögerung zu einem ebenfalls starken Anstieg der negativen Entscheidungen.

58 Vgl. Caspari 1987, S. 86, und Padoa-Schioppa 1988, S. 31, sowie EG, Kommission 1986a, S. 143.

59 Vgl. EG, Kommission 1988a, S. 142, und 1989a, S. 152.

60 Vgl. Zippel 1984, S. 13. Die Transparenz wird in föderal organisierten MS noch erschwert. Vgl. EG, Kommission 1972a, S. 128, und Caspari 1982, S. 8.

61 Vgl. Färber 1993, S. 4. Auch in Großbritannien sind die Regeln zur Offenlegung sehr restriktiv. Veröffentlichte Entscheidungen der Kommission enthielten daher teils Informationen, die zumin-

62 Vgl. Schina 1987, S. 139, und Gilchrist/Deacon 1990, S. 42. dest früher dem nationalen Palament vorenthalten wurden. Vgl. Bullinger 1978, S. 177.

63 Gerade in oligopolistischen Marktsituationen kann hier auch eine implizite Akzeptanz von Mindestmarktanteilen der Konkurrenten vorherrschen in der Erkenntnis, daß bei deren Unterschreiten die jeweilige Regierung massiv einschreiten würde. Vgl. Holmes 1991, S. 34. 
Tab. 5.3-1

Maßnahmen im Rahmen der Kontrolle staatlicher Beihilfen

(mit Ausnahme von Landwirtschaft, Fischerei und Verkehr)

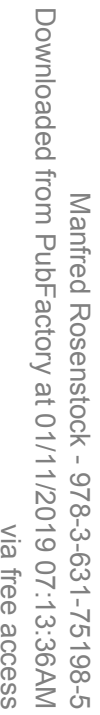

\begin{tabular}{|c|c|c|c|c|c|c|c|}
\hline \multirow[t]{2}{*}{ Jahr } & \multirow{2}{*}{$\begin{array}{l}\text { Gemeldete } \\
\text { Vorhaben }\end{array}$} & \multirow[b]{2}{*}{ Insgesamt } & \multicolumn{4}{|c|}{ Maßnahmen der Kommission } & \multirow{2}{*}{$\begin{array}{l}\text { Zurückgezogene } \\
\text { Vorhaben }\end{array}$} \\
\hline & & & $\begin{array}{l}\text { Keine } \\
\text { Einwände }\end{array}$ & $\begin{array}{l}\text { Eröffnung des } \\
\text { Verfahrens* }\end{array}$ & $\begin{array}{l}\text { Einstellung des } \\
\text { Verfahrens* }\end{array}$ & $\begin{array}{l}\text { Abschließende } \\
\text { Entscheidung* }\end{array}$ & \\
\hline 1970 & n.v. & 21 & 15 & & 6 & 1 & n.v. \\
\hline 1971 & n.v. & 18 & 11 & & 7 & 3 & n.v. \\
\hline 1972 & n.v. & 35 & 24 & & 1 & 3 & n.v. \\
\hline 1973 & n.v. & 22 & 15 & & 7 & 4 & n.v. \\
\hline 1974 & n.v. & 35 & 20 & & 5 & - & n.v. \\
\hline 1975 & n.v. & 45 & 29 & & 6 & 2 & n.v. \\
\hline 1976 & n.v. & 47 & 33 & & 4 & 2 & n.v. \\
\hline 1977 & n.v. & 112 & 99 & & 3 & 1 & n.v. \\
\hline 1978 & n.v. & 137 & 118 & & 9 & - & n.v. \\
\hline 1979 & n.v. & 133 & 79 & & 4 & 3 & n.v. \\
\hline 1980 & n.v. & 105 & 72 & & 3 & 2 & n.v. \\
\hline 1981 & 92 & 142 & 79 & 30 & 19 & 14 & - \\
\hline 1982 & 200 & 233 & 104 & 86 & 30 & 13 & - \\
\hline 1983 & 174 & 195 & 101 & 55 & 18 & 21 & 9 \\
\hline 1984 & 162 & 314 & 201 & 58 & 34 & 21 & 6 \\
\hline 1985 & 133 & 178 & 102 & 38 & 31 & 7 & 11 \\
\hline 1986 & 124 & 181 & 98 & 47 & 26 & 10 & 5 \\
\hline 1987 & 326 & 274 & 205 & 27 & 32 & 10 & 1 \\
\hline 1988 & 375 & 387 & 311 & 31 & 32 & 13 & - \\
\hline 1989 & 296 & 334 & 254 & 37 & 27 & 16 & 7 \\
\hline 1990 & 429 & 421 & 352 & 33 & 24 & 12 & 2 \\
\hline 1991 & 417 & 475 & 415 & 36 & 18 & 6 & n.v. \\
\hline 1992 & 452 & 502 & 455 & 30 & 31 & 6 & n.v. \\
\hline 1993 & 475 & 435 & 399 & 30 & 19 & 7 & n.v. \\
\hline
\end{tabular}

* nach Art. 93 Abs. 2 EGV oder Art. 8 Abs. 3 der Entscheidung 2320/81/EGKS bzw. der folgenden Stahlkodizes Quelle: EG, Kommission 1981a, S. 122; 1991a, S. 155; 1994d, S. 42. 
spielen. So zitiert Schina64 einen britischen Anwalt auf die Frage, warum die Kommission nicht über Beihilfen an den Konkurrenten eines von ihm vertretenen Unternehmens informiert worden sei, mit den Worten "We don't do things that way in this country". Eine Ausnahme zeigt sich lediglich im Beschwerdeverfahren bei Auftragskonkurrenz im Schiffbau, wo der Wille zur Beschwerde bei den Werften vorhanden zu sein scheint.

Für eine effektive Prüfung ist es auch essentiell, daß der Beihilfenbegriff sehr weit gefaßt ist und die MS sich nicht der Notifizierungspflicht durch Uminterpretation ihrer Maßnahmen entziehen können. Entsprechende Bemühungen der Kommission hat der EuGH regelmäßig unterstützt und klargestellt, daß alle Arten von Beihilfen zu melden sind, wobei der Kommission das alleinige Recht zusteht zu überprüfen, ob die Bedingungen der Wettbewerbsverzerrung und Handelsbeeinträchtigung aus Art. 92,I erfüllt sind65. Dies schließt auch aus, daß MS auf eine Notifizierung deswegen verzichten können, weil nach ihrer Ansicht aufgrund nur geringer Ausfuhren des begünstigten Unternehmens keine Verzerrung vorliegt. Auch diese Beurteilung steht allein der Kommission zu66.

Eine Verstärkung ihrer Position erhielt die Kommission durch das sog. BoussacUrteil des EuGH von 199067. Auf der Basis dieses Urteils konnte die Kommission ihre Verfahrensmodalitäten in Fällen fehlender Notifizierung verschärfen: So kann sie, wenn ein MS die Aufforderung zur Übermittlung von Auskünften zu einem Projekt, von dem die Kommission anderweitig Kenntnis erhalten hat, ignoriert oder unzureichende Informationen liefert, sofort eine vorläufige Entscheidung erlassen, in der sie die Aussetzung der Regelung anordnet und den MS binnen 15 Tagen zur schriftlichen Bestätigung dieser Entscheidung auffordert68. Danach muß sie das Hauptverfahren nach Art. 93,II eröffnen. Äußert sich der betreffende MS auch hier nicht, so kann die Kommission eine abschließende negative Entscheidung auf der Grundlage der ihr vorliegenden Informationen erlassen, die dann die Rückforderung bereits gewährter Beihilfen einschließlich der Zinsen vom Zeitpunkt der Gewährung

64 1987, S. 175.

65 Vgl. Flynn 1987, S. 126.

66 Vgl. EG, Kommission 1987a, S. 133.

${ }^{67}$ EuGH 1990a (Französische Republik vs. Kommission). Es handelte sich hierbei um die Anfechtung einer negativen Entscheidung der Kommission aus dem Jahre 1987 gegen nicht-notifizierte

68 Beihilfen an einen französischen Textilproduzenten.

${ }^{2}$ Weigert sich der MS, diese Erklärung abzugeben, so kann die Kommission den EuGH befassen, der dann wohl die Entscheidung der Kommission bestätigen wird. Vgl. Lasok 1990, S. 126. 
der Beihilfe beinhaltet 69 . Eine solche vorläufige Entscheidung auf der Grundlage dieses Urteils erließ die Kommission erstmals 1991 im Fall der französischen Rennwettenorganisation PMU70.

Allerdings ist die Kommission aufgrund ihrer begrenzten administrativen Kapazitäten auch nicht an einer Meldung aller geringfügigen Beihilfeprojekte mit nur unbedeutenden Auswirkungen auf Handel und Wettbewerb interessiert71. Daher sind, wie in Abschnitt 3.2 dargelegt, Anwendungsfälle genehmigter regionaler Beihilfensysteme oder horizontaler Beihilfensysteme unterhalb gewisser Schwellenwerte für Beihilfenintensität und -höhe nicht notifizierungspflichtig72. Aufgrund der deminimis-Regelung (s. Abschnitt 4.1.4.1) sind zudem Beihilfen außerhalb eines Regimes bis zu zweimal 50.000 ECU über einen Dreijahreszeitraum auch nicht meldepflichtig73. Allerdings gilt diese de-minimis-Regelung nicht in besonders sensiblen Sektoren. Die Festlegung von Obergrenzen für Anwendungen genehmigter Programme, oberhalb derer auch Einzelfälle anmeldepflichtig sind, rechtfertigt sich in sensiblen Sektoren mit den hier auch bei relativ geringer Beihilfenhöhe zu erwartenden Wettbewerbsverzerrungen 74 , bei den horizontalen Beihilfen bspw. zur FuE-Förderung mit deren erheblichen Umfängen. Für Beihilfensysteme geringer Intensität oder Höhe an KMU gilt ein vereinfachtes Anmeldungsverfahren ${ }^{75}$. Trotz dieser Schwellenwerte werden der Kommission lediglich $20 \%$ der tatsächlichen Beihilfezahlungen notifiziert. Die restlichen $80 \%$ werden im Rahmen regionaler und allgemeiner Programme vergeben, die in der Vergangenheit, möglicherweise unter völlig anderen Umständen genehmigt wurden76. Aufgrund dieser Problematik

69 Vgl. EG, Kommission 1991a, S. 148f., 254.

70 Vgl. EG, Kommission 1992a, S. 136, 188f.

71 Vgl. EG, Kommission 1985a, S. 147, und Padoa-Schioppa 1988, S. 32 und 61f. In Gilchrist/Deacon (1990, S. 44) wird das Problem anschaulich dargelegt: Während in DG IV weniger als drei Dutzend Beamte für die Prüfung aller Beihilfen zur Verfügung stehen, sind allein in Wallonien 150 Beamte mit der Vergabe von Fördermitteln beschäftigt.

72 Vgl. Schina 1987, S. 140, Padoa-Schioppa 1988, S. 61f., und EG, Kommission 1979e.

73 Zur Problematik der Überwachung der Einhaltung dieser Regelung vgl. oben Abschnitt 4.1.4.1.

74 Diese Schwellenwerte wurden allerdings nicht einheitlich festgesetzt. So gilt z.B. für Beihilfen an die Kfz-Industrie eine Schwelle von 12 MECU Investitionsvolumen, während im FuE-Rahmen 20 MECU festgesetzt wurden. In diesem Fall hat der sektorale Rahmen Vorrang. Der erste Versuch der Kommission, überhaupt eine Anmeldeptlicht von Einzelanwendungsfällen allgemeiner Beihilfen zu erreichen, scheiterte bereits 1968 am Widerstand des Rates. Vgl. EG, Kommission 1983 e, S. 401.

75 Vgl. EG, Kommission 1985a, S. 148, und 1992c, S. 7f., sowie 1993a, S. 208f; s. auch unten Abschnitt 5.3.2.

76 Vgl. The Economist 1989a, S. 87. 
begann die Kommission, wie in Abschnitt 4.1 erläutert, ab 1989 mit der laufenden Überprüfung solcher allgemeinen Regelungen nach Art. 93,I und setzte präzisere Zielsetzungen für diese Regelungen durch.

Weiterhin hat die Kommission nach Konsultation der MS in multilateralen Sitzungen beschlossen, das Meldeverfahren über die Entwicklung von Standardformularen zu beschleunigen und zu erleichtern, die dann wichtige Informationen zum Förderungszweck, Subventionsbudget, den möglichen Empfängern und den Gewährungsbedingungen enthalten sollen. Es wird ergänzt durch die Verpflichtung zur Erstellung standardisierter Jahresberichte zu bestehenden Beihilferegimes 77 . Für Beihilfen im beschleunigten Verfahren wurden diese Standardformulare bereits genutzt 78 . Dies ist sicherlich der Transparenz und der administrativen Vereinfachung und damit auch Beschleunigung förderlich ${ }^{79}$ und erlaubt auch eine größere Konzentration auf wichtige Fälle.

\subsubsection{Entwicklung der Regelung des Prüfungsverfahrens und deren Umsetzung}

Bereits in Abschnitt 3.2 wurden die Regeln und Fristen der zwei Stufen des Prüfungsverfahrens dargelegt. Insbesondere die Fristen sind jedoch nicht so im Vertrag festgelegt, sondern stellen Richterrecht dar, das der EuGH bei Entscheidungen zu einzelnen Fällen festlegte. Kürzere Fristen bspw. für KMU und für Fälle der THA legte die Kommission in ihren Leitlinien fest 80 .

Die Kommission hatte allerdings bereits 1966 versucht, über einen Vorschlag zum Erlaß einer Ratsverordnung nach Art. 94 eine Präzisierung und Kodifizierung dieser Verfahrensfristen $\mathrm{zu}$ erreichen 81 . Auch damals war eine Frist von 8 Wochen vorgesehen, nach deren Ablauf der MS die Beihilfe bei Nichteinschreiten der Kommission in Kraft setzen konnte. Diese Frist sollte in dringenden Fällen verkürzt werden können, aber auch für die Einholung zusätzlicher Informationen, für multilaterale Treffen und für Modifikationen des ursprünglichen Beihilfeplans durch den MS unterbrochen werden können. Zu deren Verabschiedung durch den Rat kam es aber mangels Einstimmigkeit nicht, so daß die Kommission ihren Vorschlag zurückzog82.

\footnotetext{
77 Vgl. EG, Kommission 1992a, S. 137, und 1993a, S. 209, sowie 1993m.

78 Vgl. DTI 1993, S. 18.

79 Vgl. Lehner/Meiklejohn/Reichenbach 1991, S. 71.

80 Sie betragen 20 bzw. 15 Arbeitstage. Vgl. EG, Kommission 1993a, 208f.

81 Vgl. EWG, Kommission 1967, S. 110 f.
}

82 Die Verordnung sollte außerdem bestimmte Beihilfen vom Ex-ante-Meldeverfahren befreien, aber auch für diese, wie für alle genehmigten Regeln, die MS verpflichten, die Kommission vom Inkrafttreten der Beihilfe zu unterrichten und den Rechtstext vorzulegen. Der Vorschlag wurde 
Dasselbe Schicksal erlitt ein Vorschlag der Kommission zur Einführung eines Verfahrens zur Überwachung der Anwendung der regionalen Koordinierungsgrundsätze, den die Kommission 1973 auch nach Art. 94 unterbreitete 83 . Später unternahm die Kommission solche Versuche nicht mehr, auch um ihre Unabhängigkeit gegenüber direkten Eingriffen der MS in Verfahren und Inhalt der Beihilfenkontrolle mittels solcher RL zu bewahren 84 . Zudem sei durch Kommissionsentscheidungen und Urteile des EuGH der Regelungsbedarf gedeckt 85 .

Zwar ist die Dauer des Vorprüfverfahrens auf 30 Werktage für Einzelfälle begrenzt, dies bedeutet jedoch nicht, daß alle innerhalb dieses Verfahrens entschiedenen Fälle bereits nach 6 Wochen abgeschlossen sind. Angesichts vielfach unvollständiger Notifizierungen wird diese Frist häufig durch Nachfragen der Kommission ausgedehnt, da mit den Antworten der MS auf solche Nachfragen die Frist erneut zu laufen beginnt 86 . Dies gilt um so mehr bei nicht-notifizierten Beihilfen, bei denen die Kommission aus eigener Inititative die notwendigen Informationen erfragen muß87. Zudem fanden auch häufig Gespräche mit den MS schon im Vorprüfverfahren statt, die zu weiteren Informationen durch die MS, zu Änderungen des Projekts oder auch zum Verzicht führen können88. Die effektive Prüfungszeit der Kommission wurde dadurch verlängert. Diese Verfahren ist allerdings der Transparenz der Beihilfenkontrolle nicht förderlich, da in dieser Phase andere MS oder Konkurrenten nicht informiert werden. Hinsichtlich des sog. Claes-Planes für die belgische Textilindustrie, der nach solchen informellen Verhandlungen, die zu fundamentalen Änderungen des Vorhabens geführt hatten, genehmigt worden war, entschied der EuGH aufgrund einer deutschen Klage gegen die Kommission. Er stellte klar, daß ein Verzicht auf das Verfahren nach Art. 93,II und eine Genehmigung von Beihilfen nur dann erfolgen kann, wenn die geplante Beihilfe als solche unzweifelhaft mit dem Vertrag vereinbar ist. In Zweifelsfällen ist das Verfahren zu eröffnen, v.a. um allen Beteiligten die Möglichkeit zur Äußerung zu geben ${ }^{89}$. Ohne dessen Eröffnung kann

niemals von der Kommission veröffentlicht, aber in der Sekundärliteratur dargestellt. Vgl. z.B. Schina 1987 , S. 144.

83 Vgl. EG, Kommission 1974a, S. 78.

84 Vgl. DTI 1993, S. 6, und Caspari 1987, S. 78.

85 Vgl. della Cananea 1993, S. 73.

86 Vgl. Thies 1989, Annex 1, S. 5, und Schütterle 1993, S. 627, sowie Slot 1993, S. 38

87 Vgl. Slot 1993, S. 41.

88 Vgl. Caspari 1987, S. 87

89 Vgl. Ross 1986, S. 874f., und EG, Kommission 1985a, S. 143. 
die Kommission lediglich unbedingte Genehmigungen aussprechen 90 , die allerdings zeitlich begrenzt sein können oder Einzelfallnotifizierungen verlangen können.

In der Folge nahm diese Praxis in ihrer Bedeutung ab und das formelle Prüfverfahren wurde häufiger eröffnet ${ }^{91}$. Allerdings werden in jüngster Zeit Beihilfenprojekte der Kommission häufiger informell vorgelegt, um eine erste Reaktion zu erhalten und ggfs. das Projekt dann noch modifizieren zu können ${ }^{92}$.

Bis zum Ende der 70er Jahre hatte die Kommission fast alle ihr vorgelegten Fälle genehmigt, nur in wenigen Ausnahmen war es zur Eröffnung des Hauptverfahrens gekommen. Die erste negative Entscheidung wurde erst 1964 erlassen, die Wirksamkeit der Beihilfenkontrolle war also recht gering93. Seit 1979 ist jedoch hier eine schrittweise Verschärfung sichtbar, die vorübergehend in ca. einem Drittel aller Fälle zu Verfahrenseröffnungen nach Art. 93,II und zu einer steigenden Anzahl negativer Entscheidungen führte (vgl. Tab. 5.3-1) ${ }^{94}$. Diese Verschärfung wurde neben dem Urteil zum Claes-Plan auch durch eine interne Festlegung der Kommission ausgelöst, in allen Fällen, in denen die Kommission aus dritten Quellen Kenntnis von Beihilfeprojekten erhält und der betroffene MS auf eine Aufforderung zur Notifizierung nicht innerhalb einer bestimmten Frist reagiert, das Hauptprüfverfahren immer zu eröffnen95. Durch das Boussac-Urteil (vgl. oben Abschn. 5.3.1) wurde diese Vorgehensweise bestätigt und noch verschärft. Diese Entwicklungen wiederum führten zu einem Lerneffekt bei den MS bzgl. der Ausgestaltung ihrer Subventionen 96 , so daß heute wiederum der Anteil der Verfahrenseröffnungen und die Zahl der negativen Entscheidungen sinken. Allerdings besteht dafür auch die inzwischen häufiger angewandte Möglichkeit, Projekte unter Bedingungen zu akzeptieren bzw. im Laufe des Hauptprüfungsverfahrens Einigung mit dem MS über Modifizierungen des Projekts zu erzielen ${ }^{97}$. Da das Hauptprüfverfahren häufig länger als 3 Monate dauert (vielfach 6 Monate) ${ }^{98}$, ist die Drohung einer Eröffnung,

90 Vgl. Thies 1989, Annex 1, S. 6.

91 Vgl. Caspari 1985, S. 53.

92 Vgl. Slot 1993, S. 45, und DTI 1993, S. 17.

93 Vgl. Caspari 1987, S. 86, 90.

94 Vgl. Padoa-Schioppa 1988, S. 31, und BMF 1983, S. 54.

95 Vgl. EG, Kommission 1986a, S. 146.

96 Vgl. Caspari, 1987, S. 87.

97 Vgl. Caspari 1984, S. 28, und Thies 1989, Annex 1, S. 6. Die MS werden allerdings durch Lobbyieren während des Verfahrens auch versuchen, eine Akzeptanz ihres Projekts ohne bedeutende Modifizierungen zu erreichen. Vgl. DTI 1993, S. 27.

98 Lediglich im Stahlbereich setzte sich die Kommission selbst eine Frist von drei Monaten. Vgl. Schina 1987, S. 150. 
die das Projekt blockieren würde, ein probates Mittel, um den MS zu Modifizierungen zu veranlassen 99 . Zudem ziehen die MS einzelne Beihilfeprojekte auch gänzlich zurück, wenn sie auf Bedenken der Kommission stoßen und die Eröffnung der Hauptverfahrens droht 100 . In diesem Fall wirkt das Verhalten der MS de facto wie eine negative Kommissionsentscheidung.

\subsubsection{Transparenz des Kommissionshandelns}

Ein wichtiger Kritikpunkt an der Beihilfenkontrollpraxis der Kommission bestand lange Zeit in ihrer mangelnden Transparenz ${ }^{101}$. So wurde jeweils nur der betroffene MS über eine positive Entscheidung ohne Eröffnung des Verfahrens nach Art. 93,II unterrichtet 102 . Weiterhin bestanden Verfahrenseröffnungen nur aus einer standardisierten Mitteilung, in der weder der Name des betroffenen Unternehmens noch die möglichen Zweifel der Kommission bezüglich des betreffenden Projekts spezifiziert wurden 103. Die politische Sensibilität der Fälle und potentielle Probleme der Offenlegung von Geschäftsgeheimnissen dürften hierbei eine Rolle gespielt haben ${ }^{104}$. Diese Politik hat sich jedoch seit Mitte der 80er Jahre stetig zum Besseren gewandelt. Eine Ankündigung der Kommission im Wettbewerbsbericht, ausführlichere Mitteilungen zur Verfahrenseröffnung und zu Verfahrenseinstellungen nach bedeutenden Modifizierungen der Beihilfeprojekte im ABl. mitzuteilen sowie den dritten Parteien, die sich im Verfahren geäußert hatten, eine Entscheidungskopie zuzusenden, wurde mehr und mehr auch umgesetzt 105 . Hierzu gehörte dann auch die namentliche Nennung der Beihilfeempfänger und die vermehrte Information der Öffentlichkeit über Presseerklärungen zu einzelnen Entscheidungen 106. Inzwischen erscheint auch bei Beihilfen, die ohne Verfahrenseröffnung genehmigt wurden, eine kurze Notiz im Amtsblatt, die Empfänger, MS und Budget (bei einem Programm) bzw. Betrag (bei einem Projekt) identifiziert ${ }^{107}$. Die häufig zu beobachtenden erheblichen Verzögerungen bei der Veröffentlichung sind dabei eine Konsequenz der Notwendigkeit zur Übersetzung der Entscheidung in alle Amtssprachen der Gemein-

\footnotetext{
99 Vgl. Thies 1989, Annex 1, S. 7.

100 Vgl. Caspari 1987, S. 87, und EG, Kommission 1984a, S. 147.

$101 \mathrm{Vgl}$. Neundörfer 1984, S. 100.

102 Vgl. Schina 1987, S. 146. Positive Entscheidungen am Ende des formellen Prüfverfahrens wurden nur im Bulletin oder den Wettbewerbsberichten summarisch aufgelistet.

103 Vgl. z.B. EG, Kommission 1984f, S. 3, und Schina 1987, S. 149.

$104 \mathrm{Vgl}$. Warnecke 1978, S. 145.

105 Vgl. EG, Kommission 1986a, S. 146, Schina 1987, S. 153, und Thies 1989, S. 6.

106 Vgl. EG, Kommission 1988a, S. 140.

107 Vgl. DTI 1993, S. 21.
} 
schaft 108 , aber auch der Notwendigkeit, die Klarheit der Rechtssprache in allen diesen Versionen erneut zu prüfen und evtl. in der internen Version erwähnte Geschäftsgeheimnisse zu eliminieren.

Als Konsequenz zweier Entscheidungen des EuGH aus den Jahren 1984/85 (Leeuwarden und Intermills), in denen negative Entscheidungen der Kommission zu Beihilfeprojekten deshalb aufgehoben wurden, weil die entsprechenden Entscheidungen keine detaillierte ökonomische Analyse zu den wettbewerbs- und handelsverzerrenden Effekten der Beihilfen enthielten ${ }^{109}$, sind auch die veröffentlichten Entscheidungen oder Zusammenfassungen inzwischen wesentlich detaillierter und sorgfältiger ausgestaltet 110 . Auf diese Weise ist es auch für Dritte möglich, die Gründe des Kommissionshandelns nachzuvollziehen und evtl. dagegen vorzugehen.

Ein weiterer Aspekt der erhöhten Transparenz besteht in der vermehrten Aufstellung und Veröffentlichung detaillierter Beurteilungsregeln (Gemeinschaftsrahmen etc.), die den betreffenden MS und Unternehmen Anhaltspunkte zur Ausgestaltung ihrer Subventionsprogramme und -projekte geben und gleichzeitig die Kommission vor dem Vorwurf willkürlicher Entscheidungen schützen (vgl. hierzu auch unten Abschn. 5.4.2) ${ }^{111}$. Über diese Rahmenregelungen und andere wichtige Aspekte der Beihilfenkontrolle diskutiert die Kommission zudem mindestens zweimal jährlich mit Sachverständigen der MS in multilateralen Sitzungen 112.

Zur Transparenz des beihilfenpolitischen Handelns der MS trug die Kommission in jüngster Zeit auch verstärkt bei, indem sie in ihren "Berichten über staatliche Beihilfen" die Subventionssysteme der MS systematisch erfaßt und quantifiziert. Durch die hierfür eingeholten Informationen wird der Kommission auch die laufende Überprüfung bestehender Systeme nach Art. 93,I erleichtert. Allerdings war in einigen MS die Bereitschaft zur Kooperation dabei sehr gering. So hatte Italien für den 1. Bericht nur sehr unvollständige bzw. keine Angaben geliefert, so daß die Kommission Schätzwerte ermitteln mußte. Diese enthielten dann allgemeine Verwaltungsund Infrastrukturausgaben und präsentierten Italien als größten Subventionsgeber der

108 Vgl. Thies 1989, Annex 1, S. 8.

109 Vgl. Caspari 1985, S. 55, und 1987, S. 80. Der EuGH setzt hier nicht seine eigene ökonomische Analyse an die Stelle der von der Kommission durchgeführten. Er prüft lediglich, ob anhand der der Kommission vorliegenden Informationen die Schlußfolgerungen nachvollziehbar sind. Vgl. Ross 1986, S. 881-883.

110 Vgl. Cownie 1986, S. 252, Schina 1987, S. 154, und (zu Leeuwarden) Hoischen 1989, S. 110 112.

111 Vgl. Andel 1990, S. 178, und Ehlermann 1994, S. 414.

112 Vgl. Petersen 1993, S. 26, und EG, Kommission 1991a, S. 145. 
Gemeinschaft. Unter dem Eindruck dieser negativen Darstellung war Italien dann bereit, für den zweiten Bericht die gewünschten Daten zu liefern, die dann für die Periode des 1. Berichts zu einer Korrektur der Werte um $29 \%$ nach unten führten 113. Beim dritten Bericht hatte die Kommission ähnliche Probleme mit Griechenland114. Diese Erfahrungen zeigen, wie sensibel einige MS auf die Offenlegung ihres Handelns reagieren, die sie offensichtlich als Eingriff in ihre Souveränität begreifen. Es ist sicherlich kein Zufall, daß die betroffenen MS zu den im Verhältnis zur Wertschöpfung höchsten Subventionsgebern gehören.

\subsubsection{Durchsetzung der Kommissionsentscheidungen}

Der Aspekt der Durchsetzung der Entscheidungen besitzt zwei Facetten: Zum einen geht es darum, sicherzustellen, daß die MS solche Entscheidungen, die sie akzeptiert haben, auch korrekt umsetzen. Zum anderen ist auch zu fragen, inwieweit die Kommission einen von den MS bekundeten Widerstand, bestimmte Entscheidungen zu akzeptieren, überwinden konnte, vor allem durch die Einschaltung des EuGH.

Eine erfolgreiche Subventionskontrolle verlangt nach der Genehmigung von Beihilfesystemen eigentlich eine detaillierte Durchführungskontrolle, um zu verhindern, daß die MS bei der konkreten Subventionierung einzelner Projekte die festgelegten Regeln umgehen. Hierzu wäre eine umfassende Ex-post-Kontrolle aller Fälle und eine zusätzliche Ex-ante-Prüfung größerer Projekte nötig. Dieser Weg wäre jedoch sehr aufwendig und angesichts der sehr begrenzten personellen Kapazitäten der Kommission nicht durchführbar. Daher wurde er nur in Teilbereichen beschritten.

Wie oben dargelegt, verlangte die Kommission solche Einzelfallnotifizierungen wichtiger Projekte bei den allgemeinen Beihilfesystemen der MS zumindest außerhalb der Regionalfördergebiete ebenso wie Jahresberichte. Bei den regionalen Systemen hingegen wurde dieser Weg nicht beschritten. Hier allerdings werden die Förderpläne der MS auch nur für einen begrenzten Zeitraum genehmigt, so daß danach eine Neubewertung erfolgen kann. Bei den sektoralen Beihilfen außerhalb der Krisensektoren setzte die Kommission eine derartig detaillierte Prüfung nur in Einzelfällen durch115. In Problemsektoren, wie bspw. der Automobilindustrie, wurden auch Meldeschwellen für eine Ex-ante-Prüfung und Jahresberichte eingeführt. Dasselbe gilt für FuE-Beihilfen. Die Jahresberichte haben allerdings

\footnotetext{
113 Vgl. Färber 1993, S. 35.

114 Vgl. EG, Kommission 1992d, S. 7.

115 Vgl. EG, Kommission 1982a, S. 149f., zu einem belgischen Textilbeihilfensystem.
} 
wohl eher informatorischen Charakter und führten kaum zu Aktionen der Kommission.

Angesichts der oben erwähnten Tatsache, daß auf der Basis dieser Regelungen der Kommission lediglich $20 \%$ des vergebenen Beihilfevolumens ex ante notifiziert wird, fordern Gilchrist/Deacon 116 eine intensivere Prüfung der bestehenden Systeme und insbesondere der größeren Fälle. Inzwischen hat die Kommission ein Konzept standardisierter Jahresberichte eingeführt ${ }^{117}$. Diese erlauben nicht nur die Nachprüfung der Umsetzung konkreter Entscheidungen, sondern auch eine laufende Überprüfung bestehender Beihilferegelungen, um so evtl. nach Art. 93,I Vorschläge zu deren Anpassung an geänderte Erfordernisse zu machen.

Auch wenn die Kommission bestimmte Fälle ex ante einzeln prüfen kann, entstehen Kontrollprobleme, und zwar vor allem bei bedingten Entscheidungen. Solche bedingten Entscheidungen wurden, wie oben gesehen, in jüngerer Zeit häufiger eingesetzt. Sie waren bspw. an Umstrukturierungsauflagen, an Beihilfenverbote für bestimmte Fristen oder auch an Einzelfallnotifizierungen aller Beihilfen an das betroffene Unternehmen auch außerhalb von sensiblen Sektoren geknüpft ${ }^{118}$. Hier wurde in der Vergangenheit beklagt, daß eine Ex-post-Kontrolle der Erfüllung dieser Auflagen häufig unterblieb ${ }^{119}$, was sicherlich auch mit den personellen Engpässen in DG IV zu tun hat. Einige jüngere Entscheidungen, bspw. im Automobilsektor ${ }^{120}$, in denen die Vorlage regelmäßiger Berichte zu den einzelnen Projekten gefordert wurden, zeigen zumindest den Willen, die Durchführungskontrolle zu intensivieren.

Zur Durchsetzung ihrer Entscheidungen bei einem Widerstand des MS kann die Kommission den Rechtsweg einschalten. Bspw. hatten sich Frankreich und Italien geweigert, negative Kommissionsentscheidungen zu Textilbeihilfen umzusetzen. Erst durch ein Urteil des EuGH konnten diese MS dazu gezwungen werden. In beiden Fällen war das jeweilige Regime mehr als 4 Jahre in Kraft gewesen, da die MS auch die Stillhaltepflicht während des Verfahrens mißachtet hatten ${ }^{121}$. Da es der Kommission in solchen Fällen an Sanktionsmöglichkeiten fehlt, die Prozeduren sehr lange dauerten und auch die Rückzahlung der Beihilfen zu jener Zeit noch nicht durch-

\footnotetext{
116 1990, S. 44-46.

117 Vgl. oben Abschnitt 5.3.1 und EG, Kommission 1994a, S. 258.

118 Vgl. auch EG, Kommission 1989a, S. 188.

119 Vgl. Neundörfer 1984, S. 99.

120 Vgl. bspw. EG, Kommission 1991 i und 1993p.

121 Vgl. Neundörfer 1984, S. 94, und Chard/Macmillen 1979, S. 147-150, 154, sowie zum französischen Fall EG, Kommission 1984a, S. 168f.
} 
gesetzt wurde (s.u.), entstand hier eine Wettbewerbsverzerrung, die nicht rückgängig gemacht wurde 122 .

Dennoch war der vermehrte Rückgriff auf Klagen vor dem EuGH bei Nichtumsetzung von Entscheidungen durch die MS ein Mittel zur Verschärfung der Kontrolle. Angesichts des Widerstandes der MS oder der Firmen, insbesondere bei großen Beihilfeprojekten und in Krisensituationen, stieg bspw. die Zahl der Urteile des EuGH in Beihilfesachen von 22 in den 70er Jahren auf 62 im folgenden Jahrzehnt ${ }^{123}$. Urteile des EuGH im Industriebereich wurden dann allerdings von den MS auch umgesetzt ${ }^{124}$. Umgekehrt war bis 1979 der Gerichtshof in keinem Falle von einem MS oder einem Unternehmen zur konkreten Auslegung der Kommissionsbefugnisse in Beihilfefragen angerufen worden, was sicherlich auch ein Indiz für die relativ großzügige Haltung der Kommission ist. Dies änderte sich dann jedoch angesichts der Zunahme negativer Kommissionsentscheidungen 125 .

Dabei läßt sich generell sagen, daß der EuGH die Position von DG IV v.a. gegenüber den MS regelmäßig stärkte. So stellte er in mehreren Urteilen klar, daß die MS sich nicht auf Elemente ihrer nationalen Rechtsordnung berufen können, um die Unmöglichkeit der Umsetzung einer Kommissionsentscheidung oder auch eines Gerichtsurteils zu behaupten ${ }^{126}$. Er unterband auch den Versuch der MS, über das Ausweichen auf Maßnahmen, die formell anderen Zielen dienten, in ihrer Wirkung aber die eigenen Unternehmen bevorzugten, der Beihilfenkontrolle auszuweichen, indem er die Wirkungen einer Maßnahme als Beurteilungskriterium definierte ${ }^{127}$. Er unterstützte die harte Haltung der Kommission gegenüber innergemeinschaftlichen Exportbeihilfen und aus parafiskalischen Abgaben finanzierten Beihilfen voll 128 . Zudem legte er im Urteil zum Fall Philip Morris (vgl. oben 4.1.3) die Beurteilungsbefugnisse der Kommission detailliert fest. Diese bestehen vor allem in der Nutzung eines weiten Beurteilungsspielraumes, einschl. der Anwendung eines sehr weiten Beihilfenbegriffs ${ }^{129}$, nach Maßgabe wirtschaftlicher und sozialer Wertungen und in

122 Vgl. Neundörfer 1984, S. 107, und Chard/Macmillen 1979, S. 154.

123 Vgl. Ehlermann 1994, S. 417, sowie Cownie 1986, S. 251, und zu Beispielen Kap. 4.4 (Alfa Romeo, Rover) und Curzon Price 1986, S. 219 zu einem Programm französischer Textilbeihilfen.

124 Vgl. Caspari 1984a, S. 92.

125 Vgl. EG, Kommission 1984a, S. 226, und Caspari 1987, S. 75.

126 Vgl. EG, Kommission 1992a, S. 226, und EuGH 1991a.

127 Vgl. EG, Kommission 1975a, S. 108.

128 Vgl. Neundörfer 1984, S. 104.

$129 \mathrm{Vgl}$. Thies 1989 , S. 5. 
Anwendung dieser Kriterien auf die Gemeinschaft als Ganzes. Der letzte Aspekt schließt die Genehmigung von Beihilfen allein aufgrund positiver Effekte auf nationaler Ebene aus, während der erste Aspekt zur Umsetzung der Kann-Ausnahmen des Art. 92,III essentiell ist, da sonst die Kommission gezwungen wäre, bei rein formeller Erfüllung der Kriterien dieses Artikels eine Genehmigung auszusprechen 130 . Durch dieses Urteil wurde die Position der Kommission in Beihilfefällen signifikant gestärkt. Der Gerichtshof entschied in der Regel nur dann gegen die Kommission, wenn sie Verfahrensfehler begangen hatte bzw. grobe Analysefehler vorlagen 131,132 .

Schließlich können nicht nur betroffene MS, sondern auch betroffene Konkurrenzunternehmen gegen Kommissionsentscheidungen zur Genehmigung von Beihilfen klagen. Die Zulässigkeit solcher Klagen ist allerdings davon abhängig, daß die Unternehmen direkt und individuell von der Beihilfe betroffen sind und sich auch im Prüfungsprozeß durch Beschwerden u.ä. geäußert haben 133. Aufgrund dieser hohen Hürden sind solche Klagen nicht allzu häufig, die Klage von Matra gegen die Entscheidung der Kommission im Fall Ford/VW-Setubal (vgl. oben 4.4.8) zeigt jedoch, daß diese Möglichkeit doch genutzt wurde. Das Urteil in diesem Fall demonstriert jedoch auch, daß der EuGH eine fundierte Analyse der Kommission (in diesem Fall durch einen externen Experten) i.d.R. akzeptiert, selbst wenn der Kläger eine Alternativanalyse vorlegt. Wiederum wird daran der weite Spielraum der Kommission deutlich.

Die Befürchtung, daß die Durchsetzung der Kommissionskompetenz in Beihilfefragen durch häufigen Rückgriff auf die Möglichkeit des Rates, einzelne Beihilfen als mit dem GM vereinbar zu erklären, ausgehebelt wird, hat sich nicht bewahrheitet. Nachdem dieses Instrument in den Anfangsjahren der Gemeinschaft auf Beihilfen an die französische Zellstoffindustrie angewandt wurde ${ }^{134}$, ist es danach nicht mehr eingesetzt worden 135 .

130 Vgl. EG, Kommission 1981a, S. 162-165.

131 Vgl. Caspari 1985, S. 53. Damit regelte der EuGH gleichzeitig selbst angesichts des Fehlens einer entsprechenden Ratsverordnung nach Art. 94 die grundlegenden Verfahrensfragen. Vgl. Beutler et al. 1987, S. 365.

132 Letzteres führte dann bspw. im COFAZ-Fall, in dem es um die Genehmigung niederländischer Erdgastarife durch die Kommission ging, die Düngemittelhersteller in diesem MS bevorteilten, 133 zu einer Verschärfung der K

134 Diese Beihilfen wurden 1960 nach Art. 92, IIId durch den Rat für zulässig erklärt. Ihre Verlängerung in den Folgejahren wurde jeweils akzeptiert, obwohl die ursprünglich geforderte 


\subsubsection{Erreichung der Rückzahlung illegaler Subventionen}

In Abschnitt 3.2 wurde bereits das Problem der Rückforderung von Beihilfen angesprochen, das dann auftritt, wenn Beihilfenprojekte nicht notifiziert und/oder nach Verfahrenseröffnung die Beihilfen unrechtmäßig weitergezahlt wurden. Die Rückforderungsmöglichkeit ist somit das Instrument der Kommission zur Durchsetzung der Notifizierungs- und Stillhaltepflicht 136 .

Lange Zeit hatte die Kommission dieses Problem ignoriert und auf die Rückzahlungsforderung aus praktischen (große Zahl von Empfängern), rechtlichen (Vertrauensschutz nach nationalem Recht) oder politischen Gründen verzichtet und so Wettbewerbsverzerrungen in Kauf genommen ${ }^{137}$. Eine Entscheidung des Gerichtshofes aus dem Jahre 1973 zu deutschen Beihilfen nach dem Kohlegesetz, die während des Prüfverfahrens und trotz einer negativen Entscheidung weitergewährt worden waren, wurde der Kommission ausdrücklich das Recht zuerkannt, Rückforderungen durchzusetzen ${ }^{138}$. Dieses Recht wurde in diesem Fall von der Kommission jedoch nicht ausgeübt. Sie untersuchte zunächt die rechtlichen Konsequenzen solcher Rückforderungen im Detail. Eine Umsetzung dieser Entscheidung erfolgte erst zehn Jahre später, als die Kommission im Amtsblatt den zukünftigen Einsatz dieses Instruments ankündigte, da die Tendenz zur Nichtnotifizierung von Beihilfevorhaben und zur Gewährung illegaler Subventionen immer mehr zugenommen habe ${ }^{139}$. Bereits 1984 verlangte die Kommission in einigen Fällen die Rückzahlung 140 . In ihrer Folge wurden dann auch regelmäßig die Mitteilungen über Verfahrenseröffnungen im ABl. um einen Passus ergänzt, in dem potentielle Empfänger von der unsicheren rechtlichen Situation und den Möglichkeiten einer Rückforderung

Degressivität nicht eingehalten worden war. Vgl. EWG, Rat 1960, und EWG, Kommission 1966, S. 86f. Bei ihrer später beabsichtigten Umwandlung in eine aus parafiskalischen Abgaben finanzierte Beihilfe (s. hierzu oben 4.1.2) mit partiellem Betriebsbeihilfencharakter erreichte die Kommission im Verfahren nach Art. 93,II eine Aufhebung der diskriminierenden 135 Bestimmungen. Vgl. EG, Kommission 1973a, S. 112f.

Vgl. Caspari 1987, S. 78, und Thies 1989, Annex 1, S. 7.

$136 \mathrm{Vgl}$. Thies 1989, S. 4.

137 Vgl. Rengeling 1984, S. 50.

$138 \mathrm{Vgl}$. EuGH 1973, und Schina 1987, S. 163.

139 Vgl. EG, Kommission 1983h, S. 3.

140 Vgl. Cownie 1986, S. 247f. Zum ersten Fall der Rückforderung von Beihilfen an ein belgisches Unternehmen der Kunstfaserindustrie vgl. EG, Kommission 1985a, S. 171. Da die belgische Regierung sich außerstande erklärte, diese Rückforderung umzusetzen, klagte die Kommission vor dem EuGH. Vgl. EG, Kommission 1986a, S. 174. 
unterrichtet wurden ${ }^{141}$. Im Bereich der Landwirtschaft nutzte die Kommission zudem die Möglichkeit, bei illegalen Beihilfen der MS Zahlungen aus dem EAGFL an diese MS zurückzuhalten ${ }^{142}$. Diese Verschärfung der Verwaltungspraxis ging einher mit dem vermehrten Einsatz bedingter Entscheidungen, also einer gewissen Verschärfung auch im inhaltlichen Aspekt der Kontrolle143. Eine bedingte Entscheidung, die beide Aspekte verknüpft, traf die Kommission 1991 unter dem Kunstfaserrahmen, als sie die Genehmigung einer Beihilfe an die Textilwerke Deggendorf an die Bedingung knüpfte, daß frühere illegal gewährte Beihilfen, deren Rückzahlung die Kommission in einer negativen Entscheidung gefordert hatte, zunächst tatsächlich restituiert werden. Die neue Entscheidung wie auch die beiden früheren werden derzeit vor dem EuGH verhandelt ${ }^{144}$. Wird dieses Vorgehen vor dem EuGH akzeptiert, so erwirbt die Kommission somit einen neuen Hebel zur Durchsetzung der Notifizierungspflicht und der Vertragseinhaltung durch die MS.

Gleichzeitig wurde die Rückforderungsmöglichkeit ab 1986 systematisch in die Tat umgesetzt. So wurden bis Ende 1989 in 25 Fällen Rückerstattungen verlangt, das betroffene Beihilfevolumen belief sich dabei auf ca. 1 Mrd. ECU145. Die Umsetzung der Rückforderung geschah dabei häufig durch Umwandlung der Beihilfen in einen normal verzinsten Kredit, den das Unternehmen dann abzutragen hatte 146. Während hierdurch der direkte Vorteil der Beihilfe zunichte gemacht wurde, blieb das Unternehmen dennoch begünstigt, wenn es auf dem Kapitalmarkt aufgrund seiner finanziellen Lage entweder keinen Kredit bekommen hätte oder einen wesentlich höheren Zins hätte zahlen müssen ${ }^{147}$. Gegen mehrere solcher Rückforderungen reichten die betroffenen MS Klagen beim EuGH ein 148 , so bspw. im Fall Rover/BAe (vgl. oben 4.4.7); umgekehrt mußte auch die Kommission in einigen Fällen mittels einer Klage die Restitution durchsetzen, wenn die MS die entsprechenden Entscheidungen ignorierten ${ }^{149}$. Zum Teil ist allerdings die nachträgliche

141 Vgl. Schina 1987, S. 165f., und Neundörfer 1984, S. 104f., sowie Thies 1989, Annex 1, S. 5.

142 Vgl. Lehner/Meiklejohn/Reichenbach 1991, S. 55.

143 Vgl. Geister 1984, S. 157, und EG, Kommission 1988a, S. 172f., sowie Slot 1993, S. 48.

144 Vgl. Borde/Kirch 1993, S. 492, und EG, Kommission 1992a, S. 167.

145 Vgl. Thies 1989, Annex 1, S. 5, und Hanke 1989, S. 44. Zum Stand Ende 1987 waren es 22 Fälle gewesen, die sich wie folgt auf die MS verteilten: B 10, F 5, D 4, NL 2, UK 1. Vgl. EG, Kommission 1988a, S. 141f.

146 Vgl. bspw. EG, Kommission 1991a, S. 178f. Dieser Weg wurde auch für die als inkompatibel deklarierten FIM-Darlehen an Renault gewählt. Vgl. oben Abschnitt 4.4.7.

147 Vgl. Gilchrist/Deacon 1990, S. 47f.

148 Vgl. EG, Kommission 1988a, S. 142.

149 Vgl. z.B. EG, Kommission 1990a, S. 156f. 
Rückforderung einer Beihilfe de facto unmöglich; dies gilt v.a. für staatliche Bürgschaften ${ }^{150}$. Eine Rückforderung von Beihilfen kann allerdings dann ausgeschlossen werden, wenn die Kommission das Verfahren nach Art. 93, II aus eigenem Verschulden über einen zu langen Zeitraum ausgedehnt hat, da dann auf seiten des Empfängers legitime Erwartungen geschaffen wurden 151 .

Das bei der Restitution zu verfolgende Verfahren nach dem Boussac-Urteil wurde oben in Abschnitt 5.3.1 dargestellt. Es sichert das Recht zur Rückforderung, auch wenn der Empfänger der illegalen Beihilfen dadurch in den Konkurs gezwungen wird 152 . Ein Problem stellt sich hierbei dadurch, daß die Rückforderung nach nationalem Verwaltungsrecht erfolgt, das nicht harmonisiert ist, so daß bspw. die Regelungen über Verzugszinsen, Rückforderungsfristen und den Umfang des Vertrauensschutzes stark divergieren, was Wettbewerbsverzerrungen hervorrufen kann 153 . Im Konkursfall hat der MS zudem keinen Anspruch auf bevorzugte Behandlung, er wird wie ein normaler ungesicherter Schuldner behandelt. Hier soll also nicht das Recht des Staates auf die Rückforderung von ihm selbst gezahlter illegaler Beihilfen gesichert werden, sondern lediglich die Wettbewerbsverzerrung aufgehoben werden, was bei einem Marktaustritt des Empfängers gesichert erscheint ${ }^{154}$. Eine völlige Aufhebung der Wettbewerbsverzerrung würde bei einer Rückzahlung einer illegalen Beihilfe auch verlangen, daß der Zinsvorteil des Unternehmens ebenfalls restituiert wird. Diese Forderung wurde von der Kommission allerdings erst in jüngster Vergangenheit, wie bspw. bei der Rückzahlung der "Sweeteners" an Rover (vgl. Abschnitt 4.4.7), durchgesetzt 155 . Während hier die Zinsen vom Zeitpunkt der ersten negativen Entscheidung der Kommission, die später annulliert wurde, berechnet wurden, zählt nunmehr der Zeitpunkt der illegalen Gewährung als Ausgangs-

150 Vgl. Petersen 1993, S. 27, und Bernitsas 1993, S. 122, letzterer mit einer Kritik am EuGH, der der Kommissionsauffassung zwar in solchen Fällen zustimmte, aber keine Wege zur Umsetzung aufzeigte.

$151 \mathrm{Vgl}$. Slot 1993, S. 43.

152 Vgl. Lasok 1990, S. 127.

153 Vgl. Rengeling 1984, S. 49f., und Borde/Kirch 1993, S. 494. Das deutsche Verwaltungsverfahrensgesetz gewährt dabei einen sehr hohen Grad an Vertrauensschutz. Allerdings dürfen die nationalen Vorschriften eine Rückforderung nicht faktisch unmöglich machen. Der EuGH akzeptiert dabei die Existenz eines solchen Vertrauensschutzes nicht bei illegal gewährten Beihilfen und verptlichtet die Unternehmen, sich der Einhaltung der Verfahrensregeln zu versichern. Vgl. EuGH 1990c, und Slot 1993, S. 47.

154 Vgl. Lasok 1990, S. 127.

155 Vgl. DTI 1993, S. 8. 
datum für die Berechnung der Verzugszinsen 156 . Dies entspricht auch dem wirtschaftlichen Vorteil des Unternehmens. Vom ökonomischen Standpunkt konsequent wäre eine Ausweitung dieses Ansatzes dergestalt, daß bei Beihilfen, die zwar gerechtfertigt sind, aber ohne vorherige Anmeldung und Genehmigung gezahlt wurden, der Zinsvorteil des Unternehmens aus der zu frühen Verfügbarkeit der Mittel zurückgefordert würde157.

In der Kommission wurde sogar zeitweise erwogen, illegal gewährte Beihilfen generell zurückzufordern, unabhängig von ihrer möglichen Vereinbarkeit mit dem $\mathrm{GM}^{158}$. Diesem Vorgehen stehen jedoch auch nach dem Boussac-Urteil des EuGH juristische Bedenken entgegen. Dort wird spezifiziert, daß die Kommission den Nachweis der Inkompatibilität der rechtswidrig gewährten Beihilfen weiterhin erbringen muß, eine Rückforderung allein aufgrund von Verfahrensfehlern ist nicht möglich ${ }^{159}$. Auch wenn somit die Rückzahlung erst nach einer materiellen Prüfung der Beihilfe gefordert werden kann, sichern jedoch die verschiedenen öffentlichen Erklärungen der Kommission vorher zumindest, daß der Empfänger der Beihilfe sich nicht auf legitime Erwartungen stützen kann 160 . Allerdings wird in der jüngsten juristischen Literatur auf eine Veränderung der Rechtsinterpretation in diesem Punkt hingewiesen 161: Da auch der EuGH in neueren Entscheidungen betont hat, daß selbst eine spätere Genehmigung durch die Kommission die Rechtswidrigkeit der Gewährung nichtnotifizierter oder während des Verfahrens gezahlter Beihilfen nicht heilen kann, besteht für die nationalen Gerichte zur Durchsetzung von Art. 93, III die Möglichkeit, eine Beihilfengewährung im Falle von Konkurrentenklagen für illegal und damit nichtig zu erklären und auf ihre Rückzahlung zu entscheiden, auch wenn das Kommissionsverfahren noch in Gang ist ${ }^{162}$. Nach einer späteren Genehmigung des Projekts durch die Kommission kann der MS dann die Beihilfe erneut gewähren 163 . Eine praktische Umsetzung einer solchen Sichtweise erfolgte jedoch bisher nicht. Sie wäre sicherlich gut geeignet, die MS stärker zu einer Einhaltung der Meldepflicht zu veranlassen, da dann auch die betroffenen

\footnotetext{
156 Vgl. Borde/Kirch 1993, S. 497, und EG, Kommission 1994a, S. 264.

157 Vgl. DTI 1993, S. 8.

158 Vgl. EG, Kommission 1986a, S. 146.

$159 \mathrm{Vgl}$. Sharpe 1993, S. 94.

$160 \mathrm{Vgl}$. Lasok 1990, S. 126f.

161 Vgl. Jestaedt 1993, S. 51, und Ehlermann 1994, S. 435f.

162 Vgl. Slot 1993, S. 45f., DTI 1993, S. 9, und Borde/Kirch 1993, S. 478-480, sowie EuGH $1991 b$.

163 Vgl. Borde/Kirch 1993, S. 481.
} 
Unternehmen einen entsprechenden Druck auf ihre MS ausüben würden. Allerdings würde ein solches Vorgehen die Unternehmen für eine verwaltungsmäßige Nachlässigkeit der MS (bei genehmigungsfähigen Beihilfen) bestrafen, ohne daß dies durch den Charakter der Förderung gerechtfertigt wäre. Jedoch wird hier unterstellt, daß die Unternehmen verpflichtet sind, beim Erhalt von Beihilfen deren Rechtmäßigkeit nachzuprüfen 164 . Daneben können die MS auch zu Schadensersatz an die Konkurrenzunternehmen verurteilt werden, wobei allerdings bezweifelt werden muß, ob eine zunächst illegale Beihilfe, die später von der Kommission genehmigt wird, einen einklagbaren Schaden für Konkurrenzunternehmen verursachen $\operatorname{kann}^{165}$.

Vor allem vom EP wurde regelmäßig gefordert ${ }^{166}$, die Wiedereinziehung rechtswidriger Beihilfen nicht zugunsten der nationalen Haushalte der MS, sondern zugunsten des Gemeinschaftshaushalts erfolgen zu lassen. Eine solche Vorgehensweise würde dem Strafcharakter der Rückforderung stärker betonen 167 , da bei der augenblicklich praktizierten Rückforderung zugunsten der nationalen Haushalte die rechtswidrig handelnde Partei, d.h. der MS, keinerlei Risiko eingeht . Drohte hingegen der Verlust zugunsten des EG-Haushalts, so wäre wohl ein größerer Anreiz für gemeinschaftsrechtkonformes Handeln gegeben. Andererseits ist auch vorstellbar, daß dann eine größere Kollusion zwischen MS und betroffenen Unternehmen auftreten würde, um die Beihilfe vor der Kommission zu verbergen 168 . Zudem wäre für eine derartige Verfahrensänderung die Verabschiedung einer Verordnung nach Art. 94 EWGV169 mit qualifizierter Ratsmehrheit erforderlich, deren Erreichung zumindest zweifelhaft erscheint.

\subsection{Inhaltliche Beurteilung der Subventionskontrollpolitik}

\subsubsection{Subventionskontrolle unter wechselnden Rahmenbedingungen}

Läßt man die Anfangsjahre der Gemeinschaft bis zur Vollendung der Zollunion 1968 außer Betracht, in der die Beihilfenkontrolle eine untergeordnete Bedeutung

164 Vgl. Slot 1993, S. 48

165 Vgl. Slot 1993, S. 46, und Borde/Kirch 1993, S. 486-488. Eine solche Schadensersatzforderung hätte nach innerstaatlichem Amtshaftungsrecht zu erfolgen. Vgl. Beutler et al. 1987, S. 363.

166 Vgl. z.B. EP 1985, S. 108, 1985a, S. 90, und 1990, S. 110.

167 Sie ist allerdings zur strikten Wettbewerbssicherung nicht notwendig.

168 Wie der Fall der "Sweeteners" an Rover zeigte (vgl. Abschnitt 4.4.7), ist allerdings eine solche

Kollusion selbst unter
169 Vgl. EP 1990, S. 110. 
besaß, so zeigt die detaillierte Untersuchung der Politik der Kommission in diesem Bereich im 4. Kapitel, die für verschiedene Branchen und diverse Beihilfekategorien erfolgte, daß man diese Politik anhand ihres Erfolges und ihrer Intensität deutlich in zwei unterschiedliche Zeiträume untergliedern kann. Dies sind zum einen die 70er und frühen 80er Jahre und zum anderen die Jahre seit Ingangsetzung des Binnenmarktprojekts 1985. Während die Politik der Kommission insbesondere in der Zeit vor 1985 als wenig wirksam und zu großzügig kritisiert wurde170, ist sie gerade in der jüngeren Vergangenheit als recht erfolgreich zu bezeichnen. In verschiedenen Phasen sektoraler und konjunktureller Krisen ab Mitte der 70er Jahre sah die Kommission sich einer zunehmend interventionistischen Haltung in der Industriepolitik der MS gegenüber. Diese führte zu einer Flut nationaler Maßnahmen zur Verzögerung des nötigen Wandels und seiner Auswirkungen auf die Beschäftigung171. In den 70er und frühen 80er Jahren machte die Kommission häufig weitreichende Konzessionen an die nationalen Industriepolitiken ${ }^{172}$, was wohl auch zum guten Teil mit der unterschiedlichen wirtschaftlichen Entwicklung der MS in dieser Phase zusammenhing, die den Widerstand insbesondere der schwächeren MS gegen eine Einschränkung ihrer Subventionierung hervorrief 173 . Eine Analyse aus der Rezessionsphase 1982/83174 spricht angesichts der mangelnden Kontrolle von Beihilfen in den in Kapitel 4 diskutierten Sektoren von einer "conspiracy of silence", die einen Anstieg der Beihilfen "with only cosmetic Commission policing" bewirkte, da die Kommission in dieser Phase den Konflikt mit MS und Rat scheute, um ihre Position in anderen Bereichen nicht zu gefährden 175 .

In der zweiten Hälfte der 80er Jahre, unterstützt von den Schubwirkungen des Binnenmarktprogramms, ist jedoch die Überwachung strikter und das Regelwerk dichter geworden, so daß die Gewährleistung des Wettbewerbs erheblich verbessert

170 Vgl. Wissenschaftlicher Beirat beim BMWi 1986, S. 4381, und Gilchrist/Deacon 1990, S. 32.

171 Vgl. Swann 1988, S. 139, und Hitiris 1991, S. 295, 300.

172 Vgl. hierzu bspw. EG, Kommission 1983a, S. 118, und auch die ausgesprochen "weichen" Formulierungen zur Genehmigungsfähigkeit von Betriebs-, Beschäftigungs- und Rettungsbeihilfen bei Schlieder/Schröter 1981, S. 509f. Die Stellung der Kommission wurde allerdings auch dadurch geschwächt, daß die MS auf dem Gipfel von Kopenhagen 1978 Beihilfen als temporäres Mittel zur Anpassung der Industrie an die Konkurrenz v.a. aus den NIC guthießen. Vgl. Harrop 1989, S. 94.

173 Insbesondere die britische Regierung wurde dabei vom damaligen (ebenfalls britischen) Wettbewerbskommissar George Thomson unterstützt, der Initiativen von DG IV gegen britische Beihilfen blockierte. Vgl. Warnecke 1978, S. 166f.

$175 \mathrm{Vgl}$. ebenda. 
werden konnte ${ }^{176}$. Dieser Erfolg wurde erleichtert durch einen Paradigmenwechsel in den nationalen Wirtschaftspolitiken: Die defensiven sektoralen Aspekte der Industriepolitik in Form des Versuchs der Erhaltung von Problemindustrien traten in den Hintergrund, während horizontale Aspekte, wie z.B. Forschungs- oder Ausbildungsförderung oder die Unterstützung von KMU an Gewicht gewannen ${ }^{177}$. Die Kommission kam dieser Schwerpunktverlagerung nach, indem sie Regelwerke zur Kontrolle dieser Beihilfeformen erarbeitete. Diese striktere Kontrolle war allerdings auch notwendig, da mit dem Abbau anderer innergemeinschaftlicher Handelsbarrieren die Gefahr bestand, daß die MS das einzig verbleibende Instrument - die Beihilfen - verstärkt nutzen würden ${ }^{178}$. Hierdurch gelang es im Laufe der Zeit, verzerrende Beihilfenprogramme und -projekte einzuschränken oder abzuschaffen bzw. ihre Einführung zu verhindern oder Modifikationen durchzusetzen ${ }^{179}$. Mit dieser Erhöhung war ein Einflußzuwachs der Kommission verbunden, der ihr jedoch nur stufenweise gelang, da sie stets nationale Ziele, Souveränitätsansprüche, Machtstrukturen und Traditionen überwinden mußte 180 .

\subsubsection{Kontrollprobleme in den Krisenphasen}

In allen drei betrachteten Industriezweigen 181 verlief die Entwicklung während der 70er Jahre weitgehend ähnlich: Als durch externe Faktoren sich in den jeweili-

176 Vgl. Monopolkommission 1990, S. 388, und DTI 1993, S. 2. Bei den Beihilfen, die nicht der Federführung der DG IV unterliegen, d.h. Agrar-, Verkehrs- und Kohlebeihilfen, muß allerdings die Beurteilung sicherlich vorsichtiger ausfallen.

177 Vgl. Malkin 1990, S. 33, 57, und Gerritse 1990, S. 147f. Allerdings darf nicht übersehen werden, daß auch sog. horizontale Politiken häufig sektorale Schwerpunkte haben und somit nicht völlig neutral sind. Zudem liegen High-tech-Firmen, die überproportional von FuEBeihilfen profitieren, häufig gerade in den reichen Zentralregionen der Gemeinschaft. Vgl. Deacon 1990, S. 66.

178 Vgl. Gilchrist/Deacon 1990, S. 34f., und Junginger-Dittel 1993, S. 1. Dieses Argument verstärkt sich noch, wenn mit der möglichen Erreichung der WWU auch die Möglichkeit zur Erhöhung der Wettbewerbsfähigkeit über Abwertungen der eigenen Währung verschwindet.

179 Vgl. Harden 1993, S. 15.

179 Vgl. Andel 1990, S. 180.

180 Vgl. Geister 1981, S. 22, 24.

181 Die betrachteten Branchen weisen zwar gewisse Ähnlichkeiten auf; so besitzen sie eine hohe Kapitalintensität und werden von Großunternehmen dominiert. Zudem sind Stahl und Werften insofern Ausnahmesektoren, als für sie schon frühzeitig spezielle Regeln jenseits der allgemeinen Vorschriften der Art. 92-94 EGV galten. Jedoch erlaubt gerade die Existenz solcher formalisierten und detaillierten Regeln eine wesentlich bessere Analyse der Kommissionstätig- 
gen Sektoren der Druck auf eine beschleunigte Strukturanpassung erhöhte und die Industrien sich diesem Druck nur schlecht gewachsen zeigten, was zu krisenhaften Entwicklungen führte, versuchten die MS, dem durch vermehrte Subventionsvergabe entgegenzuwirken ${ }^{182}$. Hier stand wohl die Hoffnung der MS im Vordergrund, durch die Vergabe solcher Rettungs- und auch Modernisierungshilfen eine Umverteilung der internationalen Anpassungslasten zugunsten der eigenen Unternehmen zu erreichen bzw. deren Existenz überhaupt zu sichern ${ }^{183}$. Daneben spielte auch die Tatsache eine wichtige Rolle, daß mit dem allgemeinen Konjunktureinbruch nach 1974 die Beschäftigungsprobleme aus dem Schrumpfen alter Industrien nicht mehr so leicht durch die Förderung anderer expandierender Bereiche gelöst werden konnten. Der Schutz dieser alten Industrien kam allerdings i.d.R. nicht den ärmsten Regionen der Gemeinschaft zugute ${ }^{184}$.

Als Reaktion darauf begann die Kommission dann, systematische Regeln zur Beihilfenkontrolle im jeweiligen Bereich zu erarbeiten 185 . Die ersten Ansätze waren dabei, v.a. wegen des Widerstandes der MS gegen Kompetenzübertragungen an die Gemeinschaft, aber auch wegen der permanenten Unterschätzung der Schwere der Krise und ihres strukturellen Charakters ${ }^{186}$, stets zu eng und zu unscharf gefaßt und erlaubten den nationalen Regierungen über offene Schlupflöcher weiterhin, ihre konkurrierende Industriepolitik zu betreiben ${ }^{187}$ (1-4. Schiffbaurichtlinie; Mitteilung 1977 und 1. Stahlkodex; Automobilsektor 1975-83 mit dem Scheitern der Ex-postKontrolle). So wurde in den betrachteten Sektoren stets nur ein Teil der vergebenen Beihilfen der speziellen Kontrolle unterzogen, andere konnten weiterhin vergeben werden. Eine Ex-ante-Kontrolle von Investitionsbeihilfen bzgl. ihrer regionalen und sektoralen Wirkungen wurde bspw. für den Schiffbau 1977 noch vom Rat abgelehnt, ebenso wie die schwächere Form der Ex-post-Kontrolle im Kfz-Bereich 1981/83 scheiterte. Auch eine effektive Kontrolle der Beihilfen an öffentliche Unternehmen

keit, um so die Probleme der Beihilfenkontrolle aufzuzeigen. Außerdem zeigt der Erfolg der Subventionskontrolle gerade in Extrembereichen ihre wirkliche Stärke.

182 Vgl. Curzon Price 1990, S. 169, und Malkin 1990, S. 34f.

183 Vgl. Hummel 1985, S. 20, und Malmgren 1978, S. 216, sowie Gerritse 1990, S. 146f.

184 Vgl. Färber 1988, S. 10, und Gilchrist/Deacon 1990, S. 41.

185 Vgl. Butt Philip 1983, S. 139.

186 Dies ist, wie Malmgren (1978, S. 229) zeigt, ein generelles Problem. Die Handlungen der Regierungen beruhen immer auf einer Abschätzung des Anpassungszeitraums und des nötigen Anpassungsumfangs, deren wahre Größe sich jedoch erst im Laufe des Umstrukturierungs187 prozesses erweist.

Vgl. Franzmeyer 1981, S. 504f. Warnecke (1978, S. 152) spricht dabei von einem "struggle among the member states", der sich hinter der Gemeinschaftsfassade abspielte. 
über Kapitalzuführungen fand nicht statt. Rettungsbeihilfen für Großunternehmen in Zahlungsschwierigkeiten wurden praktisch stets genehmigt, häufig ohne oder mit nur sehr geringen Umstrukturierungsauflagen, ohne daß die Kommission aufgrund ihrer rechtlichen und personellen Einschränkungen in der Lage gewesen wäre, die Durchführung dieser Umstrukturierungen nachzuprüfen ${ }^{188}$. Es gelang ihr nicht, angesichts der vorhandenen Überkapazitäten durch eine strikte Beihilfenkontrolle mit einer Bindung an Kapazitätsreduktionen das Gemeinschaftsinteresse und v.a. das Interesse der gering oder gar nicht subventionierten Konkurrenten zu schützen ${ }^{189}$. Vielmehr dienten die großzügigen und unscharfen Regeln zur Beihilfenvergabe Unternehmen in Niedrigsubventionsländern als Rechtfertigung für die Forderung nach "Ausgleichssubventionen"190, wie dies bspw. in der deutschen Stahl- und Werftindustrie geschah. Zudem scheuten sich die MS in solchen Krisen auch nicht, die gegebenen Regeln zu verletzen (vgl. Abschnitt 5.3)191, was zu einer weiteren Aufweichung der Kontrolle führte, die z.T. von der Kommission nachträglich sanktioniert wurde 192 .

Weiter oben wurde diese Situation als "konstatierende Kontrolle" bezeichnet, in der die Kommission immer wieder den sozialen Problemen und dem politischen Druck nachgeben mußte193 und in der ihr die wettbewerbspolitische Gestaltungskraft gegenüber den nationalen Industriepolitiken fehlte ${ }^{194}$. Eine Harmonisierung der Subventionierung durch die Kommission fand in diesen Phasen, wenn überhaupt, lediglich nach oben im Sinne einer Ausrichtung an der Leistungsfähigkeit der schwächsten Unternehmen statt. Notwendige Anpassungen im Sinne eines Strukturwandels in Richtung auf wissensintensivere Branchen wurden hierdurch verzögert bzw. sogar verhindert, nicht lebensfähige Unternehmen in schrumpfenden Industrien wurden durch die den Marktaustritt hemmende Wirkung der Subventionen überlang am Leben erhalten 195. Durch das massive staatliche Eingreifen in einzelnen Branchen hatten Marktentwicklungen eine politische Dimension erhalten und den Wert der subventionierten Unternehmen erhöht, was

188 Vgl. Gilchrist/Deacon 1990, S. 41, 43.

189 Vgl. Neundörfer 1984, S. 99. S. auch unten Abschnitt 5.4.3.

190 Vgl. Andel 1990, S. 178f., und Pelkmans 1984, S. 262f.

191 Vgl. Cownie 1986, S. 249f.

192 Geister (1984, S. 154) spricht hier von bedrohlich ausufernder Disziplinlosigkeit.

193 Vgl. Andel 1990, S. 179f., und Franzmeyer 1981, S. 506, sowie Pelkmans 1984, S. 262.

194 Vgl. Geister 1982, S. 216, und Neundörfer 1984, S. 98.

195 Vgl. Butt Philip 1983, S. 132, und Zippel 1984, S. 15. "One of the problems with government assistance to industry is that it often tends to be aimed at adjustment resistance as opposed to adjustment assistance." Malmgren 1978, S. 218. 
den Widerstand gegen einen Subventionsabbau natürlich erhöhte196. Der "Erfolg" der Beihilfenkontrolle in dieser Phase beschränkte sich darauf, ein befürchtetes Auseinanderbrechen des Gemeinsamen Marktes 197 im eben beschriebenen Sinne durch ein Mindestmaß an Regelungen zu verhindern. Die Schwierigkeiten der Kommission bei der Durchsetzung einer effektiven Kontrolle beruhten auch darauf, daß ihr zu jener Zeit als Pendant zur "Peitsche" des Beihilfenverbots das "Zuckerbrot" in Gestalt der Vergabe weniger verzerrender Gemeinschaftsbeihilfen bspw. zur Regional- oder FuE-Förderung oder von öffentlichen Aufträgen der EG fehlte198. Einige Versuche der Kommission zu einer direkten industriepolitischen Lenkung, wie bspw. über die Dekretierung von "Gemeinschaftsbeihilfen" im Schiffbau 1965/67, scheiterten am Widerstand der MS ebenso wie der Versuch, finanzielle Mittel für eine eigenständige Industriepolitik in größerem Umfang zu erhalten.

Lediglich bei der Koordination der nationalen Regionalbeihilfen wurden Fortschritte gemacht, indem die Regionen klassifiziert und Obergrenzen festgelegt wurden. Eine Berücksichtigung der durch überhöhte Regionalfördermaßnahmen ausgelösten möglichen sektoralen Probleme erfolgte jedoch nicht (s.u. Abschnitt 5.4.6.). Daneben gelang es der Kommission, die MS daran zu hindern, mögliche Skalenerträge in Wachstumsindustrien durch deren gezielte Förderung zu Lasten möglicher Konkurrenten in anderen MS auszunutzen 199 .

Einen weiteren Problemfaktor bei der Durchsetzung der Beihilfenkontrolle stellte die unterschiedlich hohe Bereitschaft zur Akzeptanz von Regeln durch die Mitgliedstaaten, auch aufgrund ihrer divergierenden Entwicklungsstände dar. Dies betraf, wie oben dargelegt, in den 70er Jahren die Länder mit starken Strukturproblemen und dazu vor allem die Neumitglieder bei den verschiedenen Erweiterungen der Gemeinschaft. Hier wurden den Beitrittsländern regelmäßig Konzessionen gemacht, so z.B. das in Kap. 3 erwähnte Ausnahmeprotokoll für Irland, großzügigere Regeln für die britische Regionalförderung, Ausnahmen für die südeuropäischen Beitrittsländer in den Sektoren Stahl und Schiffbau200. Auch wenn solche Ausnahmeregeln aus den spezifischen Problemen der jeweiligen Sektoren bzw. bestimmter Regionen in diesen Ländern und auch aus den wirtschaftlichen Entwicklungsunterschieden

196 Vgl. Malmgren 1978, S. 216.

197 So z.B. Geister 1983, S. 166.

198 Vgl. Pelkmans 1984, S. 263.

199 Vgl. Curzon Price 1986, S. 218, und Warnecke 1978, S. 167, sowie Jacquemin/Sapir 1991, S.

$200 \begin{aligned} & 88 f . \\ & \text { Vgl. z.B. Franzmeyer 1990, S. } 160 .\end{aligned}$ 
gerade der südlichen Beitrittsländer im Vergleich zum EG-Durchschnitt verständlich sind 201 , so besteht ständig die Gefahr, daß solche Übergangsregeln zu Dauereinrichtungen werden (bspw. Regionalbeihilfen für Stahlunternehmen in Griechenland) und damit die Konsistenz der gemeinschaftlichen Beihilfenkontrolle aushebeln 202 .

\subsubsection{Binnenmarktprogramm und Verschärfung der Beihilfenkontrolle}

Erst katastrophale Entwicklungen im jeweiligen Sektor, durch die die Subventionierung der MS und die Wirkungen auf den Binnenhandel außer Kontrolle zu geraten drohten, gestatteten eine weitere progressive Kompetenzverlagerung zugunsten der Kommission 203 mit einer ebensolchen Schließung der Schlupflöcher (von der 5. zur 6. SchiffbauRL, vom 1. über den 2. zum 3./4. Stahlkodex, von der Übergangsphase zum Gemeinschaftsrahmen im Kfz-Sektor) ${ }^{204}$.

Es ist dabei bezeichnend, daß die MS einen solchen Kompetenztransfer zunächst lediglich in den Krisensektoren akzeptierten, in denen externe Einflüsse durch massive Strukturveränderungen auf den Weltmärkten effektive nationale Politiken nicht mehr zuließen, während sie umgekehrt versuchten, in den vielversprechenden Wachstumsindustrien ihre nationalen Ziele ohne "Störungen" durch die Kommission weiterzuverfolgen 205 . Auch hier hat sich jedoch ein Wandel vollzogen.

Parallel zur Ingangsetzung des Binnenmarktprojekts fand nämlich die Diskussion um die "Eurosklerose" statt 206 . Ein Mittel zu ihrer Überwindung sollte eine Verstärkung der FuE-Anstrengungen sein. Diese Entwicklung reflektiert sich auch auf Gemeinschaftsebene. Das Ende der Krisenphasen in Schiffbau und Stahl 1986/87 fiel nämlich mit der Verabschiedung des FuE-Gemeinschaftsrahmen und dem Aufbau

201 Vgl. Warnecke 1978, S. 167.

202 Vgl. auch Geister 1982, S. 217.

203 Vgl. Warnecke 1978, S. 152f.

204 Eine solche Entwicklung konstatiert generell auch Butt-Philip (1983, S. 129f.) Im Stahl- und im Kfz-Bereich erwies sich eine solche Schließung der Schlupflöcher auch im Hinblick auf verwandte Produktionen als notwendig, indem durch die Gemeinschaftsrahmen einerseits auch sog. Nicht-EGKS-Stahlerzeugnisse, andererseits im Kfz-Bereich die Komponentenherstellung durch Autoproduzenten in die Kontrolle einbezogen wurden.

Der Stahlsektor zeigt aber auch, daß neben einer verstärkten Beihilfenkontrolle sich in Krisenphasen eine weitere Interventionsspirale entwickeln kann, die dort Richtpreise, 205 Produktionsquoten und Exportdumping enthielt. Vgl. Geister 1983, S. $164 f$.

206 Vgl. Curzon Price 1990, S. 174. 
gemeinschaftlicher Forschungsprogramme, wie z.B. ESPRIT oder BRITE, zusammen. Dies sowie der Errichtung einer eigenen Abteilung für FuE-Beihilfen in DG IV zeigt den Versuch der Kommission, die Beihilfenkontrolle von der "defensiven" Erhaltung und Lenkung der Sanierung alter Industrien hin zur Förderung hochtechnologischer Industrien als Vehikel einer "aggressiven" Handelspolitik zur Markteroberung in Zukunftsindustrien umzugestalten 207 , wobei, wie oben erläutert, die Kontrolle im FuE-Beihilfenbereich sehr großzügig gehandhabt wurde. Hinter dieser Politik stand die Hoffnung zur Entwicklung einer gemeinschaftlichen FuE- und Technologiepolitik unter Führung der Kommission 208. Die MS unterstützten diese Neuausrichtung der Beihilfenpolitik, wie an der Verlagerung des Schwerpunktes der Subventionierung deutlich wird (s.o.). Angesichts der hohen Kosten von Forschungsprogrammen waren sie zudem für kooperative Lösungen empfänglicher. Außerdem wurden zunehmend Aufgaben und Haushaltsmittel in diesem Bereich auf die EG-Ebene verlagert, vor allem im Gefolge der EEA, die der Gemeinschaft Kompetenzen im FuE-Bereich zuteilte 209 . Färber 210 sieht eine Motivation der MS darin, "ihre bedrohten Subventionsrechte auch durch Verschiebung auf die EGEbene zu schützen." Angesichts der sehr großzügigen Haltung der Kommission ist allerdings die Bedrohung gerade in diesem Bereich nicht als sehr hoch anzusehen. So bestehen auch weiterhin nationale, gemeinschaftliche und EUREKA-Förderprogramme, z.T. unkoordiniert nebeneinander 211 . Jedoch ist auch fraglich, ob eine Lenkung der Forschungspolitik über den Gemeinschaftshaushalt und die Kommission generell zu besseren Ergebnissen führte212 (s. hierzu auch Abschn. 6.2 und 6.3).

Auch in den "traditionellen" Bereichen konnte die Kommission die Qualität der Subventionskontrolle verbessern. Das Problem von Schlupflöchern durch

207 Vgl. Caspari 1990, S. 25, und Curzon Price 1990, S. 174. Zweifel an dieser Interpretation ergeben sich aus der Analyse der Verteilung der staatlichen und privaten FuE-Ausgaben in Deutschland von Krakowski et al. (1992, S. 127-130, 137). Hiernach hat die staatliche FuEFörderung zwischen 1979 und 1987 gerade in den alten schrumpfenden Industriezweigen zugenommen bzw. ist auf außergewöhnlich hohem Niveau verharrt, was andeuten würde, daß auch die FuE-Förderung als Instrument zur Abfederung des Anpassungsprozesses und zur Wiedergewinnung der Wettbewerbsfähigkeit eingesetzt wird.

208 Vgl. Cownie 1986, S. 251. Programme und Projekte der MS wären dann nach Art. 92, IIIb als Vorhaben von gemeinsamem europäischen Interesse genehmigt worden. Vgl. Caspari 1987, S.

2098

209 Einen Abriß der Entwicklung liefert Curzon Price 1990, S. 177-79.

210 1993, S. 6.

211 Vgl. Färber 1993, S. 140f.

212 Vgl. Franzmeyer 1987, S. 165-169. 
"innovative Subventionsformen" der MS213 ging die Kommission in ihren Regelwerken durch immer umfassendere Definitionen des Subventionsbegriffs und die Erweiterung des Berechnungsverfahrens für Beihilfenäquivalente auf immer weitere Subventionsformen, insbesondere in der Regionalpolitik, an214. Den wichtigsten Aspekt stellten dabei die verschiedenen Schritte zur Erfassung von Beihilfeelementen in den Beziehungen zwischen den MS und ihren öffentlichen Unternehmen dar. Die Privatisierungstendenzen der letzten Jahre in mehreren MS, v.a. in Großbritannien, nun auch in Frankreich und Italien, werden dabei die Bedeutung dieses Problems reduzieren und damit die Beihilfenkontrolle erleichtern ebenso wie die nunmehr eingeführte Informationspflicht der MS an die Kommission über ihre Finanzbeziehungen zu öffentlichen Unternehmen (s.o. Abschn. 4.1.4.3). Daneben gelang die Ausweitung des Beihilfenbegriffs u.a. auf Grundstücksverkäufe unterhalb der Marktpreise, wie bspw. im Fall Daimler-Benz Berlin215. In der Regel verlangte die Kommission hier bei wichtigen Fällen unabhängige Bewertungsgutachten 216 . In jüngster Zeit wurden die Untersuchungen zu möglichen Beihilfen auf den Dienstleistungsbereich bei öffentlichen Monopolen wie Post (Quersubventionierung und dadurch Verzerrung zu privaten Konkurrenten) und Banken, die einen Sonderstatus besitzen (wie Postbanken), erweitert ${ }^{217}$. Bei der Schließung solcher Definitionslücken mußte die Kommission jedoch, wie am Beispiel des Schiffbaus deutlich wurde, z.T. zusätzliche Kompromisse eingehen, so etwa durch Akzeptanz höherer Fördersätze, großzügigere Berechnungsformen oder vorübergehende Ausnahmen. Heute ist allerdings eine Situation erreicht, in der spezifisch sektorale Betriebsbeihilfen nur noch in zwei Sektoren, dem Kohlebergbau und dem Schiffbau, gestattet sind 218 .

Auch im Bereich der Umstrukturierungs- und Investitionsbeihilfen konnte die Kommission ihre Kontrolle verstärken und damit ihren Einfluß erhöhen. Es gelang

213 Färber (1988, S. 12) weist darauf hin, daß eine solche Tendenz auch durch nationale Überwachungsmechanismen auftreten kann. So versuchte nach dem Regierungswechsel 1982 die CDU/FDP-Regierung, solche Subventionsformen zu entwickeln, die nicht unter die für den Subventionsbericht gültige Definition fielen, um so den Widerspruch zwischen der proklamierten Subventionskürzung und der tatsächlichen Entwicklung zu verschleiern.

214 Ein Instrument zur Durchforstung solcher intransparenten Förderungen waren die Beihilfenberichte. Vgl. auch DTI 1993, S. 4.

215 Andere vergleichbare Fälle waren Sony am gleichen Ort sowie Fresenius und Saint-Gobain. Vgl. EG, Kommission 1992a, S. 180-82, und 1994a, S. 262.

216 Vgl. EG, Kommission 1993a, S. 213

217 Vgl. ebenda, S. 251f.

218 Vgl. Petersen 1993, S. 24. 
ihr, mittels auf der Basis der jeweiligen Regelwerke erlassener bedingter Entscheidungen die Genehmigung von Beihilfen an Kapazitätsreduktionen, Modernisierung und Umstrukturierungen zu koppeln und damit eine Art indirekter Investitionsbeeinflussung durchzuführen ${ }^{219}$, die weg von Massenproduktion hin zu einer höheren Wertschöpfung führen sollte220 und die Schrumpfungsprozesse der jeweiligen Branchen beschleunigen und abfedern sollte. Allerdings ist hier zu fragen, inwieweit die Kommission lediglich der gewachsenen Einsicht der Unternehmen bzw. der MS in die Notwendigkeit solcher Schließungen die notwendige Autorität verlieh bzw. einen idealen Sündenbock abgab 221, d.h. die oben erwähnte Ankerfunktion (vgl. Abschn. 2.3.2) ausübte, während der Kapazitätsabbau ohnehin erfolgt wäre. Die analysierten Beispiele zeigen jedoch, daß eine scharfe Grenze zwischen wettbewerbspolitisch orientierter Beihilfenkontrolle, wie sie vom EWGV intendiert ist 222 , und industriepolitischer Beeinflussung des Strukturwandels, die u.U. eine (indirekte) Investitionslenkung einschließt, gerade in Problemsektoren nicht möglich ist ${ }^{223}$. Bei der Durchsetzung dieses Kompetenztransfers profitierte die Kommission von der verbesserten Konjunkturlage und dem Ende der akuten Krise in den betrachteten Branchen 224 . In den Fällen Rover und Renault spielten auch ordnungspolitische Überlegungen eine Rolle, da die Beihilfen an Privatisierung bzw. Umwandlung in privatrechtliche Formen gebunden waren 225 .

219 Vgl. Geister 1983, S. 163, und Franzmeyer 1989, S. 144. Solche Entscheidungen boten dann auch die Flexibilität, wie im Falle Renault, bei veränderten Marktgegebenheiten auf Kapazitätskürzungen zugunsten einer partiellen Beihilfenrückzahlung zu verzichten. Gegen eine direkte Kontrolle von Investitionen und Investitionsbeihilfen leisteten die MS jedoch zunächst energischen Widerstand.

220 Vgl. Curzon Price 1986, S. 56 (218). Konzentrationsprozesse wurden dabei zumindest toleriert.

221 Vgl. Warnecke 1978, S. 152.

222 Vgl. Seidel 1984, S. 57.

223 Dementsprechend ordnet auch bspw. der BDI (1990, S. 111) die Beihilfenkontrolle in seiner Beurteilung der Industriepolitik zu, wobei er die strikte Beihilfenkontrolle der letzten Jahre als Teil einer "marktwirtschaftlichen Industriepolitik" ansieht. Eine ähnliche Position vertritt auch Swann (1983, S. 4), der erklärt, daß "competition policy may be regarded as an ingredient of industrial policy", die die optimale Ressourcenverwendung sichern soll. Auch die Position der Kommission selbst deckt sich mit dieser Analyse. Vgl. hierzu EG, Kommission 1972a, S. 127.

224 Wie der Stahlbereich zeigt, versuchen allerdings die MS in von ihnen als strategisch angesehenen Bereichen, sich über Konsultations- und Entscheidungsrechte bei wichtigen Einzelfällen gewisse Kompetenzen zu erhalten und quasi als Filter der Kommissionsentscheidungen zu agieren. Wie oben erläutert, führt dies i.d.R. zu einer Aufweichung des Kommissionshandelns. Ähnliches gilt für die Versuche des Rates, über Diskussionen mit der Kommission zur Entscheidungspraxis im Schiffbau- und Stahlbereich Einflußmöglichkeiten zurückzugewinnen. Vgl. Franzmeyer 1989, S. 144. 
Eine Ex-ante-Kontrolle von regionalen Investitionsbeihilfen bzgl. ihrer sektoralen Wirkungen war ebenfalls ein wichtiges Mittel bei der Intensivierung der Kontrolle. Heute hat die Kommission solche Kontrollmöglichkeiten in den durch besondere Rahmen geregelten Sektoren erreicht, im Kunstfasersektor, Schiffbau und Stahl sind dabei sogar alle Beihilfen für Kapazitätserweiterungen verboten, im Kfz-Bereich führen Expansionen zu geringeren Förderintensitäten 226.

Die Konzentration der staatlichen Beihilfen auf Zukunftsindustrien mittels FuEFörderung einerseits und auf schrumpfende Branchen über Betriebs- und Rationalisierungsbeihilfen beeinflußt die Branchenstruktur der Wirtschaft indirekt insoweit, als der breite "Mittelbereich" nicht geförderter Industriezweige für die Finanzierung der Beihilfen mit aufzukommen hat und damit in seiner Entwicklung gebremst wird227.

\subsubsection{Gemeinschaftsrahmen als Instrument der Beihilfenkontrolle - Bedeutung und Kritik}

Wie an den Beispielen im 4. Kapitel illustriert, gelang es der Kommission im Laufe der Zeit über den vermehrten Einsatz von Gemeinschaftsrahmen, Richtlinien u.ä. ein System detaillierter Regelwerke zur Subventionskontrolle zu schaffen und auch besser durchzusetzen, so daß ihr relativer Einfluß sich erhöhte228.

Mit Hilfe dieser Regelwerke konnte auch die Transparenz und Konsistenz der Beihilfenkontrolle erhöht ${ }^{229}$ und durch die Spezifizierung von Beurteilungskriterien eine "Art allseits tolerierter Ordnungsrahmen"230 geschaffen werden, der die Grenzen der von der Kommission akzeptierten Subventionierung aufzeigte und auf den sich die Kommission dann in ihren Entscheidungen berufen konnte231. Da die MS die Ausgestaltung ihrer Programme nunmehr an diesen Regeln ausrichten konnten, erlaubt dies auch eine Beschleunigung der Kontrolle232. Zudem wird durch die veröffentlichten Beurteilungskriterien die Rechtssicherheit und Gleichbehandlung der

226 Vgl. Lehner/Meiklejohn/Reichenbach 1991, S. 63-66. In der Automobilindustrie können die Unternehmen bei Vermeidung der Errichtung von Überkapazitäten höhere Beihilfen erhalten (top-up). Die Höhe der infragestehenden Summen scheint allerdings für einen wirksamen Anreiz zu gering zu sein.

227 Vgl. EG, Kommission 1970b, S. 261.

228 Vgl. auch della Cananea 1993, S. 72.

229 Vgl. Lehner/Meiklejohn/Reichenbach 1991, S. 14, 57.

230 Geister 1985, S. 159.

231 Vgl. Cownie 1986, S. 250f., und Caspari 1984, S. 27.

232 Vgl. Rawlinson 1993, S. 56. 
betroffenen Wirtschaftssubjekte besser gesichert, und ein Verstoß gegen sie ist auch leichter feststellbar233. Mit den Rahmen hat die Kommission allerdings neben demjenigen der MS auch ihren eigenen diskretionären Spielraum beschränkt ${ }^{234}$, was aber zur Erzielung dieser eben genannten Vorteile notwendig und wünschenswert ist.

Das Zustandekommen der Regelwerke zeigt aber auch, daß die Kommission dabei stets auf die Erzielung und Erneuerung eines gewissen Grundkonsenses mit den MS angewiesen war, ohne den ihre Politik ins Leere gelaufen wäre235 - bei den von der Kommission verabschiedeten Rahmen holt sie stets die Zustimmung der MS ein 236 . Zeigt sich dabei oder bereits bei der kommissionsinternen Abstimmung eine generelle Ablehnung des Vorschlages, so werden Rahmenregelungen auch zurückgezogen oder abgeschwächt, wie bspw. der Rahmen für Beihilfen im audiovisuellen Sektor ${ }^{237}$. Formal allerdings kann die Kommission, wie im Kfz-Bereich geschehen, bei einem Widerstand eines MS gegen einen Gemeinschaftsrahmen das Prüfverfahren nach Art. 93,II eröffnen und den MS so zur Einhaltung der Regeln zwingen238. Die MS achteten jedoch sehr darauf, daß die Kompetenz des Rates in bestimmten Sektoren durch die Kommission nicht ausgehöhlt wurde. Dies gilt bspw. im Stahlbereich, wo es der Kommission nicht gelang, die Regeln für FuE- und Umweltschutzbeihilfen so zu formulieren, daß eine Änderung der entsprechenden horizontalen Rahmen automatisch auch auf diesen Sektor übernommen würde. Vielmehr ist hierzu weiterhin ein Ratsbeschluß nötig.

Hieraus wird auch deutlich, daß die Regeln der sektoralen Rahmen Vorrang vor den horizontalen Regelwerken besitzen 239 . Die sektoralen Rahmen erlauben der Kommission die Prüfung von Einzelfällen 240 und führten dazu, daß in diesen Sektoren der Überblick der Kommission über die Verteilung der Beihilfen auf Regionen und einzelne Unternehmen wesentlich erhöht wurde und damit auch die Erkenntnisse

233 Vgl. Jallon 1993, S. 328, und Rawlinson 1993, S. 57.

234 Vgl. Harden 1993, S. 17.

235 Vgl. Geister 1985, S. 159. Die MS werden dabei auch versuchen, die Gestaltung der Regelwerke in ihrem Sinne zu beeinflussen. Vgl. DTI 1993, S. 9.

236 Vgl. della Cananea 1993, S. 63.

237 Vgl. Rawlinson 1993, S. 55, 60.

238 Vgl. Jallon 1993, S. 336. Bei einer mehrheitlichen Ablehnung eines Rahmenentwurfs durch die MS wäre ein solches Vorgehen allerdings politisch schwer vorstellbar.

239 Vgl. DTI 1993, S. 12.

240 Aus juristischer Sicht entziehen die Gemeinschaftsrahmen sektoral begrenzt den Anwendungsfällen genehmigter allgemeiner Beihilfenregime eben diese Genehmigung und stellen sie neuen Beihilfen gleich, die wiederum der Melde- und Prüfungspflicht unterliegen. Vgl. Jallon 1993, S. 335 . 
darüber verbessert werden konnten, ob die nationalen Beihilfen zu Wettbewerbsverzerrungen führen und andere Gemeinschaftsziele, wie etwa die Kohäsion konterkarieren 241 . Bei regionalen Investitionsbeihilfen bspw., die einen bedeutenden Bereich der durch die Rahmenregelungen eingeführten zusätzlichen Kontrolle darstellen, muß die Kommission in jedem Einzelfall die positiven regionalen Effekte mit den negativen sektoralen abwägen und kann beim Überwiegen solcher negativen Effekte ex ante eingreifen und somit ihr Eintreten durch Verbot oder Verminderung der Beihilfe verhindern ${ }^{242}$. Die sektoralen Rahmen modifizieren somit zum Teil die Regeln der horizontalen Rahmen spezifisch für den jeweiligen Sektor. Ihre Einführung als Reaktion auf spezifisch sektorale Probleme verlangt eine regelmäßige Überprüfung der Beurteilungskriterien und ggfs. ihre Modifikation durch die Kommis$\operatorname{sion}^{243}$.

Bei den regionalen und allgemeinen Rahmen beschränkt sich der Spielraum hingegen weitgehend auf die Prüfung von Programmen, da hier nur eine begrenzte Einzelfallmeldepflicht besteht 244 . Der Zweck dieser Rahmen besteht darin, sektorübergreifend für bestimmte Beihilfetypen einheitliche Anwendungsregeln und Förderobergrenzen zu definieren und damit zu verhindern, daß die MS im Gewande allgemeiner Fördermaßnahmen, die dem Namen nach mit Gemeinschaftszielen in Einklang stehen (bspw. Forschungsförderung), eine verdeckte sektorale Industriepolitik betreiben. Dies ist wichtig, da die MS gerade solche Beihilfetypen in steigendem Maße nutzen 245. Derartige Gefahren bestehen v.a. in den besonders kontrollierten Sektoren, in denen die Vergabe anderer Beihilfen schärfer überwacht wird. Durch die einheitliche Anwendung der allgemeinen Rahmen, z.B. für FuE- oder Umweltschutzbeihilfen, auf sie erreicht die Kommission einerseits Konsistenz und Transparenz, andererseits doch eine zumindest sektoral begrenzte Einzelfallprüfung. Die horizontalen Rahmen decken inzwischen alle wesentlichen aktuellen Schwerpunkte der Gemeinschaftspolitik ab: Regionalentwicklung, FuE-Förderung, Umweltschutz und seit kurzem auch die Unterstützung von KMU. Sie schaffen damit eine Verbindung zwischen der kontrollierenden Wettbewerbspolitik und dem eigenen

\footnotetext{
241 Vgl. Deacon 1990, S. 70.

242 Vgl. Jallon 1993, S. 339 und 343. Die Art und Weise der Definition eines solchen Ungleichgewichts zwischen regionalen und sektoralen Effekten erfolgt allerdings, wie oben gesehen, in den Regeln auf unterschiedliche Weise.

244 In Fällen des Mißbrauchs kann die Kommission hier lediglich ex post über den Vorschlag zweckdienlicher Maßnahmen nach Art. 93,I eingreifen. Vgl. Jallon 1993, S. 327 und 338.

245 Vgl. Gilchrist/Deacon 1990, S. 38f.
} 
Handeln der Gemeinschaft 246 . Weitere horizontale Rahmen sind in den Bereichen der Beschäftigungsbeihilfen und kurzfristiger Exportkreditversicherungen geplant 247 .

Die z.T. geäußerte Kritik, daß die Veröffentlichung solcher Regelwerke und der Beurteilungskriterien "leicht als Aufforderung zur Beihilfegewährung mißverstanden" 248 werden könnten und damit zur Ausweitung der Subventionierung beitrügen, ist m.E. überzogen. Mittels der Regelwerke versuchte die Kommission in Reaktion auf zunehmende Subventionierung durch die MS in einigen Branchen, diese zu kanalisieren und einzuschränken, um dort eine geordnete Anpassung zu unterstützen 249 sowie die Transparenz des Kommissionshandelns zu erhöhen, was im Laufe der Zeit auch immer besser gelang250. Dabei handelte es sich zumeist um Industriezweige, die in allen Ländern der EG mit schweren Anpassungsproblemen zu kämpfen hatten 251 oder aufgrund ihrer hohen Bedeutung für die Beschäftigung und Wertschöpfung insbesondere einzelner Regionen von den MS bevorzugt gefördert wurden, bzw. um horizontale Bereiche, die von den MS als wichtig angesehen wurden. Die betroffenen Sektoren waren zudem i.d.R. solche mit "großen" Marktteilnehmern, oligopolistischen Strukturen und einer Tendenz zu Überkapazitäten, in denen staatliche Beihilfen für einen Wettbewerber diesem aufgrund der Kapazitätsreserven eine wesentlich stärkere Ausweitung seiner Produktion erlaubten mit entsprechend stärkerer Wirkung auf Handel und Intra-EG-Wettbewerb als im Falle vieler kleiner Unternehmen 252 . Die Rahmenregeln entstanden dabei i.d.R. aus der Entwicklung von Kriterien bei Einzelentscheidungen und Urteilen des EuGH253. Die Regeln schufen ein Bezugssystem zur Beurteilung der "Zulässigkeit von Zielen und Modalitäten der Maßnahmen der Mitgliedstaaten"254, dessen Fehlen die Kommission noch 1972 moniert hatte und das den MS einen Entscheidungs- und Planungsrahmen gibt sowie die Rechtssicherheit für Unternehmen verstärkt ${ }^{255}$. Sie beeinflußt dabei gleichzeitig das beihilfenpolitische Handeln und erreicht eine gewisse Ver-

\footnotetext{
246 Vgl. Jallon 1993, S. 329.

247 Vgl. Ehlermann 1994, S. 421.

248 Seidel 1984, S. 60

249 Vgl. Cownie 1986, S. 254.

250 Vgl. Neundörfer 1984, S. 88, und Rawlinson 1993, S. 57f.

251 Vgl. Zippel 1984, S. 8, und Cownie 1986, S. 250 f.

$252 \mathrm{Vgl}$. Jallon 1993, S. 330f.

253 Vgl. della Cananea 1993, S. 67

254 EG, Kommission 1972, S. 129.

255 Vgl. Petersen 1993, S. 23.
} 
gemeinschaftung bestimmter Politikbereiche 256 . Die Beihilfenkontrolle hat sich durch die Existenz der Rahmen von einem weitgehend diskretionären zu einem vorwiegend regelgebundenen System entwickelt 257 .

Etabliert der Rahmen allerdings bestimmte Beihilfenkategorien, die ohne seine Existenz verboten wären, werden auch solche Unternehmen, die Beihilfen nicht benötigen, einen Anreiz erhalten, nach diesen nachzusuchen 258 . Dies war allerdings lediglich im Stahl und Schiffbau gegeben 259 . Eine solche Abweichung von den Regeln der Verträge bedarf dann allerdings auch einer Entscheidung des Rates nach Art. 92,III e, da die Kommission durch die Verabschiedung von Regelwerken weder die inhaltlichen noch die prozeduralen Regeln der Verträge verändern kann 260 .

Ein weiterer Kritikpunkt, der sich gegen die sektoralen Rahmen richtet, lautet, daß sie zur Investitionslenkung mißbraucht werden können 261 . Dieser Vorwurf ist nicht völlig von der Hand zu weisen, auch wenn die Lenkung eher indirekt erfolgt, indem andere weniger kontrollierte Sektoren von höherer Förderung profitieren können. Es stellt sich jedoch die Frage nach dem verwendeten Referenzmaßstab. Wie oben erläutert, sind die spezifisch kontrollierten Sektoren nämlich gerade diejenigen, die von den MS vorher intensiv subventioniert wurden und Objekt nationaler Industriepolitiken waren. Zudem sind es auch solche Sektoren mit besonderen strukturellen Problemen, in denen die Wettbewerbsverzerrungen aus Beihilfen stärker zu spüren sind 262. Man kann die spezifisch sektorale Kontrolle einiger Branchen somit auch als Instrument zur Wiederherstellung des sektoralen Gleichgewichts sehen. Das aufwendigere Kontrollverfahren legt den Unternehmen dabei in diesen Sektoren allerdings höhere Kosten auf und kann Investionsanreize hemmen ${ }^{263}$. Die Bedeutung dieses Faktors sollte allerdings nicht überschätzt werden, da die Rentabilität der Projekte dominierende Überlegung für die Unternehmen sein wird, während die Verfügbarkeit von Beihilfen v.a. die konkrete Standortwahl beeinflussen

256 Vgl. della Cananea 1993, S. 68.

257 Vgl. Rawlinson 1993, S. 53.

258 Vgl. Chard/Macmillen 1979, S. 142. Dies trägt innerhalb des Sektors dann sogar zur Verminderung subventionsinduzierter Verzerrungen im Wettbewerb der gemeinschaftlichen Produzenten bei. Es verstärkt allerdings intersektorale Verzerrungen der Faktorallokation mit evtl. indirekten Handelsverzerrungen über vermiedene Marktaustritte.

259 Vgl. hierzu auch EuGH 1993a, RN 33.

260 Vgl. della Cananea 1993, S. 71, und Jallon 1993, S. 332f.

261 Vgl. Schütterle 1993a, S. 78.

262 Vgl. Petersen 1993a, S. 84.

263 Vgl. Schütterle 1993a, S. 83. 
wird. Zudem erlaubten die klareren Regeln, wie oben erläutert, schnellere Entscheidungen zu den Fällen.

Hinsichtlich des rechtlichen Status der Rahmenregelungen kann man unterscheiden zwischen solchen, die auf Ratsbeschlüssen beruhen (Schiffbau, Stahl, Kohle) und solchen, die von der Kommission erlassen werden (Kunstfaser, Automobil, FuE, Umweltschutz). Formal ist die rechtliche Bindungswirkung der ersten Gruppe für die MS höher, während die zweite Gruppe lediglich Empfehlungen der Kommission darstellt, mit denen sie die Vertragsregeln für ihr eigenes Handeln interpretiert. Dieser Unterschied wird allerdings aufgehoben, wenn die MS auf Verlangen der Kommission einem Rahmen der zweiten Gruppe formell zugestimmt haben. In der praktischen Anwendung durch die Kommission führt dies in solchen Fällen dann nicht zu Unterschieden, da sie selbst sich, wie auch die MS, an die Regeln bindet 264 .

\subsubsection{Das Problem der Beeinflussung der Kapazitätsentwicklung}

Die Analyse der drei betrachteten Sektoren legt nahe, daß die durch die Kontrollund Lenkungsmaßnahmen der Kommission bewirkte Kapazitätsentwicklung nicht mit derjenigen unter reinen Marktbedingungen übereinstimmte. So wurde in den VorKrisenphasen der subventionierte Aufbau von Überkapazitäten vor allem durch staatliche Unternehmen toleriert, es war "die Beihilfenkontrolle verloren gegangen" 265 .

Auch in den Krisen gelang es zunächst nicht, eine umfassende Subventionskontrolle durchzusetzen. Die hohen in diesen Phasen von der Kommission genehmigten und von den MS gewährten Rettungs- und Umstrukturierungsbeihilfen sind ein deutliches Indiz dafür, daß ohne solche Beihilfen die betreffenden Unternehmen aus dem Markt verschwunden wären. Die hohen verfügbaren Beihilfen boten hingegen einen Anreiz für die Unternehmen, weniger zu schrumpfen, als es sowohl unter volks- wie unter betriebswirtschaftlichen Aspekten optimal gewesen wäre266. So wurden im Werftenbereich höhere Hilfen bspw. in Frankreich, Großbritannien und Italien toleriert, die dort als effektive Marktaustrittsbarrieren 267 höhere Kapazi-

\footnotetext{
264 Vgl. Rawlinson 1993, S. 59, und della Cananea 1993, S. 69.

265 Caspari 1990, S. 26.

266 Vgl. Zippel 1984, S. 5. Das staatliche Subventionsangebot bot zudem einen Anreiz für die Unternehmen, nicht zu diversifizieren, sondern bspw. ihre Stahlbereiche auszugliedern, um somit dem Staat subventionsbedürftige Unternehmen, d.h. solche mit hohen Verlusten, zu

267 präsentieren. Vgl. Neumann 1984.
} 
täten erhalten halfen. Diese Hilfen wanderten in hohe Maße an die ineffizientesten Firmen und verhinderten so deren Bankrott, ohne daß entsprechende Umstrukturierungen in ausreichendem Maße durchgeführt wurden, da durch die Erweiterung und auch Aufweichung ihrer Budgetbeschränkungen die X-Ineffizienz eher noch gefördert wurde 268. Durch die speziellen Formen der Subventionierung, die auch innerhalb der Gemeinschaft de facto eine Marktabschottung gestatteten, wurden die schwächeren Werften noch zusätzlich geschützt. Fristen zur Beendigung der Subventionsregime wurden hier wie im Stahl gesetzt und dann wieder geopfert; eine wirksame Beendigung des Wettbewerbs der Staatskassen gelang nicht.

Auch im Stahl lagen den Kapazitätsabbauauflagen des 2. Kodex, wie in Abschnitt 4.3 erläutert, eher national orientierte Konzepte einer gleichen Belastung als solche der Wettbewerbsfähigkeit zugrunde269. Diese Haltung korrespondiert mit Bhagwatis 270 Beobachtung, daß das Verlangen der Wirtschaftssubjekte nach Unterstützung und Anpassungshilfe dann wesentlich stärker ist, wenn der auslösende Faktor der Veränderung aus dem Ausland zu kommen scheint. Auch andere MS der Gemeinschaft werden dabei als Ausland empfunden. Dieser Ansatz wird nach dem Ende des 2. Kodex noch deutlicher, als zunächst weitere Beihilfen ohne Kapazitätsabbau und sogar eine Harmonisierung des Schuldendienstes mittels der Subventionen gestattet wurden 271 (vgl. oben Abschnitt 4.3.3.4).

Dennoch muß die erzwungene annähernde Gleichheit des Kapazitätsabbaus für die wettbewerbsstärkeren Produzenten langfristig nicht von großem Nachteil sein, v.a. dann, wenn regional- oder beschäftigungspolitisch beschränkende Auflagen durch die MS für die Wettbewerbsrückstände der anderen Produzenten verantwortlich sind und weiterhin bestehen bleiben ${ }^{272}$. Im Vergleich zu einer Lösung ohne Subventionen allerdings, die in einer Wettbewerbssituation den Marktaustritt der schwächeren Produzenten erzwungen und die Expansion der effizienteren Hersteller ermöglicht

268 Vgl. Carmoy 1978, S. 38, und Gerritse 1990, S. 147.

269 Vgl. Franzmeyer 1987, S. 169, und Mestmäcker 1987, S. 29.

270 1988, S. $118 \mathrm{f}$.

271 Das Argument, daß Betriebsbeihilfen von den unrentablen Unternehmen verwirtschaftet wurden und somit keine langfristigen Wettbewerbswirkungen auftraten (so bspw. bei Tomann 1984a, S. 94), ist sicherlich nicht haltbar. Da durch den Marktverbleib dieser Unternehmen mittels Beihilfen die Preise fielen und die Verluste der Konkurrenten stiegen, somit ihre Kapitalbasis und ihre Investitionsmöglichkeiten fielen, wurde der Wettbewerb signifikant verzerrt. Die subventionierten Unternehmen hingegen konnten ihre Kapitalbasis erhalten.

272 Solche Beschränkungen existierten v.a. für die nationalisierten Stahlindustrien. Vgl. Mutti 1982, S. 27f. 
hätte273, stellt die verbleibende Produktionsstruktur nach einer gelenkten Kapazitätsbereinigung, die Effizienzunterschiede nicht als Maßstab für Schließungsauflagen verwandte, die ineffizientere Lösung dar, v.a. auch dann, wenn den produktiveren Herstellern durch Zwangsstillegungen ihre Größenvorteile genommen werden 274 . Wie für die Stahlindustrie gezeigt wurde, gehen die Wohlfahrtswirkungen einer solchen Politik über den Sektor hinaus und betreffen Abnehmer und Lieferanten, aber auch andere Sektoren, denen Produktionsfaktoren vorenthalten werden oder nur zu höheren Preisen zur Verfügung stehen 275 . Die Verteilung der Kosten und Risiken bleibt hierbei relativ unbestimmt, was politisch sicher von Vorteil ist ${ }^{276}$.

Im Automobilsektor wurde eine bessere Annäherung an die Marktlösung erreicht, indem lediglich den Unternehmen in finanziellen Problemen, die Restrukturierungsbeihilfen benötigten, signifikante Stillegungen auferlegt wurden, somit quasi ein partieller Marktaustritt der am wenigsten effizienten Unternehmen erzwungen wurde. Zur zukünftigen Behandlung solcher Probleme wurde jüngst eine Rahmenregelung für Rettungs- und Umstrukturierungsbeihilfen von der Kommission verabschiedet 277 .

Jedoch muß hier die Frage gestellt werden, ob eine Lösung ohne Subventionen die relevante Alternative war bzw. ob selbst bei einer solchen Situation mit einer schnellen Bereinigung des Marktes zu rechnen gewesen wäre. Geroski/Jacquemin 278 zeigen, daß in einer Situation schrumpfenden Outputs auf einem oligopolistischen Markt und der Existenz von Austrittsbarrieren, bspw. in Form von Sunk costs in der Gestalt branchenspezifischer Anlageinvestitionen, die Frage des Marktaustritts zu einem strategischen Spiel wird, in dem es für jede der beteiligten Firmen optimal ist, im Markt zu verbleiben und auf den Austritt der Konkurrenten zu warten. Da diese Bedingung für alle Beteiligten gilt, werden alle Teilnehmer trotz der geringen Erträge im Markt bleiben, aber wegen dieser geringen Erträge nicht in der Lage sein, in Innovation und Modernisierung zu investieren. Im Falle der Verfügbarkeit von Subventionen kann dieser Prozeß langanhaltend sein, ohne daß die notwendige Rationalisierung und Kapazitätsschrumpfung stattfindet. In einer solchen Situation werden nicht die effizientesten Anbieter langfristig überleben, sondern diejenigen mit

273 Vgl. Franzmeyer 1981, S. 501.

274 Vgl. ebenda.

275 Vgl. Zippel 1984, S. 15.

276 Vgl. dazu Mestmäcker 1987, S. 33f., und oben Abschnitt 2.3.2.

277 Vgl. EG, Kommission 1994i, S. 12-20, und Petersen 1993, S. 24, sowie Ehlermann 1994, S. 424f.

278 1985, S. 189-191, 195-198. 
der größten Verfügbarkeit staatlicher Hilfen ${ }^{279}$. Hier ermöglicht erst eine externe supranationale Intervention die kooperative Lösung mit einem höheren Wohlfahrtsniveau an Stelle der Beggar-my-neighbour-Strategie, wobei diese supranationale Institution bei einem solchen Strukturkrisenkartell allerdings das Problem der Prognose zukünftiger Marktentwicklungen zu lösen hat ${ }^{280}$. Im Lichte dieser Überlegungen erscheint die von der Kommission verfolgte Strategie im Stahlbereich (und zu einem geringeren Grad im Schiffbau) als der wohlfahrtsmaximierende Weg281. Dies ist sicher einleuchtend im Vergleich zu einer Situation ungehemmter Subventionierung. Da diese aber ein Versagen der Kommission in ihrer wettbewerbspolitischen Aufgabe unterstellt, wäre dies ein Vergleich einer second-best mit einer thirdbest Option. Selbst im Vergleich zu einer Lösung ohne Subventionen jedoch legt die Argumentation der Autoren nahe, daß möglicherweise die Schrumpfung des Sektors und Reallokation seiner Ressourcen beschleunigt werden konnte, so daß auch hier ein Wohlfahrtsgewinn zi verzeichnen war, obwohl die Struktur der Schließungen allokativ suboptimal war. Eine noch bessere Lösung hätte dann sicherlich in einer Schließung der ineffizientesten Anlagen bestanden. Die erzielten Gewinne hätten gleichzeitig zum Teil für Transferzahlungen an die Länder die die größere soziale Last der Schließungen zu tragen hatten, dienen können. Ein solcher Konsens war aber EG-weit nicht zu erreichen 282 .

Das Problem der Behandlung des (Über-)kapazitätsproblems wird sich auch in Zukunft stellen. Dies gilt nicht nur für Umstrukturierungsbeihilfen, sondern auch für die Behandlung von Regionalbeihilfen. Während es für die durch sektorale Regelungen erfaßten Industrien mit unterschiedlicher Schärfe als Kriterium zur Begrenzung der Beihilfen herangezogen wird, spielt es in den anderen Sektoren keine Rolle. Größere Projekte mit höheren Kapazitäten werden dort auch nominal stärker gefördert. Angesichts bestehender Überkapazitätsprobleme in den durch Rahmenregelungen erfaßten Sektoren erscheint es hier logisch, den subventionierten Aufbau zusätzlicher Anlagen, die dem Investor bei Überkompensation der strukturellen Nachteile einen Kostenvorteil gegenüber den Konkurrenten verschaffen, zu begrenzen bzw.

279 Vgl. Krüger 1992, S. 594f., und Kap. 4.3, FN 17.

280 Vgl. ebenda, S. 595. Zudem führt ein solches Kartell de facto zur Schließung des Marktes für neue, potentiell wettbewerbsstärkere Konkurrenten und zur Kollusion bei der Preissetzung mit negativen Folgen für die Abnehmer. Dieser Effekt war auch in der Kunstfaserindustrie zu beobachten.

281 Allerdings müssen hierbei die Konsensfindungskosten für eine solche supranationale Strategie in die Analyse einbezogen werden. Vgl. Venables 1985, S. 214.

282 Vgl. Krüger 1992, S. 595. 
nicht noch zu belohnen. Andererseits können solche Beschränkungen Investoren zur Verlagerung in andere Regionen der Welt veranlassen, womit den Beschäftigungsund Entwicklungszielen der Gemeinschaft auch nicht gedient ist ${ }^{283}$. Dieses Problem stellt sich allerdings nicht nur für die bestehenden sektoralen Regelungen, sondern auch für den geplanten Rahmen für kapitalintensive Industrien (vgl. unten Abschnitt 6.5.2).

\subsubsection{Politökonomische Aspekte der Beihilfenkontrolle}

\subsubsection{Das Verhalten der beteiligten Gruppen}

Betrachtet man die allgemeinen Voraussagen der Theorie der neuen politischen Ökonomie, so muß die in Kap. 2.3.2 erläuterte Hypothese Messerlins, daß Bürokraten eher noch protektionsfördernder als Politiker sind, für den untersuchten Bereich abgelehnt werden. Wie die Entwicklungen im Schiffbau und der Stahlindustrie zeigen, in denen der Rat starke Entscheidungskompetenzen besitzt, gingen relativ "weiche" Entscheidungen, die die Kontrolle der gemeinschaftlichen Regelwerke abschwächten, vom Rat aus, wie an den Beispielen der verzögerten Anwendung der 6. Schiffbaurichtlinie auf Italien oder den Ausnahmegenehmigungen für Beihilfen an ILVA/Finsider und andere staatliche Stahlproduzenten deutlich wird. Auch die ständigen und häufig erfolgreichen Versuche der MS, Richtlinien- oder Entscheidungsentwürfe der Kommission aufzuweichen, bspw. für die Kontrolle von Beihilfen an öffentliche Unternehmen, weisen in dieselbe Richtung 284.

Es waren also i.d.R. die Politiker und nicht die Bürokraten, die die Interessen der industriellen Lobbies vertraten, um Marktaustritte und darauf folgende regionale Arbeitsmarktprobleme zu verhindern. Ihre Abhängigkeit von den Lobbies ist wohl auch höher einzuschätzen als die der Bürokraten, deren Einkommen und Position gesichert sind. Zudem dürfte von den Lobbies der indirekte Weg der Beeinflussung der Beihilfenkontrolle über die nationalen Regierungen und den Rat gerade in Beihilfefragen auch deshalb gewählt werden, da die Kommission, deren Legitimität

283 Vgl. DTI 1993, S. 43.

284 Auch die geringe Bereitschaft der Regierungen zu Beschwerden im Verlaufe der Verfahren nach Art. 93, II zeigt, daß die Politiker hier Subventionen in Partnerstaaten zu akzeptieren bereit waren, wenn im Austausch eigene Beihilfen akzeptiert wurden, wobei die Hoffnung auf Trade diversion-Effekte im Hintergrund stand. Swann (1983, S. 186) stellt klar: "if there are villains in this piece they are to be found in the Council of Ministers and the member state governments." Diese Erfahrung spricht auch dagegen, dem Rat über Verordnungen nach Art. 94 einen größeren Einfluß zu geben. Vgl. Rawlinson 1993, S. 60. 
und Möglichkeit der Einflußnahme allein auf den Regeln der Verträge beruht, einen hohen Anreiz hat, diese auch korrekt einzuhalten 285 , v.a. auch, da sie einer intensiven juristischen Kontrolle unterliegt. Ihr Spielraum ist damit generell geringer; dies gilt verstärkt in den Bereichen, die durch spezifische Regelwerke erfaßt sind, da hier die Genehmigungskriterien, wie oben erläutert, präziser sind.

Die Betrachtung der unterschiedlichen Behandlung verschiedener Industriebereiche verstärkt diese Schlußfolgerungen. Der Einfluß der Lobbies erwies sich in Bestätigung der theoretischen Überlegungen (vgl. oben Abschn. 2.3.2) in jenen Sektoren als besonders stark, in denen die regionale Konzentration der Industrien ihre Bedeutung für politische Repräsentanten aus den jeweiligen Regionen erhöhte. Eine wichtige Rolle spielt auch die Struktur der Branche: Geringe kurzfristige Preiselastizitäten des Angebots aufgrund von Eintrittsbarrieren aus sinkenden Durchschnittskosten oder laufendem Bedarf an qualifizierten Arbeitskräften und Technikern und hohe Austrittsbarrieren aufgrund hoher Spezifität des eingesetzten Kapitals erhöhen den Willen der (i.d.R. geringen Zahl von) Produzenten zur Kooperation, um Protektion bzw. Beihilfen zu erhalten und ermöglichen auf der anderen Seite eine Appropriierung der Gewinne daraus ohne die Gefahr des Markteintritts neuer Konkurrenten (s. oben Abschn. 2.3.2). Hohe spezifische Qualifikationen der Arbeitnehmer verbunden mit überdurchschnittlichen Löhnen erhöhen ihre Organisationsbereitschaft und -fähigkeit und ihr Interesse am Erhalt dieser Situation durch protektionistische Maßnahmen286. Verreydt/Waelbroeck 287 sprechen im Zusammenhang mit der Stahlindustrie von einer "textbook illustration of the forces which bring about demands for protection", die letzten Endes nur durch den Gegendruck der Abnehmer von Stahl (bzw. im Schiffbau der Reeder) gebremst bzw. in Richtung auf Subventionen anstelle von Zöllen gelenkt wird.

Angesichts der politökonomischen Überlegungen überrascht es nicht, daß die MS Subventionen in immenser Höhe gerade in solchen Sektoren, wie bspw. der Stahlindustrie, gegeben haben, in denen Großunternehmen dominieren und ein hoher Grad regionaler Konzentration herrscht, während Sektoren mit fast ausschließlich kleinen und mittleren Unternehmen, wie bspw. die Textilindustrie in Deutschland, den Strukturwandel weitgehend selbst bewältigen mußten 288 . Wäre lediglich die

\footnotetext{
$285 \mathrm{Vgl}$. Verreydt/Waelbroeck 1980, S. 7-9.

286 Vgl. zu diesen Aspekten Lehner/Meiklejohn/Reichenbach 1991, S. 26, und Verreydt/ Waelbroeck 1980, S. 20-23.

287 1980, S. 20.

288 Vgl. Westphal 1984, S. 43f.
} 
Zahl der Arbeitnehmer für die Subventionsbereitschaft der MS entscheidend, so hätte man das Umgekehrte erwarten müssen, da in der Textilindustrie 6\%, im Stahl dagegen nur $1,5 \%$ der Industriebeschäftigten tätig sind 289 . Auch wenn die Kommission in den betrachteten Sektoren dieser Entwicklung lange Zeit nicht wirksam Einhalt gebieten konnte, so wurde dies in jüngerer Zeit z.T. dadurch ausgeglichen, daß Beihilfen für KMU großzügiger behandelt wurden 290 .

\subsubsection{Das Problem der Kontrolle von Beihilfen an öffentliche Unternehmen}

Neben den systematischen Unterschieden in der Behandlung verschiedener Branchen bei der Beihilfenkontrolle treten auch ebensolche Unterschiede bei der generellen Position der MS in den betrachteten Bereichen zu den Bemühungen der Kommission um eine umfassende Subventionskontrolle auf. Die Analyse zeigt hier eine weitgehende Konsistenz der politischen Frontstellungen: Während v.a. Deutschland und die Niederlande die Kommission bei der Durchsetzung strengerer Regeln unterstützten, waren insbesondere Frankreich und Italien, aber auch lange Zeit Großbritannien und Belgien an weicheren Regeln und der Akzeptanz höherer Beihilfen interessiert. Wie bereits oben in Kap. 4 erläutert, werden hieran Unterschiede in den jeweiligen Eigentums- und Wirtschaftsordnungen deutlich 291 . Die deutlich höhere Intensität des lenkenden staatlichen Eingriffs in die nationalen Wirtschaften der letztgenannten Länder und der wesentlich höhere Anteil des staatlichen Eigentums an Industrieunternehmen292 veränderten die Präferenzen der handelnden nationalen Politiker und Bürokraten. Als quasi-Arbeitgeber war ihr Interesse primär auf die Erhaltung der Betriebe ausgerichtet, was verbunden mit evtl. ideologischen Druck, die "demokratische Kontrolle der Schlüsselindustrien zu sichern", den Willen zur Subventionierung, die Anfälligkeit für Forderungen der Lobbies und den Widerwillen gegen eine Kontrolle dieser Subventionen durch Dritte massiv erhöhte293. Die intensive Subventionierung aber auch Regulierung dieser Industrien diente dann sozialund regionalpolitischen Zielen, bspw. Vollbeschäftigung in einer gegebenen Sektoral- und Regionalstruktur ${ }^{294}$, sowie allgemein der Stabilisierung des politischen

289 Vgl. Hitiris 1991, S. 304, 306.

290 Vgl. die Erläuterungen zum Gemeinschaftsrahmen für KMU-Beihilfen in Abschnitt 4.1.4.

291 Vgl. Franzmeyer 1987, S. 164, und auch Butt Philip 1983, S. 128.

292 Vgl. dazu erläuternd mit Zahlen Franzmeyer 1981, S. 501f., daneben Nicolaysen 1984, S. 111113.

293 Vgl. Pelkmans 1984, S. 267, und Müller 1983, S. 243.

294 Vgl. Müller 1983, S. 253 f. 
Systems 295 . Die in dieser Situation aufgrund bürokratischer Restriktionen und des Wissens um die Verfügbarkeit weiterer Subventionen i.d.R. geringere Wettbewerbsfähigkeit der Staatsunternehmen fördert im Sinne der in Abschnitt 2.3.1 diskutierten Präferenz für industrielle Produktion diese Tendenz noch296, v.a. wenn die o.g. Kriterien für die jeweiligen Branche erfüllt sind 297 . Die Klagen Frankreichs, Italiens und Großbritanniens gegen die Transparenzrichtlinie vor dem EuGH zeigen zudem deutlich den Bedrohungscharakter, den diese MS einer solchen Kontrolle beimaßen, und geben damit indirekt einen Hinweis darauf, daß hier ein wesentlicher Ansatz zur Umgehung der Subventionskontrolle lag298. Dieser Eindruck wird dadurch unterstrichen, daß der europäische Industrieverband UNICE explizit eine strikte Anwendung dieser Richtlinie forderte 299.

Die in den betrachteten Fällen deutlich gewordene positivere Haltung von Regierungen, die eine Privatisierung staatlicher Unternehmen durchführten, zu einer strengeren Subventionskontrolle paßt in dieses Bild, da diese Regierungen (bspw. in Großbritannien 300 ) den Arbeitgeberstatus von Regierung und Verwaltung mit den entsprechenden Incentives aufgaben 301 . In einer umgekehrten Situation des steigenden Staatsanteils am Unternehmenssektor, wie bspw. in Deutschland nach der Wiedervereinigung, tritt dann konsequenterweise auch eine entsprechende Veränderung der Haltung der Regierung zur Beihilfenkontrolle ein. Private Produzenten verstärken diese Haltung ihrer Regierungen noch. In Ländern, in denen geringe Subventionen für sie verfügbar sind, werden sie auf supranationale Kontrollen drängen, um gegenüber Konkurrenten in anderen MS nicht an Wettbewerbsfähigkeit zu verlieren ${ }^{302}$.

295 Gerade der letzte Aspekt einschl. des Erhalts einer prekären nationalen Stabilität wird für die Beurteilung der Situation Italiens von Warnecke (1978, S. 152) besonders in den Vordergrund gestellt. Die jüngsten Entwicklungen in diesem MS weisen jedoch hier auf eine Veränderung hin.

296 Vgl. Peacock 1990, S. 29.

297 Vgl. Caspari 1985, S. 58, und Warnecke 1978, S. 151f. Dies erklärt auch, warum die Durchsetzung der Regeln in einer weitgehend privatwirtschaftlich organisierten Industrie, wie der

298 Textilbranche, weniger schwer fiel.

298 Ob die Initiative zur Umgehung direkt von den Regierungen ausging oder auf Druck der Führung der entsprechenden Unternehmen erfolgte, ist dabei von untergeordneter Bedeutung.

299 Vgl. BDI 1984, S. 44.

300 Vgl. Gilchrist/Deacon 1990, S. 33.

301 Vgl. Peacock 1990, S. 29.

302 Vgl. Chard/Macmillen 1979, S. 140, und oben Abschnitt 4.3 zur Haltung bspw. der deutschen Stahlindustrie. 
Während diese Analyse sehr gut das Verhalten der Regierungen im Stahl- und Schiffbausektor und auch den Widerstand einiger MS gegen eine stärkere Überwachung der Finanzbeziehungen zwischen ihnen und ihren öffentlichen Unternehmen erklärt, scheint die Haltung Deutschlands zum Gemeinschaftsrahmen im Automobilsektor der Theorie zu widersprechen. Zwar wurden hier grundsätzliche ordnungspolitische Bedenken und die Furcht vor industriepolitischer Lenkung mit höheren Subventionen von deutscher Seite als Argumente angeführt ${ }^{303}$, doch erscheint vor allem der letztere Aspekt angesichts der noch relativ großzügigen Haltung der Kommission in den Fällen der Übergangsphase nicht besonders stichhaltig, da hier doch wohl eher mit einer strengeren Kontrolle durch den Gemeinschaftsrahmen gerechnet werden konnte. Wichtiger erscheint der Aspekt, daß von den deutschen Automobilherstellern VW den weit überwiegenden Teil seiner Produktion in Regionalfördergebieten herstellt und auch BMW und Daimler Benz zum Teil in solchen Gebieten fertigen. Hier bestand möglicherweise die Befürchtung, daß aufgrund einer strengeren Kontrolle von Regionalbeihilfen die Möglichkeiten des Einsatzes der Regionalpolitik zur Unterstützung dieser Firmen beschränkt ${ }^{304}$ und damit ihre relative Wettbewerbsposition sich verschlechtern würde.

Die Etablierung einer Überwachung der öffentlichen Unternehmen erwies sich also angesichts des großen Widerstandes der betroffenen MS als schwierig. Aber selbst nach der Einführung dieser Kontrollen bleibt das Problem, daß die Kontrolle möglicher Beihilfen an diesen Unternehmenstyp durch die Kommission weniger leicht möglich ist ${ }^{305}$, so daß es hier zu einer Ungleichbehandlung privater und staatlicher Unternehmen kommt ${ }^{306}$. Die Überwachungsprobleme der Kommission entstehen einerseits, wie oben in Abschnitt 4.1.4.3 erläutert, aus der größeren Möglichkeit der Vergabe intransparenter Subventionen an Staatsunternehmen 307 , andererseits aus dem höheren politischen Druck seitens der MS, dem sie bei diesen Unternehmen auch in jedem Einzelfall ausgesetzt ist ${ }^{308}$. Die Bewertung ihres Subventionsgehaltes aus dem Vergleich mit privaten Unternehmern ist häufig nur begrenzt möglich, v.a. wenn im betreffenden MS nur Staatsunternehmen in diesem Sektor

\footnotetext{
303 Vgl. auch Franzmeyer 1990, S. 160.

$304 \mathrm{Vgl}$. auch Schütterle 1993a, S. 85.

305 Vgl. Geister 1983, S. 163, und Caspari 1990, S. 18.

306 Vgl. Butt Philip 1983, S. 136.

307 Verreydt/Waelbroeck (1980, S. 21) sehen die Verstaatlichung als die "ultimate subsidy" an.

308 Vgl. Gilchrist/Deacon 1990, S. 44, Neundörfer 1984, S. 105f., und Nicolaysen 1984, S. 123, sowie Hellingman 1986, S. 125.
} 
existieren bzw. der Sektor gemeinschaftsweit durch öffentliche Unternehmen dominiert wird. In einem solchen Fall wird es auch schwieriger, den von der Kommission zur Beurteilung des Beihilfencharakters üblicherweise benutzten Vergleich mit einem nach wirtschaftlichen Kriterien handelnden Privateigner anzuwenden 309 . Dennoch hat die Kommission bspw. im Stahlsektor eine sehr strikte Haltung eingenommen, indem sie aufgrund der finanziellen Verhältnisse der Unternehmen und der Marktaussichten alle Kapitalzuführungen zu $100 \%$ als Beihilfen klassifizierte 310 . Ein weiteres Problem auch nach Verabschiedung der Richtlinien von 1980 und 1985, die zwar erste Ansätze zur Erhöhung des Informationsstandes der Kommission und damit zum Abbau der Ungleichbehandlung darstellten 311 , bestand darin, daß die Staatsunternehmen zwar verpflichtet waren, Dokumente über ihre finanziellen Beziehungen zum staatlichen Eigner fünf Jahre aufzubewahren und auf Anfrage an die Kommission zu übergeben, daß aber dadurch Beihilfen möglicherweise erst Jahre nach ihrer Zahlung entdeckt werden, was zu einer Rückzahlungsforderung mit den in Abschnitt 5.3.5 dargelegten Problemen führen kann. Eine Lösung liegt hierbei in jährlichen Prüfung dieser Finanzbeziehungen, wie sie die Kommission auch für Unternehmen mit mehr als 250 MECU Umsatz kürzlich eingeführt hat, während sie vorher lediglich aufgrund der Leitlinien von 1984 für Kapitalzuführungen oder Neubeteiligungen vorgeschrieben waren 312 . Dies ist auch deswegen wichtig, weil mit zunehmender Deregulierung die Möglichkeiten subventionierter öffentlicher Unternehmen, Wettbewerb und Handel auch außerhalb ihrer nationalen Grenzen zu beeinflussen, zunehmen 313 . Eine effektivere Kontrolle des Finanzgebarens öffentlicher Unternehmen ist auch nötig, um ihre Akzeptanz und Glaubwürdigkeit bei den privaten Konkurrenten zu erhöhen 314 . Eine endgültige Lösung dieser Überwachungsprobleme wird allerdings wohl nur bei einer Privatisierung der öffentlichen Unter-

309 Dieser Vergleichsansatz stärkt die marktwirtschaftliche Ordnung der Gemeinschaft, da er die MS daran hindert, über staatliche Unternehmen die Wettbewerbsprinzipien auszuhebeln und andere Ziele zu verfolgen. Vgl. The Economist 1991a, S. 17. Swann (1983, S. 185) stellt die Anwendung einer Zielrentabilitätsrate für öffentliche Unternehmen als Maßstab zur Beurteilung möglicher Beihilfen zur Diskussion. Die Festlegung dieser Rate dürfte sich allerdings angesichts von Schwankungen der allgemeinen und der Branchenkonjunktur sehr schwierig gestalten.

310 Vgl. BMF 1983, S. 55.

311 Siehe auch Abschnitt 4.4.4.

312 Vgl. The Economist 1991a, S. 17, und EG, Bulletin 1984a, S. 99, Punkt 3.2 und 4.2.

313 Vgl. Rawlinson 1993, S. 56.

314 Vgl. Ehlermann 1992, S. 614. 
nehmen v.a. in Krisensektoren gelingen 315 . Inzwischen ist in DG IV eine Task Force "Öffentliche Unternehmen" eingerichtet worden, die dieses Problem verstärkt angehen soll 316 .

\subsubsection{Zum Verhältnis von Wettbewerbs- und Regionalpolitik}

Mit der Beinflussung von Kapazitätsentwicklung und Investitionsentscheidungen, bspw. auch durch die Ausgestaltung und Anwendung von Gemeinschaftsrahmen, hatte die wettbewerbspolitisch motivierte Beihilfenkontrolle auch Auswirkungen auf andere Politikbereiche der Gemeinschaft, insbesondere die Regionalpolitik. Diese indirekten Wirkungen traten neben die direkte Beeinflussung der nationalen Regionalpolitiken über die Beurteilung der Regionalförderprogramme der MS.

Das Problem der Kommission bei der Subventionskontrolle besteht dabei im potentiellen Konflikt zwischen Wettbewerbs- und Regionalpolitik oder auch zwischen Allokationsverbesserung und gleichmäßigerer interregionaler Einkommensverteilung, insbesondere nachdem das Kohäsionsziel durch die EEA noch einmal aufgewertet wurde und ab 1988 die gemeinschaftlichen Strukturfonds erheblich aufgestockt wurden 317 . Mit der Einrichtung des Kohäsionsfonds durch den Vertrag von Maastricht wird diese Tendenz noch verstärkt. Allerdings ist zu berücksichtigen, daß diese Ausweitung der gemeinschaftlichen Regionalförderung vorwiegend auf Infrastrukturmaßnahmen und die ärmsten Gebiete der Gemeinschaft konzentriert sind, wo das Verzerrungspotential geringer ist ${ }^{318}$, da diese Förderung keine direkten Vorteile für einen spezifischen Investor vermittelt, sondern das regionale Entwicklungspotential einer Region insgesamt erhöht und damit die regionalspezifischen Nachteile vermindert 319 .

Was die direkte Förderung von Unternehmensinvestitionen betrifft, die den Kern der mitgliedstaatlichen Regionalpolitik bildet, zeigte die allokative Analyse in Abschnitt 2.1.2 zwar, daß Externalitäten für eine aktive Regionalpolitik sprechen, aus Abschnitt 2.2 wurde aber auch deutlich, daß eine Überkompensation regionaler Nachteile zu allokativen Verzerrungen führt. Somit kann die sektorale Anwendung regionaler Programme zu sektoralen Verzerrungen führen, auch wenn ihre regional-

\footnotetext{
315 Vgl. Schaub 1993, S. 43, der diese Ansicht für die Stahlindustrie vertritt.

316 Vgl. Ehlermann 1994, S. 424.

317 Vgl. Franzmeyer 1991, S. 151.

318 Vgl. Franzmeyer 1992, S. 157.

319 Vgl. Biehl 1988, S. 90, 94f., und 1992, S. 76f. Sie ist damit nicht rein distributiv, sondern auch allokativ orientiert.
} 
fördernde Wirkung sowohl allokativ als auch distributiv positiv zu sehen ist. Da der regionale Niederlassungsnachteil an einem Standort wohl nicht für alle Branchen gleich hoch ist ${ }^{320}$, würde dies für eine Einzelfallprüfung vor allem in Sektoren mit intensivem innergemeinschaftlichen Handel sprechen, um so Konflikte zwischen sektoralen und regionalen Aspekten zumindest transparent zu machen und evtl. Verzerrungen zu minimieren ${ }^{321}$. Dies gilt insbesondere auch angesichts der außerordentlich hohen Obergrenzen von $75 \%$ NSÄ in den 92,IIIa-Gebieten, die zu einer erheblichen Umverteilung des unternehmerischen Risikos führen und somit gerade in kapitalintensiven Branchen geradezu einen Anreiz zum Aufbau von Überkapazitäten bieten $^{322}$. Tatsächlich ist nach der Genehmigung der regionalen Programme der MS eine solche Einzelfallkontrolle kaum gegeben; sie findet detailliert und systematisch lediglich in den durch gemeinschaftliche Regelwerke erfaßten Sektoren statt, wobei im Schiffbau und im Stahlsektor ihre Einbeziehung in die Höchstgrenzen erst im Laufe der Zeit gelang; heute sind solche Beihilfen im Stahlsektor abgesehen von Ausnahmen verboten. Die Ergebnisse der im Automobilsektor durchgeführten Kosten-Nutzen-Analysen deuten auch darauf hin, daß die jeweiligen regionalen Beihilfehöchstgrenzen häufig $z u$ hoch gewählt worden sind 323 . Unterstellt man, daß diese Tatsache auch für andere Branchen mit starkem Intra-EG-Handel gilt, so führt eine strengere Kontrolle der Regionalbeihilfen mit ihrer stärkeren Beschränkung in einigen Sektoren einerseits zur Diskriminierung dieser Sektoren mit der Folge einer möglichen Abwanderung von Kapital in andere Branchen. Andererseits führt ihre zu geringe Kontrolle in anderen Sektoren zu Verzerrungen dergestalt, daß Investoren in Regionalfördergebieten Wettbewerbsvorteile gewinnen.

320 Vgl. EG, Kommission 1972a, S. 145.

321 Tatsächlich zeigen einzelne Anwendungsfälle in anderen Sektoren, daß die Kommission z.T. bewußt sektorale Verzerrungen tolerierte, um die gewünschte regionale Wirkung zu erreichen. Vgl. EG, Kommission 1985a, S. 198f.

322 Vgl. Caspari 1990, S. 17, und Eekhoff 1993, S. 53, der den Wert von $75 \%$ als "unanständig" bezeichnet.

323 Angesichts der Tatsache, daß infrastrukturverbundene Nachteile ein bedeutendes Gewicht in diesen NKA haben, könnten die Ergebnisse ein Indikator dafür sein, daß bisherige regionalpolitische Maßnahmen zur Infrastrukturverbesserung die Nachteile der entsprechenden Regionen vermindert haben und die historisch gewachsenen Förderhöchstgrenzen inzwischen überholt und zu hoch sind. Gegen diese Argumentationslinie läßt sich allerdings einwenden, daß andere Beihilfen, vor allem solche für FuE, eher entwickelte Regionen bevorteilen, so daß auch sie zuerst durch Regionalbeihilfen zu kompensieren sind, was wiederum für höhere Intensitäten spräche. Vgl. Padoa-Schioppa 1988, S. 62. 
Diese Argumente sprechen also eher für eine höhere Kontrollintensität bei Regionalbeihilfen. Insbesondere von regionalwirtschaftlicher, aber auch von juristischer Seite wird jedoch die bestehende Kontrollintensität bereits als zu hoch angesehen. Der Kommission wird insbesondere vorgeworfen, zu interventionistisch zu sein, den nationalen Regionalpolitiken nicht genügend Spielraum zu lassen bzw. sie durch das lange Prüfverfahren zu hemmen und damit ihre Kompetenzen aus dem EGV zu überschreiten ${ }^{324}$. So wird kritisiert, daß bei der Beurteilung nicht die regionalwirtschaftlichen Ziele der fördernden Institution, sondern die Beeinflussung des Marktes durch das geförderte Unternehmen im Vordergrund stehen 325 . Dies ist allerdings angesichts der wettbewerbspolitischen Zielsetzung der Beihilfenaufsicht, die einen Teil des konstitutiven Rahmens der Gemeinschaft bildet, kein stichhaltiger Kritikpunkt, da die Kommission bei der Beurteilung gerade prüfen muß, ob ein gefördertes Unternehmen durch überhöhte Beihilfen einen ungerechtfertigten Wettbewerbsvorteil im Markt erringt. Berechtigter erscheint schon die Kritik, daß die Kommission insbesondere in den letzten Jahren dem Konvergenzziel den Vorrang vor der Wettbewerbssicherung eingeräumt hat, indem sie bei der Genehmigung von Regionalförderprogrammen in den ärmeren MS zu großzügig handelte und andererseits die Regionalpolitik der reicheren MS zu stark einschränkte. Auf diese Weise seien Wettbewerbsverzerrungen und Handelsverlagerungen aufgetreten 326 . Die obigen Darlegungen haben gezeigt, daß Tendenzen in eine solche Richtung sicherlich zu beobachten waren 327 (und die Betrachtung der Automobilindustrie in Abschnitt 4.4. hat gezeigt, daß solche Verlagerungen tatsächlich auftraten), auf der anderen Seite sind auch in den reicheren MS noch bis zu einem Drittel des Staatsgebietes Förder-

324 Vgl. Yuill/Allen/Hull 1981, S. 310, und Rolfes 1991, S. 161f., 196f., der auch einzelne Positionen in der Literatur aufzeigt. Auch die Indikatorwahl bleibt nicht unwidersprochen, insbesondere die fehlende Berücksichtigung von potentialorientierten Indikatoren, wie z.B. Infrastrukturdaten oder der Ausschöpfung des Arbeitskräftepotentials, und der Verzicht auf die Verwendung von Kaufkraftstandards beim Vergleich der BIP-pro-Kopf-Werte zwischen den MS bei der Ermittlung der Grenzen nach Art. 92,IIIc. Vgl. Biehl 1988, S. 92, und Eser 1989,

325 Vgl. Eser 1989, S. 203.

326 Vgl. Eser 1989, S. 204.

327 Die Kommission selbst (1992a, S. 135) hebt die Bedeutung eines solchen Vorgehens mit dem Ziel der Förderung der ärmeren Regionen hervor. Diese Politik wird durch die Mittelkonzentration der EG-Strukturfonds auf die ärmeren MS noch verstärkt. Die Vergabe von allgemeinen Beihilfen, bspw. für FuE oder Umweltschutz, führt allerdings erfahrungsgemäß eher zu einer Unterstützung der reicheren Regionen, in denen z.B. Forschungseinrichtungen konzentriert sind. 
gebiet, und auch die Differenz der Förderintensität ist, wie in Abschn. 4.1.3 erläutert, geringer, als es die Obergrenzen vermuten lassen.

Eine Lösung zur Erweiterung des nationalen Spielraums wird darin gesehen, der Kommission zwar die Kompetenz zur Festlegung des in jedem MS förderfähigen Bevölkerungsanteils zu belassen, den MS jedoch die Auswahl der einzelnen Regionen zu überlassen, wobei die Kommission dann bei grober Verletzung der Gemeinschaftsinteressen in Einzelfällen intervenieren sollte 328 . Abgesehen davon, daß ein solcher Eingriff in Einzelfällen von den MS wohl als noch interventionistischer angesehen würde und ebenfalls eindeutiger und konsistenter Meßkriterien bedarf, öffnete die vorgeschlagene Vorgehensweise den MS für industriepolitische Eingriffe Tür und Tor. Zwar würde sicherlich im Sinne des Subsidiaritätsprinzips der Spielraum der MS zur Gestaltung einer eigenen Regionalpolitik und zur Setzung von Entwicklungszielen wesentlich erweitert. Zudem würde auch das Kontrollverfahren vereinfacht und beschleunigt, was den Investitionsanreiz in benachteiligten Regionen erhöhen würde. Auf der anderen Seite würde den MS die Möglichkeit an die Hand gegeben, bestimmte sehr eng definierte Regionen zu Fördergebieten zu erklären, um so bestimmte Unternehmen oder Branchen in diesen Regionen, die von der jeweiligen Regierung als strategisch angesehen werden, im Sinne einer aktiven Industriepolitik gezielt zu fördern mit entsprechend negativen wettbewerbspolitischen Auswirkungen ${ }^{329}$. Ein solch hoher Freiheitsgrad ist daher mit einem Gemeinsamen Markt unvereinbar.

Regionalpolitische Überlegungen spielten auch bei der Verteilung von Anpassungslasten eine Rolle, insbesondere der Schrumpfung alter Industrien, wie z.B. Stahl und Schiffbau. Hier mußte die Kommission auch die Dominanz des (sozialund regionalpolitischen) Verteilungsaspekts über Wettbewerbsfähigkeitsüberlegungen tolerieren, die die Strukturanpassung verschleppte 330 und ihr eine andere Gestalt gab, als es wettbewerbspolitische Kriterien verlangt hätten 331 . Ob diese Erhaltung schrumpfender Industrien in benachteiligten Regionen allerdings langfristig deren Entwicklung fördert, muß doch stark bezweifelt werden. Während die Schrumpfung

328 Vgl. Eser 1989, S. 215, und Rolfes 1991, S. 198-201.

329 Da gerade der letzte Aspekt z.T. bereits heute auftritt, ist die behauptete (vgl. bspw. Eekhoff 1993, S. 45f.) Sektorneutralität der Regionalförderung eher kritisch zu betrachten.

330 Vgl. Franzmeyer 1989, S. 144, und EG, Kommission 1990f, S. 7, sowie Eekhoff 1993, S. 48f.

331 Im Stahlbereich wurde zwar zur Rechtfertigung dessen mit positiven externen Effekten argumentiert (vgl. Abschnitt 4.3.3.3), doch basierten diese auf einer fragwürdigen QuasiZuteilung von Eigentumsrechten an bestehenden Kapazitäten. 
nämlich lediglich verzögert wurde, war der Anreiz zur Ansiedlung neuer Firmen aufgrund der geringeren Verfügbarkeit qualifizierter Arbeitnehmer vermindert.

Auch im Innenbereich der Kommission ergaben sich Auswirkungen der Regionalbeihilfenkontrolle v.a. dadurch, daß hier eine Konsistenz der Genehmigungskriterien der DG IV mit den Vergabekriterien für Regionalbeihilfen durch EFRE oder EIB notwendig wurde 332 .

\subsubsection{Subventionskontrolle und Außenhandelspolitik - Kommissions- vs. Ratskompetenz}

Ebenso wie innerhalb der Gemeinschaft, so findet auch im externen Bereich eine Vermischung zwischen Wettbewerbs- und Industriepolitik statt, die zudem noch durch die Vermischung von Kommissions- und Ratskompetenz verstärkt wird.

So konnte die Kommission ihre Beihilfenkontrollkompetenzen gegenüber den EFTA-Staaten, mit denen Freihandelsabkommen bestehen, erweitern, wie dies im Kfz-Sektor am augenfälligsten wurde. Sie war aber hier für Durchsetzungsmaßnahmen, wie z.B. Strafzölle, auf die Zustimmung des Rates angewiesen, bei dem wiederum andere als wettbewerbspolitische Motivationen im Vordergrund stehen. Mit dem Inkrafttreten des EWR-Abkommens hat sich diese Situation allerdings insoweit geändert, als mit der EFTA Surveillance Authority eine Behörde errichtet wurde, deren Kompetenzen denen der Kommission nachempfunden sind. Mittels gegenseitiger Informations- und Kooperationsverfahren sowie der Übernahme der spezifischen EG-Regeln zu einzelnen Beihilfetypen durch die EFTA wird der Geltungsbereich der EG-Beihilfenkontrolle quasi auf die EFTA-Staaten im EWR ausgedehnt ${ }^{333}$.

Die Möglichkeiten der Kommission, über strengere internationale Rahmen zur Beihilfenbegrenzung, wie über die OECD im Schiffbau oder das GATT im Stahl, den internen Widerstand einzelner MS gegen verschärfte interne Regeln auszuhebeln, sind ebenfalls beschränkt. Wiederum müssen die MS solchen Abkommen zustimmen, was häufig nur über Aufweichungen der Bestimmungen möglich wird. Die untersuchten Beispiele zeigten jedoch auch, daß die Beihilfenpolitik der Gemein-

332 Vgl. Lehner/Meiklejohn/Reichenbach 1991, S. 66f. Die Abgrenzung der Förderregionen ist allerdings nicht deckungsgleich zwischen nationalen und gemeinschaftlichen Förderregeln.

333 Vgl. Junginger-Dittel 1993, S. 5. Durch diese Erweiterung des Geltungsbereiches ist die Notwendigkeit handelspolitischer Abwehrmaßnahmen gegenüber diesen Ländern nicht mehr gegeben. Vgl. Ehlermann 1994, S. 426-429. 
schaft, soweit diese Außenwirkungen hat, nicht völlig autonom, sondern in internationale Rahmen eingebunden und damit limitiert ist ${ }^{334}$.

Den industriepolitischen Charakter am deutlichsten zeigen protektionistische Maßnahmen nach außen, mit denen die Kommission einerseits den Willen der MS zur Umstrukturierung und Beihilfenbegrenzung erkaufen, andererseits die subventionierte Umstrukturierung im Innenbereich absichern und ergänzen kann 335 . Dahinter dürfte die Absicht stecken, mittels dieses Schutzes verbunden mit nationaler und gemeinschaftlicher Forschungs- und Innovationsförderung und evtl. auch der wohlwollenden Duldung von Fusionen bestehende Wettbewerbsrückstände gegenüber außereuropäischen Konkurrenten aufzuholen ${ }^{336}$. Hier besteht allerdings neben einer verstärkten Politisierung ökonomischer Rivalitäten mit einer weiteren Entliberalisierung des internationalen Handels 337 die Gefahr, daß die gewünschte Umstrukturierung durch Verminderung des Konkurrenzdrucks im innern eher geschwächt bzw. der Druck nach außen verlagert wird 338 . Diese Deadweight losses durch zunehmende Monopolisierung wurden lange Zeit ebenso unterschätzt, wie die möglichen Gewinne aus steigenden Skalenerträgen und aus dem vermuteten höheren Innovationsgrad in großen Unternehmen überschätzt wurden 339 . Auch für solche Maßnahmen ist die Kommission von der Zustimmung des Rates abhängig, der hier allerdings i.d.R. wenig Widerstand leistete, vielmehr drängten protektionistische Kräfte in einigen MS geradezu auf solche Maßnahmen340. Die Bereitschaft, der Kommission dabei Spielraum zu geben, resultiert wohl aus der Erkenntnis, daß auf internationaler Ebene die Verhandlungsmacht einzelner MS wesentlich geringer gewesen

334 Vgl. Verreydt/Waelbroeck 1980, S. 24.

335 Vgl. Butt Philip 1983, S. 130, und 1986, S. 16, der dabei im Zusammenhang mit dem MFA von der Einführung einer Industriepolitik durch die Hintertür spricht. Aus Sicht der MS, die notleidende Industrien schützen wollen, haben Außenschutzmaßnahmen hier eine Ersatzfunktion für Beihilfen im Inneren. Vgl. Geister 1981, S. 186.

336 Vgl. Franzmeyer 1990, S. 160f., und Forschungsschwerpunkt Marktprozeß 1989, S. 11. Die Konzeption erinnert ein wenig an das in Kap. 2.1.4 dargelegte Infant-industry-Argument, mutet allerdings in den betrachteten reifen Industrien und bei Berücksichtigung der Größe der involvierten europäischen Unternehmen grotesk an.

337 Vgl. Zippel 1984, S. 20.

338 Vgl. Geister 1982, S. 215f., 1983, S. 165, und Mestmäcker 1987, S. 34. Beim Aufbau größerer Marktmacht über Fusionen leiden zudem häufig auch die Abnehmer der Produkte. Außerdem ist die Wettbewerbsfähigkeit großer Konzerne nicht notwendigerweise höher als die kleiner Einheiten. Vgl. Westphal 1984, S. 47f.

339 Diese Einstellung wurde durch einige empirische Studien aus den 50er Jahren noch verstärkt. Vgl. Geroski/Jacquemin 1985, S. 171-175.

340 Vgl. Franzmeyer 1990, S. 160f. 
wäre 341 . Möglicherweise ist hier allerdings aufgrund der zunehmenden weltwirtschaftlichen Verflechtung über Direktinvestitionen mit einer Wandlung zu rechnen. Da solche Direktinvestitionen von EG-Firmen häufig auch für den Reexport in die Gemeinschaft produzieren, besteht hier kein Interesse an Importrestriktionen 342 . Umgekehrt bietet die Möglichkeit solcher Direktinvestitionen, vermehrt jetzt auch in Osteuropa, den Unternehmen ein starkes Druckmittel, für Neu- oder Modernisierungsinvestitionen innerhalb der Gemeinschaft Beihilfen von ihren Regierungen zu fordern. Die Kommission dürfte dann wieder dem Druck ausgesetzt sein, solche Beihilfen verstärkt zu tolerieren.

Restriktive Außenhandelspolitiken machen allerdings auch die beschränkte Zielsetzung der gemeinschaftlichen Beihilfenkontrollpolitik deutlich: Sie ist lediglich auf die Bekämpfung von Wettbewerbsverzerrungen innerhalb der Gemeinschaft ausgerichtet und nimmt zur Durchsetzung dieses Ziels z.T. Verzerrungen gegenüber Drittlandskonkurrenten in Kauf.

\subsubsection{Subventionskontrolle als supranationale Lösung des Konflikts zwischen "freier Marktwirtschaft" und "Wohlfahrtsstaat"}

Die Erfolge der Beihilfenkontrolle während der letzten Jahre stehen sicherlich außer Zweifel. Mit der Intensivierung der Kontrolle im Zuge des Binnenmarktprojekts wurden Wettbewerbsverzerrungen erfolgreicher bekämpft. Die Politik der Kommission beweist, daß es für eine übernationale Stelle grundsätzlich möglich ist, die notwendige Koordinierung zwischen konfligierenden nationalen Industriepolitiken vorzunehmen und auch mit entsprechenden rechtlichen Kompetenzen durchzusetzen. Sie übt damit quasi in der Art eines Schiedsrichters einen Schutz des Wettbewerbs aus, der in keinem der MS auf nationaler Ebene existiert ${ }^{343}$. Es ist ausgesprochen unwahrscheinlich, daß ohne die Kontrolle der Kommission, so unvollkommen sie auch lange Zeit gewesen sein mag, das politische tolerierte Tempo der Strukturanpassung in den MS höher gewesen wäre 344 .

\footnotetext{
341 Vgl. Butt Philip 1986, S. 14.

342 Vgl. Herrmann 1989, S. 24.

343 Vgl. Caspari 1982, S. 1f., und Ehlermann 1992, S. 615. Allerdings ließe sich einwenden, daß auf nationaler Ebene eine demokratische Kontrolle und Abwägung von Beihilfen und ihren Zielen erfolgt, die dann zu akzeptablen Entscheidungen vom nationalen Standpunkt aus führt. Vgl. Caspari 1984, S. 23. Berücksichtigt man allerdings die zur politökonomischen Theorie der 344 Vgl. Franzmeyer 1981, S. 509.
} 
Mit der Intensivierung der Kontrolle hat sich diese allerdings auch tendenziell in Richtung auf eine Mischung aus Überwachung im strengen juristischen Sinne, prozeduraler und horizontaler Regulierung und sektoraler Orientierungsvorgabe, v.a. in Krisensektoren, gewandelt 345 . Die Kontrolle der Kommission sicherte eine Art "internationaler Transparenz"346 und hat die MS gezwungen, ihre Beihilfesysteme transparenter zu gestalten, in föderalen Staaten ist auch die innerstaatliche Information verbessert worden 347 . Zudem haben die Diskussionen im Rat in den Sektoren, in denen er wie im Schiffbau und im Stahl Zuständigkeiten besitzt, und in den multilateralen Sitzungen zu aktuellen Problemen, die in den letzten Jahren regelmäßig stattfanden, sicherlich dazu beigetragen, daß die MS bei der Formulierung ihrer Ziele die Gemeinschaftsperspektive besser im Auge behalten 348 .

Allerdings ist bei der Beurteilung der Dauerhaftigkeit dieses Erfolges auch in Betracht zu ziehen, daß die Jahre seit Ingangsetzung des Binnenmarktprojekts von einer günstigen gesamtwirtschaftlichen Entwicklung gekennzeichnet waren. Ob die Erfolge in einer langandauernden Rezession gehalten werden können, muß sich somit noch zeigen. Die Analyse der Kapitel 4 und 5 demonstrierte, daß die Wirksamkeit der Wettbewerbssicherung in der Vergangenheit zyklisch mit den sich wandelnden wirtschaftlichen Rahmenbedingungen schwankte. Die betrachteten Sektoren zeigten nicht nur, daß das von den MS gewährte Subventionsvolumen in Rezessionen stieg und in Boomphasen sank ${ }^{349}$, sondern auch, daß die Fähigkeit der Kommission zur Kontrolle dieser Beihilfen einer genau umgekehrten Entwicklung unterlag350. Beide Aspekte, also steigende Subventionierung und weniger wirksame Kontrolle in Krisen, sprechen gegen allokative Erklärungsansätze, die ja zu konjunkturunabhängiger Subventionierung führen würden, und eher für eine politökonomische Erklärung der Entwicklung bzw. eine konservative soziale Wohlfahrtsfunktion in den MS, die von der Kommission nicht in Frage gestellt wurde/werden konnte. Dieser Ansatz erklärt auch die massive Förderung von Großbetrieben gerade alter schrumpfender Industrien durch die MS.

Hierbei zeigten sich, wie oben gesehen, gewisse strukturelle Unterschiede zwischen dem Subventionierungsverhalten verschiedener MS. Während Länder, wie Italien, Frankreich und (früher) Großbritannien mit einem hohen Staatsanteil und

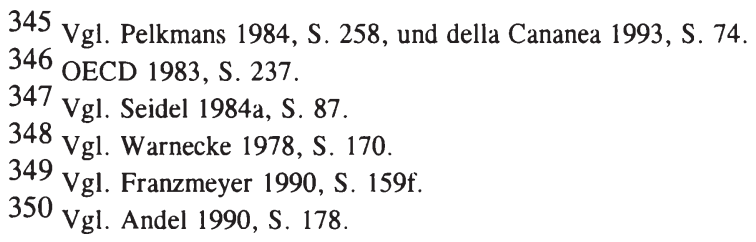


-einfluß in wichtigen Industrien mittels intensiver Subventionierung aber auch Regulierung dieser Industrien sozial- und regionalpolitische Ziele, bspw. Vollbeschäftigung in einer gegebenen Sektoral- und Regionalstruktur sowie allgemein die Stabilisierung des politischen Systems verfolgten, war dies in anderen MS, wie Dänemark, den Niederlanden, Deutschland (vor der Wiedervereinigung) oder auch Großbritannien (heute) nur in geringerem Maße der Fall. Trotz der Arbeiten der Kommission zur Kontrolle von Beihilfen gelang es in den Krisenphasen der Vergangenheit in den Problemindustrien nicht, den Einfluß der Hochsubventionierer auf die Industrieentwicklung in den gering subventionierenden Staaten zu eliminieren. Krauss 351 klassifiziert die beiden Ansätze als den "wohlfahrtsstaatlichen" und den des "freien Marktes" und erklärt die Ausbildung des wohlfahrtsstaatlichen Ansatzes mit der Unsicherheit in relativ kleinen offenen Volkswirtschaften aus der Weltmarktentwicklung. Wie die theoretische Analyse in Kapitel 2.2 zeigte, können einzelne Staaten durch Subventionierung ihre Wohlfahrt zu Lasten anderer Staaten erhöhen, so daß sich dann in den "freien Marktwirtschaften" die Frage einer adäquaten Antwort stellt. Eine mögliche Antwort, die die inländischen Produzenten fordern werden, ist ihre Gleichstellung mit den subventionierten Konkurrenten durch Zahlung von Beihilfen an sie 352 . Diese "Harmonisierung nach oben" ließ sich in den aufgezeigten Beispielen häufig beobachten ${ }^{353}$, vor allem da das alternative Mittel von Ausgleichszöllen in der Gemeinschaft nicht zur Verfügung steht, auch wenn die so erreichte Obergrenze wohl unter derjenigen in einer Situation ohne Kontrollinstrumente gelegen haben dürfte. Auf diese Weise gelang es den nationalen Regierungen, den akuten politischen Druck zu vermindern 354 . In Krauss' Terminologie paßt sich der freie Markt an den Wohlfahrtsstaat an 355 , wobei die strukturelle Anpassung der Industrie dadurch verzögert wird ${ }^{356}$. Die Alternative für einen einzelnen Staat besteht jedoch darin, den eigenen Produzenten diese Hilfen zu verweigern und den Wohlfahrtsverlust als Preis für die Erhaltung des eigenen politischökonomischen Systems zu zahlen, u.U. in der Hoffnung, daß der Druck der subventionierten Konkurrenz die eigenen Firmen zu noch stärkeren Rationalisierungsanstrengungen zwingen wird und sich damit langfristig die Wohlfahrt erhöht. Auch

351 1979, S. $93 \mathrm{f}$.

352 Vgl. Müller 1983, S. 263.

353 Allerdings ist wohl anzuzweifeln, daß es sich hierbei in allen Fällen um Antworten auf solch "optimale" Beggar-thy-neighbour-Beihilfen der Partnerstaaten handelte.

354 Vgl. Curzon Price 1986, S. 218.

355 Vgl. Krauss 1979, S. 95.

356 Vgl. Müller 1983, S. 263. 
wenn Ansätze zu solchem Verhalten in einigen MS partiell zu beobachten waren, so legen die bisherigen Erfahrungen in Bestätigung der Ansätze aus Kap. 2.3 doch nahe, daß solches Verhalten in wirklichen Krisensituationen nicht durchzuhalten ist. Die supranationale Variante zur Lösung des Problems liegt in der Durchsetzung einer Beschränkung durch eine übergeordnete Kontrollinstanz. Während Krauss 357 hier vor allem an eine massive Stärkung des GATT denkt, ihr jedoch aufgrund des fehlenden politischen Willens der Vertragsparteien die Durchsetzungsmöglichkeit abspricht, hat die EG genau diesen Ansatz auf einer regionalen Ebene umzusetzen versucht.

Da neben der Wettbewerbssicherung die EG auch noch andere Ziele verfolgt, ist es unvermeidbar, daß neben ökonomischen Beurteilungen auch gesellschaftliche und politische Notwendigkeiten in die Entscheidungsfindung einflossen und auch weiterhin einfließen ${ }^{358}$. Eine explizite Einführung beschränkender politischer Auflagen für die Beihilfenkontrolle über eine Ratsverordnung nach Art. 94, wie sie 1990 von Italien gefordert und einigen anderen MS unterstützt wurde, konnte von der Kommission mit Unterstützung anderer MS immerhin verhindert werden 359 . Die Entwicklung der Subventionskontrolle zeigt aber auch, wie weit die Integration und der Souveränitätstransfer (einschl. der Unterwerfung unter die Entscheidungen eines übernationalen Gerichtes) gehen müssen, um effektiv zu sein 360 . Konflikte aus der Tatsache, daß die wirtschaftspolitische Kompetenz zwar weiterhin bei den MS verbleibt und laut EGV lediglich einer Koordinierungspflicht unterworfen ist ${ }^{361}$, ein wichtiges Element dieser Kompetenz, nämlich die Vergabe von Subventionen, jedoch der Kontrolle der Kommission unterliegt, werden jedoch weiterhin unvermeidlich bleiben 362 . Nachdem die Analyse in Kap. 4 und 5 diese Konflikte und die aufgetretenen Probleme aufgezeigt hat, soll das folgende Schlußkapitel sich der Frage widmen, inwieweit durch Reformen verschiedener Radikalität der Erfolg dieses supranationalen Ansatzes verbessert werden kann.

357 1979, S. 95f

358 Vgl. Mathijsen 1975, S. 187, und Caspari 1987, S. 89f., sowie Chard/Macmillen 1979, S. 133.

359 Vgl. FAZ 1990a.

360 Vgl. Curzon Price 1986, S. 219.

361 Vgl. Seidel 1984a, S. 88.

362 Vgl. Thies 1989, S. 9. 
Manfred Rosenstock - 978-3-631-75198-5

Downloaded from PubFactory at 01/11/2019 07:13:36AM

via free access 
However, harmonisation is a positive act which requires not only concerted action but also, in a number of areas, a certain degree of political commitment with implications for the sensitive issue of sovereignty

A.M. El-Agraa 1

\section{MöGLICHE REFORMANSÄTZE UND ALTERNATIVEN ZUR JETZIGEN REGELUNG}

Die bisherigen Darlegungen haben deutlich gemacht, daß eine effektive wettbewerbspolitische Kontrolle der Subventionsvergabe der MS durch die Kommission nicht in allen Fällen gelang. Die Kommission hatte lange Zeit Schwierigkeiten dabei, die Einhaltung der Vertragsregeln durch die MS durchzusetzen; sie unterlag bei der Festsetzung ihrer Beurteilungskriterien industriepolitisch motiviertem Druck durch die MS und versuchte zum Teil selbst industriepolitische Strategien durchzusetzen, die über den eigentlichen wettbewerbspolitischen Auftrag hinausgingen. Sie hatte zudem Probleme bei der Durchsetzung der von ihr getroffenen Entscheidungen. Wettbewerbs- und Handelsverzerrungen ließen sich daher nicht immer vermeiden. Schließlich war auch die Transparenz der Kommissionsentscheidungen zur Subventionskontrolle nicht immer gegeben. Die letzten Jahre seit Ingangsetzung des Binnenmarktprojekts haben in allen diesen Bereichen signifikante Verbesserungen gebracht, jedoch traten bei sensiblen Einzelfällen oder Subventionsbereichen immer wieder Probleme für die Kommission auf.

\subsection{Generelles Subventionsverbot}

Der radikalste Ansatz zur Lösung dieser Probleme bestünde sicherlich in einem absoluten Subventionsverbot. Eine solche Vorgehensweise würde intransparente Prüfverfahren ebenso ausschließen wie Versuche einer industriepolitischen Einflußnahme ${ }^{2}$. Es bleiben jedoch zwei Fragen bei der Beurteilung dieser scheinbar einfachen Lösung offen: Ist sie sinnvoll, d.h. theoretisch zu rechtfertigen? und: Ist sie realistisch, d.h. politisch durchsetzbar?

\footnotetext{
1 1982, S. 266.

2 In den Worten von Caspari (1984, S. 102) "gäbe es weniger europäische Spannungen" in einer solchen Situation.
} 
Bei Heranziehung der allokativen Argumente für Subventionen, insbesondere des Externalitätenansatzes, der v.a. auf FuE-Beihilfen, eine Förderung der Regionalentwicklung und in dynamischer Betrachtung auf die Förderung der Infant industries anwendbar ist (vgl. oben Abschn. 2.1.2 und 2.1.3), scheint die erste Frage mit einem klaren Nein zu beantworten zu sein. Jedoch wird in der theoretischen Diskussion auch die gegenteilige Auffassung vertreten. Sie stützt sich auf das Argument, daß die behaupteten Externalitäten gering seien bzw. daß in irgendeiner Art alle Industrien positive Externalitäten erzeugen, bspw. im Ausbildungsbereich. Existierten hingegen signifikante positive externe Effekte bestimmter Tätigkeiten, so sei der Öffentlich-Guts-Charakter dieser Tätigkeit so groß, daß die Bereitstellung ohnehin staatlicherseits erfolge, wobei als Beispiel die Straßenbeleuchtung genannt wird 3 . Diese Behauptung in ihrem allgemeinen Charakter kann sicherlich weder pauschal verworfen noch akzeptiert werden, sondern ist in jedem Einzelfall zu beurteilen. Gerade im Bereich der industriellen Grundlagenforschung ist jedoch m.E. mit hohen positiven Externalitäten zu rechnen, während andererseits der Unsicherheitsgrad für das forschende Unternehmen sehr groß ist. Aus dem letzten Grund sind hier auch vielfach kooperative Forschungsvorhaben verschiedener Unternehmen zu beobachten. Diese Argumentationslinie liefert also keine uneingeschränkte Rechtfertigung für ein absolutes Subventionsverbot, spricht jedoch für eine strenge Prüfung des Externalitätenarguments in jedem Einzelfall. Angesichts des begrenzten Auftrages der Kommission, den unverzerrten Handel und Wettbewerb zwischen den MS zu sichern, ist hier noch eine weitere Einschränkung zu machen. Solche Subventionen, die nationale Ziele fördern, ohne einen Einfluß auf den innergemeinschaftlichen Handel zu haben, sind auf Gemeinschaftsebene harmlos und wären damit auch keinem Verbot zu unterwerfen, selbst wenn keine allokativen Rechtfertigungen für sie vorliegen 4 . Allerdings wäre hier aus allokativer Sicht möglicherweise ein Eingriff auf nationaler Ebene nötig. In diesem Zusammenhang ist vor allem an lokale Beihilfen für KMU zu denken.

Ein anderer Ansatz zur Rechtfertigung eines absoluten Subventionsverbots stützt sich auf die politökonomischen Konzepte aus Abschnitt 2.3. Er anerkennt die Existenz von Marktversagen, sieht aber gleichzeitig einen politischen Spielraum zu ihrer Korrektur als gefährlich an, da dieser den Unternehmen einen Anreiz böte, ihre eigene Situation möglichst schlecht darzustellen bzw. auch nicht durch eigene Anstrengung zu verbessern, um auf diese Weise mehr Beihilfen zu bekommen. Es

\footnotetext{
3 Vgl. Curzon Price 1986, S. 208.

4 Vgl. Cownie 1986, S. 248.
} 
bestünde vielmehr im Sinne des Rent-seeking-Ansatzes ein Anreiz, in Lobby-Aktivitäten zu investieren, was zu allokativen Ineffizienzen führen würde ${ }^{5}$. Als Lösung dieses Problems wird ein Subventionsverbot gesehen. Eine andere Möglichkeit zur Umgehung des Rent-seeking-Problems bestünde in der Festlegung fixer Vergaberegeln ohne Ermessensspielräume.

Ein weiteres Argument für ein absolutes Subventionsverbot liegt in der faktischen Unsicherheit, unter der staatliche Eingriffe vorgenommen werden, während die Subventionsrechtfertigungen aus Abschnitt 2.1 immer vollkommene Information oder bessere Information des Staates unterstellen. Aus diesem Grund glichen gerade staatliche Maßnahmen zur Förderung der Anpassung immer einem "Stochern im Nebel", da zum Zeitpunkt ihres Ergreifens der wahre Umfang von Verzerrungen und Problemen unbekannt ist und sich erst im Laufe des Prozesses herausstellt. Wenn dies so ist, sind Eingriffe möglicherweise schädlich. Sie können vorhandene Strukturprobleme sogar intensivieren, v.a. wenn punktuelle Eingriffe an mehreren Stellen gleichzeitig und in inkonsistenter Weise vorgenommen werden 6 .

Aus allokationstheoretischer Sicht lassen sich also sowohl Argumente für als auch gegen ein absolutes Subventionsverbot ableiten. Aber selbst wenn ein klares Argument für ein Verbot vorläge, so wären die Möglichkeiten zu seiner Durchsetzung in einem System, wie es die Gemeinschaft darstellt, außerordentlich zweifelhaft. Die Möglichkeit der Vergabe von Beihilfen wird von allen MS als wesentliches Instrument der nationalen Wirtschaftspolitik, vor allem auch zur Bekämpfung konjunktureller und sozialer Probleme angesehen, dessen Blockierung nicht toleriert würde 7 . Zudem bestünde die Gefahr, daß andere Restriktionen dann vermehrt aufträten ${ }^{8}$. Die Einführung von Quoten oder VERs wäre zwar in der EU kaum denkbar, aber im Bereich der öffentlichen Aufträge bestehen sicherlich trotz der Harmonisierungsrichtlinien noch Spielräume. Zudem besteht auf lokaler und regionaler Ebene die Möglichkeit zur Gewährung von Unterstützung über günstige Grundstückstransaktionen oder spezielle Verkehrs- oder Stromtarife. Diese Maßnahmen sind noch wesentlich intransparenter als die üblichen Formen von Beihilfen ${ }^{9}$. Zwar hat die Kommission hier in Einzelfällen schon eingegriffen, aber die Kontrolle solcher Maß-

\footnotetext{
5 Vgl. Hiemenz/Weiss 1984, S. 15, und Curzon Price 1986, S. $204 \mathrm{f}$.

6 Vgl. Malmgren 1978, S. 229f.

7 Vgl. Beutler et al. 1987, S. 357. Gilchrist/Deacon (1990, S. 48) weisen ebenfalls darauf hin, daß eine solche Maßnahme, selbst wenn sie auf Großunternehmen beschränkt wäre, höchstwahrscheinlich einer Ratszustimmung bedürfte.

8 Vgl. Andel 1970, S. 126 und 141f.

9 Vgl. Deacon 1990, S. 67.
} 
nahmen gestaltet sich gerade in föderalen Systemen oder bei Staatsbetrieben extrem schwierig. Solche Ausweichreaktionen der MS bei einem absoluten Subventionsverbot würden für die Kommission das Definitionsproblem des Vorliegens von Beihilfen noch vergrößern, bei dem sie schon in der Vergangenheit dem Einfallsreichtum der MS zum Teil hinterherlief.

Die oben untersuchten Beispiele der Stahlindustrie und des Kohlebergbaus liefern einen Anschauungsunterricht der Folgen eines absoluten Beihilfenverbots, wie es der EGKS-Vertrag vorsieht. Bereits in der Kohlekrise der 60er Jahre wurde dieses Verbot umgedeutet, in der Stahlkrise wurden zunächst formal "allgemeine" Maßnahmen aus dem Verbot wegdefiniert, und später hatte die Kommission große Probleme bei der Klassifizierung von Verlustausgleichen und Kapitalzuführungen als Beihilfen. In beiden Sektoren wurde das Verbot von den MS umgangen, da es politisch nicht tolerierbar war, und die Kommission mußte diese Entwicklung hinnehmen. Nachdem das absolute Verbot erst gefallen war, trat ein weiteres Problem deutlich zutage: Im Gegensatz zum EWGV fehlten nun Regeln zum Kontrollverfahren, die erst später durch die Kodizes etabliert werden konnten. Es überrascht daher nicht, daß die Subventionsvergabe und -kontrolle nirgendwo so außer Kontrolle geraten ist wie gerade im Stahlsektor ${ }^{10}$. Das absolute Verbot wurde dann zur "historisch überholten Rechtslage" 11 deklariert, die großzügig angepaßt wurde.

Als Konsequenz aus diesen Betrachtungen ergibt sich, daß ein absolutes Subventionsverbot, insbesondere in von den MS als wichtig angesehenen Sektoren, nicht durchsetzbar ist. Ein Verbot aber, das nicht eingehalten wird, untergräbt die Autorität der dieses Verbot aussprechenden Behörde. Daher muß man Regeln finden, die auf ein absolutes Verbot verzichten, aber die Möglichkeit einer klaren Kanalisierung und Beschränkung der Beihilfenvergabe bieten ${ }^{12}$.

\subsection{Zentralisierung der Subventionen}

Da ein generelles Verbot von Beihilfen aus den oben angeführten Gründen heraus weder wünschenswert noch durchsetzbar ist, wäre als Alternative angesichts des potentiell protektionistischen Charakters nationaler Subventionen eine Lösung in Analogie zu den ebenfalls protektionistischen Zöllen denkbar: Sie würde eine schrittweise Beseitigung der nationalen Subventionen, des nach der weitgehenden Abschaffung anderer Handelshemmnisse einzig verbliebenen Instruments des Pro-

\footnotetext{
10 Vgl. Caspari 1987, S. 83, 89.

11 Schlieder/Schröter 1981, S. 501.

12 Vgl. Stotz 1983, S. 260.
} 
tektionismus ${ }^{13}$, und ihre Ersetzung durch eine zentrale Befugnis zur Subventionsvergabe seitens der Kommission beinhalten, die durch eine Gleichbehandlung der Unternehmen aus allen MS regionale Wettbewerbsverzerrungen verhindert ${ }^{14}$. Tinbergen 15 spricht in diesem Zusammenhang von der Notwendigkeit der "negativen Zentralisierung konfligierender Instrumente" zur Verwirklichung einer optimalen Wirtschaftspolitik, d.h. hier zur Verhinderung eines Subventionswettlaufs und der Konterkarierung der Wirtschaftspolitik der Zentralebene durch diejenigen der untergeordneten Ebenen.

Die Subventionspolitik der Zentralebene kann sowohl allokative als auch distributive und konjunkturpolitische Motivationen besitzen. Ein Argument für einen solchen Zentralisierungsansatz anstelle eines völligen Verbots besteht jedoch darin, daß Subventionen allokativ gerechtfertigt sein können. Da aber externe Effekte auf allen Ebenen auftreten können, würde dies auch für eine ebensolche Kompensation sprechen, die dann auf gesetzlicher Basis über Steuern/Subventionen oder auf vertraglicher Basis zwischen Verursachern und Betroffenen stattfinden würde16. Da hier auf lokaler Ebene das Problem der Erfassung und Organisation der Betroffenen sowie der Durchsetzung der Kompensation entsteht, vor allem wenn die Effekte viele Individuen betreffen und politische und administrative Grenzen überschreiten, wäre eine zentrale Kompensation nach einheitlichen Kriterien als zweitbeste Lösung akzeptabel17. Im FuE-Bereich, v.a. bei der Grundlagenforschung, wird die Auffassung vertreten, daß bei der Integration von Staaten mit ähnlichem technologischem Niveau positive Spillovers zum guten Teil transnational sind und somit eine zentrale Förderung sogar optimal wäre ${ }^{18}$. Vor allem für den Bereich der Regionalpolitik läßt sich hingegen argumentieren, daß die Probleme der Ballungskosten und die adäquaten Maßnahmen auf nationaler oder auch regionaler Ebene besser festzustellen seien. Andererseits wurde weiter oben (vgl. Abschnitt 5.4.5) auch das Problem angesprochen, daß MS unter dem Deckmantel der Regionalförderung eine sektorale Industriepolitik betreiben könnten, was wiederum

13 Vgl. Deacon 1990, S. 71.

14 Vgl. Geister 1981, S. 23, und Poelmans 1970, S. 302. Die letztgenannte Autorin sieht eine solche Lösung sogar als notwendig zur Erreichung gleicher Wettbewerbsbedingungen in der Gemeinschaft an.

15 1954, S. 75 (Übersetzung des Verfassers).

16 Ähnlich für öffentliche Güter argumentiert Oates 1972, S. 33-36.

17 Vgl. Oates 1972, S. 68-71.

18 Vgl. Olson 1977, S. 69. 
für eine Zentralisierung der Regionalpolitik zur Vermeidung dadurch verursachter Verzerrungen spräche.

Häufiger jedoch wird die Forderung nach Zentralisierung als Teil einer gemeinschaftlichen Industriepolitik zur Verbesserung der sektoralen Struktur der europäischen Wirtschaft erhoben ${ }^{19}$. Sie bezieht sich dabei auf Krisensektoren ebenso wie auf sog. Zukunftsindustrien.

In Krisensektoren sollen dabei Subventionen als Teil einer Europäischen Industriepolitik den Zusammenbruch wichtiger Branchen verhindern ${ }^{20}$. In der oben (s. Abschnitt 5.4.3) diskutierten Situation eines schrumpfenden Oligopolmarktes mit Austrittsschranken wäre eine zentrale Anpassungsstrategie optimal mit einer ebenso zentralen Festlegung der Zahlungen zur Schaffung von Ersatzarbeitsplätzen und für Abfindungen an diejenigen MS, die Kapazitäten opfern müßten, da der Gewinn aus den Schließungen allen MS zukommt. Solche Zahlungen hätten dann durch den ESF oder den EFRE zu erfolgen 21 . Diese Strategie wäre allokativ besser als die in der Vergangenheit durchgeführten gleichmäßigen Kapazitätsschließungen ohne Umverteilung der Gewinne und könnte den Strukturwandel fördern.

Für Spitzentechnologien mit starker Auswirkung auf andere Branchen, wie etwa Halbleiter, ist die Forderung nach einer zentralen Forschungsförderung mit EG-Beihilfen verbreitet, um hier ein japanisches Monopol mit entsprechender Preis- und (restriktiver) Mengensetzung zu verhindern, das die europäische Wohlfahrt stärker vermindern würde als ein inländisches Monopol22. Eine Lösung wird dabei in der Schaffung eines Euro-MITI mit zentraler Zielvorgabe und Förderung sowie Koordination der Forschungsaktivitäten gesehen ${ }^{23}$. Wie bereits oben erläutert, stellt sich dabei das Problem der korrekten Festlegung der wichtigen Bereiche (Informationsproblem), die einen besseren Informationsstand des Euro-MITI gegenüber den Marktteilnehmern voraussetzt ${ }^{24}$. Um überhaupt eine Aussicht auf Erfolg zu bieten, würde dieser Ansatz zudem eine hohe Konzentration von Wissen über wirtschaftliche Entwicklungen auf der Kommissionsebene verbunden mit einer erheblichen Personalaufstockung und einer Verlagerung von Finanzmitteln in großem

\footnotetext{
19 Vgl. Poelmans 1970, S. 313-315.

20 Diese Forderung wird bspw. vom EP erhoben. Vgl. Woche im Bundestag 1990, S. 38.

21 Vgl. Geroski/Jacquemin 1985, S. 205.

22 Vgl. Meyer 1992, S. 154f.

23 Vgl. Erlei 1992, S. 56f.

24 Vgl. Curzon Price 1990, S. $161 \mathrm{f}$.
} 
Umfang auf den EG-Haushalt erfordern 25 . Zur Umsetzung wäre bspw. eine detaillierte Strukturberichterstattung einschl. einer Investitionsmeldepflicht nötig, die als eine Vorstufe zur Investitionslenkung ordnungspolitisch sehr bedenklich ist ${ }^{26}$. Auch der dynamische Effekt eines solchen Vorgehens auf die Industrie wird negativ gesehen, da bei einer solchen Zielsetzung von staatlicher Seite jeder Mittelbedarf geleistet wird, was Ineffizienzen fördert, während gleichzeitig die japanische Industrie wegen ihrer bereits geleisteten FuE-Aufwendungen (sunk costs) einen Preissenkungssprielraum besitzt, so daß die europäischen Firmen nie wettbewerbsfähig werden 27 . Obwohl hier eine allokative Rechtfertigung für eine Zentralisierung vorliegen kann, ist doch mit starken Problemen der Umsetzung zu rechnen. Dennoch besteht im gemeinschaftlichen FuE-Bereich seit 1986 die Tendenz zu einer derartigen Politik mit einer Verlagerung von Kompetenzen auf die EG-Ebene (gemeinschaftliche Forschungsprogramme) und der Vergabe von Subventionen aus dem EG-Haushalt. Damit stehen der Gemeinschaft hier erstmalig nennenswerte Mittel für eine eigene Industriepolitik zur Verfügung. Mit der EUREKA-Initiative gehen solche Ansätze gleichzeitig über die Gemeinschaftsgrenzen hinaus.

Würde man diese Tendenzen bis zum Endpunkt einer Verlagerung der gesamten Subventionskompetenz auf die Gemeinschaftsebene weiterführen, so stellt sich die Frage, ob dies weiterhin mit einer wettbewerblichen Kontrolle der Beihilfenvergabe kompatibel wäre. Analog zur Argumentation, die häufig gegen eine Notwendigkeit einer Kontrolle von Beihilfen auf nationaler Ebene verwandt wird, nämlich daß im politisch-parlamentarischen Prozeß bereits die negativen Auswirkungen auf andere Unternehmen berücksichtigt würden 28 , wäre eine solche Kontrolle im Prinzip nicht nötig. Auch von juristischer Seite wird angeführt, daß die EG-eigene Beihilfenvergabe als Element der Wirtschaftspolitik bei entsprechender Beteiligung des EP eine gerichtliche Kontrolle im Prinzip ausschlösse ${ }^{29}$. Dennoch existiert sicherlich die Gefahr nationaler Bevorzugungen bei der Vergabeentscheidung oder auch nur des

25 Vgl. Schatz 1984, S. 98, und Geister 1981, S. 125f.

26 Vgl. Geister 1981, S. 120 und 122f., der darauf hinweist, daß solche Konzepte für industrielle Entwicklungsverträge in High-tech-Industrien bereits 1972 getestet wurden, aber gescheitert sind.

27 Vgl. Meyer 1992, S. 154f.

28 Vgl. Petersen 1993, S. 20.

29 Vgl. Seidel 1984, S. 59. 
Eindrucks, daß dies geschähe. In einem solchen Fall bestünde das Risiko, daß die MS kompensierend eingriffen 30 .

Aus diesen Überlegungen würde auch eine zentrale Subventionierungskompetenz eine parallele Wettbewerbskontrolle verlangen. Schon jetzt hält sich die EG bei gemeinschaftlichen Subventionierungsentscheidungen informell an die Regeln des Art. 9231. Bei einer Zentralisierung der Beihilfenvergabe wäre allerdings die Erfassung leichter. Jedoch gilt hier ebenso wie in Abschnitt 6.1, daß die MS Ausweichmöglichkeiten besitzen und die Kontrolle der Gemeinden, die auf Investitionsentscheidungen der Unternehmen einen starken Einfluß nehmen können, schwierig bleibt.

Selbst wenn eine wettbewerbliche Kontrolle erhalten werden könnte, so stellt sich die Frage, ob die Subventionierung rationaler und begrenzter abliefe, wenn Vergabe und Kontrolle auf der gleichen Ebene stattfänden. Hier sind Zweifel angebracht. Neben der Frage, welche Seite kommissionsintern die Oberhand gewänne, ist auch weiterhin mit immensem Druck der MS zur Weiterführung von Subventionen für viele Industrien insbesondere in Krisenzeiten zu rechnen 32 . Auch die Rent-seekingAktivitäten der Unternehmen würden dann lediglich auf die Zentralebene verlagert, wobei nicht damit zu rechnen ist, daß diese Ebene nunmehr in ihrer aktiven politischen Rolle anders reagieren würde, als es die nationalen oder regionalen politischen Ebenen bisher taten 33 .

Eine weitere Verlagerung hin zur Gemeinschaftsebene, gar zu einer ausschließlichen EG-Subventionskompetenz, dürfte allerdings schon am massiven Widerstand der MS scheitern ${ }^{34}$. Dies gilt insbesondere angesichts des hohen Gewichts, das dem Subsidiaritätsprinzip in der jüngsten politischen Diskussion und auch im Vertrag von Maastricht beigemessen wird.

30 Diese Gefahr ist bereits dann akut, wenn die MS die Gemeinschaftsinterventionen als unzureichend ansehen. So wurde bspw. im Stahlbereich, wo die Kommission eine - wenn auch nicht exklusive - Subventionskompetenz hat, diese von den MS weit übertroffen. Vgl. Geister 1981, S. $162 f$.

31 Vgl. Reichenbach 1993, S. 14, und Schlieder/Schröter 1981, S. 503.

32 Swann (1983, S. 178) beschreibt die mögliche Entwicklung sehr treffend: "politics would fly in at the door and economics would fly out of the window."

33 Der Stahlbereich, in dem die Kommission eine stärker gestaltende Rolle besitzt, bietet hier anschauliche Beispiele. Vgl. Swann 1983, S. 181. Dasselbe gilt für die Landwirtschaft, in der die Subventionsvergabekompetenz sehr stark zentralisiert ist.

34 Vgl. Swann 1983, S. 180. 
Eine Rechtsgrundlage für einen solchen Schritt ist im EGV ohnehin nicht vorhanden, da dies z.B. auch die Verpflichtung der MS zur Zahlung von Beihilfen im Rahmen einer gemeinsamen Wirtschaftspolitik beinhalten würde 35 . Ein anschauliches Beispiel für den Widerstand der MS bietet z.B. das Schicksal der gescheiterten ursprünglichen 1. RL für Schiffbaubeihilfen von 1965 (vgl. oben Abschnitt 4.2.3.1).

Daneben muß man sich vergegenwärtigen, daß die Unterwerfung souveräner Staaten unter die externe Kontrolle eines wichtigen wirtschaftspolitischen Instruments in dem Ausmaß, wie es bei der Beihilfenkontrolle in der EG der Fall ist, ohnehin ein einmaliges Phänomen ist, vor allem wenn man bedenkt, daß die Gemeinschaft lediglich ein präföderales Gebilde darstellt. Selbst in vollentwickelten föderalen Staaten existiert eine derartige Kontrolle der Gliedstaaten durch den Zentralstaat nicht ${ }^{36}$. Eine noch weitergehende vollständige Zentralisierung der Subventionskompetenz ist selbst in föderalen Staaten nicht denkbar und dementsprechend auch in der Gemeinschaft unrealistisch. Daher dürfte wohl auch weiterhin eine nationale Industriepolitik neben einer Koordination über die EGWettbewerbspolitik zur Erhaltung der integrationspolitisch gebotenen Abstimmung bestehen. Dies gilt nicht zuletzt angesichts der zwischen den MS sehr unterschiedlichen Subventionsvergabestrukturen und -methoden, die unterschiedliche politische Präferenzen und Kulturen zeigen ${ }^{37}$. Eine Zentralisierung dieser Formen bedingte eine Vereinheitlichung, die deshalb heute schwer erreichbar sein dürfte.

\subsection{Aufteilung der Subventionskompetenz auf verschiedene Ebenen mit Höchstgrenzen}

Auch die Zentralisierungslösung der Subventionsvergabe wird somit aufgrund der hohen Informationsanforderungen an die Kommission ineffizient und aufgrund des Verstoßes gegen das Subsidiaritätsprinzip nicht zu verwirklichen sein. Eine mögliche Lösung dieses Problems bestünde darin zu versuchen, die Subventionierungskompetenz in der Art eines Trennsystems auf die verschiedenen politisch-administrativen Ebenen optimal so aufzuteilen, daß in jedem Bereich nur jeweils eine Ebene exklusiv fördert.

Zunächst könnte die Kommission anerkennen, daß bestimmte Beihilfen v.a. lokaler Körperschaften de facto keine Wirkung auf den innergemeinschaftlichen Wett-

35 Vgl. Geister 1982, S. 213 und 217, sowie Seidel 1984, S. 59, 81.

36 Vgl. Thies 1989, Annex 1, S. 1, und Färber 1993, S. 7.

37 Färber (1993, S. 141-153) zeigt diese Unterschiede mittels eines Vergleichs zwischen Deutschland, Frankreich und Großbritannien auf. 
bewerb und Handel besitzen. Aus dieser Einsicht heraus wären Beihilfen geringer Intensität unschädlich und könnten den MS und ihren Regionen ohne Prüfung überlassen werden ${ }^{38}$, da sie den wettbewerbspolitischen Auftrag der Beihilfenkontrolle nicht berühren. Mit der Einführung der De-minimis-Regelung wird dieser Gedanke bereits zum Teil in die Tat umgesetzt ${ }^{39}$, wobei die Höchstgrenze recht restriktiv gewählt zu sein scheint. Auch der Gemeinschaftsrahmen für Beihilfen an KMU, der nach Genehmigung des Programms durch die Kommission solche Beihilfen ohne Überprüfung der Einzelfälle bis zu den von der Kommission definierten Höchstgrenzen erlaubt, entspringt der gleichen Motivation. Daneben ist die oben angesprochene administrative Überlastung von DG IV sicherlich ein wichtiger Grund für die Einführung solcher Regeln. Der Gefahr, daß Großunternehmen den KMU-Rahmen mißbrauchen, indem sie Tochterunternehmen als KMU gründen, wurde durch eine Regel zur höchstmöglichen Beteiligung solcher Unternehmen verhindert ${ }^{40}$.

Akzeptiert man im Bereich der Regionalpolitik das o.a. Argument, daß allokative Spillovers am besten auf der nationalen oder regionalen Ebene erkannt und korrigiert werden können, so spräche dies für eine Zuweisung der Kompetenz für eine Regionalpolitik auf die MS oder nachgeordnete Ebenen mit einer geringstmöglichen Beeinflussung durch die Kommission. Dies könnte bspw. bedeuten, daß die Kommission nur die Einhaltung der Grundsätze sichert, jedoch den MS die Auswahl der Fördergebiete überläßt. Sie könnte dann lediglich im Vollzug gegen einzelne Maßnahmen der MS einschreiten, die die Grundsätze verletzten 41 . Die Probleme dieser Vorgehensweise wurden bereits in den Abschnitten 6.2 und 5.4.6 erläutert. Um den MS eine effektive Regionalpolitik zu erlauben, würde anstelle der Projektförderung des EFRE ein allgemeiner Finanzausgleich treten.

Umgekehrt würde dann die FuE-Förderung exklusiv auf Gemeinschaftsebene angesiedelt, sofern man die oben erwähnten Informationsprobleme überwinden könnte, da hier, v.a. im Bereich der Grundlagenforschung, weitgehend mit transnationalen externen Effekten zu rechnen ist. Bereits heute sind (subventionierte) Forschungskooperationen, wie es die EG- und EUREKA-Projekte zeigen, weitgehend grenzüberschreitend organisiert.

38 Vgl. Gilchrist/Deacon 1990, S. 45.

39 Vgl. Petersen 1993, S. 21.

40 Vgl. Gilchrist/Deacon 1990, S. 48.

41 Vgl. Rolfes 1991, S. 196-200. 
Eine solche Kompetenztrennung wäre ein Versuch, sich an föderalismustheoretischen Argumenten zu orientieren 42 und gleichzeitig den Grad der Subsidiarität, vor allem im Regionalförderbereich zu erhöhen. Ein solches System erscheint jedoch generell als zu starr, weil es sehr pauschal Höchstgrenzen definieren müßte, unterhalb derer kein Eingriff erfolgte, da keine Wettbewerbsverzerrung vorliegt. Einzelfallbetrachtungen wären dann ausgeschlossen. Auch die Zuordnung auf die jeweiligen Ebenen kann problematisch sein, da bspw. einerseits in zunehmendem Maße interregionale externe Effekte erkannt werden, die nationale Grenzen überschreiten und damit ein Eingreifen auf supranationaler Ebene nahelegen, und andererseits aufgrund der hohen Mobilität von Investitionen externe Wirkungen einer zu großzügigen unkontrollierten nationalen Regionalpolitik, die industriepolitische Ziele verfolgt, auftreten werden. Umgekehrt kann im FuE-Bereich nicht immer mit übernationalen externen Effekten gerechnet werden, und der Umweltbereich bietet sicherlich das beste Beispiel dafür, daß bei Anwendung des Gemeinlastprinzips über die Vergabe von Subventionen der Kreis der zu erfassenden Gemeinschaft je nach Problem stark variiert. Schließlich ist angesichts der in Kap. 5.3 dargelegten Tatsache, daß die Kommission effektiv nur 20\% der Beihilfenzahlungen auch tatsächlich kontrolliert, zu fragen, ob eine weitere Delegation von Kompetenzen an die MS noch mit dem Auftrag der Sicherung der Wettbewerbsneutralität vereinbar wäre.

\subsection{Internationale Regeln in Orientierung am GATT}

Insbesondere im Schiffbau und der Stahlindustrie zeigte die Analyse des 4. Kapitels, daß die EG-Produzenten ihre einstmals dominierende Stellung auf dem Weltmarkt verloren haben und eine solche Entwicklung auch auf dem Binnenmarkt stattfindet. Gleichzeitig führten Beschwerden über Subventionen für ausländische (d.h. nicht-EG-) Produzenten immer wieder zu importbeschränkenden Maßnahmen. In dieser Situation stellt sich die Frage, ob die Gemeinschaft der richtige Rahmen für eine effektive Beihilfenkontrolle ist und ob diese nicht stattdessen auf einer "höheren" Ebene, wie es das GATT (oder auch die OECD) darstellt, erfolgen sollte.

Wie oben dargelegt, fanden solche Gespräche/Verhandlungen auch bereits auf OECD-Ebene für den Schiffbau und auf GATT-Ebene im Stahlbereich statt. Daneben wurden auf OECD-Ebene allgemeine Schritte zur Liberalisierung und zur Beihilfenkontrolle unternommen: So versucht die OECD, umfassende Daten zur Subventionierung zu erheben, um die Transparenz zu erhöhen und die Wirkungen der Beihilfen evaluieren zu könnnen. Da die Gemeinschaft hier mit ihren Beihilfen-

42 Vgl. z.B. Olson 1977, S. 71, und Oates 1972, S. 33-36. 
berichten eine Art Vorreiterrolle einnimmt, fordert sie ähnliche Berichte in anderen Mitgliedstaaten der OECD 43 . Daneben wurden auf der OECD-Ebene Vereinbarungen zu den erlaubten Konditionen für Exportkredite getroffen ${ }^{44}$.

Derartige Abmachungen betreffen jedoch jeweils nur Randbereiche oder Vorstufen einer wirksamen Beihilfenkontrolle. Wie schon in Kapitel 3.3 deutlich wurde, entspringt der Ansatz des GATT, der bei Subventionen Gegenmaßnahmen in Form von Countervailing duties erlaubt, einem anderen Denksystem, dem eine zentrale Kontrollinstanz mit exekutiven Befugnissen fehlt ${ }^{45}$. Ein derartiger destruktiver Ansatz, der auch keine Aufhebung der Maßnahme an der Quelle einschließt, ist für die EG nicht tauglich, da er ihrem Integrationskonzept widerspricht und einen möglichen Rückschritt in segmentierte Märkte einschlösse. Das GATT enthält bisher auch nur ein Verbot von Exportsubventionen, das den Anforderungen des GM nicht genügt, wie die theoretische Analyse aus Kapitel 2.2 offenbarte. Zudem besteht hier auch die Gefahr des offensiven Einsatzes solcher Instrumente zur Schädigung erfolgreicher ausländischer Lieferanten 46 . Die Countervailing duties des GATT sind somit eher ein Ausdruck der Sicherung der Produzentenrechte, da ausländische Konsumenten durch Exportsubventionen gewinnen können 47 . Eine prozedurale Schwäche des GATT liegt auch darin, daß Verschärfungen der Regeln nur über langwierige Verhandlungen zu erreichen sind, denen alle Vertragsparteien zustimmen müssen. Dies wiederum fördert weiche Kompromisse und verhindert eine effektive Disziplinierung des Verhaltens der Staaten 48 . Angesichts dieser Überlegungen zieht Franzmeyer 49 die Schlußfolgerung, daß "sich, wie die Ohnmacht des GATT beweist, Wettbewerb im globalen Maßstab nur unvollkommen organisieren" läßt.

Soll also eine effektive Beihilfenkontrolle auf der Ebene des GATT etabliert werden, so wäre es unumgänglich, dessen Macht zu erhöhen und die Durchsetzungsverfahren zu stärken sowie mehr auf die Verhinderung von Beihilfen als auf

\footnotetext{
43 Vgl. Reichenbach 1993, S. 9.

44 Vgl. OECD 1989, S. 5.

45 Vgl. Krauss 1979, S. 88.

46 Vgl. Krauss 1979, S. 89. Als Beispiel für einen solchen offensiven Einsatz mag das Verhalten der USA dienen, die im Zeitraum von 1980-85 das Instrument der Countervailing duties 252mal einsetzten; im gleichen Zeitraum nutzte es die EG nur siebenmal, sie wandte aber andere Instrumente verstärkt an. Vgl. Bhagwati 1988, S. 49.

47 Vgl. Krauss 1979, S. 87, und Lehner/Meiklejohn/Reichenbach 1991, S. 24.

48 Vgl. Curzon Price 1986, S. 219.

49 1989, S. 143.
} 
Gegenmaßnahmen zu setzen ${ }^{50}$. Als erster Schritt wird dabei bspw. eine Bindung der Subventionen analog der Zölle verbunden mit einer Verpflichtung zur stufenweisen Senkung und zeitlichen Beschränkung gefordert und zur Absicherung eine Verankerung dieser Verpflichtung im nationalen Recht verlangt ${ }^{51}$. Eine solche Vorgehensweise würde allerdings eine internationale Kontrolle der Einhaltung solcher Regeln durch die Vertragsparteien erfordern. Malmgren 52 macht in diesem Zusammenhang den Vorschlag, innerhalb des GATT eine multilaterale Institution zu kreieren, die für die gegenseitige Konsultation, die Aufsicht und Konfliktlösung bei Fällen von Produktionsbeihilfen, also bspw. Betriebs- aber auch Investitions- oder FuE-Beihilfen, zuständig sein sollte 53 . Ihr sollte die Autorität zugesprochen werden, bei verzerrenden Beihilfen, d.h. solchen, bei denen Unternehmen in anderen Staaten zu zusätzlichen Anpassungen gezwungen werden, die Rückzahlung zu verlangen und bei Scheitern dieses Weges andere Staaten zur Erhebung von Ausgleichszöllen bzw. zu anderen Gegenmaßnahmen bei Schädigung auf Drittmärkten zu ermächtigen. Außerdem sollte sie Marktverzerrungen überwachen und Regeln zur Beurteilung von Produktionsbeihilfen sowie ein Inventar schädigender Maßnahmen im Beihilfenbereich entwickeln. Innerhalb dieses generellen Rahmens soll in Sektoren mit hoher Interventionsintensität eine Harmonisierung der nationalen Politiken, u.U. auch innerhalb der Industrieausschüsse der OECD, angestrebt werden. Die Ausgestaltung dieses Vorschlages zeigt m.E. eine deutliche Anlehnung an das Konzept der EG-Beihilfenkontrolle, die damit offensichtlich als nachahmenswertes Beispiel angesehen wird. Der vorgeschlagenen multilateralen Institution fehlen jedoch die exekutiven Vollmachten der EG-Kommission, so daß sie zur Durchsetzung der Ergebnisse ihrer Untersuchungen auf die Kooperation der Regelverletzer angewiesen ist und bei fehlender Kooperation den betroffenen MS wiederum das Instrument der Ausgleichszölle gestatten muß. Wenngleich ein solches Konzept gegenüber den bestehenden Regeln des GATT ein beachtlicher Fortschritt wäre ${ }^{54}$, so wäre es doch für die Weiterentwicklung der Gemeinschaft keine brauchbare Option, da es die Möglichkeit der Aufhebung des Binnenmarktes und die Wiedereinführung von Ursprungszeugnissen immer noch beinhaltet 55 .

\footnotetext{
50 Eine solche Position wird auch vom früheren EG-Kommissar für Wettbewerbspolitik, Sir Leon Brittan, vertreten. Vgl. Hill 1992, S. 1.

51 Vgl. Müller 1983, S. 279-281.

52 1978, S. 221-227.

53 Exportbeihilfen sollten weitgehend verboten sein.

54 Dies nicht zuletzt auch deswegen, weil es die Aufgabe aller Grandfather clauses der Vertragsparteien voraussetzt. Vgl. Malmgren 1978, S. 221.

55 Vgl. Caspari 1985, S. 52.
} 
Solche weitreichenden institutionellen Stärkungen des GATT waren jedoch nicht Element der Diskussionen zu diesem Themenkomplex im Rahmen der gerade abgeschlossenen Uruguay-Runde. Hier wurde eine Einteilung der Beihilfen in drei Kategorien (Ampelansatz) vereinbart. Exportbeihilfen und ähnliche Regime wären danach verboten (rote Kategorie), Regional-, Umweltschutz-, vorwettbewerbliche FuE-Beihilfen sowie solche zur Umschulung von Beschäftigten hingegen erlaubt, sofern sie zeitlich begrenzt und degressiv sind, notifiziert werden und keine Vertragspartei eine Schädigung demonstrieren kann (grüne Kategorie). Alle anderen Beihilfen (gelbe Kategorie) gäben weiterhin das Recht zu Gegenmaßnahmen, wenn eine Schädigung auftritt, wobei dies oberhalb einer Beihilfenintensität von 5\% für ein Produkt bzw. bestimmten Exportanteilen des unterstützten Unternehmens unterstellt wird. Zudem wurde eine Beschleunigung der Untersuchungsverfahren und eine zeitliche Begrenzung der Countervailing duties vereinbart ${ }^{56}$. Selbst gegen diesen Vorschlag, der weitgehend im Rahmen der bestehenden Regeln bleibt und punktuelle Klarstellungen bietet, bestand jedoch seitens der USA und der Gemeinschaft lange Zeit erheblicher Widerstand 57.

Allerdings können solche multilateralen Vereinbarungen, wie die Bereiche Schiffbau und Stahl zeigten, für die Kommission eine Rückendeckung gegenüber den MS zur Durchsetzung strikter Regeln darstellen und somit zur Ergänzung, nicht aber dem Ersatz, eines gemeinschaftlichen Systems dienen 58 . Ein weiterer Weg zur Festigung der Beihilfenkontrolle und zur Erhöhung ihrer Wirkungskraft besteht in der Ausweitung des EG-Ansatzes auf andere Staaten. Auch hier sind Erfolge sichtbar. So wurden mit Inkrafttreten des EWR von den EFTA-Staaten mit Ausnahme der Schweiz alle EG-Regelungen zur Beihilfenkontrolle einschließlich des Sekundärrechts (bspw. der Gemeinschaftsrahmen) übernommen und auch die EuropaAbkommen mit den Visegrad-Staaten (Tschechische Rep., Slowakei, Polen und Ungarn) übertragen den Beurteilungsrahmen der Gemeinschaft auf die Beziehungen mit diesen Staaten 59 . Auf diese Weise wird für einige Produkte der von diesen Regeln erfaßte Anteil des Weltmarkts erheblich erhöht und damit die Beihilfen-

56 Vgl. GATT 1992, S. 6-8. Für Entwicklungsländer und ehemalige Staatshandelsländer gelten Ausnahmen und Übergangsfristen für alle diese Regeln.

57 Vgl. Lehner/Meiklejohn/Reichenbach 1991, S. $78 f$.

$58 \mathrm{Vgl}$. Brittan 1992, S. 8.

59 Vgl. BDI 1993, S. 68. Dies geschah analog den oben dargelegten früheren Freihandelsabkommen mit den EFTA-Staaten, aber unter deutlicherer Festlegung, daß auch das gemeinschaftliche Sekundärrecht Anwendung findet. 
kontrolle wirksamer. Umgekehrt muß die Gemeinschaft bei ihren Beihilfeentscheidungen nunmehr auch die Interessen dieser Drittländer berücksichtigen 60 .

\subsection{Festigung des bestehenden regelgebundenen Systems}

Die bisherigen Überlegungen in diesem Kapitel haben gezeigt, daß für das Problem einer wirksamen und effizienten Subventionskontrolle die Lösungen über ein absolutes Verbot oder eine Zentralisierung aus ökonomischen ebenso wie aus politischen Gründen abzulehnen sind. Die in den Abschnitten 6.3 und 6.4 diskutierten Ansätze einer partiellen Kompetenzverlagerung nach unten auf die MS und nach oben auf internationale Organisationen wie das GATT können hingegen in Grenzen akzeptiert werden. Sie sind jedoch nicht als Alternativen zum existierenden System, sondern quasi als oberer und unterer Rahmen der Kommissionskompetenz zu sehen. Da jedoch die Darlegungen in den Kapiteln 4 und 5 zeigten, daß die jetzigen Regeln durchaus zu Problemen geführt haben, stellt sich die Frage, inwieweit diese im Rahmen des bestehenden Systems durch strukturelle Verbesserungen korrigierbar sind.

Färber61 identifiziert drei Elemente eines binnenmarktgerechten Steuerungsanspruchs der Kommission: Transparenz, Durchsetzungsmacht und problemgerechte Entscheidungskriterien. Transparenz wird hierbei als verbesserte Information der Kommission über Beihilfen der MS definiert, an der es in der Vergangenheit durch ständiges Ausweichen der MS in intransparente Beihilfeformen mangelte, während unter Durchsetzungsmacht die Möglichkeit der Ergreifung von Sanktionen zu verstehen ist. Während die beiden ersten Elemente in erster Linie Aspekte des Verfahrensablaufs und der Machtverteilung ansprechen, bezieht sich der letzte Aspekt auf die inhaltliche Ausgestaltung des Prüfungsanspruchs. Für beide Bereiche sollen nun Vorschläge zur Verbesserung der Kontrolle diskutiert werden, wobei allerdings der Begriff Transparenz wie bereits im 5. Kapitel sich vor allem auf die Transparenz des Handelns der Kommission selbst beziehen soll.

\subsubsection{Erhöhung der Effektivität des Prüfungsverfahrens}

Hinsichtlich des Prüfungsverfahrens hatte die Kommission immer wieder Probleme damit, daß die MS ihre Notifizierungspflichten in einzelnen Fällen nicht einhielten oder über intransparente Formen der Unterstützung diese der Kommissionskontrolle entziehen wollten bzw. auch Kommissionsentscheidungen in Beihilfefragen

60 Vgl. Reichenbach 1993, S. $15 f$.

61 1993, S. 154. 
nicht umsetzten. Das Fehlen von Sanktionsmöglichkeiten erwies sich dabei als Handicap. Die Änderung des Artikels 171 EGV durch den Vertrag von Maastricht gibt hier dem EuGH die Möglichkeit, auf Antrag der Kommission gegen MS Zwangsgelder zu verhängen, wenn diese gegen ihre Verpflichtungen aus dem Vertrag verstoßen haben. Es ist jedoch zu vermuten, daß dieser Artikel lediglich bei der Nichtumsetzung von Beihilfenentscheidungen anwendbar sein wird und nicht schon bei Nichtnotifizierung. Schon dies erscheint als wesentlicher Fortschritt, um die MS zu einer besseren Einhaltung ihrer Pflichten anzuhalten. Dennoch fehlt es für die MS weiterhin an einem Anreiz, kritische Beihilfen zu notifizieren, da selbst bei einer Entdeckung lediglich das normale Prüfverfahren eingeleitet wird (also kein zusätzlicher "Verlust" eintritt), während bei Nichtentdeckung eine möglicherweise verzerrende Beihilfe gewährt werden kann (also ein "Gewinn" entsteht). Dies würde für die Möglichkeit sprechen, den MS auch schon aufgrund der mangelnden Notifizierung Strafgelder auferlegen zu können.

Im Prüfungsverfahren leidet die Kommission unter der unvollständigen oder nur verzögerten Bereitstellung von Informationen durch die MS, was zu einer Verzögerung der Verfahren oder, wie bspw. im Falle Rover/BAe, zu Entscheidungen in Unkenntnis aller Beihilfeelemente führt. Um diese Probleme zu lösen, wird vorgeschlagen, der Kommission Untersuchungsbefugnisse vor Ort analog der Möglichkeiten in Kartell- und Marktbeherrschungsfällen nach Art. 85/86 zu geben62. Dies enthielte die Möglichkeit, ohne Anmeldung direkt bei Behörden und Firmen Unterlagen einzusehen und zu kopieren (sog. dawn raids). Auch wenn ein solches Recht die Prüfungsmöglichkeiten der Kommission erheblich verbessern könnte, so erscheint es doch mit der Souveränität der MS nur schwer vereinbar, der Kommission eine Art Polizeigewalt gegenüber nationalen Behörden zu verleihen. In den Fällen der Art. 85/86 bezieht sich das Durchsuchungsrecht auch lediglich auf Unternehmen, da Behörden nicht betroffen sind.

Die Transparenz des Kommissionshandelns ist in den letzten Jahren erheblich verbessert worden, indem über Verfahrenseröffnungen nach Art. 93,II und deren Schließung ausführlicher im Amtsblatt und durch Presseerklärungen berichtet wurde. Durch die Ausarbeitung und Publikation der Gemeinschaftsrahmen sind auch die Beurteilungskriterien einer breiteren Öffentlichkeit zugänglich gemacht worden. Mängel bestehen hingegen noch bei der großen Zahl der ohne Eröffnung des formellen Prüfverfahrens genehmigten Beihilfen. Hier besteht die Publikation im ABl. häufig nur aus einer kurzen Notiz, die lediglich das Subventionsregime oder bei

62 Vgl. Lehner/Meiklejohn/Reichenbach 1991, S. 74. 
einer Ad-hoc-Beihilfe den Empfänger identifiziert und das Beihilfevolumen oder budget nennt. Ausführlichere Informationen auch zu diesen Fällen wären für die Öffentlichkeit und die betroffenen Konkurrenten nützlich63 und gäben u.U. eine Möglichkeit zur Beschwerde, würden aber auf jeden Fall den Eindruck vermeiden, daß hier Beihilfen ohne ersichtliche Rechtfertigung genehmigt wurden. Transparenz und Beschwerdemöglichkeiten würden noch weiter verbessert, wenn, ähnlich wie bei Fusionsfällen, die durch die Merger Task Force geprüft werden, schon bei Notifizierung einer Beihilfe (bzw. bei ihrer Registrierung im Falle nichtnotifizierter Beihilfen) eine kurze Veröffentlichung der Kerndaten im Amtsblatt erfolgte.

Gerade in der Automobil- und der Stahlindustrie wurde die hohe Bedeutung einer Ex-post-Kontrolle der gewährten (Regional-) Beihilfen deutlich. Ihre systematische Durchführung würde allerdings zu einer weiteren starken administrativen Belastung von DG IV führen. Eine Lösung dieses Problems könnte dabei in der Schaffung von Instanzen zur Ex-post-Beihilfenkontrolle in den MS bestehen, die von den gewährenden Behörden unabhängig sein müßten und durch die nationalen Rechnungshöfe oder den Europäischen Rechnungshof regelmäßig zu kontrollieren wären. Ihre Finanzierung könnte bspw. durch eine Abgabe der begünstigten Unternehmen in Höhe eines bestimmten Prozentsatzes der gewährten Beihilfen erfolgen. Ein regelmäßiger Informationsaustausch zwischen diesen Kontrollorganen und DG IV könnte letzterer auch nützliche Informationen zur Verbesserung der Beihilfenkontrolle zur Verfügung stellen.

Die Rückforderung illegal gewährter Beihilfen hat in den letzten Jahren, wie oben erläutert, eine immer größere Bedeutung gewonnen. Probleme für die Kommission entstanden hierbei daraus, daß diese Restitution nach nationalem Verwaltungsrecht erfolgt, das nicht harmonisiert ist. Eine stärkere Vereinheitlichung dieser Verfahren würde Wettbewerbsverzerrungen durch relativ günstigere Behandlung in einzelnen MS vermindern 64 . Hierbei ist vor allem an eine Angleichung der Rückzahlungsfristen und der von den Unternehmen zu verlangenden Zinsen zu denken. Früher wurde in Einzelentscheidungen den MS eine Frist von zwei Monaten zur Einforderung der Beträge gegeben, bevor eine Zinszahlungspflicht der Unternehmen entstand. Dies kann angesichts der häufig langen Fristen zwischen einer illegalen Beihilfengewährung und der Rückforderungsentscheidung für die Unternehmen einen signifikanten finanziellen Vorteil bedeuten. Korrekt ist stattdessen eine Zinsberechnung vom Zeitpunkt der Gewährung an, die die Kommission als Folge des Boussac-

63 Vgl. Gilchrist/Deacon 1990, S. 50, und Schina 1987, S. 175.

64 Vgl. Seidel 1985, S. 75. 
Urteils nunmehr verlangen kann (s. oben Abschnitt 5.3.1) und auch verlangt 65 . Auch die von den MS zu verlangenden Zinssätze orientieren sich nicht an den Marktzinsen, sondern sind häufig aus dem nationalen Konkurs- oder Steuerrecht entnommen. Hier läge eine denkbare Lösung in der Verwendung der für die Regionalbeihilfen verwendeten Referenzzinssätze, die in einem engeren Bezug zu den Kapitalmarktzinsen im jeweiligen MS und damit zu dem dem Unternehmen zufließenden finanziellen Vorteil stehen. Die oben (s. Abschnitt 5.3.5) diskutierte Anrechnung (und mögliche Rückforderung) der Zinsvorteile der Unternehmen durch die Auszahlung von Beihilfen vor der Anmeldung und Genehmigung durch die Kommission würde eine weitere Lücke der Beihilfenkontrolle, die zu Wettbewerbsverzerrungen führt, schließen.

Zur Vermeidung der in vielen bedeutenden Fällen in wichtigen Sektoren konstatierten politischen Einflußnahme werden jedoch auch wesentlich radikalere Vorschläge zur Umgestaltung des Prüfungsverfahrens gemacht. Einer dieser Vorschläge besteht darin, ähnlich wie beim Bundeskartellamt die politische von der administrativen Ebene zu trennen. Dies würde bedeuten, die Beihilfendirektion in DG IV von der Kommission abzukoppeln und die Ergebnisse ihrer Prüfung als Entscheidung der administrativen Ebene zu veröffentlichen. Besteht dann auf der politischen Ebene der Wille, eine abgelehnte Beihilfe doch zu genehmigen, so wäre eine separate Kommissionsentscheidung notwendig, die dann wie die deutsche Ministererlaubnis den politischen Ausnahmecharakter dieser Genehmigung der Öffentlichkeit deutlich machen würde und somit auch gezielte Reaktionen anderer Gruppen im politischen Prozeß ermöglichen würde. Die Verfechter eines solchen Ansatzes wollen auf diese Weise politische Einflußnahme im Verborgenen verhindern66. Auch wenn dieser Ansatz zunächst sehr einleuchtend erscheint, so muß doch darauf hingewiesen werden, daß der Vergleich mit dem Bundeskartellamt nicht vollkommen stimmig ist. Während sich letzteres nämlich nur mit Kartell- und Fusionsentscheidungen befaßt, die das Verhältnis zwischen Unternehmen betreffen, geht es bei der Beihilfenkontrolle um das Verhältnis zwischen Unternehmen und Staaten, wodurch ein politisches Element unweigerlich in allen wichtigen Fällen enthalten ist. Gerade bei den bedingten Entscheidungen wird die Durchsetzung immer wieder auch einer politischen Unterstützung bedürfen, die ein unabhängiges "Beihilfenkontrollamt" wohl nicht in ausreichendem Maße hätte. Zudem ist die Annahme, daß politische Einflußnahmen auf die Entscheidungen des Amtes ausgeschlossen werden könnten, wohl eher realitätsfern.

65 Vgl. EG, Kommission 1994a, S. 264.

66 Vgl. The Economist 1991a, S. 17. 
Stattdessen wäre wohl damit zu rechnen, daß der politische Druck dann bereits bei der Besetzung der höchsten Beamtenstellen auftreten und auch bei der späteren Beurteilung von Einzelfällen auf dieser Ebene weiterhin erfolgen würde.

\subsubsection{Verbesserung der inhaltlichen Aspekte der Beihilfenkontrolle}

Geht man nun zur Frage der inhaltlichen Ausgestaltung der Beihilfenkontrolle und damit der problemgerechten Entscheidungskriterien über, so ist zunächst zu konstatieren, daß sich durch das Binnenmarktprogramm die Rahmenbedingungen verändert haben. Durch die Maßnahmen zur Harmonisierung und Liberalisierung im Binnenmarkt sind den MS eine Reihe von protektionistischen Instrumenten, wie z.B. Normen, genommen worden, ihre Souveränität ist somit reduziert worden, während gleichzeitig der Wettbewerb sich verschärft hat. Hieraus ergibt sich ein dringender Bedarf für eine verschärfte Beihilfenkontrolle, um zu verhindern, daß die MS diese verlorengegangene Souveränität über vermehrte Beihilfen wiederzugewinnen versuchen bzw. den Wettbewerb dämpfen 67 . Diese Notwendigkeit wird sich noch verschärfen, sofern durch die WWU die Möglichkeit zur Wechselkursanpassung als Mittel zur Exportförderung in Zukunft ausfällt68. Der Binnenmarkt erfordert eine verschärfte Beihilfenkontrolle auch deshalb, weil die Unternehmen bei ihrer Standortwahl hierdurch erheblich flexibler geworden sind, so daß diese bei großen Nettoförderdivergenzen ihre Entscheidung verstärkt nach Subventionsgesichtspunkten ausrichten und einen Subventionswettbewerb zwischen den MS und ihren Regionen auslösen könnten69. Eine solche Intensivierung der Beihilfenkontrolle hat in den letzten Jahren stattgefunden. Bei einer langandauernden wirtschaftlichen Krise wäre jedoch möglicherweise mit Widerständen der MS gegen eine weitere Entwicklung in diese Richtung $z u$ rechnen, die als übermäßiger Eingriff in den nationalen Handlungsspielraum empfunden werden kann. Somit stellt sich die Frage, auf welche Weise die Qualität und Effizienz der Kontrolle verbessert werden können und gleichzeitig den Forderungen nach mehr Subsidiarität Rechnung getragen werden kann.

Die Kommission befindet sich hier in einer Zwickmühle, da die Freiheit der MS zur Subventionierung im Regional- oder FuE-Bereich, nachdem ihre Förderprogramm durch die Kommission genehmigt worden sind, deren Möglichkeit erhöht, Gemeinschaftsziele zu unterminieren. Daher wäre eine genauere Untersuchung der

\footnotetext{
67 Vgl. Sachverständigenrat 1991, S. 218.

68 Vgl. Buchan 1989, S. 4.

69 Vgl. Eekhoff 1993, S. 54.
} 
Auswirkungen bestimmter Maßnahmen auf den Wettbewerb im Einzelfall nötig. Eine Genehmigung dürfte nicht schon ausgesprochen werden, wenn lediglich die formalen Voraussetzungen des jeweiligen Regelwerkes erfüllt sind ${ }^{70}$. Eine solche Einzelfallkontrolle oder regelmäßige Überprüfung bestehender Beihilfen wäre auch aufgrund der oben erwähnten Tatsache sehr nützlich, daß über solche Regime $80 \%$ aller jährlich gewährten Beihilfen vergeben werden. Sie ist jedoch angesichts der Flut jährlich neu gemeldeter Beihilfen schwer durchführbar 71 .

Hier bietet die neue De-minimis-Regel einen Fortschritt, da viele kleine durch lokale Behörden vergebene Hilfen ohne signifikante Wirkung auf den innergemeinschaftlichen Wettbewerb nun nicht mehr von der Kommission kontrolliert werden müssen. Gleichzeitig kann sie als Umsetzung des Subsidiaritätsprinzips angesehen werden. Die Freisetzung von Ressourcen durch diese Maßnahmen erlaubt nunmehr eine verstärkte Kontrolle nach Art. 93,I für bestehende Beihilfen. Da die Schwellenwerte sehr niedrig gewählt worden sind, wäre ihre Erhöhung eine Möglichkeit, große Förderprogramme und -projekte genauer prüfen zu können ${ }^{72}$. Auf diese Weise kann die Effizienz der Kontrolle durch Konzentration auf Projekte mit spürbaren Auswirkungen auf den Intra-EG-Handel erhöht werden, ohne daß gleichzeitig die Qualität der Kontrolle signifikant leiden würde ${ }^{73}$. Ein solcher Rückgriff auf Schwellenwerte, wie er bereits im FuE-Bereich und dem Kfz-Rahmen erfolgt, müßte dabei bei allen Förderprogrammen erfolgen.

In dieselbe Richtung der konsequenten Überprüfung bestehender Beihilfen geht auch die Forderung nach zeitlicher Befristung aller Programme und der Vorlage von Jahresberichten, wie es bereits von der Kommission vorgeschlagen wurde und für die Jahresberichte nunmehr in standardisierter Form verwirklicht wurde ${ }^{74}$. Dies entspricht weitgehend den schon seit langem in der Literatur vertretenen Auffassung 75 , alle Beihilfen temporär, degressiv und selektiv zu gestalten und laufend zu überprüfen. Dies würde sich nicht nur auf Regime erstrecken, sondern ebenso Beihilfen

\footnotetext{
70 Vgl. Gilchrist/Deacon 1990, S. 42f.

71 Vgl. ebenda, S. 44f, und Deacon 1990, 71 f.

72 Vgl. Gilchrist/Deacon 1990, S. 46.

73 Vgl. Padoa-Schioppa 1988, S. 61f.

74 Vgl. Lehner/Meiklejohn/Reichenbach 1991, S. 71, und DTI 1993, S. 34f., sowie EG, Kommission 1994a, S. 258. Solche Jahresberichte existieren bereits in einigen durch Gemeinschafts-

rahmen geregelten Bereichen, wie z.B.
So bspw. bei Andel 1970, S. 147-149.
} 
beim Auftreten plötzlicher externer Schocks oder zur sozialpolitisch erträglichen Umstellung alter Industrien betreffen 76 .

Eine Weiterentwicklung des Schwellenwertansatzes stellt die Forderung dar, die 1500 größten Firmen der Gemeinschaft einer genaueren Kontrolle mittels regelmäßiger Berichte zu unterwerfen, da sie 2/3 der EG-Wertschöpfung und den größten Teil des innergemeinschaftlichen Handels bestreiten. Ein solcher Ansatz entspräche einer Konzentration auf Maßnahmen mit einem "appreciable effect", wie sie bereits bei der Kartellkontrolle nach Art. 85 erfolgt ${ }^{77}$. Diese Art der Kontrolle würde noch erleichtert, wenn über eine weitere Harmonisierung der Rechnungslegungsvorschriften für Kapitalgesellschaften ein einheitlicher Ausweis empfangener Beihilfen im Jahresabschluß zu erfolgen hätte ${ }^{78}$. Hiermit würden zwar intransparente Beihilfeformen wie z.B. subventionierte Grundstücksverkäufe nicht erfaßt, aber zumindest Beihilfezahlungen in Anwendung genehmigter Programme wären dadurch sehr leicht zu erkennen.

Eine solche Konzentration der Kontrolle auf große Unternehmen müßte selbstverständlich auch öffentliche Unternehmen einschließen, die ein wichtiges Element nationaler Industriepolitik sind und gegen deren Subventionierung in der Vergangenheit nicht energisch genug vorgegangen wurde ${ }^{79}$. Dies gilt insbesondere, da öffentliche Unternehmen häufig in Krisensektoren mit Überkapazitäten zu finden sind, aus sozialen und politökonomischen Überlegungen häufig notwendige Rationalisierungen aufgeschoben oder unterlassen haben und somit Anpassungslasten auf private Konkurrenten verlagerten 80 . Auch bei der Privatisierung solcher Unternehmen, die häufig über direkte Verkäufe an andere Unternehmen ohne öffentliche Ausschreibung erfolgt (vgl. bspw. die Privatisierungen von Alfa-Romeo, Rover oder NedCar), muß vermehrt darauf geachtet werden, daß hier nicht etwa Beihilfen über einen zu geringen Verkaufspreis vergeben werden. Bei solch großen Projekten muß dies fast zwangsläufig die Einholung eines unabhängigen Bewertungsgutachtens beinhalten 81 ,

76 Vgl. Zippel 1984, S. 19f.

77 Vgl. Gilchrist/Deacon 1990, S. 47.

78 Vgl. auch Dickertmann/Diller 1990, S. 544.

79 Hierzu wird häufig die Auffassung vertreten, daß eine wirksame Kontrolle nur durch die Privatisierung solcher Unternehmen zu erreichen sein wird. Vgl. bspw. BDI 1993, S. 63. Aufgrund der in Art. 222 EGV festgelegten Eigentumsneutralität der Gemeinschaft kann die Kommission dies

$80 \mathrm{Vgl}$. Deacon 1990, S. 73. allerdings nicht erzwingen.

81 Vgl. Lehner/Meiklejohn/Reichenbach 1991, S. 73f. 
welches dann als Referenzgröße zu nutzen ist, um im Vergleich mit dem tatsächlich erzielten Kaufpreis mögliche Beihilfen zu ermitteln.

Ähnliches gilt für die Veräußerung öffentlicher Grundstücke (vgl. bspw. DaimlerBenz, Potsdamer Platz). Das Argument, daß der Verkehrswert am Markt nicht erzielbar sei, weil keine anderen Kaufinteressenten existierten 82 , ist dann nicht schlüssig, wenn exklusiv nur mit einem Interessenten verhandelt und die Kaufmöglichkeit nicht publiziert wurde, da sich der Staat dem einzigen Nachfrager gegenüber dann quasi in eine Geiselstellung begibt. Das für den Grundstücksverkauf gleichzeitig vorgebrachte Argument, daß deren Verfügbarkeit entscheidend für die Erreichung einer Ansiedlung sei 83 , daß also Grundstücke knapp seien, spricht noch mehr dafür, daß ein adäquater Preis um so leichter zu erzielen sein müßte. Wichtig ist für die Beurteilung des Beihilfencharakters also die Transparenz, d.h. die öffentliche Kenntnis der Verkaufbarkeit. Die Verabschiedung einer gemeinschaftlichen Kodifizierung der Regeln für Grundstücksverkäufe scheiterte allerdings Mitte der 80er Jahre wegen Divergenzen zwischen den nationalen Bestimmungen, die eine Einigung verhinderten 84 .

Im Bereich der Regionalpolitik sieht sich die Kommission zwei Problemfeldern gegenüber. Dies ist zum einen der potentielle Konflikt zwischen dem Gemeinschaftsziel der Verminderung des regionalen Gefälles zwischen den reicheren MS und den ärmeren Staaten am Rand der Gemeinschaft (Kohäsionsziel) und dem nationalen Ziel eines ebensolchen Ausgleichs innerhalb des jeweiligen MS, da auch in den reicheren MS starke Gefälle existieren (vgl. dazu oben Abschn. 4.1.3). Das andere Problemfeld besteht zwischen dem Ziel der Förderung der Regionalentwicklung und den möglichen sektoralen Nebeneffekten, die dadurch in einigen Branchen verursacht werden können.

Stellt man beim ersten Problembereich das Kohäsionsziel in den Vordergrund, so spräche dies für eine drastische Verringerung der Beihilfen in den Zentralregionen bei gleichzeitiger Konzentration auf die am stärksten benachteiligten Regionen der Gemeinschaft mit dann dort entsprechend geringerer Intensität, da auf diese Weise dennoch der Fördervorsprung dieser Regionen zumindest gleich bliebe85. Da der

\footnotetext{
82 Vgl. Schütterle 1993, S. 625.

$83 \mathrm{Vgl}$. ebenda.

84 Vgl. Schütterle 1993, S. 627.

$85 \mathrm{Da}$ die ärmeren MS die hohen Obergrenzen aufgrund von Budgetproblemen häufig nicht ausschöpfen können, würde auf diese Weise in vielen Fällen ein effektiver Fördervorsprung sogar erst geschaffen. Vgl. DTI 1993, S. 38f.
} 
finanzielle Vorteil für Unternehmen aus der Investition in Fördergebieten deutlich sinken würde, jedoch bei Übertragbarkeit der Ergebnisse der Analysen im Automobilbereich immer noch zur Kompensation der regionalen Nachteile und damit zur Attrahierung der Investition ausreichend wäre ${ }^{86}$, die Gefahr regionalsubventionsbedingter Wettbewerbsverzerrungen somit erheblich gemindert würde, ließe sich bei Wahl dieser Strategie möglicherweise sogar auf spezielle sektorale Rahmen mit ihrer schärferen Kontrolle verzichten 87 . Gleichzeitig ließen sich hierdurch erhebliche Haushaltseinsparungen sowohl auf Gemeinschafts- als auch auf nationaler Ebene erzielen ${ }^{88}$. Die Kontroll- und Anreizwirkungen dieser Modifikation ließen sich noch dadurch erhöhen, daß die Gemeinschaft bei Akzeptanz einer Regionalfördermaßnahme eine Kofinanzierung aus eigenen Mitteln garantierte, ansonsten jedoch die Förderung untersagte 89 .

Diese kohäsionsorientierte Strategie ließe sich noch dadurch verstärken, daß gleichzeitig nicht-regionale Beihilfen in Zentralregionen, die der Kohäsion entgegenwirken, schärfer kontrolliert würden. Ein Problem dieser Vorgehensweise läge jedoch darin, daß es sich bei der letzten Kategorie vorwiegend um FuE-Beihilfen handelt, die sowohl aufgrund des Externalitätenansatzes als auch des industriepolitischen Ansatzes als wünschenswert angesehen werden. Jedoch läßt sich hiergegen einwenden, daß in diesem Bereich ein starker Mitnahmeeffekt existiert, d.h. eine Förderung von FuE-Vorhaben, die ohnehin allein aufgrund ihres internen Nutzens von den Unternehmen durchgeführt würden. Weiterhin wird kritisiert, daß sich die FuE-Beihilfen auf Großunternehmen konzentrierten und eine Verzerrung der FuEStruktur verursachten 90 . Das letzte Argument der Strukturverzerrung steht allerdings in einem gewissen Widerspruch zu dem postulierten Mitnahmeeffekt, der keine oder nur eine sehr geringe Beeinflussung von FuE-Struktur und -volumen unterstellt. Dennoch sprechen alle diese Punkte für eine strikte Kontrolle insbesondere der Beihilfen für Entwicklung aber evtl. auch für angewandte Forschung.

86 Es ist zu bemerken, daß nirgendwo eine Studie erwähnt wird, die eine ökonomische Rechtfertigung für die bestehenden hohen Obergrenzen liefert. Sie sind vielmehr wohl historisch bedingt; vgl. oben Abschn. 4.1.3.

87 Die oben aufgezeigten strukturellen Unterschiede zwischen den verschiedenen Sektoren sprächen allerdings doch weiterhin für eine besondere Kontrolle.

88 Vgl. EG, Kommission 1990f, S. 9.

89 Vgl. Bullinger 1978, S. 177f. Die Möglichkeit der kooperativen Subventionierung kann auch den

Anreiz der MS zur Notifizierung eines Projekts erhöhen.

90 Vgl. Gilchrist/Deacon 1990, S. 47-49. 
Eine solche kohäsionsorientierte Strategie würde allerdings den föderalen Charakter der Gemeinschaft/Union außer Acht lassen, in der die Gliedstaaten eine eigene Staatsqualität besitzen und eigene Ziele verfolgen, mit denen sich ihre Bürger auch stark identifizieren. Folgt man dieser Überlegung, so muß auch den reicheren MS die Möglichkeit verbleiben, ihre regionalen Gefälle auf nationaler Ebene zu bekämpfen. In diesem Fall wird die Regionalförderkulisse in der Gemeinschaft dann allerdings umfänglicher bleiben und mit ihr die Möglichkeit eines wettbewerbsverzerrenden Subventionswettlaufs 91 . Um dann insbesondere in sensiblen Sektoren, wie den im Kap. 4 im Detail untersuchten, derartige Verzerrungen zu verhindern, ist dort weiterhin eine schärfere Beihilfenkontrolle notwendig. Sie hätte vor allem eine verdeckte nationale Industriepolitik im Gewande der Regionalförderung mit der Schaffung subventionierter Überkapazitäten $z u$ verhindern ${ }^{92}$. Ohne eine adäquate Kontrolle wären die Möglichkeiten einer solchen Industriepolitik vor allem deshalb als recht hoch einzuschätzen, da für Großunternehmen in Sektoren, wie der Automobil- oder Chemieindustrie, bei Investitionsentscheidungen der relevante Betrachtungsraum zumindest die gesamte Gemeinschaft umfaßt. Eine solche Kontrolle könnte wie bisher sektorspezifisch oder, wie im Augenblick diskutiert, sektorübergreifend für kapitalintensive Industrien erfolgen.

Dieses Alternativkonzept entstand zum einen deswegen, weil die Erfahrung mit der Kontrolle sektoraler Beihilfen durch sektorale Rahmenregelungen lange Zeit nicht sonderlich positiv war. Wie aus den Abschnitten 4.2 - 4.4 deutlich geworden ist, wurden solche Rahmen von den MS v.a. in den 70er und frühen 80er Jahren häufig dahingehend umgestaltet, daß die notwendige Strukturanpassung alter Industrien nicht erleichtert, sondern vielmehr verschleppt wurde93. Zwar gelang der Kommission danach eine bessere Beschränkung der Erhaltungssubventionen, jedoch weist das "neue industriepolitische Konzept" von 199094 in eine andere Richtung, indem es eine "aktive Förderung positiver Anpassung" fordert. Sektorspezifische Beihilfen werden hierbei abgelehnt, da sie zur Fehlallokation der Ressourcen und zu Haushaltsungleichgewichten geführt haben. Deshalb fordert das Konzept eine schärfere Kontrolle solcher Beihilfen, insbesondere an kapitalintensive Industrien ${ }^{95}$, und

91 Diese Gefahr ließe sich allerdings auch bei einer solchen Vorgehensweise zumindest reduzieren, wenn die Förderobergrenzen gesenkt würden, auch wenn bei einer breiteren Förderkulisse der Spielraum hierzu geringer wäre.

92 Vgl. Gilchrist/Deacon 1990, S. 46.

93 Vgl. EG, Kommission 1990f, S. 5, und Hirn 1990, S. $25,28$.

94 Vgl. EG, Kommission 1990f, S. 5.

95 Vgl. ebenda, S. 21, 24. 
einen eher horizontalen Ansatz ${ }^{96}$. Diese Betrachtung beruht darauf, daß gerade in kapitalintensiven Produktionen die Bedeutung von Beihilfen für die Standortentscheidung als sehr hoch einzuschätzen ist, da die Beihilfenvergabe an die Investitionssumme gebunden ist ${ }^{97}$. Als weiterer wichtiger Aspekt wird die Bedeutung vieler solcher Industrien für die Entwicklung der Randregionen der Gemeinschaft hervorgehoben, da sie zur Schaffung von stabilen Primär- und zahlreichen Sekundärarbeitsplätzen führen. Diese Regionen sind jedoch trotz der ihnen zugestandenen hohen Fördergrenzen von bis zu $75 \%$ nicht in der Lage, solche Branchen zu attrahieren, da sie bei den hohen involvierten Investitionsvolumina aus finanziellen Gründen nicht in der Lage sind, de facto eine Förderintensität von $75 \%$ zu erreichen. Im Durchschnitt sind solche MS und Regionen nur in der Lage, 25-30\% Beihilfenintensität zu gewähren, was nur wenig über den genehmigten Fördersätzen in den Förderregionen der reichen MS liegt, und somit nicht ausreicht, solche Industrien anzuziehen und damit einen höheren Grad an Kohäsion zu verwirklichen 98 .

Im Sinne dieser Ideen hat die Kommission den Entwurf eines Gemeinschaftsrahmens für Beihilfen an kapitalintensive Industrien erstellt, der veränderte Höchstgrenzen für solche Beihilfen in Regionalfördergebieten anstrebt. Neben der hohen Anreizwirkung solcher Beihilfen ist dabei auch der relativ geringe Beschäftigungseffekt solcher an die Investitionssumme gebundenen Förderungen ein Anlaß zur Diskussion neuer Konzepte, wie z.B. der Bindung der Beihilfen an die Zahl der geschaffenen Arbeitsplätze 99 . Das maximal förderfähige Investitionsvolumen soll dabei 175.000 ECU pro geschaffenen Arbeitsplatz betragen, um so das förderfähige Volumen zu begrenzen und den ärmeren MS zu ermöglichen, ihre Förderintensitäten auch auszuschöpfen. Gleichzeitig würde die Fördermöglichkeit der reicheren MS gekürzt. Diese Regelung könnte dann die sektoralen Rahmen ersetzen 100.

98 Vgl. DTI 1993, S. 39.

Vgl. Hirn 1990, S. 28.

Vgl. Caspari 1987, S. 72.

Vgl. EG, Kommission 1992a, S. 138. Eine Alternativlösung bestünde in der Orientierung der Beihilfen an der zusätzlichen Wertschöpfung des Projekts. Obwohl auf diese Weise eine feinere Messung der sektoralen Wirkungen möglich wäre, werden hierbei jedoch Probleme bei der Messung dieser Größe gesehen. Vgl. OECD 1983, S. 236. Da jedoch bereits die in allen MS erhobene Mehrwertsteuer, wenn auch indirekt über die Steuerschuldberechnung, im Prinzip auf einer Messung der Wertschöpfung aufbaut, müßten diese Probleme zu lösen sein. Ein Problem läge jedoch darin, für ein Investitionsprojekt ex ante eine konjunkturneutrale Auslastung mit entsprechender Wertschöpfung zu ermitteln, um so eine prozyklische Beihilfenvergabe zu vermeiden.

100 Vgl. DTI 1993, S. 39. 
Das gleichzeitig zur Rechtfertigung vorgebrachte Argument, daß an Investitionen gebundene Beihilfen zu erhöhten Wettbewerbsverzerrungen führen, da kapitalintensivere Investitionen im Vergleich zu den Gesamtkosten des Unternehmens (Kapitalund Arbeitskosten) stärker gefördert werden als weniger kapitalintensive ${ }^{101}$, ist allerdings wenig überzeugend. Der direkte Wettbewerb auf den Gütermärkten erfolgt vorwiegend zwischen verschiedenen Produzenten einer Branche. Da hier jedoch die Produktionstechnologie und damit die Kapitalintensität in der Regel vom letzten Stand der technologischen Entwicklung determiniert wird, dürfte auch die Kapitalintensität derartiger Investitionen sehr ähnlich sein, was wiederum Wettbewerbsverzerrungen aufgrund der Bindung von Beihilfen an Investitionen de facto ausschließt, v.a. dann wenn alle MS diesen Sektor fördern 102 . Hingegen ist eine Verzerrung des intersektoralen Wettbewerbs auf den Faktormärkten möglich. Die Bindung von (Regional-) Beihilfen an Ausgaben für den Faktor Kapital wird die relative Entlohnung dieses Faktors erhöhen bzw. den Wandel zu einer höheren Kapitalintensität der Produktion noch beschleunigen, falls der Faktor Kapital mobil und vermehrbar ist (vgl. Abschnitt 2.2). Ob diese Entwicklung allerdings negativ zu sehen ist, erscheint angesichts der weitverbreiteten Auffassung, daß aufgrund der hohen Lohnkosten die europäische Industrie ohnehin nur in kapital- und technologieintensiven Sektoren überleben kann, eher zweifelhaft. Aus dieser Sichtweise wäre auch der gewünschte Arbeitsplatzschaffungseffekt, der einen solchen Ansatz auf den ersten Blick sehr attraktiv erscheinen läßt, nicht zu erwarten, da eine mögliche (wenn auch unwahrscheinliche) subventionsbedingt höhere Arbeitsintensität der Produktion dem Ziel der internationalen Wettbewerbsfähigkeit zuwiderliefe103.

Aufgrund dieser Überlegungen sind an der Nützlichkeit des sektorübergreifenden Ansatzes in der vorgeschlagenen Form erhebliche Zweifel angebracht. Dies gilt um so mehr, als bei einer möglichen Kopplung der Förderung an die Zahl der geschaffenen Arbeitsplätze bei gegebener Produktionstechnologie die Unternehmen geradezu zur Schaffung neuer subventionierter Kapazitäten angehalten werden, was zu neuen Verzerrungen führen kann und im Schrumpfungsfall das Problem der Marktaustrittsbarrieren verschärft. Zudem erlaubte dieser Ansatz auch keine Berücksichtigung

101 Vgl. EG, Kommission 1992a, S. 138

102 Im Vergleich zu einer nicht geförderten Investition nimmt allerdings der finanzielle Vorteil des Unternehmens mit steigender Kapitalintensität zu, v.a. wenn die regionalen Nachteile nicht vom Kapitaleinsatz abhängen.

103 Unabhängig von der Beeinflussung der Arbeitsintensität könnte für manche Branchen die Förderintensität bei dieser Methode im Vergleich zu den strukturellen Nachteilen zu niedrig liegen, so daß die Investition dort unterbleibt und kein Arbeitsplatzschaffungseffekt auftritt. 
sektorspezifischer Unterschiede in der Kontrolle. Dies spricht für die Beibehaltung einer sektororientierten Beihilfenkontrolle mit Prüfung von Einzelfällen in sensiblen Bereichen, sofern in den letzten Jahren beobachtete Intensivierung der Kontrolle und Verschärfung der Regelwerke beibehalten und möglichst noch ausgebaut werden kann 104 .

Dieser sektorspezifische Ansatz erlaubt dann neben der Begrenzung der Regionalbeihilfen auch die schärfere Überwachung anderer Subventionen wie bspw. für FuE, die bei der Beibehaltung der Regionalfördermöglichkeit in reicheren MS um so notwendiger bleibt. Hierbei erfolgte die Festsetzung von Rahmenregeln für regionale und horizontale Beihilfen, die wie oben dargelegt, auch einer Verschärfung bedürfte, weiterhin einheitlich in den entsprechenden Abteilungen, um so eine prinzipielle Gleichbehandlung der Sektoren zu erreichen. Sie würde dann weiterhin in den sensiblen Sektoren durch eine Einzelfallprüfung ergänzt, wobei hier v.a. für FuEBeihilfen die Heranziehung externen Expertenwissens notwendig wäre.

Ein gegenläufiger Ansatz propagiert, die Beihilfenkontrolle in den Dienst einer lenkenden Industriepolitik zu stellen. Hier wird ähnlich wie bei den Vorschlägen für eine Zentralisierung der Subventionsvergabekompetenz argumentiert, daß die hohen Kosten neuer Investitionen bzw. von Anpassungsinvestitionen in wichtigen oder zukunftsweisenden Branchen eine Unterstützung staatlicherseits erfordern, wobei wiederum auf das Beispiel Japan verwiesen wird. Um hier einen Subventionswettlauf der MS zu verhindern, wird gefordert, die Finanzmittel der Gemeinschaft zu erhöhen, also eine partielle Zentralisierung zu betreiben. Gleichzeitig soll "a more effective and constructive use of existing powers with respect to state aids" 105 erfolgen, was man wohl als Abgehen von wettbewerbspolitischen Beurteilungskriterien und eine verstärkte Hinwendung zu einer interventionistischen Industriepolitik übersetzen kann. Passend hierzu wird eine Verschmelzung von DG IV mit DG III vorgeschlagen 106. Ein solcher Ansatz ist problematisch wegen der divergierenden Sichtweisen und der - zumindest in der Vergangenheit beobachtbaren - Präferenz der DG III für eine Unterstützung der Großindustrie107. Abgesehen davon, daß auch eine solche partielle Zentralisierung der Subventionsvergabekompetenz angesichts der in Kap. 4 dargestellten früheren gescheiterten Versuche der Kommission ver-

\footnotetext{
104 Dabei könnten weitere Sektoren, die ebenfalls eine oligopolistische Struktur und hohe Ein- und Austrittsbarrieren aufweisen, einbezogen werden. Zu denken ist dabei an die Computerindustrie oder die Fluglinien.

105 Pinder 1983, S. 36f., der den eben dargestellten Ansatz vertritt.

106 Vgl. Butt Philip 1983, S. 141, und 1986, S. 18

107 Vgl. oben Abschn. 4.2.3.2 und 4.4.3
} 
mutlich am Widerstand der MS scheitern würde, enthält sie, wie bereits in Abschnitt 6.2 erläutert, die Gefahr, unter dem Vorwand eines "picking the winners" doch eher, wie im Schiffbau- und Stahlbereich geschehen, das Schrumpfen der alten Industrien zu verzögern.

Da die Zielrichtung der Art. 92-94 EGV jedoch primär wettbewerbspolitisch ist und die Vermeidung von subventionsbedingten Verzerrungen anstrebt, ist ein solcher Ansatz nicht akzeptabel. Eine effektive Kontrolle der Beihilfenvergabe durch die MS mit dem Ziel einer Harmonisierung der Förderung, v.a. bei sektoralen Beihilfen, gewinnt mit der weitestgehenden Öffnung der Märkte durch den Binnenmarkt und der damit einhergehenden Verschärfung des Wettbewerbs eine zusätzliche Bedeutung. Bezieht man zusätzlich subventionsbedingte intersektorale Fehlallokationen der Produktionsfaktoren in die Betrachtung ein, so ist, außer in Fällen der Korrektur externer Effekte, eine Harmonisierung nach unten geboten. Eine verstärkte Kontrolle dient dabei im Hinblick auf die geplante Wirtschafts- und Währungsunion auch der Einhaltung der strengen Konvergenzkriterien für Budgetdefizite, da die Länder mit den höchsten Budgetdefizite auch gleichzeitig jene mit dem höchsten relativen Beihilfenniveau sind 108 . Eine solche Ausrichtung der Beihilfenkontrolle wird jedoch weiterhin spürbare - und eher zunehmende - Eingriffe in die Souveränität der MS mit sich bringen und damit nur einen sehr geringen Spielraum für einen Rücktransfer von Kompetenzen im Sinne des Subsidiaritätsprinzips bieten. Sie wird vielmehr das oben zitierte "political commitment" der MS zur gemeinschaftlichen Wettbewerbsordnung weiterhin einer ständigen Prüfung unterziehen.

108 Vgl. EG, Kommission 1992d, S. 42f. 


\section{ANHANG: VERTRAGSARTIKEL}

\section{EGKS-Vertrag}

Artikel 4

Als unvereinbar mit dem gemeinsamen Markt für Kohle und Stahl werden innerhalb der Gemeinschaft gemäß den Bestimmungen dieses Vertrages aufgehoben und untersagt:

a) $\ldots$

b) ...

c) von den Staaten bewilligte Subventionen oder Beihilfen oder von ihnen auferlegte Sonderlasten, in welcher Form dies auch immer geschieht;

d) $\ldots$

\section{EG-Vertrag}

\section{Artikel 92}

(1) Soweit in diesem Vertrag nicht etwas anderes bestimmt ist, sind staatliche oder aus staatlichen Mitteln gewährte Beihilfen gleich welcher Art, die durch die Begünstigung bestimmter Unternehmen oder Produktionszweige den Wettbewerb verfälschen oder zu verfälschen drohen, mit dem Gemeinsamen Markt unvereinbar, soweit sie den Handel zwischen Mitgliedstaaten beeinträchtigen.

(2) Mit dem Gemeinsamen Markt vereinbar sind:

a) Beihilfen sozialer Art an einzelne Verbraucher, wenn sie ohne Diskriminierung nach der Herkunft der Waren gewährt werden;

b) Beihilfen zur Beseitigung von Schäden, die durch Naturkatastrophen oder sonstige außergewöhnliche Ereignisse entstanden sind;

c) Beihilfen für die Wirtschaft bestimmter, durch die Teilung Deutschlands betroffener Gebiete der Bundesrepublik Deutschland, soweit sie zum Ausgleich der durch die Teilung verursachten wirtschaftlichen Nachteile erforderlich sind.

(3) Als mit dem Gemeinsamen Markt vereinbar können angesehen werden: 
a) Beihilfen zur Förderung der wirtschaftlichen Entwicklung von Gebieten, in denen die Lebenshaltung außergewöhnlich niedrig ist oder eine erhebliche Unterbeschäftigung herrscht;

b) Beihilfen zur Förderung wichtiger Vorhaben von gemeinsamem europäischen Interesse oder zur Behebung einer beträchtlichen Störung im Wirtschaftsleben eines Mitgliedstaats;

c) Beihilfen zur Förderung der Entwicklung gewisser Wirtschaftszweige oder Wirtschaftsgebiete, soweit sie die Handelsbedingungen nicht in einer Weise verändern, die dem gemeinsamen Interesse zuwiderläuft. Beihilfen für den Schiffsbau, soweit sie am 1. Januar 1957 bestanden und lediglich einem fehlenden Zollschutz entsprechen, werden jedoch entsprechend den für die Abschaffung der Zölle geltenden Bestimmungen und vorbehaltlich der Vorschriften dieses Vertrags über die gemeinsame Handelspolitik gegenüber dritten Ländern schrittweise abgebaut;

d) Beihilfen zur Förderung der Kultur und der Erhaltung des kulturellen Erbes, soweit sie die Handels- und Wettbewerbsbedingungen nicht in einem Maß beeinträchtigen, das dem gemeinsamen Interesse zuwiderläuft; ${ }^{*}$

e) sonstige Arten von Beihilfen, die der Rat durch eine Entscheidung mit qualifizierter Mehrheit auf Vorschlag der Kommission bestimmt.

\section{Artikel 93}

(1) Die Kommission überprüft fortlaufend in Zusammenarbeit mit den Mitgliedstaaten die in diesen bestehenden Beihilferegelungen. Sie schlägt ihnen die zweckdienlichen Maßnahmen vor, welche die fortschreitende Entwicklung und das Funktionieren des Gemeinsamen Marktes erfordern.

(2) Stellt die Kommission fest, nachdem sie den Beteiligten eine Frist zur Äußerung gesetzt hat, daß eine von einem Staat oder aus staatlichen Mitteln gewährte Beihilfe mit dem Gemeinsamen Markt nach Artikel 92 unvereinbar ist oder daß sie mißbräuchlich angewandt wird, so entscheidet sie, daß der betreffende Staat sie binnen einer von ihr bestimmten Frist aufzuheben oder umzugestalten hat.

\footnotetext{
* Buchstabe d eingefügt gemäß Artikel G Nummer 18 des Vertrages über die Europäische Union.
} 
Kommt der betreffende Staat dieser Entscheidung innerhalb der festgesetzten Frist nicht nach, so kann die Kommission oder jeder betroffene Staat in Abweichung von den Artikeln 169 und 170 den Gerichtshof unmittelbar anrufen.

Der Rat kann einstimmig auf Antrag eines Mitgliedstaats entscheiden, daß eine von diesem Staat gewährte oder geplante Beihilfe in Abweichung von Artikel 92 oder von den nach Artikel 94 erlassenen Verordnungen als mit dem Gemeinsamen Markt vereinbar gilt, wenn außergewöhnliche Umstände eine solche Entscheidung rechtfertigen. Hat die Kommission bezüglich dieser Beihilfe das in Unterabsatz 1 dieses Absatzes vorgesehene Verfahren bereits eingeleitet, so bewirkt der Antrag des betreffenden Staates an den Rat die Aussetzung dieses Verfahrens, bis der Rat sich geäußert hat.

Äußert sich der Rat nicht binnen drei Monaten nach Antragstellung, so entscheidet die Kommission.

(3) Die Kommission wird von jeder beabsichtigten Einführung oder Umgestaltung von Beihilfen so rechtzeitig unterrichtet, daß sie sich dazu äußern kann. Ist sie der Auffassung, daß ein derartiges Vorhaben nach Artikel 92 mit dem Gemeinsamen Markt unvereinbar ist, so leitet sie unverzüglich das in Absatz 2 vorgesehene Verfahren ein. Der betreffende Mitgliedstaat darf die beabsichtigte Maßnahme nicht durchführen, bevor die Kommission eine abschließende Entscheidung erlassen hat.

\section{Artikel $94^{* *}$}

Der Rat kann auf Vorschlag der Kommission und nach Anhörung des Europäischen Parlaments mit qualifizierter Mehrheit alle zweckdienlichen Durchführungsverordnungen zu den Artikeln 92 und 93 erlassen und insbesondere die Bedingungen für die Anwendung des Artikels 93 Absatz 3 sowie diejenigen Beihilfen festlegen, die von diesem Verfahren ausgenommen sind.

\footnotetext{
** In der Fassung des Artikels G Nummer 19 des Vertrages über die Europäische Union.
} 
Manfred Rosenstock - 978-3-631-75198-5

Downloaded from PubFactory at 01/11/2019 07:13:36AM

via free access 


\section{LITERATURVERZEICHNIS}

\section{Publikationen der Organe der Europäischen Gemeinschaften}

EG (Europäische Gemeinschaften), 1987, Verträge zur Gründung der Europäischen Gemeinschaften, 2 Bde., Luxemburg.

EG, Bulletin, 1972, Beihilfen für den Schiffbau: Neue Vorschläge der Kommission, Nr. 1, S. 45-47.

-, 1981, Sanierung der Eisen- und Stahlindustrie, Nr. 3, S. 95-97.

-, 1982, Sektorale Beihilfen - Stahlindustrie: Belgien, Nr. 3, S. 39-40.

-, 1982a, Ausfuhren von Stahlerzeugnissen, Nr. 10, S. 14-15.

-, 1982b, Wettbewerb - Staatliche Beihilfen, Nr. 7/8, S. 29

-, 1984, Sektorale Beihilfen - Stahlindustrie, Nr. 12, S. 62-63.

-, 1984a, Anwendung der Artikel 92 und 93 EWG-Vertrag auf staatliche Beteiligungen, Nr. 9, S. 98-100.

-, 1986, Neue Politik gegenüber Beihilfen für den Schiffbau, Nr. 10, S. 10-12.

-, 1988, Stahlpolitik - Die Stahlindstrie in der Gemeinschaft, Nr. 7/8, S. 20.

EG (Europäische Gemeinschaften), Kommission, 1968-1993, 1.-26. Gesamtbericht über die Tätigkeit der Europäischen Gemeinschaften, Brüssel-Luxemburg.

-, 1970b, Die Industriepolitik der Gemeinschaft, Memorandum der Kommission an den Rat, Brüssel.

-, 1971b, Mitteilung der Kommission - Allgemeine Beihilferegelungen mit regionaler Zwecksetzung, in: ABl. C 111, S. 7-13.

-, 1971c, Gemeinschaftsrahmen für die Beihilfen zugunsten der Textilindustrie, SEC(71) 363 endg.

-, 1972a-1994a, 1.-23. Bericht über die Wettbewerbspolitik, Brüssel-Luxemburg.

-, 1972b, Antwort auf die Schriftliche Anfrage Nr. 398/71 von Herrn Vredeling an die Kommission der Europäischen Gemeinschaften, in: ABl. C 35, S. 6-7.

-, 1972c, Abkommen zwischen der Europäischen Wirtschaftsgemeinschaft und der Republik Österreich, in: AB1. L 300, S. 2-93.

-, 1973b, Entwurf einer Richtlinie des Rates über die Gewährung von Beihilfen für den Schiffbau, in: ABl. C 114, S. 23-27.

-, 1974b, "Gemeinschaftsrahmen" für staatliche Umweltschutzbeihilfen, Mitteilung an die Mitgliedstaaten S/74/30807 vom 7.11., abgedruckt in: Dies., Wettbewerbsrecht in den Europäischen Gemeinschaften, Band II: Wettbewerbsregeln für staatliche Beihilfen, Brüssel-Luxemburg, 1990. 
-, 1975b, Vorschlag einer Richtlinie des Rates betreffend die Beihilfen für den Schiffbau, KOM(75) 195 endg., Brüssel.

-, 1975c, La Situation actuelle et les Perspectives d'avenir de l'Industrie automobile de la Communauté, Document de travail - DG III, 10 Février.

-, 1975d, Critères d'acceptation d'aides publiques à l'industrie automobile, Document de travail - DG IV, 17 Mars.

-, 1976b, Mitteilung der Kommission an den Rat zur Lage im Schiffbau, KOM(76) 224 endg., Brüssel.

-, 1976c, Mitteilung über ein Arbeitsprogramm bezüglich der europäischen Automobilindustrie, Vermerk für die Kommission, SEC(76) 4407.

-, 1977b, Schiffbau - Sanierungsprogramm, Beılage 7/77 zum Bulletin der Europäischen Gemeinschaften.

-, 1977c, Vorschlag einer Richtlinie des Rates betreffend die Beihilfen für den Schiffbau, in: AB1. C 294, S. 4-7.

-, 1977d, Prüfung der gegenwärtigen Lage auf dem Gebiet der Beihilfen zugunsten der Textil- und Bekleidungsindustrie, Schreiben an die Mitlgliedstaaten SG(77) D/1190 vom 4.2. und Anlage Dok. SEK(77) 317 vom 25.1., abgedruckt in: Dies., Wettbewerbsrecht in den Europäischen Gemeinschaften, Band II: Wettbewerbsregeln für staatliche Beihilfen, Brüssel-Luxemburg, 1990.

-, 1978b, Entwurf der Entscheidung der Kommission zur Einführung von gemeinschaftlichen Bestimmungen über Beihilfen und Interventionen der Mitgliedstaaten zugunsten der Eisen- und Stahlindustrie, $\operatorname{KOM}(78) 175$ endg., Brüssel.

-, 1978c. Mitteilung an den Rat über die Politik der Kommission auf dem Gebiet der sektoralen Beihilfen, $\operatorname{KOM}(78) 221$ endg., Brüssel.

-, 1979b, Erster Halbjahresbericht über die Lage der Schiffbauindustrie in der Gemeinschaft, Beilage 7/79 zum Bulletin der Europäischen Gemeinschaften.

-, 1979c, Entwurf der Entscheidung der Kommission zur Einführung von gemeinschaftlichen Bestimmungen über spezifische Beihilfen zugunsten der Eisen- und Stahlindustrie, K(79) 70/3, Brüssel.

-, 1979d, Mitteilung (Anwendung der Koordinierungsgrundsätze der regionalen Beihilferegelungen, in: ABl. C 31, S. 9-15.

-, 1979e, Meldung wichtiger Einzelfälle bei Investitionsbeihilfen, Schreiben an die Mitgliedstaaten SG(79) D/10478 vom 14.9., abgedruckt in: Dies., Wettbewerbsrecht in den Europäischen Gemeinschaften, Band II: Wettbewerbsregeln für staatliche Beihilfen, Brüssel-Luxemburg, 1990.

-, 1980b, Vorschlag einer Richtlinie des Rates betreffend die Beihilfen für den Schiffbau, in: ABl. C 261, S. 3-7. 
-, 1980c, Bericht über die Lage der Schiffbauindustrie in der Gemeinschaft (Stand am 1. Januar 1980), KOM(80) 443 endg., Brüssel.

-, 1980d, Entscheidung Nr. 257/80/EGKS der Kommission vom 1. Februar 1980 zur Einführung von gemeinschaftlichen Regeln über spezifische Beihilfen zugunsten der Eisen- und Stahlindustrie, in: ABl. L 29, S. 5-8.

-, 1980e, Entscheidung Nr. 257/80/EGKS der Kommission vom 1. Februar 1980 zur Einführung von gemeinschaftlichen Regeln über spezifische Beihilfen zugunsten der Eisen- und Stahlindustrie, in: ABl. L 29, S. 5-8.

-, 1980f, Schreiben an die Mitgliedstaaten SG(80) D/8287 vom 7.7. (Umweltschutzbeihilfen), abgedruckt in: Dies., Wettbewerbsrecht in den Europäischen Gemeinschaften, Band II: Wettbewerbsregeln für staatliche Beihilfen, BrüsselLuxemburg, 1990.

-, 1980g, Die Unterrichtung der Kommission über staatliche Beihilfen gemäß Artikel 93 Absatz 3 EWGV - Nichterfüllung ihrer Verpflichtungen durch die Mitgliedstaaten, in: ABl. C 252, S. 2.

-, 1980h, Richtlinie 80/723/EWG der Kommission vom 25. Juni 1980 über die Transparenz der finanziellen Beziehungen zwischen den Mitgliedstaaten und den öffentlichen Unternehmen, in: AB1. L 195, S. 35-37.

-, 1981b, Bericht über die Lage der Schiffbauindustrie in der Gemeinschaft (Stand am 1. Januar 1981), KOM(81) 432 endg., Brüssel.

-, 1981c, Entscheidung Nr. 2320/81/EGKS der Kommission vom 7. August 1981 zur Einführung gemeinschaftlicher Regeln für Beihilfen zugunsten der Eisen- und Stahlindustrie, in: ABl. L 228, S. 14-18.

-, 1981d, Entscheidung Nr. 2320/81/EGKS der Kommission vom 7. August 1981 zur Einführung gemeinschaftlicher Regeln für Beihilfen zugunsten der Eisen- und Stahlindustrie, in: ABl. L 228, S. 14-18.

-, 1981e, Erster Bericht über die Anwendung der Beihilferegelung zugunsten der Eisen- und Stahlindustrie, KOM(81) 71 endg., Brüssel.

-, 1981f, The European Automobile Industry, Commission Statement, COM(81) 317 final, Brussels.

-, 1981g, Industrie automobile européenne: Structures et perspectives (SEC(81) 821), Note d'information P-36, Bruxelles.

-, 1982b, Bericht der Kommission an den Rat über die Lage der Schiffbauindustrie in der Gemeinschaft (Stand am 1. Januar 1982), KOM(82) 564 endg., Brüssel.

-, 1982c, Zweiter Bericht über die Anwendung der Regeln für Beihilfen zugunsten der Eisen- und Stahlindustrie, KOM(82) 34 endg., Brüssel.

-, 1982d, Zweiter Bericht über die Anwendung der Regeln für Beihilfen zugunsten der Eisen- und Stahlindustrie - Addendum, $\operatorname{KOM}(82) 344$ endg., Brüssel. 
-, 1982e, Beihilfen für die Stahlindustrie - Erste Runde, P-74, Brüssel, November.

-, 1983b, Bericht der Kommission an den Rat: Beihilfen zugunsten des Schiffbaus in der Gemeinschaft, $\mathrm{KOM}(83) 676$ endg., Brüssel.

-, 1983c, Orientierungen für die Umstrukturierung im Schiffbausektor (Bericht der Kommission), KOM(83) 65 endg., Brüssel.

-, 1983d, Bericht der Kommission an den Rat über die Lage der Schiffbauindustrie in der Gemeinschaft (Stand Anfang 1983), KOM(83) 483 endg., Brüssel.

-, 1983e, Dreißig Jahre Gemeinschaftsrecht, Sammlung Europäische Perspektiven, Brüssel.

-, 1983f, Vierter Bericht über die Anwendung der Regeln für Beihilfen zugunsten der Eisen- und Stahlindustrie, KOM(83) 178 endg., Brüssel.

-, 1983g, Entscheidungen 83/391 - 83/399/EGKS der Kommission über die von den Regierungen der Mitgliedstaaten vorgesehenen Beihilfen zugunsten der Stahlindustrie, in: ABl. L 227, S. 1-40.

-, 1983h, Mitteilung (Unrechtmäßig gewährte Beihilfen), in: ABl. C 318, S. 3.

-, 1983i, Commission activities and EC rules for the Automobile Industry 1981/ 1983, $\operatorname{COM(83)~} 633$ final, Brussels.

-, 1984b, Vorschlag für eine Richtlinie des Rates zur Änderung der Richtlinie 81/363/EWG über Beihilfen für den Schiffbau, $\operatorname{KOM(84)~} 73$ endg., Brüssel.

-, 1984c, Bericht der Kommission an den Rat: Staatliche Beihilfen an den Schiffbau im ersten Halbjahr 1983, KOM(84) 236 endg., Brüssel.

-, 1984d, Bericht der Kommission an den Rat über die Lage der Schiffbauindustrie in der Gemeinschaft (Stand Anfang 1984), KOM(84) 550 endg., Brüssel.

-, 1984e, Fünfter Bericht über die Anwendung der Regeln für Beihilfen an die Eisenund Stahlindustrie, $\mathrm{KOM}(84) 142$ endg., Brüssel.

-, 1984f, Staatliche Beihilfen (Artikel 92 bis 94 des Vertrages zur Gründung der EWG), Mitteilung der Kommission, in: ABl. C 34, S. 3.

-, 1985b, Bericht der Kommission an den Rat: Staatliche Beihilfen zugunsten der Schiffbauindustrie in den Jahren 1983 und 1984, KOM(85) 728 endg., Brüssel.

-, 1985c, Bericht der Kommission an den Rat über die Lage der Schiffbauindustrie in der Gemeinschaft (Stand Anfang 1985), KOM(85) 548 endg., Brüssel.

-, 1985d, Entscheidung Nr. 3484/85/EGKS der Kommission vom 27. November 1985 zur Einführung gemeinschaftlicher Vorschriften für die Beihilfen zugunsten der Eisen- und Stahlindustrie, in: AB1. L 340, S. 1-4.

-, 1985e, Die Vollendung des Binnenmarktes, Weißbuch der Kommission an den Rat, Brüssel. 
-, 1985f, Entscheidung Nr. 1018/85/EGKS der Kommission vom 19. April 1985 zur Änderung der Entscheidung Nr. 2320/81/EGKS zur Einführung gemeinschaftlicher Regeln für Beihilfen zugunsten der Eisen- und Stahlindustrie, in: ABl. L 110, S. 5/6.

-, 1985g, Regeln für Beihilfen und Finanztransfers zugunsten der Stahlindustrie der Gemeinschaft nach 1985, KOM(85) 515 endg., Brüssel.

-, 1985h, Entscheidung Nr. 3484/85/EGKS der Kommission vom 27. November 1985 zur Einführung gemeinschaftlicher Vorschriften für die Beihilfen zugunsten der Eisen- und Stahlindustrie, in: ABl. L 340, S. 1-4.

-, 1985i, Regeln im Fall der Kumulierung von Beihilfen mit unterschiedlicher Zielsetzung, in: ABl. C 3, S. 2-3.

-, 1985k, Richtlinie 85/413/EWG der Kommission vom 24. Juli 1985 zur Änderung der Richtlinie 80/723/EWG über die Transparenz der finanziellen Beziehungen zwischen den Mitgliedstaaten und den öffentlichen Unternehmen, in: ABl. L 229, S. 20-21.

-, 1985m, Entscheidung der Kommission vom 19. Dezember 1984 über die französische Beihilferegelung für die Industrie in Form von Sonderdarlehen für Investitionen, Vorzugsdarlehen für Unternehmen, Zusatzdarlehen für Refinanzierungen und Darlehen des Industriellen Modernisierungsfonds, in ABl. L 216, S. 12-19.

-, 1986b, Vorschlag für eine Richtlinie des Rates über Beihilfen für den Schiffbau, in: AB1. C 281, S. 4-8.

-, 1986c, Leitlinien für eine künftige Beihilfenstrategie für den Schiffbau (Mitteilung der Kommission an den Rat), KOM(86) 324 endg., Brüssel.

-, 1986d, Schiffbau: Industrielle, soziale und regionale Aspekte (Mitteilung der Kommission an den Rat), $\operatorname{KOM(86)~} 553$ endg., Brüssel.

-, 1986e, Bericht über die Anwendung der Regeln für Beihilfen an die Eisen- und Stahlindustrie 1984-1985, KOM(86) 235 endg., Brüssel.

-, 1986f, Bericht der Kommission an den Rat über die Ausführung der allgemeinen Ziele Stahl 1990, KOM(86) 515 endg., Brüssel.

-, 1986g, Gemeinschaftsrahmen für staatliche Forschungs- und Entwicklungsbeihilfen, in: ABl. C 83, S. 2-6.

-, 1986h, Staatliche Beihilfen (Artikel 92 bis 94 des Vertrages zur Gründung der EWG), Mitteilung der Kommission, in: ABl. C 144, S. 3.

-, 1986i, Staatliche Beihilfen (Artikel 92 bis 94 des Vertrages zur Gründung der EWG), Mitteilung der Kommission, in: ABl. C 269, S. 3.

-, 1986j, Staatliche Beihilfen (Artikel 92 bis 94 des Vertrages zur Gründung der EWG), Mitteilung der Kommission, in: AB1. C 336, S. 4-5. 
-, 1987b, Schiffbau: Industrielle, soziale und regionale Aspekte (zweite Mitteilung der Kommission), KOM(87) 275 endg./2, Brüssel.

-, 1987c, Staatliche Beihilfen (Artikel 92 bis 94 des Vertrages zur Gründung der EWG), Mitteilung der Kommission, in: ABl. C 213, S. 4-5.

-, 1987d, Staatliche Beihilfen - Italien (Artikel 92 bis 94 des Vertrages zur Gründung der EWG), Mitteilung der Kommission, in: ABl. C 276, S. 5.

-, 1987e, Staatliche Beihilfen - Frankreich (Artikel 92 bis 94 des Vertrages zur Gründung der EWG), Mitteilung der Kommission, in: ABI. C 289, S. 10.

-, 1987f, Staatliche Beihilfen (Artikel 92 bis 94 des Vertrages zur Gründung der EWG), Mitteilung der Kommission, in: ABl. C 24, S. 7.

-, 1988b, Sanierung des Schiffbaus auf internationaler Ebene: Die Kommission erwägt Verhandlungen mit Japan und Korea, Informatorische Aufzeichnung P-39, Brüssel.

-, 1988c, Bericht über die Lage der Schiffbauindustrie in der Gemeinschaft Stand Anfang 1988 (von der Kommission vorgelegt), KOM(88) 723 endg., Brüssel.

-, 1988d, Framework for certain steel sectors not covered by the ECSC Treaty, in: ABl. C 320, S. 3-7.

-, 1988e, Commission Decisions on Steel, IP(88) 575, Brüssel, 28. September.

-, 1988f, Mitteilung über die Methode zur Anwendung von Artikel 92 Absätze 3 a und c auf Regionalbeihilfen, in: AB1. C 212, S. 2-10.

-, 1988g, Staatliche Beihilfen - Spanien (Artikel 92 bis 94 des Vertrages zur Gründung der EWG), Mitteilung der Kommission, in: ABl. C 124, S. 4-5.

-, 1988h, Staatliche Beihilfen - Italien (Artikel 92 bis 94 des Vertrages zur Gründung der EWG), Mitteilung der Kommission, in: ABl. C 213, S. 4.

-, 1988i, Staatliche Beihilfen - Frankreich (Artikel 92 bis 94 des Vertrages zur Gründung der EWG), Mitteilung der Kommission, in: ABl. C 60, S. 2.

-, 1988j, Staatliche Beihilfen (Artikel 92 bis 94 des Vertrages zur Gründung der EWG), Mitteilung der Kommission, in: ABl. C 106, S. 2.

-, 1988k, Mitteilung der Kommission über die Methode zur Anwendung von Artikel 92 Absätze 3 a und c auf Regionalbeihilfen, in: ABl. C 212, S. 2-10.

-, 19881, Staatliche Beihilfen - Frankreich (Artikel 92 bis 94 des Vertrages zur Gründung der EWG), Mitteilung der Kommission, in: ABl. C 39, S. 3.

-, 1988m, Entscheidung der Kommission vom 29. März 1988 über die von der französischen Regierung gewährten Beihilfen für die Unternehmensgruppe Renault, ein hauptsächlich Kraftfahrzeuge herstellendes Unternehmen, in ABl. L 220, S. $30-40$. 
-, 1989b, Bericht der Kommission an den Rat und das Europäische Parlament über die Durchführung der sechsten Richtlinie des Rates über Beihilfen für den Schiffbau 1987-1988, SEK(89) 518 endg., Brüssel.

-, 1989c, Staatliche Beihilfen C 12/89 Italien (Art. 92 bis 94 des Vertrages zur Gründung der Europäischen Wirtschaftsgemeinschaft), in: ABl. C 293, S. 3.

-, 1989d, Entscheidung Nr. 322/89/EGKS der Kommission vom 1. Februar 1989 zur Einführung gemeinschaftlicher Vorschriften über Beihilfen an die Eisen- und Stahlindustrie, in: AB1. L 38, S. 8-11.

-, 1989e, Entscheidung der Kommission vom 23. Dezember 1988 betreffend Beihilfen der italienischen Regierung an staatseigene Stahlunternehmen, in: ABl. L 86, S. 76-81.

-, 1989f, Entscheidung Nr. 322/89/EGKS der Kommission vom 1. Februar 1989 zur Einführung gemeinschaftlicher Vorschriften über Beihilfen an die Eisen- und Stahlindustrie, in: AB1. L 38, S. 8-11.

-, 1989g, Schreiben an die Mitgliedstaaten SG(89) D/5521 vom 27.4. (Vorherige Notifizierung der staatlichen Beihilfevorhaben und Prüfung durch die Kommission), abgedruckt in: Dies., Wettbewerbsrecht in den Europäischen Gemeinschaften, Band II: Wettbewerbsregeln für staatliche Beihilfen, Brüssel-Luxemburg, 1990, S. 19.

-, 1989h, Schreiben an die Mitgliedstaaten SG(89) D4328 vom 5.4. (Staatliche Bürgschaften), abgedruckt in: Dies., Wettbewerbsrecht in den Europäischen Gemeinschaften, Band II: Wettbewerbsregeln für staatliche Beihilfen, Brüssel-Luxemburg, 1990, S. 38.

-, 1989i, Schreiben an die Mitgliedstaaten SG(89) D12772 vom 12.10. (Staatliche Bürgschaften), abgedruckt in: Dies., Wettbewerbsrecht in den Europäischen Gemeinschaften, Band II: Wettbewerbsregeln für staatliche Beihilfen, BrüsselLuxemburg, 1990, S. 39.

-, 1989j, Erster Bericht über staatliche Beihilfen in der Europäischen Gemeinschaft, Brüssel-Luxemburg.

-, 1989k, Entscheidung der Kommission vom 13. Juli 1988 betreffend die Beihilfe der britischen Regierung an den Kraftfahrzeughersteller Rover Group, in: ABl. L 25, S. 92-100.

-, 19891, Entscheidung der Kommission vom 3.5.1989 über eine Beihilfe der spanischen Regierung an ENASA, Hersteller von Nutzfahrzeugen mit dem Markennamen "Pegaso", in: ABl. L 367, S. 62-70.

-, 1989m, Gemeinschaftsrahmen für staatliche Beihilfen in der Kfz-Industrie, in: ABl. C 123, S. 3-11.

-, 1989n, Entscheidung der Kommission vom 31.5.1989 über eine Beihilfe der italienischen Regierung an Alfa Romeo (Unternehmen im Kraftfahrzeugsektor), in: AB1. L 394, S. 9-18. 
-, 1989o, Entscheidung der Kommission vom 21.12.1988 betreffend die Beihilfen der französischen Regierung zugunsten des Automobilunternehmens Peugeot SA, in ABl. L 123, S. 52-58.

-, 1989p, Peugeot repays state aid following negative commission decision, Mitteilung an die Presse IP(89)452.

-, 1989q, Renault Case, Mitteilung an die Presse IP(89)864.

-, 1989r, Staatliche Beihilfen N497/88 - Niederlande (Artikel 92 bis 94 des Vertrages zur Gründung der EWG), Mitteilung der Kommission, in: ABl. C 281, S. 36.

-, 1989s, Staatliche Beihilfen E4/89 - Bundesrepublik Deutschland (Artikel 92 bis 94 des Vertrages zur Gründung der EWG), Mitteilung der Kommission, in: ABl. C 281, S. 6-7.

-, 1989t, Staatliche Beihilfen E5/89 - Spanien (Artikel 92 bis 94 des Vertrages zur Gründung der EWG), Mitteilung der Kommission, in: ABl. C 281, S. 8-9.

-, 1990b, Vorschlag für eine Richtlinie des Rates über Beihilfen für den Schiffbau, KOM(90) 248 endg., Brüssel.

-, 1990c, Bericht über die Anwendung der Beihilferegeln in der Stahlindustrie 19861988, SEK(90) 18 endg., Brüssel.

-, 1990d, Allgemeine Ziele Stahl 1995, KOM(90) 201 endg., Brüssel.

-, 1990e, Anmeldung von Beihilferegelungen von geringer Bedeutung, in ABl. C 40, S. 2.

-, 1990f, Industriepolitik in einem offenen und wettbewerbsorientierten Umfeld, KOM(90) 556 endg., Brüssel.

-, 1990g, Zweiter Bericht über staatliche Beihilfen in der Europäischen Gemeinschaft im verarbeitenden Gewerbe und in einigen weiteren Wirtschaftssektoren, Brüssel-Luxemburg.

-, 1990h, Staatliche Beihilfen C 33/89 - Spanien (Artikel 92 bis 94 des Vertrages zur Gründung der EWG), Mitteilung der Kommission, in: AB1. C 159, S. 13.

-, 1990i, Commission Decision of 21 February 1990 amending German aid schemes for the motor vehicle industry, in: ABl. L 188, S. 55-60.

-, $1990 \mathrm{j}$, A Single Community Motor-vehicle Market, Communication from the Commission, SEC(89) 2118 final, Brüssel.

-, 1990k, Commission renews framework on state aid to the motor vehicle industry, Mitteilung an die Presse, IP(90)1006.

-, 19901, Commission opens procedure on Belgian car project, Mitteilung an die Presse IP(90)309.

-, 1991b, Bericht über die Anwendung der Vorschriften über staatliche Beihilfen an die Eisen- und Stahlindustrie, SEK(91) 1681 endg., Brüssel. 
-, 1991c, Staatliche Beihilfen C 5/90 (ex NN 90/89) Spanien, Mitteilung der Kommission, in: ABl. C 54, S. 2.

-, 1991d, Entscheidung der Kommission vom 5. Juni 1991 über die von der autonomen Region Sardinien zugunsten des Unternehmens Ferriere Acciaierie Sarde gewährte Beihilfe, in: ABl. L 298, S. 1-3.

-, 1991e, Entscheidung Nr. 3855/91/EGKS der Kommission vom 27. November 1991 zur Einführung gemeinschaftlicher Vorschriften über Beihilfen an die Eisenund Stahlindustrie, in: ABl. L 362, S. 57-60.

-, 1991g, Mitteilung der Kommission an die Mitgliedstaaten: Anwendung der Artikel 92 und 93 EWG-Vertrag und des Artikels 5 der Richtlinie 80/723/EWG der Kommission über öffentliche Unternehmen in der verarbeitenden Industrie, ABl. C 273, S. 2-17.

-, 1991h, Staatliche Beihilfen, C 45/91 (ex N 255/91) - Italien (Artikel 92 bis 94 des Vertrages zur Gründung der EWG), Mitteilung der Kommission, in: ABl. C 299, S. 4-8.

-, 1991i, Genehmigung staatlicher Beihilfen nach den Artikeln 92 und 93 EWGVertrag. Fälle, in denen die Kommission keine Einwände erhebt, in: ABl. C 257, S. 5-7.

-, 1991j, Gemeinschaftsrahmen für staatliche Beihilfen an die Kraftfahrzeug-Industrie, in: ABl. C 81, S. 4.

-, 1991k, Staatliche Beihilfen, C 8/88 (vormals N 119/88) - Vereinigtes Königreich (Artikel 92 bis 94 des Vertrages zur Gründung der EWG), Mitteilung der Kommission, in: ABI. C 21, S. 2-10.

-, 19911, Staatliche Beihilfen, C 38/87 - Frankreich, (Artikel 92 bis 94 des Vertrages zur Gründung der EWG), Mitteilung der Kommission, in: ABl. C 11, S. 3-9.

-, 1991m, Genehmigung staatlicher Beihilfen nach den Artikeln 92 und 93 EWGVertrag. Fälle, in denen die Kommission keine Einwände erhebt, in: ABl. C 160, S. 4-5.

-, 1991n, Entscheidung der Kommission vom 28.11.1990 betreffend Pläne der belgischen Region Brüssel zur Gewährung von Beihilfen für den $\mathrm{Kfz}-\mathrm{Hersteller}$ Volkswagen Bruxelles SA, in: ABl. L 123, S. 46-50.

-, 1991o, Staatliche Beihilfen C 32/89 (ex N 497/88) - Niederlande (Artikel 92 bis 94 des Vertrages zur Gründung der EWG), Mitteilung der Kommission, in: ABl. C 143, S. 6-9.

-, 1992b, Gemeinschaftsrahmen für Beihilfen zugunsten der Kunstfaserindustrie, in: AB1. C 346, S. 2-3.

-, 1992c, Gemeinschaftsrahmen für staatliche Beihilfen an kleine und mittlere Unternehmen, in: ABl. C 213, S. 2-9. 
-, 1992d, Dritter Bericht über staatliche Beihilfen in der Europäischen Gemeinschaft im verarbeitenden Gewerbe und in einigen weiteren Sektoren, Brüssel-Luxemburg.

-, 1992e, Kommission verweist drei italienische Beihilfefälle an den Gerichtshof, IP(92)662, 31. Juli.

-, 1992f, Entscheidung der Kommission vom 14. April 1992 über eine Beihilfe des Landes Berlin an die Daimler-Benz AG, Deutschland (C 3/91 ex NN 5/91), in ABl. L 263, S. 15-25.

-, 1992g, Die europäische Automobilindustrie: Situation und vorrangige Aktionen, Mitteilung der Kommission, KOM(92) 166 endg., Brüssel.

-, 1992h, Staatliche Beihilfen C 61/91 (ex NN 74/91 und 80/91) - Deutschland (Artikel 92 bis 94 des Vertrages zur Gründung der EWG), Mitteilung der Kommission, in: ABl. C 68, S. 8-13.

-, 1992i, Commission examines a series of aids in New Länder and Berlin, Mitteilung an die Presse IP(91)1174.

-, 1992j, Staatliche Beihilfen C 60/91 (ex NN 73/91 und 76/91) - Deutschland (Artikel 92 bis 94 des Vertrages zur Gründung der EWG), Mitteilung der Kommission, in: ABl. C 68, S. 2-7.

-, 1992k, Staatliche Beihilfen C 5/92 (ex NN 23/92) - Vereinigtes Königreich (Artikel 92 bis 94 des Vertrages zur Grünaung der EWG), Mitteilung der Kommission, in: ABl. C 122, S. 3-5.

-, 19921, Entscheidung der Kommission vom 31.7.1991 über Beihilfen des Derbyshire County Council zugunsten des Kraftfahrzeugherstellers Toyota Motor Corporation, in: ABl. L 6, S. 36-44.

-, 1992m, Staatliche Beihilfen C 3/92 (ex N 645/91) - Niederlande (Artikel 92 bis 94 des Vertrages zur Gründung der EWG), Mitteilung der Kommission, in: ABI. C 105, S. 16-21.

-, 1992n, Staatliche Beihilfen C 62/91 (ex NN 75/91, 77/91, 78/91 und 79/91) Deutschland (Artikel 92 bis 94 des Vertrages zur Gründung der EWG), Mitteilung der Kommission, in: ABl. C 68, S. 14-19.

-, 1993b, Leitfaden für die Anwendung der im Gemeinschaftsrahmen für Beihilfen an KMU vorgesehenen "De-minimis"-Regelung, Schreiben Nr. IV/D/6878 der DG IV an die Mitgliedstaaten vom 23.3., abgedruckt in: EG, Kommission 1994a, S. 453-454.

-, 1993c, Richtlinie 93/84/EWG der Kommission vom 30. September 1993 zur Änderung der Richtlinie 80/723/EWG über die Transparenz der finanziellen Beziehungen zwischen den Mitgliedstaaten und den öffentlichen Unternehmen, ABl. L 254, S. 16-18. 
-, 1993d, Mitteilung der Kommission an die MS: Anwendung der Art. 92 und 93 EWG-Vertrag und des Artikels 5 der Kommissionsrichtlinie 80/723/EWG über öffentliche Unternehmen in der verarbeitenden Industrie, ABl. C 307, S. 3-14.

-, 1993e, Kommission genehmigt deutsche Entwicklungshilfe an Indonesien für den Bau zweier Containerschiffe durch die Mathias-Thesen-Werft in Wismar, IP(93) 127, Brüssel.

-, 1993f, Kommission genehmigt Änderung der deutschen Wettbewerbshilfe für den Schiffbau, IP(93) 47, Brüssel.

-, 1993g, Kommission beschließt, die Freigabe einer zweiten Beihilfentranche für die Warnow-Werft in Warnemünde - Mecklenburg-Vorpommern (Deutschland) zu genehmigen, IP(93) 1210, Brüssel.

-, 1993h, Bericht der Kommission über den Stand der Schiffbauindustrie in der Gemeinschaft, Stand 1992, KOM(93) 562 endg., Brüssel.

-, 1993i, Kommission ordnet Rückzahlung der Beihilfe von British Aerospace für ihren Erwerb der Rover Group Holdings an, IP(93)167, 10. März.

-, 1993j, British Aerospace zahlt Beihilfe der britischen Regierung für Erwerb des Unternehmens Rover zurück, IP(93)405, 26. Mai.

-, 1993k, Durchführung der mit Österreich geschlossenen Vereinbarung über die Verringerung von Beihilfen an das Chrysler-Autowerk in Graz, IP(93)200, 19. März.

-, 19931, Kommission genehmigt Ausfallbürgschaften der Treuhand für Sächsische Automobilbau GmbH, IP(93) 479, 16. Juni.

-, 1993m, Die Kommission führt bei staatlichen Beihilfen ein Anmeldungsverfahren und standardisierte Berichte ein, IP(93)215, 24. März.

-, 1993o, State Aid C 45/91 (ex N 255/91) - Italy, (Articles 92 to 94 of the Treaty establishing the EEC, Commission notice, in: ABl. C 37, S. 15-19.

-, 1993p, Staatliche Beihilfen C 60/91 (ex NN 75/91, NN 76/91) - Deutschland, (Artikel 92 bis 94 des Vertrages zur Gründung der EWG), Mitteilung der Kommission, in: ABl. C 31, S. 14-20.

-, 1993q, The Community framework for State aid to the motor vehicle industry, in: ABl. C 36, S. 17.

-, 1993r, Commission Decision of 9 March 1993 concerning aid provided by the Untied Kingdom Government to British Aerospace for its purchase of Rover Group Holdings over and above those authorized in Commission Decision 89/58/EEC authorizing a maximum aid to this operation subject to certain conditions, in: ABl. L 143, S. 7-16.

-, 1994b, Staatliche Beihilfen C 36/93 (NN 27/93) - Belgien, (Artikel 92 bis 94 des Vertrages zur Gründung der EG), Mitteilung der Kommission, in: ABl. C 31, S. 4-8. 
-, 1994c, Staatliche Beihilfen C 38/93 (NN 43/93 und NN 58/93) - Niederlande, (Artikel 92 bis 94 des Vertrages zur Gründung der EG), Mitteilung der Kommission, in: ABl. C 31, S. 9-16.

-, 1994d, Community competition policy in 1993, Brüssel-Luxemburg.

-, 1994e, Commission approves aid towards restructuring of EKO Stahl, IP(94) 1275, 21. Dezember.

-, 1994f, Commission adopts the second monitoring report on the implementation of the restructuring of steel companies, IP(94) 985, 26. Oktober.

-, 1994g, Commission decides on conditions that the sale of the government's share in Netherlands Car BV (NedCar) does not contain elements of State aids, IP(94) 891, 28. September.

-, 1994h, La Commission prend une décision finale sur des aides d'État en faveur de projets de restructuration mis en oeuvre par VW dans les nouveaux Länder, IP(94) 727, 27. Juli.

-, 1994i, Leitlinien für die Beurteilung von staatlichen Beihilfen zur Rettung und Umstrukturierung von Unternehmen in Schwierigkeiten, in: ABl. C 368, S. 1220.

EG (Europäische Gemeinschaften), Rat, 1969, Richtlinie des Rates vom 28. Juli 1969 über die Gewährung von Beihilfen für den Schiffbau zum Ausgleich der Wettbewerbsverzerrungen auf dem internationalen Markt, in: ABl. L 206, S. 2526.

-, 1971, Entschließung vom 20.10. (Grundsätzliche Regelungen auf dem Gebiet der Regionalbeihilfen, in: ABl. C 111, S. 1-6.

-, 1972, Richtlinie des Rates vom 20. Juli 1972 betreffend die Beihilfen für den Schiffbau, in: ABl. L 169, S. 28-30.

-, 1974, Richtlinie des Rates vom 17. Dezember 1973 zur Verlängerung der Geltungsdauer der Richtlinie vom 20. Juli 1972 über die Gewährung von Beihilfen für den Schiffbau, in: ABl. L 38, S. 1.

-, 1974a, Richtlinie des Rates vom 27. Juni 1974 zur Verlängerung der Geltungsdauer der Richtlinie 72/273/EWG über die Gewährung von Beihilfen für den Schiffbau, in: ABl. L 180, S. 32.

-, 1974b, Richtlinie des Rates vom 19. Dezember 1974 zur Verlängerung der Geltungsdauer der Richtlinie 72/273/EWG betreffend die Beihilfen für den Schiffbau, in: ABl. L 349, S. 62.

-, 1975, Richtlinie des Rates vom 10. Juli 1975 betreffend die Beihilfen für den Schiffbau, in: ABl. L 192, S. 27-29.

-, 1976, Richtlinie des Rates vom 16. November 1976 zur Änderung der Richtlinie 75/432/EWG betreffend die Beihilfen für den Schiffbau, in: ABI. L 320, S. 27. 
-, 1978, Entschließung des Rates vom 19. September 1978 über die Sanierung des Schiffbaus, in: ABl. C 229, S. 1-2.

-, 1978a, Richtlinie des Rates vom 4. April 1978 betreffend die Beihilfen für den Schiffbau, in: ABl. L 98, S. 19-22.

-, 1981, Richtlinie des Rates vom 28. April 1981 betreffend die Beihilfen für den Schiffbau, in: ABI. L 137, S. 39-43.

-, 1982, Richtlinie des Rates vom 21. Dezember 1982 zur Änderung der Richtlinie 81/363/EWG betreffend die Beihilfen für den Schiffbau, in: ABl. L 371, S. 46.

-, 1987, Richtlinie des Rates vom 26. Januar 1987 über Beihilfen für den Schiffbau, in: AB1. L 69, S. 55-64.

-, 1990, Richtlinie des Rates vom 21. Dezember 1990 über Beihilfen für den Schiffbau, in: ABl. L 380, S. 27-36.

-, 1992, Richtlinie des Rates vom 20.7.1992 zur Änderung der Richtlinie 90/684/EWG über Beihilfen für den Schiffbau, in: ABI. L 219, S. 54-55.

EGKS, Hohe Behörde, 1953-1967, 1.-15. Gesamtbericht über die Tätigkeit der Gemeinschaft, Luxemburg.

-, 1965a, Entscheidung Nr. 3/65 vom 17. Februar 1965 über das gemeinschaftliche System von Maßnahmen der Mitgliedstaaten zugunsten des Steinkohlenbergbaus, in: ABl. 31, S. 480-484.

-, 1967, Entscheidung Nr. 1/67 vom 21. Februar 1967 über Kokskohle und Koks für die Eisen- und Stahlindustrie der Gemeinschaft, in: AB1., S. 562-567.

EP (Europäisches Parlament), 1976, Zwischenbericht im Namen des Ausschusses für Wirtschaft und Währung über die Schiffahrtindustrie der Gemeinschaft, Dokument 479/76.

-, 1978, Bericht im Namen des Ausschusses für Wirtschaft und Währung über den Vorschlag der Kommission der Europäischen Gemeinschaften an den Rat (Dok. 391/77) für eine Richtlinie betreffend die Beihilfen für den Schiffbau, Dokument $465 / 77$.

-, 1980, Bericht im Namen des Ausschusses für Wirtschaft und Währung über den Vorschlag der Kommission der Europäischen Gemeinschaften an den Rat (Dok. 1472/80) für eine Richtlinie betreffend die Beihilfen für den Schiffbau, Dokument $1-638 / 80$.

-, 1980a, Proposition de Resolution présentée par M. Sergio Pininfarina pour une politique européenne de l'automobile, Dokument 1-280/80.

-, 1985, Entschließung zum 13. Bericht der Kommission der Europäischen Gemeinschaften über die Wettbewerbspolitik, in: ABl. C 12, S. 101-109.

-, 1985a, Entschließung zum 14. Bericht der Kommission der Europäischen Gemeinschaften über die Wettbewerbspolitik, in: ABl. C 345, S. 84-91. 
-, 1986, Bericht im Namen des Ausschusses für Wirtschaft, Währung und Industriepolitik über den Vorschlag der Kommission der Europäischen Gemeinschaften an den Rat (KOM(86) 531 endg. - Dok. C2-121/86) für eine 6. Richtlinie über Beihilfen für den Schiffbau, Dokument A2-181/86/Teil A und B.

-, 1990, Entschließung zum 18. Bericht der Kommission der Europäischen Gemeinschaften über die Wettbewerbspolitik, in: ABl. C 38, S. 110.

-, 1991, Report of the Committee on Economic and Monetary Affairs and Industrial Policy on the European Car Industry, Rapporteur: Carole Tongue, Dokument: A3-0140/91.

EuGH 1970, Urteil vom 25.6. in der Rechtssache 47/69, Frankreich gegen Kommission der Europäischen Gemeinschaften, in: Sammlung der Rechtsprechung des EuGH, S. 487.

-, 1973, Urteil vom 12.7. in der Rechtssache 70/72, Kommission der Europäischen Gemeinschaften gegen Deutschland (Kohlegesetz), in: Sammlung der Rechtsprechung des EuGH, S. 813.

-, 1980, Entscheidung vom 17.9. in der Rechtssache 730/79, Philip Morris gegen Kommission der Europäischen Gemeinschaften, in: Sammlung der Rechtsprechung des EuGH, S. 2671.

-, 1982, Entscheidung vom 6.7. in den Rechtssachen 188 bis 190/80, Frankreich, Italien und Großbritannien gegen Kommission der Europäischen Gemeinschaften, in: Sammlung der Rechtsprechung des EuGH, S. 2545.

-, 1984, Entscheidung vom 14.11. in der Rechtssache 323/82, Intermills gegen Kommission der Europäischen Gemeinschaften, in: Sammlung der Rechtsprechung des EuGH, S. 3809.

-, 1985, Entscheidung vom 13.3. in den Rechtssachen 296 und 318/82, Niederlande und Leeuwarder Papierwarenfabriek BV gegen Kommission der Europäischen Gemeinschaften, in: Sammlung der Rechtsprechung des EuGH, S. 817.

-, 1990, Entscheidung vom 6.12. in der Rechtssache C-180/88: Wirtschaftsvereinigung Eisen- und Stahlindustrie gegen Kommission der Europäischen Gemeinschaften, in: Sammlung der Rechtsprechung des EuGH, S. 4413.

-, 1990a, Urteil vom 14.2. in der Rechtssache C-301/87 Französische Republik gegen Kommission der Europäischen Gemeinschaften (Boussac), in: Sammlung der Rechtsprechung des EuGH, S. I-307.

-, 1990b, Urteil vom 12.7. in der Rechtssache C-169/84, CFD Chimie AZF gegen Kommission der Europäischen Gemeinschaften, in: Sammlung der Rechtsprechung des EuGH, S. I-3083.

-, 1990c, Urteil vom 20.9. in der Rechtssache C-5/89, Kommission der Europäischen Gemeinschaften gegen Deutschland (BUG-Alutechnik), in: Sammlung der Rechtsprechung des EuGH, S. I-3437. 
-, 1991, Entscheidung vom 21.3 in der Rechtssache 305/89: Italienische Republik gegen Kommission der Europäischen Gemeinschaften (Alfa Romeo), in: Sammlung der Rechtsprechung des EuGH, S. I-1603.

-, 1991a, Entscheidung vom 19.2. in der Rechtssache C-375/89, Kommission der Europäischen Gemeinschaften gegen Belgien, in: Sammlung der Rechtsprechung des EuGH, S. I-367.

-, 1991b, Entscheidung vom 21.11. in der Rechtssache C-354/90 Fédération Nationale du Commerce Exterieur des Produits Alimentaire gegen Frankreich (Saumon), in: Sammlung der Rechtsprechung des EuGH, S. I-5523.

-, 1992, Entscheidung vom 4.2. in der Rechtssache C-294/90, British Aerospace und Rover gegen Kommission der Europäischen Gemeinschaften, in: Sammlung der Rechtsprechung des EuGH, S. I-493.

-, 1993, Entscheidung vom 15. Juni in der Rechtssache 225/91, Matra SA gegen Kommission der Europäischen Gemeinschaften, in: Sammlung der Rechtsprechung des EuGH, S. I-3203.

-, 1993a, Entscheidung vom 18.5. in den Rechtssachen C-356/90 und C-180/91, Belgien gegen Kommission der Europäischen Gemeinschaften, in: Sammlung der Rechtsprechung des EuGH, S. I-2523.

-, 1993b, Entscheidung vom 16.6. in der Rechtssache C-325/91, Frankreich gegen Kommission der Europäischen Gemeinschaften, in: Sammlung der Rechtsprechung des EuGH, S. I-3283.

EWG, Kommission, 1958-1967, 1.-10. Gesamtbericht über die Tätigkeit der Gemeinschaft, Brüssel.

-, 1961a, Entscheidung zur Änderung der in Italien zugunsten der Schiffbauindustrie bestehenden Beihilferegelung, in: AB1. 61, S. 582-583.

-, 1963a, Antwort der Kommission auf die schriftliche Anfrage Nr. 48 des Abgeordneten Burgbacher, in: ABl., S. 2235-2236.

-, 1964a, Entscheidung 64/651/EWG der Kommission vom 28. Oktober zu Beihilfen an die Ford Traktorenwerke, in: AB1. 195, S. 3257-3259.

-, 1965a, Vorschlag der Kommission der Europäischen Wirtschaftsgemeinschaft an den Rat zu einer Richtlinie über die Einführung einer gemeinschaftlichen Beihilferegelung zum Ausgleich der Wettbewerbsverzerrungen auf dem Weltschiffbaumarkt, in: Europäisches Parlament, Sitzungsdokument 1965-1966, Dokument 52 (PE 14079), Brüssel.

EWG, Rat, 1960, Beschluß des Rates vom 19. Dezember zu Beihilfen an die französische Zellstoffindustrie, in: ABl. 84. 


\section{Andere Veröffentlichungen}

Aeppel, T., 1992, Mercedes Drops Plans to Build Truck Plant In Eastern Germany, Cites Sales Decline, Wall Street Journal, 3 November.

Andel, N., 1965, Zur Harmonisierung öffentlicher Ausgaben in einem Gemeinsamen Markt, Finanzarchiv, N.F. 24, S. 1-33.

-, 1970, Subventionen als Instrument des finanzwirtschaftlichen Interventionismus, Tübingen.

-, 1983, Finanzwirtschaftliche Aspekte regionaler wirtschaftlicher Zusammenschlüsse: Europäische Gemeinschaften, in: F. Neumark, N. Andel und H. Haller (Hrsg.), Handbuch der Finanzwissenschaft, 3. Aufl., Bd. IV, Tübingen, S. 311364.

-, 1990, Public Finance and Trade: The European Community, in: V. Tanzi (ed.), Public Finance, International Trade, and Development, Detroit, S. 171-187.

-, 1992, Finanzwissenschaft, 3. Aufl., Tübingen.

Anjaria, S.J., et al., 1982, Developments in International Trade Policy, IMF Occasional Paper 16, Washington D.C.

Arrangement entre la Communauté et le Japon concernant les véhicules automobiles japonais, 1991, in: Assemblée Nationale, 10e législature, Rapport d'Information sur l'application de l'arrangement entre la Communauté et le Japon sur les importations d'automobiles de ce pays, présenté par Mme. Monique Rousseau, Paris, 6.7.1993.

Ashoff, G., 1988, Rent-Seeking: Zur Relevanz eines relativ neuen Konzeptes in der ökonomischen Theorie der Politik und der entwicklungstheoretischen Diskussion, in: Vierteljahresberichte der Friedrich-Ebert-Stiftung, 112, S. 103-125.

Averch, H., und L. Johnson, 1962, Behavior of the Firm under Regulatory Constraint, American Economic Review, 52, S. 1052-1069.

Bartels, W., 1978, Die deutsche Schiffbauindustrie im Nachfragetief, in: HANSA, S. 631-633.

Bartling, H., 1984, Europäischer Stahlmarkt, Teil 1: Ursachen der Krise und gesamtwirtschaftliche Folgen, Wirtschaftswissenschaftliches Studium, S. 443-448.

-, 1984a, Europäischer Stahlmarkt, Teil 2: Wirtschaftspolitische Maßnahmen zur Überwindung der Krise, Wirtschaftswissenschaftliches Studium, S. 487-493.

Baxter, A., 1993, Questions of history and health for steel, in: Financial Times, 25. Februar.

Bayliss, B.T., 1985, Competition and Industrial Policy, in: A.M. El-Agraa (ed.), The Economics of the European Community, 2nd ed., Oxford-New York, S. 209227. 
BDI, 1984, Jahresbericht 1982-84, Köln.

-, 1986, Jahresbericht 1984/86, Köln.

-, 1990, Jahresbericht 1988/90, Köln.

-, 1993, Arbeitspapier: Leitlinien für eine wettbewerbsorientierte Beihilfenpolitik in Deutschland, der Gemeinschaft und international, in: ders. (Hrsg.), EG-Beihilfenpolitik im Prozeß der europäischen Integration, Köln, S. 62-68.

Becker, E., 1989, Zum ordnungspolitischen Konzept der Bundesregierung für die Stahlindustrie, in: B. Röper, (Hrsg.), Wettbewerb und Anpassung in der Stahlindustrie, Berlin, S. 105-112.

Belcredi, M., L. Caprio und P. Ranci, 1988, The aid element in state participation to company capital, Brüssel-Luxemburg.

Beplat, K.H., 1968, Entwicklungstendenzen im Weltschiffbau bis zum Jahre 1980, in: Wirtschaftsdienst, 48, S. 656-661.

Bernholz, P., und F. Breyer, 1984, Grundlagen der Politischen Ökonomie, 2. Aufl., Tübingen.

Bernitsas, P., 1993, State Aids and Public Undertakings in: I. Harden (ed.), State Aid Community Law and Policy, Bonn, S. 110-123.

Betts, P., 1993, BAe pays $£ 57.6 \mathrm{~m}$ to settle case over Rover sweeteners, in: Financial Times, 27 May.

Beutler, B., et al., 1987, Die Europäische Gemeinschaft - Rechtsordnung und Politik, 3. Aufl., Baden-Baden.

Bhagwati, J.N., 1971, The generalized theory of distortions and welfare, in: J.N. Bhagwati et al. (eds.), Trade, balance of payments and growth, AmsterdamLondon, S. 69-90.

-, 1988, Protectionism, Cambridge, Mass.

-, und V.K. Ramaswami, 1963, Domestic Distortions, Tariffs and the Theory of Optimum Subsidy, in: Journal of Political Economy, 71, S. 44-50.

-, V.K. Ramaswami und T.N. Srinivasan, 1969, Domestic Distortions, Tariffs and the Theory of Optimum Subsidy: Some Further Results, in: Journal of Political Economy, 77, S. 1005-1010.

Bhaskar, K., 1988, Innovation in the EC Automotive Industry, Brüssel - Luxemburg.

-, und MIRU, 1990, The Effect of Different State Aid Measures on Intra-Community Competition, Luxemburg (EG).

Biehl, D., 1976, Bestimmungsfaktoren des regionalen Entwicklungspotentials Lage, Verkehrsinfrastruktur und Umwelt als Anwendungsbeispiele des Potentialfaktorkonzepts: Die Grundzüge des Potentialfaktorkonzepts, in: Die Weltwirtschaft, S. 60-65. 
-, 1981, Europäische Regionalpolitik - Eine ziel- und handlungsorientierte Analyse, in: D. Pohmer (Hrsg.), Probleme des Finanzausgleichs III, Schriften des Vereins für Socialpolitik, N.F. Bd. 96/III, Berlin, S. 125-180.

-, 1988, Thesen zum Verhältnis zwischen Wettbewerbspolitik und Regionalpolitik innerhalb der Europäischen Gemeinschaft, in: Ministerium für Justiz-, Bundesund Europaangelegenheiten Baden-Württemberg (Hrsg.), Perspektiven und Grenzen regionaler Problemlösungen in der Europäischen Gemeinschaft, Heilbronn, S. 88-96.

-, 1992, Regionalpolitik in der EG und die Rolle des EG-Regionalfonds, in: C. Smekal und E. Thöni (Hrsg.), Wirtschaftsförderung und öffentliche Auftragsvergabe - Anpassungserfordernisse Österreichs bei einem EG-Beitritt, Innsbruck, S. 67-82.

-, und U.A. Münzer, 1980, Agglomerationsoptima und Agglomerationsbesteuerung Finanzpolitische Konsequenzen aus der Existenz agglomerationsbedingter sozialer Kosten, in: H. Zimmermann (Hrsg.), Ballung und öffentliche Finanzen, Hannover.

Bleckmann, A., 1984, Subventionsprobleme des GATT und der EG, in: Rabels Zeitschrift, 48, S. 419-456.

BMF, 1983, 9. Subventionsbericht, Bonn.

-, 1985, 10. Subventionsbericht, Bonn.

-, 1987, 11. Subventionsbericht, Bonn.

BMWi, 1987, BMWi-Tagesnachrichten, 6. EG-Richtlinie über Schiffbaubeihilfen, Bonn 22.1.1987, Nr. 9014.

Boadway, R.W., und D.E. Wildasin, 1984, Public Sector Economics, 2nd ed., Boston-Toronto.

Boie, C., 1978, Das Schiffbaujahr 1977, in: HANSA, S. 143-153.

Borde, D., und P. Kirch, 1993, La restitution des aides d'Etat (Le point de vue français), in: Revue trimestrielle de droit européen, S. 477-502.

Borggrefe, S., 1978, 10 Jahre OECD-Exportkreditabkommen für Schiffe, in: HANSA, S. 319-322.

Breton, A., 1964, The Economics of Nationalism, in: Journal of Political Economy, 72, S. 376-386.

Brittan, L., 1992, A framework for international competition, Address to the World Economic Forum, Davos, 3 February.

Browning, E.S., 1991, Paris Returns Aid to Renault Despite EC Subsidies Ruling, The Wall Street Journal (Europe), 21st January.

Brümmerhoff, D., 1987, Finanzwissenschaft, 2. Aufl., München-Wien.

Buchan, D., 1989, Building from a disputed blueprint, Financial Times, July 10. 
-, 1994, Paris rethinks line on ships, Financial Times, November 17.

-, und W. Dawkins, 1990, France and EC agree deal on Renault aid, Financial Times, May 23.

Buchanan, J.M, und J.E. Moes, 1960, A Regional Countermeasure to National Wage Standardization, in: American Economic Review, 50, S. 434-438.

Buchanan, J.M., und W.C. Stubblebine, 1962, Externality, in: Economica, N.S., 29, S. 371-84.

Bünnagel, H.L., 1984, Die Subventionsproblematik in der Europäischen Gemeinschaft - Diskussion, in: Ludwig-Erhard-Stiftung (Hrsg.), Symposion X, Mehr Soziale Marktwirtschaft - Weniger Subventionswirtschaft, Stuttgart-New York, S. $87-102$.

Bullinger, M., 1978, Nationales Subventionsrecht - Generalbericht, in: B. Börner und M. Bullinger (Hrsg.), Subventionen im Gemeinsamen Markt, Köln u.a.O., S. 161- 210.

Butt Philip, A., 1983, Industrial and Competition Policies: A New Look, in: A.M. El-Agraa, Britain within the European Community - The Way Forward, LondonBasingstoke, S. 125-146.

-, 1986, Europe's Industrial Policies: An Overview, in: G. Hall (ed.), European Industrial Policy, New York, S. 1-20.

Calvet, J., 1992, L'Industrie Automobile face à l'Invasion Japonaise, Intervention devant les membres de la societé franco-allemande à Francfort le 18 mars 1992.

Carmoy, G. de, 1978, Subsidy Policies in Britain, France and West Germany: An Overview, in: S.J. Warnecke (ed.), International Trade and Industrial Policies, London-Basingstoke, S. 35-57.

Caspari, M., 1982, Staatssubventionen und Wetbewerb, in: Schwerpunkte des Kartellrechts 1980/81. Verwaltungs- und Rechtsprechungspraxis Bundesrepublik Deutschland und Europäische Gemeinschaften. Referate des 9. FIW-Seminars 1981, Köln u.a.O., S. 1-9.

-, 1984, Subventionen in der EG - Gefahr für den Gemeinsamen Markt?, in: Ludwig-Erhard-Stiftung (Hrsg.), Symposion X, Mehr Soziale Marktwirtschaft Weniger Subventionswirtschaft, Stuttgart-New York, S. 17-35.

-, 1984a, Die Subventionsproblematik in der Europäischen Gemeinschaft - Diskussion, in: Ludwig-Erhard-Stiftung (Hrsg.), Symposion X, Mehr Soziale Marktwirtschaft - Weniger Subventionswirtschaft, Stuttgart-New York, S. 87-102.

-, 1985, Subventions- und Anti-Subventionspolitik der Europäischen Gemeinschaften, in: Strukturanpassung durch Wettbewerb oder Staatshilfen?, Referate des XVIII. FIW-Symposiums, Köln u.a.O., S. 49-64. 
-, 1987, Die Beihilferegeln des EWG-Vertrags und ihre Anwendung, in: E.-J. Mestmäcker, H. Möller und H.-P. Schwarz (Hrsg.), Eine Ordnungspolitik für Europa, Baden-Baden.

-, 1990, Zur Abgrenzung von Industriepolitik und Wettbewerbspolitik der EG (incl. Diskussion), in: H. Gröner (Hrsg.), Wettbewerbsfragen der Europäischen Gemeinschaft, Schriften des Vereins für Socialpolitik, Bd. 201, Berlin, S. 9-34.

Chard, J.S., und M.J. Macmillen, 1979, Sectoral Aids and Community Competition Policy: The Case of Textiles, in: Journal of World Trade Law, 13, S. 132-157.

Coase, R.H., 1960, The problem of social cost, in: Journal of Law and Economics, 3, S. 1-44.

Cohen, R.B., 1983, The Prospects for Trade and Protectionism in the Auto Industry, in: W.R. Cline (ed.), Trade Policy in the 1980s, Washington D.C.

Colombo, U., H. Friderichs und J. Mayoux, 1987, Die Stahlpolitik der Gemeinschaft. Diagnose und Empfehlungen, erschienen als: Mitteilung der EG-Kommission an den Rat, KOM(87) 640 endg., Brüssel.

Corden, W.M., 1957, Tariffs, Subsidies and the Terms of Trade, in: Economica, S. 235-242.

-, 1974, Trade Policy and Economic Welfare, London.

Cornes, R., und T. Sandler, 1986, The Theory of Externalities, Public Goods, and Club Goods, Cambridge u.a.O.

Cownie, F., 1986, State Aids in the Eighties, in: European Law Review, 11, S. 247267.

Cox, H., 1984, Probleme der Wirtschaftspolitik bei der Bewältigung der Stahlkrise, in RWI (Hrsg.), Stahlkrise - Ist der Staat gefordert?, Berlin, S. 21-28.

Curzon-Price, V., 1974, The Essentials of Economic Integration, London.

-, 1981, Industrial Policies in the European Community, London.

-, 1986, Industrial and Trade Policy in a Period of Rapid Structural Change, in: Außenwirtschaft, 41, S. 201-223.

-, 1990, Competition and industrial policies with emphasis on industrial policy, in: A.M. El-Agraa (ed.), The Economics of the European Community, 3rd ed., New York u.a.O., S. 156-186.

Dam, K.W., 1970, The GATT. Law and International Economic Organisation, Chicago, London.

Dawkins, W., 1988, Brussels plans to curb car industry subsidies and trade restrictions, Financial Times, July, S. 1.

-, 1988a, Tougher rules on aid to car industry, Financial Times, 23rd December. 
de Ghellinck, E., 1988, European Industrial Policy Against the Background of the Single European Act, in: P. Coffey (ed.), Main Economic Policy Areas of the EEC - Towards 1992, 2nd ed., Dordrecht-Boston-London, S. 133-156.

de Melo, J., und P.A. Messerlin, 1988, Price, Quality and Welfare Effects of European VERs on Japanese Autos, in: European Economic Review, 32, S. 15271546.

Deacon, D., 1990, Current state aid policy in the EC and the implication of 1992, in: R. Gerritse (ed.), Producer Subsidies, London-New York, S. 64-75.

della Cananea, G., 1993, The Policy Guidelines of the Commission in the Field of State Aids, in: I. Harden (ed.), State Aid, Community Law and Policy, Bonn, S. 61-75.

Dicke, H., et al., 1987, EG-Politik auf dem Prüfstand, Kieler Studien 209, Tübingen.

Dickertmann, D., und K. D. Diller, 1990, Subventionsabbau - Strategien zur Reduktion des subventionspolitischen Interventionismus, Wirtschaftswissenschaftliches Studium, S. 538-544.

Diebold, W. jr., 1978, Subsidies and other International Economic Issues, in: S.J. Warnecke (Ed.), International Trade and Industrial Policies, London-Basingstoke, S. 175-199.

Diekmann, A., 1992, Die europäische Automobilindustrie - Aufgaben, Struktur und Perspektiven, Wirtschaftsdienst, 71, S. 73-79.

Dohnanyi, K. von, 1978, Die Wettbewerbs-Probleme des Schiffbaus, in: HANSA, S. 301-303.

Dominick, M.F., 1984, Countervailing State Aids to Steel: A Case for International Consensus, Common Market Law Review, 21, S. 355-403.

-, 1986, Abjudicating European Steel Policy: Judicial Review of the State Aids and Production Quota Systems in 1986, Common Market Law Review, 23, S. 591616.

DTI, 1993, European Community State Aids Guidance for all Departments and Agencies, 4th print, London.

Dunne, N., und L. Barber, 1993, US puts duties on steel imports, in: Financial Times, 28. Januar.

Eekhoff, J., 1993, Abschlußvortrag: Die EG-Beihilfenpolitik im Prozeß der europäischen Integration aus deutscher Sicht, in: BDI (Hrsg.), EG-Beihilfenpolitik im Prozeß der europäischen Integration, Köln, S. 44-54.

EFTA, 1975, Übereinkommen zur Errichtung der Europäischen Freihandelsassoziation. Textausgabe mit Einführung, Baden-Baden.

-, 1980, The European Free Trade Association, 2nd ed., Genf. 
-, 1988 und 1989, 27. und 28. Jahresbericht der Europäischen Freihandelsassoziation, Genf.

EFTA Surveillance Authority, 1994, Summary of the EFTA Surveillance Authority Decision not to raise objections to the aid which the Austrian Government plans to provide to BMW Motoren Gesellschaft $\mathrm{mbH}$ in support of an R\&D and investment project in Steyr, Austria, in: ABl. C 250, S. 3-5.

Ehlermann, C.D., 1992, Les entreprises publiques et le contróle des aides d'Etat, in: Revue du Marché commun et de l'Union européenne, S. 613-620.

-, 1994, State aids under European Community competition law, Fordham International Law Journal, 18, S. 410-436.

El-Agraa, A.M., 1982, ASEAN and Overall Conclusions, in: ders. (ed.), International Economic Integration, London-Basingstoke, S. 262-267.

Emerson, M., et al., 1988, The Economics of 1992, Oxford.

Emmerich, E., 1992, Brief an Bundesminister Jürgen W. Möllemann vom 24.11.1992, Frankfurt.

Erlei, M., 1992, Das "Euro-MITI": Ordunungspolitische Fehlkonzeption oder technologiepolitische Notwendigkeit?, in: Hanns-Martin-Schleyer-Stiftung (Hrsg.), Dynamik des Weltmarktes - Schlankheitskur für den Staat?, 6. Internationaler Kongreß "Junge Wissenschaft und Wirtschaft", Innsbruck, 10.-12.6., S. 56f.

Eser, T.W., 1989, Die Kontrolle regionaler Beihilfen im Rahmen der Wettbewerbspolitik der Europäischen Gemeinschaften, Raumforschung und Raumordnung, S. 202-216.

Esser, J., et al., 1982, Steel Crisis and Steel Policy - A Comparison, Intereconomics, S. 279-285.

EUROPE, 1993, Cour de Justice: Le recours de la Belgique contre des decision de la Commission Européenne condamnant des aides à la construction navale est rejeté, Jeudi 27 mai 1993, No. 5988 (Nouvelle série), S. 11.

-, 1993a, CE/Acier: La Commission a fait le point sur les négociations avec l'Espagne, l'Italie et l'Allemagne à propos de la restructuration des sidérurgies publiques et des aides y relatives, en confirmant les dernières évolutions positives, 16. September.

-, 1993b, CE/Etats-Unis: La Commission a ouvert les procédures du GATT à l'egard des droits anitdumping frappant certains produits sidérurgiques communautaires, 3. März.

-, 1994, Conseil Industrie: Les Douze partagent, avec regret, les conclusions de la Commission sur l'échec du plan de restructuration de la sidérurgie communautaire - conséquences limitées sur les mésures d'accompagnement, 9. November. 
Eußner, A., 1983, Industrial Policy and Southward Enlargement of the European Community: The Case of Shipbuilding and Repairs, Journal of Common Market Studies, 22, S. 147-172.

-, 1983a, Industriepolitik und Süderweiterung der EG am Beispiel der Werftindustrie, Berlin.

Färber, G., 1988, Subventionen in der sozialen Marktwirtschaft - Subventionsbegriff und Subventionspolitik in der Bundesrepublik Deutschland im Licht gewandelter finanzpolitischer Konzeptionen, Tagungsunterlagen, Jahrestagung des Vereins für Socialpolitik, Währungspolitik und soziale Marktwirtschaft - Entwicklungen und Perspektiven nach 40 Jahren, Freiburg.

-, 1993, Subventionen vor dem EG-Binnenmarkt, Forschungsinstitut für öffentliche Verwaltung bei der Hochschule für Verwaltungswissenschaften, Speyer.

Fante, W., 1967, Die Finanzierungsbedingungen im Weltschiffbau, Der langfristige Kredit, 18, S. 120-122.

-, 1975, The German Shipbuilding Industry in the World Market, Intereconomics, S. 175-178

-, 1976, Gefahren des Dirigismus in der Schiffbauindustrie, in: HANSA, S. 76-77.

-, 1976a, Anpassung erfordert staatlichen Flankenschutz, Wirtschaftsdienst, 56, S. 386-391.

-, 1978, Der neue Subventionswettlauf im Weltschiffbau, in: HANSA, S. 107-108.

-, 1983, Staatliche Interventionen in der Marktwirtschaft, Wirtschaftsdienst, 63, S. 227-230.

-, 1983a, Dangers of Governmental Intervention and Subsidies for the World Shipbuilding Market - Part II, in: HANSA, S. 2262-2263.

-, 1983b, Dangers of Governmental Intervention and Subsidies for the World Shipbuilding Market - Part I, in: HANSA, S. 2150-2152.

FAZ (Frankfurter Allgemeine Zeitung), 1986, Höchstsatz für Schiffbauhilfen in der EG, 24. Dezember.

-, 1986b, EG-Verfahren gegen Rastatter Förderung, 30. Oktober.

-, 1990, Strengere Beihilfenregeln im Schiffbau, 5. Mai.

-, 1990a, Streit um Wettbewerbspolitik in der EG, 16. Oktober.

-, 1992, Brüssel will Auto- und Flugzeugherstellern Flankenschutz geben, 30. April.

-, 1992a, Mercedes-Benz streicht neues Werk in Brandenburg, 3. November, S. 15.

-, 1993, Der Bund revidiert die Streichung in der Schiffbau-Förderung, 22. März.

-, 1993a, Die EG soll aus der Stahlkrise helfen, 28. Januar. 
Fendel, F., 1981, Industriepolitik der Europäischen Wirtschaftsgemeinschaft, Frankfurt-Bern.

Field, G.M., and P.V. Hills, 1976, The administration of industrial subsidies, in: A. Whiting (Ed.), The Economics of Industrial Subsidies, London (HMSO), S. 1-22.

Financial Times, 1984, Peugeot asks for FFr 2bn state aid to develop model, 15 November.

-, 1991, Fiat to take $51 \%$ of privatised Polish motor company, 12/13 October, S. 12.

-, 1992, EC acts against Daimler on Berlin site, April 15, S. 2.

Fisher, A., 1992, German carmakers warn of job losses, Financial Times, 31 January, S. 18.

Flieshardt, P., und R. Sablotny, 1981, Struktur und Entwicklung der bundesdeutschen Schiffbauindustrie, Bremen.

Flynn, J., 1987, State aids - Recent case law of the European Court, European Law Review, 12, S. 124-137.

Forschungsschwerpunkt Marktprozeß und Unternehmensentwicklung, 1989, Zwischen Markt und Staat, WZB-Mitteilungen 46, S. 10-14.

Frankfurter Neue Presse (FNP), 1992, Schwache Nachfrage drückt Stahlproduktion nach unten; Thyssen muß die Dividende kürzen, 27. November, S. 5.

Franzmeyer, F., 1981, Europäische Industriepolitik im Spannungsfeld zwischen Wettbewerb und Beschäftigungsgarantie, in: R. Bieber et al. (Hrsg.), Das Europa der zweiten Generation, Gedächtnisschrift für Christoph Sasse, Baden-Baden, S. 495-509.

-, 1987, Wettbewerbs- und Industriepolitik, in: Jahrbuch der Europäischen Integration, Bonn, S. 163-171.

-, 1989, Industrie- und Wettbewerbspolitik, in: Jahrbuch der Europäischen Integration, Bonn, S. 143-150.

-, 1990, Industrie- und Wettbewerbspolitik, in: Jahrbuch der Europäischen Integration, Bonn, S. 159-166.

-, 1991, Wettbewerbs- und Industriepolitik, in: Jahrbuch der Europäischen Integration, Bonn, S. 149-156.

-, 1992, Wettbewerbs- und Industriepolitik, in: Jahrbuch der Europäischen Integration, Bonn, S. 157-164.

-, und B. Seidel, 1976, Überstaatlicher Finanzausgleich und europäische Integration, Bonn.

Frey, B.S., 1985, Internationale Politische Ökonomie, München.

-, und H. Buhofer, 1986, Integration and Protectionism: A Comparative Institutional Analysis, in: Außenwirtschaft, 41, S. 329-350. 
Friz, C.A., 1976, Lösungsvorschläge der EG-Kommission, Wirtschaftsdienst, 56, S. 383-386.

GATT, 1987, International Trade 86-87, Genf.

-, 1992, The draft final act of the Uruguay-Round, Press Summary, 3 December.

Geister, H.A., 1981, Wettbewerbs- und Industriepolitik der Europäischen Gemeinschaft, Berlin.

-, 1982, Wettbewerbs- und Industriepolitik, in: Jahrbuch der Europäischen Integration, Bonn, S. 209-219.

-, 1983, Wettbewerbs- und Industriepolitik, in: Jahrbuch der Europäischen Integration, Bonn, S. 159-167.

-, 1984, Wettbewerbs- und Industriepolitik, in: Jahrbuch der Europäischen Integration, Bonn, S. 154-161.

-, 1985, Wettbewerbs- und Industriepolitik, in: Jahrbuch der Europäischen Integration, Bonn, S. 155-163.

Geroski, P.A., und A. Jacquemin, 1985, Industrial change, barriers to mobility, and European industrial policy, Economic Policy, Nov., S. 169-218.

Gerritse, R., 1990, Producer Subsidies: issues and arguments, in: Ders. (ed.), Producer Subsidies, London-New York.

Gerstenberger, W., et al., 1985, Subventionen in Europa - Konsequenzen einer Laissez-Faire-Politik am Beispiel der deutschen Stahlindustrie, ifo studien zur industriewirtschaft Nr. 29, München 1985.

Gilchrist, J., und D. Deacon, 1990, Curbing Subsidies, in: P. Montagnon (ed.), European Competition Policy, London, S. 31-51.

Gooding, K., 1985, Japan sells more than a million in U.S. in half-year, Financial Times, August 9, S. 9.

Graaff, J. de V., 1950, On Optimum Tariff Structures, The Review of Economic Studies, 17, S. 47-59.

- , 1957, Theoretical Welfare Economics, Cambridge.

Gröbner, B. F., 1983, Subventionen - eine kritische Analyse, Göttingen.

Gutowski, A., E. Thiel und M. Weilepp, 1984, Analyse der Subventionspolitik am Beispiel der Schiffbau-, Luft- und Raumfahrtindustrie, Hamburg.

Handelsblatt, 1992, An Subventionen wurden 121 Milliarden DM gezahlt, 17. Februar.

-, 1993, Bei vielen Konkurrenten in der EG türmen sich riesige Schuldenberge auf, 26. Februar.

-, 1993a, Japaner kürzen Autoexport, 6. September. 
-, 1993b, Kommission beanstandet Wiener Subventionen, 24. Juli.

Hanke, T., 1989, Beängstigendes Wachstum, Die Zeit, Nr. 47, S. 44.

HANSA, 1965, Schiffbauprobleme der Gegenwart, S. 1256-1257.

-, 1968, Schiffbaubeihilfen in der EWG, S. 388.

-, 1968a, Für Harmonisierung der Schiffbau-Beihilfen, S. 959-961.

-, 1972, Schiffbau ohne Staatshilfen? Dreijahresprogramm der OECD, S. 21152116.

-, 1981, Schiffbauförderung im Ausland. Eine VDS-Studie, S. 889-890.

-, 1981a, Schiffbausubventionen - Was tun die Konkurrenzländer für ihre Werften?, S. $1056-1060$.

-, 1982, Neue Struktur im französischen Schiffbau, S. 1560.

-, 1984, Eine VDS-Dokumentation; Subventionierung des Schiffbaues in den Konkurrenzländern, S. 2234-2236.

-, 1985, EG-Kommission genehmigt Schiffbau-Subventionen, S. 1430-1431.

-, 1986, EG-Orientierungsgespräch über Schiffbauhilfen, S. 371.

-, 1986a, EG-Kommission sondiert Werftbeihilfen, S. 533.

-, 1987, Einigung über Schiffbaubeihilfen, S. 98.

-, 1988, Werftbeihilfen für Frankreich und Niederlande, S. 376.

Hansmeyer, K.-H., 1977, Transferzahlungen an Unternehmen (Subventionen), in: F. Neumark, N. Andel und H. Haller (Hrsg.), Handbuch der Finanzwissenschaft, Bd. I, S. 959-996.

Harbrecht, W., 1984, Die Europäische Gemeinschaft, 2. Aufl., Stuttgart.

Harden, I., 1993, State Aids and the economic constitution of the Community, in: Ders. (ed.), State Aid Community Law and Policy, Bonn, S. 12-19.

Harrop, J., 1989, The Political Economy of Integration in the European Community, Aldershot.

Harzem, K., 1988, Subventionen aus der Sicht der Neuen Politischen Ökonomie, Köln.

Hausner, A., 1987, Die Zulässigkeit von Subventionen nach Art. 4 c EGKSVertrag, Köln u.a.O.

Haussmann, H., 1990, Schiffbau im freien Wettbewerb, in: HANSA, S. 14.

Heeckt, H., 1965, Die Schiffbauindustrie in der Bundesrepublik Deutschland im internationalen Wettbewerb, Weltwirtschaftliches Archiv, 95, S. 316-357. 
Hellingman, K., 1986, State Participation as State Aid under Article 92 of the EEC Treaty: The Commission's Guidelines, Common Market Law Review, 23, S. 111-133.

Hencke, D., 1989, Young 'deception' over Rover, The Guardian, December 8, S. 1.

-, 1990, Young boasts of his success in Rover secret sweeteners deal, The Guardian, January 18.

Herdmann, U., und F.D. Weiss, 1985, Wirkungen von Subventionen und Quoten Das Beispiel der EG-Stahlindustrie, Die Weltwirtschaft, H. 1, S. 101-113.

Herrmann, A., 1989, Außenhandelspolitische Aspekte der Verwirklichung des EGBinnenmarktes, ifo-schnelldienst, Heft 35/36, S. 16-26.

Heusdens, J.J., und R. de Horn, 1980, Crisis policy in the European steel industry in the light of the ECSC Treaty, Common Market Law Review, 17, S. 31-74.

Hiemenz, U., und F.D. Weiss, 1984, Das internationale Subventionskarussell. Dabeisein oder abspringen?, Kiel.

Hill, A., 1992, Brittan urges role for Gatt in competition enforcement, Financial Times, 3 February, S. 1.

-, 1993, Brussels to tell BAe to repay Rover cash, Financial Times, 5 March, S. 2.

-, 1993a, Steelmakers under Brussels microscope, Financial Times, 20. Dezember.

-, 1993b, Brussels extends shipbuilding aid, Financial Times, 22.12.1993, S. 2.

-, und D. Buchan, 1992, Brussels loses case over BAe's $£ 44 m$ "sweeteners", Financial Times, 5 February.

Hill, A., R. Graham und A. Genillard, 1993, Italy rejects EU steel compromise, Financial Times, 19. November, S. 18.

Hill, A., und Reuter, 1993, EU retaliates in Austrian subsidy row, Financial Times, 21 December, S. 2.

Hindley, B., 1974, Theory of International Trade, London.

Hirn, W., 1990, EG-Industriepolitik - Sieg der Liberalen, Wirtschaftswoche, 23.11, S. $25,28$.

Hitiris, T., 1991, European Community Economics, 2nd ed., London u.a.O.

Hochbaum, M., 1962, Das Diskriminierungs- und Subventionsverbot in der EGKS und EWG, Baden-Baden, Bonn.

Hoischen, S., 1989, Die Beihilferegelung in Artikel 92 EWG-Vertrag, Köln u.a.O.

Holmes, P., 1991, Non-Tariff Barriers, in: G. McKenzie and A.J. Venables (eds.), The Economics of the Single European Act, London-Basingstoke, S. 27-50. 
Hübner, T., und K. Feiler, 1982, Ökonomisch begründbare Subventionen und öffentliche Finanzen, Orientierungen zur Wirtschafts- und Gesellschaftspolitik, 4, S. 15-21.

Hufbauer, G.C., und J. Shelton Erb, 1984, Subsidies in International Trade, Washington, DC.

Hummel, M., 1985, Subventionen in Europa, ifo-schnelldienst, Nr. 32, S. 12-20.

-, und K.D. Knörndel, 1985, Subsidiaritätsprinzip als Leitlinie für einen Subventionsabbau - Generelle Problematik und Fallstudien, München.

Imhoff, L.P., 1952, GATT-Kommentar.

Jacquemin, A., 1989, International and Multinational Strategic Behaviour, Kyklos, 42, S. 495-513.

Jacquemin, A., und A. Sapir, 1991, Competition and imports in the European market, in: L.A. Winters und A.J. Venables (eds.), European Integration: trade and industry, Cambridge, S. 82-95.

Jallon, A., 1993, Le contróle par la Commission des aides d'Etat aux entreprises des secteurs industriels soumis à encadrements communautaires, Revue Internationale de Droit Economique, S. 325-347.

Jestaedt, T., 1993, Das Rückzahlungsrisiko bei "formell rechtswidrigen" Beihilfen, Europäische Zeitschrift für Wirtschaftsrecht, Heft 2, S. 49-52.

Johnson, H.G., 1958, International Trade and Economic Growth, London.

-, 1965, Optimal Trade Intervention in the Presence of Domestic Distortions, in: R.E. Caves, H.G. Johnson und P.B. Kenen (eds.), Trade, Growth and the Balance of Payments, Amsterdam, S. 3-34.

-, 1965a, An Economic Theory of Protectionism, Tariff Bargaining, and the Formation of Customs Unions, Journal of Political Economy, 73, S. 256-283.

-, 1971, Aspects of the Theory of Tariffs, London.

Journal de la Marine Marchande et de la Navigation Aérienne, 1973, Les aides dans la Communauté économique européenne, No. 2785 vom 3.5.1973.

Jublin, J., und M. Paoloni, 1990, Renault divise la Commission, La Tribune, 22 mai.

Junginger-Dittel, K., 1993, Möglichkeiten nationaler Regionalpolitik in EG und EWR, Vortrag auf einer Konferenz der Arbeitskammer Oberösterreich und der österreichischen Bundesarbeitskammer zum Thema "Regionalpolitik im neuen Europa", Linz, 28 Januar.

Jürgensen, H., 1984, Anpassungsprobleme der deutschen Stahlindustrie - Ursachen und Lösungschancen -, in: H.J. Ewers und H. Schuster (Hrsg.), Probleme der Ordnungs- und Strukturpolitik, Festschrift für H. St. Seidenfus, Göttingen, S. $112-134$. 
Kellaway, L., und G. Graham, 1990, Renault asked to repay FFr. 8.4bn of debt write-off, Financial Times, 18 May.

Kenen, P.B., 1989, The International Economy, 2nd ed., Englewood Cliffs.

Klodt, H., 1987, Wettlauf um die Zukunft, Tübingen.

Knight, F.H., 1924, Some fallacies in the interpretation of social cost, The Quarterly Journal of Economics, 38, S. 582-606.

Kokalj, L., und H. Albach, 1987, Industriepolitik in der Marktwirtschaft, Stuttgart.

Kolbe, H., 1962, Der Schiffbau in der EWG, Wirtschaftsdienst, 42, S. I-VIII.

Koppensteiner, H.G., 1965, Das Subventionsverbot im Vertrag über die Europäische Gemeinschaft für Kohle und Stahl, Baden-Baden.

Krägenau, H., 1986, Stahlpolitik und Strukturanpassung in der EG-Stahlindustrie, Hamburg.

Krakowski, M., et al. 1992, Die deutsche Wirtschaft im Anpassungsschock Strukturbericht 1991, Hamburg (HWWA).

Krauss, M.B., 1972, Recent Developments in Customs Union Theory: An Interpretive Survey, Journal of Economic Literature, 10, S. 413-436.

-, 1979, The New Protectionism; The Welfare State and International Trade, Oxford.

Kriwet, H., 1987, Die aktuellen Probleme beim Stahl drängen den Gedanken an 1992 zurück, Handelsblatt, 31. Dezember, S. 42.

-, 1988, Stahlindustrie, Wertpapier, Nr. 1, S. 32-35.

-, 1989, Diskussion zu J.P. Ulrich, in: B. Röper, (Hrsg.), Wettbewerb und Anpassung in der Stahlindustrie, Berlin, S. 39-44.

-, 1989a, Die deutsche Stahlindustrie zwischen Krise und Anpassung, in: B. Röper, (Hrsg.), Wettbewerb und Anpassung in der Stahlindustrie, Berlin, S. 45-55.

Krueger, A.O., 1974, The Political Economy of the Rent-Seeking Society, American Economic Review, 64, S. 291-303.

Krüger, R., 1992, Privatisierung ostdeutscher Unternehmen in EG-koordinierten Krisenbranchen, Wirtschaftsdienst, 72, S. 594-601.

Krugman, P., 1983, New Theories of Trade Among Industrial Countries, American Economic Review, 73, Papers and Proceedings, S. 343-347.

Kuhnert, G.W., 1969, Wettbewerbsbedingungen auf dem internationalen Seeschiffbaumarkt, Diss. Kiel.

Kurylko, D.T., und E. Wendt, 1992, Battle with EC perils Chrysler Austria plant, Automotive News, 16. November. 
Küsters, H.J., 1982, Die Gründung der Europäischen Wirtschaftsgemeinschaft, Baden-Baden.

Kutscher, H., 1989, Zur Stahlpolitik der Europäischen Gemeinschaft, in B. Röper, (Hrsg.), Wettbewerb und Anpassung in der Stahlindustrie, Berlin, S. 75-85.

-, 1989a, Diskussion zu H. Kutscher, in: B. Röper, (Hrsg.), Wettbewerb und Anpassung in der Stahlindustrie, Berlin, S. 86-104.

-, 1989b, Diskussion zu E. Becker, in: B. Röper, (Hrsg.), Wettbewerb und Anpassung in der Stahlindustrie, Berlin, S. 113-120.

Kwasniewski, K., 1983, Krise der Großwerften, Wirtschaftsdienst, 63, S. 160.

Lalitch, O., 1991, Les aides d'Etat aux entreprises publiques du secteur automobile, Mémoire de DEA de droit communautaire et de DESE, Centre Européen universitaire de Nancy, Année 1990-1991.

Lammers, K., 1984, Subventionen für die Schiffbauindustrie, Kieler Arbeitspapier Nr. 211.

-, 1988, Subsidization of the Shipbuilding Industry in the Federal Republic of Germany, Kiel Working Paper No. 326.

-, 1989, Regionalförderung und Schiffbausubventionen in der Bundesrepublik, Tübingen.

Langer, J., 1974, Subventionierung der deutschen Werftindustrie, Hamburg.

Lasok, K.P.E., 1990, The Commission's Powers over Illegal State Aids, European Competition Law Review, S. 125-127.

Latz, H.-L., 1989, Subventionen in einer offenen Volkswirtschaft, Pfaffenweiler.

Le Monde, 1984, L'industrie automobile gravement atteinte par une forte baisse des ventes, 12 juillet, S. 1, 24.

Le Nouveau Journal, 1984, L'Etat devrait étre plus généreux avec les constructuers estime le Comité économique et social, 13 juin, S. 8.

-, 1984a, Rapport Dalle: prendre exemple sur le modèle japonais, 20/21 octobre, S. 1f.

Lehner, S., R. Meiklejohn und H. Reichenbach, 1991, Fair competition in the internal market: Community State aid policy, European Economy, 48, S. 7-114.

Les Echos, 1985, 9,5 milliards de dotation minimale pour le FIM cette année, 22 janvier.

-, 1992, Chrysler va verser plus de 1 milliard de F à Renault, 21 février.

Leuthner, R., 1993, Einert fordert neues "Resider"-Programm der EG, Handelsblatt, 4. Februar.

Lipinski, G., 1994, Scheitert das Schiffbauabkommen? Kollisionskurs, Handelsblatt, 28. September. 
Lösch, D., 1984, Current EC-US Economic Conflicts, Interconomics, S. 51-56.

Malkin, D.M., 1990, Assistance to industry and structural adjustment: an overview of economic effects of industrial subsidies, in: R. Gerritse (ed.), Producer Subsidies, London-New York, S. 32-63.

Malmgren, H., 1978, Negotiation of Rules on Subsidies in a World of Economic Interventionism, in: S.J. Warnecke (Hrsg.), International Trade and Industrial Policies, London-Basingstoke, S. 210-231.

Marketing Systems, 1993, Financial Analyses of Major Automotive Manufacturers Appendix, London.

Mathijsen, P.S.R.F., 1975, A Guide to European Community Law, London.

Matthöfer, H., 1978, Die Werftsituation aus der Sicht der Bundesregierung, HANSA, S. 461-464.

McLachlan, D.L., und D. Swann, 1967, Competition Policy in the European Community, London.

Meade, J.E., 1952, A Geometry of International Trade, London.

-, 1955, The Theory of International Economic Policy, Vol. II: Trade and Welfare, London-New York-Toronto.

-, 1973, The Theory of Economic Externalities, Leiden-Genf.

Mény, Y., und V. Wright, 1987, State and Steel in Western Europe, in: Dies. (eds.), The Politics of Steel: Western Europe and the Steel Indstry in the Crisis Years (1974-1984), Berlin-New York, S. 1-110.

Messerlin, P.A., 1981, The Political Economy of Protectionism: The Bureaucratic Case, Weltwirtschaftliches Archiv, 117, S. 469-496.

Mestmäcker, E.J., 1987, Auf dem Wege zu einer Ordnungspolitik für Europa, in: E.J. Mestmäcker, H. Möller und J. Schwarz (Hrsg.), Eine Ordnungspolitik für Europa, Baden-Baden, S. 9-50.

Meyer, M., 1992, Forschungssubventionen zur Stärkung der internationalen Wettbewerbsfähigkeit? in: Hanns-Martin-Schleyer-Stiftung (Hrsg.), Dynamik des Weltmarktes - Schlankheitskur für den Staat?, 6. Internationaler Kongreß "Junge Wissenschaft und Wirtschaft", Innsbruck, 10.-12.6., S. 154 f.

Michaelis, H., 1987, Vollendung des Binnenmarktes im Bereich Energie, in: Vollendung des Binnenmarktes in der Europäischen Gemeinschaft - Folgen und Folgerungen für Österreich, Volkswirtschaftliche Tagung 1987 der Österreichischen Nationalbank, Wien, S. 81-105.

MIRU, 1987, State Aid to the European Motor Industry, Norwich.

-, 1990, EC-State Aid Framework programme in the automotive sector, Norwich.

Monopolkommission, 1990, Wettbewerbspolitik vor neuen Herausforderungen, Hauptgutachten 1988/89, Baden-Baden. 
Moreau, Ph., 1993, Construction navale: une cohésion européenne fragile, in: Les Echos, 2.6.1993.

Müller, U., 1983, Wohlstandseffekte des internationalen Handels unter den Regeln des Allgemeinen Zoll- und Handelsabkommens (GATT), Köln.

Mutti, J., 1982, Taxes, Subsidies and Competitiveness Internationally, Washington D.C.

Nakamoto, M., und J. Griffiths, 1993, Japan agrees to reduce vehicle exports to EC, Financial Times, 2 April, S. 1.

Narjes, K.H., 1988, Speech during the opening session of the seminar on "New Applications for Steel in View of the Challenge from Substitute Material", 2nd May in Luxembourg.

Neumann, M., 1984, Hemmnisse und Chancen für die Anpassung der Stahlindustrie im Gemeinsamen Markt, in: RWI (Hrsg.), Stahlkrise - Ist der Staat gefordert?, Berlin, S. 15-20.

-, 1984a, Plenumsdiskussion, in: RWI (Hrsg.), Stahlkrise - Ist der Staat gefordert?, Berlin, S. 75-96.

Neundörfer, K., 1984, Die Politik von Kommission und Rat sowie die Judikatur des Gerichtshofs im Bereich der sektoriellen Beihilfen, in: B. Börner und K. Neundörfer (Hrsg.), Recht und Praxis der Beihilfen im Gemeinsamen Markt, Köln u.a.O, S. 83-110.

Nicolaysen, G., 1984, Subventionen für öffentliche Unternehmen und Wettbewerb im Gemeinsamen Markt, in: B. Börner und K. Neundörfer (Hrsg.), Recht und Praxis der Beihilfen im Gemeinsamen Markt, Köln u.a.O, S. 111-136.

Ninz, L., 1993, EG stellt Wien Ultimatum bei Förderung, Der Standard, 20./21. März.

Nölling, W., 1976, Need for Greater Competitiveness, Intereconomics, S. 240-242.

Oates, W.E., 1972, Fiscal Federalism, New York u.a.O.

Oberösterreichische Nachrichten, 1993, Steyr: EG will jetzt BMW-Förderung prüfen, 16. März.

OECD, 1983, Transparency for Positive Adjustment, Paris.

-, 1989, Tagung des OECD-Ministerrats, Kommuniqué; OECD-Press Release, Paris, 1. Juni, wiederabgedruckt in: Deutsche Bundesbank/Auszüge aus Presseartikeln, Nr. 44, S. 2-8.

Olson, M., 1977, Das Prinzip "fiskalischer Gleichheit": Die Aufteilung der Verantwortung zwischen verschiedenen Regierungsebenen, in: G. Kirsch (Hrsg.), Föderalismus, Stuttgart-New York, S. 66-76.

Padoa-Schioppa, T. (Hrsg.), 1988, Effizienz, Stabilität und Verteilungsgerechtigkeit, Wiesbaden. 
Paoloni, M., 1990, Renault: compromis en trompe l'oeil entre Paris et la Commission, La Tribune, 23 mai, S. 3.

-, 1993, Sidérurgie - Les ministres des Douze feront le point sur les quotas, La Tribune, 5. Mai.

Peacock, A.T., 1990, Identifying and applying norms for subsidies to industry, in: R. Gerritse (ed.), Producer Subsidies, London-New York, S. 20-31.

Pelkmans, J., 1984, Market Integration in the European Community, The HagueBoston-Lancaster.

Peters, H.-R., 1981, Mesoökonomische Theorie der Strukturpolitik als Teil der Neuen Politischen Ökonomie, Wirtschaftsdienst, 61, S. 228-233.

Petersen, A., 1993, Kontrolle nationaler Beihilfen durch die Kommission der Europäischen Gemeinschaften, in: BDI (Hrsg.), EG-Beihilfenpolitik im Prozeß der europäischen Integration, Köln, S. 18-27.

-, 1993a, State Aid and European Union: State Aid in the Light of Trade, Competition, Industrial and Cohesion Policies (incl. Diskussion), in: I. Harden (ed.), State Aid Community Law and Policy, Bonn, S. 20-27 und 76-87.

Pfähler, W., 1984, Sinkende Durchschnittskosten und Allokationspolitik, das wirtschaftsstudium, 13, S. 470-475.

Pfeiffer, F., 1971, Die deutsche Schiffbaupolitik, in: HANSA, S. 529-532.

Pigou, A.C., 1962, The Economics of Welfare, 4th ed., London.

Pinder, J., 1983, History, Politics and Institutions of the EC, in: A.M. El-Agraa, Britain within the European Community - The Way Forward, LondonBasingstoke, S. 21-40.

Poelmans, J., 1970, L'aide des Etats aux secteurs de production, in: Institut d'Etudes Européennes (ULB), Vers une politique industrielle européenne, Bruxelles, S. 297-319.

Prest, A.R., 1976, The economic rationale of subsidies to industry, in: A. Whiting (ed.), The Economics of Industrial Subsidies, London.

Preuße, H.G., 1992, Freiwillige Exportselbstbeschränkungsabkommen und internationale Wettbewerbsfähigkeit der europäischen Automobilindustrie, Außenwirtschaft, 47, S. 361-388.

PSA, 1987, Communiqué à la presse No. 44, le 30 Octobre.

Radzio, H., 1993, Hilfe mit Selbsthilfe, Handelsblatt, 5. Februar.

Rawlinson, F., 1993, The Role of Policy Frameworks, Codes and Guidelines in the Control of State Aid, in: I. Harden (ed.), State Aid Community Law and Policy, Bonn, S. 52-60.

Regierungsausschuß eingesetzt von der Konferenz von Messina, 1956, Bericht der Delegationsleiter an die Außenminister (Spaak-Bericht), Brüssel. 
Reichenbach, H., 1993, EG-Förderpolitik und nationale Beihilfen: Gesamtwirtschaftliche Herausforderungen aus europäischer Sicht, in: BDI (Hrsg.), EG-Beihilfenpolitik im Prozeß der europäischen Integration, Köln, S. 9-17.

Reichert, P., 1993, Feuer am Dach, Wirtschaftswoche, 21.5., S. 138-140.

Rengeling, H.W., 1984, Das Beihilferecht der Europäischen Gemeinschaften, in: B. Börner und K. Neundörfer (Hrsg.), Recht und Praxis der Beihilfen im Gemeinsamen Markt, Köln u.a.O, S. 23-54.

Ridding, J., 1994, Shipbuilding nations avert trade war over yard subsidies, Financial Times, July 18.

Ritzen, J.M.M., 1990, Public intervention in R\&D: right and wrong, in: R. Gerritse (ed.), Producer Subsidies, London-New York, S. 76-90.

Robert, M., 1994, L'Europe approuve l'accord OCDE sur les chantiers navals, Les Echos, 20 décembre.

Rodger, I., A. Genillard und R. Graham, 1994, EU steel cuts plan verges on collapse, Financial Times, 2. Februar, S. 1 und 12.

Rolfes, K.H., 1991, Regionale Wirtschaftsförderung und EWG-Vertrag, Köln u.a.O.

Rose, K., 1986, Theorie der Außenwirtschaft, 9. Aufl., München.

Ross, M., 1986, Challenging State Aids: The Effect of Recent Developments, Common Market Law Review, 23, S. 867-894.

Rother, D., 1984, Strukturwandel im Weltschiffbau - Auswirkungen auf die westeuropäische Schiffbauindustrie, dargestellt an den Beispielen der Schiffbauindustrien der Bundesrepublik, Japans und Schwedens. Erfolge und Mißerfolge sektoraler Strukturpolitik, Beihefte zur Konjunkturpolitik, 31, S. 131-154.

Rother, T., 1988, Deutsche Schiffbauindustrie - Subventionierung in den letzten zehn Jahren, HANSA, S. 472-478.

Sachverständigenrat zur Begutachtung der gesamtwirtschaftlichen Entwicklung (SVR), 1983, Ein Schritt voran, Jahresgutachten 1983/84, Stuttgart-Mainz.

-, 1991, Auf dem Wege zur wirtschaftlichen Einheit Deutschlands, Jahresgutachten 1990/91, Stuttgart-Mainz.

Schatz, K.W., 1984, Die Subventionsproblematik in der Europäischen Gemeinschaft - Diskussion, in: Ludwig-Erhard-Stiftung (Hrsg.), Symposion X, Mehr Soziale Marktwirtschaft - Weniger Subventionswirtschaft, Stuttgart-New York, S. 87102.

Schaub, A., 1993, Spannungsverhältnis zwischen Beihilfen- und Wettbewerbspolitik am Beispiel der Stahlindustrie (incl. Diskussion), in: BDI (Hrsg.), EG-Beihilfenpolitik im Prozeß der europäischen Integration, Köln, S. 35-43.

Schina, D., 1987, State Aids and the EEC Treaty Articles 92 to 94, Oxford. 
Schlieder, W.C., und H. Schröter, 1981, Europäische Wettbewerbspolitik, in: H. Cox, H. Jens und K. Markert (Hrsg.), Handbuch des Wettbewerbs, München, S. 485-532.

Schütterle, P., 1993, EG-Beihilfenkontrolle und kommunale Grundstücksverkäufe, Europäische Zeitschrift für Wirtschaftsrecht, S. 625-628.

-, 1993a, Discussion, in: I. Harden (ed.), State Aid Community Law and Policy, Bonn, S. 76-85.

Schütz, C., 1993, Die Eingliederung der ehemaligen DDR in die Europäische Gemeinschaft unter dem Aspekt der staatlichen Beihilfen, Frankfurt am Main u.a.O.

Schumann, J., 1987, Grundzüge der mikroökonomischen Theorie, 5. Aufl., Berlin u.a.O.

Schuster, H., 1984, Wirtschaftsförderung als beschäftigungspolitische Strategie, in: H.J. Ewers und H. Schuster (Hrsg.), Probleme der Ordnungs- und Strukturpolitik, Göttingen.

Scitovsky, T., 1954, Two concepts of external economies, Journal of Political Economy, 62, S. $143 \mathrm{ff}$.

Seidel, M., 1984, Grundfragen des Beihilfenaufsichtsrechts der Europäischen Gemeinschaften, in: B. Börner und K. Neundörfer (Hrsg.), Recht und Praxis der Beihilfen im Gemeinsamen Markt, Köln u.a.O, S. 55-82.

-, 1984a, Die Subventionsproblematik in der Europäischen Gemeinschaft, in: Ludwig-Erhard-Stiftung (Hrsg.), Symposion X, Mehr Soziale Marktwirtschaft Weniger Subventionswirtschaft, Stuttgart-New York, S. 87-102.

-, 1985, Aktuelle Rechtsprobleme der Subventionsgewährung und der Beihilfenaufsicht in der Europäischen Wirtschaftsgemeinschaft, in: J. Schwarze (Hrsg.), Integrationsrecht, Baden-Baden.

Senti, R., 1986, GATT. Allgemeines Zoll- und Handelsabkommen als System der Welthandelsordnung, Zürich.

Sharpe, T., 1993, The Role of National Courts in Relation to the Community Law of State Aids, in: I. Harden (ed.), State Aid Community Law and Policy, Bonn, S. 88-95.

Simonian, H., 1992, Finmeccanica deal produces indifference, Financial Times, 24 March.

Sinclair Scott, M.A., 1966, Die Wettbewerbsfähigkeit britischer Werften, Wirtschaftsdienst, 46, S. 477-479.

Slot, P.J., 1993, Procedural Law of State Aids, in: I. Harden (ed.), State Aid Community Law and Policy, Bonn, S. 36-51.

Södersten, B., 1980, International Economics, 2nd ed., London-Basingstoke. 
Sohmen, E., 1976, Allokationstheorie und Wirtschaftspolitik, Tübingen.

Sohmen, H., 1983, Profitability in Shipping, Tübingen.

Soltwedel, R., et al., 1988, Subventionssysteme und Wettbewerbsbedingungen in der EG, Kiel.

Somai, M., 1993, The car industry and motorization in Hungary, Institute for World Economics, Hungarian Academy of Sciences Working Papers No. 26.

Stegemann, K., 1989, Policy rivalry among industrial states. What can we learn from models of strategic trade policy?, International Organization, 43, S. 73-100.

Stotz, R., 1983, Die EG-Stahlkrise im Lichte der Wirtschaftsverfassung des EGKSVertrages, Baden-Baden.

Student, D., 1991, EG-Stahlindustrie: Kolossal konzentriert, Wirtschaftswoche, Nr. 43, 18.10., S. 174.

Süddeutsche Zeitung 1986, Ergänzungsetat wegen Daimler-Benz, Nr. 195, 27.8., S. 22.

Swann, D., 1983, Competition and Industrial Policy in the European Economic Community, London.

-, 1984, The Economics of the Common Market, 5th ed., Harmondsworth.

-, 1988, The Economics of the Common Market, 6th ed., Harmondsworth.

The Economist 1985, Reassemble Europe's cars, April 20, S. 14-15.

-, 1989, Regional mismatch, July 29, S. 59.

-, 1989a, European state aid - Loaded down with lolly, November 18, S. 87.

-, 1990, Renault and the EC - Victory for all, May 26, S. 75/76.

-, 1991, Schools Brief: The business of Europe, December 7th, S. 41-42.

-, 1991a, Survey: Business in Europe, Beilage, 8 June.

-, 1992, America's steel industry: Protection's stepchild, May 16th, S. 101/102.

-, 1992, Car makers of the world - Unite, August 1st, S. 54/55.

-, 1992a, European Competition Policy: Aid addicts, August 8th, S. 61.

-, 1992b, Before the flood, November 28th, S. 79.

-, 1992c, Steel trade: Not cast iron, December 5th, S. 74.

-, 1992d, German steel: Metal fatigue, December 19th, S. 62-64.

-, 1992e, European steel: Hot blast, November 21st, S. 91.

Thies, G., 1989, The Community Competition Policy in the Perspective of the Completion of the Internal Market, Vortrag. 
Thiesing, J., 1983, Staatliche Beihilfen, in: H. von der Groeben et al., Kommentar zum EWG-Vertrag, 3. Aufl., Bd. 1, Baden-Baden.

Thöni, E., und M. Ciresa, 1990, EG-Beihilfen: Der Fall "Chrysler", EconomyFachmagazin, Nr. 10, S. 13-20.

Tinbergen, J., 1954, Centralization and Decentralization in Economic Policy, Amsterdam.

Tomann, H., 1984, Die Stahlkrise - Prüfstein der Wettbewerbs- und Strukturpolitik, in: RWI (Hrsg.), Stahlkrise - Ist der Staat gefordert?, Berlin, S. 45-58.

Tomann, H., 1984a, Plenumsdiskussion, in: RWI (Hrsg.), Stahlkrise - Ist der Staat gefordert?, Berlin, S. 75-96.

Tsoukalis, L., und R. Strauss, 1985, Crisis and Adjustment in European Steel: Beyond Laisser-Faire, Journal of Common Market Studies, XXIII, S. 207-228.

Tucker, E., 1994, Ministers back flexibility over Europe state aid, Financial Times, 23 June, S. 2.

-, Q. Peel und A. Baxter, 1994, German-Dutch steelmakers in aid challenge, Financial Times, 24 June, S. 2.

Tullock, G., 1971, The Cost of Transfers, Kyklos, 24, S. 629-643.

Ulrich, J.P., 1989, Probleme der französischen Stahlindustrie, in B. Röper (Hrsg.), Wettbewerb und Anpassung in der Stahlindustrie, Berlin, S. 33-38.

Vandoorne, J.-L., 1990, Leon Brittan demande 8,4 milliards de francs à Renault, Les Echos, 17 mai.

van Gerven, M.W., 1993, Conclusions de l'Avocat Général, Affaire C-225/91, Matra SA contre Commission des CE, Luxembourg, 28 avril.

van Meerhaeghe, M.A.G., 1971, International Economic Institutions, 2nd ed., New York.

VDA, 1985, Subventionen in der europäischen Automobilindustrie, 4. April.

Verreydt, E., und J. Waelbroeck, 1980, European Community Protection Against Manufactured Imports from Developing Countries: A Case Study in the Political Economy of Protection, World Bank Staff Working Paper No. 432, Washington D.C.

Voltz, P., 1966, Die Wettbewerbsverzerrungen aus deutscher Sicht, Wirtschaftsdienst, 46, S. 471-474.

-, 1966a, Wie können wir den Schiffbau in Deutschland weiter betreiben?, HANSA, S. 1940-1943.

von der Groeben, H., 1967a, Die Wettbewerbspolitik als Teil der Wirtschaftspolitik im Gemeinsamen Markt, Rede am 16.6.1965 vor dem EP in Straßburg, abgedruckt in: Ders., Europa - Plan und Wirklichkeit, Baden-Baden, S. 193-212. 
-, 1982, Aufbaujahre der Europäischen Gemeinschaft, Baden-Baden.

Vondran, R., 1987, Was erwarten die deutschen Erzeuger von einer europäischen Stahlmarktordnung?, Vortrag aus Anlaß des 38. VFE-Verbandstages am 22. Oktober 1987.

-, 1989, Diskussion zu H. Kutscher, in: B. Röper (Hrsg.), Wettbewerb und Anpassung in der Stahlindustrie, Berlin, S. 101.

von Freyend, E.J., und R. Linkohr, 1986, Europäische Struktur- und Industriepolitik - Marktanpassung über verstärkte Interventionen?, RationalisierungsKuratorium der Deutschen Wirtschaft: Themen \& Thesen, Eschborn.

von Wallenberg, G., 1992, Abschnitt 3: Staatliche Beihilfen, in: E. Grabitz und M. Hilf (Hrsg.), Kommentar zur Europäischen Union, München.

VSM (Verband für Schiffbau und Meerestechnik), 1989, Die Subventionierung des Schiffbaus in den Konkurrenzländern, Hamburg.

-, 1990 und 1994, Jahresberichte 1989 und 1993, Hamburg.

Wallace, H., 1977, The Establishment of the Regional Development Fund: Common Policy or Pork Barrel?, in: H. Wallace, W. Wallace und C. Webb, PolicyMaking in the European Communities, London u.a.O., S. 137-164.

Warnecke, S.J., 1978, The European Community and National Subsidy Policies, in: ders. (Hrsg.), International Trade and Industrial Policies, London-Basingstoke, S. 143-174.

Weilepp, M., 1989, Subventionierung im Weltschiffbau, Hamburg.

Westphal, J., 1984, Krisenbranchen und -regionen - Was kann und muß der Staat tun?, in: Ludwig-Erhard-Stiftung (Hrsg.), Symposion X, Mehr Soziale Marktwirtschaft - Weniger Subventionswirtschaft, Stuttgart-New York, S. 39-49.

Wienert, H., 1988, Europäische Stahlpolitik: wirtschaftliche Zwänge und Beschäftigungshoffnungen, Wirtschaftsdienst, 68, S. 136-143.

-, 1990, Stahlpolitik: Ein Lehrstück für die Risiken der industriepolitischen Intervention?, Wirtschaftsdienst, 70, S. 207-211.

Williams, F., 1993, Sparks fly in steel clash, Financial Times, 23 November, S. 6.

Wirtschaftsdienst, 1990, Schiffbau - Neuer Großkonzern?, 70, S. 493

Wirtschaftsvereinigung (WV) Eisen- und Stahlindustrie, 1982, Praktische Erfahrungen mit Beihilfen zugunsten der EG-Stahlindustrie, Düsseldorf.

-, 1984, EG-Stahlpolitik vor neuer Bewährungsprobe. Positionspapier der deutschen Stahlindustrie, Düsseldorf.

-, 1985, Chancengleicheit im Wettbewerb - Die deutsche Stahlindustrie beziffert ihre Ausgleichsforderungen, Düsseldorf.

-, 1987, Fünfzehn Fragen und Fakten zur europäischen Stahlpolitik, Düsseldorf. 
-, 1987a, Flankenschutz durch die Politik bleibt unverzichtbar, 2. Aufl., Düsseldorf.

-, 1992-1994, Statistisches Jahrbuch der Stahlindustrie 1992-1994, Düsseldorf.

Wiseman, J., 1981, Is there a logic of industrial subsidization?, in: K. Häuser (ed.), Subsidies, Tax Reliefs and Prices, Paris, S. 59-68.

Wissenschaftlicher Beirat beim BMWi, 1986, Stellungsnahme zum Weißbuch der EG-Kommission über den Binnenmarkt, Bundesanzeiger, 10. April, S. 4380f.

Woche im Bundestag, 1988, Feste Haltung zu Stahlsubventionen, Nr. 23, 14. Dezember, S. 38.

-, 1990, Für mehr Wettbewerb in der EG, Nr. 5, S. 38.

Wolf, J., und A. Cornelius, 1990, Renault told to repay $£ 600 \mathrm{~m}$ in state aid, The Guardian, May 23.

Yuill, D., K. Allen und C. Hull, (Hrsg.), 1981, Regionale Wirtschaftsförderung in der EG: Anreize für die gewerbliche Wirtschaft, Königstein.

Zachau-Mengers, G., 1930, Subventionen als Mittel moderner Wirtschaftspolitik, Dessau.

Zippel, W., 1984, Die Implikationen der bisherigen und gegenwärtigen Beihilfenpraxis der EG-Kommission für die Zukunft des Gemeinsamen Marktes, in: B. Börner und K. Neundörfer (Hrsg.), Recht und Praxis der Beihilfen im Gemeinsamen Markt, Köln u.a.O, S. 1-22. 


\section{FINANZWISSENSCHAFTLICHE SCHRIFTEN}

Band 1 Werner Steden: Finanzpolitik und Einkommensverteilung. Ein Wachstums- und Konjunkturmodell der Bundesrepublik Deutschland. 1979.

Band 2 Rainer Hagemann: Kommunale Finanzplanung im föderativen Staat. 1976.

Band 3 Klaus Scherer: Maßstäbe zur Beurteilung von konjunkturellen Wirkungen des öffentlichen Haushalts. 1977.

Band 4 Brita Steinbach: "Formula Flexibility" - Kritische Analyse und Vergleich mit diskretionärer Konjunkturpolitik. 1977.

Band 5 Hans-Georg Petersen: Personelle Einkommensbesteuerung und Inflation. Eine theoretisch-empirische Analyse der Lohn- und veranlagten Einkommensteuer in der Bundesrepublik Deutschland. 1977.

Band 6 Friedemann Tetsch: Raumwirkungen des Finanzsystems der Bundesrepublik Deutschland. Eine Untersuchung der Auswirkungen der Finanzreform von 1969 auf die Einnahmenposition der untergeordneten Gebietskörperschaften und ihrer regionalpolitischen Zieladäquanz. 1978.

Band 7 Wilhelm Pfähler: Normative Theorie der fiskalischen Besteuerung. Ein methodologischer und theoretischer Beitrag zur Integration der normativen Besteuerungstheorie in der Wohlfahrtstheorie. 1978.

Band 8 Wolfgang Wiegard: Optimale Schattenpreise und Produktionsprogramme für öffentliche Unternehmen. Second-Best Modelle im finanzwirtschaftlichen Staatsbereich. 1978.

Band 9 Hans P. Fischer: Die Finanzierung des Umweltschutzes im Rahmen einer rationalen Umweltpolitik. 1978.

Band 10 Rainer Paulenz: Der Einsatz finanzpolitischer Instrumente in der Forschungs- und Entwicklungspolitik. 1978.

Band 11 Hans-Joachim Hauser: Verteilungswirkungen der Staatsverschuldung. Eine kreislauftheoretische Inzidenzbetrachtung. 1979.

Band 12 Gunnar Schwarting: Kommunale Investitionen. Theoretische und empirische Untersuchungen der Bestimmungsgründe kommunaler Investitionstätigkeit in NordrheinWestfalen 1965-1972. 1979.

Band 13 Hans-Joachim Conrad: Stadt-Umland-Wanderung und Finanzwirtschaft der Kernstädte. Amerikanische Erfahrungen, grundsätzliche Zusammenhänge und eine Fallstudie für das Ballungsgebiet Frankfurt am Main. 1980.

Band 14 Cay Folkers: Vermögensverteilung und staatliche Aktivität. Zur Theorie distributiver Prozesse im Interventionsstaat. 1981.

Band 15 Helmut Fischer: US-amerikanische Exportförderung durch die DISC-Gesetzgebung. 1981.

Band 16 Günter Ott: Einkommensumverteilungen in der gesetzlichen Krankenversicherung. Eine quantitative Analyse. 1981.

Band 17 Johann Hermann von Oehsen: Optimale Besteuerung. (Optimal Taxation). 1982.

Band 18 Richard Kössler: Sozialversicherungsprinzip und Staatszuschüsse in der gesetzlichen Rentenversicherung. 1982.

Band 19 Hinrich Steffen: Zum Handlungs- und Entscheidungsspielraum der kommunalen Investitionspolitik in der Bundesrepublik Deutschland. 1983.

Band 20 Manfred Scheuer: Wirkungen einer Auslandsverschuldung des Staates bei flexiblen Wechselkursen. 1983. 
Band 21 Christian Schiller: Staatsausgaben und crowding-out-Effekte. Zur Effizienz einer Finanzpolitik keynesianischer Provenienz. 1983.

Band 22 Hannelore Weck: Schattenwirtschaft: Eine Möglichkeit zur Einschränkung der öffentlichen Verwaltung? Eine ökonomische Analyse. 1983.

Band 23 Wolfgang Schmitt: Steuern als Mittel der Einkommenspolitik. Eine Ergänzung der Stabilitätspolitik? 1984.

Band 24 Wolfgang Laux: Erhöhung staatswirtschaftlicher Effizienz durch budgetäre Selbstbeschränkung? Zur Idee einer verfassungsmäßig verankerten Ausgabengrenze. 1984.

Band 25 Brita Steinbach-van der Veen: Steuerinzidenz. Methodologische Grundlagen und empirisch-statistische Probleme von Länderstudien. 1985.

Band 26 Albert Peters: Ökonomische Kriterien für eine Aufgabenverteilung in der Marktwirtschaft. Eine deskriptive und normative Betrachtung für den Allokationsbereich. 1985.

Band 27 Achim Zeidler: Möglichkeiten zur Fortsetzung der Gemeindefinanzreform. Eine theoretische und empirische Analyse. 1985.

Band 28 Peter Bartsch: Zur Theorie der längerfristigen Wirkungen 'expansiver' Fiskalpolitik. Eine dynamische Analyse unter besonderer Berücksichtigung der staatlichen Budgetbeschränkung und ausgewählter Möglichkeiten der öffentlichen Defizitfinanzierung. 1986.

Band 29 Konrad Beiwinkel: Wehrgerechtigkeit als finanzpolitisches Verteilungsproblem. Möglichkeiten einer Kompensation von Wehrungerechtigkeit durch monetäre Transfers. 1986.

Band 30 Wolfgang Kitterer: Effizienz- und Verteilungswirkungen des Steuersystems. 1986.

Band 31 Heinz Dieter Hessler: Theorie und Politik der Personalsteuern. Eine Kritik ihrer Einkommens- und Vermögensbegriffe mit Blick auf die Leistungsfähigkeitstheorie. 1994.

Band 32 Wolfgang Scherf: Die beschäftigungspolitische und fiskalische Problematik der Arbeitgeberbeiträge zur Rentenversicherung. Eine Auseinandersetzung mit der Kritik an der lohnbezogenen Beitragsbemessung. 1987.

Band 33 Andreas Mästle: Die Steuerunion. Probleme der Harmonisierung spezifischer Gütersteuern. 1987.

Band 34 Günter Ott: Internationale Verteilungswirkungen im Finanzausgleich der Europäischen Gemeinschaften. 1987.

Band 35 Heinz Haller: Zur Frage der zweckmäßigen Gestalt gemeindlicher Steuern. Ein Diskussionsbeitrag zur Gemeindesteuerreform. 1987.

Band 36 Thomas Kuhn: Schlüsselzuweisungen und fiskalische Ungleichheit. Eine theoretische Analyse der Verteilung von Schlüsselzuweisungen an Kommunen. 1988.

Band 37 Walter Hahn: Steuerpolitische Willensbildungsprozesse in der Europäischen Gemeinschaft. Das Beispiel der Umsatzssteuer-Harmonisierung. 1988.

Band 38 Ulrike Hardt: Kommunale Finanzkraft. Die Problematik einer objektiven Bestimmung kommunaler Einnahmemöglichkeiten in der gemeindlichen Haushaltsplanung und im kommunalen Finanzausgleich. 1988.

Band 39 Jochen Michaelis: Optimale Finanzpolitik im Modell überlappender Generationen. 1989.

Band 40 Bernd Raffelhüschen: Anreizwirkungen der sozialen Alterssicherung. Eine dynamische Simulationsanalyse. 1989.

Band 41 Berend Diekmann: Die Anleihe- und Darlehenstransaktionen der Europäischen Gemeinschaften. 1990.

Band 42 Helmut Kaiser: Konsumnachfrage, Arbeitsangebot und optimale Haushaltsbesteuerung. Theoretische Ergebnisse und mikroökonometrische Simulation für die Bundesrepublik Deutschland. 1990. 
Band 43 Rüdiger von Kleist: Das Gramm-Rudman-Hollings-Gesetz. Ein gescheiterter Versuch der Haushaltskonsolidierung. 1991.

Band 44 Rolf Hagedorn: Steuerhinterziehung und Finanzpolitik. Ein theoretischer Beitrag unter besonderer Berücksichtigung der Hinterziehung von Zinserträgen. 1991.

Band 45 Cornelia S. Behrens: Intertemporale Verteilungswirkungen in der gesetzlichen Krankenversicherung der Bundesrepublik Deutschland. 1991.

Band 46 Peter Saile: Ein ökonomischer Ansatz der Theorie der intermediären Finanzgewalten Die Kirchen als Parafisci. 1992.

Band 47 Peter Gottfried: Die verdeckten Effizienzwirkungen der Umsatzsteuer. Eine empirische allgemeine Gleichgewichtsanalyse. 1992.

Band 48 Andreas Burger: Umweltorientierte Beschäftigungsprogramme. Eine Effizienzanalyse am Beispiel des "Sondervermögens Arbeit und Umwelt". 1992.

Band 49 Jeanette Malchow: Die Zuordnung verteilungspolitischer Kompetenzen in der Europäischen Gemeinschaft. Eine Untersuchung aufgrund einer Fortentwicklung der ökonomischen Theorie des Föderalismus. 1992.

Band 50 Barbara Seidel: Die Einbindung der Bundesrepublik Deutschland in die Europäischen Gemeinschaften als Problem des Finanzausgleichs. 1992.

Band 51 Ralph Wiechers: Markt und Macht im Rundfunk. Zur Stellung der öffentlich-rechtlichen Rundfunkanstalten im dualen Rundfunksystem der Bundesrepublik Deutschland. 1992.

Band 52 Klaus Eckhardt: Probleme einer Umweltpolitik mit Abgaben. 1993.

Band 53 Oliver Schwarzkopf: Die Problematik unterschiedlicher Körperschaftsteuersysteme innerhalb der EG. 1993.

Band 54 Thorsten Giersch: Bergson-Wohlfahrtsfunktion und normative Ökonomie. 1993.

Band 55 Li-Fang Chou: Selbstbeteiligung bei Arzneimitteln aus ordnungspolitischer Sicht. Das Beispiel der Bundesrepublik Deutschland. 1993.

Band 56 Harald Schlee: Einkommensteuerliche Behandlung von Transferzahlungen. Zur Neuordnung der Familienbesteuerung sowie der Besteuerung von Versicherungsleistungen und Sozialtransfers. 1994.

Band 57 Alexander Spermann: Kommunales Krisenmanagement. Reaktionen baden-württembergischer Stadtkreise auf steigende Sozialhilfekosten und Einnahmenausfälle (198092). 1993.

Band 58 Otto Roloff / Sibylle Brander / Ingo Barens / Claudia Wesselbaum: Direktinvestitionen und internationale Steuerkonkurrenz. 1994.

Band 59 Claudia Wesselbaum-Neugebauer: Internationale Steuerbelastungsvergleiche. 1994.

Band 60 Stephanie Miera: Kommunales Finanzsystem und Bevölkerungsentwicklung. Eine Analyse des kommunalen Finanzsystems vor dem Hintergrund der sich abzeichnenden Bevölkerungsentwicklung am Beispiel Niedersachsens unter besonderer Berücksichtigung des Landkreises Wolfenbüttel und seiner Gemeinden. 1994.

Band 61 Wolfgang Scherf: Die Bedeutung des kaldorianischen Verteilungsmechanismus für die gesamtwirtschaftlichen Wirkungen der staatlichen Neuverschuldung. 1994.

Band 62 Rainer Volk: Vergleich der Vergünstigungseffekte der verschiedenen investitionsfördernden Maßnahmen. 1994.

Band 63 Hans-Georg Napp: Kommunale Finanzautonomie und ihre Bedeutung für eine effiziente lokale Finanzwirtschaft. 1994. 2., unveränderte Auflage 1994.

Band 64 Bernd Rahmann / Uwe Steinborn / Günter Vornholz: Empirische Analyse der Autonomie lokaler Finanzwirtschaften in der Europäischen Gemeinschaft. 1994. 
Band 65 Carsten Kühl: Strategien zur Finanzierung der Altlastensanierung. 1994.

Band 66 Stephan Boll: Intergenerationale Umverteilungswirkungen der Fiskalpolitik in der Bundesrepublik Deutschland. Ein Ansatz mit Hilfe des Generational Accounting. 1994.

Band 67 Karl Justus Bernhard Neumärker: Finanzverfassung und Staatsgewalt in der Demokratie. Ein Beitrag zur konstitutionellen Finanztheorie. 1995.

Band 68 Christian Haslbeck: Zentrale versus dezentrale Internalisierung externer Effekte bei unvollständiger Information. 1995.

Band 69 Regina Müller: Horizontale oder vertikale Transfers zur Durchsetzung eines horizontalen Finanzausgleichs. 1995.

Band 70 Christian Hockenjos: Öffentliche Sportförderung in der Bundesrepublik Deutschland. Darstellung und finanztheoretische Analyse. 1995.

Band 71 Manfred Rosenstock: Die Kontrolle und Harmonisierung nationaler Beihilfen durch die Kommission der Europäischen Gemeinschaften. 1995. 


\title{
Peter Mendler
}

\section{Zur ökonomischen und politisch-institutionellen Analyse öffentlicher Kredithilfen}

\author{
Frankfurt/M., Bern, New York, Paris, 1992. X, 427 S., zahlr. Abb. u. Tab. \\ Hohenheimer volkswirtschaftliche Schriften. Bd. 14 \\ Verantwortlicher Herausgegeber Cay Folkers \\ ISBN 3-631-44394-3 br. DM 106.--*
}

Die staatliche Subventionsgewährung erfolgt vielfach in der Form öffentlicher Kredithilfen, die häufig von außerbudgetären Einrichtungen vergeben und finanziert werden. Im Rahmen einer positiven Wirkungsanalyse wird untersucht, wie sich die Individuen an gegebene Kredithilfeprogramme anpassen und welche allokativen und distributiven Konsequenzen daraus resultieren. Um die Entscheidung zugunsten öffentlicher Kredithilfen als Subventionsform und deren verbreitete Realisierung außerhalb des Budgets zu erklären, wird der politische Prozeß in die weitere Analyse einbezogen. Dabei wird insbesondere diskutiert, inwieweit einzelne Gruppen von Subventionsnachfragern und -anbietern durch Kredithilfen und die Einschaltung außerbudgetärer Einrichtungen Verteilungsvorteile zu Lasten der Allgemeinheit erzielen können. Schließlich wird analysiert, wie durch konstitutionelle Regeln mögliche Schäden für die Allgemeinheit aufgrund von Kredithilfen und außerbudgetären Einrichtungen begrenzt werden können.

Aus dem Inhalt: Öffentliche Kredithilfen in Deutschland · Kreditmarkttheorie - Theorie der Subventionswirkungen - Inzidenztheorie - Politische Ökonomie der Kredithilfen und außerbudgetärer Einrichtungen . Konstitutionelle Theorie

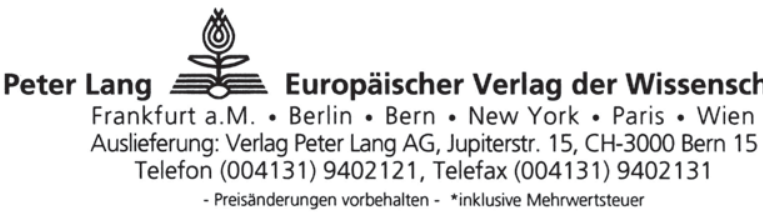

